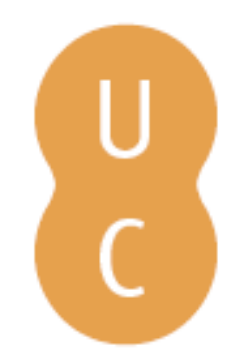

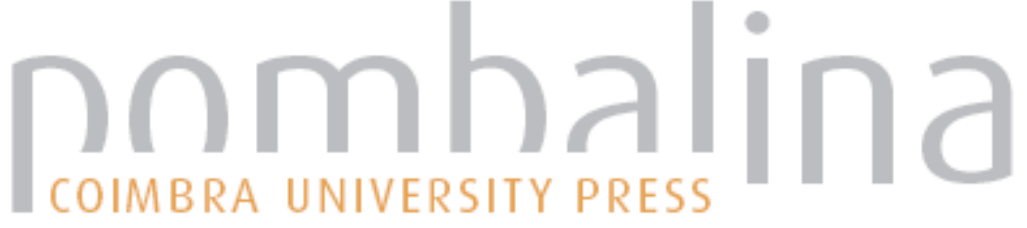

\section{Tychè et Pronoia: la marche du monde selon Plutarque}

Autor(es): $\quad$ Leão, Delfim F., ed.lit.; Frazier, Françoise, ed.lit.

Publicado por: Centro de Estudos Clássicos e Humanísticos

URL

persistente: URI:http://hdl.handle.net/10316.2/2345

DOI: $\quad$ DOI:http://dx.doi.org/10.14195/978-989-8281-53-1

Accessed : $\quad$ 26-Apr-2023 13:31:08

A navegação consulta e descarregamento dos títulos inseridos nas Bibliotecas Digitais UC Digitalis, UC Pombalina e UC Impactum, pressupõem a aceitação plena e sem reservas dos Termos e Condições de Uso destas Bibliotecas Digitais, disponíveis em https://digitalis.uc.pt/pt-pt/termos.

Conforme exposto nos referidos Termos e Condições de Uso, o descarregamento de títulos de acesso restrito requer uma licença válida de autorização devendo o utilizador aceder ao(s) documento(s) a partir de um endereço de IP da instituição detentora da supramencionada licença.

Ao utilizador é apenas permitido o descarregamento para uso pessoal, pelo que o emprego do(s) título(s) descarregado(s) para outro fim, designadamente comercial, carece de autorização do respetivo autor ou editor da obra.

Na medida em que todas as obras da UC Digitalis se encontram protegidas pelo Código do Direito de Autor e Direitos Conexos e demais legislação aplicável, toda a cópia, parcial ou total, deste documento, nos casos em que é legalmente admitida, deverá conter ou fazer-se acompanhar por este aviso. 


\section{Tychè et Pronoia}

\section{La marche du monde selon Plutarque}

Françoise Frazier et Delfim F. Leão (eds.)

IMPRENSA DA UNIVERSIDADE DE COIMBRA
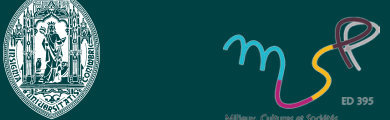


\section{Tychè et Pronoia La marche du monde selon Plutarque}

Françoise Frazier et Delfim F. Leão (eds.)
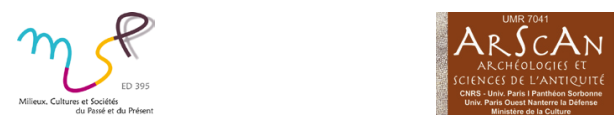
Toutes les oeuvres de cette série sont soumises à un arbitrage scientifique indépendant.

\section{ÉDITEURS}

Françoise Frazier et Delfim F. Leão

Titre

Tychè et Pronola - La marche du monde selon Plutarque

LIBRAIRIE

Centre d'Études Classiques et Humanistiques de l'Université de Coimbra

Imprensa da Universidade de Coimbra

Coordonnateur Scientifique du Projet d’Édition

Maria do Céu Fialho

Conseil d'Édition

José Ribeiro Ferreira, Maria de Fátima Silva, Francisco de Oliveira et Nair Castro Soares

Directeur Technique de la Collection

Delfim F. Leão

Conception Graphique et Pagination

Ana Seiça Carvalho, Elisabete Cação, Nelson Ferreira, Rodolfo Lopes

ISBN: 978-989-8281-52-4

ISBN DigiTAL: 978-989-8281-53-1

DÉPÔT LÉGAL: 316681/10

(C) IMPRENSA DA UNIVERISDADE DE COIMBRA

(C) Centro de Estudos Clássicos e Humanísticos da Universidade de Coimbra

(C) Classica Digitalia Vniversitatis Conimbrigensis

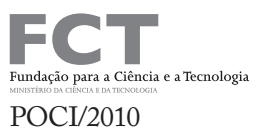

\section{SoPlutarco}

Sociedade Portuguesa de Plutarco

Volume intégré dans les activités du projet « Plutarque et les fondements de l'identité européenne ».

Reservés tous droits. Dans les termes légaux, la reproduction totale ou partielle est expressément interdite quel que soit le moyen, sur papier ou en édition électronique, sans l'autorisation des titulaires des droits. Est d'ores et déjà objet d'exception l'utilisation dans les circuits académiques fermés pour l'enseignement ou extension culturelle par e-learning. 


\section{TABle des Matieres}

Préface

Éditeurs, Françoise Frazier et Delfim F. Leão

Introduction: La marche du Monde et Les incertitudes de LA Tychè

Françoise Frazier (Université de Paris Ouest - Nanterre La Défense)

\section{Doctrines et Débats Philosophiques}

LA VISIÓN DEL MUNDO SEGÚN LAS REVELACIONES:

DE SERA 563 E-568 A y DE GENIO 590 A-592 E

Rosa Maria Aguilar (Universidad Complutense de Madrid)

LA DOCTRINA DE LAS $\dot{\pi} \pi \varepsilon \lambda \varepsilon v ́ \sigma \varepsilon I \zeta$ Y LA LIBERDAD DE INDIFERENCIA:

de Aristón de Quíos a Arcesilao (Plut., Stoic. REP. 23, 1045 B-F)

Raúl Caballero Sánchez (Universidad de Málaga)

Fato e fortuna negli opuscoli contro gli Stoici di Plutarco:

UN PROBLEMA ANCORA APERTO

Paola Volpe Cacciatore (Università di Salerno)

L'écrit de Plutarque Sur la Fortune:

HISTOIRE D'UNE INTERPRÉTATION

Francesco Becchi (Université de Florence)

Superstición y ateísmo en la crítica antiepicúrea de Plutarco

Juan Francisco Martos Montiel (Universidad de Málaga)

\section{Entre Philosophie et Religion, les relations des hommes et des dieuX}

Le DE SERA, Dialogue PythiQue :

Hasard et Providence, Philosophie et Religion dans la pensée de Plutarque

Françoise Frazier (Université de Paris Ouest - Nanterre La Défense)

Socrates' $\delta \alpha \mu$ óviov in Maximus of Tyre, Apuleius, and Plutarch

Geert Roskam (Catholic University of Leuven)

Embaucadores y falsos adivinos en Oráculos de la Pitla 407 B-C

Ana Isabel Jiménez San Cristóbal (Universidad Complutense de Madrid)

Le Monde des Rêves À l’Époque Hellénistique dans les Vies et les Moralia.

Étude sur le vocabulaire et la pensée de Plutarque

Monica Durán Mañas (Universidad Complutense de Madrid) 


\section{INTERPRÉTER L'ACTION HUMAINE}

Polybe, la Tú $\chi$ et la marche de L’Histoire

Marie-Rose Guelfucci (Université de Franche-Comté, Besançon)

La Providencia como salvaguarda de los Proyectos Históricos Humanos EN LAS VIDAS PARALELAS

Aurelio Pérez Jiménez (Universidad de Málaga)

Tyche, Kairos et Kronos dans le Phocion de Plutarque

Delfim F. Leão (Université de Coimbra)

The Inter play of textual references in Plutarch's Life of Phocion

Maria do Céu Fialho (University of Coimbra)

I doni di Zeus, il dono di Prometeo.

STRUTTURE RETORICHE ED ISTANZE ETICO-POLITICHE NELLA RIFLESSIONE PLUTARCHEA SULLA $\tau u ́ \chi \eta$

Rosario Scannapieco (Università di Salerno)

Fortuna e carattere da Menandro a Plutarco con una nota testuale su alcune citazioni di Menandro in Plutarco

Angelo Casanova (Università di Firenze) 


\section{Préface}

Le présent volume trouve son origine dans la rencontre annuelle du Réseau International de recherche et de formation à la recherche Plutarque (RED) qui s'est tenue à la Maison de l'Archéologie et de l'Ethnologie René Ginouvès de Nanterre en novembre 2009 sur le thème « Hasard, Fortune, Providence: la marche du monde selon Plutarque ». Pour constituer ce recueil, l'intitulé a été un peu modifié: l'adoption de la translittération, Tychè et Pronoia, veut mettre d'emblée en lumière la spécificité des notions grecques ici examinées, spécificité qui intéresse le philosophe comme le philologue. Les communications s'étaient alors réparties sur quatre demi-journées: enrichies des contributions de Marie-Rose Guelfucci et Maria do Céu Fialho, elles ont été réorganisées selon trois axes, et s'adressent, non seulement aux «Plutarquistes», mais aussi aux historiens de la philosophie, aux historiens des religions et aux spécialistes d'historiographie.

Ayant éprouvé lors de cette rencontre le poids et les affres d'une organisation en solitaire, je tiens à exprimer d'abord toute ma gratitude à Delfim Leão, qui a accepté de collaborer avec moi pour la publication et de m'apporter son aide et son expérience éditoriale. Les deux éditeurs désormais réunis adressent aussi leurs remerciements aux institutions sans qui cette entreprise n'aurait pas été possible : pour Nanterre, l'équipe ArScAn-THEMAM (UMR 7041) et l'École doctorale 395, Milieux, cultures et sociétés du passé et du présent, qui ont soutenu la rencontre comme la publication, pour Coimbra, l'équipe du projet «Plutarque et les fondements de l'identité européenne » et le Conseil Éditorial des Classica Digitalia - la division éditoriale du Centre d'Études Classiques et Humanistiques de l'Université de Coimbra.

Enfin, derrière les institutions, derrière les mises au point et les mises en pages, ily a des personnes et plus que tout autre, «notre » auteur est là pour nous rappeler l'importance de l'humain. Que les referees qui, sans se laisser rebuter par la brièveté des délais impartis, ont accepté de faire profiter les auteurs et les éditeurs de leur lecture éclairée en soient chaleureusement remerciés : si 
cet ouvrage peut apporter quelque chose aux lecteurs, ils y ont toute leur part. Nous aurions garde enfin d'oublier l'aide précieuse qui nous a été apportée par Ana Carvalho, Nelson Henrique, Elisabete Cação, Manuel Tröster et Rodolfo Lopes dans la préparation du volume pour la typographie.

Paris, juillet 2010

Les éditeurs,

Françoise Frazier et Delfim F. Leão 


\title{
INTRODUCTION
}

\section{LA MARCHE DU MONDE ET LES INCERTITUDES DE LA TYCHÈ}

Françoise Frazier

\author{
Université Paris Ouest - Nanterre La Défense
}

Depuis l'œuvre pionnière de Daniel Babut, qui, il y a maintenant plus de quarante ans ${ }^{1}$, précisait, en quelque sorte, « en creux ", à travers la confrontation avec le stoïcisme, les contours de la pensée de Plutarque et invitait à en reconsidérer la cohérence sous un jour plus favorable, le regain des études sur le médioplatonisme et la réflexion sur la place qu'y a tenue Plutarque ont permis de préciser un platonisme qui n'est plus contesté ni marqué du signe infamant de «l'éclectisme ». Pour esquisser à grands traits sa conception philosophique sur le problème qui nous intéresse $\mathrm{ici}^{2}$, l'univers est régi selon lui par une Providence divine, qu'on ne saurait mettre en doute pour abandonner le monde au Hasard, à l'instar des Épicuriens: il se situe ainsi dans la droite ligne de Platon, condamnant déjà au livre $\mathrm{X}$ des Lois (888 e sqq.), les théories physiques de son temps, qui considéraient que « toutes choses qui sont, furent ou seront prennent leur existence ou de la nature ou de l'art ou du hasard ${ }^{3}$ » et que le monde s'est formé « sans aucune intervention de l'intelligence, ni de quelque dieu que ce soit, ni de l'art, mais, comme nous le disions, par la nature et le hasard ${ }^{4}$ ». Mais, symétriquement, on ne saurait non plus faire intervenir indiscrètement partout la Providence et admettre que la divinité se mêle à la matière, comme le font les Stoïciens ${ }^{5}$. De là le recours en particulier à la démonologie ${ }^{6}$, qui permet, dans le prolongement des réflexions du Banquet, de penser le metaxu, la médiation entre monde divin et monde humain, inscrite dans la distinction fondamentale, attribuée à Platon, entre cause supérieure

${ }^{1}$ D. Babut, 1969.

${ }^{2}$ Esquissé aussi par J. Opsomer, 1997, et, en se limitant à la question des oracles, par F. ILDEFONSE, 2006, en part. 10-54.

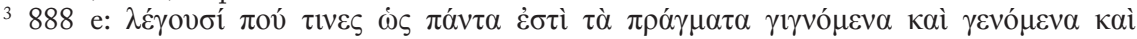

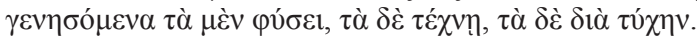

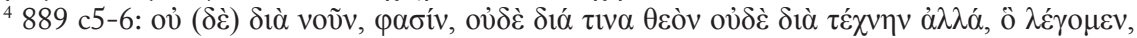

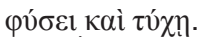

${ }^{5}$ À cet égard, Plutarque partage les reproches sarcastiques qu'il prête à son ami épicurien Boéthos dans le De Pyth. orac. 398 A-B (trad. F. Ildefonse): «Oui, il ne suffit pas d'enfermer le dieu claquemuré dans un corps mortel une fois par mois, mais nous le mêlerons à chaque pierre et à chaque bronze ", mais il n'admet pas sa solution «comme si nous n'avions pas dans la fortune

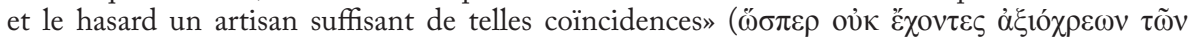

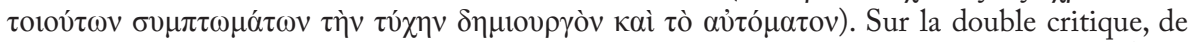
l'épicurisme et du stoïcisme, voir l'introduction de la solution dualiste du De Iside 45, 369 A-B.

${ }^{6}$ Même si je ne le mets pas ici en avant, je ne méconnais pas non plus son emploi dans une théodicée qui exonère le divin de toutes les manifestations surnaturelles malveillantes et donc s'ancre derechef dans le postulat fondamental de la bonté divine. Sur les démons malfaisants, D. BABUt, 1969, 394 sqq, dont l'analyse (en part. 435-436) devrait amener à nuancer l'accusation d'incohérence de S. Swain, 1987, 274. 
ou finale (qui relève de la divinité) et cause naturelle ou nécessaire (qui se déploie dans notre monde matériel) ${ }^{7}$. Exclue de la formation et de la marche de l'univers, la tychè intervient donc dans notre monde: elle est un facteur inévitable de l'action humaine, nouveau point d'opposition majeur avec le stoïcisme et qui peut déjà s'appuyer sur un autre passage des Lois, célèbre dans l'Antiquités ${ }^{8}$ où l'Athénien s'efforce de déterminer les circonstances favorables qui permettront au législateur de déployer son art avec succès. On pourrait, à première vue, dit-il, considérer que les affaires humaines ne sont que tychai, «vicissitudes» (IV 709 b1), et que ce sont ces tychai et les «malheurs de toutes sortes qui s'abattent de toutes sortes de manières ${ }^{9} »$ les véritables législateurs. D'eux sans doute dépendent les succès de l'art du législateur comme de celui du navigateur, du pilote, du médecin ou du général, mais il ne faut pas s'en tenir là et les facteurs entrant en jeu sont en réalité au nombre de trois: à la divinité, et, avec elle, à la tychè et l'occasion (qui ne font qu'un), doit être ajouté le troisième facteur qu'est l'art ${ }^{10}$. Et l'Athénien se met en devoir d'examiner après cela, " parmi les circonstances qui doivent échoir à un pays ${ }^{11}$ " pour qu'il soit heureusement administré, l'importance capitale d'un " législateur attaché à la vérité ». Réduction du rôle de la tychè et accentuation de la part humaine de savoir et de mérite, ou, au contraire, dans les temps troublés, et singulièrement à

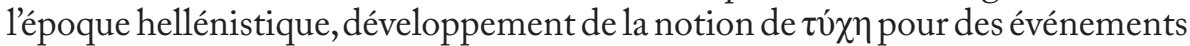
qui semblent échapper à la prise humaine ${ }^{12}$ : il en résulte « divers visages » de la tychè, qu'a soigneusement inventoriés Luigi Torraca dans un précédent congrès Plutarque ${ }^{13}$, et qui ne laissent pas de rendre délicate l'interprétation de tel ou tel passage de notre auteur. Il ne s'agit pas ici de résoudre, ni même de traiter l'ensemble de la question et seuls quelques aspects de la marche du monde pourront être abordés, en fonction des intérêts et des spécialités propres de chacun des contributeurs. L'expression même, volontairement très large, qui a été choisie comme sous-titre, la "marche du monde ", permet d'envisager les divers niveaux, celui des dieux, de l'univers, comme celui de l'histoire et de l'humanité. Il paraît néanmoins souhaitable, en préambule, de préciser les données du problème et d'en donner une vision d'ensemble, en se concentrant

${ }^{7}$ Sur cette distinction capitale (qui sera développée infra) et son importance fondamentale dans le platonisme de Plutarque, voir D. Babut, 2007, en part. 72-81.

${ }^{8}$ Cf note ad loc. de E. Des Places, CUF, t. XI-2, p. 55: «Ce texte devait passer dans les anthologies, et le seul Stobée le cite en trois endroits. Au lieu de regarder les affaires humaines comme pures vicissitudes (b1), il faut les expliquer par trois principes: $1^{\circ}$ un dieu ; $2^{\circ}$ la fortune et l'occasion (celle-ci, kairos, plus positive que celle-là, tykhè); $3^{\circ}$ le métier» (c'est moi qui souligne).

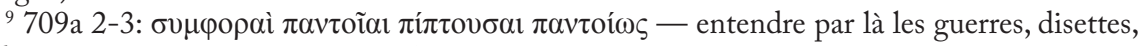
épidémies, intempéries, évoquées en 709 a3-6.

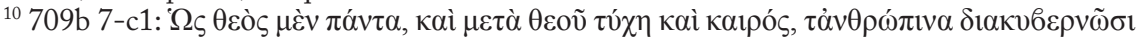

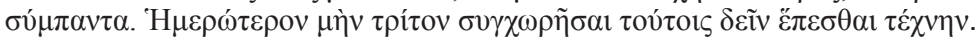

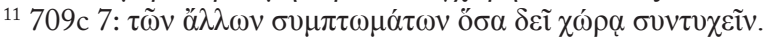

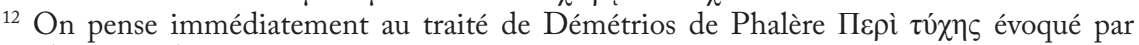

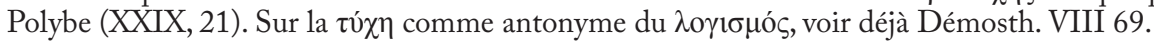

${ }^{13}$ L. Torraca, 1996. 
sur les notions grecques de $\tau \hat{\chi} \chi \eta$ et de $\pi \rho$ óvot $\alpha$, sur leurs occurrences ${ }^{14}$, le champ de chacune, leurs relations entre elles et les difficultés qu'elles soulèvent, avant de détailler les contributions ici présentées.

$* *$

Des deux notions, la plus délicate est sans aucun doute celle de $\tau \hat{\chi} \chi \eta$, que je me contenterai de translittérer, parce que toute traduction est déjà une interprétation : je commencerai, modestement, par inventorier les difficultés que pose le simple choix d'une traduction ${ }^{15}$, car elles sont les plus clairs révélateurs des problèmes de fond posés à l'exégète. D'abord, comme beaucoup de mots, $\tau \hat{\chi} \chi \eta$ recouvre certes un concept philosophique ${ }^{16}$, mais c'est aussi un mot de la langue courante: pour prendre un exemple en français, le « hasard " n'a évidemment pas la même portée selon que, personne privée, je rends à des amis une visite imprévue, que j'explique d'un « je passais par hasard dans votre quartier ", ou que je suis un scientifique, tel Jérôme Monod, m’interrogeant sur « le hasard et la nécessité » dans un «essai sur la philosophie naturelle de la biologie moderne ${ }^{17} »$. Selon les contextes, on est donc fondé à distinguer quel type d'emploi fait Plutarque de cette notion, en se demandant s'il exprime ses propres conceptions de philosophe ou s'il énonce l'opinion la plus couramment reçue, et si, alors, il se contente de la reproduire ou l'adopte lui-même ${ }^{18}$.

${ }^{14}$ Une telle étude suppose que l'on prenne la remarque de S. Swain, 1989, 272 : «The difficulty in estimating Plutarch's belief of providential interference in history lies principally in his terminology» comme une invitation à réexaminer cette terminologie - le répertoire des termes donné en appendice par le savant anglais (298-302) est utile, mais demanderait à être élargi aux Moralia et précisé. Dans ce réexamen, il faut partir du postulat que l'emploi de tel mot plutôt que de tel autre est important et que, en tout état de cause, le philologue ne saurait admettre a priori du «flou» sans s'interroger sur le sens d'une apparente synonymie.

${ }^{15} \mathrm{Au}$ moins au traducteur français: les problèmes sont sans doute un peu différents selon les langues (la «fortuna» italienne et la «chance» anglaise n'ont pas non plus d'exact équivalent français) et l'on comprendra sans peine que, sur une question aussi délicate, je me limite à ma langue maternelle. Le problème est longuement traité infra par Marie-Rose Guelfucci à propos de Polybe: nos conversations ont leur part dans l'exposé que je donne ici.

16 Voir, par ex., F. E. Peters, 1967, sv tyche: «As a metaphysical term, tyche falls under the general heading of accidental causes (symbebekos), i-e a cause having an unintended effect. Aristoteles distinguishes such accidental causes (which are efficient causes, Phys. II, 198 a) into those where there is no deliberation, automaton (spontaneity), and those where there is some degree of rational choice (proairesis), in which case it is tyche (Phys. II, 197a-198a). The role of tyche as a causal principle found its strongest appeals to the Atomists (see DL IX, 45; Ar. Phys. II, 196 a24) where chance is equated with a kind of blind physical necessity (ananke) operating without purpose. The identification of chance and physical necessity is made quite specific by Plato in his castigation of current physical theories (Laws X 889 c). Aristotle's final view on tyche is to separate it from material ananke and to render it inferior to both nous and physis, the two causes that operate with purpose (telos), Phys II, 198 a».

17 Ouvrage publié en 1970 aux éditions du Seuil. J'évite à dessein l'exemple, évident, du philosophe professionnel.

${ }^{18}$ Et cela ne saurait être mis sur le compte de l'incohérence : en dehors des dialogues, où les interlocuteurs peuvent avoir précisément à harmoniser leurs notions, on rencontre ce genre 
Une seconde distinction, plus évidente dans une édition moderne qui marque la différence en employant ou non la majuscule, se fait entre la notion, plus ou moins précise, et une force quasi hypostasiée, qui implique nécessairement une certaine vision du monde. Prenons par exemple la présentation de la première prise d'Athènes par Démétrios Poliorcète. Voici le texte grec:

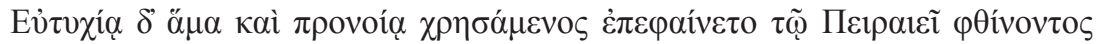

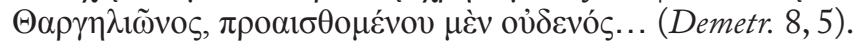

R. Flacelière choisit de traduire le participe apposé initial par «La Fortune ayant secondé sa prévoyance ${ }^{19}{ }$ : sans doute, dans le texte grec tel que nous l'imprimons, la majuscule est-elle «mécaniquement» entraînée par la ponctuation, mais rien ne justifie de la conserver en français, en dehors d'un préjugé où l'importance de la Tychè à l'époque hellénistique doit avoir sa part. Car le texte de départ se borne à noter, très platement, «l'utilisation»

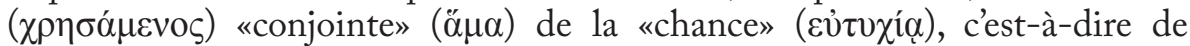

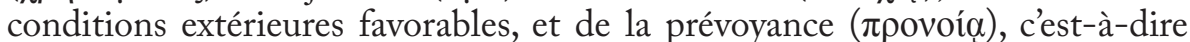
d'une bonne analyse et d'une bonne préparation de l'action ${ }^{20}$. Rien n'y autorise

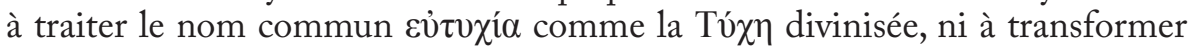
une simple concomitance ( $\alpha \mu \alpha)$ en aide («ayant secondé») qui renforce encore la personnification du facteur. Il faut donc se garder de retrouver trop vite la

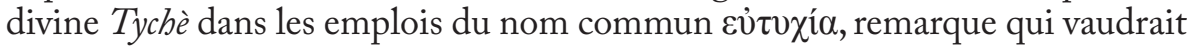
aussi pour les nombreuses occurrences de $\tau \hat{\chi} \chi \eta \tau \imath \varsigma$, accompagnée ou non d'un qualificatif $^{21}$.

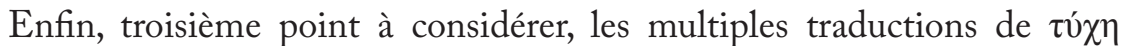
(ou des dérivés et composés), comme on l'a déjà dit pour justifier ici le choix de la translittération, sont déjà des interprétations orientant le lecteur et suggèrent telle philosophie, ou renvoient à telle ou telle période historique. Ainsi la traduction du passage de Démétrios déjà citée semble se ressentir de l'atmosphère de l'époque hellénistique ; ailleurs, c'est l'influence de la Fortuna

de difficultés partout, jusque dans les traités d'Aristote, qu'il paraît imprudent d'accuser de mal conduire sa pensée - je pense en particulier, pour ce que je connais le mieux, aux emplois de mythos dans la Poétique. Dans le récit historique de même, Marie-Rose Guelfucci est amenée à opérer des distinctions en faisant intervenir la notion de «focalisation » (voir infra, pp. 143 sqq).

${ }_{19}$ Par opposition, B. Perrin (Loeb, t. IX) traduit plus près du texte grec «by virtue of forethought combined with good fortune».

${ }^{20}$ Dans ce type de contexte le mot $\pi \alpha \rho \alpha \sigma \kappa \varepsilon v \eta ́$ (ou un synonyme) peut être associé à $\pi \rho o ́ v o t \alpha$ (voir Eum. 5, 5 et les remarques de Marie-Rose Guelfucci sur Polybe).

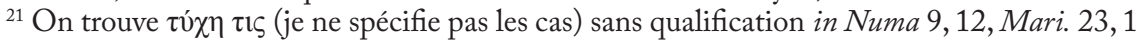

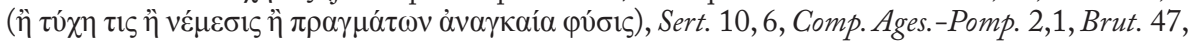
5, De def. 39, 431 D, avec $\theta$ cía in Thes. 36, 2, Numa 3, 6 et 20, 9, Luc. 3, 8, 4, 4 et 19, 6; Alex. 17, 6, Dio 4, 3, Sept. Sap. Conv. 162 B, De fort. Rom. 322 A et Amat. 762 A, avec Sauóvios in Numa

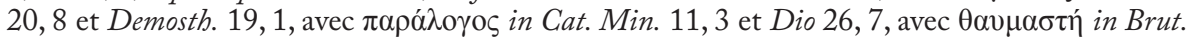

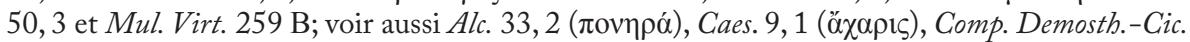

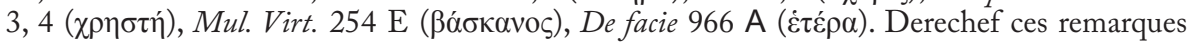
rejoignent celles de Marie-Rose Guelfucci, infra, pp. 142-43. 
romaine qui pourra être plus sensible. Il en résulte toute une série de sens, « hasard » ou « Hasard », «fortune » ou «Fortune », « chance » ou « Chance », qui esquisse les contours incertains du « contingent ${ }^{22}$ » et rend plus pressante la nécessité de prendre en compte tous les éléments textuels et contextuels. Le pluriel, qui se réfère à des "vicissitudes», souvent dommageables, ou, le singulier avec un génitif possessif, comme " la Fortune de César » (Caes. 38, $\left.{ }^{23}\right)$, ne posent pas a priori de gros problèmes de traduction, mais, outre quon ne peut pas en dire autant de leurs implications sur la conception des relations entre divin et humain, ils sont loin de représenter la majorité des cas. Plutarque lui-même semble jouer de la multiplicité possible des sens dans sa polémique contre Chrysippe, lorsqu'il dénonce l'inconséquence du Stoïcien, qui retirerait à Dieu et à la Providence la responsabilité de «la permanence du monde»:

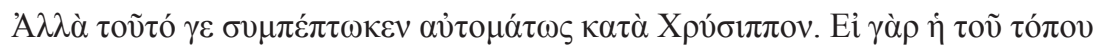

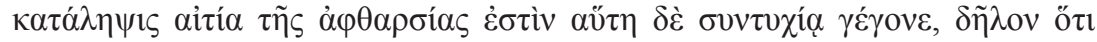

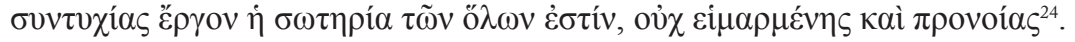

La seconde phrase a suscité de nombreuses gloses sur la place que la syntychia, entendue comme «hasard», pouvait avoir dans la pensée de Chrysippe, mais cette interrogation repose sur l'interprétation du terme suggérée par

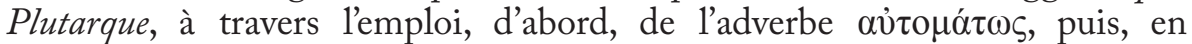

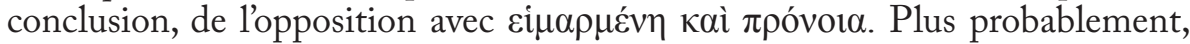
comme le suggère Daniel Babut dans son commentaire, " ces mots ne se rapportent nullement dans le contexte de la citation de Chrysippe, à la notion de " hasard ", mais indiquent seulement que la place occupée par le monde n'existe pas indépendamment de celui-ci: la place du monde n'est rien d'autre que ce qui "se trouve" occupé par celui-ci $\mathrm{i}^{25}$ ».

Cette " inflexion » se fait donc ici à travers des jeux d'associations et d'oppositions. C'est en effet toujours un élément important à considérer pour préciser le sens des mots, en particulier chez un auteur qui cultive avec prédilection l'usage des doublets. Se pose ainsi le problème, délicat, sur lequel je reviendrai, mais dont la reprise détaillée excède de loin les limites de ce préambule, de la $\theta \varepsilon i ́ \alpha$ ou $\delta \alpha ı \mu o ́ v ı s ~ \tau u ́ \chi \eta^{26}$ ou des associations de $\delta \alpha i ́ \mu \omega v$ et

${ }^{22}$ En dehors du contesté De fato 570 E-571 E, on ne trouve pas l'emploi technique en ce sens de $\tau$ ò $\dot{\varepsilon} v \delta \varepsilon \chi o ́ \mu \varepsilon v o v:$ sur le seul passage où la question peut se poser, De facie $938 \mathrm{C}$, voir le commentaire ad loc. de H. Cherniss (Loeb, vol. XII, p. 163), qui conclut à un emploi non technique.

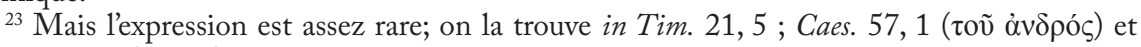
Demetr. 47, 3 (avioũ) semblent un peu différents.

${ }^{24}$ De Stoic. rep. 1055 D: «Mais si l'on en croit Chrysippe, ce résultat s'est trouvé acquis par hasard. Si en effet la cause de l'incorruptibilité du monde est la place qu'il a occupée, et si celle-ci a été le fait d'un accident fortuit, il est clair que le salut de l'univers est l'œuvre d'un accident fortuit, non du destin et de la Providence» (trad. D. Babut, c'est moi qui souligne).

${ }^{25}$ D. BABut, 2004 , n. 572 , pp. 348-9 - avec renvoi aux notes 548 et 567 pour le détail de la position de Chrysippe (c'est à nouveau moi qui souligne).

${ }^{26}$ Voir supra n. 21. 
$\tau u ́ \chi \eta^{27}$. Je m’en tiendrai pour l'instant aux associations et / ou oppositions avec la notion de $\pi \rho o ́ v o 1 \alpha$ dont la traduction, infiniment moins délicate que $\tau u ́ \chi \eta$, rappelle néanmoins la différence entre niveau humain et niveau divin ${ }^{28}$, que le français distingue, en parlant de "Providence » divine et de " prévoyance » humaine. Se mêlent dans cette notion, en des proportions variables selon les passages, pensée et réflexion d'une part, soin et sollicitude de l'autre. L'accent sur la " pensée " divine, dans la droite ligne du Timée 29 —et qui s'épanouit plus tard avec la providence " pré-pensée » du néoplatonisme, antérieure à l'Intellect ${ }^{30}$ - , se trouve, par exemple, dans le De Iside, où c'est la connaissance qui est au premier plan: ainsi l'œil, utilisé pour représenter Osiris, est interprété comme l'emblème de sa pronoia $(51,371 \mathrm{E})$, de même que l'appellation $\mu \eta ́ \sigma \tau \omega \rho$ employée par Homère ("arbitre ») désigne «sa prudence et sa sagesse » (

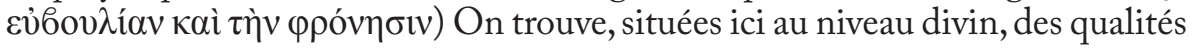
d'intelligence qui interviennent pareillement chez les hommes ${ }^{31}$ : dans les Définitions transmises à l'intérieur du corpus platonicien, la $\pi \rho$ óvor $\alpha$ apparaît

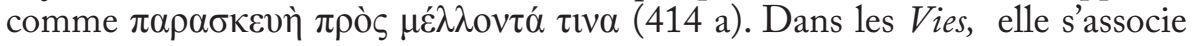
volontiers à $\tau o ́ \lambda \mu \alpha$, chez la même personne pour permettre une action à la fois hardie et réfléchie (Comp. Alc.-Cor. 1, 2, Ant. 3, 932) ou grâce à l'association de deux chefs complémentaires, Alcibiade $(\tau o ́ \lambda \mu \alpha)$ et Nicias ( $\pi \rho o ́ v o r \alpha, A l c .18,1)$

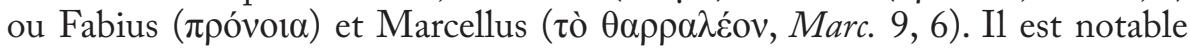
cependant que, dans le Ad principem ineruditum, qui n'est pas sans évoquer la théorie du bon roi telle qu'a pu l'élaborer l'époque hellénistique et que l'utilise le principat, pour soumettre le monde humain à la pronoia du roi ou du prince, comme le monde suit celle de la divinitée ${ }^{33}$, Plutarque, s'il fait bien du souverain «'image de Dieu qui ordonne toute chose ${ }^{34}$ », insiste sur la vertu, la justice, la

${ }^{27}$ Sur lesquelles a attiré l'attention F. E. Brenk, 1977, 145-183.

${ }^{28}$ Voir, par ex., Lyc. 29, 1, où Plutarque, après avoir comparé Lycurgue, parvenu à la fin de

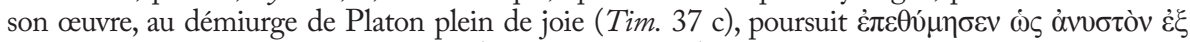

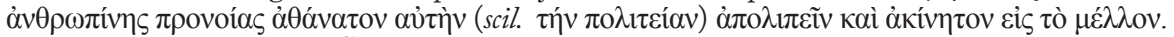

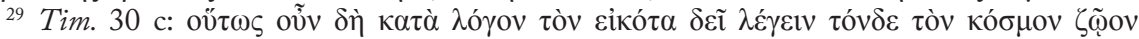

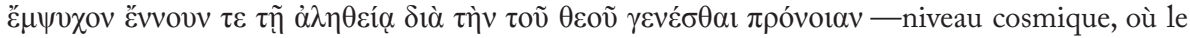
spécialiste de philosophie qu'est Luc Brisson (Paris, GF, $5^{\mathrm{e}}$ ed. corrigée et mise à jour, 2001) choisit de traduire par « décision réfléchie ", pour éviter le terme "providence» ( $c f$. n. 125, p. 231) ; on retrouve le mot au pluriel en 44c: «concernant la génération de chaque partie des corps

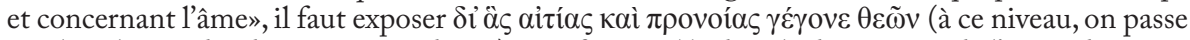
au pluriel aussi des divinités secondaires) et enfin en 45 b, dans la description de l'avant du corps, qui doit aussi avoir fonction de direction («magnifique exemple de description téléologique»,

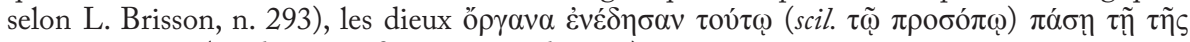

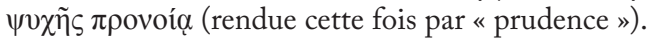

${ }^{30}$ Voir sur ce point J. Opsomer \& C. Steel, 1999, 232.

${ }^{31}$ Exposé rapide par F. Frazier, 1996,209 -à lintérieur de la section consacrée à la vertu de prudence.

${ }^{32}$ Opposition des deux in Cleom. 25, 4, où Plutarque se fait l'écho du jugement de Polybe (II, 64, 1-2).

${ }_{33}$ J.-P. Martin, 1986, dessine bien ce cadre de l'époque: l'idée que Plutarque incarnerait parfaitement cette époque et que l'idéologie serait plus importante dans sa conception que la philosophie me paraît en revanche fort contestable.

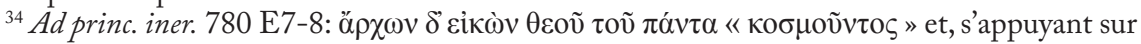
le mot síćv, il oppose à l'œuvre d'un sculpteur le travail sur lui-même du gouvernant (F1-2): 
douceur et la philanthropia, sans jamais utiliser le mot $\pi \rho o ́ v o r \alpha-$ non plus

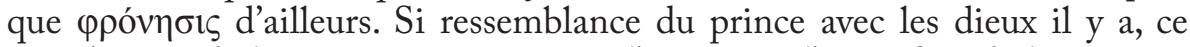
sera du côté de la philanthropia : par où l'on rejoint l'autre face de la $\pi \rho o ́ v o 1 \alpha$

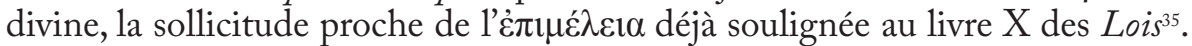
Son expression la plus claire se trouve sans doute dans l'objection faite aux Épicuriens par Chrysippe, que ne désavoue pas Plutarque, mais qu'il met simplement en contradiction avec la théorie stoïcienne de l'ekpyrosis. Alors qu'il « combat surtout Épicure et ceux qui abolissent la Providence en s'appuyant sur les notions que nous détenons au sujet des dieux, conçus par nous comme bienfaisants et philanthropes ${ }^{36}$ ", Chrysippe commettrait la même erreur qu'eux en dépouillant les dieux de leur incorruptibilité (1052 $\left.\mathrm{B}^{37}\right)$.

Cet examen rapide des problèmes que suscite la traduction exacte de $\tau u ́ \chi \eta$ et, à un moindre degré, de $\pi \rho \operatorname{vó}_{\mathrm{v}} \alpha$, destiné d'abord à mettre en évidence les difficultés d'interprétation qu'ils révèlent, rappelle quelques vérités, d'évidence sans doute, mais parfois négligées : l'extension du champ sémantique des notions grecques, l'impossibilité qu'une seule notion moderne le recouvre, les différences d'emploi d'une école à l'autre, d'une époque à l'autre, que peut refléter Plutarque. Il confirme aussi, je crois, la nécessité d'être attentif à l'emploi explicite des notions lorsque l'on veut essayer de préciser la représentation que Plutarque donne de la marche du monde. Est-il légitime de parler de " providence » quand il n'emploie pas le mot $\pi \rho o ́ v o r \alpha ?$ Que signifie le « remplacement » à l'intérieur d'un développement de $\tau \hat{\chi} \chi \eta$ par $\delta \alpha i ́ \mu \omega v$ ? Faut-il postuler dans tous

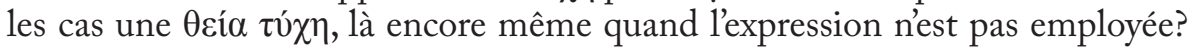
Sans prétendre apporter ici de réponse à toutes ces interrogations, il faut, sur ces bases, reprendre la question, fort débattue, de la diversité des occurrences et de la possibilité d'en tirer une vision cohérente de la marche du monde.

Pour réduire cette diversité et tâcher de l'éclairer, il est tentant, et l'on a tenté, d'opposer Vies et CEuvres morales. Cette position de départ est bien résumée par $\mathrm{S}$. Swain en préambule à une étude centrée sur les Vies et sur les moments historiques majeurs qui semblent marquer une "direction providentielle »:

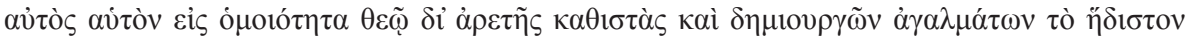

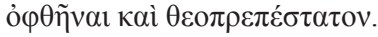

${ }^{35}$ Et qui, malgré les homonymies, malgré l'inflexion religieuse qu'elle reçoit à l'époque de Plutarque, ne doit à aucun moment être confondue avec l'amour divin du dieu de la Bible. Cette différence éclate en particulier dans le dialogue auquel je consacrerai ma propre contribution, le $D e$ sera, où la juste thérapeutique du dieu médecin des âmes n'a rien à voir avec la miséricorde divine.

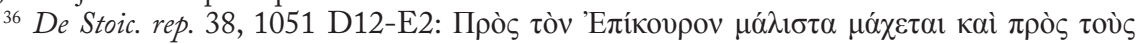

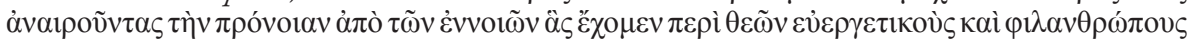

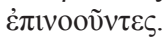

${ }^{37}$ La critique de cette critique est faite par D. BABUt, 2004, n. 473 et 474, p. 309, qui renvoie aussi à D. BАвUт, 1969, 460-462. 
In the religious and philosophical Works of the Moralia Plutarch distinguishes clearly enough between events which are predetermined or guided by providence and those which happen by chance... God is in control of all that is important in the world, and anything that comes about by chance should be held to be irrelevant. In the Lives the posture is different. Here we still find $\theta \varepsilon$ ó $\varsigma$ directing actions, but $\pi$ óvor $\alpha$ has practically disappeared along with 'the divine' and $\delta \alpha i \mu \omega v$ is very much more frequent (with the distinction between $\delta \alpha i \mu \omega v$ and $\theta \varepsilon$ ó $\varsigma$ now blurred). The greatest difference is the meaning of $\tau$ v́ $\chi \eta$. We expect this to mean 'fortune' or 'luck'; but often it is made into a guiding force and is used in contexts where we might have expected God or providence ${ }^{38}$.

Cette distinction, posée comme un donné acquis, a été remise en question très justement par F. Becchi, lors d'un Congrès Plutarque consacré aux genres littéraires, où il la situe toutefois dans un cadre un peu différent:

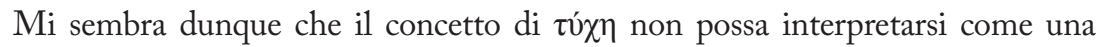
variabile secondo il genere spiegabile con il ricorso all'opposizione tra la teoria e la pratica, tra la posizione teorico-ideale dei Moralia e quella pratico-reale delle Vitae, anche perché si registra un perfetto accordo tra Vitae e Moralia nel riconoscere che la felicità dipende in massima parte dal carattere e dalla disposizione d'animo di ognuno di noi e che la sorte non è in grado di mutare radicalmente una virtù conforme a ragione (Sert. 10.6; Dem. 1.4 ; tranq. an. 471 D) ${ }^{39}$.

De la nature même de "l'accord » entre Vies et Euvres morales mis en avant, il ressort clairement qu'il ne s'agit pas ici d'interprétation historique, comme dans l'étude de S. Swain, mais d'éthique personnelle, dont la fin est le bonheur, et de l'importance respective de la vertu et de la tychè pour l'atteindre. Aussi F. Becchi ne se réfère-t-il pas à l'article de S. Swain comme exemple de l'interprétation qu'il repousse, mais il renvoie au commentaire qu'a donné D. Babut du passage de Sertorius cité par lui entre parenthèses ${ }^{40}$. Pour donner tous les termes du débat, j'en reproduis ici le début et la conclusion, tirée après l'examen d'un second exemple, celui de la Vie de Timoléon ${ }^{41}$ :

Le mouvement de ce texte (scil. Sert. 10) mérite d'attirer l'attention, Plutarque reprenant en quelque sorte d'une main ce qu'il a paru concéder de l'autre : on

${ }^{38}$ S. SwaIn, 1989, 273: c'est moi qui souligne des expressions qui me semblent révélatrices de la différence de méthode entre cette approche et celle que je propose; plutôt que de mettre en avant ce que nous attendons ou attendrions, je suggère, au moins dans un premier temps, d'essayer d'adopter la perspective de Plutarque. Voir aussi les réserves exprimées à la fin de ce volume par A. Casanova, p. 241.

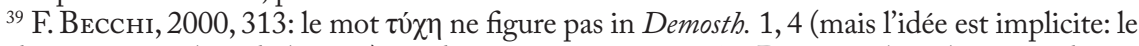
lieu de naissance relève de la tychè), tandis que De tranq. an. $471 \mathrm{D}$ évoque bien la sottise de qui

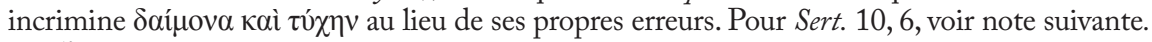

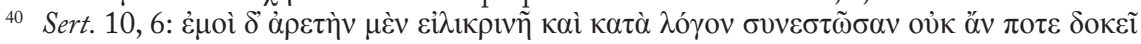

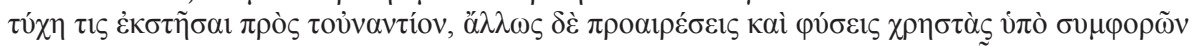

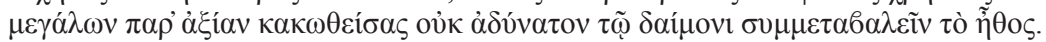

${ }^{41}$ D. Babut, 1969 303-4, n. 5; je mets en gras le passage extrait par F. BЕсCHI , 2000, 313, n. 132 ; le passage sur la Vie de Timoléon est remplacé par [...]. 
peut admettre en principe, semble-t-il vouloir dire, que la véritable vertu est totalement indépendante de la fortune [thèse stoïcienne, cf. SVF III, 237 sqq., I, 449]; mais, d'un autre côté, les caractères vertueux que l'on rencontre dans la réalité ne sont pas à l'abri des défaillances... C'est l'opposition entre la théorie et la pratique, entre les enseignements de l'école et la réalité, que l'on retrouve ici comme dans les textes où Plutarque s'en prend directement au dogmatisme stoïcien. [...] Le mouvement et la conclusion de cette page (scil. Tim. 6) sont les mêmes que dans le passage cité de la Vie de Sertorius: sans doute en théorie, au niveau des concepts, la véritable vertu est-elle à l'abri des coups du sort; mais dans la réalité humaine, il en va en fait tout autrement ${ }^{42}$.

Ce développement, qui n'appartient d'ailleurs pas aux pages spécifiquement consacrées à la tychè ${ }^{43}$, permet donc à $\mathrm{F}$. Becchi de donner un contenu à l'opposition des Vies et des Euvres Morales ${ }^{44}$, mais la visée de D. Babut était autre et s'inscrivait dans le cadre de la polémique antistoïcienne, pour mettre en lumière une attaque précise du dogmatisme stoïcien.

À partir de ces trois analyses, centrées sur un aspect de la question, on peut essayer, je crois, d'esquisser une vision plus globale et de dégager quelques grandes lignes de force pour mieux cerner la manière dont les concepts de $\tau u ́ \chi \eta$ et de $\pi$ póvota sont utilisés dans la description de la marche du monde. Plutôt que la notion de genre ${ }^{45}$, assez floue dans l'Antiquité, ou que l'opposition entre théorie et pratique, il me paraît plus efficient de considérer les problématiques philosophiques dans lesquelles s'inscrit la réflexion de Plutarque. Et l'on en voit immédiatement deux se détacher, où les niveaux de réalité platoniciens fournissent une explication plus satisfaisante, je crois, qu'une opposition entre problèmes d'école et réalités existentielles. La première se situe donc au niveau

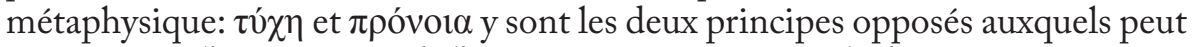

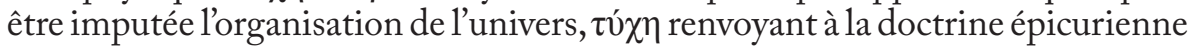
et étant éventuellement attribuée aussi à Aristote ${ }^{46}, \pi \rho o ́ v o เ \alpha$ étant adoptée par Platoniciens et Stoïciens -qui n'en ont cependant pas la même conception. On ne sétonne donc pas de trouver cette problématique avec prédilection

${ }^{42}$ Que l'attaque du dogmatisme stö̈cien prévale ici est des plus probables et D. Babut conclut sa note en remarquant « le parallélisme entre l'image de cette vertu purement théorique

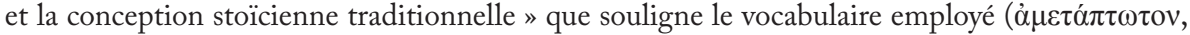
en particulier) ; on peut aussi, je crois, faire un sort à la notion de "pureté » contenue dans

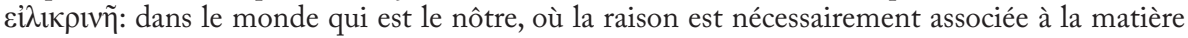
(De def. 435 F par ex. et D. Baвut, 1969, 285, n. 2), il ne peut y avoir de pure vertu, ce n'est pas seulement une vision dogmatique, c'est une erreur anthropologique.

${ }^{43}$ Fait en soi révélateur, la tychè est l'objet de deux développements, l'un, dans les pages qui suivent l'extrait cité, traite du hasard et de la Providence (308-313), l'autre, au chapitre suivant, plus diffus, s'inscrit dans l'étude de l'intervention divine (479-483).

${ }^{44}$ Que, je pense, D. Babut n'aurait pas plus acceptée que lui.

${ }^{45}$ Imposée à F. Becchi, 2000, par le thème même de la rencontre.

${ }^{46}$ J. Opsomer \& C. Steel, 1999, 2.1. «The Platonic middle position » et en part. p.232, sur cette tendance à mettre Épicuriens et Aristotéliciens dans le même camp ; synthétisant les deux analyses, l'idée (aristotélicienne) selon laquelle la Providence ne s'étend pas au-delà des corps célestes est justifiée par la nécessité (épicurienne) de maintenir les dieux à l'abri du trouble. 
dans les traités polémiques de Plutarque ${ }^{47}$ et dans les dialogues platoniciens. Qu'il s'agisse de réfléchir à l'existence et au sens des oracles dans les Dialogues Pythiques, de développer une théodicée dans les Délais de la justice divine ou de montrer " comment la finalité de la Providence vient corriger, dans l'univers, le mécanisme des lois naturelles ${ }^{48} »$ dans le Visage qui est dans la lune, la Pronoia situe la réflexion au niveau supérieur de la cause finale, celle dont Plutarque fait gloire à Platon ${ }^{49}$, qui vient ordonner la matière et y introduire la raison, qui intervient aussi en ce monde pour «signifier» certains messages. C'est ainsi, probablement, dans le Déclin des oracles que l'on voit le mieux s'articuler cause finale de la Providence — celle qu'abordent d'entrée, sous des angles diamétralement opposés, le Cynique Planétiade, qui suppose un départ de la divinité ulcérée de l'indignité humaine (413 A-B), et le maître de Plutarque, Ammonios, qui voit dans la diminution du nombre des oracles un signe de la bonté divine, soucieuse de pas accuser les malheurs de la dépopulation (413 E-414 C) - et causes du fonctionnement - que Cléombrote et Lamprias traitent à deux niveaux différents, celui de la transmission par les daimones ou du mécanisme physique induit par le pneuma, mais qui, dans aucun des deux cas, ne doivent entraîner la suppression du niveau supérieur, comme le rappelle le même Ammonios à Lamprias : « il est terrible, objecte-t-il, de ne pas attribuer la découverte et le principe (scil. de l'oracle) à la divinité et à la Providence, mais à la Tychè et au hasard ${ }^{50}$ ». Plus simple encore, parce qu'il n'appartient pas à une discussion philosophique, mais constitue un commentaire annexe au récit biographique, le passage sur le bélier unicorne de Périclès, cristallisant

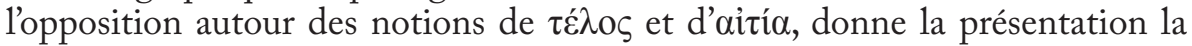
plus claire des deux niveaux de causalité. Anaxagore, par une dissection, avait expliqué la cause du phénomène, tandis que le devin Lampon en avait compris le sens - annoncer le pouvoir de Périclès. Plutarque poursuit:

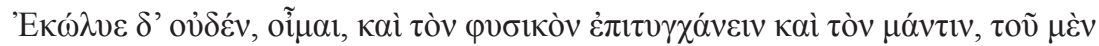

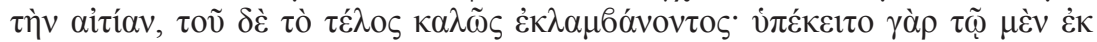

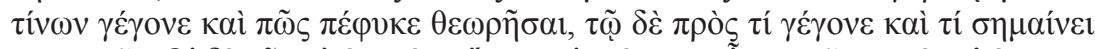

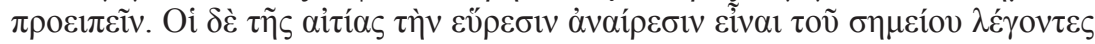

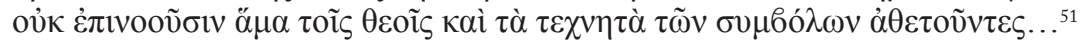

${ }^{47}$ De Stoic. rep. 1035 B, 1043 B, 1044 C et F, 1048 B, C et E, 1050 B et D, 1051 D et E, 1052 C, 1053 B, 1055 D, Stoic. abs. 1057 E, De com. not. 1059 B, 1059 C et D, 1065 D, 1075 B et E, 1077 D et E, Non posse 1092B, 1100 D et E, 1101 C, 1102 A et 1103 A, Adv. Col. 1111 B, 1123 A et $1124 \mathrm{E}$, De lat. viv. $1129 \mathrm{~B}$.

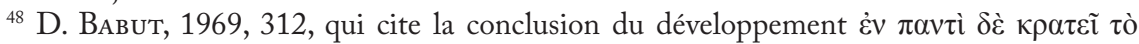

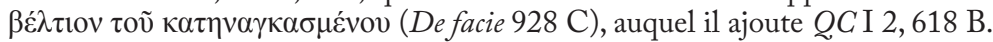

${ }^{49}$ De def. $414 \mathrm{~F}$ et $435 \mathrm{E}$; voir aussi Nic. 23,3-4. De même Proclus considère la doctrine de la Providence comme « la gloire particulière du platonisme » [Theol. Plat. 1, $15(76,10)]$.

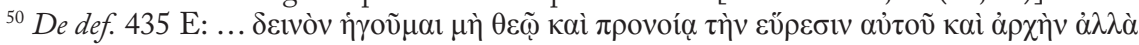

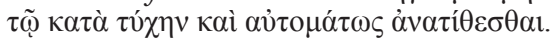

${ }^{51}$ Per. 6, 4-5: «Au reste, rien n'empêchait, je pense, le savant et le devin de rencontrer juste tous les deux, en saisissant correctement l'un la cause et l'autre la fin. Car l'un se proposait de considérer les causes et les modalités naturelles du phénomène, l'autre de prédire en vue de quoi il s'était produit et ce qu'il signifiait. Mais ceux qui prétendent que découvrir le cause, c'est 
Si le concept de $\pi \rho o ́ v o t \alpha$ n'est pas introduit ici, dans un ouvrage qui n'est pas technique ${ }^{52}$, et où Plutarque se contente du vague $\theta \varepsilon o i ́$, il est notable que l'on retrouve le problème des signes, de la communication entre hommes et dieux, qui est au cœur du Déclin des oracles comme des Oracles de la Pythie. À cet égard, sans doute n'est-ce pas un hasard si l'Epsilon, qui débouche sur l'affirmation de l'infinie distance entre la plénitude divine et la faiblesse humaine, est aussi le seul dialogue pythique à ne comporter aucune occurrence de $\pi \rho \operatorname{có} \mathrm{ol}^{53}$. Au contraire, dès qu'il est question du soin que les dieux prennent des hommes ou de la formation du $\operatorname{cosmos}^{54}$, la notion apparaît et l'on pourrait dire que, là où Proclus, par exemple, privilégiera l'antériorité (ontologique) que peut signifier le préfixe $\pi \rho 0-$, Plutarque est plus attentif au sème de sollicitude que comporte $\pi \rho 0-$ pris au sens de « en faveur de ».

Essentielle pour le philosophe, cette opposition s’était aussi répandue au-delà des limites des écoles et faisait partie, pour ainsi dire, des «structures mentales » de l'homme cultivé. De la même manière que, à notre époque, les lycéens français apprennent ${ }^{55}$ que le mouvement thèse / antithèse / synthèse doit structurer une dissertation digne de ce nom, sans que cette version affadie de Hegel enlève rien à la pensée philosophique de celui-ci, de même cette opposition, se retrouve dans une doxographie comme les Opinions des philosophes transmises à l'intérieur du corpus plutarquéen ${ }^{56}$, et, ce qui est plus intéressant encore, dans une conférence comme la Fortune des Romains. Dans un grand mouvement d'amplification, après

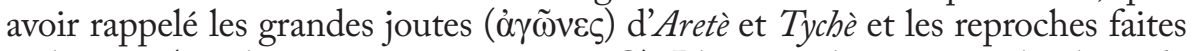
à chacune (stérilité ou inconstance, $316 \mathrm{C}$ ), Plutarque les tourne à la gloire de Rome, témoin décisif pour faire pencher la balance d'un côté ou de l'autre, (316 C9-D2). Bien plus, s'appuyant sur le poète Ion, qui attribuait mêmes œuvres à tychè et sophia, sources l'une et l'autre d'élévation pour les hommes, il conclut son préambule par une grandiose comparaison :

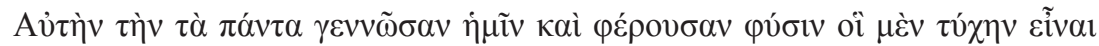

détruire le signe ne réfléchissent pas qu'en même temps que ceux des dieux ils rejettent les signes créés par l'art humain» (trad. R. Flacelière, légèrement modifiée) — suivent les exemples du son émis par les disques, de la lumière des torches ou de l'ombre produite par l'aiguille des cadrans solaires.

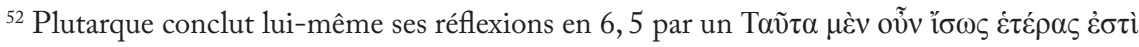
$\pi \rho \alpha \gamma \mu \alpha \tau \varepsilon i \alpha \varsigma$.

${ }_{53}$ Sans surprise, c'est dans le De def. que les occurrences sont le plus nombreuses, (7, $413 \mathrm{~A} 8$ et C8, 8. $414 \mathrm{~F} 1,19,420 \mathrm{~B} 3,24,423 \mathrm{C} 8,29,425 \mathrm{E} 10$ et 426 A3, 30, 426 E1, 46, 435 D10 et 47, 436 D4); pour le De Pyth. 8, 398 A7, 18, 402 E3 et 24, 406 B6.

${ }^{54}$ Voir sur ce point le développement sur la pluralité des mondes dans le De def. (ch. 23-37 : occurrences citées à la note précédente), ainsi que De facie $927 \mathrm{~A} 12$ et C1 (Loeb) et De Iside 369 A8.

${ }_{55} \mathrm{Ou}$, du moins, apprenaient encore au $\mathrm{XX}^{\mathrm{e}} \mathrm{s}$.

${ }^{56}$ Plac. Phil. 2, 3 886D-E; voir là aussi J. Opsomer \& C. Steel, 1999, 233: «Also in the doxographical tradition, marked by its tendency to reduce complex philosophical doctrines and discussion to a few crudely simplified tenets, Epicurus' and Aristotle's doctrine on Providence had been put side by side». 


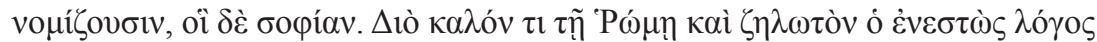

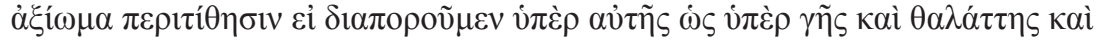

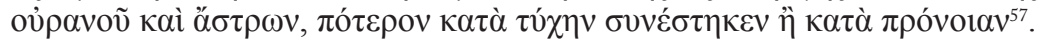

Ce passage a le double intérêt de nous montrer une certaine «banalisation» de l'opposition ${ }^{58}$ et de nous amener à la seconde grande problématique. $\mathrm{Si}$, en effet, dans l'ouverture de sa conférence, Plutarque se situe au niveau des principes, personnifiés avant même d'apparaître en deux superbes cortèges allégoriques inspirés de la mise en scène de l'apologue de Prodicos, Tyché et Aretè, lorsque l'on descend au niveau de la réalisation humaine de l'empire romain, on trouve dans le couple tychè et aretè les deux facteurs essentiels déterminant l'action des hommes.

Dans cette problématique éthique - qui, trouve son expression philosophique dans le Sur la vertu éthique ${ }^{59}$, mais qui, elle aussi, comme le montre la nature même de la Fortune des Romains, a dépassé le strict domaine du philosophe et constitue une structure anthropologique utilisée en dehors des écoles, en particulier dans les éloges rhétoriques ${ }^{60}$ - la tychè représente tout ce que "l'agent moral » rencontre et sur lequel il n'a pas de prise, tandis que l'aretè, qui peut se spécifier en vertus plus particulières, souvent de l'ordre de l'intelligence ${ }^{61}$, représente la part « intérieure », ou, pour mieux dire, personnelle, celle qui dépend de chacun de nous ${ }^{62}$. Consacrées à l'action des hommes d'État, les Vies mettent particulièrement en lumière cette sorte de «face à

${ }^{57}$ De fort. Rom. 316 D9-E5 (je continue de translittérer, là où, dans la CUF, j’ai dû adopter constamment la traduction «fortune», Plutarque lui-même jouant de la polysémie dans l'opposition finale avec $\left.\pi \rho \operatorname{cov}_{\mathrm{v}} \alpha\right)$ : «La nature elle-même, qui pour nous produit et porte toute chose, est, pour les uns, tychè, pour les autres, sagesse. Aussi la présente discussion confère-t-elle à Rome un bel honneur, digne d'envie, puisque nous nous demandons, pour elle comme pour la terre, la mer, le ciel et les astres, si sa constitution est l'œuvre de la Tychè ou de la Providence » (je n'entre pas ici dans la discussion qu'on pourrait avoir sur l'usage des majuscules et donc

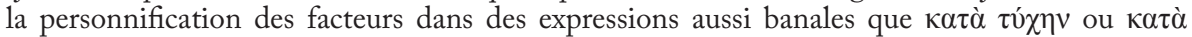
$\pi \rho o ́ v o l \alpha v$ : voir infra, n. 74).

${ }_{58}^{5}$ On la retrouve aussi dans le «badinage » polémique qui ouvre le De com. not. $1059 \mathrm{~B}-\mathrm{D}$.

${ }_{59}$ Après avoir rappelé la distinction du domaine théorétique, objet de la бoøía, et du

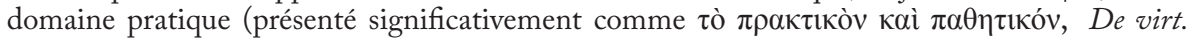

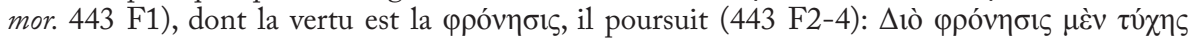

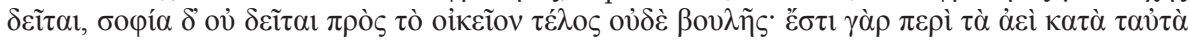

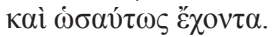

${ }^{60}$ Sans naturellement disqualifier pour autant la discussion philosophique ni reléguer automatiquement qui en discute au rang d'Halbphilosoph: comme on l'a souligné en commençant, l'importance de la tychè dans l'action morale est un élément de divergence majeur entre le stoïcisme et Plutarque. Cette coïncidence entre structures rhétoriques et pensée éthique est mise en lumière infra par Rosario Scannapieco.

${ }^{61}$ En quoi l'on retrouve, transposée au niveau humain,l'opposition métaphysique précédente ; pour introduire l'image de l'univers, Plutarque, dans l'introduction du De Fort. Rom. passe, on l'a vu, par le relais de la sophia; dans le De Fortuna, étudié par F. Becchi, l'antonyme majeur est

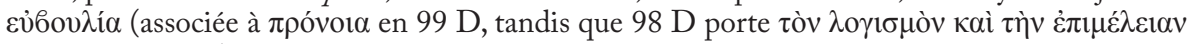

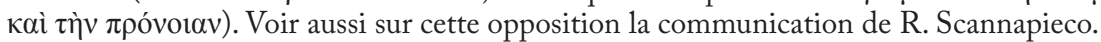

${ }^{62}$ La part de responsabilité humaine est particulièrement appuyée dans une analyse comme celle de Polybe : voir infra la contribution de Marie-Rose Guelfucci. 
face » entre un homme et des circonstances ${ }^{63}$ et aucune préface ne le marque mieux que celle de Phocion et Caton d'Utique, deux héros dont « l'austérité et la grandeur de la vertu nétaient plus en rapport avec les circonstances d'alors ${ }^{64}$ ». Aucun passage cependant n'est plus éclairant que l'introduction de ce dialogue extraordinaire qu'est le Démon de Socrate, où l'on retrouve la matière historique des Vies utilisée comme matière philosophique d'un dialogue platonicien. Il s'ouvre sur une comparaison avec l'amateur de peinture, qui scrute les détails du travail sans se contenter d'une vision générale du tableau:

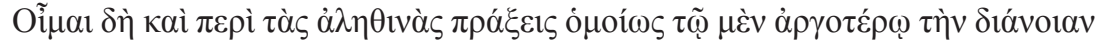

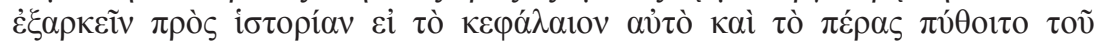

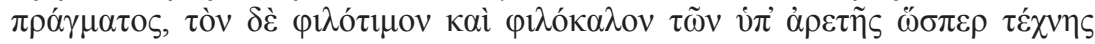

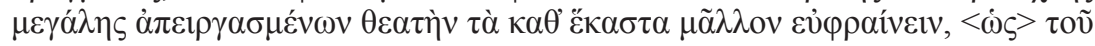

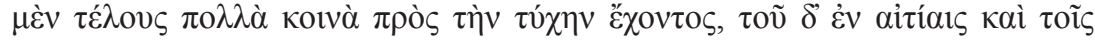

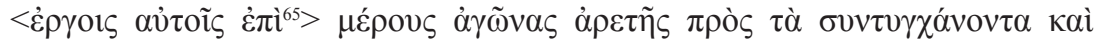

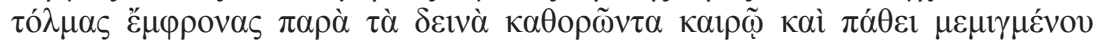
$\lambda \circ \gamma 1 \sigma \mu \tilde{o}^{66}$.

L'historia ainsi visée n'est pas conçue comme simple information factuelle, pur résultat où la tychè a nécessairement sa part, mais comme une « histoire qui ne soit pas inutile ${ }^{67}$ ", où l'on voie l'aretè en action, où, autrement dit, doivent être

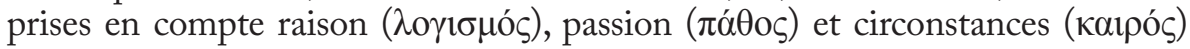
dans une sorte de "gros plan " sur les actions individuelles et les moments particuliers. C'est ce qu'illustre bien la suite du récit où se multiplient les imprévus

${ }^{63}$ J'ai, dans un de mes premiers articles (" À propos de la composition des couples dans les Vies Parallèles de Plutarque ", R.Ph. 61 (1987) 65-75), effleuré une comparaison entre les époques en montrant que ce nétait pas leur spécificité, mais le caractère, favorable ou non, des circonstances offertes au héros qui entrait en jeu (69-70). Elle serait à reprendre et à développer à la lumière de l'opposition entre aretè et tychè à laquelle je n'avais pas encore suffisamment réfléchi à l'époque.

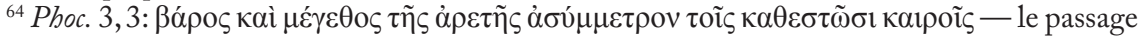
sera commenté par D. Leão et M. do Céu Fialho. La même préface montre qu'il faut aussi tenir

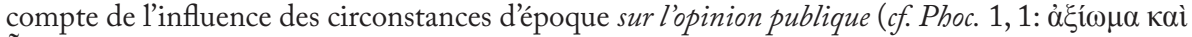

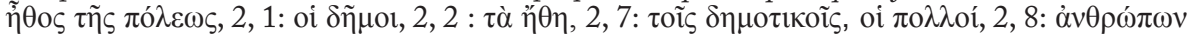
— à côté de la mention des $\tau u ́ \chi \alpha \iota ~ \tau \tilde{\eta} \varsigma ~ ' E \lambda \lambda \alpha ́ \delta o \varsigma, 1,4)$; c'est que le maniement des hommes est un élément majeur de l'action politique, aussi important que la gestion des événements (cf. F. Frazier, 1996, 121-124).

${ }^{65}$ Le texte présente ici une lacune, que je comble selon la proposition de Pohlenz. Si le détail n'est pas clair, le sens général et l'opposition qui nous intéresse ne laissent aucun doute.

66575 B10-C9: «Je crois qu'il en va de même pour les actions réelles : l'esprit paresseux se contente pour l'histoire d'être informé en gros de la substance et de l'issue de l'affaire, tandis que le spectateur épris d'honneur et de noblesse des réalisations de la grande artiste qu'est la vertu trouve plus de plaisir aux détails, pensant que, si le résultat final tient beaucoup de la tychè, quand il s'agit des causes et des actions mêmes, c'est le détail des combats de la vertu contre les conjonctures de la tychè [j'appuie la traduction du participe] qu'il contemple, et les audaces réfléchies face aux dangers d'une raison aux prises avec circonstances et passion.»

${ }^{67}$ Je paraphrase Nic. 1, 5, qui établit aussi une hiérarchie entre les grands événements déjà racontés fort bien par Thucydide et Philistos et qui ne peuvent être totalement passés sous

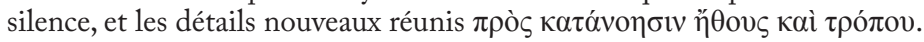


qui mettent à l'épreuve les conjurés, les aléas, ignorés de la Vie de Pélopidas, que la tychè oppose à leur entreprise ${ }^{68}$. Même si elle n'est peut-être pas uniquement éthique - tout dépend de l'interprétation donnée à la discussion sur le démon de Socrate ${ }^{69}$ - la perspective ne correspond en tout cas nullement à ce que nous attendons d'une analyse historique: elle reste au niveau du vécu, que ce soit pour les agents de l'histoire, aux prises avec la tychè, ou pour Socrate, dont il s'agit de comprendre comment il pouvait ici-bas être réceptif aux signes divins.

L'histoire humaine en effet, troisième domaine à considérer, est aussi le plus délicat à interpréter, parce qu'il ne correspond vraiment à aucune problématique claire, comme c'était le cas pour les domaines métaphysique et éthique examinés jusqu'ici ${ }^{70}$. Lorsque le Platonicien veut " prendre de la hauteur ", il considère la formation du monde ou le destin de l'âme - c'est bien la démarche que décrit le Démon de Socrate, où Plutarque recourt au mythe pour expliquer la vraie nature du daimon et l'on pourrait encore citer, toujours dans le même registre, l'interprétation " quelque peu téméraire ", selon les termes de D. Babut ${ }^{71}$, mais significative, du mythe d'Er que propose Lamprias (Q. C. IX 5, $740 \mathrm{C}-\mathrm{D})$ : dans "nos affaires ", le choix du genre de vie ressortit au libre-arbitre ( $\tau \tilde{\varphi} \dot{\varepsilon} \varphi \varphi^{\prime} \eta \mu \tilde{v} v$ ), les conséquences inéluctables de ce choix, qui font que vit bien qui a bien choisi et mal qui a fait un mauvais choix,

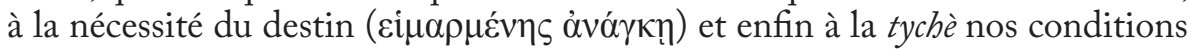
de vie, c'est-à-dire l'éducation et le régime politique qui nous échoient ( $\tau \alpha i ̃ \varsigma$

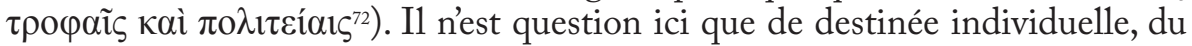
choix de chaque âme. S'il s'agit d'élargir au cours historique des événements, Plutarque nous livre dans la préface de Sertorius une approche qu'il peut être intéressant de relire. Il l'introduit avec une remarque qui a toute chance d'être sienne:

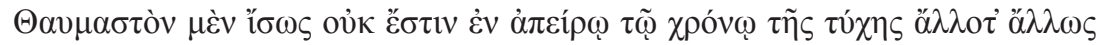

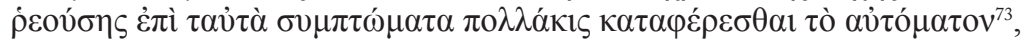

${ }^{68}$ Voir l'introduction par Caphisias du dernier rebondissement, la lettre de dénonciation que reçoit Archias, mais qu'il est, heureusement, trop ivre pour lire in De genio 30, 596 D8-E3; on en retient généralement la métaphore théâtrale (cf. F. Frazier, «À propos de l'influence de la comédie dans l'Érotikos ", in A. Casanova (a cura di), Plutarco e l'età ellenistica, Firenze, 2005, 195-199), mais il est peut-être plus remarquable qu'elle soit encadrée par des notations éthiques

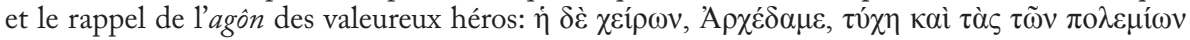

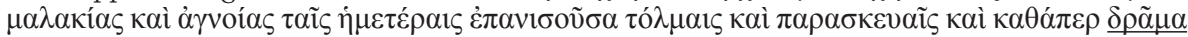

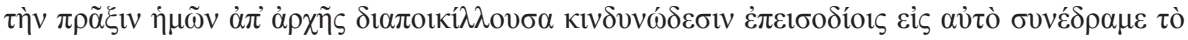

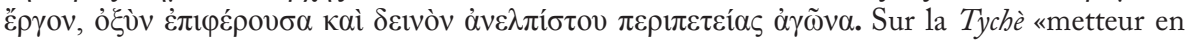
scène», voir aussi la lecture de la fin de Philippe V que propose infra Marie-Rose Guelfucci.

${ }^{69}$ C'est tout le problème de l'articulation du récit avec la discussion philosophique. Les diverses interprétations sont rappelées infra par G. Roskam, n. 73, p. 102.

${ }^{70}$ Voir J. Opsomer, 1997, 343.

${ }^{71}$ D. Babut, 1969, 308.

${ }^{72} \mathrm{Ce}$ qui fait que, sans la philosophie, on a pu, selon Platon, bien vivre, mais dans l'ignorance du bien, faute de cultiver la philosophie, en sorte que l'on fait au moment crucial un mauvais

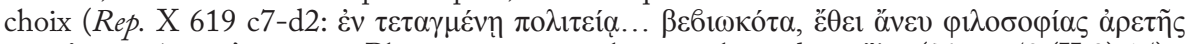

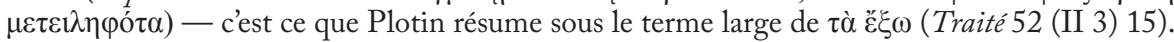

${ }^{73}$ Sert. 1, 1 : «Dans l'infinité du temps, et compte tenu de la variété du cours de la tychè, il 
avant d'évoquer l'attitude d'autres personnes:

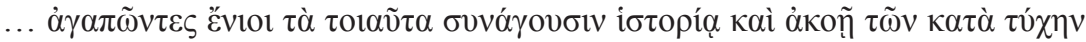

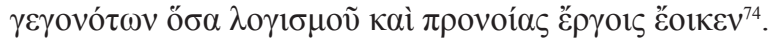

Et de citer en exemples l'existence de deux Attis illustres, de deux Actéons, de deux Scipions, l'intervention de chevaux à chaque prise de Troie, le fait que Ios et Smyrne, l'une lieu de naissance, l'autre lieu de mort d'Homère, portent toutes deux un nom de plantes odoriférantes, avant d'arriver à une liste de grands génies militaires borgnes, où figure celui qui l'intéresse, Sertorius. Tous ces faits isolés relèvent du domaine des « curiosités ", et n'ont guère à voir avec le sens de l'Histoire et quelque intervention providentielle que ce soit pour lui imprimer une direction: comme Plutarque le dit lui-même, ce qui pique l'intérêt, c'est une ressemblance, l'impression que cela résulte d'un calcul, mais lui-même n'y voit, d'après sa réflexion initiale, que hasard et coïncidence.

Plusgénéralement,Plutarquen'évoque jamais explicitementl'intervention de la $\pi$ óvora dans les Vies: le seul passage où le mot ait ce sens se trouve dans la Vie de Pompée (75, 4 et 5), lorsque celui-ci discute avec le philosophe péripatéticien Cratippe de Pergame. C'est un sujet philosophique, bien adapté aux heures difficiles que vit alors le Romain, mais ce n'est pas Plutarque qui parle ${ }^{75}$. Il s'agit donc, ici comme dans la préface de Sertorius, de l'opinion d'autrui et de la manière dont les événements sont vécus et interprétés soit par le héros soit par les gens qu'il a à commander, élément important de la situation politique à laquelle il fait face - et qu'il peut éventuellement «manipuler ${ }^{76}$ », mais qui reste au niveau humain et concerne des faits isolés. Cependant, dans les affaires humaines, bien des éléments échappent au calcul humain, dans lesquels on peut voir "des causes invisibles s7 $^{77}$, qu'on a tendance à attribuer à une puissance supérieure ${ }^{78}$ : de là chez le biographe lui-même, lorsque ces événements imprévus ou imprévisibles (la différence est importante, puisqu'elle met en jeu l'euboulia humaine, pour employer le vocabulaire du Sur la Fortune ${ }^{79}$ ), l'évocation de plusieurs causes possibles. Je

ne faut sans doute pas s'étonner que le hasard aboutisse souvent aux mêmes événements » (trad. D. Babut in D. Babut, 1969, 310).

${ }^{74}$ Sert. 1, 3 : « il y a des gens qui recueillent avec prédilection, par enquête ou ouï-dire, tous ceux des événements arrivés du fait de la tychè qui ressemblent à des œuvres du calcul et d'une providence (ou, avec un hendiadyn, d'un calcul providentiel) ».

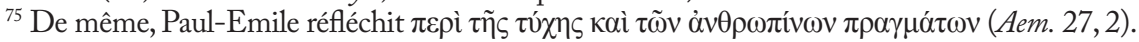

${ }^{76}$ Voir sur ce point les contributions de Monica Duran Mañas et de Marie-Rose Guelfucci.

${ }^{77}$ Voir, par ex., Tim. 14,2, où sont présentées les réactions de ceux qui ont vu tomber Denys, les uns se réjouissant de le voir abattu par la Tychè, tandis que les autres, pleins de compassion, $\dot{\varepsilon} \theta \varepsilon \tilde{\omega} v \tau$ to

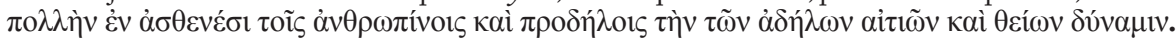

${ }^{78}$ Sur cette bipartition, voir encore ce que dit Paul-Emile, qui se présente, dans un discours

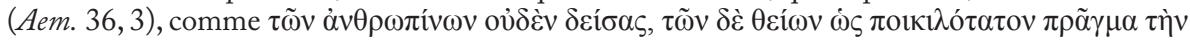

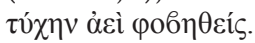

${ }^{79}$ Voir infra la contribution de F. Becchi et, pour la distinction, Cras. 27, 6 (après le désastre

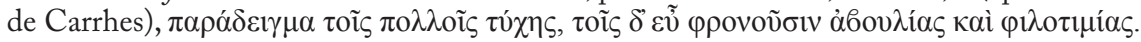


me contenterai pour le montrer de l'introduction du récit de Chéronée dans la Vie de Démosthène :

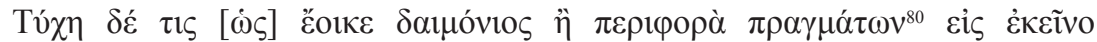

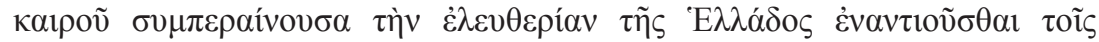
$\pi \rho \alpha \tau \tau O \mu \varepsilon^{\prime} \vee{ }^{81} \varsigma^{81}$.

Dans ce passage, où Plutarque se souvient peut-être du récit de Démosthène lui-même ${ }^{82}$, tout mériterait commentaire : l'emploi, à nouveau, du verbe "sembler ", la modalisation de la dite tychè par $\tau ı \varsigma$ et la mention du

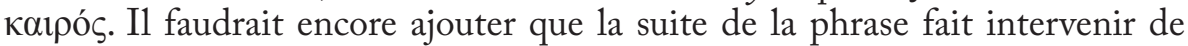
nombreux «signes», qu'énumère Plutarque avant de confesser la difficulté qu'il y a à «arbitrer» en ce domaine ${ }^{83}$.

Échec majeur et décisif où semble se manifester un pouvoir surnaturel, Chéronée présente les caractéristiques mêmes des grands moments qui invitent à s'interroger sur une certaine direction providentielle de l'Histoire. Au déclin de la Grèce, S. Swain ajoute, dans cette même catégorie, la libération de la Sicile, l'origine de Rome, l'extension du pouvoir romain dans l'Orient grec, la chute de la république et l'établissement d'un pouvoir monarchique à Rome ${ }^{84}$. Le savant anglais ne méconnaît nullement l'importance que garde toujours le facteur humain et éthique, et l'on pourrait, dans le même esprit, souligner que les interrogations sur les raisons de tel ou tel événement interviennent avec prédilection quand un héros vertueux échoue, à l'instar de Phocion et Caton ${ }^{85}$, et surtout de Brutus ${ }^{86}$. Ce point acquis, on peut aussi se demander si, au-delà des problématiques que constituent les conditions d'action de la vertu humaine ou l'existence d'interventions divines dans le monde humain, se dégage la conception d'une certaine finalité de l'histoire, qui excède le simple constat a posteriori du cours qu'ont pris les événements ${ }^{87}$. D. Babut le suggère ${ }^{88}$, tout

${ }^{80} \mathrm{Il}$ existe dans la tradition une autre leçon $\dot{\varepsilon} v \pi \varepsilon \rho 1 \varphi \circ \rho \tilde{\alpha}$, adoptée par B. Perrin dans la Loeb: voir le commentaire de F. E. Brenk, 1977, 169 et n. 23 ; elle me semble moins bonne que la leçon retenue par Ziegler dans l'édition Teubner et reprise dans la CUF que je donne ici.

${ }^{81}$ Demosth. 19, 1: "Il semble qu'une sorte de tychè divine (R. Flacelière force à nouveau la traduction en parlant de "destin surnaturel ») ou le cours des événements fixant à ce moment décisif les bornes de la liberté de la Grèce s'opposait à ce qui était fait.»

${ }^{82}$ R. Flacelière (CUF, t. XII, note ad loc. p. 140) rapproche de $S$. cour. 271: ... $\alpha \dot{v} \theta \rho \omega ́ \pi \omega v$

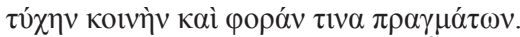

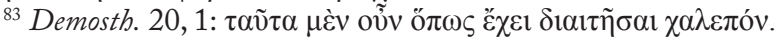

${ }^{84}$ S. Swain, 1989, 276: «Certains periods and / or major events clearly attract comments on

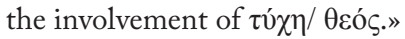

${ }^{85}$ Mais l'échec peut s'expliquer dans leur cas par une certaine inadaptation à la situation : voir infra la contribution de Delfim Leão.

${ }^{86}$ Voir D. Babut, 1969, 480: «Il arrive souvent qu'elle (scil. l'intervention divine) tende à infléchir le cours de l'histoire indépendamment, pourrait-on penser, des mérites ou démérites des acteurs du drame »; suivent les exemples de Démosthène et de Brutus.

${ }^{87}$ Point qui sera abordé infra pour Polybe, témoin et analyste de l'ascension de Rome, par Marie-Rose Guelfucci.

${ }^{88}$ D. BAвит, 1969, 481 : «Le scepticisme instinctif avec lequel Plutarque accueille ce genre de traditions, particulièrement nombreuses quand on aborde la période la plus ancienne de 
en soulignant à quel point Plutarque reste attentif à «éviter un recours abusif à l'intervention divine ${ }^{89} "$, «hasard, causalité naturelle, providence divine... concour(a)nt, en un équilibre subtil, à l'enchaînement des événements», tandis que S. Swain exprime cette finalité à travers l'hypothèse que certains événements semblent non seulement se produire, mais plaire aux dieux $x^{90}$ et il conclut son étude en s'interrogeant sur « les fins de la Providence ${ }^{91}$ ». Derrière le problème philosophique se profile aussi la question si débattue de l'opinion de Plutarque sur Rome. Ce nest pas ici le lieu de la reprendre, mais il me semble que parler de concours de causes de nature différente, de plaisir des dieux ou de finalité de l'Histoire n'est pas exactement la même chose et qu'il vaudrait la peine de réexaminer ce qui nous est dit dans les Vies, en attachant aussi la plus grande attention au vocabulaire employé et aux points de vue. Pour le dire autrement, l'existence d'une «philosophie de l'histoire ${ }^{92}$ » chez le platonicien qu'est Plutarque ne me semble pas aller de soi et mériterait sans doute un réexamen pour la confirmer ou l'infirmer.

Laissant pendante la question d'un « sens de l'Histoire » et de l'intérêt de Plutarque pour ce que nous appelons philosophie de l'histoire, le présent recueil propose donc modestement quelques aperçus sur la «marche du monde», aperçus divers d'où l'on peut dégager trois grands axes.

Une première partie aborde les questions sous l'angle le plus philosophique, et place la réflexion dans le cadre des discussions polémiques entre écoles. Seule fait exception «l'ouverture», qui, avec Rosa Maria Aguilar, rend hommage au platonisme de Plutarque en esquissant le tableau comparatif des deux grandes visions du monde peintes respectivement dans le mythe de Timarque et dans le mythe de Thespésios. Les auteurs suivants se concentrent sur des notions plus techniques et problématiques, qui mettent en jeu le libre-arbitre, le destin ou la fortune. Dans une longue et minutieuse étude, Raúl Caballero revient sur

l'histoire (scil. les légendes extraordinaires comme celles de Romulus et Rémus), se trouve ainsi tempéré par la conviction que la simple explication par les causes naturelles ne suffit pas à rendre compte de la complexité des faits, et surtout de la finalité que révèle parfois l'histoire.»

${ }^{89}$ Ibid. 482-483.

90 S. Swain, 1989, 276 : «Plutarch did not simply muddle what happened with what was destined to happen. The present order and good government of the world was pleasing to the divine in his eyes, and indeed divine interest was obvious in the natural world around him also. »

${ }^{91}$ Ibid. 292-298, «V. The Aims of Providence».

${ }^{92}$ Voir, par exemple, la conclusion de son étude sur daimon et tyche par F. E. BRENK, 1977, 183: "It is evident that for Plutarch's philosophy of history tyche was a very important element indeed "; l'importance de la tychè est indéniable, mais une " philosophie de l'histoire ", au sens où nous l'entendons, va-t-elle de soi? Quant à l'hypothèse d'une « cosmologie de l'histoire » que C. Darbo-Péchanski, L'historia. Commencements grecs, Paris, 2007, 308-311, croit pouvoir tirer d'une synthèse fulgurante du De procreatione et de la préface de Sertorius, elle ne me paraît guère convaincante, pas plus que la méthode consistant à juxtaposer deux extraits aussi limités et disparates de l'œuvre de Plutarque pour tirer des conséquences aussi vastes ne me semble pertinente. 
une controverse hellénistique touchant la liberté d'indifférence dont Plutarque se fait l'écho au chapitre 23 des Contradictions des Stoïciens (1045 B) et qui a fait l'objet aussi de nombreux débats entre savants modernes. Retrouvant dans cette page du Chéronéen un épisode de la polémique du $\mathrm{III}^{\mathrm{e}} \mathrm{s}$. autour de la certitude de la connaissance et des risques d'à $\pi \rho \alpha \xi i ́ \alpha$ liés à l'àjopí $\alpha$ Ẻv $\dot{\alpha} \pi \alpha \rho \alpha \lambda \lambda \alpha \dot{\alpha} \tau \tau$ o1ร, il en propose une reconstitution dont il détaille les étapes, d'une polémique interne à la Stoa entre Ariston, l'«inventeur» de la notion d'غ̇ $\bar{\varepsilon} \lambda \varepsilon v \sigma 1 \varsigma$, et Persée, aux critiques académiciennes d'Arcésilas, qui transforme

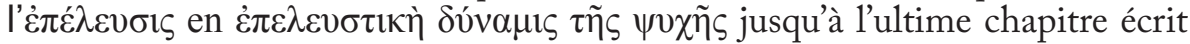
par Chrysippe, substituant à l'idée d'une indiscernabilité totale le concept

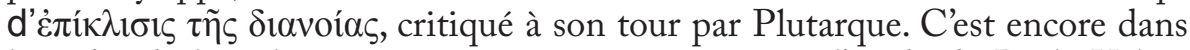
le cadre de la polémique antistoïcienne que se situe l'étude de Paola Volpe:

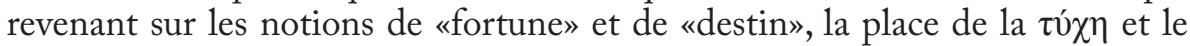
problème des possibles, elle fait la liste des objections présentées par Plutarque dans les chapitres 44-47 des Contradictions des Stö̈ciens et lit sa tentative de solution comme un effort pour concilier Providence et libre-arbitre. Centrée

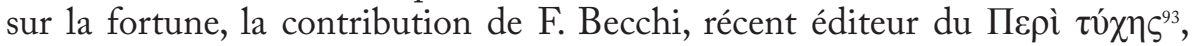
présente cet opuscule comme un «écrit de philosophie éthique, où l'auteur

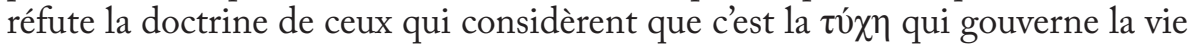
des hommes et où il défend la valeur de l'ev̉bov $\lambda$ í $\alpha$ » et il retrace l'histoire de son interprétation. La polémique encore est au cœur de l'étude de Juan Francisco Martos Montiel, mais elle vise cette fois les Épicuriens... et les interprétations modernes qui cherchent à réduire les contradictions entre les critiques, opposées, formulées par Plutarque contre la superstition dans l'opuscule homonyme et contre l'athéisme dans le Non posse. Contre ces tentatives, le savant espagnol souligne le contraste entre l'exactitude matérielle des citations épicuriennes faites par le Chéronéen et l'inexactitude tendancieuse de ses interprétations.

Les notions mises en jeu, l'athéisme et la superstition, servent de transition vers le second grand axe, où les relations entre hommes et dieux passent au premier plan. De nouveau cette partie s'ouvre sur des contributions «platoniciennes». Françoise Frazier s'attache à la théodicée de Plutarque dans les Délais de la justice divine, dialogue qui prend encore pour point de départ l'opposition de la Providence platonicienne avec la tychè épicurienne, mais qui, s'élargissant considérablement, s'inscrit, par la mise en scène, mais surtout à travers la dernière partie de la discussion et le mythe, dans le cadre delphique: philosophie et religion s'unissent et se renforcent dans ce qui peut se lire comme un dialogue pythique. Platonicien est aussi le thème du "démon de Socrate » que Geert Roskam développe: comparant son traitement par Maxime de Tyr, Apulée et Plutarque, il scrute la série, beaucoup plus élaborée, des réponses proposées par Plutarque, le seul à réserver une place à une réponse rationaliste, avec l'exposé initial de Galaxidoros. À travers les interventions successives, celle de Simmias, qui exploite de façon originale la traditionnelle pureté morale de Socrate, avant de développer un mythe à la manière platonicienne,

\footnotetext{
${ }^{93}$ La Fortuna, Napoli, d'Auria, 2010 (= CPM n $\left.{ }^{\circ} 47\right)$.
} 
jusqu'au «dernier mot» de Théanor, qui élargit la perspective, c'est tout un itinéraire qui se dessine, avant que le texte revienne à l'action immédiate de la libération de la Cadmée. Cette réalité du monde humain est au cœur des deux études suivantes : spécialiste d'histoire des religions, Ana Isabel Jiménez San Cristóbal commente de très près le passage des Oracles de la Pythie (407 B-C), où Plutarque évoque les personnages qui ont porté atteinte à la crédibilité de

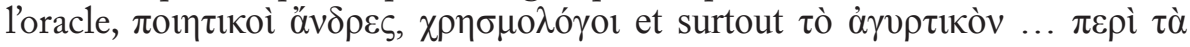

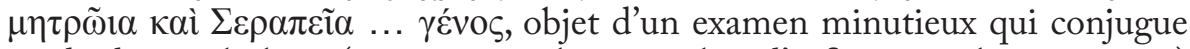
étude du vocabulaire (non exempt, lui non plus, d'influences platoniciennes) et prise en compte de la réalité des cultes orientaux; la liste s'achève sur la condamnation de $\gamma o ́ \eta \tau \varepsilon \varsigma$ et $\psi \varepsilon v \delta o \mu \alpha ́ v \tau \varepsilon 1 \zeta$, mot ultime qui résume l'activité de gens transformant la divination en activité lucrative. Remontant dans le temps, Monica Duran Mañas s'attache pour sa part aux rêves rapportés dans les Vies des héros hellénistiques - l'époque qui est le plus souvent associée au règne de Tychè - et conjugue elle aussi étude de vocabulaire et commentaire en contexte, pour faire apparaître la prééminence chez Plutarque biographe de l'utilisation psychologique.

Cette première étude sur les Vies constitue une transition vers le dernier axe, celui qui aborde l'interprétation de l'action humaine et de la part qu'y a la tychè. L'importance que cette dernière a prise au cours de l'époque hellénistique est souvent mise en avant, lieu commun, voire "idée reçue ", dont la (trop?) large utilisation invite à un réexamen. La spécialiste de Polybe qu'est MarieRose Guelfucci, s'appuyant sur le chapitre qu'elle avait consacré à ce thème dans sa thèse d'habilitation soutenue à Paris IV-Sorbonne en 1994 et restée inédite et qu'elle avait déjà retravaillé pour une communication au congrès international de Besançon de novembre 2006 intitulé " Jeux et enjeux de la mise en forme. Aux marges de l'histoire? ${ }^{94}$ ", donne en ouverture une longue et minutieuse analyse de l'ensemble des emplois de tychè dans les Histoires. Le quasi «essai» qu'elle rédige ainsi propose une vision nouvelle, à la fois cohérente et stimulante, de la démarche de l'historien qui, je crois, pourrait servir de base à un réexamen de "notre Plutarque » et nous amener à prêter plus d'attention aux « points de vue " reflétés dans le récit, en les distinguant nettement des commentaires personnels de l'auteur. Suivent trois contributions qui reviennent sur ces moments importants de l'histoire où l'on peut croire à quelque intervention divine : Aurelio Pérez Jiménez relève les passages essentiels dans l'ensemble des Vies, et singulièrement ceux qui concernent les premiers temps de Rome et son ascension, et propose de donner un contenu aux « projets de la Providence » évoqués par S. Swain, tandis que Delfim Leão et Maria do Céu Fialho se concentrent sur le personnage de Phocion, qui eut, comme Caton, à affronter des circonstances hostiles. Le premier insiste sur l'analyse des notions essentielles de tyche, kairos et chronos, tandis que la seconde s'attache à la construction textuelle de la figure, mettant au jour la comparaison interne entre le Grec et le Romain qu'on peut lire en filigrane dans le récit de cette

\footnotetext{
${ }^{94}$ À paraître prochainement aux Presses Universitaires de Franche Comté.
} 
paire dépourvue de synkrisis finale. Y participent en particulier l'utilisation du modèle de Socrate et la référence à un hypotexte sophocléen. Les textes poétiques sont encore, à divers titres, au cœur des deux dernières contributions. Des Vies on passe, avec Rosario Scannapieco, au corpus des Moralia et à l'image d'Alexandre. Prenant pour fil conducteur dans la diversité des occurrences les passages poétiques, et particulièrement les citations d'Homère et d'Hésiode,

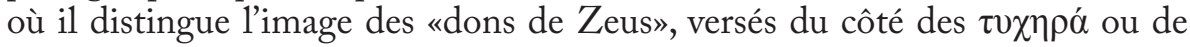

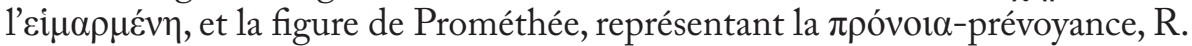
Scannapieco montre d'abord, en s'appuyant sur le Comment écouter les poètes, objet d'une minutieuse comparaison avec le Sur la fortune, puis en confrontant un passage de la Vie d'Homère (120-121), le chapitre 23 de Coriolan et les Contradictions des Stoïciens (1048 C-49 A), comment se dégagent des structures rhétoriques récurrentes qui correspondent aussi à une conception cohérente des relations de la fortune et de la volonté individuelle. Il se concentre ensuite sur le personnage d'Alexandre et les conférences qui lui sont consacrées, prenant désormais pour point majeur de comparaison le Prométhée d'Eschyle, avant d'esquisser une comparaison avec le traitement du même sujet pour Rome. Enfin, Angelo Casanova, après avoir replacé les notions de tychè et de pronoia dans le cadre large de la pensée de Plutarque et mis en lumière tous les «contrepoids» que la vertu humaine peut opposer à la tychè, attire l'attention sur les citations, qui ne sont sans doute pas «hasardeuses», d'un auteur aussi sensible que Plutarque à l'influence de la tychè sur le caractère, Ménandre. Son analyse débouche sur un examen textuel minutieux de deux de ces citations, dans la Fortune des Romains (316 C-D) et dans les Propos de Table (III 6, 654 D), concluant ainsi notre volume sur la même double note philosophique et philologique qu'a essayé de donner cette introduction. 


\section{Ouvrages et articles Cités}

Babut, D. Plutarque et le stoïcisme, Paris, 1969.

-Plutarque, Euvres Morales, t. XV-1 et 2, Traités antistoïciens, texte établi par Michel Casevitz, traduction et notes par D. Babut, Paris, 2004 et 2002.

— «L'unité de l'Académie selon Plutarque. Notes en marge d'un débat ancien et toujours actuel», in M. Bonazzi, C. Lévy \& C. Steel (eds.), A Platonic Pythagoras. Platonism and Pythagorism in the Imperial Age, Brepols, 2007, 63-98.

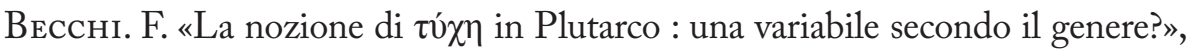
in I. Gallo \& C. Moreschini (a cura di), I generi letterari in Plutarco, Atti del VIII Convegno plutarcheo (Pisa, 2-4 giugno 1999), Napoli, 2000, 299-317.

Brenk, F. E. In Mist Apparelled: Religious Themes in Plutarch's Moralia and Lives, Leiden, 1977.

Frazier, F. Histoire et Morale dans les Vies Parallèles de Plutarque, Paris, 1996.

Ildefonse, F. Plutarque, Dialogues Pythiques, Paris, GF nº 1051, 2006.

Martin, J.-P. «Plutarque: un aspect de sa pensée et de son temps », Mélanges offerts à M. Labrousse, Pallas h.s., 1986, 59-78.

Opsomer,J., «Quelques réflexions sur la notion de Providence chez Plutarque», in C. Schrader, V. Ramón y J. Vela (eds), Plutarco y la historia, Zaragoza, 1997, 343-356.

Opsomer, J. \& \& Steel, C. «Evil without a Cause. Proclus' Doctrine on the Origin of Evil, and its Antecedents in Hellenistic Philosophy», in T. Fuhrer \& M. Erler (hrgs), Zur Rezeption der hellenistischen Philosophie in der Spätantike, Stuttgart, 1999, 229-260.

Peters, F. E. Greek Philosophical Terms. A Historical Lexicon, New York / London, 1967.

SwaIn, S. «Plutarch: Chance, Providence and History», AJPh 110 (1989) 272-302.

Torraca, L. «I presupposti teoretici e i diversi volti della tyche plutarchea», in I. Gallo (a cura di), Plutarco e la religione. Atti del VI Convegno plutarcheo (Ravello, 29-31 maggio 1995), Napoli, 1996, 105-55. 
Doctrines et Débats Philosophiques 


\title{
LA VISIÓN DEL MUNDO SEGÚN LAS REVELACIONES \\ DE SERA, 563f-568a y DE GENIO, 589f-592e
}

\author{
Rosa Ma. Aguilar \\ Universidad Complutense Madrid
}

\begin{abstract}
This paper deals with details of the myths that we can find in the two treatises De sera numinis vindicta and De genio Socratis. The aim is to make a comparison in order to establish what they have in common and what is different and has no direct parallelism. We could conclude that the dissimilar element found there - "a great abyss, round, as though a sphere had been cut away" is to be taken as our planet, the earth.
\end{abstract}

\section{Introducción}

No es nuestro propósito hacer un relato descriptivo de las visiones que tuvieron en el Más Allá los protagonistas de estos dos mitos escatológicos, pues de los mitos de estos dos diálogos se tratará aquí como podrá observar todo avisado plutarquista. Lejos, muy lejos de tal propósito estamos, que luego se nos tachará de seguro del pecado de didactismo propio de docentes. Sin embargo, tampoco es posible hablar de estas visiones sin hacer un mínimo recordatorio sobre sus protagonistas y las circunstancias en que ocurrieron las visiones, naturalmente. Queremos con esta introducción llamar la atención tan solo sobre los paralelismos y también diferencias que se nos muestran al hilo de sus narraciones cuando ya han regresado de ese otro mundo al que llegaron por causas diferentes pero con resultados semejantes.

\section{Introducción: Relato de Tespesio}

Arideo, quien después será llamado Tespesio² por su pariente y guía en la ultratumba, murió tras un vida disipada, al caerse y torcérsele el

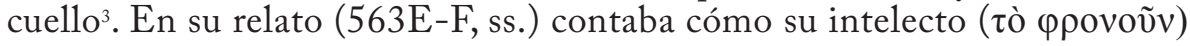
experimentó en un principio por el cambio, al salir del cuerpo, lo que un piloto al hundirse en el mar. Pero poco después le parecía respirar expandiéndose mientras subía y que contemplaba todo en su derredor como si se abriera su alma en un solo ojo. Al principio sólo veía las estrellas, muy grandes y distantes, que emitían un colorido suave y dotado de energía y así su propia alma se movía con ligereza como un barco en un mar en

${ }^{1}$ Trans. by Ph. De Lacy and B. Einarson, Mor.VIII, p.467 (De gen. Socr 590F).

${ }^{2}$ El cambio de nombre tiene un significado casi místico: se cambia el nombre al haber un cambio en la persona, así en las apoteosis como la de Sémele, la madre de Dioniso, quien recibió el nombre de Tione o la de su hermana Ino que recibió el de Leucotea.

${ }^{3}$ En Platón, Timeo, 69e, el cuello "es el istmo y límite" entre la cabeza, donde está la parte divina del alma y el cuerpo donde habita la mortal, pero ya desde Homero tenía importancia en la separación de alma y cuerpo. 
calma. Contaba también cómo veía subir las almas de los que morían como una burbuja de fuego de la que, al estallar salían con figura humana ${ }^{4}$, ligeras en su volumen y dotadas de movimientos desiguales: unas subían saltando hacia arriba con gran ligereza; otras se movían en círculo como husos $(564 \mathrm{~A})^{5}$, pero formando, al subir y bajar, espirales desordenadas. De comienzo no reconocía a ninguna de estas almas, pero cuando creyó ver a algunos conocidos (evidentemente conservaban su aspecto humano de vivos) le rehuyeron emitiendo gritos inarticulados e ininteligibles de terror, al juntarse con otras almas semejantes. Más lejos veía en una región pura del aire a otras almas que brillaban alegres y lo demostraban buscando a otras semejantes a ellas, pero que demostraban también su disgusto apartándose de las desordenadas y tumultuosas, en un caso con expansión de sí mismas, en el otro contrayéndose sobre sít. Sin duda, esta narración de Tespesio, tan centrada sobre el aspecto y comportamiento de otras almas cercanas tiene su raíz en que pertenece a un tratado donde se exponen primordialmente los castigos de las almas en el Más Allá.

\section{Introducción: Relato de Timarco.}

En este caso nos encontramos en el mito con sucesos semejantes. También un golpe en la cabeza, pero como este muchacho es muy virtuoso se lo da, en nuestra opinión, al caer en el antro de Trofonio a donde va a consultar el oráculo y desciende violentamente por la pendiente de la gruta, aunque su informe dice que, después de haber orado, juntamente con un ruido su cabeza, golpeada, dejaba salir el alma por las suturas. Cuando se recobra tiene experiencias semejantes: su alma subiendo se mezclaba con el aire puro y al respirar se hacía más grande, como una vela desplegada. Al levantar sus ojos no pudo ver ya la tierra; en cambio, vio islas iluminadas por un fuego suave, innumerables y desiguales, pero todas redondas; imaginaba él que en su movimiento circular resonaban en el éter ${ }^{7}$.

\section{Comparación}

Si comparamos el comienzo de los dos mitos podemos ver innegables paralelismos de contenido y de vocabulario como puede verse en los términos o bien frases subrayadas.

${ }^{4}$ Aquí se superponen dos tradiciones, en primer lugar la peripatética (véase Eliano, Var. Hist. 2. 11 [Hercher]) y la estoica (Crisipo, Stoic. Vet. Frag. 2. 815) en las que el alma de los muertos tiene forma esférica y después la pitagórica en la que conservan la forma del cuerpo que tuvieron en vida (Diógenes Laercio, 8.31). La burbuja de fuego podría ser una reminiscencia de Heráclito a través del estoicismo (Cf. Plu., Comm. Not.1084 D).

${ }^{5}$ Recordemos el pasaje paralelo del De genio Socratis, 592A.

${ }^{6}$ Ver el mito del De genio, 590F.

${ }^{7}$ Sobre este pasaje y la música de las esferas de tradición pitagórica, ver Y. Vernière, 1977, p.175 y n. 6. También A. Pérez Jiménez, 1996, p.299. 


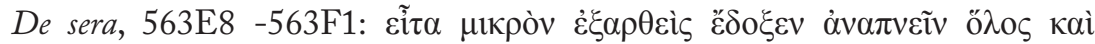

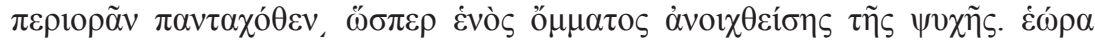

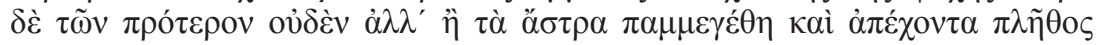

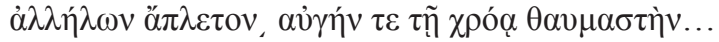

Después, tras haberse elevado un poco, le pareció que su ser entero respiraba y miraba todo alrededor abriéndose su alma como un solo ojo. No veía nada de lo anterior, solamente estrellas inmensas y distantes entre sí un enorme espacio, que emitían radiaciones admirables por su colorido (Mor. VIII, 156) .

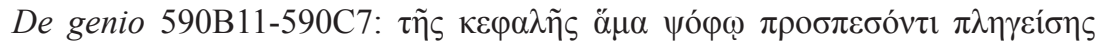

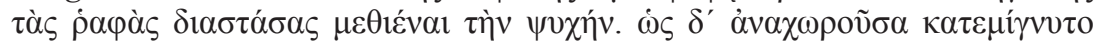

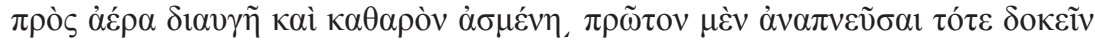

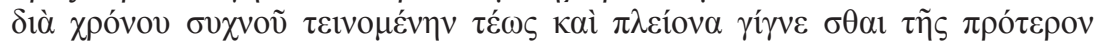

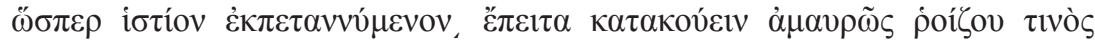

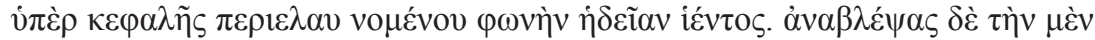

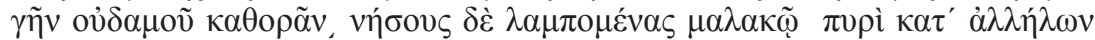

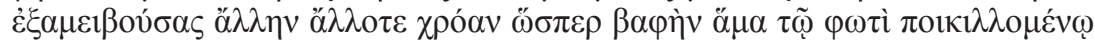

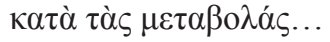

Cuando ésta se alejó y se mezcló gozosa en el aire radiante y puro, le parecía que primero tomó aliento un largo rato, tras haber estado hasta entonces comprimida, y que se hacía mayor que antes, como una vela desplegada. Después, oyó oscuramente un susurro que, corriendo por encima de su cabeza, emitía una voz suave. Al mirar hacia arriba ya no vio la tierra. Vio, en cambio, unas islas iluminadas por un suave fuego y que cambiaban entre sí de colorido, ahora un color, luego otro, como un tinte, al tiempo que la luz variaba en sus transformaciones (Mor. VIII, 244).

Pues bien, aunque en un caso, el de Tespesio, hay una muerte aparente y en el otro, el de Timarco, una consulta al oráculo mediante una incubatio, ${ }^{9}$ los sucesos que experimentan su almas son muy semejantes, a lo que debemos notar que en el primer mito (mito de Tespesio) se cita la parte intelectiva del alma ( $\tau$ ò

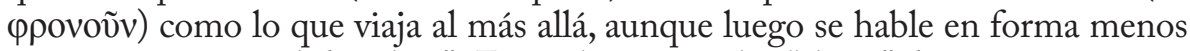
precisa y en general de "alma". En ambos mitos las "almas" de estos personajes suben, respiran, se expanden y contemplan visiones parecidas: Tespesio ve unas estrellas maravillosas, y Timarco ve unas islas que son sin duda trasunto de los planetas. Los dos hablan de coloridos suaves como fondo del movimiento de estrellas e islas. Aquí acaban los paralelismos más notorios, pues la finalidad distinta de los tratados hace que discurran luego de forma diversa.

${ }^{8}$ Todas las traducciones al español citadas pertenecen a Plutarco. Obras morales y de costumbres (Moralia) VIII,Introd., trad. y notas de Rosa Ma . Aguilar, Madrid Gredos, 1996a.

${ }_{9}$ De iniciación onírica lo califica Luis Gil, 1966, p.122 en la que "el sueño se combina con un vuelo extático del alma”. Y. Vernière, 1977, p.109 se refiere a esta iniciación como "oniromancie trophonniane". 
En efecto, Tespesio reconoce a las almas de los que ve en ese trasmundo, -son en general conocidos y parientes-, y su guía es también un pariente al que no había visto desde niño. Los lugares que visita son asimismo distintos y es que este mito trata de la retribución de las culpas en el Más Allá y por eso Tespesio oye de su guía una explicación sobre las diosas que presiden y ejecutan los juicios de las almas y contempla castigos terribles que sufren precisamente las almas de sus conocidos, e incluso ve cómo su padre los sufre.

De otra parte, Timarco obtiene, cuando han transcurrido estas primeras visiones, un guía en su visita, pero no sabe quién es y tan sólo oye una voz que le ilustra y le advierte sobre los lugares que desea conocer. Todo lo que ve se le antoja maravilloso y así le responde a su guía - probablemente un demon ${ }^{10}$ cuando le interroga sobre qué desea conocer aún:

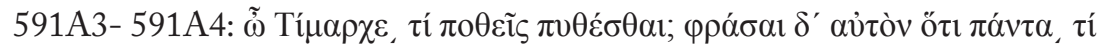

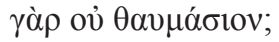

Timarco, ¿̇qué deseas saber? Y él le respondió: Todo. Pues ¿̇ qué hay aqui que no sea asombroso? (Mor. VIII, 246).

\section{La Sima}

Y esta voz, que le servirá de guía, no ha hablado sin embargo hasta este momento, esto es, cuando Timarco ha contemplado ya la visión de las islas y otra, terrible en cambio, sobre la que vamos a ocuparnos seguidamente y que es el principal objetivo de nuestro trabajo. Dice así el texto:

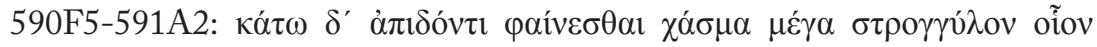

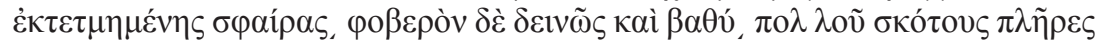

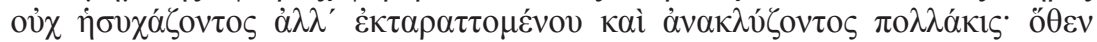

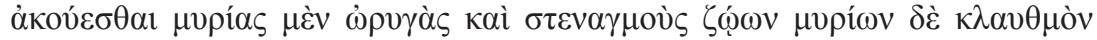

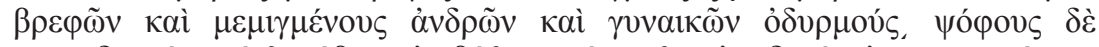

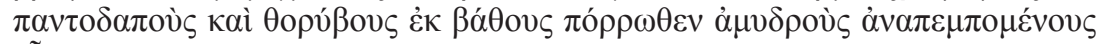

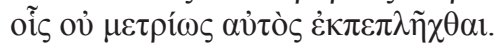

Pero cuando miró hacia abajo vio una gran sima redonda, como una esfera cortada. Era terrible y profunda, llena de una enorme obscuridad, pero no estaba en reposo sino agitada frecuentemente como por el oleaje. Desde allí se oían innumerables aullidos y gemidos de animales, llantos de innumerables recién nacidos, lamentos mezclados de hombres y mujeres, ruidos de todo género y alborotos que subían confusamente desde la profundidad con lo que él mismo se asustó no poco. (Mor. VIII, 245 - 246).

Desde luego, en el tratado De sera no hemos hallado ningún pasaje paralelo.

${ }^{10}$ Dice G.Meautis, 1950, p.207: «L' esprit-guide qui donne les explications est un de ces daemons qui habitent la lune, mais qui, en même temps dirigent la " part de Persephone ", la terre et le cône d'ombre.» 


\section{La Sima de Lete}

Tespesio, tras haber visto un buen número de castigos y haber sido aleccionado por su guía, atraviesa fácilmente un lugar inmenso llevado como por alas, hasta llegar a una sima grande y profunda, donde se vio abandonado de las fuerzas que le sostenían. Es la gruta desde donde Dioniso hizo ascender a los cielos a su madre, Sémele ${ }^{11}$. Existen ciertos paralelismos, dicho esto con toda caución, entre los lugares mencionados por uno y otro guía en su descripción de lo que pueden o deben ver sus pupilos en este viaje, pero el lugar terrible como una esfera cortada forma parte del relato de Timarco tras la visión de las islas y antes del encuentro con su guía y no tiene paralelos.

Los estudiosos de Plutarco se han ocupado desde antiguo de este pasaje. A riesgo de que se considere no up-to-date esta bibliografía comenzaremos por la referencia al Xenocrates de R. Heinze ${ }^{12}$ quien ve en este abismo al planeta tierra. Franz Cumont dice, en cambio, en sus Recherches (1966, p.136, n. 3) que este lugar sería el Tártaro, apoyándose además en el uso onomatopéyico del

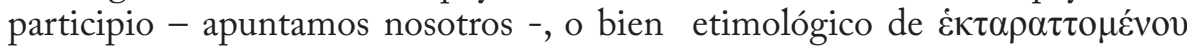
"agitado", que califica a la esfera cortada. Este mismo juicio lo sigue más recientemente Yvonne Vernière (1977, p.183) en tanto que piensa como Cumont («Mais je suis très sensible à l' argument de F. Cumont.») que desde arriba no sería posible ver así ese casquete esférico, la tierra, cóncavo, sino por el contrario, convexo: R. M. Jones y G. Meautis ${ }^{13}$ han pensado también en la tierra porque las estrellas, esto es, las almas, se mueven alrededor y se ven abocadas a un nuevo nacimiento en ella.

Lo que ha visto Timarco es realmente una sima, pero la precisión de su forma, esto es, la de esfera cortada lleva a ambiguas explicaciones, como acabamos de ver. La obscuridad es un elemento importante en la descripción pero no sabemos a qué responde: si fuera la tierra sería más bien un elemento simbólico, pensamos nosotros, que respondería a la obscuridad en que se encuentran sus moradores. El oleaje que la agita y la hace estar sin reposo no sabemos claramente dónde está: si fuera alrededor parecería ser el océano que circunda la tierra el que se mueve pero Plutarco, como vemos, no da muchas precisiones. Más importante parece lo que llega desde ella a oídos del muchacho, a saber y por este orden:

innumerables aullidos y gemidos de animales;

llantos de innumerables recién nacidos;

lamentos mezclados de hombres y mujeres;

ruidos y alborotos de todo género que subian desde la profundidad.

${ }^{11}$ Santamaría, M. A., 2007, pp.882.-884.

${ }^{12}$ R. Heinze, 1965, p.35.

${ }^{13}$ Piensan igual R. M. Jones, 1916, p.57 y G. Meautis, 1950, p.208 quien se basa en que las almas, o estrellas, se mueven a su alrededor y son atraídas a un nuevo nacimiento en ella. 
Pues bien, en ningún momento se precisa que estos llantos y demás ruidos procedan de muertos o sean el resultado de los castigos que sufren los seres citados, como es el caso de lo que contempla en sus visiones Tespesio. A nuestro ver, sería más bien una visión, aunque breve y momentánea, de la tierra, de donde se ha alejado Timarco, como lugar triste y lloroso: el lacrymarum vallis del cristianismo del que ¿podría haber aquí un reflejo en nuestro autor o se trataría simplemente de un lugar común, presente en otras culturas afines?

\section{Análisis}

Si revisamos los elementos citados vemos que en primer lugar aparecen los animales de los que no hay otra mención en estos mitos, si no es en el de Tespesio cuando se aborda el castigo de aquellos grandes pecadores, como el emperador Nerón que iba a ser transformado en víbora y finalmente parece que termina en figura de una rana por los beneficios que había hecho a la Hélade (De sera, $567 \mathrm{~F}$ ) Los animales moradores de este lugar, en cambio, aparecen lamentándose como los propios humanos. En segundo lugar se mencionan los llantos de los recién nacidos, cuya causa sería probablemente el dolor de haber nacido, el Weltweh que dicen los germanos del llanto persistente de los infantes. El tercer lugar lo ocupan los llantos mezclados de hombres y mujeres, donde se podría ver un desglose de nuestro autor en los dos géneros como siendo ambos igualmente susceptibles al llanto y teniendo iguales o parecidas causas para llorar. En cuanto el último punto, ruidos y alboroto que subían desde la profundidad, recuerda la experiencia de oír el ruido o sonido de una pequeña ciudad cuando se está en un lugar tranquilo y no muy alejado de ésta, experiencia que actualmente puede parecer insólita pero que se ha podido vivir en época de Plutarco. Por otra parte, no encontramos afirmación alguna de que se trate de muertos, no de vivos.

Todo esto nos lleva a pensar en la tierra como el lugar mencionado. Volvamos ahora, más en detalle, a la opinión de algunos estudiosos antes citados a favor de ser la tierra el objeto de la visión de Timarco. Dejando a R. Heinze y a R. M. Jones es algo después G. Meautis quien defiende más la hipótesis de la tierra pero partiendo de una lectura algo diferente del texto del mito. En efecto, dice en la pág. 208 de su artículo que Timarco estaba aterrado y preguntó qué cosa era; el demon le respondió con las explicaciones sobre la Estigia de las que él, Meautis, se había ocupado antes. Pues bien, la secuencia de los hechos no es exactamente así: Timarco contempla primero la visión de las islas - o planetas-y percibe la música de las esferas, luego viene esta visión insólita de la sima agitada y perturbada de tantos modos, pero la voz-guía o si queremos el demon, no había hecho aún acto de presencia. Dice así nuestro texto a continuación de lo último citado:

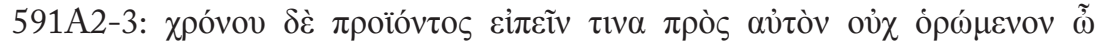

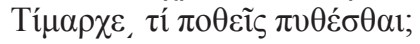


Y cuando pasó cierto tiempo, alguien a quien no veía le dijo: Timarco ¿qué deseas saber? (Mor. VIII, 246)

Es entonces cuando por primera vez Timarco tiene un acompañante, pues antes ha contemplado sus visiones solo, cuando su alma salió por las suturas de la cabeza y se expandió como una vela desplegada: véase antes $590 \mathrm{~B}-\mathrm{C}$ citado aquí sólo en parte. Plutarco no parece estar especialmente interesado por esta visión que atribuye a Timarco. La continuación de las visiones que tendrá el muchacho cuando se manifieste esa voz que será su guía son de una mayor relevancia. Así veremos que al interés de aquél por todo, cuando le pregunta su guía, "porque, qué no es asombroso" (De genio, 591A), éste precisará la limitación de la amarra del alma que tiene el joven y que no da de sí lo suficiente para ver Delfos y su gran oráculo, así como otros lugares de arriba. Ellos no participan apenas de las regiones superiores, dice, ya que pertenecen a los dioses, pero podría mostrarle la parte de Perséfone, esto es, la luna, que ellos administran, una de las cuatro ${ }^{14}$ tal como la limita la Estigia - y la Estigia es el paso que lleva al Hades ${ }^{15}$-, que es efectivamente el nombre dado a la tierra. No estamos muy seguros de que la sima de ahora con las estrellas saltando a su alrededor, - esto es, almas que suben y bajan (591 C)- sea la misma anterior, aquella de la visión aislada y solitaria de Timarco, cuando está haciendo sus primeros intentos en aquel mundo desconocido al que había llegado su alma desde el antro de Trofonio.

\section{Conclusión}

Pensamos, pues, que esta visión tan humana del mundo es solamente de Timarco, o lo que es igual de Plutarco, y que su guía, el demon, no la conoce y por eso no vuelve sobre ella como tampoco sobre la visión de las islas y sus coloridos que constituirían así, desde nuestro ver, un pequeño patrimonio poético de nuestro autor.

\section{Objeciones a nuestra tesis:}

Apéndice de textos griegos sobre el uso de $\chi \alpha ́ \sigma \mu \alpha$

La gramática puede cambiar, sobre todo a una antigua profesora pegada al texto, aquella bonita teoría que antes le había surgido con aspecto inocente de verdad. En efecto, hemos pasado revista a las veces que se usa este término de $\chi \alpha ́ \sigma \mu \alpha$ en ambos tratados y resulta francamente escaso: se reduce en el caso del De sera a dos veces en el relato de la sima de Lete:

${ }^{14}$ De las cuatro partes la primera está fuera de la esfera celestial, la segunda entre ésta y el paso del sol; la tercera entre el paso del sol y el de la luna y la cuarta que es la parte de Perséfone, está debajo del paso de la luna, esto es, de la sombra de la tierra que está difundida más allá de la luna. La tierra es Hades y su sombra la Estigia. Ver De Lacy \& Einarson,1959, p.467, n. d. Y. Vernière,1977, p.181ss. recoge todas las teorías, bastante complejas, sobre estos términos.

${ }^{15}$ «L'enfer est limité par le Styx, qui n' est rien d'autre que le cône d'ombre qui, par sa pointe, coupe la lumière», G. Meautis, 1950, p.207. 


\section{La gruta báquica:}

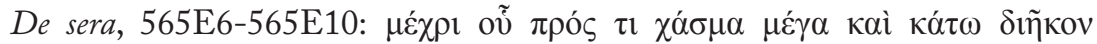

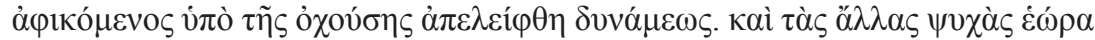

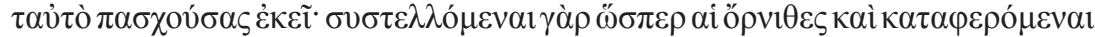

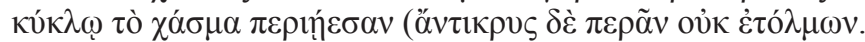

Hasta que al llegar a una sima grande y profunda, fue abandonado por la fuerza que lo sostenía. Él veía que a las demás almas les pasaba lo mismo. En efecto, en bandadas como pájaros, volaban bajo, en círculos rodeando la sima, pero no osaban atravesarla. (Mor. VIII, 162).

Según las normas acostumbradas en la lengua griega $\chi \alpha ́ \sigma \mu \alpha$ aparece la vez primera sin artículo y la segunda con presentador o artículo, ya que nos es ahora un término conocido al aparecer un poco antes.

\section{El abismo cortado como una esfera:}

De genio, 590F5- 591A2 : Para texto y traducción véase antes epígrafe 5. La Sima.

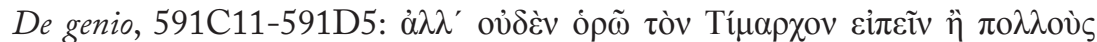

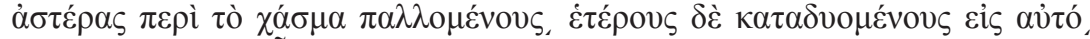

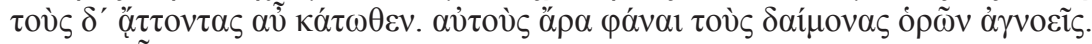

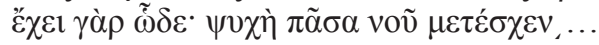

Yo no veo nada, dijo Timarco, sino muchas estrellas que tiemblan en torno a la sima y otras que se hunden dentro de ella, mientras otras saltan de nuevo de abajo.

Y la voz dijo: Ignoras que estás viendo a los propios démones. Pues sucede del modo siguiente. Todas las almas participan del entendimiento, (Mor. VIII, 248).

Ocurre lo mismo aquí con el artículo. En el primer párrafo se trata de

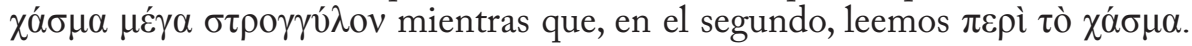
La distancia de este término entre párrafos diferentes nos haría pensar que se trata de dos abismos diferentes, aunque el uso del artículo con el segundo $\chi \alpha ́ \sigma \mu \alpha$ parece abonar la idea de que es uno solo y el mismo. Desde este punto de vista tiene también consecuencias en la intelección del pasaje.

En efecto, la visión de la "esfera cortada" es solamente de Timarco. Hasta ese momento estuvo solo. Por consiguiente si su guía parece hablar luego con conocimiento de este asunto, esto es, de aquella visión, es gracias a su función protectora, omnisciente, bien que alejada en ocasiones como ésta, pues en la secuencia de los hechos solamente Timarco la experimenta. Sería una razón más para ver al guía-demon como un anticipo de un ángel de la guarda cristiano. 


\section{Bibliografía}

Aguilar, R. Ma. (1996a) Plutarco. Obras morales y de costumbres VIII. (Moralia). Traducciones, Introducciones y notas por ----. Madrid Gredos.

- (1996b) «Elementos religiosos en los mitos de Plutarco» en I. Gallo (ed.), Plutarco e la religione, 285-295.

Betz, H. S. (1975) Plutarch's Theologicals Writings and Early Christian Literature, Leiden, Brill.

Boulogne, J. (1999) «Les couleurs du ciel ou la réécriture par Plutarque des mythes eschatologiques de Platon», Euphrosyne 27, 17-29.

Brenk, Frederick E., (1998) "From Rex to Rana: Plutarch's Treatment of Nero" en Relighting the Souls, 82-103.

Corlu, A. (1979)Plutarque. Le démon de Socrate. Texte et traduction avec une Introduction et des notes par...,Paris.

Cumont, F.(1966 )Recherches sur le symbolisme funeraire des Romans, Paris.

Gallo, I. (1999) Plutarco e la religione. Atti del VI Convegno plutarcheo, a cura di ----.M. D'Auria Editore in Napoli.

García Valdés, M. ed (1994) Estudios sobre Plutarco: ideas religiosas. Actas del III Simposio Español sobre Plutarco. Madrid Ediciones Clásicas.

GiL, L.,(1966) Los antiguos y la inspiración poética, Madrid.

Hamilton, W. (1934) “The myth in Plutarch's De genio (589F-592E) Class. Quat. 28, 175-182.

Heinze , R. (1892) Xenocrates, Leipzig.

Klaerr, R. et Vernière, Y.(1974) Plutarque. Euvres morales VII. Paris Les Belles Lettres.

De Lacy, Ph. \& Einarson, B. (1959) Plutarch's Moralia VII, Harvard University Press.

MÉautis, G. (1950) “Le mythe de Timarque”, REA , 201-211.

Nieto Ibáñez, J.Ma . y López López, R. (eds.), (2007) El amor en Plutarco.

Pérez Jiménez, A. (1996) «Elementi astrali nei mitti di Plutarco » en I. Gallo (ed.) Plutarco e la religione, 297-309.

Santamaría, M. A. (2007) «El motivo literario del viaje al Hades en el mito de Tespesio» en J.Ma . Nieto Ibáñez y R. López López (eds.) 877-886. 
Rosa Maria Aguilar

Stoike, D. A. (1975), VII. De Genio Socratis en Betz, H. D.

Vernière, Y. (1977), Symboles et mythes dans la pensée de Plutarque. Paris.

N.B. Algunas obras citadas en esta bibliografía han sido leídas pero no se ha considerado necesario hacer una nota de ellas. 


\title{
LA DOCTRINA DE LAS $\varepsilon ं \pi \varepsilon \lambda \varepsilon U ́ \sigma \varepsilon I \zeta$ Y LA LIBERTAD DE INDIFERENCIA: de Aristón de Quíos a Arcesilao (Plut., STOIC. REP.23, 1045 B-F)
}

\author{
Raúl Caballero \\ Universidad de Málaga
}

\begin{abstract}
In chapter 23 of The Contradictions of the Stoics, Plutarch, far from referring to the Epicurean theory of clinamen, gives a puzzling description of the academic interpretation of the theory of $\dot{\pi} \varepsilon \varepsilon \lambda \varepsilon v ́ \sigma \varepsilon ı /$ /occurrentia by Ariston of Chios. Arguing against the doctrine of the Stoic Ariston, Arcesilaus tried to demonstrate to his antagonist that the assent does not serve as a starting point for the impulse when one is forced to opt for one of two indistinguishable representations (e.g. to choose one of two identical drachmas). In order to release the impulse from the tyranny of such representations, and not to fall into paralysis, some philosophers - according to our hypothesis, Arcesilaus and Academics in controversy with the Stoic Ariston -, have located in the central commanding faculty of the soul a kind of adventitious movement or faculty that, providing an instantaneous inclination, sets in motion the impulse without the need of assent.
\end{abstract}

En el capítulo 23 de Las contradicciones de los estoicos (1045 B), Plutarco nos transmite las huellas borrosas de una polémica que enfrentó a Crisipo

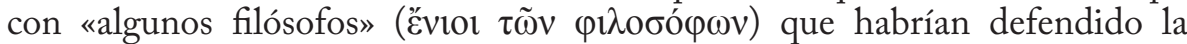
existencia de una facultad o movimiento adventicio o fortuito ( $\dot{\varepsilon} \varepsilon \varepsilon \lambda \varepsilon v \sigma \tau 1 \kappa \eta ́ v$

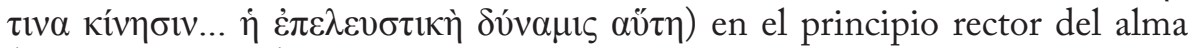
( $\dot{\varepsilon} \nu \tau \tilde{\omega} \dot{\eta} \gamma \varepsilon \mu o v i \kappa \tilde{\omega})$. De acuerdo con esos filósofos, este movimiento tendría la virtud de liberar nuestros impulsos de ser tiranizados por las causas externas

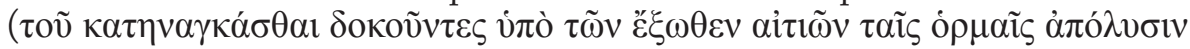
$\pi$ opí(દiv) y se pondría de manifiesto sobre todo en la decisión entre objetos

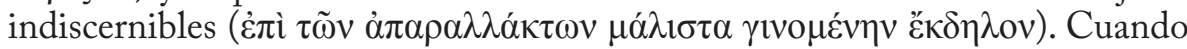
alguien está obligado a decidirse por uno de estos objetos, y no hay ninguna causa que lo empuje hacia uno o hacia otro, el movimiento adventicio permite al alma encontrar por sí misma una inclinación en uno u otro sentido y desbloquea la parálisis y la indecisión (àropía), causadas por la identidad de valor y la absoluta semejanza con que se presentan ambos objetos ${ }^{1}$.

Para la mayoría de los intérpretes (Cherniss y Babut a la cabeza) ${ }^{2}$, los filósofos misteriosamente evocados por Plutarco y combatidos por Crisipo serían los epicúreos y la facultad adventicia del alma designaría, en expresión de Crisipo, la desviación fortuita e impredecible de los átomos que Epicuro

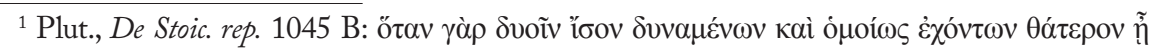

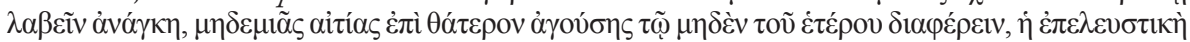

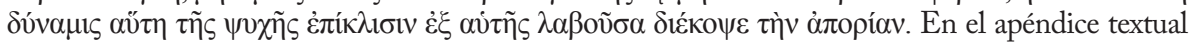
puede leerse el texto y la traducción castellana del capítulo 23 en su integridad (Texto 1).

${ }^{2}$ Cherniss, 1976, pp. 508-509 (n. a). Babut, 2004, pp. 220-221 (n. 299). 
llamó $\pi \alpha \rho \varepsilon ́ \gamma \kappa \lambda \imath \sigma ı \varsigma$ y Lucrecio clinamen. Como es sabido, la desviación atómica introduce una variación mínima e indeterminada en la trayectoria rectilínea y descendente que, en razón de su peso, todos los átomos seguirían en el vacío. Esta especie de 'principio de incertidumbre' postulado por Epicuro tiene aplicación tanto en el campo cosmológico como en la ética. En la física, explica el origen de las interacciones mutuas de los átomos de donde han surgido los mundos innumerables; en el terreno ético, da cuenta de los movimientos voluntarios y autónomos del alma, capaces de liberarla del rígido determinismo al que la condenarían tanto el movimiento natural de los átomos en caída libre como los choques atómicos provenientes del exterior ${ }^{3}$.

La hipótesis epicúrea tiene a su favor el hecho de que el ataque que Crisipo lanzó contra el clinamen coincida exactamente con la crítica demoledora que vierte sobre la facultad adventicia del alma, denunciando que en el fondo ésta consiste en un movimiento sin causa ${ }^{4}$. No obstante, en contra de esta hipótesis se acumulan indicios que no podemos soslayar. Los principales son dos:

a) No hay la más mínima huella de la terminología utilizada por Plutarco (y criticada por Crisipo) en las fuentes epicúreas. En ninguna de ellas se habla

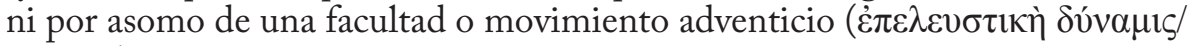

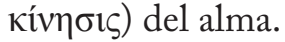

b) No tenemos ninguna noticia de que los epicúreos hubieran utilizado su doctrina del clinamen para resolver el problema de la libertad de indiferencia. Sin embargo, Plutarco subraya que ésa era la principal aplicación de la teoría de la facultad adventicia del alma: disipar la ỏ cuando se la constriñe a escoger entre objetos indistinguibles. Este hecho no es insustancial, si tenemos en cuenta que, cuando más adelante Plutarco pasa a denunciar la contradicción de Crisipo consigo mismo, los dos ejemplos escogidos por aquél para demostrar que el estoico también introduce el azar y lo incausado tratan exactamente de la libertad de indiferencia (1045 D-E): en el primero, un juez debe decidir a cuál de los dos corredores dará el premio si éstos llegan simultáneamente a la meta; en el segundo, hay que escoger entre dos dracmas idénticas. La simetría de la crítica de Plutarco a Crisipo juega en contra de la tesis epicúrea, por cuanto ésta no tiene aplicación, que sepamos, al así llamado problema del "asno de Buridán”.

${ }^{3}$ Sobre la doctrina epicúrea del clinamen, remitimos a los atinados análisis de M. Conche, Lucrèce et l'expérience, Québec, 2003 [Paris, 1996²], pp. 51-60 y A. Comte-Sponville, Lucrecio. La miel y la absenta, trad. esp., Barcelona, 2009 [Paris, 2008], pp. 95-113, así como a la completa monografía de E. A. Schmidt, Clinamen: eine Studie zum dynamischen Atomismus der Antike, Heidelberg, 2007.

${ }^{4}$ Los textos principales han sido recogidos por Cherniss y Babut: cf. supra, n. 2.

${ }^{5}$ Según esta famosa paradoja, que ridiculiza la tesis de que la voluntad obedece siempre a motivos necesarios y determinados, un asno hambriento acabaría muriendo de hambre si tuviera que decidirse entre dos haces de heno idénticos, situados a igual distancia. No encontramos este ejemplo en ninguna obra de Juan Buridán (ca. 1300-1361), pero es verosímil que se asociara a su nombre por su concepción de la libertad como una facultad de aplazar o diferir la decisión sobre cualquier juicio práctico que no se manifieste con certeza. El ejemplo más antiguo de esta paradoja, con algunas variantes, lo encontramos en Aristóteles: Arist., Cael. 295b30-34. La tradición filosófica de este problema, desde sus orígenes cosmológicos en Grecia 
Si se deja a un lado a los epicúreos, hay al menos dos hipótesis alternativas que, en principio, permitirían salvar tales obstáculos:

a) Los filósofos defensores del movimiento adventicio son los seguidores del estoico Aristón de Quíos, quien, de acuerdo con su teoría de la completa indiferencia de todo lo que media entre el bien y el mal, propondría este concepto psicológico de la facultad adventicia como criterio instrumental para la obtención de cosas absolutamente indiferentes. Ésta es la antigua tesis de Rieth, que ha sido desarrollada y matizada recientemente por Boys-Stones ${ }^{6}$, apoyándose en el testimonio de Cicerón y en el pasaje de Plutarco que tenemos entre manos. A su favor, la hipótesis de Aristón tiene sin duda un poderoso aliado, a saber: los únicos textos que contienen una muy plausible traducción latina del término ė $\pi \varepsilon \lambda \varepsilon v ́ \sigma \varepsilon 1 \zeta:$ el vocablo occurrentia, que Cicerón atribuye expresamente a Aristón ${ }^{7}$.

b) Con todo, la hipótesis de Aristón no resuelve completamente el problema. Y es que el uso que Plutarco hace de la expresión técnica 'objetos

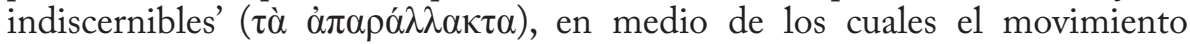
adventicio proveería de un criterio inmediato y fortuito para la acción, apunta a la Academia escéptica inaugurada por Arcesilao. Así que no sería descartable la posibilidad de que Plutarco se refiera no sólo a Aristón de Quíos, sino también a filósofos académicos que entraron en abiertas contiendas dialécticas con el estoico ${ }^{8}$.

La hipótesis académica ha sido tan sólo sugerida por Long y Sedley, basándose en el hecho constatado de que los indiscernibles fueron esgrimidos por los académicos para cuestionar la confianza de los estoicos en la veracidad de nuestras representaciones ${ }^{9}$. Ahora bien, que yo sepa nadie se ha aventurado hasta ahora en el difícil camino de desarrollar la hipótesis académica, especificando el autor, la modalidad y el sentido de una argumentación polémica que tuviese

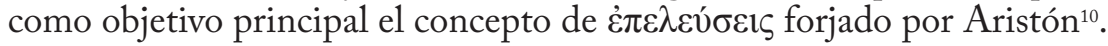

hasta sus aplicaciones a la ética, en la escolástica medieval y en la modernidad, ha sido tratada exhaustivamente por N. REsCHER, «Choice without preference : the problem of "Buridan's ass"», Kant-Studien 51 (1959-60) 142-175.

${ }^{6}$ O. R. Rieth, Grundbegriffe der stoischen Ethik: eine traditionsgeschichtliche Untersuchung, Berlin, 1933, pp. 105-108; Boys-Stones, 1996, 75-94.

${ }^{7} \mathrm{Cf}$. Apéndice, texto 2.

${ }^{8} \mathrm{El}$ mismo Plutarco refiere que los estoicos reprochaban a los académicos que «éstos trastornan todas las cosas con sus semejanzas indiscernibles, al sostener contra viento y marea que a dos sustancias les corresponde una sola cualidad individual» (Plut., De comm. not. 1077

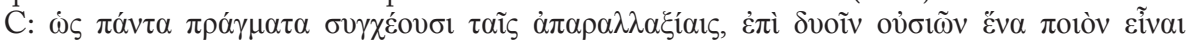

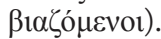

9 Long-Sedley, 1987, II, 338-339: «Los académicos son candidatos más prometedores. La crítica del determinismo estoico y el que los estoicos afronten problemas en torno a «indiscernibles» aparentes, son preocupaciones académicas bien conocidas. Si esto es así, la posición que Crisipo combate no habrá sido una doctrina oficial de escuela, sino un problema y una solución escudriñados por los académicos a fin de desconcertar a los estoicos».

${ }^{10}$ Véanse al respecto las interesantes aportaciones de SPINELLI, 1995, pp. 230-233, que ve en el pasaje de Plutarco huellas de un debate entre académicos y estoicos que obligó a estos últimos a reconocer una nueva clase de cosas indiferentes (cf. Apéndice, texto 6 e infra, n. 40 ). 
Mi propósito en este trabajo es precisamente ése: admitiendo que el autor de este concepto no es sino el estoico Aristón de Quíos, intentaré mostrar

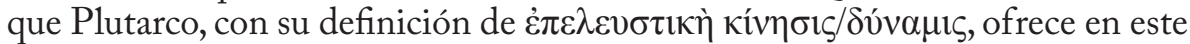

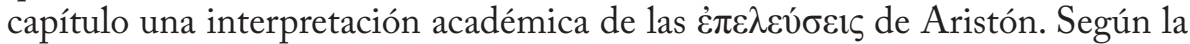
reconstrucción que quiero proponer, esta interpretación fue elaborada en el curso de la polémica que enfrentó a Aristón y a Arcesilao en torno a la teoría estoica del conocimiento y el criterio para la acción. En esa lucha doctrinal también se planteo el problema de si hay lugar en el ser humano para decisiones adventicias y fortuitas que lo saquen de un impasse en ciertas situaciones límite. Como Plutarco deja traslucir al parafrasear la crítica de Crisipo ( $\dot{\varepsilon} v \delta \dot{\varepsilon} \tau \alpha i ̃ \varsigma$

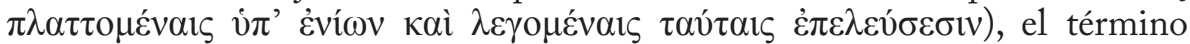
$\dot{\varepsilon} \pi \varepsilon \lambda \varepsilon v ́ \sigma \varepsilon 1 \varsigma$ es como mínimo contemporáneo de éste (s. III med.). Ahora bien, si recoge terminología de Aristón, como prueba su traducción latina occurrentia, y fue utilizado en la Academia con intenciones polémicas, su uso debería remontar por lo menos a los académicos contemporáneos del estoico Aristón, esto es, Arcesilao o alguno de sus discípulos (primera mitad del siglo III a.C.).

\section{II}

Así pues, si se quiere resolver el problema de quiénes son los misteriosos filósofos que se esconden tras las palabras de Plutarco (y de Crisipo), el punto de partida debe ser la única pista terminológica plausible que tenemos a la mano:

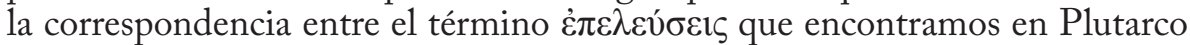
y el vocablo occurrentia que aparece en el oscuro esbozo que pergeña Cicerón cuando trata de describir este concepto del pensamiento de Aristón ${ }^{11}$.

El pasaje de Cicerón, sin embargo, debe tomarse con las debidas cautelas si lo que queremos es dar una interpretación de las occurrentia coherente con el pensamiento del estoico Aristón. En efecto, el propio Cicerón confiesa expresamente que no sabe qué es eso de las occurrentia de Aristón, y, tal como plantea el asunto en los dos textos concernientes a este problema, da la impresión de que malinterpreta el pensamiento del estoico. Lo que, con actitud de menosprecio, parece decir Cicerón acerca de Aristón de Quíos es lo siguiente: si, como sostenía el estoico, todo lo que hay entre la virtud y el vicio es igualmente indiferente y la naturaleza no nos provee de ningún criterio de preferencia en el campo intermedio entre esos extremos, la elección de esas cosas intermedias se dejará un poco al azar: uno tomará «aquello que le venga a la mente o le salga al paso» (quodcumque in mentem incideret et quodcumque tamquam occurreret $=$ occurrentia) .

Nosotros creemos que esta interpretación ciceroniana malentiende, trivializa y no toma en serio el problema de la relación del sabio estoico con las cosas indiferentes, tal como fue planteado por Aristón. Como Séneca puntualiza en su Epistola $94^{12}$, Aristón rehusaba dar consejos de ética práctica

\footnotetext{
${ }^{11}$ Cic., fin. 4.43; 4.47 (Texto 2 del Apéndice).

${ }^{12}$ Esta carta está recogida casi íntegramente en SVF 1.359.
} 
(cómo conducirse en el matrimonio, con los padres, etc.), porque consideraba cada caso particular como una condición única e irrepetible en la que el sabio puede y debe actuar. No hay respuesta sobre cómo debe actuar hasta que aquél se ve implicado en la circunstancia y ocasión concreta en que lo hace: sólo entonces el sabio, desde la autonomía moral que le concede el ejercicio libre y soberano de la razón, encontrará vías de actuación y criterios de elección acordes con la virtud, mientras que el necio, en esa misma coyuntura, actuará erróneamente. En la infinidad de casos particulares que pueden presentarse en la vida de un hombre, hay ocasiones en que convendrá a la razón del sabio obtener lo que Zenón consideraba ventajas naturales, pero surgirán otras en que éstas deberán ser rechazadas si quiere preservar su autonomía racional y su felicidad ${ }^{13}$.

Por eso, es coherente con este planteamiento el que Aristón, pese a la distorsionada interpretación ciceroniana, propusiera las occurrentia como el único contenido posible de la acción moral del sabio en el terreno intermedio entre la virtud y el vicio: en cada caso particular el sabio deseará algo (appetere aliquid), a saber, aquello que le salga al paso (quodcumque occurrat) y le venga a la mente (quodcumque in mentem veniat), sea lo que sea. Desde nuestro punto de vista, la indefinición del criterio selectivo de Aristón es deliberada y suena hasta provocativa: cualquier cosa puede ser conveniente al sabio dependiendo de las circunstancias en que éste se vea envuelto. De ahí que no tenga sentido para Aristón el proceder de Zenón cuando ofrece las ventajas naturales como pauta de comportamiento en el progreso hacia la virtud: medidas desde el patrón de la virtud, tales cosas no se diferencian en nada unas de otras, porque ninguna contribuye decisivamente a la virtud y a la felicidad ${ }^{14}$. Pero, en la circunstancia concreta en que se plantea cada decisión, Aristón no negaba que algunas de ellas, cuando le salieran al paso, pudieran ser útiles para que el sabio actuara moralmente ${ }^{15}$.

$¿$ Puede haber un hilo conductor que conecte sutilmente las occurrentia

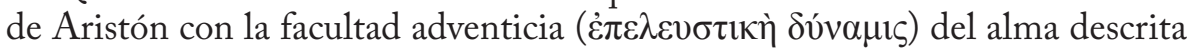
por Plutarco en el capítulo 23 de Las contradicciones de los estoicos? ¿Cómo es posible que Plutarco utilice la terminología de Aristón en este pasaje para

${ }^{13}$ Esto se ve muy bien en el ejemplo que transmite Sexto Empírico ( $M$. 11.64-67 $=S V F$ 1.361): si se da el caso de que la salud puede empujar a uno a ser esclavizado por un tirano, mientras que la enfermedad lo libera de esa situación de servidumbre, así como de la muerte, la enfermedad será preferible a la salud. El sabio actúa siempre

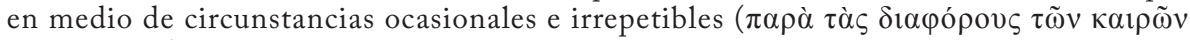

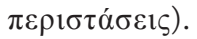

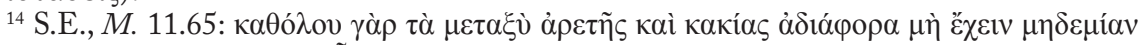

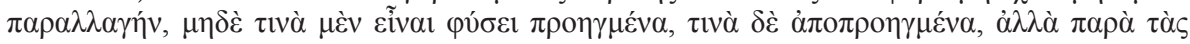

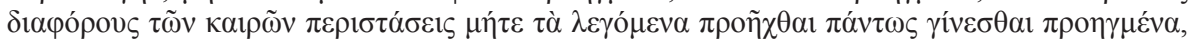

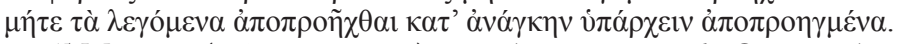

${ }^{15}$ Moreau (1979, p. 41, n. 2) ve en las occurrentia de Cicerón «les valeurs de circonstance que revêtent les choses indifférentes». En otras palabras, las occurrentia son esas mismas cosas indiferentes en tanto que no tienen en sí mismas ningún criterio selectivo, sino tan sólo "si le salen a uno al paso o le vienen a la mente", por cuanto configuran las circunstancias concretas de la acción del sabio. 
definir un movimiento adventicio del alma, esto es, un movimiento inesperado, accidental y fortuito? No parece, en principio, que las occurrentia de Aristón, en la interpretación que de ellas hemos dado arriba, tengan mucho que ver con un movimiento o facultad intrínseca del alma, que permita desbloquear

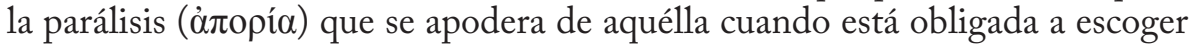
entre objetos indistinguibles ( $\dot{\alpha} \pi \alpha \rho \alpha ́ \lambda \lambda \alpha \kappa \tau \alpha)$. Como acabamos de ver, las occurrentia son para Aristón precisamente esos objetos cualesquiera que, según las circunstancias, al sabio le salen al paso y se le presentan a la mente como estímulo y contenido de la acción moral.

Resulta problemático, pues, atribuir a Aristón de Quíos la doctrina de la

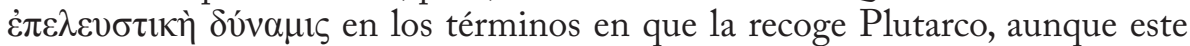
punto merece una discusión más detenida. Según Moreau ${ }^{16}$ y $\operatorname{Ioppolo}^{17}$, que desconfían de la interpretación ciceroniana de las غ̇ $\pi \varepsilon \lambda \varepsilon v ́ \sigma \varepsilon 1 \zeta$ de Aristón, es imposible atribuir a éste una facultad adventicia del alma, porque el sabio de la indiferencia absoluta no tomaría nunca decisiones al azar. Sus decisiones están todas fundadas en la autonomía soberana de la razón: si ha interiorizado la doctrina de lo bueno y lo malo, no necesita aplicar reglas de conducta ni dejarse llevar por el capricho de su deseo. Lo que decida hacer en cada circunstancia, cualquier cosa que sea, estará bien hecho, puesto que esa decisión proviene del uso recto de la razón ${ }^{18}$.

Sedley ${ }^{19}$, en cambio, establece en el pensamiento de Aristón una dicotomía entre las situaciones en que, para el sabio, está en juego la virtud y las demás situaciones en que no está en juego. En las primeras, el sabio elegirá el curso adecuado de acción como fruto de una deliberación racional; en las segundas, como fruto de una decisión puramente azarosa, generada por la facultad

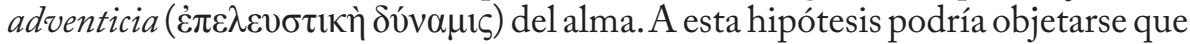
resulta problemático distinguir en Aristón una libertad de autodeterminación y una libertad de indiferencia, cuando su riguroso indiferentismo le llevaba a sostener que ninguna de las cosas intermedias entre la virtud y el vicio se

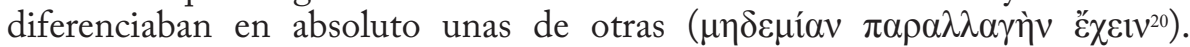
Las cosas indiferentes son todas igualmente indistinguibles en el sentido de que ninguna de ellas encierra ningún valor intrínseco para la felicidad. Por ello, la actitud coherente con esta postura es la de no plantearse siquiera el problema de la libertad de indiferencia. El sabio actuará siempre guiado por su razón y requerido por una precisa y concreta circunstancia $(\pi \varepsilon \rho i ́ \sigma \tau \alpha \sigma \iota \varsigma)$, y tal

${ }^{16}$ Moreau, 1979, p. 41, n. 2.

${ }^{17}$ Ioppolo, 1981, pp. 171-183.

${ }^{18}$ Cicerón (fin. 4.69) ofrece la respuesta de Aristón al problema de cómo actuará el sabio en medio de las cosas indiferentes: Vives, inquit Aristo, magnifice atque praeclare, quod erit cumque visum ages, numquam angere, numquam cupies, numquam timebis. Como dice Moreau (1979, p.

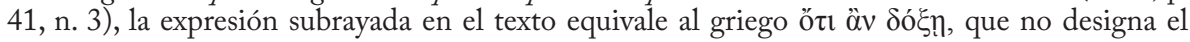
capricho de una decisión al azar, sino el resultado de una elección fundada en la determinación de la voluntad.

${ }^{19}$ Sedley, 1999, pp. 130-133; BréHier (Histoire de la philosophie, Paris, 1955', I, p. 378) ya había expresado una opinión similar.

${ }^{20}$ Cf. supra, n. 14. 
circunstancia está constituida por aquellas cosas, cualesquiera que sean, que le

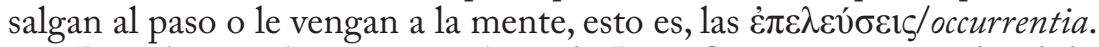

Por último, el reciente trabajo de Boys-Stones ${ }^{21}$ apuesta decididamente

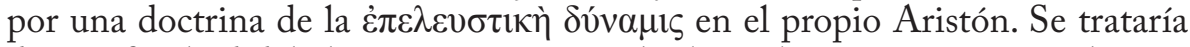
de una facultad del alma que permitiría al sabio saber intuitivamente el curso adecuado de acción en cualquier circunstancia en que estuviera envuelto, sin necesidad de una deliberación racional. La virtud transfiguraría el principio gobernante del alma, que es capaz desde entonces de generar de inmediato decisiones concretas en cualquier caso particular. $Y$ ese movimiento adventicio se aplicaría por igual a todas las decisiones entre indiferentes, incluyendo aquellas que implican indiferentes absolutamente intercambiables, como los que recoge Plutarco en nuestro pasaje.

Esta interpretación de la doctrina de Aristón, aunque sugestiva, no está avalada por ninguno de los fragmentos que hemos conservado de él. El único apoyo documental es el testimonio de Cicerón, que confiesa en primera persona no saber qué quiso decir Aristón con el término occurrentia. Por el contrario, varios testimonios importantes sobre el pensamiento de Aristón coinciden en el hecho de que sólo hay una facultad del alma en la que el sabio ha de fundar cualquier acción: «Así pues, como Aristón pensaba que la facultad del alma es una sola, aquella con la que razonamos, establecía también que una sola es la virtud del alma: la ciencia de los bienes y los males» ${ }^{22}$. El monismo psicológico de los estoicos, que fue tan criticado por Plutarco en otras obras, deviene en Aristón una opción radical, pues está en relación directa con la doctrina de la unidad de la virtud, que también se distinguía de la de Crisipo ${ }^{23}$. Y es que Aristón veía en las diferentes virtudes modos de ser de una única virtud, la ciencia de los bienes y los males. Al desplegarse en sus múltiples relaciones con las cosas indiferentes, esta única virtud da lugar a las virtudes particulares, que no son otra cosa sino nombres distintos de una única disposición de espíritu. La ciencia del sabio, a su vez, es única porque el alma, con independencia de la acción en la que se implica, conoce los bienes y los males con una sola y única razón, y sólo cuando se vuelca en las distintas acciones de la vida es cuando tal ciencia se ramifica en múltiples nombres según las múltiples circunstancias a las que se aplica ${ }^{24}$.

La doctrina de las virtudes ayuda también a entender por qué Aristón consideraba la parenética como una rama de la ética totalmente prescindible: $o$ es superflua, porque los consejos prácticos son innecesarios para quien ya posee la ciencia de los bienes y los males, esto es, «un juicio exacto acerca de las cosas

${ }^{21}$ Boys-Stones, 1996, pp. 83-94.

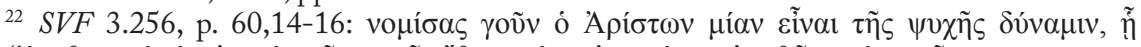

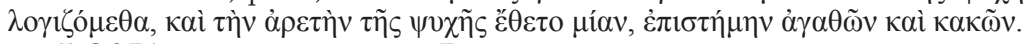

${ }^{23}$ Cf. Plut., De Stoic. rep. 1034 D.

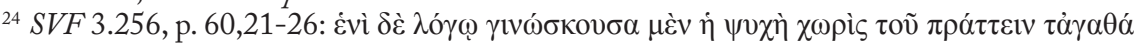

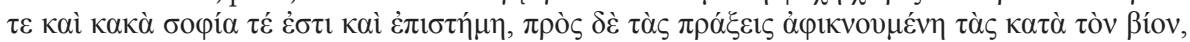

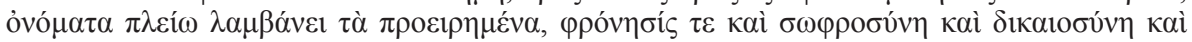

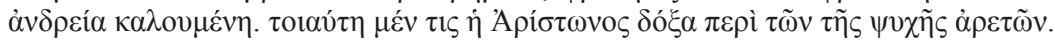


que hay que evitar y buscar» ${ }^{25}$; o es completamente inútil, porque quien carece de ese juicio seguirá siendo un enfermo por mucho que siga al pie de la letra las reglas de conducta que se le prescriban.

Igual que las virtudes son nombres diferentes de una sola ciencia, a la que se accede tras desembarazarse de las falsas opiniones y tras comprender con la razón que los indiferentes no tienen ningún valor para la felicidad, las distintas

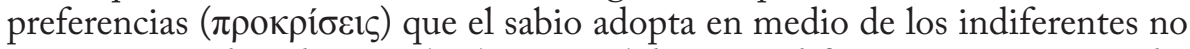
vienen nunca dictadas por el valor natural de esos indiferentes, como pretendía Zenón, sino por el ejercicio de la razón cuando se enfrenta a las innumerables circunstancias de la vida ${ }^{26}$. Así pues, para Aristón sólo hay una virtud porque sólo hay una facultad racional en el alma humana. Los vicios provienen de la desviación de esa única facultad, propiciada por las falsas opiniones. En el pensamiento ético de Aristón no hay, pues, ningún lugar para ninguna otra potencia o facultad del alma que le permita tomar decisiones inmediatas e intuitivas en medio de los indiferentes. Las decisiones del sabio implican en todas las circunstancias el uso de la razón y de la reflexión, precisamente porque los indiferentes no tienen ningún valor intrínseco: se trata, en el testimonio ya visto de Séneca, de un juicio racional (iudicium) o un principio doctrinal

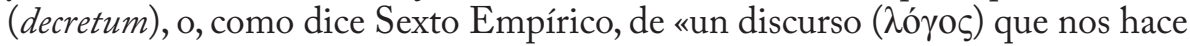
propender hacia la virtud, nos enajena del vicio y nos hace desechar lo que está en medio de éstos» ${ }^{27}$. El cultivo de este saber no es automático ni intuitivo, sino que requiere mucha ejercitación y una lucha sostenida contra lo que Aristón llama el 'tetracordio' del vicio: el placer, el dolor, el miedo y el deseo ${ }^{28}$.

Es necesario, pues, explicar esa distancia conceptual que media entre las $\varepsilon \dot{\pi} \varepsilon \lambda \varepsilon v ́ \sigma \varepsilon ı$ /occurrentia de Aristón y la definición que da Plutarco de la facultad adventicia del alma. En esta dirección, intentaré mostrar seguidamente que,

${ }^{25}$ Sen., ep. 94.12: exactum iudicium de fugendis petendisque.

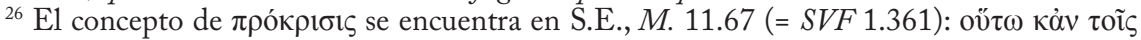

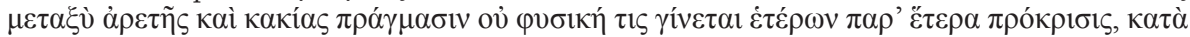
$\pi \varepsilon p i ́ \sigma \tau \alpha \sigma ı v \delta \grave{\varepsilon} \mu \tilde{\alpha} \lambda \lambda o v$. Esas preferencias, modulables según las circunstancias, determinan lo que Cicerón llama el "principio del deber» (officii principium: Cic., fin. 4.46-47) y Séneca el «orden de los deberes» (officiorum ordinem: Sen., ep. 94.5), es decir, proveen un cierto criterio para la selección de cosas indiferentes en el pensamiento de Aristón. Es evidente que tanto Cicerón como Séneca analizan la doctrina de Aristón desde la óptica tripartita de la ética estoica ortodoxa: la virtud, el vicio y el terreno intermedio entre éstos, que constituye el campo específico

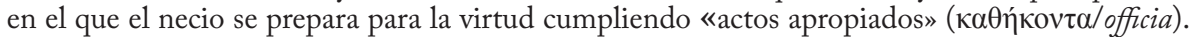
El criterio estoico para la selección de los indiferentes es el acuerdo con la naturaleza, pero, como Aristón invalida tal criterio y suprime la posibilidad de que el necio cumpla actos apropiados, sólo puede proponer como criterio selectivo un principio formal, vacío en sí mismo de contenido: si es sabio, el juicio racional por el que se rige su alma seleccionará, con absoluta independencia,

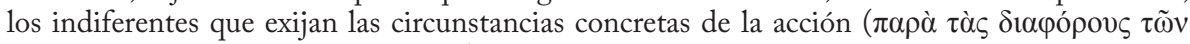

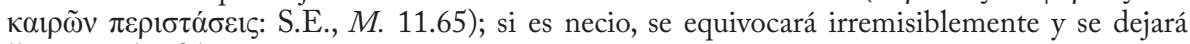
llevar por las falsas opiniones que ciegan su espíritu.

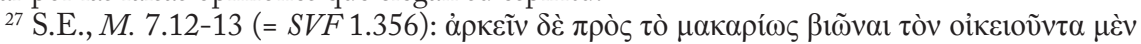

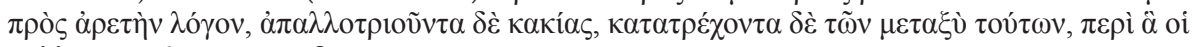

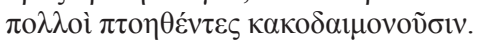

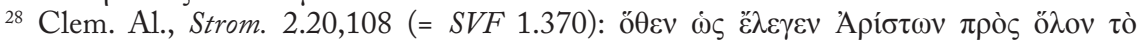

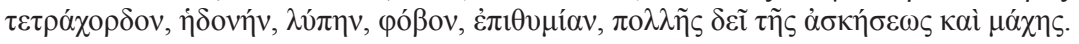


en el pasaje de Plutarco, es preciso distinguir dos niveles de análisis: en el

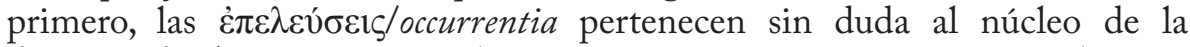
doctrina de Aristón y son coherentes con su pensamiento ético, tal como lo hemos interpretado arriba; pero, a un segundo nivel, la conversión de las

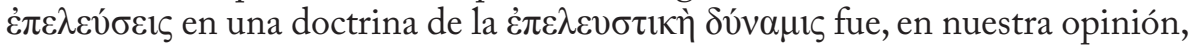
responsabilidad de los académicos (Arcesilao y sus discípulos) ${ }^{29}$, en el curso de los debates gnoseológicos que sostuvieron con Zenón y sus discípulos (entre ellos, el propio Aristón) en el s. III a.C.

\section{III}

Para desarrollar esta hipótesis, el mejor camino es, a mi juicio, investigar las interpretaciones y reinterpretaciones que de las غ̇ $\pi \varepsilon \lambda \varepsilon v ́ \sigma \varepsilon 1 \zeta$ de Aristón podrían haberse hecho en el marco del debate sostenido por los académicos y estoicos de la primera generación (Zenón y Arcesilao y sus respectivos discípulos). Las disputas entre ambas escuelas estaban centradas, como es sabido, en el problema gnoseológico de la evidencia de nuestras representaciones. Para Zenón, la posibilidad de un conocimiento firme y estable, basado en el testimonio de los sentidos, depende de la fiabilidad del acto cognoscitivo que los estoicos

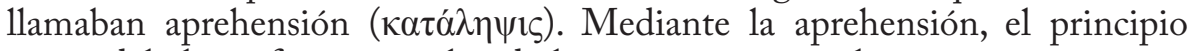
rector del alma aferra o aprehende las imágenes mentales o representaciones ( $\varphi \alpha v \tau \alpha \sigma i ́ \alpha \imath)$ que nos formamos de las cosas. Pero sólo se deben aprehender

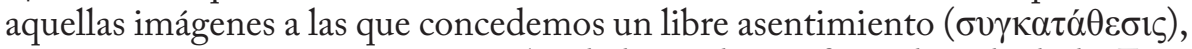
porque se nos presentan con una claridad y evidencia fuera de toda duda. Esas

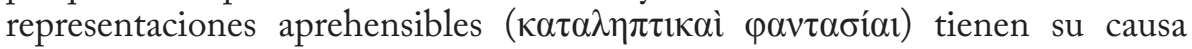
inmediata en objetos realmente existentes y por eso se imprimen adecuadamente en el alma como el sello en la cera. Además, son de tal naturaleza que no podrían ser las mismas si provinieran de otros objetos ${ }^{30}$.

Arcesilao se aplicó con esmero a desmontar el concepto zenoniano de representación aprehensible $(\kappa \alpha \tau \alpha \lambda \eta \pi \tau \imath \kappa \eta ̀ ~ \varphi \alpha v \tau \alpha \sigma i ́ \alpha)^{31}$. El más importante de sus argumentos llamaba la atención sobre el hecho de que cualquier representación que se nos muestra como verdadera puede en realidad ser falsa: por ejemplo, las dimensiones reales del Sol no se corresponden con la imagen mental que con toda claridad nos formamos de él. Un corolario de este argumento consiste en afirmar que no existe ninguna representación a la

${ }^{29}$ Así lo sugieren además las propias palabras de Crisipo, parafraseadas por Plutarco en $D e$

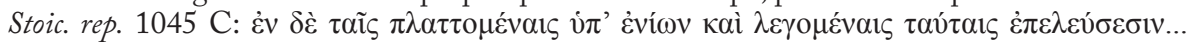
Con estas palabras Crisipo estaría atacando a los académicos, que se habrían apropiado de las $\dot{\varepsilon} \pi \varepsilon \lambda \varepsilon v ́ \sigma \varepsilon 1 \zeta$ de Aristón cambiando su significado originario por el de 'movimientos fortuitos' del alma. Para todo esto, cf. infra, sección III.4.

${ }^{30}$ Cic., Varro 40-41; Cic., Luc. 18; S.E., 7.151-152. Cf. Ioppolo, 1986, 21-28. Es probable que Zenón añadiese el último rasgo de la representación aprehensible en respuesta a las primeras críticas de Arcesilao, planteando la indiscernibilidad de representaciones de dos gemelos y ejemplos semejantes: cf. J. Brunschwig, «Estoicismo», en Brunschwig, J. - Lloyd, G. (eds.), El saber griego, trad. esp., Madrid, 2000 [Paris, 1996], pp. 676-679.

${ }^{31}$ Cic., Luc. $77-80$. 
que no se le pueda encontrar otra representación idéntica, pero proveniente de un objeto distinto: ¿cómo distinguir, por ejemplo, dos estatuas iguales? En la realidad puede concederse que no son absolutamente idénticas, pero la representación mental que nos hacemos de ellas no encuentra ninguna diferencia entre $\operatorname{ambas}^{32}$. No hay, concluye Arcesilao, en la propia representación aprehensible ningún criterio inherente de verdad.

En un segundo momento, Zenón y sus discípulos respondieron a Arcesilao señalando las graves consecuencias que podían extraerse del escepticismo académico: si el sabio no asiente a ninguna representación porque no puede establecer su veracidad, no podrá entonces formular ningún criterio válido para la acción; estará, pues, obligado a seguir el ejemplo de Pirrón y no podrá evitar caer en un precipicio o ser atropellado por un carro $^{33}$. Con los testimonios que tenemos a nuestra disposición en torno a este debate, es posible demostrar que la hipótesis de la facultad o movimiento adventicio encaja razonablemente como una de las piezas de la disputa que se produjo entre el académico Arcesilao y el estoico Aristón de Quíos en la primera mitad del siglo III a.C. Las etapas de esta disputa dialéctica habrían sido las siguientes.

1. Arcesilao (y el estoico Perseo) contra Aristón. La trampa de los dos gemelos.

Sabemos que Arcesilao entabló una intensa lucha dialéctica no sólo con Zenón, sino también con Aristón sobre el problema de qué debe hacer el sabio ante representaciones indiscernibles para evitar caer en la ó $\pi$ opía y, por ende, en la inacción: de esto parece haber un lejano recuerdo en la anécdota de los gemelos, contada por Diógenes Laercio ${ }^{34}$. En este caso, lo que tenemos es una trampa maliciosamente tendida por el estoico Perseo, uno de los discípulos de Zenón, contra uno de sus correligionarios más heterodoxos, Aristón de Quíos. Pero, como dice Ioppolo ${ }^{35}$, aquí «Perseo fa la parte di Arcesilao», esto es, toma prestado del académico el argumento que éste solía esgrimir contra los estoicos cuando trataba de acorralarlos ante la imposibilidad de distinguir entre dos representaciones idénticas.

Según la anécdota referida por Diógenes Laercio, «de dos hermanos gemelos, Perseo hizo que uno de ellos entregara a Aristón un depósito de dinero

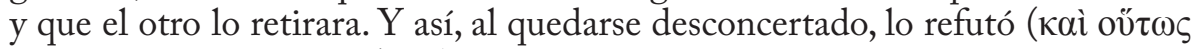

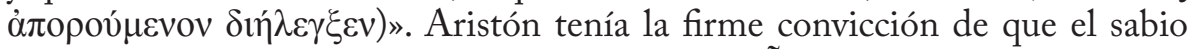
carece de meras opiniones ( indecisión, entregó el dinero al segundo hermano, asintiendo precipitadamente a una representación indiscernible de la del primer hermano. Así fue como Perseo demostró que Aristón en realidad no era un sabio, puesto que no había logrado distinguir con claridad a los hermanos ni se había mantenido en la $\alpha$ đopía, reteniendo el asentimiento.

${ }^{32}$ Cic., Luc. 85. Ésta era la respuesta de Arcesilao al tercer rasgo de la representación aprehensible (cf. supra, n. 30).

${ }^{33}$ D.L., 9.62.

${ }^{34}$ D.L., 7.162. Cf. infra, Apéndice, texto 3.

${ }^{35}$ Ioppolo, 1986, p. 82. 
Esta anécdota nos permite vislumbrar los debates que se produjeron en el interior de la propia escuela estoica por culpa de las críticas de Arcesilao a la teoría del conocimiento sostenida por Zenón. En el curso de estas disputas, Perseo no duda en utilizar argumentos ex parte Academica para refutar a Aristón, el discípulo más díscolo de Zenón. En sí misma, la anécdota ofrece dos motivos estrechamente relacionados con el problema planteado por Plutarco en el capítulo 23 de Las contradicciones de los estoicos: a) Se trata de resolver el curso adecuado de acción que el sabio ha de tomar cuando es confrontado con representaciones indistinguibles (los dos gemelos); b) En esa tesitura, no se puede evitar la vacilación ( $\left.\dot{\alpha} \pi \circ \rho^{\prime} \alpha\right)$ ni el engaño, pese a que el sabio estoico, en teoría, no se atiene a meras opiniones.

Pues bien, la ả $\pi$ opía de Aristón y la confusión entre los hermanos gemelos daban de hecho la razón a todos sus adversarios, tanto dentro como fuera de la escuela estoica:

a) Para los discípulos de Zenón, la perplejidad de Aristón ridiculizaba su pretensión de ser sabio: ni Zenón ni sus seguidores, pese a creer en la existencia del sabio estoico, se atrevían a confesarse sabios $^{36}$, pues se veían ocasionalmente expuestos a la duda y a la opinión. En el fondo, Aristón sufrió la misma experiencia que delata a todos los necios cuando se enfrentan a representaciones indiscernibles. Aristón estaba, pues, inmerso en el mundo de la opinión.

b) Para Arcesilao, de quien Perseo toma el argumento, el fracaso de Aristón demostraría que la convicción estoica de que el sabio asiente siempre a representaciones veraces es errada y en realidad le conduce a un callejón sin salida. Si Aristón quiere seguir siendo sabio y sortear la duda y la confusión ante representaciones indistinguibles, el único camino que le queda es retener el asentimiento. Pero entonces no podrá actuar, porque, desde los presupuestos del estoicismo, el asentimiento es una condición indispensable para que surja el impulso que conduce a la acción. Al final, Aristón estará expuesto a la misma inacción que los estoicos reprochaban a los académicos.

\section{El desafio de Arcesilao a Aristón: una variante del problema del 'asno de Buridán'.}

Una disensión tan significativa en el seno del estoicismo, al dar respuestas tan dispares a la trampa de los dos gemelos, allanó el camino a los académicos para acorralar a los estoicos en el debate sobre si el sabio puede actuar o no cuando se enfrenta a representaciones indiscernibles. A juicio de Arcesilao, al desafío por él planteado los estoicos sólo podían responder con evasivas o subterfugios: o negaban ser sabios, como reconocían Zenón y sus discípulos, o, si seguían obstinados en mantener la infalibilidad del sabio estoico, como pretendía Aristón, estaban abocados a la inacción.

a) La primera de estas dos evasivas atraía por sí sola la respuesta académica: el ideal del sabio estoico es irrealizable en la práctica. Así pues, replicaba Arcesilao, si el sabio estoico no existe, la doctrina gnoseológica del Pórtico que le da sustento, pese a su confianza ciega e ingenua en la veracidad de

${ }^{36}$ Esta confesión de humildad es una de las paradojas más conocidas del estoicismo ortodoxo, pues hace del sabio un ideal inalcanzable: cf. Plut., De Stoic. rep. 1048 E; De comm. not. 1076 B. 
las representaciones aprehensibles, no protege a nadie de caer en el mundo inseguro e inestable de las opiniones ${ }^{37}$.

b) Pero el caso de Aristón era distinto. Como él quería preservar la posibilidad real de la existencia del sabio estoico y no arrumbarlo en el baúl de los ideales irrealizables, Arcesilao sólo le dejaba una salida: la suspensión del juicio. Para ser sabio auténticamente, tal como ambicionaban los estoicos, es decir, para liberarse de las opiniones, era imprescindible retener siempre el asentimiento, pues el asentimiento, para Arcesilao, implicaba la aprobación de una representación que no tiene en sí misma ningún criterio de veracidad. Y como el académico concebía el asentimiento como una especie de juicio o aserción, su conclusión era tajante: el sabio estoico deberá suspender el juicio. En otras palabras: Aristón deberá transformarse en Arcesilao.

La posible respuesta de Aristón a este ataque de Arcesilao está sugerida en otra anécdota que cuenta Diógenes Laercio ${ }^{38}$. Al ver el prodigio monstruoso de un toro con matriz, Aristón se burla de Arcesilao exclamando: "Ahí tiene Arcesilao un ejemplo a mano contra la evidencia de los sentidos!". De esta broma podemos sacar la conclusión de que el estoico no se dejaba impresionar por los argumentos de Arcesilao contra la evidencia de la representación aprehensible. Probablemente creía que los ejemplos esgrimidos por su adversario de la Academia eran casos límite y excepcionales, muy poco verosímiles, y que se podía confiar en una aprehensión veraz de la mayoría de nuestras representaciones, siempre que la percepción sensorial no se viese disminuida u obstaculizada. En el resto de los casos, sobre todo cuando nos vienen al encuentro representaciones indistinguibles unas de otras, el sabio estoico no tendrá más remedio que retener el asentimiento y, por ende, refrenar el impulso que conduce a la acción ${ }^{39}$.

Precisamente, la reacción de Arcesilao a esta respuesta de Aristón podría haber consistido en plantearle un desafío, lo que podríamos considerar una

${ }^{37}$ Cf. Ioppolo, 1986 , p. 81.

${ }^{38}$ D.L., 7.162.

39 Para los estoicos, ya desde Zenón y sus discípulos, la retención del asentimiento ( $\dot{\alpha} \sigma 0 \gamma \kappa \alpha \tau \alpha \dot{\alpha} \theta \varepsilon \sigma ı \varsigma)$ se concebía tan sólo como una muestra de precaución ante representaciones no aprehensibles (es decir, falsas o engañosas), que se daban excepcionalmente: cf. Ioppolo, 1986, p. 60; Chiesara, 2007 [2004], p. 50. En cambio, si las representaciones eran indiscernibles unas de otras (como los dos gemelos), el testimonio de Lúculo en la obra homónima de Cicerón induce a pensar que, en el estoicismo primitivo, la suspensión del asentimiento no suponía un reconocimiento de la imposibilidad de captar diferencias entre indiscernibles, pues las distinciones se iban percibiendo a medida que los sentidos se familiarizaban con tales objetos. En esos casos, no asentir a los indiscernibles era una medida provisional hasta tanto la costumbre y la cercanía permitieran reconocer las mínimas diferencias entre aquéllos. Cf. Cic., Luc. 57.2-10: quin etiam concedam illum ipsum sapientem, de quo omnis bic sermo est, cum ei res similes occurrant quas non habeat dinotatas, retenturum adsensum nec umquam ulli viso adsensurum nisi quod tale fuerit quale falsum esse non possit. sed et ad ceteras res habet quandam artem qua vera a falsis possit distinguere, et ad similitudines istas usus adbibendus est: ut mater geminos internoscit consuetudine oculorum, sic tu internosces si adsueveris. No hay ningún motivo para pensar que Aristón no compartiese estas ideas de su maestro Zenón si tenemos en cuenta la confianza que albergaba en la evidencia

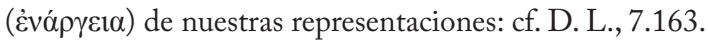


variante del dilema del asno de Buridán. En efecto, si cada vez que afronta imágenes indiscernibles, el sabio estoico se abstiene de asentir y de mover el impulso ¿cómo va a encontrar en esas circunstancias motivos para inclinarse por un objeto más que por otro? ¿Cómo va a activar el mecanismo del asentimiento y el impulso, si las representaciones aprehendidas son indistinguibles unas de otras?

Estas preguntas no inquietaron demasiado a los estoicos ortodoxos que siguieron fieles a la doctrina de Zenón acerca de los indiferentes, porque todos ellos podían permitirse el lujo de no mover un solo dedo por esos indiscernibles que tan decisivos parecían a los académicos. Al fin y al cabo, ¿qué aporta la distinción entre dos estatuas idénticas o entre dos huevos de la misma granja para la correcta discriminación no ya de la virtud y el vicio, sino de los actos apropiados que el necio cumple en su progreso hacia la virtud? Esos indiscernibles podían ser despachados sin esfuerzo: son indiferentes neutros que no excitan el impulso ni la repulsión ${ }^{40}$. En el estoicismo ortodoxo, los actos apropiados están anclados en las inclinaciones naturales (la persecución de la salud, de la buena forma corporal, de la integridad de los sentidos, etc.). Basta con seguir esos impulsos de nuestra naturaleza, asintiendo a representaciones veraces, para tomar decisiones correctas en el ámbito de los indiferentes, sin que se plantee ninguna necesidad ni urgencia de elegir entre indiscernibles de importancia irrisoria ${ }^{41}$.

Pero Arcesilao podría haber replicado a los estoicos: existen algunos indiscernibles que sí excitarían el impulso, porque forman parte de las ventajas naturales y actos apropiados que los hombres cumplen a lo largo de sus vidas. ¿Quién no se ha visto alguna vez en la necesidad de tomar una dracma entre dos dracmas idénticas? ¿A cuál de los dos corredores debe un juez dar el premio si no hay manera de distinguir quién de los dos llegó primero a la meta? Éstos son los ejemplos que Plutarco toma de Crisipo en el capítulo 23 de Las contradicciones de los estoicos y es cierto que son bastante más problemáticos que los antes citados (las estatuas iguales o los huevos idénticos). Porque, si tales indiscernibles excitan el impulso, ¿cómo inclinarse hacia una de las dos monedas, si no hay ningún motivo para hacerlo en un sentido o en otro? A este desafío, la auténtica piedra de toque del dilema del asno de Buridán, no

${ }^{40}$ Cf. Cic., Acad. post. 1.36-37 (= SVF 1.191): cetera autem etsi nec bona nec mala essent tamen alia secundum naturam dicebat alia naturae esse contraria; his ipsis alia interiecta et media numerabat. quae autem secundum naturam essent ea sumenda et quadam aestimatione dignanda docebat, contraque contraria; neutra autem in mediis relinquebat, in quibus ponebat nibil omnino esse momenti. Aquí encontramos, atribuida ya a Zenón, la clasificación tripartita de los indiferentes que será clásica en el estoicismo ortodoxo: a) aquellos que mueven un impulso de atracción (ó $\rho \mu \eta ́)$, porque tienen un valor natural ( $\dot{\alpha} \xi \dot{\xi} \alpha)$ : salud, bienestar, ventajas externas como la riqueza, el honor, etc.); b) aquellos otros, contrarios a los primeros, que mueven un impulso de repulsión ( $\dot{\alpha} \varphi \rho \rho \mu \eta ́)$, porque tienen un disvalor natural ( $\dot{\alpha} \pi \alpha \xi \dot{\xi} \alpha) ; c)$ por último, aquellos que, situados entre unos y otros, no mueven el impulso en absoluto y se consideran neutros, como extender el dedo así o asá, o tener un número par o impar de pelos en la cabeza: cf. SVF 3.118-122.

${ }^{41} \mathrm{El}$ desprecio y la indiferencia de los estoicos por los indiscernibles es puesto de relieve por Lúculo en Cic., Luc. 58.1-4: Neque id est contra vos; nam vobis satis esset ova illa non internoscere; nibilo enim magis adsentirer hoc illud esse quam si inter illa omnino nibil interesset. 
se dio respuesta en el estoicismo hasta Crisipo, que con su formidable lógica consiguió resolver el dilema. Para ello, tuvo que añadir una cuarta categoría de indiferentes: aquellos que excitan el impulso o la repulsión, pero no más en una dirección que en otra ${ }^{42}$. La ingeniosa explicación de Crisipo para evitar la $\dot{\alpha} \pi \rho \alpha \xi \hat{l} \alpha$ en estos casos de impulsos equivalentes será explicada en el punto 5.

Así pues, ni Zenón ni Aristón dieron una respuesta satisfactoria al problema del asno de Buridán planteado por Arcesilao. Sin embargo, el caso de Aristón era más grave que el de Zenón, y por eso, de acuerdo con nuestra hipótesis, recibió de la Academia un ataque específico. Aristón pensaba que, entre los indiferentes, cualquier cosa, sea cual sea la que le salga al encuentro o le venga a la mente, puede ser apetecible para el sabio en función de las circunstancias ${ }^{43}$. Las circunstancias le obligan a toparse con cualquier clase de cosas y entre ellas la razón decide. Pese a la autonomía de la razón, es imposible que el sabio se sustraiga a la tiranía de las circunstancias porque éstas no están en su poder ${ }^{44}$.

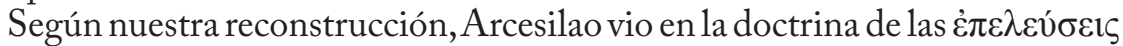
de Aristón un flanco débil y expuesto a su fino olfato crítico. El argumento del académico podía haber sido el siguiente: a) A tenor de las circunstancias, el sabio de Aristón puede inclinarse hacia cualquier cosa que le salga al encuentro o le venga a la mente, esto es, hacia cualquier representación; b) Entonces, las circunstancias podrán poner eventualmente al sabio en la tesitura de tener que elegir entre dos representaciones indiscernibles, si se da el caso de que esa elección redunda en su bien moral (y, aunque parezca extraño, eso puede ocurrir, puesto que la autonomía racional del sabio se extiende a cualquier cosa); c) Pero, una vez puesto en esta necesidad, el sabio aristónico no podrá escapar

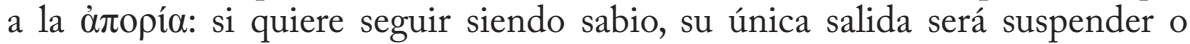
postergar el asentimiento, como recomiendan los estoicos en estas situaciones, y entonces se verá condenado a la inacción.

Aquí es donde Aristón se queda sin respuesta, en opinión de Arcesilao. Y es que no puede sino contradecirse a sí mismo cuando sostiene que el sabio

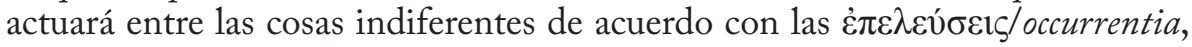
pero no es capaz de conjurar la inacción cuando retiene el asentimiento a representaciones indiscernibles. Pese a la pretensión de universalidad de la

${ }^{42}$ Cf. Apéndice, texto 6. Acerca de ese texto, hay un esclarecedor comentario de Spinelli, 1995, 230-233.

${ }^{43}$ Cf. supra, sección II.

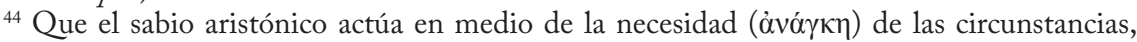
es un hecho puesto de relieve paralelamente tanto por Sexto Empírico como por Plutarco. Cf.

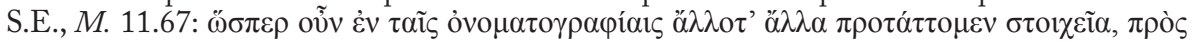

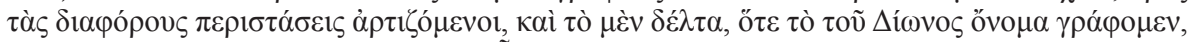

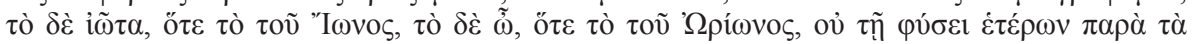

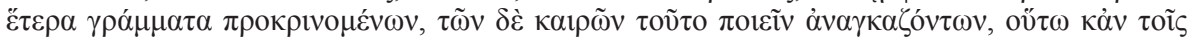

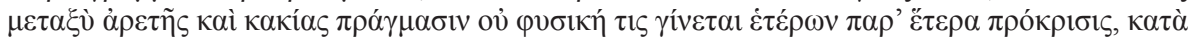

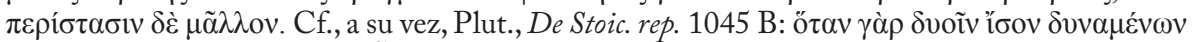

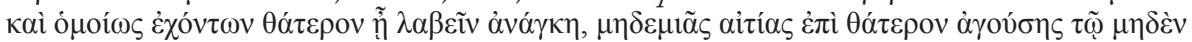

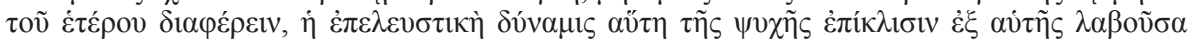

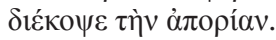


razón del sabio en medio de los indiferentes, quedará siempre un reducto, por pequeño que sea, que se resista a su acción, porque las preferencias entre indiscernibles serán bloqueadas por la retención del asentimiento.

¿Qué puede hacer Aristón para evitar la inacción y garantizar así que sus decisiones se extiendan, a tenor de las circunstancias, a todos los indiferentes sin excepción, incluidos los indiscernibles? Arcesilao le señala el camino a Aristón utilizando el léxico de su adversario, como era habitual en el académico: Aristón no tendría otra escapatoria que postular en el principio gobernante

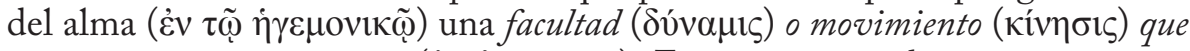

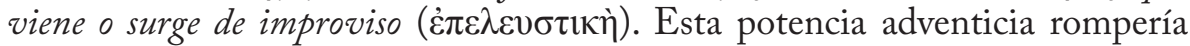
por sí sola la parálisis del proceso perceptivo cuando le vinieran al encuentro dos representaciones indiscernibles, poniendo en movimiento el impulso e inclinando el alma hacia una de las dos representaciones. Esta operación se haría al margen del asentimiento, pues éste resulta imposible cuando el alma se enfrenta a la necesidad de inclinarse ante una representación indistinguible de otra. Por eso se trata de un proceso fortuito y espontáneo: porque salta por encima del asentimiento evitando o caer en la parálisis ( $\alpha$ jopí $\alpha$ ) o precipitarse en el error.

Era necesario que Arcesilao utilizara el léxico de Aristón para volver contra éste la solución al dilema del asno de Buridán. Y no sólo porque el préstamo léxico era un procedimiento que estaba a la orden del día en las polémicas entre escuelas rivales. En realidad, pese a apropiarse del vocabulario de Aristón, el académico cambió notablemente el significado y función que ese

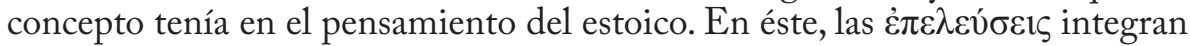
el conjunto de estímulos exteriores que el sabio aristónico encuentra a su paso cada vez que debe tomar una decisión racional entre cosas indiferentes. En manos de los académicos, las $\dot{\varepsilon} \pi \varepsilon \lambda \varepsilon v ́ \sigma \varepsilon 1 \varsigma$ se convierten en movimientos fortuitos del alma que permiten tomar decisiones al azar cuando se debe elegir

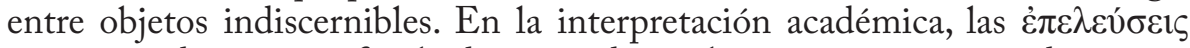
son generadas por una facultad que reside en el principio rector y se denomina $\dot{\varepsilon} \pi \varepsilon \lambda \varepsilon v \sigma \tau \iota \kappa \eta ̀ ~ \delta v ́ v \alpha \mu \iota \varsigma \tau \tilde{\eta} \varsigma \psi v \chi \tilde{\eta} \varsigma$. Para Arcesilao y sus discípulos, el movimiento adventicio, que Aristón veía como un rasgo de las representaciones, puesto que éstas nos salen súbitamente al paso y vienen a nuestra mente desde el exterior, reside de hecho en el alma, que reacciona a ellas con impulsos igualmente adventicios y repentinos. Ello hace posibles las decisiones aleatorias en el caso límite de la selección entre indiscernibles.

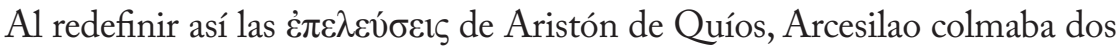
objetivos polémicos.Por un lado,demostrabaa Aristón que, para que pudiera actuar entre todos los indiferentes (incluyendo los indiscernibles), el sabio aristónico estaba obligado a postular una doctrina, la de la facultad adventicia del alma, que entraría en abierta contradicción con el monismo psicológico radical defendido por el propio Aristón ${ }^{45}$. Pero, por otro lado, esa flagrante contradicción con la psicología estoica ponía de manifiesto el talón de Aquiles de la gnoseología del

\footnotetext{
${ }^{45}$ Cf. supra, sección II.
} 
Pórtico: la presunción errónea de que el impulso depende del asentimiento para la acción. La óptica de Arcesilao era justamente la contraria, como la hipótesis polémica de la facultad adventicia del alma ponía de manifiesto: si se suprime el asentimiento, que no deja de ser un juicio, el proceso cognoscitivo que conduce de la representación hasta el impulso queda admirablemente simplificado. Pues sólo si el impulso es independiente de todo juicio, puede liberarse de ser arrastrado a la parálisis por dos representaciones indiscernibles.

\section{Arcesilao y Aristón sobre el criterio para la acción.}

Esta argumentación polémica de Arcesilao contra Aristón cuadraría muy bien con lo que las fuentes nos refieren sobre las disputas dialécticas que mantuvieron ambos filósofos sobre el criterio de acción propio del hombre sabio. Según el testimonio del propio Plutarco en el Contra Colotes ${ }^{46}$, la suspensión del juicio no impedía a Arcesilao formular un criterio de la acción coherente con su escepticismo gnoseológico: cuando la mente es afectada por las representaciones, el impulso llega súbitamente conduciendo al alma hacia la representación de lo que le pertenece por naturaleza ( los impulsos naturales sirven de guía para la acción sin necesidad de recurrir al asentimiento. El caso particular de las representaciones indiscernibles no suponía, pues, ningún desafío para Arcesilao, desde el momento en que éste consideraba el asentimiento innecesario y perjudicial para la acción del sabio, pues era la fuente de la opinión y el error.

Precisamente, el criterio de la acción de Arcesilao, basado en la representación y en el impulso natural que surge de inmediato como respuesta instintiva a lo que

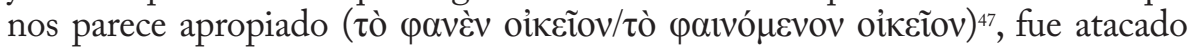
directamente por Aristón. En uno de sus fragmentos ${ }^{48}$, el estoico, sin nombrar a su adversario de la Academia, retuerce contra Arcesilao la terminología usada por éste para referirse a la representación de lo que conviene a nuestra naturaleza.

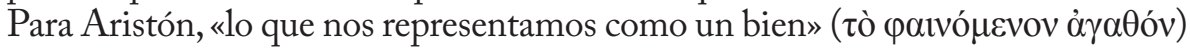
no es más que el bien aparente, al que tiende el instinto natural hacia el placer.

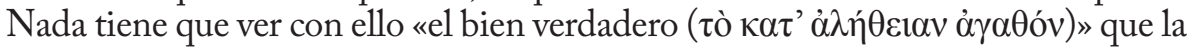
filosofía nos enseña a distinguir, sin posibilidad de error, de los bienes aparentes a los que nos conducen nuestros impulsos naturales.

En este contexto, cobra nuevo sentido y coherencia el que Arcesilao estuviera interesado en demostrar a Aristón que él mismo, en muchas ocasiones, no tendría más remedio que activar un movimiento adventicio del alma para poder tomar decisiones entre indiscernibles (غ̇ $\pi \varepsilon \lambda \varepsilon v ́ \sigma \varepsilon ı \varsigma)$. Esa facultad adventicia, que permite poner en marcha el mecanismo del impulso de forma independiente al asentimiento, entra en contradicción con el monismo psicológico de Aristón, pero daba la razón a Arcesilao en lo que se refiere al criterio de la acción.

${ }^{46}$ Cf. Apéndice, texto 4. Cf. Ioppolo, 1986, 134-136 y el reciente artículo de la misma autora: «Su alcune recenti interpretazioni dello scetticismo dell'Academia: Plutarch. Adv. Col. 26,1121 F-1122 F: una testimonianza su Arcesilao», Elenchos 21,2 (2000) 333-360.

${ }^{47}$ Plut., Adv. Col. 1122 C-D.

${ }^{48}$ Cf. Apéndice, texto 5. Cf. Ioppolo, 1986, 181-182. 


\section{La interpretación de Arcesilao en Cicerón y Plutarco.}

Al apropiarse de la terminología de Aristón, Arcesilao difuminó los rasgos de la teoría original de las $\dot{\varepsilon} \pi \varepsilon \lambda \varepsilon v ́ \sigma \varepsilon 1 \varsigma$, tal como la hemos interpretado en la sección II, hasta el extremo de volverla casi irreconocible. Esto explica también las interpretaciones que encontramos en nuestras dos fuentes principales para dicha doctrina, Cicerón y Plutarco, que nunca ocultaron su deuda con la Academia nueva en sus escritos de polémica antiestoica.

De acuerdo con el indiferentismo casi absoluto que le atribuye a Aristón, Cicerón sugiere que aquél aconsejaba subordinar el deseo de las cosas indiferentes a una especie de azar caprichoso: el sabio persigue lo que quiera que se le presente de improviso y le venga a la cabeza. Como hemos visto antes, esta interpretación trivializa la doctrina de Aristón, pero introduce en ella un elemento de azar e imprevisibilidad que seguramente remonta al propio Arcesilao, pese a que el propio Cicerón dice no entender muy bien qué son las occurrentia de Aristón.

En cuanto al testimonio de Plutarco en el capítulo 23 de Las contradicciones de los estoicos, este pasaje describe y matiza con profusión de detalles la

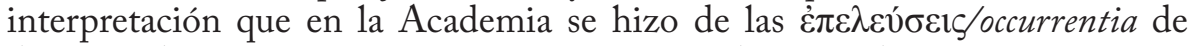
Aristón. Al polemizar con esta doctrina de Aristón, Arcesilao trataba de demostrar a los estoicos que el asentimiento no sirve como punto de partida del impulso cuando, entre dos representaciones indiscernibles, alguien se ve forzado a inclinarse por una de ellas. Para liberar a los impulsos de la tiranía de tales representaciones, que proceden del exterior (lo que Plutarco llama las causas externas $)^{49}$, y para no caer en la parálisis, algunos filósofos -según nuestra hipótesis, Arcesilao y los académicos en polémica con el estoico

${ }^{49}$ En varios pasajes de su obra, Plutarco ha hecho explícita la identificación de las causas externas con las representaciones, sobre todo cuando el punto de mira de su crítica era Crisipo. Ya en Crisipo, en efecto, la doctrina de las causas establece expresamente que las representaciones son causas del asentimiento, sólo que no causas completas o autosuficientes, sino tan sólo sus causas iniciales o antecedentes (cf. De Stoic. rep., 1055F-1056A). El hecho de que todas las representaciones acudan al alma desde el exterior, como afirmaba Zenón (Cic., Acad. post. 1.40 = SVF 1.55), y que éstas sean ineluctables como causas antecedentes de la acción libre, como quería Crisipo, bastaría para explicar la expresión utilizada por Plutarco («causas externas») para referirse a las representaciones. Además, Plutarco no es el único autor que realiza esta ecuación: véase, por ejemplo, el extenso análisis del académico Carnéades, recogido por Cicerón en Fat., 23-25. Frente a Crisipo, Carnéades negaba taxativamente que los movimientos voluntarios del alma tuviesen en las representaciones causas externas y antecedentes. Si la experiencia nos enseña que los movimientos voluntarios están en nuestra mano, su causa reside en la naturaleza misma de la voluntad, no en causas antecedentes y externas (Similiter ad animorum motus voluntarios non est requirenda externa causa; motus enim voluntarius eam naturam in se ipse continet, ut sit in nostra potestate nobisque pareat, nec id sine causa; eius rei enim causa ipsa natura est). Sin ser la misma doctrina, da la impresión de que hay una cierta continuidad de escuela entre los movimientos voluntarios del alma, defendidos por Carnéades, y la facultad adventicia del alma, que su predecesor Arcesilao, como creemos nosotros, podría haber forjado en polémica contra los estoicos -y, en particular, contra Aristón de Quíos- acerca de la libertad de indiferencia. En ambos casos, el alma actúa como causa de sus propios movimientos, desvinculada de las causas externas, es decir, totalmente libre de las representaciones y de los asentimientos que de ellas se siguen. 
Aristón de Quíos- habían postulado en el seno del principio rector una especie de movimiento o facultad adventicia que, suministrando una inclinación instantánea, ponía en marcha el impulso y sorteaba la imposibilidad de asentir en presencia de dos representaciones indiscernibles. Pero, al prescindir del asentimiento, Arcesilao demostraba contra Aristón que al sabio le bastaban las representaciones y los impulsos que surgen de ellas para encontrar vías naturales y razonables de actuación. La facultad adventicia, pues, no constituye una doctrina positiva de los académicos, sino la lectura y recepción polémicas que Arcesilao hizo de una doctrina de Aristón, tomando prestados de su adversario los conceptos y el léxico para demostrar la fragilidad de la doctrina estoica del conocimiento y de la acción. Por lo demás, la hipótesis de la facultad adventicia del alma, aunque construida con propósitos polémicos, estaría bastante próxima a lo que el propio Arcesilao pensaba acerca de las relaciones entre la representación, el impulso y la acción, tal como han sido expuestas por Plutarco en el Contra Colotes ${ }^{50}$.

\section{La solución de Crisipo al dilema de las dos dracmas.}

El último capítulo de la polémica entre académicos y estoicos en torno al

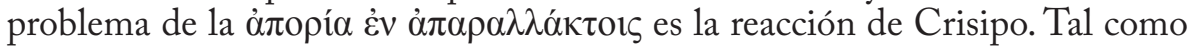
expone Plutarco la cuestión en el capítulo 23 de Las contradicciones de los estoicos, se han difuminado considerablemente las huellas de la polémica doctrinal que le precedió, pues nos presenta una doctrina más o menos acabada atribuyéndola a un misterioso Ěvioı $\tau \tilde{\omega} v$ $\varphi \imath \lambda o \sigma o ́ \varphi \omega v$. Más adelante, cuando Plutarco parafrasea a Crisipo, el estoico tampoco se molesta en nombrar a quienes son blanco de sus ataques $(\dot{v} \pi \text { ' } \dot{\varepsilon} v i ́ \omega v)^{51}$, pero éstos han de ser necesariamente Arcesilao y sus

${ }^{50} \mathrm{Cf}$. Apéndice, texto 4. Hay paralelismos significativos entre este pasaje del Contra Colotes (= A) y el capítulo 23 de Las contradicciones de los estoicos (Apéndice, texto 1 = B). La facultad

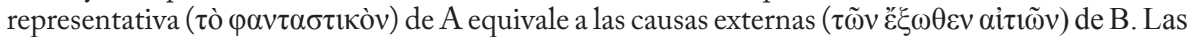

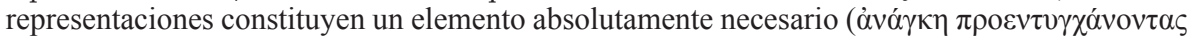

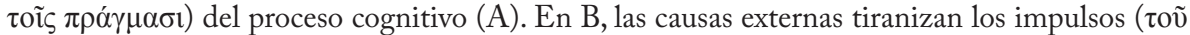

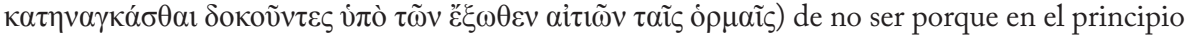

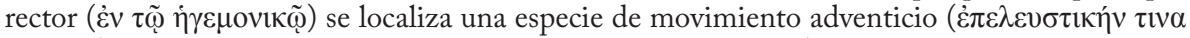

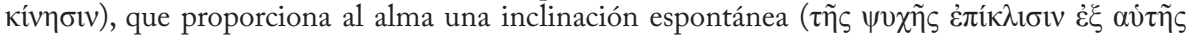
$\lambda \alpha \beta$ ov $\sigma \alpha)$; en $\mathrm{A}$, este movimiento no es otro que el del impulso, que dirige al alma hacia lo que le es propio, «como si en el principio rector se generase una especie de tendencia y propensión» (oĩov

${ }^{51}$ En sus polémicas con los académicos y otros representantes de escuelas rivales, es conocida la práctica de Crisipo de referirse a ellos con circunloquios y expresiones elusivas: cf. Plut.,

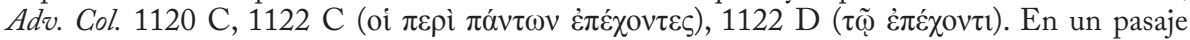
de Las contradicciones de los estoicos (Plut., De Stoic. rep. 1037 C), Crisipo se refiere a ellos de un modo bastante más oscuro y Plutarco se ve obligado a introducir una acotación a la cita

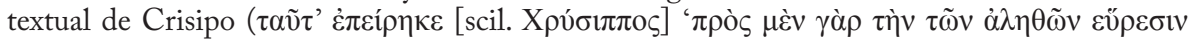

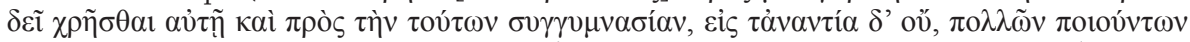

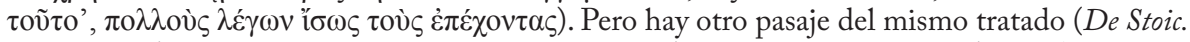

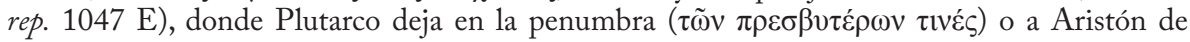
Quíos o a los académicos: al primero le cuadra muy bien la comparación de los indiferentes con el vino agrio, pero esa imagen podría haber sido utilizada también por los segundos. No es, por ello, inverosímil que, en De Stoic. rep. 1045 B, Crisipo y Plutarco se refieran a los académicos con un elíptico ěvırot. La razón de que Plutarco no desvele la identidad de ese Ěvior es que, en 
discípulos, si, como nosotros creemos, fueron los académicos quienes dieron

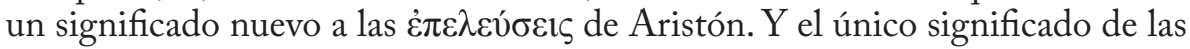
$\dot{\varepsilon} \pi \varepsilon \lambda \varepsilon v ́ \sigma \varepsilon 1 \varsigma$ que cuadra con la reacción de Crisipo es el de 'decisiones fortuitas tomadas por la facultad adventicia del alma', esto es, el que creemos que se forjó en la Academia en oposición a Aristón de Quíos. Este significado se atrajo de inmediato el reproche de Crisipo de introducir en la naturaleza un movimiento sin causa.

Pues bien, Crisipo se enfrenta al desafío planteado por los académicos a la teoría del conocimiento estoica con una doble estrategia, destructiva y constructiva. En la pars destruens, denigra el concepto de facultad adventicia del alma con uno de los más graves reproches que podían hacérsele a cualquier doctrina filosófica: elde introducir lo incausado para dar cuenta de los fenómenos. En efecto, los objetos indiscernibles, que constituyen una de las clases de cosas indiferentes establecidas por $\mathrm{Crisipo}^{52}$, no desafían el asentimiento del sabio ni lo constriñen a la perplejidad ( $\dot{\alpha} \pi$ opí $\alpha)$ y a la inacción $(\dot{\alpha} \pi \rho \alpha \xi i ́ \alpha)$. Su carácter indiscernible no es real: en ellos laten diferencias o tendencias imperceptibles

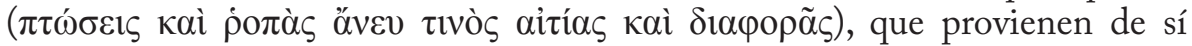

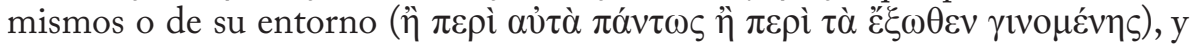
tales diferencias determinan un nexo causal oculto que proporciona la condición previa de todo impulso (y, por ende, del asentimiento). Así pues, estos objetos intercambiables tienen la facultad de mover el impulso o la repulsión, sólo que no lo mueven con mayor fuerza en una o en otra dirección, en la medida en que a nosotros nos resulta imposible captar la diferencia real que hay entre dichos objetos. No hay, para Crisipo, ninguna necesidad de inventarse movimientos

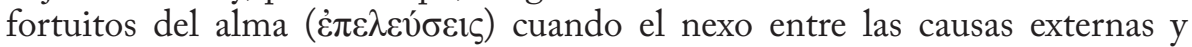
nuestros impulsos, aunque oculto, no se ha roto en absoluto.

Esta acusación de introducir lo incausado era, como se sabe, el argumento recurrente de los estoicos contra la teoría epicúrea del clinamen: de ahí que tantos intérpretes hayan pensado en los epicúreos como blanco de los ataques de Crisipo en este capítulo. Pero lo cierto es que, si Crisipo utilizó contra los académicos este argumento tan trillado contra los epicúreos, ello es congruente también con el propio concepto de facultad adventicia del alma, tal como había sido interpretado por Arcesilao y sus discípulos: se trata, en efecto, de

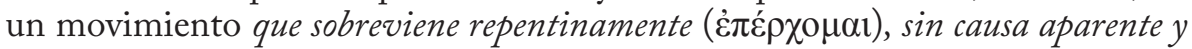
sin que se pueda predecir, y una de sus funciones primordiales es desbloquear la parálisis que se apodera del alma cuando ésta se ve obligada a escoger entre representaciones indiscernibles. Un movimiento de tal naturaleza admitía muy bien un ataque semejante al que recibió el clinamen epicúreo, pero eso no convierte en idénticas ambas doctrinas.

este capítulo, el de Queronea se limita a reproducir en la frase inicial el estilo elusivo de Crisipo

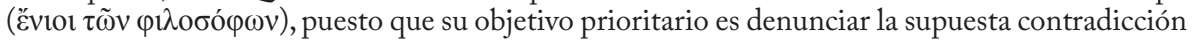
de Crisipo en la solución al problema de la libertad de indiferencia y no le conviene demorarse demasiado en reconstruir los debates que se habían producido al respecto entre académicos (Arcesilao y sus discípulos) y estoicos (Zenón y Aristón de Quíos).

${ }^{52}$ Cf. Apéndice, texto 6. 
En cuanto a la pars construens, Crisipo acepta el guante lanzado por los académicos y les contesta en su propio terreno qué es lo que debe hacerse cuando alguien está obligado a escoger entre dos objetos indistinguibles. Sin admitir ningún movimiento fortuito del alma, Crisipo sustituye este concepto

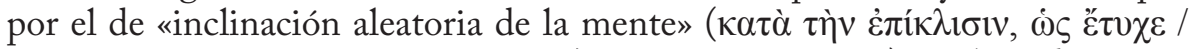

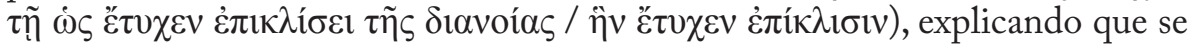

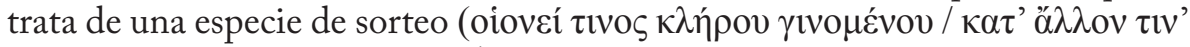

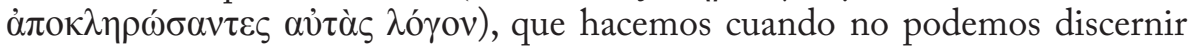
qué indiferente nos conviene aceptar por no distinguirse uno del otro, y hemos de recurrir a un criterio distinto de selección del que habitualmente usamos

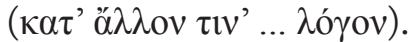

En el último ejemplo, el de las dos dracmas idénticas, el sorteo no impugna las diferencias reales pero imperceptibles entre las monedas, que se deben a causas ocultas y que sólo pueden vislumbrarse tras ser examinadas

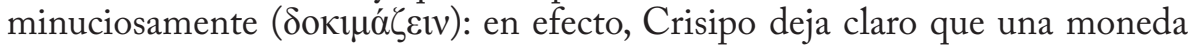
es de curso legal y la otra falsa, pero que no merece la pena molestarse en averiguar cuál es la buena y cuál la mala, sino coger al azar una de las dos (ĩv ह̌ं $\chi \chi \varepsilon)$, aunque eso suponga coger la moneda falsa.

En este punto, no debemos olvidar la definición crisipea de la $\tau u ́ \chi \eta$ (azar): «una causa oculta para la razón humana» ${ }^{53}$. Por eso, la introducción de la suerte no pone en peligro el principio de causación: en efecto, el sorteo es la única medida que nos queda cuando no tenemos medios de valorar cuál de las dos monedas nos conviene. Ahora bien, nuestra ignorancia no anula la diferencia entre ambas, sólo la pone entre paréntesis. En este sentido, no se sostiene la contradicción denunciada aquí por Plutarco, según la cual Crisipo también daba entrada al azar y la suerte tras haber impugnado la facultad adventicia del alma, por no tener causa que la justifique. Al contrario, la concesión de Crisipo al azar es tan sólo una renuncia a saber o averiguar causas ocultas que, por ser tan imperceptibles, no merece la pena conocer tratándose de cosas indiferentes. Por eso, el acto de asentir y el movimiento del impulso no se cuestionan: para justificar la inclinación aleatoria de la mente ante objetos indiscernibles basta un simple sorteo.

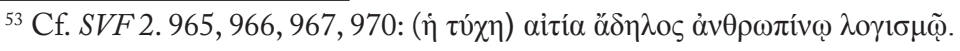




\section{Bibliografía}

Plutarch's «Moralia», XIII, 2, ed. and transl.H.Cherniss, Londres-Cambridge (Massachusetts), 1976.

Plutarque, Oeuvres Morales. Tome XV.1. Traité 70: Sur les contradictions stoïciennes; Traité 71: Synopsis du traité "Queles Stö̈ciens tiennent des propos plus paradoxaux que les poètes", texte établi par M. Casevitz, traduit et commenté par D. Babut, Paris 2004 (cf. pp. 219-227 del Commentaire).

Plutarco, Obras morales y de costumbres $=($ Moralia $) .11$, Tratados platónicos; Tratados antiestoicos, introd., trad. y notas de Ma Á. Durán López [Tratados platónicos] y R. Caballero Sánchez [Tratados antiestoicos]. Madrid, Gredos, 2004 (cf. pp. 275-279)

Boys-Stones, G., «The epeleustikè dunamis in Aristo's psychology of action», Phronesis 41 (1996) 75-94.

Chiesara, Ma L., Historia del escepticismo griego, trad. esp., Madrid, 2007 [Torino 2004].

Ioppolo A. Ma., Aristone di Chio e lo stoicismo antico, Napoli, Bibliopolis, 1981.

, Opinione e scienza. Il dibattito tra stoici e accademici nel III e nel II secolo a. C., Napoli, Bibliopolis, 1986.

Long A. A. \& Sedley D. N., The Hellenistic philosophers, I: Translations of the principal sources with philosophical commentary, Cambridge, Cambridge Univ. Pr., 1987.

Long A. A. \& Sedley D. N., The Hellenistic Philosophers, II : Greek and Latin texts, Cambridge, Cambridge Univ. Pr., 1987.

Moreau, J., «Ariston et le stoïcisme», en J. Moreau, Stoïcisme, épicurisme, tradition hellenique, Paris, 1979, pp. 21-42 [= «Ariston et le stoïcisme», REA (1948) 27-48].

Sedley, D. N., «The Stoic-Platonist debate on kathêkonta», en Ierodiakonou, K. (ed.), Topics in Stoic Philosophy, Oxford, 1999, pp. 128-152.

Spinelli, E., Sesto Empirico. Contro gli etici, ed., trad. e comm. a cura di..., Napoli, 1995. 


\section{ApÉndice}

\section{Plutarchus, De Stoicorum repugnantiis 23, 1045 B-F (ed. Babut-Casevitz 2004):}

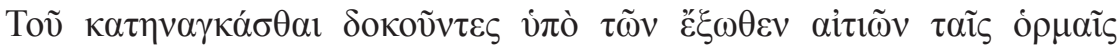

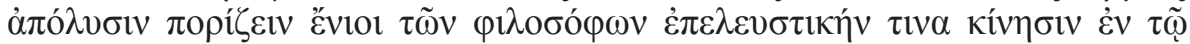

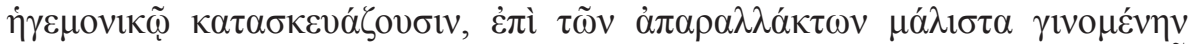

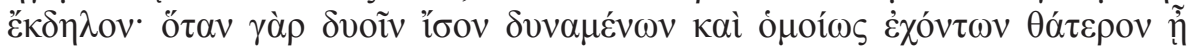

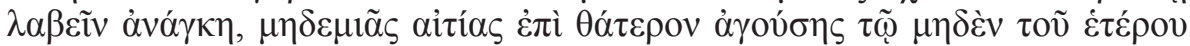

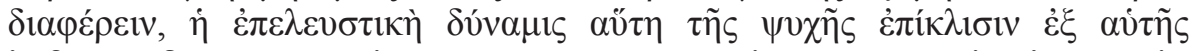

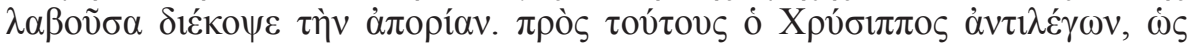

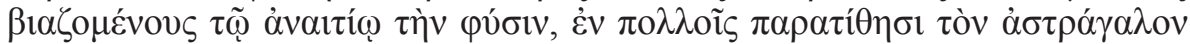

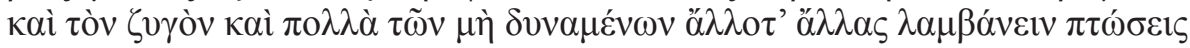

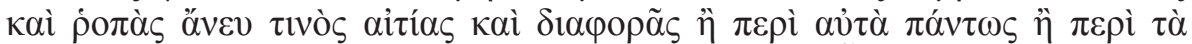

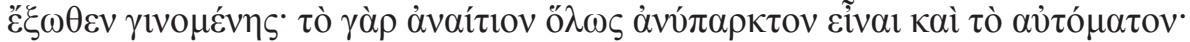

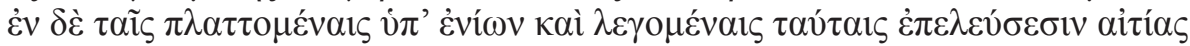

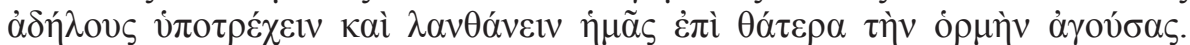

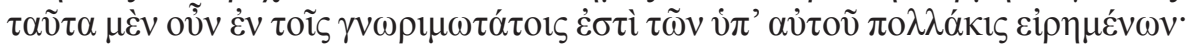

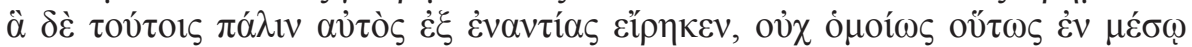

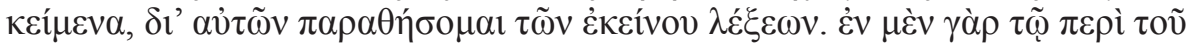

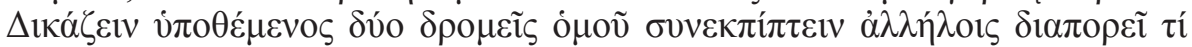

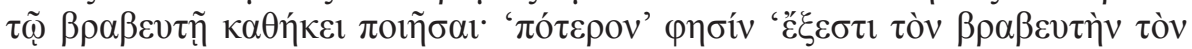

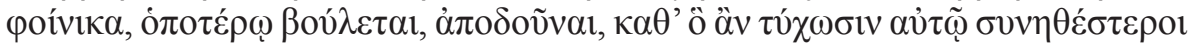

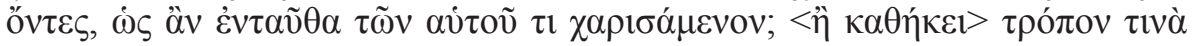

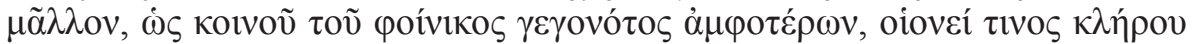

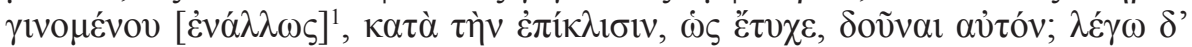

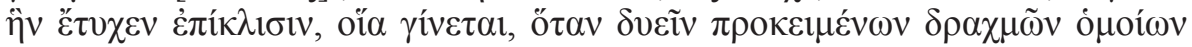

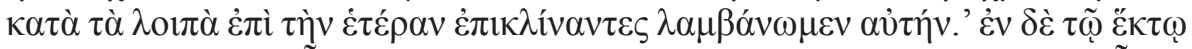

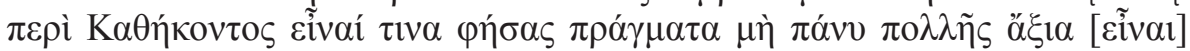

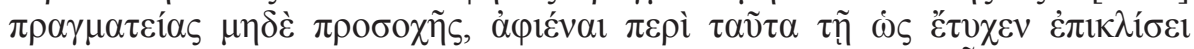

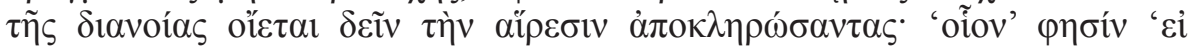

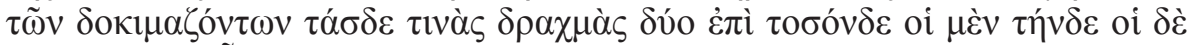

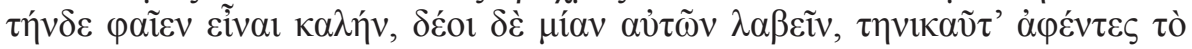

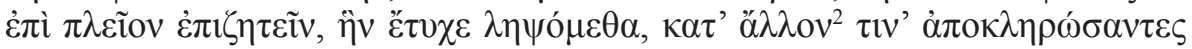

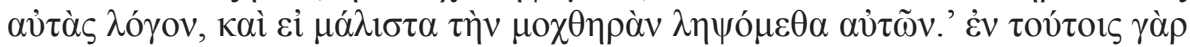

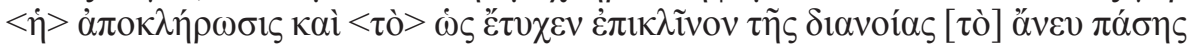

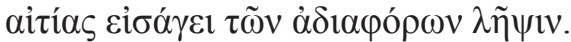

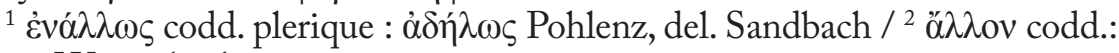

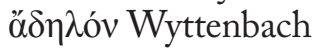

Plutarco, Las contradicciones de los estoicos 23, 1045 B-F (trad. CABALlero 2004):

Algunos filósofos, en la creencia de que proporcionan a nuestros impulsos una liberación de ser sometidos por la fuerza a las causas externas, sitúan en 
el principio rector un movimiento adventicio que se manifiesta sobre todo en las decisiones entre objetos indiscernibles. En efecto, cuando, de dos cosas de importancia equivalente y similar disposición, es forzoso aceptar una, sin que ninguna causa nos empuje hacia una de las dos porque no se diferencia en nada de la otra, esa facultad adventicia del alma, adoptando por sí misma una inclinación hacia una o hacia otra, neutraliza nuestra perplejidad. Pero Crisipo, oponiéndose a estos filósofos porque violentan la naturaleza con lo incausado, trae a colación en muchos pasajes el astrágalo, la balanza y muchas cosas que no pueden tener caídas o inclinaciones, unas veces en un sentido otras en otro, sin una causa, esto es, sin una diferencia que o bien se encuentra en su interior o bien en el exterior. Porque lo incausado y lo espontáneo -objeta Crisipoes completamente inexistente. Bajo esos movimientos imaginarios y llamados adventicios por algunos, laten causas ocultas que, sin darnos cuenta, conducen nuestro impulso en una dirección o en otra.

Pues bien, si estas opiniones están entre las más conocidas que ha formulado Crisipo en muchos pasajes, aquellas otras que él mismo ha expresado a su vez desde una posición contraria a ellas, al no estar en igual medida al alcance del público, voy a citarlas con sus palabras literales. Porque en De cómo administrar justicia, tras haber planteado el supuesto de que dos corredores llegan simultáneamente a la meta, propone el problema de cuál será la decisión más apropiada que el árbitro ha de tomar: «¿s lícito - dice - que el árbitro entregue la palma a aquel que prefiera de los dos, dependiendo de que tenga por casualidad más trato con uno o con otro, como si con esta decisión fuera a regalar algo de su propiedad? ¿ $\mathrm{O}$ en cierto modo <la decisión más apropiada> es, dado que la palma ha devenido propiedad común de ambos, hacer la entrega tras proceder a una especie de sorteo, de acuerdo con su inclinación aleatoria? Y cuando digo 'inclinación aleatoria' me refiero a la que se produce cuando, al tener delante de nosotros dos dracmas idénticas en todo lo demás, nos inclinamos por una de ellas y la aceptamos». Y en el libro sexto de Sobre lo apropiado, tras haber dicho que hay cosas que en absoluto merecen demasiado esfuerzo ni atención, piensa que respecto a ellas hemos de proceder a un sorteo, dejando nuestra elección en manos de la inclinación aleatoria de la mente: «Por ejemplo -dice-, si sometiendo a prueba en su exacto valor estas dos dracmas que tenemos aquí unos dijesen que la moneda buena es ésta, otros que esta otra, pero es preciso aceptar una, sin preocuparnos de investigar más en tales asuntos aceptaremos una de ellas al azar, sorteándolas de acuerdo con un criterio distinto, aunque hayamos aceptado precisamente la moneda mala». Entonces, en estos pasajes el sorteo, o sea, la inclinación aleatoria de la mente, introduce la aceptación de las cosas indiferentes sin que intervenga ningún tipo de causa.

\section{Cicero, De finibus bonorum et malorum 4.43:}

Itaque mibi videntur omnes quidem illi errasse, qui finem bonorum esse dixerunt honeste vivere, sed alius alio magis, Pyrrho scilicet maxime, qui virtute 
constituta nibil omnino, quod appetendum sit, relinquat, deinde Aristo, qui nibil relinquere non est ausus, introduxit autem, quibus commotus sapiens appeteret aliquid, quodcumque in mentem incideret, et quodcumque tamquam occurreret. is hoc melior quam Pyrrho, quod aliquod genus appetendi dedit, deterior quam ceteri, quod penitus a natura recessit. Stoici autem, quod finem bonorum in una virtute ponunt, similes sunt illorum; quod autem principium officii quaerunt, melius quam Pyrrbo; quod ea non occurrentia fingunt, vincunt Aristonem; quod autem ea, quae ad naturam accommodata et per se assumenda esse dicunt, non adiungunt ad finem bonorum, desciscunt a natura et quodam modo sunt non dissimiles Aristonis. ille enim occurrentia nescio quae comminiscebatur; bi autem ponunt illi quidem prima naturae, sed ea seiungunt a finibus et a summa bonorum; quae cum praeponunt, ut sit aliqua rerum selectio, naturam videntur sequi; cum autem negant ea quicquam ad beatam vitam pertinere, rursus naturam relinquunt.

Ibidem, 4.46-47:

Vobis autem, quibus nibil est aliud propositum nisi rectum atque bonestum, unde officii, unde agendi principium nascatur non reperietis. Hoc igitur quaerentes omnes, et ii, qui quodcumque in mentem veniat aut quodcumque occurrat se sequi dicent, et vos ad naturam revertemini. quibus natura iure responderit non esse verum aliunde finem beate vivendi, a se principia rei gerendae peti; esse enim unam rationem, qua et principia rerum agendarum et ultima bonorum continerentur, atque ut Aristonis esset explosa sententia dicentis nibil differre aliud ab alio, nec esse res ullas praeter virtutes et vitia, inter quas quicquam omnino interesset, sic errare Zenonem, qui nulla in re nisi in virtute aut vitio propensionem ne minimi quidem momenti ad summum bonum adipiscendum esse diceret et, cum ad beatam vitam nullum momentum cetera haberent, ad appetitionem tamen rerum esse in iis momenta diceret; quasi vero haec appetitio non ad summi boni adeptionem pertineret!

\section{Diogenes Laertius, 7.162-163 (ed. Long 1964):}

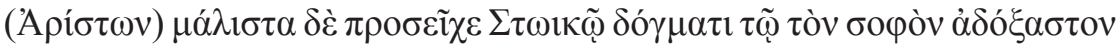

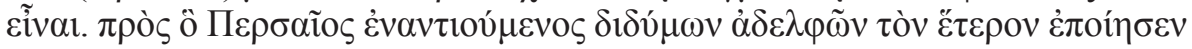

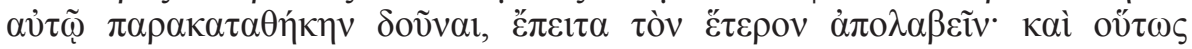

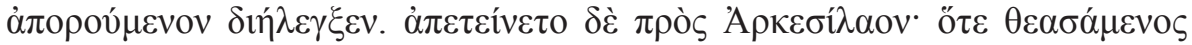

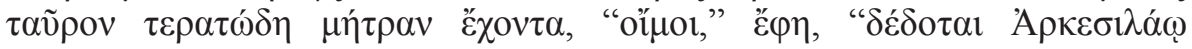

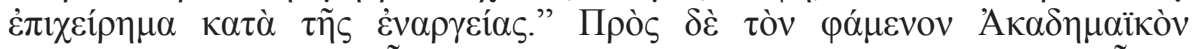

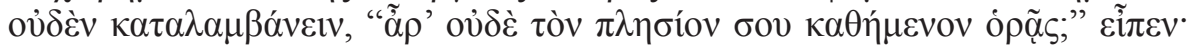

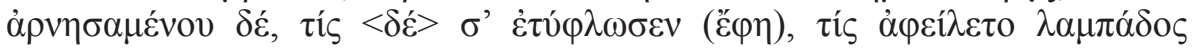

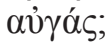

\section{Plutarchus, Adversus Colotem 26, 1122 B-D (ed. Westman 1955):}

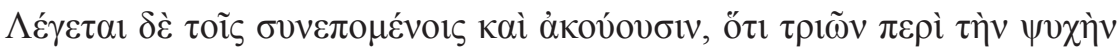

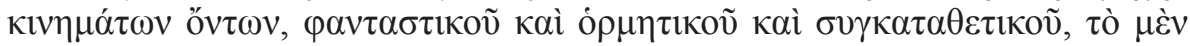

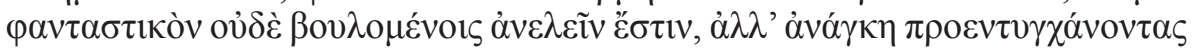




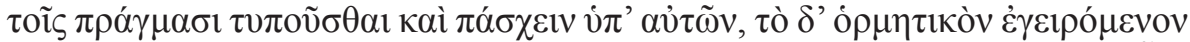

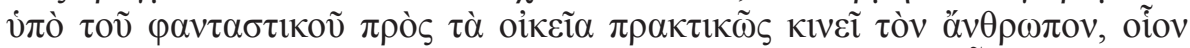

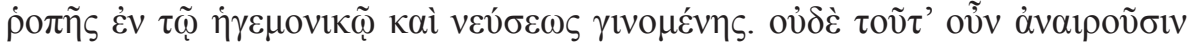

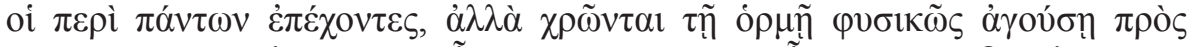

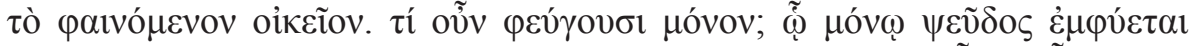

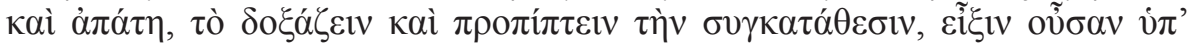

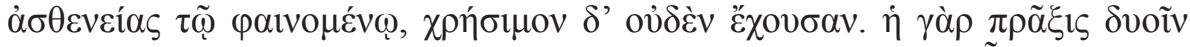

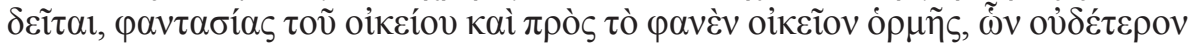

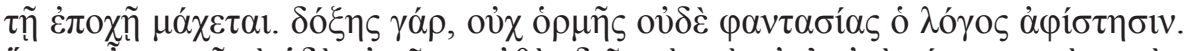

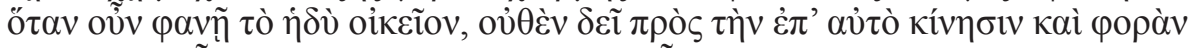

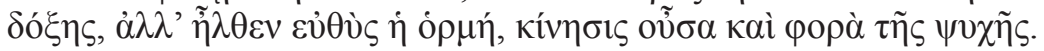

5. $S V F$ 3.256, p. 60,33-61,9 (ed. von Arnim 1905) = Galenus, de H. et Plat. decr. 7.2 (208.591 M.):

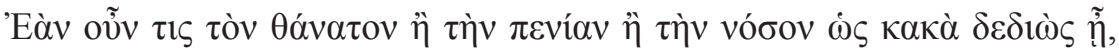

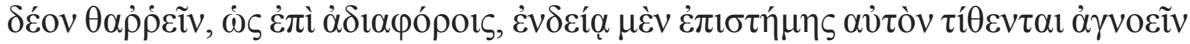

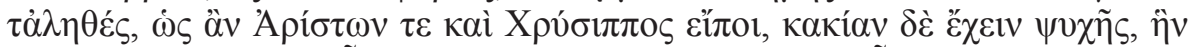

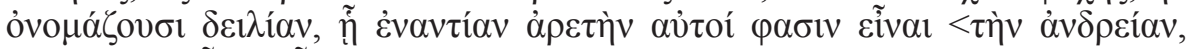

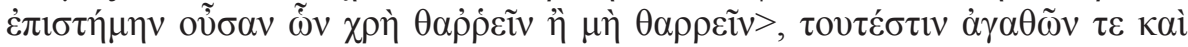

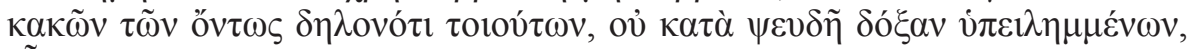

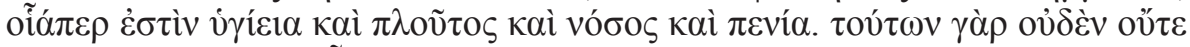

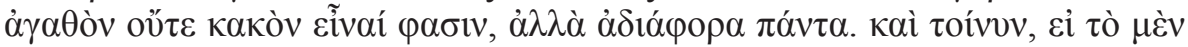

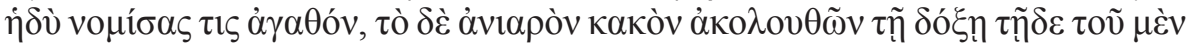

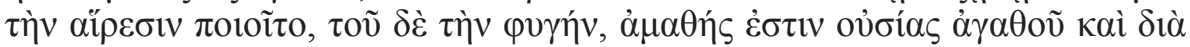

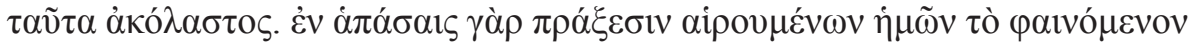

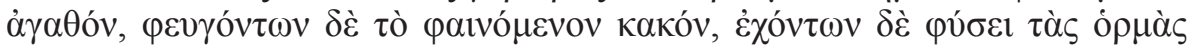

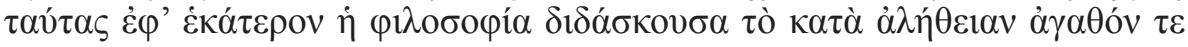

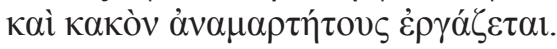

\section{6. $S V F$ 3.122, p. 29,17-28 (ed. von Arnim 1905) = Sextus Empiricus,} Adv. math. 11.59:

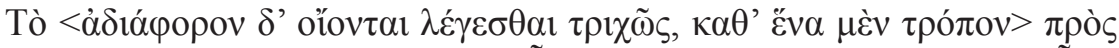

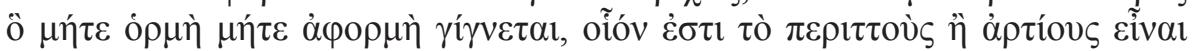

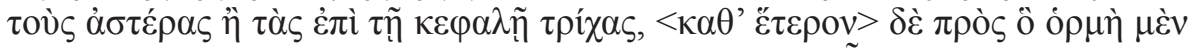

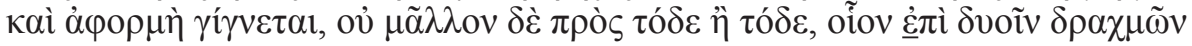

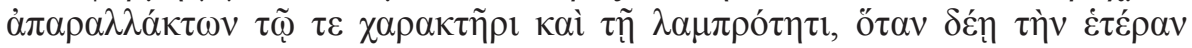

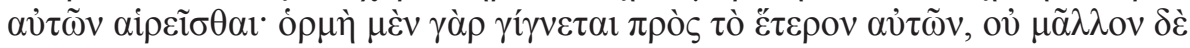

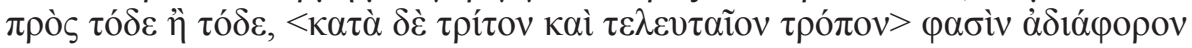

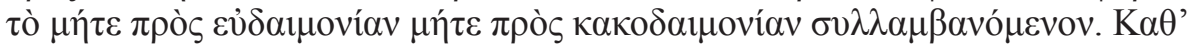

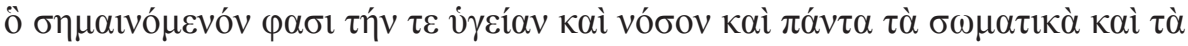

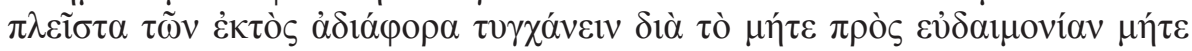

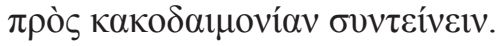




\title{
Fato e Fortuna Negli opuscoli contro gli Stoici di Plutarco:
}

\author{
UN PROBLEMA ANCORA APERTO
}

\author{
Paola Volpe Cacciatore \\ Università di Salerno
}

\begin{abstract}
In arguing that the order of necessity mingles with that of causality and with the free will, Plutarch confutes Stoic doctrines about physics and Providence. At the same time, he elaborates a somewhat 'median' theory, with the aim of balancing the relationship between Providence and free human enterprise.
\end{abstract}

Per Crisippo - e più tardi Posidonio - "il destino (che poi coincide con la provvidenza divina) è l'ordine del mondo in quanto consequenzialità seriale e intromissione simpatetica di tutti i processi causa-effetto scaturiti dal Logos" Nel De fato l'autore ${ }^{2}$, dopo aver definito il significato del termine ei $\mu \alpha \rho \mu \varepsilon ́ v \eta$, ovvero connessione, discute i rapporti tra destino, provvidenza, caso, libero arbitrio esaminando fino a che punto sia vera la formula $\pi \alpha^{\prime} v \tau \alpha \kappa \alpha \theta^{\prime}$ ' $\dot{i} \mu \alpha \rho \mu \varepsilon ́ v \eta \nu$. Sono questi i problemi che Plutarco affronta negli opuscoli contro gli Stoici in nome della libertà umana che, in quanto tale, respingeva ogni sottomissione ad un unico principio.

Il mondo secondo Crisippo occupa il centro dell'infinito vuoto e, grazie a questa sua posizione, esso si conserva unito e compatto. Ciò avviene solo ad opera della $\tau \hat{\chi} \chi \eta$, causa prima del "raccogliersi e conservarsi" di ogni parte del mondo. Un determinismo questo che portava gli Stoici a scorgere "un legame di simpatia universale" 3 ovvero un concatenarsi di avvenimenti, unica condizione per il mantenimento dell'ordine. Il destino domina tutti gli esseri: come Ragione dispensa ogni cosa con ordine e misura, come Provvidenza veglia alla conservazione degli esseri in modo da subordinarli al fine supremo che è poi il destino stesso. In tale concezione Plutarco rilevava forti contraddizioni: la prima di esse stava nell'ammissione da parte di Crisippo di un centro nell'infinito che, per essere tale, non può avere né un centro né un inizio, né una fine; la seconda nel pensare che la coesione del mondo è dovuta ad un movimento del tutto naturale delle sue parti verso il centro ${ }^{4}$ se fosse vera

${ }^{1}$ E. Magris, 2001, p. 68.

${ }^{2}$ Sulla dubbia paternità dell'opuscolo cf. tra gli altri E. VAlgiglio, 1993, pp. 34 ss.

${ }^{3}$ S. Nicolosi, 1959, p. 164.

${ }^{4}$ Cf. M. Baldassar ri, 1976, I p. 120; M. Zanatta, 1993, p. 419. "Al di là delle deviazioni e dei fraintendimenti dell'esegesi di Plutarco (...) il problema interpretativo ha indubbiamente il suo punto nodale nella comprensione di che cosa sia quel "luogo centrale" di cui si parla una volta accertato che non può essere il centro dell'universo (...) Allora l'espressione $\delta$ ì̀ $\tau$ ò $\varepsilon$ 'v

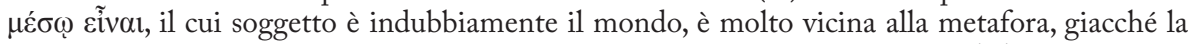
nozione stessa di centro non esprime un concetto locativo, bensì relazionale (...): si tratta cioè dello spazio centrale rispetto al sistema di equipressioni”: così ancora M. ZANATTA, 1993, p. 424). Il problema del fato doveva essere di grande attualità se numerosi sono i testi paralleli, 
questa seconda ipotesi si potrebbe negare la necessità di un mondo al centro dell'infinito vuoto. Cicerone stesso (nat. II 115), ricordava così la tesi stoica "Ita stabilis est mundus (...) Omnes enim partes eius undique medium locum capessentes nituntur aequaliter".

Vi era però un altro problema che evidenziava Plutarco (De Stoic. rep. $1055 \mathrm{D})$ in quanto, se le affermazioni stoiche riguardo alla dottrina fisica erano contraddittorie, altrettanto rivelavano grandi contraddizioni rispetto alla dottrina su Dio e la Provvidenza, cui Crisippo attribuiva cause meno importanti sottraendo quella più importante e maggiore ${ }^{5}$. Veniva così a cadere

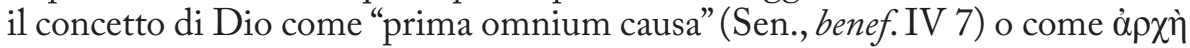
$\pi \alpha ́ v \tau \omega v$ (Hyppolytus Philosoph., 21.1, DDG p. $571=S V F$ I 153, p. $41=$ p. 78 Radice), in quanto tutto si doveva esclusivamente alla $\tau$ ú ๆ. E evidente come giustamente afferma Pohlenz - che Plutarco abbia distorto il pensiero crisippeo dal momento che "non è possibile che Crisippo abbia parlato di un centro dell'apeiron (...) Avrà semplicemente spiegato il permanere del cosmo sempre allo stesso posto con la pressione esercitata da tutte le parti verso il centro, tanto più che nello spazio vuoto non c'era né motivo né possibilità di movimento e traslazione ${ }^{6 "}$.

Continuando il suo ragionamento antistoico Plutarco considera contraddittoria anche la dottrina crisippea dei possibili in rapporto a quella del fato. A differenza di Diodoro $\mathrm{Crono}^{7}$, che aveva definito il possibile "ciò che o è vero o sarà vero", Crisippo considera che tutto ciò che è in grado di ricevere

tra i quali si ricordano Apuleio, Su Platone e la sua dottrina (in particolare I 12), la traduzione commentata del Timeo ad opera di Calcidio (ed.J. H. Waszink, 1962, pp. 142, 145-147) e il De natura hominis di Nemesio (in particolare 109, 11-12: cf. ed. M. Morani, I 98 I, 38): sulla teoria medioplatonica relativa al fato e sulle sue fonti cfr. G. Boys-Stones, 2007, pp. 433-437. Cf. inoltre R. Caballe Ro, 2005, pp. 315-336.

${ }^{5}$ Plutarco trae spunto da Crisippo, De Stoic. rep. $1054 \mathrm{C}$ (SVF II 551, p. 174 = p. 624 Radice) che così argomenta "A quella specie di incorruttibilità" che riguarda il cosmo contribuisce anche la definizione della $\tau \tilde{\eta} \varsigma \chi \omega ́ \rho \alpha \varsigma \kappa \alpha \tau \alpha ́ \lambda \eta \psi 1 \varsigma$, quando questo sia al centro, perché se si pensasse di collocarlo in altra sede, senz'altro gli toccherebbe di essere distrutto." Il problema è ripreso dal Cheronese anche in De def. orac. 425D "C'è da restare stupiti, anzi non si capisce proprio quale azione, secondo Crisippo, il cosmo dovrebbe subire per starsene fisso in mezzo peraltro insieme con la sostanza la quale occupa eternamente la posizione centrale- e quanto meno per essere ridotto alla stabilità e ad una specie di incorruttibilità". Cf. pure De fac. in orbe lun. 925F-926A.

${ }^{6}$ M.Pohlenz, 2005, p.146 ss. Cf. G. Boys-Stones, 2007, pp. 440-441:“They are committed to this position just insofar as they take god to be coextensive with matter. In fact Stoics think that god is the active aspect, or "principle" within the matter from which the cosmos is constructed. In this case, there simply is nothing else which could be responsible for the charges which matter undergoes. But if everything is to be traced back to god, then everything is due to god. One can think of this both by considering that, insofar as god is identified with the matter out of which the cosmos is made, the actions of any part of the cosmos are necessarily his actions too.(...) But this is precisely where Platonism differs most starkly from the Stoa. For the Platonist world is the product not of one, but of two causal streams. One is associated with divine providence which transcends the world; the other with matter which (at least conceptually) predates it.".

${ }^{7}$ Diodoro Crono fu uno dei maggiori dialettici della scuola di Megara. La sua concezione è basata su un assoluto determinismo: ogni situazione si sviluppa secondo una necessità rettilinea che si concreta realmente. 
l'essere, anche se non passerà all'essere, è possibile ${ }^{8}$ in tal modo sottraendo al fato la sua invincibilità e la sua forza su tutto.

" $\grave{E}$ possibile che chi è destinato a morire in mare, sia atto a morire in terraferma?" si domanda ironicamente Plutarco non allontanandosi troppo da quanto dice Cicerone nel De fato: "Crisippo, sudando sette camicie per spiegare come conciliare l'onnipotenza del destino con il fatto che cè qualcosa che dipende da noi, si avviluppa in un groviglio di contraddizioni"9. Il problema dei possibili coinvolgeva il rapporto fato-libero arbitrio ${ }^{10}$ così come il rapporto rappresentazione-assenso. Rappresentazione ( $\varphi \alpha v \tau \alpha \sigma i ́ \alpha)$ e assenso

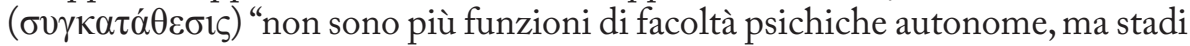
diversi di un processo che si svolge nellogos ${ }^{11}$. Si tratta così della rappresentazione che proviene dal mondo esterno ma che la ragione trasforma in una immagine mentale esprimibile in una forma proposizionale; dell'assenso che la ragione può concedere o negare al materiale proposto dalla rappresentazione (...)

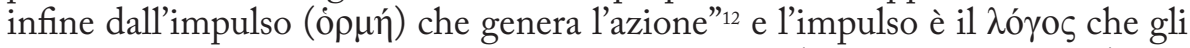
prescrive di agire, come si legge nel libro Sulla legge (De Stoic. rep. 1037F).

Ma che cosa è il logos? Il logos o retta ragione è "la legge di dio grazie alla quale a ciascuno tocca quello che gli spetta e gli si addice" (Philo, De mundi opificio cap. 142, I, p. 50,2 Wendl. = SVF III fr. 337, p. 82 = p. 113 Radice), è la virtù perfetta (Sen., epist. $31,8=S V F$ III 200, p. $48=$ p. 1064 Radice) che dà all'uomo la pienezza della felicità ${ }^{13}$, è l'oggetto della filosofia (Clemens Al. Paedag., I 13, p. 159 Potter $=$ SVF III 293, p. $72=$ p. 1110 Radice), è il

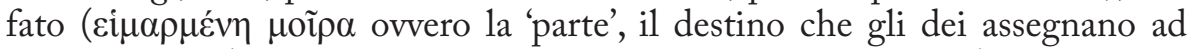
ognuno di noi) è Zeus che governa il tutto con la sua legge (così l'inno di Cleante a Zeus, Stob. I 1, 12, p. 25 Wachsmuth $=$ SVF I 357, p. $121=$ p. 236 Radice), è $\pi \rho o ́ v o t \alpha$ ovvero governo della provvidenza del mondo. In tale climax è evidente come il logos determini le scelte degli esseri viventi e come il fato "rappresenti la forma di causalità universale e perfetta e compiuta, la garanzia totale dell'ordine del mondo, la sua difesa inespugnabile di fronte ai rischi del

${ }^{8}$ Cf. a tale riguardo Alexander Aphrod., Comm. in Arist. Analyt.pr. p. 177, 25 Wallies (= SVF II 202a, p. 65 = p. 406 Radice); Procl., in Plat. Parmen. IV p. 103 Cousin (= SVF II 202b, p. $65=$ p. 406 Radice). Cf. ancora Cic., fat. 13: "quae non sint futura posse fieri dicis".

${ }^{9}$ Cic. fat. 20.

${ }^{10}$ Su fato e possibilità, Alexander Aprod., de fato 10 p. 176, 14; p. 177, 7 Bruns (= SVF II 959- 960, p. 279 = p. 834 Radice). M. Baldassarri, 1976, I p. 33 n.; M. Zanatta, 1993, p. 431, che schematizza in modo chiaro il problema posto da Plutarco: "(1) posto il concetto di possibile si distrugge quello di Fato inteso come necessità ineluttabile. (2) Stante la necessità del Fato, (a) un evento possibile che non si avveri coincide con l'impossibile; (b) ogni proposizione vera è necessaria; c) ogni proposizione falsa è impossibile".

${ }_{11}$ M. Pohlenz, 2005 p.180. Cf. Sen., epist. 113, 18 (= SVF III 169, p. 40 = p. 1048 Radice). "Nella teoria della conoscenza stoica il concetto di phantasia svolge un ruolo particolarmente significativo. Crisippo arriva a distinguere tra phantasia come affezione che sorge nell'anima (phantaston), quel che la phantasia produce (phantastikon), vale a dire il pathos alla cui produzione nell'anima non concorre nessuna phantaston e quello verso cui siamo trascinati per l'attrazione del phantastikon (phantasma)": M. Sanna, 2007, p. 24. Cf. J.-P. VERnant, 1979, pp. 65-69.

${ }_{12}$ M. Vegetti, 1989, p. 227.

${ }^{13}$ Cf. Sen., epist. 76, 19. 
caso, dell'insensatezza, della decadenza". Dunque il fato è "causa invincibile e inarrestabile e Crisippo lo chiama Atropo, Adrastea, Ananke e, in quanto impone a tutti un limite, Pepromene" (De Stoic. rep. 1056B). A ciò Plutarco obiettava: "Dobbiamo dunque dire che non dipendono da noi né l'assenso né la virtù né la malvagità né l'agire rettamente né l'errare, o dobbiamo dire che il fato viene meno, che il destino non vede rispettati i limiti da lui stesso imposti, che i movimenti e gli stati voluti da Zeus non hanno realizzazione? La prima

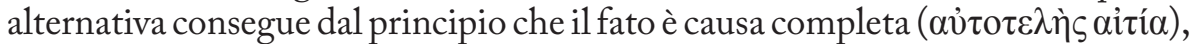
la seconda dal principio che il fato è causa solo iniziale ( Infatti se il fato è causa completa, essendo la causa completa di tutto, il fato elimina il nostro potere sulle nostre azioni e quindi la volontarietà delle azioni; se il fato è causa iniziale, crolla il suo essere inimpedibile e completamente efficace" (De Stoic. rep. 1056D) ${ }^{14}$. Il problema posto da Plutarco e già discusso in Cicerone (fat. 20) non lascia che due alternative: "se le nostre azioni dipendono da noi (e quindi c'è spazio per la responsabilità e la valutazione morale, insomma per l'etica), non sono determinate dal fato, che risulta quindi una causa imperfetta e impotente; ma se esso non è tale, come vuole Crisippo per assicurare l'ordine razionale del mondo, non ci sono più né libertà, né responsabilità né valutabilità" ${ }^{15}$. A questa evidente aporia Crisippo rispondeva con la dottrina dei confatalia ${ }^{16}$ che consiste nel pensare la causazione del fato non come una serie lineare ma come tale da produrre costellazioni di eventi causati simultaneamente ${ }^{17}$. Questa dottrina doveva apparire eticamente debole e così Crisippo ne propone un'altra nel tentativo di salvare da un lato la causalità del fato e dall'altro l'autonomia morale dell'uomo: la dottrina era inerente alla serie di cause, antecedenti o esterne e interne o 'perfette e principali'. Anche tale distinzione, a parere di Plutarco, non risolveva quella che era la questione principale che riguardava il libero arbitrio e l'atto volontario; dal momento che non era possibile ipotizzare un determinismo che in qualche modo spazzava via la libertà. Il problema era di 'determinare' in quale misura sia vero e in

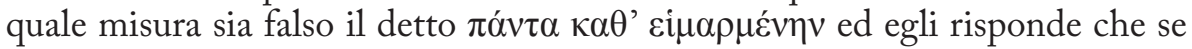
pure si ritiene che il fato comprenda o abbraccia tutte le cose, da ciò non si può dedurre che tutto sia sotto la sua dipendenza. La questione era, dunque,

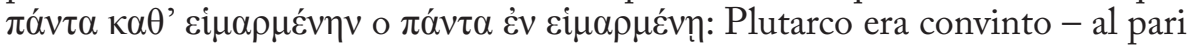
di Platone- che l'ordine della necessità si combinava con l'ordine della causalità

${ }^{14}$ Il paragone, che leggiamo in Cicerone (fat. 43) e in Gellio (Noctes Atticae, VII 2) permette di cogliere meglio il ragionamento di Crisippo: "come dunque chi ha spinto il cilindro ha dato inizio al suo moto, ma non gli ha dato la proprietà di rotolare, così la rappresentazione dell'oggetto si imprimerà nell'animo e vi lascerà la propria immagina come un sigillo, ma l'assenso sarà in nostro potere e, come si è detto del cilindro, pur essendo provocato dall'esterno, per il resto si muoverà in virtù della propria natura".

${ }^{15}$ M. Vegetti, 1989, p. 257. Cf. a tale proposito P. Donini, 1988, p. 23. “(...) da testi in cui parla del fato secondo Crisippo quali De Stoic. rep. 1050A-C, 1055E, 1056C ed 1056E si ricava certamente l'impressione che Plutarco vedesse nel fato una forza invincibile e onnicomprensiva tale da non ammettere deroghe o esenzioni in favore della volontà degli uomini”.

${ }^{16}$ Cic., fat. 30 (= SVF II 956, p. 277 = p. 830 Radice).

${ }^{17}$ M. Vegetti, 1989, p. 258. 
e con il libero arbitrio. 亡̀ quanto dice Lampria in Quaest. conv. 740C. Ancora più significativo De Hom. 2, 120, 1309-1315 (p. 59 Kindstrand) nel quale lo stesso Lampria, riprendendo il discorso sul ruolo di ciascuna causa nella vita degli uomini e citando ancora Platone, attribuiva al libero arbitrio la scelta delle nostre vite e associava al fato la scelta di vivere bene o male.

$\mathrm{Ma}$, come si è detto, tutto nasceva dal rifiuto del determinismo stoico e dalla identificazione fato/provvidenza ${ }^{18}$ dalla volontà del platonismo del I sec. d. C. di porre al centro del pensiero medioplatonico la nozione di Dio come trascendente sia rispetto al mondo che rispetto alla materia "Naturalmente i platonici avevano in comune con gli Stoici la dottrina della provvidenza e quella che ogni evento o fenomeno ha una significato positivo nel quadro dell'ordine divino del mondo (...) A differenza degli Stoici, però, i platonici non ritenevano che destino e provvidenza fossero la stessa cosa; la provvidenza è l'istanza suprema che governa tutto in vista del bene, il destino è una funzione ad esso subordinata che regola i rapporti di causa ed effetto nei processi della natura e della vita umana"19. Lo pseudo-Plutarco, infatti, in De fato 573B, dopo

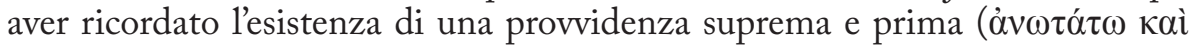
$\pi \rho \omega ́ \tau \eta)$, di una seconda ovvero quella degli dei secondi che percorrono il cielo; di una terza da considerarsi provvidenza e previdenza dei demoni preposti in terra a sorvegliare le azioni umane (572F-573A), afferma che "tutto quello

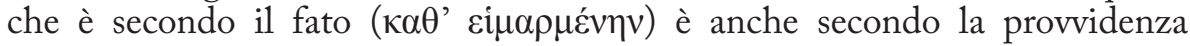
( $\alpha \alpha \tau \grave{\alpha} \pi \rho o ́ v o t \alpha v)$, non però anche il contrario, ma alcune cose sono secondo la provvidenza, (...) alcune secondo il fato, e il fato è completamente subordinato alla provvidenza; non questa a quello (...)" (trad. VALGIGLIO ${ }^{20}$ ).

Veniva così spiegata la 'formula' medioplatonica che "tutto quanto accade è nel destino (...) e tuttavia non tutto avviene anche secondo destino" ${ }^{21}$ e veniva ristabilita la superiorità della Provvidenza sul destino ${ }^{22}$, senza però rinunciare al determinismo e alla spiegazione razionale del dovere cosmico. E così, "mentre

${ }^{18}$ Cf. Gell., Noctes Atticae VII 2 ( = SVFII 1000, pp. 293-294 = pp. 862-864 Radice): «Fatum est» - inquit (sc. Chrysippus) - sempiterna quaedam et indeclinabilis series rerum et catena, volvens semetipsa sese et inplicans per aeternos consequentiae ordines, ex quibus apta nexaque

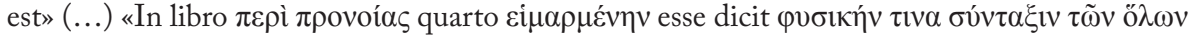

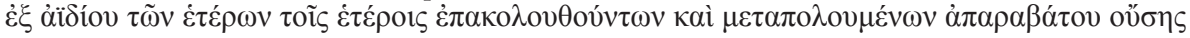

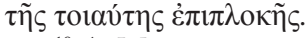

${ }^{19}$ A. MAgris, 2001, p. 89.

${ }^{20}$ E. VAlgiglio, 1993, p. 97."Il De Fato non ha altro scopo che costruire, di fronte alla teoria

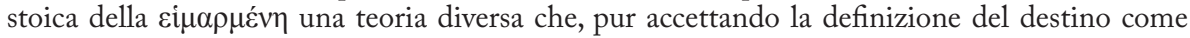
una concatenazione di cause, tenta di preservare nello stesso tempo il libero arbitrio umano e l'indipendenza di Dio": così D. BABut, 2003, p. 182. "Proprio nel medio platonismo cominciò a diffondersi una concezione della sfera divina articolata intorno ad uno schema gerarchico che conobbe probabilmente in Numenio la sua formulazione più esplicita": F. FERRARI, 1999, pp. 72-73. Cf. ancora S. Bobzien, 1998, pp. 39-40; G. Boys-Stones, 2007, pp. 431-447. Lo studioso, dopo aver analizzato il De Fato pseudoplutarcheo, afferma che la polemica antistoica potrebbe aiutare a far luce sulla cosiddetta "dottrina delle tre provvidenze", che ebbe diffusione nei circoli platonici e secondo la quale le attività del demiurgo, dell'anima del mondo e dei demoni sono tutte da ascriversi alla Provvidenza.

${ }^{21}$ A. Magris, 1995, p. 28.

22 D. Babut, 2003, p. 347. 
gli Stoici fanno di Dio o del destino l'origine delle nostre rappresentazioni, distruggendo nello stesso tempo il libero arbitrio e la possibilità di un atto volontario" (De Stoic. rep. 1057B), Plutarco, distinguendo da una parte tra la rappresentazione, che può venire da Dio, e l'impulso, che dipende sempre dalla nostra volontà, e dall'altra parte tra il normale corso della vita, interamente di competenza del libero arbitrio, e le circostanze eccezionali, che lasciano spazio a una iniziativa divina, si sforza di salvaguardare sia la libertà di azione e di scelta (...) sia il diritto della Provvidenza ad intervenire nel corso delle cose $(\ldots){ }^{23}$.

La posizione di Plutarco, dunque, è da considerarsi per alcuni aspetti 'mediana' perché egli non rinuncia alla libertà umana ma neppure alla superiorità della Provvidenza sulla necessità e alla concatenazione logica delle cause e degli effetti sul normale fluire del mondo. La sintesi di tale problema ancora aperto' è offerta da Tacito (ann. VI 22) che, ricordando l'incontro tra Trasillo e Tiberio, così conclude: "Ora io, quando considero questi e altri simili, rimango in dubbio e mi domando se gli eventi umani siano governati dal destino e da una immutabile necessità, oppure se si svolgono a caso. Infatti tu troverai discorsi tra loro i principali filosofi antichi e quelli che oggi professano le loro dottrine. Molti sono fermamente convinti che del nostro principio e della nostra fine, in una parola, di noi uomini, gli dei non si diano cura alcuna; e che perciò spesso le sventure tocchino ai buoni, la prosperità ai malvagi. Altri invece ritengono che gli avvenimenti siano legati al destino, ma non dipendente dal corso delle stelle, bensì da cause prime e dalle conseguenze che per naturale processo ne derivano. Tuttavia ammettono che ci sia lasciata la scelta del genere di vita; ma che da questa scelta, una volta fatta, derivi una successione inevitabile di conseguenze" 24 .

\footnotetext{
${ }^{23}$ D. Babut, 2003, p. 349.

${ }^{24}$ Cf. W. Theiler Forschungen, 1966, pp. 46-103.
} 


\section{RIFERIMENTI BIBLIOGRAFICI}

Babut, D., Plutarco e lo stoicismo, Milano 2003.

Baldassarri, M., Plutarco. Gli opuscoli contro gli Stoici, a cura di M. Baldassarri, Trento 1976.

Bobzien, S., Determinism and freedom in Stoic philosophy, Oxford 1998.

Boys-Stones, G., "Middle Platonists on fate and human autonomy", in R.

Sharples - R. Sorabji (eds.), Greek and roman philosophy 100 BC-200AD, II, London 2007, pp. 431-447.

Caballero, R., "Plutarco y el modelo cosmológico-espacial de Crisipo: el mundo en el centro del vacío", in A. Casanova (ed), Plutarco e l'età ellenistica; atti del convegno internazionale di studi (Firenze, 23-24 settembre 2004), Firenze 2005, pp. 315-336.

Donini, P., "Plutarco e il determinismo di Crisippo", in I. Gallo (ed.), Aspetti dello Stoicismo e dell'epicureismo in Plutarco, Ferrara 1988, pp. 21-32.

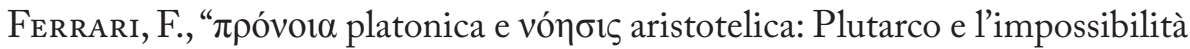
di una sintesi”, in A. Pérez Jiménez - J. Garcìa Lòpez - Rosa M. Aguilar (eds.), Plutarco, Platòn y Aristoteles. Actas del V Congreso Internacional de la I.P.S. (Madrid-Cuenca, 4-7 de Mayo de 1999) Madrid 1999, pp. 63-77.

Magris, A., Alessandro di Afrodisia, Sul fato, a cura di A. Magris, Firenze 1995.

Magris A., La filosofia ellenistica. Scuole, dottrine e interazioni col mondo giudaico, Brescia 2001.

Morani, M., Nemesii Emeseni De natura hominis, edidit M. Morani, Leipzig 1987.

Nicolosi, S., Il De Providentia di Sinesio di Cirene, Padova 1959.

Pohlenz, M., La Stoa. Storia di un movimento spirituale, a cura di O. De Gregorio e B. Proto, Milano 2005.

SAnna, M., Immaginazione, Napoli 2007.

Theiler Forschungen, W., Zum Neuplatonismus, Berlin 1966.

VAlgiglio, E., [Plutarco], Il Fato, a cura di E. Valgiglio, Napoli 1993.

Vegetti, M., L'etica degli antichi, Bari 1989.

Vernant, J.-P., Nascita di immagini e altri scritti su religione, storia, ragione, Milano 1979.

Waszink, H.J., Timaeus a Calcidio translatus commentarioque instructus (Corpus 
Paola Volpe Cacciatore

Platonicum Medi Aevi: Plato Latinus, vol. IV), London-Leiden 1962.

Zanatta, M., Plutarco, Le contraddizioni degli Stoici, a cura di M. Zanatta, Milano 1993. 


\title{
L'écrit de Plutarque Sur La Fortune: HISTOIRE D'UNE INTERPRÉTATION
}

\author{
Francesco Becchi \\ Università degli Studi di Firenze
}

\begin{abstract}

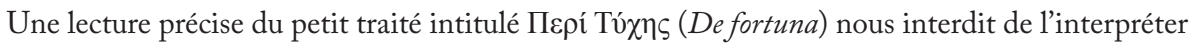
comme une œuvre d'inspiration stoïcienne dans laquelle Plutarque procéderait à une critique de la doctrine péripatéticienne du bonheur en tenant compte de plusieurs sources (Ariston de Chios, Zénon, Chrysippe, Sphairos, Posidonius). En réalité, la question posée par le philosophe de Chéronée dans ce texte ne se rapporte pas au bonheur, comme cela a été interprété jusqu'à présent, mais concerne la défense de la liberté humaine et notamment de l'autonomie intellectuelle et morale de l'homme contre le déterminisme du Portique, d'après lequel le hasard régit tout.
\end{abstract}

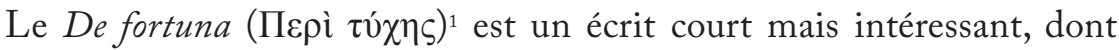
personne n'a douté jusqu'à maintenant du caractère authentique, à cause notamment de la présence de nombreux loci parallèles, parmi lesquels ne manquent pas des citations poétiques, qui font que la paternité de Plutarque est à peu près sûre. Ce texte ne figure pas dans ce qu'il est convenu d'appeler le Catalogue de Lamprias², tandis qu'il est mentionné sous le numéro 18 dans l'édition de Maxime Planude et sous le $n^{\circ} 8$ dans celle d' Henri II Estienne (Henricus Stephanus). Le ton parfois rhétorique ne doit pas nous induire en erreur, parce qu'il ne s'agit pas d'un simple exercice sophistique, d'un $\pi$ aírviov sur le thème de la tyché, ni d'une déclamation rhétorique dont le déroulement ne reflète pas la pensée de l'auteur et où la technique l'emporte sur le thème. Cet écrit ne veut pas être un acte d'accusation contre

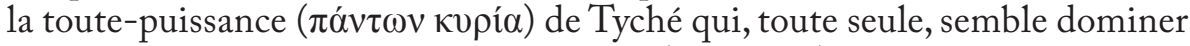
la destinée des hommes, ni une défense ( $\dot{\alpha} \pi 0 \lambda \mathrm{o} \gamma \dot{\alpha} \alpha)$ contre les accusations qui étaient lancées contre la déesse, et encore moins une célébration ou une

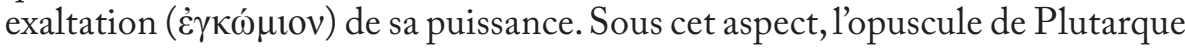
se distingue des ouvrages de ses contemporains, comme l'écrit portant le

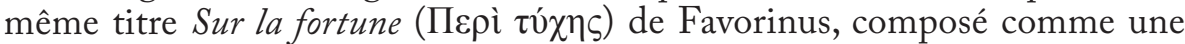

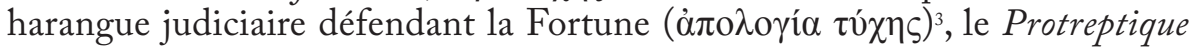

${ }^{1}$ Sur la "fortune" qui contrairement au " hasard" se réfère seulement à l'homme en ayant une incidence sur $\tau$ ò $\dot{\varepsilon} \varphi$ ’ $\dot{\eta} \mu \mathrm{i} v$ voir Arist., Phys. 196-197; Ps.-Plutarco, De fato, a cura di E. Valgiglio, Roma 1964, p. XVII.

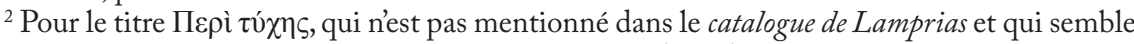
ne pas répondre exactement au contenu, voir Barigazzi (1966), pp. 129-130. Ce dernier pense que " un titolo come De fortuna et ratione, oppure Utrum fortuna an ratio plus valeat in rebus humanis regendis o ancora Non fortuna sed prudentia regi res humanas» est convenable.

${ }^{3}$ Barigazzi (1966), p. 249: «Opposto è il concetto informatore dell'opuscolo omonimo di Plutarco (97 C-100 A) : in esso... a differenza delle esercitazioni retoriche de Alexandri fortuna sive Virtute e de Romanorum fortuna, viene impugnata l'importanza di Tyche nella vita e

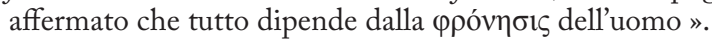


de Galien, qui est un acte d'accusation contre la Fortune, ou le Ménippe de Lucien de Samosate, qui se révèle comme étant une célébration ou une exaltation $(\dot{\varepsilon} \gamma \kappa \omega ́ \mu 10 v)$ de la toute-puissance de Tyché4. La déesse à laquelle

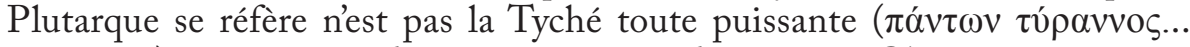
$\tau \tilde{\omega} \nu \theta \varepsilon \tilde{\omega} \nu$ ), pour reprendre une expression du tragique Chérémon, qui joue avec le sort des hommes ${ }^{5}$, mais plutôt cette tyché-hasard qui, surtout durant la période hellénistique, a fait son chemin et qui s'est affirmée avec les écoles de pensée modernes, Épicuriens et Stoïciens, selon lesquelles le hasard régit tout ${ }^{6}$.

Le texte de Plutarque est un écrit de philosophie éthique, au caractère polémique, où l'auteur réfute la doctrine de ceux qui considèrent que c'est la

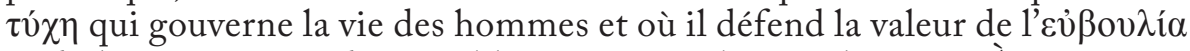
et de la $\varphi \rho o ́ v \eta \sigma ı s$, indispensables pour vivre bien et heureux. À ce propos, je pense que l'on ne se trompera pas de beaucoup si l'on fait remonter l'opuscule à une époque de toute façon postérieure à celle des écrits typiquement rhétoriques et si on le situe durant la période de l'activité philosophique de Plutarque qui n'est pas éloignée de celle où virent le jour les oeuvres de polémique antistoïcienne, vu l'allure moralisante de cet écrit, la culture philosophique qui le sous-tend et son contenu fortement critique et polémique qui fait qu'il est difficile de le considérer comme un simple exercice d'école?

En revanche, des doutes demeurent sur l'achèvement de l'ouvrage. Les jugements formulés par les chercheurs s'accordent à relever la présence de négligences dans la composition, ainsi que son caractère incomplet et fragmentaire: Paton, en effet, le considère comme une «declamatio non perpolita, quam Plutarchus materiem librorum ipse praeparaturus conscripsisse videtur» ${ }^{8}$ et Ziegler, en soulignant le laisseraller dans l'élaboration de quelques passages, le caractère fragmentaire et l'incohérence globale, le range de par son contenu et son style parmi les écrits rhétorico-épidictiques ${ }^{9}$. Cette incohérence a été confirmée aussi récemment par Klaerr, qui le considère comme " une espèce de plan ou de brouillon rassemblant du matériel pour un développement futur ou en vue d'un débat $\aleph^{10}$; Barigazzi semble au contraire s'éloigner de ces auteurs et

${ }^{4}$ Luc., XI 16.

${ }^{5}$ Luc., III 20.

${ }^{6}$ Pour le " matérialisme des Épicuriens, selon qui le hasard régit tout " voir Boulogne (2003), p. 224 ; pour les Stoïciens voir Becchi (2010), p. 79.

${ }^{7}$ Voir Klaerr (1989) p. 231: «On peut donc le dater de la période de jeunesse et de formation de l'auteur, soit entre 70 et 80 , mais sans avoir aucun indice qui permette de préciser davantage ». 197.

${ }^{8}$ Plutarchus, Moralia I, recc. W. R. Paton, I. Wegehaupt, M. Pohlenz, Lipsiae, 1925, p.

9 Ziegler (1965), p. 113: « ....appare molto verosimile che si tratti non di un'opera finita e pubblicata da Plutarco, ma di una raccolta di materiale molto diversamente elaborato riguardante

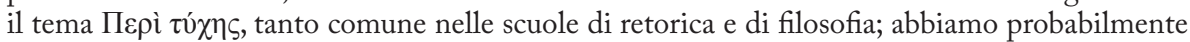
dinanzi un'esercitazione retorica del periodo giovanile di Plutarco, pubblicata più tardi con le sue opere postume...».

${ }^{10}$ Plutarque, De la fortune, op. cit., p. 232. 
ramener à de plus justes proportions la négligence et l'incohérence de la structure $^{11}$.

Cet ouvrage qui a été étudié moins pour sa valeur intrinsèque que pour certaines affirmations qu'il contient et qui concernent d'importantes thématiques, commence ex abrupto, sans aucune introduction didactique ${ }^{12}$ et sans aucune préparation ni explication éclairant les circonstances qui ont conduit Plutarque à affronter le sujet. Il s'ouvre par la citation d'un vers du poète tragique Chérémon, que Stobée attribue au drame perdu Achille meurtrier de Thersite ${ }^{13}$ et il s'interrompt aussi brusquement ${ }^{14}$.

En principe on ne peut pas exclure que le début et la fin puissent manquer ${ }^{15}$, mais je n'exclurais pas que Plutarque se soit servi de la citation du

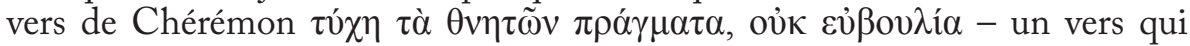
était devenu proverbial déjà à l'époque de Cicéron - comme un expédient pour introduire le point de vue contre lequel il s'apprêtait à présenter des arguments et à entrer tout de suite in medias res. En effet ce vers est cité en guise de proverbe dans le livre $\mathrm{V}$ des Tusculanae disputationes ${ }^{16}$ par Cicéron qui rapporte les vives critiques qui avaient été adressées à Théophraste, le chef de l'école péripatéticienne, dans les ouvrages et dans les leçons de tous les philosophes. Cet elegantissimus omnium philosophorum et eruditissimus ${ }^{17}$, c'est ainsi que Cicéron appelle Théophraste, dont il reconnaît la cohérence ${ }^{18}$, même s'il ne

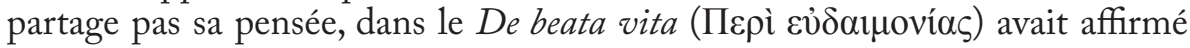
que celui qui est torturé et martyrisé ne peut pas être heureux et surtout parce que in Callisthene suo (K $\left.\left.\alpha \lambda \lambda \_\sigma \theta \dot{v} \eta\right\rceil\right)$ ) il avait approuvé «illam sententiam»: itam regit fortuna, non sapientia concept éloigné de toute approche philosophique ${ }^{19}$. Cette concordance avec Cicéron dans la citation du même vers de Chérémon a fini par fortement conditionner l'exégèse de l'opuscule plutarquien, interprété comme une réponse philostoïcienne à la doctrine de Théophraste qui spoliavit... virtutem suo decore imbecillamque reddidit quod negavit in ea sola positum esse beate vivere ${ }^{20}$.

Déjà à la fin du XIX $\mathrm{X}^{\mathrm{e}}$ siècle, Ferdinand Dümmler, en appendice à ses Akademika (Anhang I.: "Ein stoischer Gegner Theophrasts ")21 avança

${ }^{11}$ Barigazzi (1993), p. 12 : «Quanto poi alla struttura, non si può affatto affermare che essa è trascurata e sconnessa ».

${ }^{12}$ Voir Siefert (1896), p. 97: "At miramur quod omnis deest praefatio... ”.

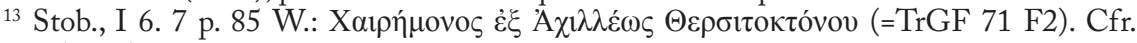
Collard (1970), p. 22 sqq.

${ }^{14}$ Babut (1969), p. 24.

${ }^{15}$ Selon Nachstädt $\left(1971^{2}\right)$, p. 75, il manque probablement le début et la fin du De Alexandri Magni virtute aut fortuna.

${ }^{16}$ Cic., Tusc. V 23-25 = Thphr., Fr. L 53 Fortenbaugh.

${ }^{17}$ Cic., Tusc., V 9. 24 . Cf. Cic., Acad. I 33 : vir et oratione suavis et ita moratus, ut prae se probitatem quandam et ingenuitatem ferat.

${ }^{18}$ Cic., Tusc. V 9, 24-25.

${ }^{19}$ Thphr., Fr. L 59 Fortenbaugh = Cic., Tusc. V 85; Thphr., Fr. L 58 = Cic., De fin. V 12; Thphr., Fr. L 55 Fortenbaugh = Cic., De fin. V 77; Thphr., Fr. L 56 Fortenbaugh = Cic., De fin. V 85-86.

${ }^{20}$ Thphr., Fr. L 57 Fortenbaugh = Cic., Acad. I 33 e 35.

${ }^{21}$ Dümmler (1889), pp. 211- 216 : «Wahrscheinlicher ist mir jedoch, dafs wir entweder eine 


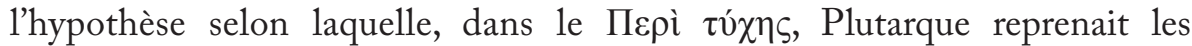
argumentations polémiques d'un stoïcien contre la doctrine de Théophraste

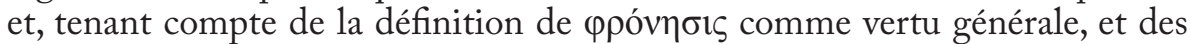
vertus comme étant des expressions particulières de la $\varphi \rho o ́ v \eta \sigma ı \varsigma$, il a cru trouver l'une des sources de l'opuscule en la personne du stoïcien Ariston de Chios ${ }^{22}$; Dümmler émit même l'hypothèse que Cicéron aurait trouvé le nom d'Ariston sous une forme à peu près semblable dans l'original grec à partir duquel il traduisait le nom d'Ariston sous une forme à peu près semblable: 'A

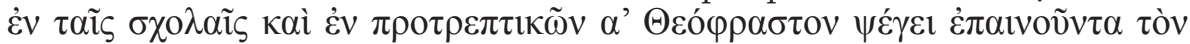
$\varphi \eta ́ \sigma \alpha v \tau \alpha$ « $\tau \hat{\chi} \chi \eta \kappa$. T. $\dot{\alpha} . »^{23}$. L’hypothèse formulée par Dümmler fut reprise peu après par Alfred Giesecke ${ }^{24}$ et jugée peu probable par August $\mathrm{Schlemm}^{25}$ vu les argumentations « leviores ... quam ut rem comprobare possint ${ }^{26}$. Ce dernier crut identifier la source de l'opuscule affirmant qu'il s'agissait du fondateur du Portique ("Plutarchum in hac commentatione conscribenda Zenonis philosophiam secutum esse apparet » ${ }^{27}$, dans la mesure où Zénon admettait

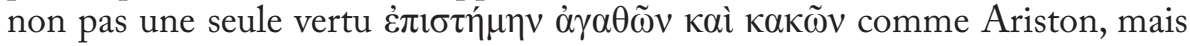
une myriade de vertus différentes, des spécialisations en quelque sorte de la vertu générale ou suprême, qu'est la $\varphi \rho \operatorname{có} \eta \sigma \mathrm{c}^{28}$.

En 1895, Hermann Hobein ${ }^{29}$ crut pouvoir corriger l'erreur de Schlemm («Schlemmii...errorem ») ${ }^{30}$. Relevant que la doctrine stoïcienne de la supériorité de l'homme sur les bêtes, qui est développée dans le chapitre 3 (98CF) renvoie sans aucun doute à Chrysippe (" sine dubio in hoc tertio quidem capite Plutarchum e Chrysippo sua mutuatum esse elucet») et que les réflexions sur les arts dans le chapitre 4 apparaissent comme étant conformes à la doctrine stoïcienne ( Sed ne ea quidem quae in sequenti de artibus quae

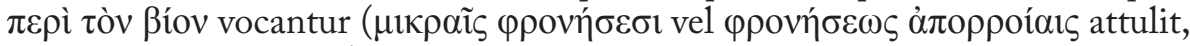
absona sunt a stoicis $)^{31}$, Hobein en concluait que Plutarque avait puisé non seulement chez Zénon mais aussi chez Chrysippe ${ }^{32}$.

frühe oder eine etwas ungenauere Aeufserung des Ariston selbst vor uns haben» ..

${ }^{22}$ Mais voir D. L., VII 163 = SVF I 333.

${ }^{23}$ Dümmler (1889), p. 214.

${ }^{24}$ Giesecke (1891), p. 104 sqq.

${ }^{25}$ Schlemm (1893), pp. 84-100 ( «Excursus de Plutarchi commentatione quae inscribitur

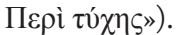

${ }^{26}$ Schlemm (1893), p. 86.

${ }^{27}$ Schlemm (1893), p. 100.

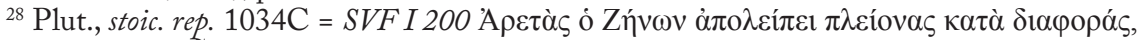

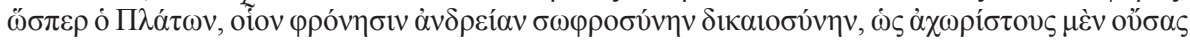

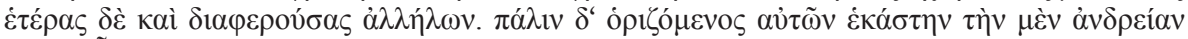

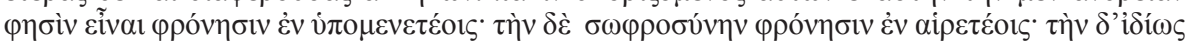

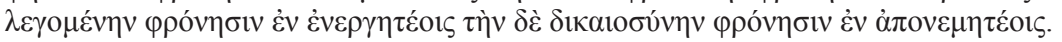

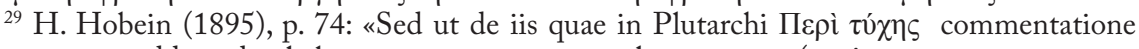
exstant, pauca addam, duo habemus, quorum consensu haec quoque (tertium quartumque caput dico) Chrysippea esse evincere possimus».

${ }^{30}$ Hobein (1895), p. 70.

${ }^{31}$ Hobein (1895), p. 76.

${ }^{32}$ Hobein (1895), p. 77: «Cum Zenonea sit virtutum definitio quam in secundo capite Plutarchus exposuit, nec non divisio illa inter $\pi \rho \circ \gamma \mu \varepsilon \dot{v} \alpha$ et $\dot{\alpha} \pi \rho \circ \eta \gamma \mu \varepsilon ́ v \alpha$ (in capite sexto) a 
L'année suivante, en 1896, tout en acceptant l'hypothèse d'après laquelle dans le De fortuna, Plutarque aurait conservé les argumentations d'un stoïcien contre la doctrine de Théophraste, Georg Siefert ${ }^{33}$ se limita à relever d'une part, le ton stoïcien de l'opuscule (" id tantum constare mihi videtur Stoam redolere hanc commentationem »), et de l'autre, la consonance thématique avec d'autres écrits de Plutarque, parmi lesquels les deux écrits zoo-psychologiques les plus importants (Bruta animalia ratione uti et De sollertia animalium) et des opuscules vraiment éthiques comme l'An virtus doceri possit, le De virtute et vitio, le De tranquillitate animi et le De exilio à partir desquels on peut affirmer « quomodo hic liber cohaereat cum aliis Plutarchi scriptis »" À la fin

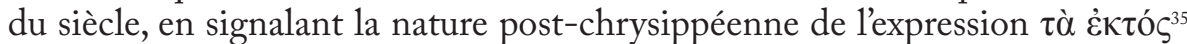
pour indiquer les biens extérieurs, Dyroff mentionna Posidonius ${ }^{36}$ en fonction de la doctrine des quatre vertus cardinales d'ascendance platonicienne. Parmi celles-ci il manque l'eủßoviía, ce qui constitue une objection sérieuse à son hypothèse ${ }^{37}$.

La recherche des sources stoïciennes dont se serait inspiré Plutarque a continué encore pendant toute la première moitié du XX ${ }^{\mathrm{e}}$ siècle: en 1940

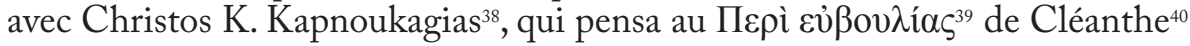

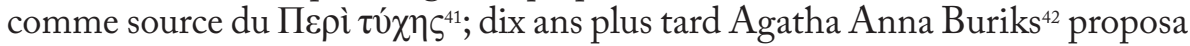
le nom de Sphairos, un élève de Zénon et de Cléanthe, surtout parce que

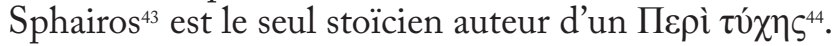

Ce n'est qu'en 1951 que Ziegler, conscient de l'inconsistance des éléments sur lesquels reposaient la plupart des hypothèses formulées, conseilla une plus grande prudence, considérant que trouver l'auteur stoïcien que Plutarque avait

Zenone sit excogitata, videturne Plutarchus cum tertium et sextum scripturus esset Zenonem adiisse, cum quartum et quintum Chrysippum evolvisse?», où apparaît de toute évidence l'erreur dans l'énumération des chapitres.

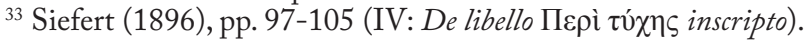

34 Siefert (1896), p. 97: "Quem hominem quocum Plut. digladiatur Theophrastum Peripateticum esse Duemmler (p. 201 sq.) egregie demonstravit ».

${ }^{35}$ Plut., fort. 100A.

${ }^{36}$ Dyroff(1897), p. 326 n.6: «Wir wissen aber nichts von einer derartigen Schrift Zenons. Ob sich Zenon selbst gegen Theophrastos in den Diatriben verteidigte, ist fraglich. Der Ausdruck

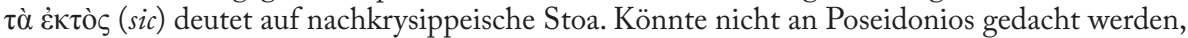

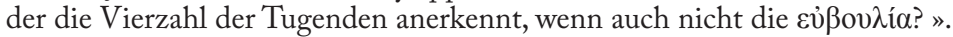

${ }^{37}$ Buriks (1950), p. 66.

${ }^{38}$ Kapnoukagias (1940), pp. 107-121.

${ }^{39}$ SVF I 481.

${ }^{40}$ Pour le dualisme de Cléanthe voir SVF I 493.

${ }^{41}$ Le nom de Cléanthe a été cité précédemment par Dyroff pour les chapitres 4 e 5 et en

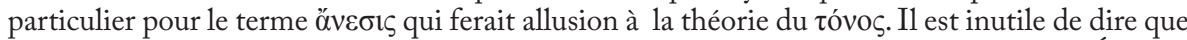

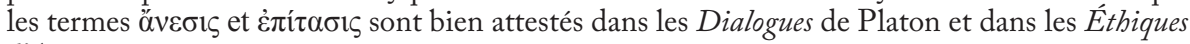
d'Aristote.

${ }^{42}$ Cf. Buriks (1950), p. 62.

${ }^{43}$ Sur la personnalité de Sphaïros de Borysthène voir Plut., Cleom. 2.1 (= Agis 23. 1.) Cf. SVF I 623.

${ }^{44}$ SVF I $620=$ D. L. 7, 178. 
suivi était une entreprise vaine a priori ${ }^{45}$. En 1969, dans sa monographie Plutarque et le stö̈cisme, Babut essayait d'expliquer la " prépondérance de

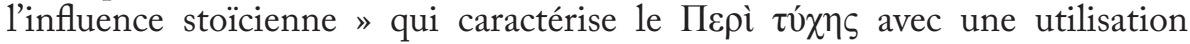
" purement rhétorique et non philosophique » de thèmes stoïciens, et avec l'intention manifeste d'exclure que Plutarque ait fait siennes quelques-unes des idées maîtresses de l'éthique stoïcienne ${ }^{46}$. Les français Robert Klaerr ${ }^{47}$ et Christian Froidefond ${ }^{48}$ vont dans la même direction quand ils reconnaissent une utilisation de thèmes stoïciens qui "n'implique nullement une adhésion, même momentanée, de Plutarque à la doctrine du Portique $»^{49}$. Le dernier

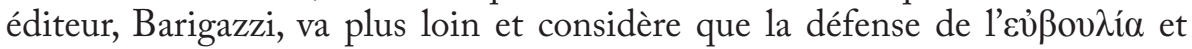

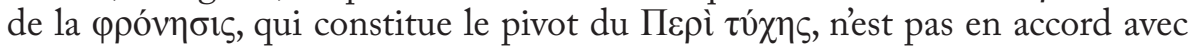
la thèse stoïcienne illustrée par Cicéron dans le livre $\mathrm{V}$ des Tusculanes et que, dans la substance, elle n'est pas différente ... des principes éthiques de l'école péripatéticienne ${ }^{50}$.

Cet opuscule se présente avec la structure d'une reductio ad absurdum: s'il est vrai que la tyché gouverne la destinée de l'homme, alors il n'y a pas de place pour le jugement juste, l'eủßov $\lambda i ́ \alpha$, ni pour la science du bon savoir faire, la $\varphi \rho o ́ v \eta \sigma i \varsigma$, ni pour les vertus, qui sont les arts les plus complets et auxquelles revient la tâche d'évaluer, de distinguer et de juger non seulement l'honnête, le juste et l'utile mais aussi l'infâme, l'injuste et le nuisible, ni pour les sens, ni pour les arts, qui sont l'expression de l'intelligence humaine. Il ne traite ni le thème des vertus - un terme qui n'apparaît pas du tout dans

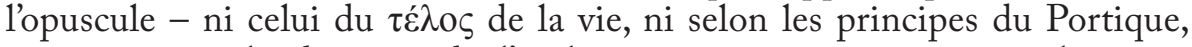
ni en suivant la doctrine de l'école péripatéticienne, comme cela a été interprété jusqu'à présent, mais cet opuscule est une défense de la liberté humaine et notamment de l'autonomie intellectuelle et morale de l'homme

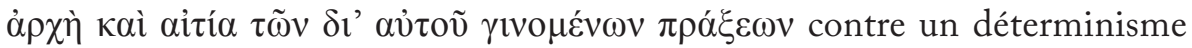

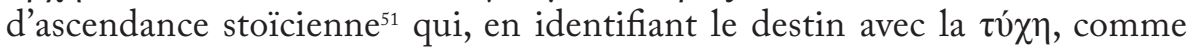

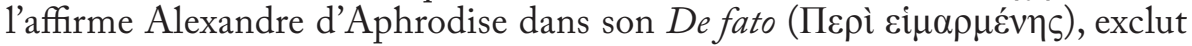
de fait de notre pouvoir ( $\tau$ ò $\dot{\varepsilon} \varphi$ ' $\dot{\eta} \mu \tilde{v} v$ ) en premier lieu les vertus et les vices,

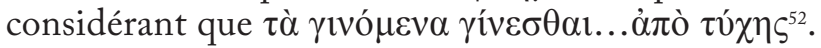

${ }^{45}$ Ziegler $\left(1965^{2}\right)$, p. 113.

${ }^{46}$ Babut (1969), pp. 79-83.

${ }^{47}$ Klaerr (1989), p. 233.

${ }^{48}$ Froidefond (1990), p. 97 n. 93.

${ }^{49}$ Klaerr (1989), p. 233.

${ }^{50}$ Barigazzi (1993), p. 53.

${ }^{51}$ Voir les objections avancées chez Sénèque (Ep. 16.4) par un hypothétique interlocuteur: Dicet aliquis: "Quid mibi prodest philosophia, si fatum est? Quid prodest, si deus rector est? Quid prodest, si casus imperat?». Sur les idées de déterminisme et de causalité partageant le même fondement voir maintenant Boncinelli - Giorello (2009), p. 96.

${ }^{52}$ Alex. Aphr., fat. VIII, «Suppl. Arist.» II 2, ed. I. Bruns, Berolini 1892, p. 173; de anim. II,

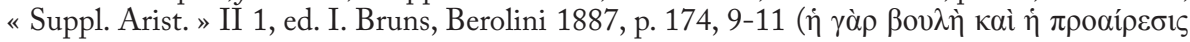

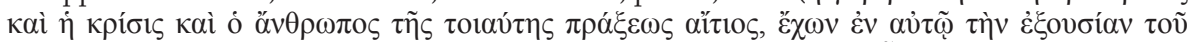

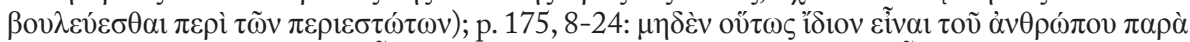

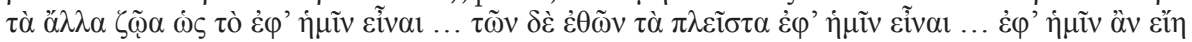

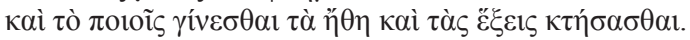




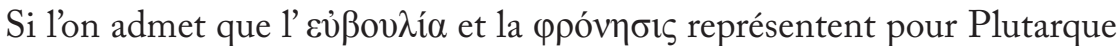

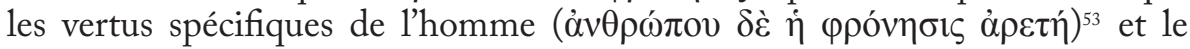
fondement de la $\mu \varepsilon \gamma \alpha \lambda o \psi v \chi i \alpha^{54}$, c'est le manque de celles-ci que Plutarque dénonce à la société de son temps, tant dans les Euvres morales que dans

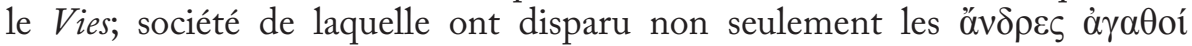
mais aussi où celui qui se dit philosophe semble plus soucieux d'apparaître

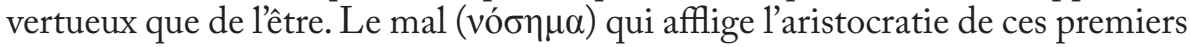
siècles - de plus en plus encline à croire et non à juger, possédée par l'avidité

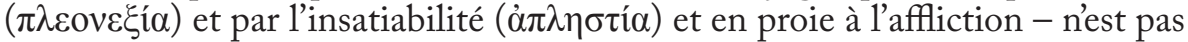
représenté pour le philosophe de Chéronée par les passions naturelles de l'âme,

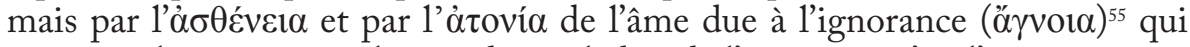
constitue la première et la pire des maladies de l'esprit, car c'est l'organe même qui formule les jugements, les seuls capables de produire une solide disposition dans l'esprit, qui est frappé ${ }^{56}$. Pour Plutarque, ces jugements représentent les

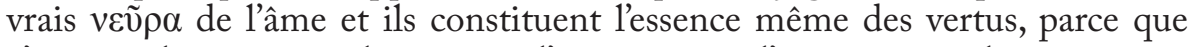
c'est avec le jugement, bien avant l'exercice, que l'on surmonte les passions ${ }^{57}$.

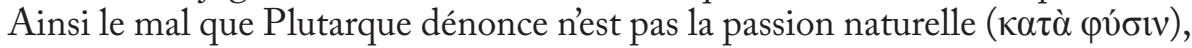
sujet à l'excès et au défaut, comme cela a été interprété jusqu'à présent, mais la passion contre nature ( $\pi \alpha \rho \alpha \grave{~} \varphi v ́ \sigma l v)$, c'est-à-dire les passions qui pénètrent de

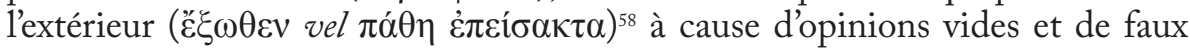

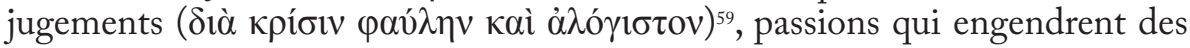
habitudes dont il semble impossible de se libérer si l'on n'arrache pas de l'esprit le faux jugement comme un nœud pervers à la gorge ${ }^{60}$.

Pour une interprétation correcte de l'éthique du philosophe de Chéronée, cette distinction entre passions par nature, qui sont enracinées dans l'âme humaine, et passions contre nature, venues de l'extérieur et qui représentent donc

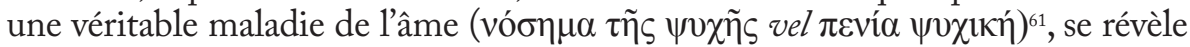
fondamentale non seulement parce qu'elle explique et justifie la coexistence à l'intérieur de l'opus plutarquien de différentes idées contradictoires ou presque à l'égard du phénomène passionnel et de l'idéal de l'à $\pi \alpha ́ \theta \varepsilon 1 \alpha$, mais aussi parce quelle permet de dépasser la distinction artificielle qui dans les écrits de Plutarque distingue deux niveaux, l'un philosophique et l'autre purement rhétorique. ${ }^{62}$

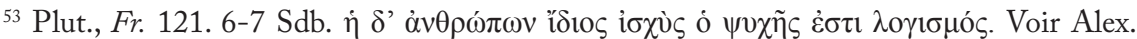

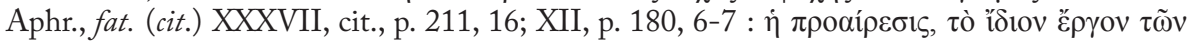
$\dot{\alpha} v \theta \rho \omega ́ \pi \omega v$.

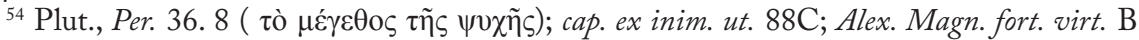

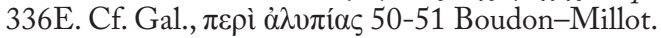

${ }^{55}$ Vd. Plut., cup. div. 523D; cons. ad uxor. 609E, 611A ; ad princ. ind. 782A. Cf. [Plut.], cons.

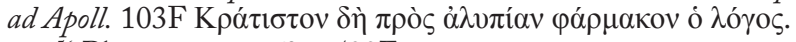

${ }_{56}$ Plut., an corp. affect. 500E.

${ }^{57}$ Plut., garr. 510CD.

${ }^{58}$ Plut., exil. 599C ( $\left.\ddot{\varepsilon} \xi \omega \theta \varepsilon v\right) ;$ bruta anim. 989C.

${ }^{59}$ Plut., cup. div. 524D; exil. 600E, 602B.

${ }^{60}$ Sur ces passions qui, comme la colère, ne conviennent pas à des hommes pourvus de sagesse voir Plut., cup. div. 524D; exil. 600E, 602B; Per. 39. 2.

${ }^{61}$ Plut., cup. div. 524E.

${ }^{62}$ Babut (1969), pp.332-333. 
Or, si telles apparaissent l'explication et la justification des points de vue apparemment si incohérents et contradictoires dans l'œuvre de Plutarque sur l'apathie, sur le rôle et la thérapeutique des passions, il est nécessaire de dessiner un nouveau tableau des rapports qui lient l'intellectuel de Chéronée avec le Portique, en distinguant l'école ancienne de Zénon et de Chrysippe de celle, moderne, inaugurée par Posidonius, en accord avec le jugement formulé sur le Portique par Plutarque lui-même dans la Vie de Cléomène (2. 6 = Agis-Cleom. 23. 1): «La doctrine stoïcienne, si elle comporte quelque risque et quelque danger pour les natures grandes et impétueuses, lorqu'elle imprègne un caractère profond et doux, l'aide éminemment à trouver l'oíkeĩov

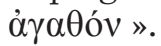




\section{Bibliographie}

Babut, D. (1969), Plutarque et le Stoïcisme, Paris.

Barigazzi, A. (1966), Favorino di Arelate, Opere, Firenze.

Barigazzi, A. (1993), Plutarco, Se la virtù si debba insegnare, Napoli.

Becchi, F. (2010), Plutarco, La fortuna, Napoli (CPM 47), 272 pp.

Boncinelli, E. -Giorello, G. (2009), Lo scimmione intelligente, Milano.

Boulogne, J. (2003), Plutarque dans le miroir d'Épicure, Lille.

Buriks A. A. (1950), The Source of Plutarch's PERI TYXHS, Phoenix 4.

Collard, C. (1970), On the tragedian Chaeremon, JHS 90.

Dümmler, F.(1889), Akademika. Beiträge zurLiteraturgeschichte der Sokratischen Schulen, Giessen.

Dyroff, A. (1897), Die Ethik der alten Stoa, Berlin.

Froidefond, Chr. (1990), Plutarque, Oeuvres Morales. Tome V - $1^{\text {re }}$ Partie, Paris.

Giesecke, A. (1891), De philosophorum veterum quae ad exilium spectant sententiis, Diss. Lipsiae.

Hobein, H. (1895), De Maximo Tyrio quaestiones philologae selectae, Dissertatio inauguralis quam ... scripsit Hermannus Hobein, Gottingae.

Kapnoukagias, Chr. K. (1940), Tesserakontaeteris Theophilou Borea, Athens 1940, I, pp. 107-121.

Klaerr, R. (1989), Plutarque, De la fortune, «Oeuvres Morales» Tome I, 2 partie, Paris.

Nachstädt, W. (19712), dans Plutarchi, Moralia, 2, Lipsiae.

Schlemm, A. (1893), De fontibus Plutarchi commentationum «de audiendis poetis» et "de fortuna », Dissertatio inauguralis, Göttingae.

Siefert,G.(1896), De aliquot Plutarchi Scriptorum Moralium compositione atque indole, Diss. Philologica, Lipsiae.

Ziegler, K. (1949, 1965²), Plutarco. Ed. it. a cura di B. Zucchelli e M. R. Zancan Rinaldini, Brescia. 


\title{
Superstición y ATEÍSMo \\ en la crítica antiepicúrea de Plutarco ${ }^{1}$
}

\author{
Juan Francisco Martos Montiel \\ Universidad de Málaga
}

\begin{abstract}
Resumen
Plutarco conocía bien la obra de Epicuro, y es fidedigno citando los textos epicúreos, pero a veces omite datos e ideas que sin duda sabía, y otras veces los interpreta a su conveniencia. Tanto es así, que llega a contradecirse en un tema tan cercano a él como es el de la religión, y en concreto en el tratamiento de la dicotomía superstición / ateísmo; y esto ocurre básicamente porque, en un momento determinado, le conviene sostener otra cosa que encaje mejor en su argumentación antiepicúrea.
\end{abstract}

Como han puesto de relieve algunos valiosos estudios en las últimas décadas ${ }^{2}$, podemos afirmar, sin temor a equivocarnos, que Plutarco tuvo un conocimiento de primera mano del epicureísmo; así lo sugiere, sin ir más lejos, el hecho de que tuviese diversos amigos epicúreos, que menciona en distintos lugares de los Moralia y a los que trata en general con corrección y a veces incluso con cierta simpatía: Boeto, amigo de los días de estudiante de Plutarco convertido luego al epicureísmo ${ }^{3}$; Jenocles de Delfos, «seguidor de las doctrinas de Epicuro» y viejo amigo del Queronense; Alejandro «el epicúreo», calificado por Plutarco de «encantador y bastante erudito» ${ }^{5}$ Z Zópiro, un médico «completamente familiarizado con los escritos de Epicuro» ${ }^{6}$. Plutarco, pues, a pesar de su conocido rechazo de la doctrina epicúrea, mantuvo buenas relaciones con miembros contemporáneos de la escuela y, aunque ocasionalmente muestre cierta antipatía hacia algunos epicúreos ${ }^{7}$, en general se muestra amistoso y cortés con la mayoría de los que aparecen en sus obras; una amistad que, sin duda, ayudó bastante a su conocimiento de la doctrina de Epicuro. De hecho, Epicuro es, tras Platón, Aristóteles y Crisipo, el filósofo que recibe mayor atención en la obra de Plutarco, como podemos comprobar en el conocido repertorio de citas plutarqueas de Helmbold-O'Neil ${ }^{8}$, donde se

1 Agradezco las valiosas indicaciones y precisiones del revisor anónimo, varias de las cuales he incorporado a este trabajo.

${ }^{2}$ Me refiero fundamentalmente a los trabajos de J. Boulogne, Plutarque et l'épicurisme, París, 1986 (reelaborado y profundizado en su libro Plutarque dans le miroir d'Épicure, Villeneuve d'Ascq, 2003), y de J. P. Hershbell, "Plutarch and Epicureanism", ANRW, II 36.5 (1992) 3353-3383.

${ }^{3}$ Cf. Pyth. or. 5, 396 E; en Quaest. conv. V 1, 673 C se le llama "el epicúreo".

${ }^{4}$ Quaest. conv. II 2, 635 A-C.

${ }^{5}$ Cf. Quaest. conv. II 3, $635 \mathrm{E}-636 \mathrm{~A}$; se trata probablemente del mismo Alejandro a quien Plutarco dedicó su tratado De Herodoti malignitate.

${ }^{6}$ Cf. Quaest. conv. III 6, 1-2 653 C-654 B, donde Zópiro explica con detalle los argumentos del Simposio de Epicuro sobre el momento más conveniente para mantener relaciones sexuales.

7 Así ocurre con el anónimo epicúreo que aparece en Ser. num. vind. 548 C, o con el Heraclides de Suav. viv. Epic. 21086 E).

${ }^{8}$ W. C. Helm bold - E. N. O’Neil, Plutarch's Quotations, Oxford, 1959, un trabajo útil aún, 
recogen casi cuatro columnas y media de citas de Epicuro, frente a seis y media de Crisipo, ocho y media de Aristóteles y casi catorce de Platón.

Aunque en el seno de la Academia y también de la Estoa se habían producido diversos tratados polémicos contra los epicúreos que Plutarco debió de conocer y que pudo haber utilizado en sus escritos, no fueron éstos (con frecuencia simples panfletos) la fuente principal de su conocimiento del epicureísmo. Ya Ziegler estableció que Plutarco leyó sin duda las fuentes epicúreas originales, aunque pudiera haberse servido de tratados polémicos de académicos como Clitómaco de Cartago, según sugirió Usener ${ }^{9}$; a similares conclusiones han llegado Hershbell ${ }^{10}$ y Boulogne, si bien este último insiste en no desdeñar totalmente la tradición polémica, pues, a pesar de que es innegable un conocimiento directo de los escritos y pensamiento epicúreos por parte de Plutarco, su actitud hacia el epicureísmo habría venido dictada, según Boulogne, por «una doble tradición: la de las prácticas polémicas habituales de la época, y la de la polémica antiepicúrea propiamente dicha» ${ }^{11}$. No hay que olvidar, por otra parte, que Plutarco, además de sacerdote de Apolo en Delfos, fue maestro de filosofía en Queronea, por lo que estaba obligado a conocer con seriedad y rigor las teorías del Jardín, aunque solo fuera para criticarlas en sus clases confrontándolas con las suyas ${ }^{12}$.

No cabe duda, pues, de que Plutarco conocía bien los escritos epicúreos: algunos de ellos los tendría a mano en su pequeña biblioteca de Queronea, aunque probablemente habría tenido bastantes oportunidades de consultarlos durante sus estancias en Atenas, Alejandría y Roma. Podemos afirmar incluso que los utilizaba directamente, pues así lo demuestran sus numerosas referencias a ellos, a menudo de una precisión tal que hace suponer que su conocimiento de los textos epicúreos no era de segunda mano, sino directo y personal, sin el intermedio de resúmenes críticos o de colecciones de extractos, que habrían dificultado, cuando no imposibilitado, la determinación de la procedencia de la cita $^{13}$. En efecto, a través de la obra de Plutarco, especialmente de sus escritos antiepicúreos, nos ha llegado más de un centenar de fragmentos textuales de Epicuro y de algunos de sus discípulos, particularmente Metrodoro y Colotes, aparte de otros muchos pasajes en los que el Queronense se refiere indirectamente a las doctrinas de Epicuro o reflexiona sobre ellas ${ }^{14}$.

aunque incompleto y necesitado de una revisión a fondo.

${ }_{9}^{9}$ K. Ziegler, Plutarco (ed. italiana, trad. por Ma Rosa Zancan Rinaldini, del libro Plutarchos von Chaironeia, Stuttgart, 1949), Brescia, 1965, p. 161. La sugerencia de H. Usener, Epicurea, Leipzig, 1887, p. LXIV, choca, sin embargo, con el hecho de que en ningún lugar de la obra de Plutarco aparece referencia alguna a Clitómaco.

${ }^{10}$ Hershbell, op. cit., p. 3360.

${ }^{11}$ Boulogne, Plutarque et l'épicurisme, p. 463.

${ }^{12}$ Cf. Boulogne, Plutarque dans le miroir d'Épicure, pp. 19-38.

${ }^{13}$ Cf. Boulogne, Plutarque et l'épicurisme, pp. 456-458, y Plutarque dans le miroir d'Épicure, pp. 16-18; Hershbell, op. cit., pp. 3356 y 3360.

${ }^{14} \mathrm{Un}$ buen número de esos fragmentos pueden ser asignados con razonable certeza a obras 
Este conocimiento, incluso familiaridad, de Plutarco con los escritos epicúreos está en relación directa con una importante cuestión: la de su mayor o menor fidelidad u objetividad al citar las obras de Epicuro y sus seguidores o al exponer sus ideas. Obviamente, aquí debe tenerse muy en cuenta la propia naturaleza polémica de los escritos epicúreos de Plutarco, pero esto no debe llevarnos necesariamente a concluir que Plutarco citara mal de forma deliberada o que incluso llegara a falsear los escritos de sus oponentes. De hecho, el propio Plutarco acusa al epicúreo Colotes de mutilar y descontextualizar las citas e ideas de los filósofos que critica ${ }^{15}$, por lo que no parece que quisiera exponerse de buena gana a similares acusaciones. Es cierto, como ha estudiado Hershbell ${ }^{16}$, que Plutarco tiende a abreviar y adaptar pasajes de Epicuro, pero cuando podemos comparar sus citas con otras que encontramos en otros autores antiguos, particularmente en Diógenes Laercio, por lo general parecen precisas y concordantes, si no en la forma, sí en el fondo. No hay razón, por tanto, para dudar en principio de la honestidad intelectual de Plutarco a la hora de citar los escritos epicúreos: la afirmación de Bailey de que «Plutarco pone buen cuidado, siempre que le es posible, en citar las propias palabras de Epicuro", parece sustancialmente correcta $^{17}$.

Sin embargo, una cita fidedigna no garantiza una interpretación fiable. En este sentido, ya Ziegler llamaba la atención sobre la fiabilidad de Plutarco en sus exposiciones de la doctrina epicúrea, presentada a menudo de forma unilateral y claramente hosti ${ }^{18}$. Posteriormente, autores como Hershbell o Boulogne han puesto de relieve cómo la interpretación plutarquea de la filosofía epicúrea se muestra a veces poco consistente e incluso claramente tendenciosa. Así ocurre, por ejemplo, cuando ataca la teoría atomista por no explicar cómo cuerpos sin cualidades, como son los átomos epicúreos, pueden producir cualidades de todo tipo simplemente al juntarse ${ }^{19}$, o cómo puede salir

específicas (Cartas, Máximas capitales, Casos dudosos, Sobre el criterio o Canon, Sobre la naturaleza, Simposio, etc.), aunque hay también muchas otras citas o paráfrasis de escritos de Epicuro cuyas fuentes no pueden determinarse con precisión: $c f$. Hershbell, op. cit., pp. 3357-3360.

${ }^{15}$ Adv. Col. 31108 D: «Colotes compone su libro arrancando ciertas partes o frases de un argumento privadas de su sentido real y sacando de contexto fragmentos mutilados que silencian aquello que los confirma y los hace comprensibles y creíbles». Plutarco reprocha a Colotes esta misma práctica en Suav. viv. Epic. 1086 D; vid. también Ser. num. vind. 548 C, donde se critica a un epicúreo que, tras «desbordarse en razonamientos apretados, pero sin orden alguno, cogidos de acá y de allá, contra la providencia», se marcha sin despedirse y deja a sus interlocutores sin posibilidad de responderles.

${ }^{16}$ Hershbell, op. cit., pp. 3357-3361.

${ }^{17}$ C. Bailey, The Greeks Atomists and Epicurus, Oxford, 1928, p. 230 (citado por Hershbell, op. cit., p. 3368). No ocurre así, sin embargo, con las citas plutarqueas de Metrodoro, que a veces parecen menos dignas de crédito: $c f$. Hershbell, op. cit., pp. $3368 \mathrm{~s}$.

${ }^{18}$ Ziegler, op. cit., pp. 159 s.

${ }^{19}$ Adv Col.1111 C). 
nada estable del constante movimiento y colisión de los átomos ${ }^{20}$. Respecto a la primera objeción, es cierto que el razonamiento de Plutarco parece sostenerse en motivaciones aparentemente objetivas ${ }^{21}$, al señalar que, mientras que los átomos, aunque difieren en magnitud y en forma, carecen de cualidades, son inalterables y están, por lo tanto, desprovistos de toda capacidad generativa ${ }^{22}$, sin embargo no ocurre así con los principios elementales de Platón, Aristóteles y otros, que están ya dotados de diferentes cualidades que, al mezclarse entre sí e interectuar unas sobre otras, generan naturalmente una pluralidad de objetos diversos ${ }^{23}$. Pero este problema, como apunta Hershbell, está mal planteado, pues una cosa son los átomos y otra distinta los objetos por ellos constituidos ${ }^{24}$ : para un epicúreo, en efecto, no hay inconsistencia en afirmar que un objeto puede tener cualidades que no tienen los átomos que lo conforman. En cuanto a la segunda objeción, cabría admitir también que la aparente incapacidad plutarquea de comprender el concepto epicúreo de $\pi \varepsilon \rho \imath \pi \lambda$ oкń pueda haberse visto abonada por las complicadas precisiones de los epicúreos al respecto, pero ello no disculparía el hecho de que Plutarco pase por alto ideas fundamentales que sin duda debió de conocer, como la pequeñez de los átomos, su propia imperceptibilidad y la de sus movimientos. Además, aunque los argumentos utilizados por Plutarco - empleados ya en su mayoría por estoicos y académicos - son en general pertinentes y reveladores de un examen atento de los textos epicúreos, sin embargo están basados en última instancia en el apriorismo de juzgar inferior toda explicación cosmológica que no se apoye en la teoría platónico-aristotélica de los cuatro elementos $(\sigma \tau o \chi \chi \varepsilon i \widetilde{\alpha} \alpha)^{25}$. Lo mismo sucede cuando critica Plutarco la psicología y gnoseología epicúreas sin profundizar en ellas, sino más bien recurriendo en demasiadas ocasiones al fácil expediente de las generalizaciones y simplificaciones a menudo abusivas ${ }^{26}$, o cuando polemiza contra la ética epicúrea, y especialmente su teoría del placer, malinterpretando en diversas ocasiones -o sencillamente pasándolas por alto cuando le convieneideas centrales como la distinción entre placeres «cinéticos» $\mathrm{y}$ «catastemáticos» o la creencia epicúrea de que la ausencia de dolor es el sumo placer, ideas que Plutarco casi con toda seguridad conocía, a juzgar por las razones que hemos expuesto anteriormente ${ }^{27}$.

${ }^{20}$ Cf. por ejemplo Adv Col. 91111 E y 1112 B-C.

${ }^{21}$ Aunque no necesariamente persuasivas: cf. EpIC., frags. 288 ss. Usener.

${ }^{22}$ Cf. Adv. Col. $1110 \mathrm{~F}$ y $1111 \mathrm{E}$.

${ }^{23}$ Cf. Adv. Col. 1111 D-E.

${ }^{24}$ Vid. Hershbell, op. cit., p. 3370.

${ }^{25}$ En general, sobre la crítica de Plutarco a la teoría atomista epicúrea, vid. Hersh bell, op. cit., pp. 3370 s. y 3374-3376, y especialmente la detallada exposición de Boulogne, Plutarque et l'épicurisme, pp. 560-611.

${ }^{26}$ Cf. Adv. Col. 20-21 1118 C-1119 C, 1121 A-E o 1123 B-1124 B, entre otros pasajes, y véanse Hershbell, op. cit., pp. 3371 s., y especialmente Boulogne, Plutarque et l'épicurisme, pp. 513-559 y 644-655.

${ }^{27}$ Cf. especialmente Suav. viv. Epic. 1087 D-1091 A, y véanse Hersh bell, op. cit., pp. 3372 s., y Boulogne, Plutarque et l'épicurisme, pp. 679-686. 
Plutarco, pues, conocía bien la obra de Epicuro, y es fidedigno citando los textos epicúreos, pero también es cierto que a veces omite datos e ideas que sin duda sabía, y que otras veces los interpreta a su conveniencia. Tanto es así, que, en su afán por criticar la doctrina epicúrea, llega a contradecirse en un tema tan cercano a él como es el de la religión, y en concreto en el tratamiento de la dicotomía superstición / ateísmo. Me refiero, como puede suponerse, al conflicto que encontramos entre dos obras suyas cuyo desacuerdo se señala a menudo entre los estudiosos: el De superstitione y el Non posse suaviter vivi secundum Epicurum. En ambos textos, Plutarco se plantea la misma cuestión: entre la superstición y el ateísmo, ¿qué es lo peor? La superstición, responde en De superstitione; el ateísmo, afirma en Non posse suaviter vivi secundum Epicurum ${ }^{28}$.

La religión, según Plutarco, está hecha de dos sentimientos: la esperanza en la providencia divina y el temor a los dioses ${ }^{29}$. El hombre piadoso tiene confianza en el porvenir, mientras que la superstición obliga a vivir en el temor; en cuanto al ateo, no tiene ni temor ni esperanza, pues cree en una ciega Fatalidad. La $\dot{\theta \varepsilon o ́} \tau\rceil$, en efecto, niega que los dioses existan o que sean dioses dignos de tal nombre, que se ocupen de los humanos y sean providenciales. La $\delta \varepsilon 1 \sigma ı \delta \alpha \mu \rho v i ́ \alpha$, por su parte, los representa con rasgos indignos de ellos: como amos orgullosos y malvados, que tienen celos e injustos ataques de cólera para con los hombres, que se dejan conmover si uno se humilla a sus pies; el supersticioso tiembla sin cesar ante la idea de que los dioses van a castigarlo por haber olvidado algún rito o desatendido algún presagio, y vive aterrorizado por vanas imaginaciones que le hacen ver por todas partes signos de la cólera de un dios contra él, y que lo llevan a blasfemar y a acusar a los dioses de todas sus desgracias. La tesis paradójica de Plutarco en De superstitione es que, siendo males equivalentes el ateísmo, que ignora a los dioses, y la superstición, que se hace de ellos una idea indigna, sin embargo esta última iguala e incluso supera al ateísmo en impiedad. De ahí las conocidas palabras del Queronense: «Preferiría que se dijera de mí: "Plutarco no existe ni ha existido nunca", que oír decir: "Plutarco es un hombre inseguro, inconstante, colérico, vengativo, susceptible"». ${ }^{30}$

${ }^{28}$ En general, para un análisis de las ideas de Plutarco, y de su relación con la tradición filosófica precedente, sobre los temas del ateísmo, la supestición y la verdadera religión, $c f$. M. BAldassarri, "Inquadramento filosofico del «De superstitione» plutarcheo", en I. Gallo (cur.), Plutarco e la religione: atti del VI convegno plutarcheo (Ravello, 29-31 maggio 1995), Nápoles,

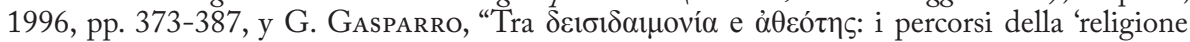
filosofica' di Plutarco", en A. Pérez Jiménez - F. Titchener (eds.), Valori letterari delle opere di Plutarco, Málaga - Logan, 2005, pp. 163-184. En concreto, para la cuestión que aquí nos ocupa, remitimos a los clásicos estudios de H. Erbse, "Plutarchs Schrift Peri deisidaimonias", Hermes, 80 (1952) 296-314, y H. A. Moellering, Plutarch. On superstition, Boston, 1963, y sobre todo a la atinada introducción de R. Laurenti y C. Santaniello a su edición, para el Corpus Plutarchi Moralium, de Plutarco, La superstizione, Nápoles, 2007.

${ }^{29}$ Cf. Adv. Col. 1125 E.

${ }^{30}$ Superst. 169 F-170 A. 
Sin embargo, cuando se pasa del De superstitione al Non posse suaviter vivi secundum Epicurum, nos encontramos con la negación de esta teoría. $\mathrm{Si}$ se suprime la creencia en los dioses, escribe Plutarco, la pérdida predominará sobre el beneficio; se habrá expulsado la vergüenza y el temor, sí, pero con ellos se habrán desvanecido la esperanza, la gratitud, la tranquilidad sobre nuestro estado presente y un refugio en lo divino en caso de desgracia ${ }^{31}$. Como leemos en Non posse suaviter vivi secundum Epicurum 21 (1101 C): «Sin duda, hay que quitar la superstición de la creencia en los dioses, como se quita una legaña del ojo; pero, si esto es imposible, no debemos extirpar ambas a la vez y cegar así la fe que la mayoría de la gente tiene en los dioses».

Así pues, mientras que la tesis sostenida por Plutarco en De superstitione es que la superstición es peor y más censurable que el ateísmo, aquí en cambio parece sostenerse justamente lo contrario. En el ardor de la crítica contra el impío Epicuro y sus ideas pretendidamente ateas, la tesis de una à $\theta \varepsilon o ́ \tau \eta \varsigma$ preferible a la $\delta \varepsilon \imath \sigma 1 \delta \alpha \mu o v i ́ a$ se vuelve del revés cuando prevalece el interés demostrativo en sentido contrario. Desmintiendo a los epicúreos, Plutarco se desmiente a sí mismo.

Hay que reconocer, por supuesto, que numerosos estudiosos han tratado, con notable éxito, de minimizar esta contradicción o incluso de hacer ver que es sólo aparente. Se suele citar, en este sentido, un famoso pasaje del tratado De Iside et Osiride, donde se califica la superstición de «un mal no inferior al ateísmo» ${ }^{32}$, para subrayar que, a fin de cuentas, nuestro autor consideraba ambas cosas como males, y se han avanzado diversos argumentos que explican la aparente inversión de la balanza en el tema que nos ocupa, tanto por la evolución de su pensamiento como por razones de contenido. Respecto a lo primero, hay un acuerdo casi general de los críticos en considerar que De superstitione es obra de juventud, mientras que el Non posse suaviter vivi secundum Epicurum es uno de sus últimos escritos, con el consiguiente conservadurismo y mayor religiosidad que la edad suele implicar -sin olvidarnos de su cargo de sacerdote en Delfos.

Respecto a las razones de contenido, se insiste en que el De superstitione es una obra escrita siguiendo las artes escolares de la retórica, mientras que el Non posse suaviter vivi secundum Epicurum es un tratado filosófico de polémica antiepicúrea $^{33}$, y se subraya, además, que, en realidad, en el De superstitione se condenan los dos vicios opuestos, superstición y ateísmo, para exaltar, según

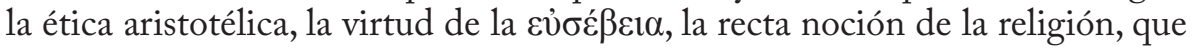

${ }^{31}$ Cf. Suav. viv. Epic. 1101 B-C.

${ }^{32}$ Is. et Os. 355 D. No es ocioso recordar que Plutarco dedicó esta obra a Clea, una joven sacerdotisa.

${ }^{33}$ Del que no hay que excluir una motivación didáctica, dado que, además de su condición de sacerdote en Delfos, Plutarco fue también, y quizá sobre todo, maestro de filosofía en su escuela de Queronea. 
está en el medio ${ }^{34}$, conectando esto con la distinción, en Non posse suaviter vivi secundum Epicurum, de tres categorías de personas según su actitud y creencias en relación con la divinidad ${ }^{35}$, al objeto de concluir que, a pesar de las divergencias con la tripartición que encontramos en De superstitione, tampoco aquí habría una sustancial diferencia en la condena de supersticiosos y epicúreos (que Plutarco considera ateos, en cuanto que negadores de la providencia) ${ }^{36}$, y que,

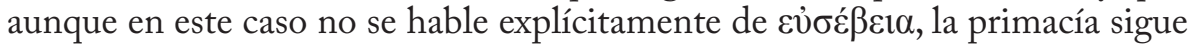
estando siempre del lado de quien conoce rectamente la naturaleza divina.

Estas razones de contenido, aceptadas actualmente por la mayoría de los estudiosos para salvar la aparente contradicción de Plutarco en este tema ${ }^{37}$, llevan aparejada la cuestión de la distinta finalidad y del distinto público $^{38}$ de ambas obras, lo que también ha dado pie a distinguir entre dos variedades sociales de superstición. En este sentido, Paul Veyne ha defendido recientemente el argumento de que, bajo el mismo nombre de $\delta \varepsilon 1 \sigma 1 \delta \alpha \mu o v i ́ \alpha$, Plutarco apunta y ataca dos cosas distintas: «la nueva superstición de la gente culta», los $\pi \varepsilon \pi \alpha 1 \delta \varepsilon v \mu \varepsilon ́ v o 1$, a quienes podía concedérseles «ese lujo intelectual que era la ausencia de $\delta \varepsilon 1 \sigma ı \delta \alpha \mu \mu v i ́ \alpha$, aunque fuera al precio del ateísmo», y «la superstición ancestral y venial del común de las gentes», a quienes, «en su humilde condición, se les haría más mal que bien si se pretendiera purificar su creencia». Estas dos variedades de superstición no pertenecen a los mismos grupos sociales y deben ser juzgadas con parámetros diferentes, lo que explica, según Veyne, la aparente contradicción de los textos plutarqueos, o al menos la hace menos radical de lo que parece, pues se reduciría a distinguir dos escalas de apreciación muy diferentes ${ }^{39}$.

${ }^{34}$ Cf. Superst. $171 \mathrm{E}$.

${ }^{35}$ Cf. Suav. viv. Epic. $1101 \mathrm{C}-1102 \mathrm{E}$, donde se distingue entre: 1) las personas malvadas, cuyo temor supersticioso a los castigos divinos puede tener el beneficioso efecto de retraerlos de cometer injusticia; 2) las personas simplemente ignorantes pero no del todo malas, que constituyen la mayoría, las cuales experimentan también un leve temor supersticioso pero gozan, en cambio, de las alegrías del trato con sus semejantes y con la divinidad en las fiestas religiosas (alegrías vedadas para quienes, como los epicúreos, no creen en la providencia); y 3) las personas virtuosas y sensatas, a quienes está reservado el conocimiento de la verdad sobre los dioses y saben que es propio de la naturaleza divina hacer el bien y no el mal. A la misma tripartición se recurre en Suav. viv. Epic. 1104 A.

${ }^{36}$ En Def. orac. 420 B, Plutarco critica la consideración epicúrea de la providencia divina como cuento o mito ( $\mu$ ṽ $0 \varsigma$ ); vid. también $A d v$. Col. 1125 A, donde dice que los epicúreos «desprecian estas ideas por considerarlas cuentos».

${ }^{37} \mathrm{Vid}$. Gasparro, op. cit., pp. $168 \mathrm{~s}$.

${ }^{38}$ Para la cuestión general del público al que presumiblemente iban dirigidos los tratados de Plutarco, remitimos al trabajo de C. Santaniello, "Rapporti fra generi letterari e pubblico nel corpus plutarcheo”, en I. Gallo - C. Moreschini (eds.), I generi letterari in Plutarco, Nápoles, 2000, pp. 271-286.

39 P. Veyne, "Los problemas religiosos de un pagano inteligente: Plutarco", en su libro El imperio grecorromano, Madrid, 2009, pp. 563-606 (ed. original francesa: París, 2005). Las citas pertenecen en concreto a pp. 604-605. 
Probablemente sean ciertas todas estas explicaciones, que tienden, en último término, a exonerar a Plutarco de toda contradicción y a hacer ver que, en el fondo, su rigor de pensamiento apenas cambió durante los años que median entre una obra y otra, lo que subrayaría su honestidad intelectual. Pero insisto en que, al menos en sus escritos de polémica antiepicúrea, como he señalado antes, Plutarco no interpreta honestamente a Epicuro, tampoco en la cuestión de su pretendida impiedad o ateísmo, como veremos en el siguiente ejemplo, con el que concluiremos este ensayo.

En Non posse suaviter vivi secundum Epicurum 21 (1102 B) se dice que el epicúreo, que no tiene fe en la providencia, no participa de los placeres que proporcionan las fiestas religiosas, de los que sí participan quienes tienen fe, y, aunque los epicúreos critican que la gente participa en los rituales religiosos por miedo, en realidad ellos también lo hacen por miedo a que la gente los critique, fingiendo una devoción que no tienen, y además perdiéndose esos placeres proporcionados por fiestas y ceremonias religiosas. Escribe Plutarco: «Para una persona así, [participar en las fiestas religiosas] es algo completamente desagradable y penoso, pues, por miedo a la mayoría, finge plegarias y actos de veneración cuya necesidad no siente y pronuncia palabras contrarias a sus principios filosóficos». Lo cierto es que, en su intento por desprestigiar a Epicuro, Plutarco incurre en afirmaciones que, como ésta, son más indicio de parcialidad en la crítica que prueba de desconocimiento de la doctrina del Jardín. Esta doctrina, en efecto, no se despreocupa en realidad de los dioses, como habitualmente se piensa, sino que, como señaló García Gual, «partiendo de que el conocimiento de los dioses es evidente, y depurando la noción popular de todo lo que es incompatible con la serenidad dichosa que es requisito básico de la esencia divina, el epicúreo concibe una nueva forma

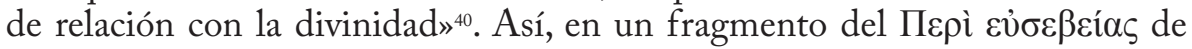
Filodemo, contemporáneo de Plutarco, por cierto, leemos: «El sabio tiene en todo momento opiniones puras y reverentes acerca de la divinidad y estima excelsa y augusta su naturaleza. [...] admira la naturaleza y disposición de los dioses, se esfuerza por convivir con ellos, aspira, por decirlo así, a tocarlos, y llama a los sabios amigos de los dioses y a los dioses amigos de los sabios» $»^{41}$, y más adelante continúa: «Sacrifiquemos, pues, piadosa y rectamente como conviene, y cumplamos con todas las demás cosas de acuerdo con las leyes, sin dejarnos turbar por las vanas opiniones acerca de los seres más perfectos y augustos» ${ }^{42}$. Recuérdese, además, que de esta recomendación epicúrea de seguir las costumbres religiosas y los cultos locales, participando en las ceremonias con devoción, daba buen ejemplo el propio maestro, que «respetaba todas las

${ }^{40}$ C. García Gual, Epicuro, Madrid, 1981, p. 170. Cf. al respecto Sexto Empírico, Contra los dogmáticos III 58 (= Adv. Math. IX 58): «Epicuro, según algunos, admite la existencia de dios para el común de las gentes, pero no la admite en absoluto para explicar la naturaleza de las cosas».

${ }^{41}$ Epicuro, frag. 386 Usener.

${ }^{42}$ Epicuro, frag. 387 Usener (= 114 Arrighetti). 
fiestas y los sacrificios tradicionales» $»^{43}$ y cuya piedad «estaba por encima de toda expresión $»^{44}$.

En suma, una cosa son las citas epicúreas que aparecen en Plutarco, por lo general fidedignas, y otra bien distinta la interpretación plutarquea de la doctrina epicúrea. En efecto, nuestro autor procura citar bien las palabras epicúreas, pero sólo las que le interesan para sustentar mejor sus críticas, y además las interpreta a menudo pro domo sua. Plutarco, como afirma Hershbell benévolamente, «no siempre es exacto en sus discusiones» ${ }^{45}$. Yo diría más, y me atrevería a hablar, parafraseando el título de su conocido opúsculo sobre Heródoto, de Plutarchi malignitate, no tanto en el sentido de malevolencia cuanto de parcialidad: porque, respecto a Epicuro, Plutarco dice la verdad, sí, pero no toda la verdad ni nada más que la verdad.

${ }^{43}$ Epicuro, frag. 169 Usener (= 93, 12-15 Arrighetti).

${ }^{44}$ Diógenes Laercio, X 10.

${ }^{45}$ Hershbell, op. cit., p. 3372. 


\section{Bibliografía Citada}

Bailey, C. The Greek Atomists and Epicurus, Oxford, 1928.

BALDASSARri,M."Inquadramento filosofico del «De superstitione» plutarcheo”, en I. Gallo (cur.), Plutarco e la religione: atti del VI convegno plutarcheo (Ravello, 29-31 maggio 1995), Nápoles, 1996, pp. 373-387.

J. Boulogne, Plutarque et l'épicurisme, París, 1986.

J. Boulogne, Plutarque dans le miroir d'Épicure, Villeneuve d'Ascq, 2003.

H. Erbse, "Plutarchs Schrift Peri deisidaimonias", Hermes, 80 (1952) 296-314.

C. García Gual, Epicuro, Madrid, 1981.

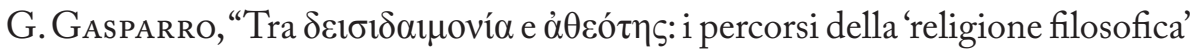
di Plutarco", en A. Pérez Jiménez - F. Titchener (eds.), Valori letterari delle opere di Plutarco, Málaga - Logan, 2005, pp. 163-184.

W. C. Helmbold - E. N. O’Neil, Plutarch's Quotations, Oxford, 1959.

J. P. Hershbell, "Plutarch and Epicureanism", ANRW, II 36.5 (1992) 3353-3383.

R. Laurenti e C. Santaniello, Plutarco, La superstizione, introduzione, testo critico, traduzione e commento a cura di ---, Nápoles, 2007.

H. A. Moellering, Plutarch. On superstition, Boston, 1963.

C. Santaniello, "Rapporti fra generi letterari e pubblico nel corpus plutarcheo", en I. Gallo - C. Moreschini (eds.), I generi letterari in Plutarco, Nápoles, 2000, pp. 271-286.

H. Usener, Epicurea, Leipzig, 1887.

P. Veyne, "Los problemas religiosos de un pagano inteligente: Plutarco", en su libro El imperio grecorromano, Madrid, 2009, pp. 563-606 (ed. original francesa: París, 2005).

K. Ziegler, Plutarco (ed. italiana, trad. por Ma Rosa Zancan Rinaldini, del libro Plutarchos von Chaironeia, Stuttgart, 1949), Brescia, 1965. 
Entre Philosophie et Religion, LES RELATIONS DES HOMMES ET DES DIEUX 


\title{
Le DE SERA, Dialogue PythiQue Hasard et Providence, Philosophie et Religion dans la pensée de Plutarque
}

\author{
Françoise Frazier \\ Université de Paris Ouest Nanterre - La Défense
}

\begin{abstract}
This reconsideration of the structure of the De sera focuses first on the major opposition of Tyche and Pronoia: anti-Epicurean trend, Academic eulabeia and intensive use of eikos characterize a methodical and consistent reflexion, very far from being «a jumble of disordered remarks» - a tentative analysis of the composition is given in appendix. It proceeds to a second couple of terms, not opposed as are Tyche and Pronoia, but complementary, Philosophy and Religion, that allow to read the De sera as a Pythian Dialogue: already in the logos, - especially through what I would call the «Delphic proof» of the immortality of the soul -, but foremost in the celestial description of the mythos, Plutarch shows how much he is concerned with saving both (philosophical) transcendence and (religious) relations between men and God.
\end{abstract}

Seul dialogue situé à Delphes qu'Henri Estienne ait laissé en dehors du groupe des Dialogues Pythiques qu'il constitua dans sa grande édition princeps de $1572^{1}$, le De sera n'a de ce fait pas profité du regain d'intérêt qu'ont connu dans les années récentes les trois autres dialogues, et dont témoignent tant l'étude fondamentale de la composition de D. Babut que les traductions récentes et abondamment commentées, de l'ensemble des dialogues par F. Ildefonse, ou de l'Epsilon seul par une équipe de spécialistes de Plutarque et de l'histoire de la philosophie ${ }^{2}$. Quelques études thématiques, présentées à la faveur des rencontres internationales, ont sans doute eu à considérer cette œuvre, mais, si importants que soient ces thèmes, comme la défense de la Providence ou le mal et la Providence ${ }^{3}$, ils nont pas donné lieu à une réflexion d'ensemble sur la construction du dialogue et la conduite de la réflexion. La seule étude à s'attacher à cet aspect - qui est aussi la plus récente - a été elle aussi suscitée par une rencontre internationale, celle de Barcelone, en 2003, mais C. Helmig', son auteur, ne me semble pas éclairer une structure dans laquelle il relève surtout des faiblesses. Il faut dire que, si, depuis la Renaissance, le dialogue a été considéré comme le chef d'œuvre, ou du moins, un des chefs d'œuvre religieux de l'Antiquités , cette valorisation religieuse a eu pour conséquence inverse une

${ }^{1}$ Dans la tradition planudéenne, De E, De Pythiae et De defectu portent les n ${ }^{\circ} 68,72$ et 69, et dans l'Aldine, qui servit de base à Estienne, les n ${ }^{\circ} 21,71$ et 20. Ils deviennent chez Estienne les traités 24-26.

${ }^{2}$ Voir D. Babut, 1992, F. Ildefonse, 2006 et, pour le volume sur le De E, en particulier la contribution de J. Opsomer, 2006.

${ }^{3}$ M. Baldassari, 1994 et G. del Cerro Calderón, 1994. L. Torraca, 1991, donne un commentaire minutieux et utile du texte, mais, pour ce qui concerne la construction, se concentre surtout sur le double recours au logos et au mythos.

${ }^{4}$ C. Helmig, 2004.

${ }^{5}$ Le premier traducteur français - qui traduit la traduction latine de W. Pirkheimer [Nürnberg, 1513 = BNF, R8262] —, Jean de Marconville [1563 = BNF, E*-2664 (4)], souligne 
dévalorisation de sa teneur philosophique: C. Helmig semble s'inscrire dans cette tradition ${ }^{6}$, et, encouragé sans doute encore dans ce sens par la forme choisie, celle du dialogue, il insiste sur le caractère " non-philosophe » du public'. Cependant, même si, à l'évidence, l'ouvrage n'est pas un commentaire «technique» comme le De procreatione, fruit des cours de Plutarque, on peut douter que les lecteurs en soient très différents, et moins encore en déduire que la pensée serait dispensée de suivre une démarche cohérente. Or, dans sa propre analyse, C. Helmig se réfère très souvent à un papier antérieur de T.J. Saunders ${ }^{8}$, savant qui s'intéresse à la "peinologie ${ }^{9}$ » et s'est efforcé de chercher dans le $D e$ sera les grandes lignes d'une législation humaine, après l'avoir fait, de façon beaucoup plus légitime, dans les Lois. C. Helmig marque très bien la difficulté d'une telle perspective, qui oblige à croire que Plutarque s'intéresserait aux

que " par la lecture de ses livres on le [scil. Plutarque] jugerait avoir puisé sa philosophie de la claire fontaine de la vérité de Dieu, et non des fangeux bourbiers des cisternes des idolastres » et il relève soigneusement tous les lieux de l'Écriture où l'on trouve des idées similaires. Plus près de nous, D. Wyttenbach, au moment d'entreprendre sa grande édition, le choisit comme "prototype» (premier essai publié à Leyde en 1772). La traduction-adaptation de Joseph de Maistre de 1816 témoigne aussi de cette lecture «christianisée» [voir F. FRAZIER, «Le «dialogue» de Joseph de Maistre et de Plutarque. Quelques remarques textuelles sur la version maistrienne des Délais de la justice divine» et J.- M. Roh rbasser, «La théodicée noire de Joseph de Maistre: Plutarque contre Leibniz», à paraître in O. Guerrier (ed.), Plutarque de l'Âge classique au XIXe siècle. Présences, interférences et dynamique. Actes du Colloque International de Toulouse, 13-15 mai 2009]. G. MÉautis ne dit pas autre chose dans l'introduction de sa traduction de 1935 et H. Görgemanns, 2003, de même, affirme que «der Dialog Über die späte Strafe der Gottheit ist unter den religionsphilosophischen Werken Plutarchs vielleicht das bedeutendste» (p. 318), rappelant encore en note les avis concordants de Ziegler, Lacy et Klauck.

${ }^{6}$ Il conclut en tout cas en insistant sur une « tension » entre la philosophie et la «foi populaire».

${ }^{7}$ La distinction entre philosophes et non-philosophes apparaît dès la note 2 (p. 323): «By a non-philosophical audience we mean an audience which does not consist of what might be termed "professional" philosophers. Such philosophers are, for instance, to be found in De Eapud Delphos (e.g Ammonius and Lamprias)» et il renvoie, pour les dramatis personae, à Y. Vernière (CUF, t. VII-2, 1974). Je comprends mal ce qui est désigné ici par «audience»: les lecteurs ou les dramatis personae? L'exemple d'Ammonius et de Lamprias semble aller dans le second sens, mais en quoi Lamprias est-il plus philosophe que Plutarque, protagoniste du De sera ? En outre, comme le signale Y. Vernière, Patrocléas et Timon étaient aussi les interlocuteurs d'un Sur l'âme, dont nous n'avons plus que des fragments (177-178 Sandbach), mais qui traitait du sujet éminemment philosophique de l'immortalité de l'âme, preuve que la philosophie devait les intéresser. Enfin, n'est-ce pas du sujet et du genre que l'on peut tirer des conclusions plutôt que des personnages?

${ }^{8} \mathrm{Il}$ est cité aux notes 13 («For an analysis of Plutarch's arguments, $c f$. SAUnders (1993)»), 14, $15,16,18,22$ («For a criticism of the argument»), 24, 25 («Also SAUNDERs has difficulties with his argument») -l'article comporte au total 28 notes.

${ }^{9}$ Ce qui nest pas le cas de C. Helmig : historien de la philosophie, il marque bien la différence d'orientation de leurs études dès la première note où est cité T. J. Saunders (n.13, p. 326-327), mais la conclusion qu'il en tire (voir note 10, infra) ne l'amène pas du tout à remettre en cause les remarques de Saunders sur la structure ni ses critiques. On est ainsi fort étonné de lire un peu plus loin, sous la plume d'un spécialiste de philosophie, que «It is ...not clear why a concealment of a crime in our world can say something about the severity of the criminal's vice» (p. 330); il me semblait pourtant que la référence au Gorgias était aussi évidente qu'éclairante. 
peines humaines à établir ici-bas ${ }^{10}$, alors que toute la réflexion est menée, autant que faire se peut pour un esprit humain, dans la perspective de la Providence. Il ne remet cependant pas en cause l'analyse de l'argumentation très générale donnée par T.J. Saunders, ne cherche pas une cohérence de la démarche, que celui-ci n'avait pas de raison d'étudier, et donne même l'impression d'y avoir renoncé d'emblée, influencé sans doute par la piètre estime dans laquelle il semble tenir le public comme le genre du De sera ${ }^{11}$.

Peut-être l'analyse, précise, qu'a donnée H. Görgemanns ${ }^{12}$, l'auraitelle amené à prendre plus au sérieux la réflexion de Plutarque, mais elle n'a été publiée qu'après le congrès de Barcelone. Le mouvement du texte y est fermement dessiné ${ }^{13}$; seul un point, mineur dans l'exposé du savant allemand, mais essentiel pour le sujet qui est celui du présent recueil, me semble devoir être écarté. Il reprend en effet, en l'estimant « possible », l'hypothèse soutenue il y a plus d'un demi-siècle par Ph. de Lacy, selon laquelle l'attaque contre

${ }^{10}$ T.J. Saunders, 1993,73: «Consequently, I suggest, when Plutarch discusses the justification and purposes of divine punishments he is in effect discussing the justification and purposes of buman punishments. For divine punishments are not a separate set, distinct from those of ordinary life.» Sans dire nettement que cette affirmation est totalement fausse, C. Helmig (n. 13, p. 327) relève néanmoins qu'elle n'est pas tenable et que Saunders lui-même est obligé d'en convenir à plusieurs reprises.

${ }^{11}$ Sa conception du dialogue semble devoir être trouvée dans la conclusion de la note 13 (p. 327): «Contrary to SAUnders, it is our concern to show that due to the character of the dialogue most of Plutarch's arguments should be taken with a pinch of salt. They are employed for the sake of the argument and do not represent the philosophical tenets of the author». C'est moi qui souligne le point qui me semble le plus contestable: le sujet n'est pas de ceux qu'un Plutarque traiterait cum grano salis et un tel parti-pris traduit une double méconnaissance, et des techniques de la polémique (laquelle accepte provisoirement la position de l'adversaire pour mieux la réfuter et en souligner les absurdités) et de la cohérence des dialogues de Plutarque. Dans les deux cas, la lecture de D. BABut 1992 et 1998 (savant totalement absent de la bibliographie de C. Helmig) me paraît un préalable nécessaire à toute réflexion sur la composition d'un dialogue de Plutarque.

12 H. Görgemanns, 2003, 329-330. Il y a aussi, dans le cadre de l'édition intégrale des Obras morales y de costumbres, aujourd'hui achevée, une traduction récente en espagnol, par R. Ma Aguilar (De la tardanza de la divinidad en castigar, t. VIII, Madrid, 1996), mais le principe de l'édition est de privilégier le texte et de s'en tenir à des introductions très brèves. Le texte est encore à paraître dans le CPM italien. L'introduction de la CUF (t. VII-2, Paris, 1974), par Y. VERnière, traite de «la doctrine» (pp. 102-118) et réduit la construction du texte à une " mise en œuvre », qui se subdivise en «art du dialogue» (118-122) et " poésie du mythe » (122-124): les intertitres mêmes témoignent d'une tendance regrettable à séparer forme et fond; or, plus qu'ailleurs encore, ils sont étroitement solidaires dans un dialogue philosophique où le mouvement du texte est aussi mouvement de la pensée, effort en commun pour réfléchir à une question philosophique.

${ }^{13}$ On trouvera en appendice un tableau succinct, qui ne diffère de la Gliederung du Pr Görgemanns que par un effort pour définir non seulement le contenu des passages, mais aussi leur fonction: par exemple, les chapitres 5-8 et 9-11 sont chez lui simplement numérotés «Der erste Argumentationsstrang: Sinn der Strafverzögerung», puis «Der zweite Argumentationsstrang: Das sich selbst betrafene Böse...", là où j'essaie de préciser un rapport ("Discussion de la thèse... ", puis "Correction de la thèse ») -voir aussi, ch. 8, "redéfinition » ou encore ch. 11, «conséquences paradoxales». 
les Épicuriens masquerait en réalité une critique dirigée contre l'Académie ${ }^{14}$ : or toute la recherche récente a à la fois réfuté le prétendu " athéisme " de l'Académie ${ }^{15}$ et insisté sur la continuité dans la pensée de Plutarque entre Platon et l'Académie. L'introduction " polyphonique » de ce dialogue en est la parfaite illustration: tout en se mettant sous l'égide de l'eulabeia académique, Plutarque y pose très nettement l'opposition majeure entre la Tychè épicurienne et la Providence platonicienne.

Or, en affirmant ainsi le rôle de la Providence, le danger de n'y plus croire, et en sopposant à la conception d'un monde sans orientation théologique, livré à la Tychè, la réflexion du De sera se meut dans le même orbe que les Dialogues Pythiques, où s'articulent étroitement aussi « divination, providence et causalité16 »: alors que le De defectu est a priori le moins " religieux » des Dialogues Pythiques ${ }^{17}$, il présente de nombreux points de contact avec le De sera, dont je voudrais montrer qu'il a toute sa place parmi les Dialogues Pythiques. Simplement, là où le De defectu ou le De Pythiae se concentrent sur les oracles et la communication entre hommes et dieux, le De sera développe une réflexion morale, une théodicée qui lie Providence et Justice. Le bonheur des méchants était certes un thème apologétique bien établi dans les discussions de l'époque, mais il était souvent associé au terme complémentaire du malheur des Sages ${ }^{18}$; il est surtout présenté ici dans une optique très platonicienne. Pour le dire plus précisément encore, Plutarque met ses pas dans ceux de Platon pour composer une actualisation et une réécriture du livre $\mathrm{X}$ de la République ${ }^{19}$, enrichi en particulier des réflexions du Gorgias sur le malheur du coupable et les stigmates gardés par son âme, mais aussi de la lecture des Lois, en particulier du livre X contre les athées, sans parler du Timée, pourvoyeur d'un cadre cosmologique qui n'est pas des plus courants sur cette thématique. Une comparaison, ponctuelle et rapide, avec les Dix Problèmes concernant la Providence de Proclus, dont les Problèmes VIII et IX reprennent les deux thèmes et en grande partie les réponses de Plutarque ${ }^{20}$, permettra de mettre en lumière la spécificité de

${ }^{14}$ P. H. DE LAcY, «Plutarch and the Academic sceptics», Cl. J. 49 (1953/ 1954) 79-85, en part. 84, cité par H. Görgemanns, 2003, p. 321, n. 14.

${ }^{15}$ Voir, entre autres, J. Opsomer, In Search of the Truth, Brussel, 1998, cité aussi par C. Helmig (p. 324, n. 7), qui n'a, pour sa part, pas de doute sur le caractère anti-épicurien du texte, mais absent de la bibliographie de H. Görgemanns. On peut ajouter, du même auteur, «Divination and Academic "Scepticism" according to Plutarch», in L. van der Stockt (ed.), Plutarchea Lovaniensia, Louvain, 1996, 165-194.

${ }^{16}$ C'est le premier point traité par F. IldDefonse, 2006, 10-15 - le point suivant a pour intertitre «Hasard vs Providence», 15-17.

${ }^{17}$ Mais celui où l'esprit de l'Académie est le plus affirmé : en témoigne la seule conclusion, qui invite, par la voix de Lamprias, à « examiner ces sujets souvent, parce qu'ils contiennent de nombreux points controversés et des conjectures opposées, que la circonstance ne nous permet pas de passer tous en revue " (438 D, trad. F. Ildefonse).

${ }^{18}$ On trouve les deux dans le De Providentia de Philon comme dans le De Natura Deorum de Cicéron ; il est vrai que Sénèque, au rebours de Plutarque, ne retient dans son propre $D e$ Providentia qu'un des deux thèmes, celui du (prétendu) malheur du Sage.

${ }^{19}$ Voir sur ce point les suggestions de J. Sirinelli, 2000, 406-410.

${ }^{20}$ Ces questions ne sont conservées que dans la traduction latine du XIII ${ }^{\mathrm{e}}$ s. de G. 
la démarche dialogique ${ }^{21}$ et l'inflexion delphique de la réflexion. Car, dans ce cadre, philosophie et religion s'épaulent et se soutiennent mutuellement: ainsi, après avoir souligné l'orientation anti-épicurienne, clairement dessinée d'entrée, et avoir analysé de près le préambule, $\mathrm{j}$ 'indiquerai plus rapidement les grandes lignes du développement en relevant toujours les notes anti-épicuriennes et j'insisterai sur l'arrière-plan religieux et delphique qui s'épanouit, d'une certaine façon, dans le mythe final.

\section{Une perspective anti-épicurienne}

(1) tychè et pronoia dans le préambule polyphonique (ch. 1-4)

Le dialogue commence sur un départ, celui d'«Épicure», selon la tradition manuscrite, ou de "l'Épicurien ", selon la correction proposée dès longtemps par Fabricius: le problème est ici inessentiel, puisque, quelle que soit la solution retenue, la dénomination du personnage signale de toute façon son appartenance philosophique, tout en lui refusant la parole. Ce départ évoque à n'en pas douter - et la chose a déjà été maintes fois soulignée - le départ de Planétiade le Cynique dans le De defectu ou encore, si l'on remonte au modèle platonicien, celui de Thrasymaque dans la République. Mais alors que l'un comme l'autre se sont exprimés, et que le Cynique a permis de rappeler d'emblée les attributs divins essentiels, la bonté, pour Lamprias ${ }^{22}$, et la puissance, pour Ammonios ${ }^{23}$, ici on ne l'entend pas et c'est entre eux que les amis vont définir le sujet, après un premier temps de silence et de stupéfaction. Cette indication de mise en scène, remarquable, car il ne va pas de soi de commencer sur un silence et une sortie, souligne le retentissement «affectif» de ces attaques, les problèmes existentiels qu'elles soulèvent. Ainsi, par opposition à un «Problème » philosophique, le dialogue pose tout autre chose qu'une question purement théorique relevant du savoir et il revient à Plutarque de le préciser. Voici sa question:

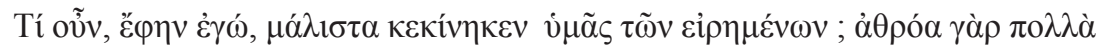

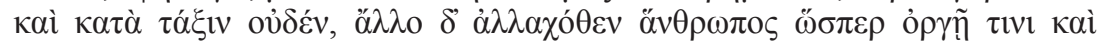

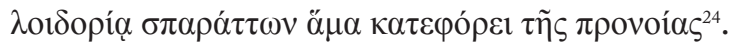

de Moerbeke ; on dispose toutefois d'un abrégé en grec d'Isaac Comnène. Je me réserve d'approfondir la comparaison ailleurs.

${ }^{21}$ Dont on n'a compris que la labelliser comme « destinée à des non-philosophes » ne me paraît ni satisfaisant ni même utile à une meilleure compréhension du texte.

${ }^{22} 413 \mathrm{C}$, où l'on retrouve notre Providence, présentée comme «une mère bienveillante et dévouée, qui produit et conserve tout pour nous».

${ }^{23} 413$ D-E: «Prends garde à ce que nous faisons, Lamprias, et fais attention à ce que nous disons, de peur d'enlever toute responsabilité au dieu... Il n'existe en effet aucune puissance, plus grande et plus forte, qui soit en mesure de détruire et de supprimer la divination, qui est l'œuvre d'un dieu.»

${ }^{24}$ 1, 548 C4-8: "Quel est donc, dis-je, celui de ses propos qui vous a le plus émus? Car enfin il charriait en bloc et sans aucun ordre une foule d'arguments puisés à droite et à gauche, dans une sorte de débordement convulsif de colère et d'injures contre la Providence » (toutes les traductions du De sera sont miennes). 


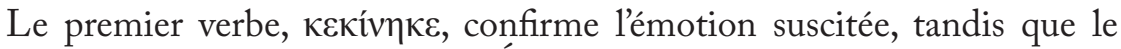
dernier définit clairement la cible de l'Épicurien: la Providence. Mais l'attaquant lui-même devient cible et le «résumé» qui est donné de ses propos tient de la

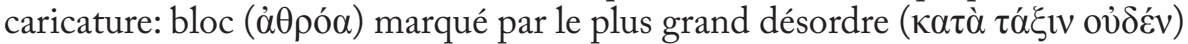

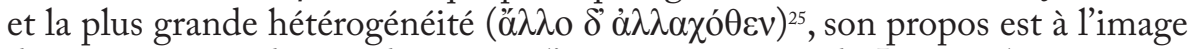
de sa conception du monde, comme l'est aussi son attitude. Là aussi le sentiment se glisse, et sa haine convulsive lui inspire un comportement aux antipodes de l'ataraxie chère au Jardin. L'Épicurien en énergumène vociférant à l'instar du Cynique du De defectu: on a ici à l'œuvre, mais sur le mode descriptif, la mise en contradiction qui est une des armes majeures de la polémique philosophique.

Le sujet demandé va être défini en deux temps par Patrocléas et Olympichos - Timon intervient ensuite pour annoncer un autre point, «troisième vague» qui mettra le comble à leur perplexité, mais ce n'est qu'un jalon pour la suite et rien n'est encore précisé (4, 549 D11-E2). Le premier choisit un thème lié à la justice, dont les retards sont, du côté de la divinité, signe de "nonchalance», cette $\dot{\rho} \alpha \theta 0 \mu$ í $\alpha$ qui, d'après les Lois (X 901e4-6), ne saurait appartenir aux dieux, tandis que, du côté humain, une telle justice perd toute utilité, pour la victime comme pour le coupable. Patrocléas se situe ainsi au plus près de la faute, dans une optique d'utilité immédiate, et encadre son intervention par deux références euripidéennes. Il cite d'abord un vers de l'Oreste (420), qui met l'atermoiement dans la nature divine, et finit sur un plus long fragment de quatre vers (979 Kannicht), où il dénonce la «bizarrerie» d'Euripide ${ }^{26}$ :

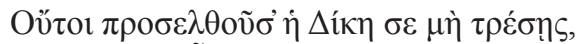

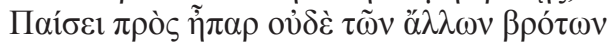

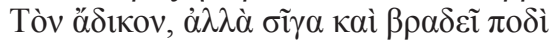

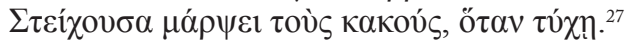

L'étonnement « moderne » pour ce qui, à l'époque archaïque, aurait été consolation, certitude que la Justice, tôt ou tard, serait rétablie, n'a rien que d'attendu: l'essentiel réside dans le syntagme final, hellénisme courant aussi ${ }^{28}$, mais qui fait affleurer la notion de tychè, une "coïncidence ", un impact dans un point quelconque du temps, qui devient ici antonyme implicite de la Providence.

${ }^{25}$ C'est ce qui a dû inspirer le titre de C. Helmig, 2003, «A Jumble of Disordered Remarks?», mais la chose ne vaut que pour l'adversaire.

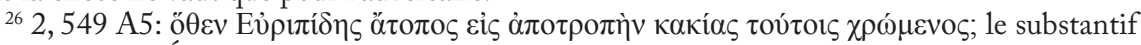
définissait déjà l'Épicurien (1, 548 B3; voir aussi C2); on le retrouve au début de l'intervention d'Olympichos $(3,549$ B8) et encore au commencement de la seconde partie, pour qualifier les exemples de Timon (13, $557 \mathrm{C} 8)$.

${ }^{27}$ 2, 549 A7-10: «Justice ne viendra pas vers toi —ne tremble pas—/ Pour te frapper au foie, ni vers aucun des autres / Injustes: en silence, à pas lents, elle avance / et prendra les méchants quand cela se trouvera.»

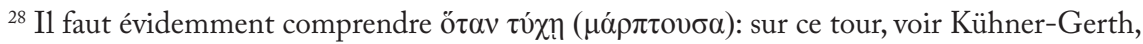
II $§ 284$ (t. 2, p. 67, Anmerk.). 
C'est bien sur ce point que rebondit Olympichos, auquel il appartient de donner à ce reproche toute sa portée et de mettre en lumière une « bizarrerie » de bien plus de conséquence:

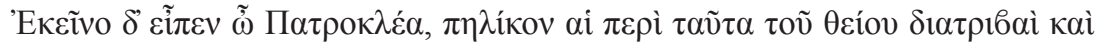

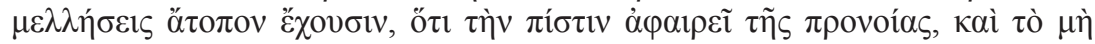

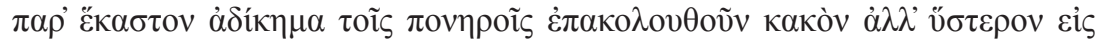

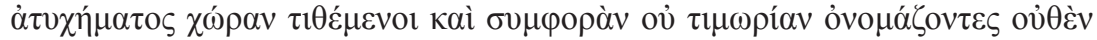
$\dot{\omega} \varphi \varepsilon \lambda \sigma \tilde{v} v \tau \alpha .^{29}$

La conséquence aussi grave quétrange, c'est la disparition de la confiance en la Providence: le danger est envisagé du point de vue humain. Il rappelle le reproche récurrent formulé dans les dialogues de Plutarque contre tout ce qui détourne la pensée du divin: c'est ce que peuvent faire les critiques contre la forme des oracles selon Théon ${ }^{30}$, la divinisation $\mathrm{du}$ soleil ${ }^{31}$, ou encore la théorie du pneuma soutenue par Lamprias ${ }^{32}$. La deuxième partie de la phrase se concentre sur les méchants et, reprenant l'immédiateté revendiquée par Patrocléas, montre comment le châtiment, coupé de la faute par un trop grand laps de temps, apparaît désormais comme un simple atychèma, privé de sens. Derechef, le mot choisi n'est pas innocent et s'inscrit toujours dans la même série ${ }^{33}$, si bien qu'Olympichos peut passer, de cet aveuglement initial du coupable, à une réinterprétation plus large de la Justice lente d'Euripide:

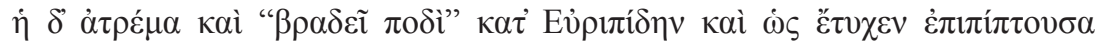

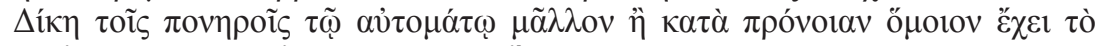

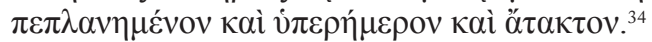

29 3, 549 B7-C3: «Et l'importante conséquence, Patrocléas, qu'impliquent délais et atermoiements du divin en cette matière, tout à fait étrange, c'est que cette lenteur détruit la confiance en la Providence et que, comme le malheur, au lieu de frapper les méchants après chaque faute, ne survient que plus tard, ils n'y voient qu'infortune, et, le nommant malheur au lieu de châtiment, ils n'en tirent aucun profit. »

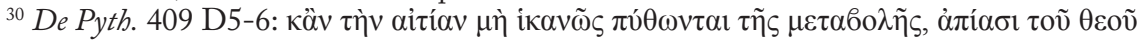

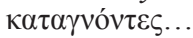

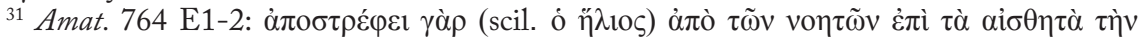

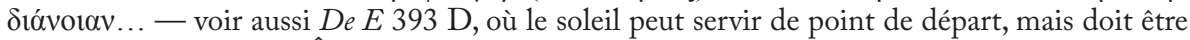
dépassé pour aller vers l'Être.

32 De def. $435 \mathrm{~A}$, où Ammonios laisse de côté la question de l'assimilation du Soleil et d'Apollon et entame l'exposé de ses craintes devant la manière dont leur discussion dépossède

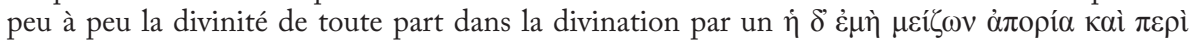
$\mu \varepsilon i \zeta o ́ v \omega v$, qui n'est pas sans évoquer la « grande conséquence » d'Olympichos.

${ }_{33}$ Pour comparaison, Proclus emploie ici un synonyme, symptomata (Decem dub. 49; voir aussi infra, n. 35) que G. de Moerbeke se contente de translittérer; le sens est le même, mais la récurrence du thème et la perspective anti-épicurienne (qu'ignore en effet Proclus) s'effacent.

${ }_{34}^{34}$ 3, 549 D3-6: «Mais la Justice qui, tranquillement, vient s'abattre sur les méchants “ à pas lents", comme dit Euripide, et " quand cela se trouve", a un caractère erratique, tardif et désordonné qui ressemble plus au hasard qu’à la Providence. » 
Ce triple caractère " erratique », comme le sensible dans lequel s'enfonce l'âme trop attachée au sensible du Phédon, "tardif » et « désordonné ", point ultime qui était aussi la caractéristique initiale des propos de l'Épicurien, image sensible de sa pensée, est cette fois rattaché au grand principe de l'automaton dont l'opposition avec la pronoia est aussi à l'œuvre dans les Dialogues Pythiques.

C'est bien en effet la même perspective que l'on trouve dans le De Pythiae (ch. 8-9), lorsque s'affrontent Boéthos l'Épicurien et Philinos le narrateur à propos de prodiges comme la chute de la colonne d'Hiéron le jour de sa mort. Là où le second voit un signe prémonitoire, le seul " démiurge » qu'avance ironiquement le premier est la tychè et l'automaton ${ }^{35}$. Plus éclairant encore est le grand développement sur la pluralité des mondes du De defectu: Cléombrote, avec une prudence tout académicienne, a souligné d'abord « que rien ne contredit et n'empêche d'être ainsi ${ }^{36}$ » la thèse qu'il propose —que les démons interviennent dans le fonctionnement des oracles. Il poursuit en la confrontant aux objections possibles des autres Écoles: les Stoïciens nont pas une doctrine différente sur les démons ; quant aux Épicuriens, leurs objections ne sont pas pertinentes:

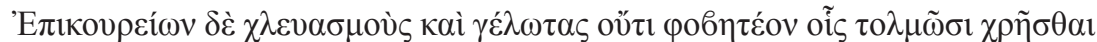

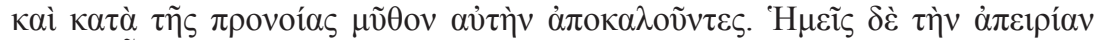

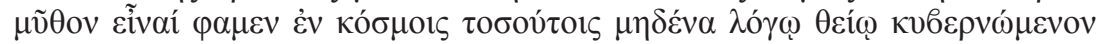

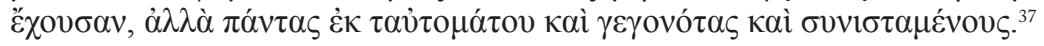

À côté du «hasard», s'introduit cette autre notion majeure, et essentielle dans la réflexion sur la pluralité des mondes, qu'est l'apeiria, illimitation inacceptable pour Plutarque. Ce préambule, on le voit, prépare une réflexion cosmologique plus large. C'est aussi un cadre cosmologique que va dessiner Plutarque, lorsqu'il entreprend de répondre à la question dans notre dialogue.

Avant de regarder de plus près le texte et la conception du monde qui rend inadmissible la remise en cause de la Providence, il faut souligner, à côté des ressemblances de fond et d'un commun rapprochement avec le Timée ${ }^{38}$, deux différences révélatrices avec le De defectu: d'abord, au lieu de se situer au

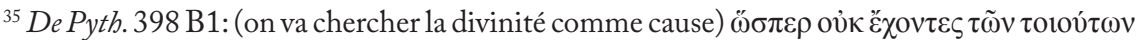

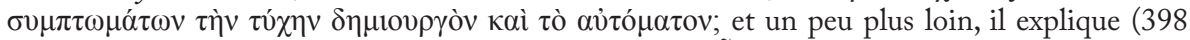

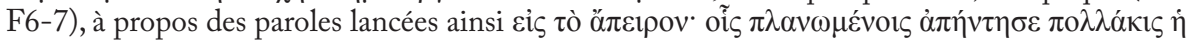

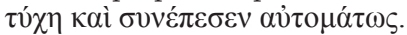

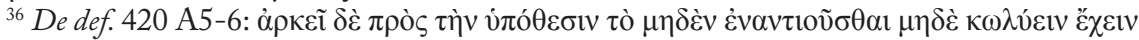
ov๊ $\omega \tau \tau \alpha \tilde{\tau} \tau \alpha$. Le commentaire d'Ammonios, au chapitre suivant (20, $420 \mathrm{C}$ ), va dans le même sens et admet une opinion " respectable et hautement philosophique», qui «n'entraîne aucune conséquence qui soit impossible ou inconsistante».

${ }^{37}$ De def. 420 B1-6: "Quant aux Épicuriens, il ne faut pas avoir peur de leurs rires et de leurs sarcasmes, qu'ils ont l'audace de diriger même contre la Providence, en la traitant de fable. $\mathrm{Au}$ contraire, selon nous, ce qui est une fable, c'est leur «infinité» qui, parmi un si grand nombre de mondes, n'en comporte aucun qui soit gouverné par une raison divine, tous ne tenant que du hasard leur origine et leur persistance. » (trad. R. Flacelière; F. Ildefonse préfère rendre ả $\pi \varepsilon \imath \iota^{\prime} \alpha v$ par «illimitation», que je lui emprunte ici).

${ }^{38}$ Les deux passages peuvent apparaître comme une sorte de commentaire de la constitution du monde selon le Timée. 
cœur du texte ${ }^{39}$, cet exposé cosmologique intervient dès le début, il est comme le postulat de départ de toute la discussion; ensuite et surtout, il adopte ainsi le point de vue de la divinité, même s'il a d'entrée souligné le gouffre qui sépare notre faiblesse humaine de la connaissance de Dieu, seul capable de discerner le kairos (4, 549 F). Son exposé commence ensuite, sous l'égide de Platon, en rappelant que, selon lui, « Dieu, en se présentant à tous comme le paradigme de tous les biens, met la vertu humaine, qui est en quelque sorte une assimilation à lui-même, à la portée des êtres capables de “suivre Dieu” ». La suite se déploie en une vaste évocation de la mise en ordre du cosmos:

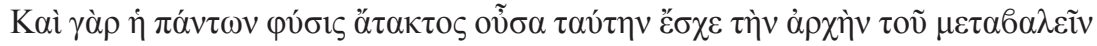

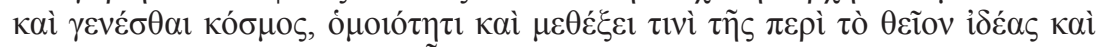

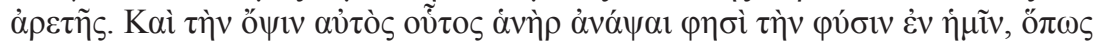

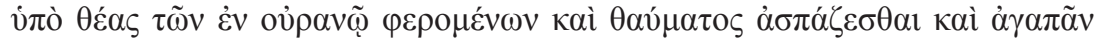

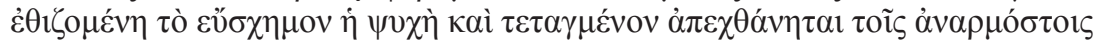

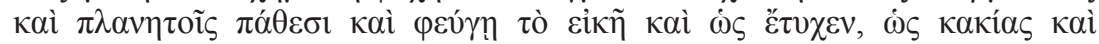

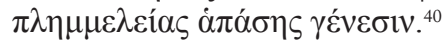

On trouve d'abord évoqué le désordre premier de la matière et sa mise en ordre, objet important de son commentaire de la Procréation de l'âme dans le Timée ${ }^{41}$. Il poursuit, en adaptant toujours le Timée, et en transférant ce qui y est dit des lumières allumées des astres à la vue, «allumée» aussi, et moyen d'accéder, par l'admiration, au goût de l'ordre. L'effet du spectacle du ciel concorde parfaitement avec ce que dit Platon, en particulier dans le Timée $e^{42}$ :

Ayant contemplé les mouvements périodiques de l'intelligence dans le ciel, nous les utiliserons en les transportant aux mouvements de notre propre pensée, lesquels sont de même nature, mais troublés ( $\tau \varepsilon \tau \alpha \rho \alpha \gamma \mu \varepsilon ́ v \alpha \varsigma)$, alors que

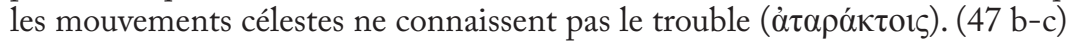

Ici il s'agit moins de régler la pensée que, selon la perspective éthique qui prévaut dans notre dialogue, d'évacuer le trouble, d'adopter « bonne tenue » et

${ }^{39}$ Où il prévient aussi, selon D. BABUt, 1992 (224-229), toute confusion entre les (pro) positions de Cléombrote et de Lamprias et les conceptions stoïciennes.

${ }^{40}$ 5, 550 D4-E2: «En effet, la nature universelle qui ignorait tout ordre, a trouvé le principe de sa métamorphose en monde organisé (cosmos) dans une certaine ressemblance et participation à la forme et à la vertu divines. C'est encore cet auteur qui affirme que la nature a allumé la lumière de la vue afin que notre âme, par la contemplation émerveillée des astres qui cheminent dans le ciel, s'accoutume à aimer et chercher l'ordre et l'harmonie, à prendre en horreur les passions livrées à l'errance et la dysharmonie et à fuir le “ à l'aventure " et "comme cela se trouve", en tant qu'origine de tout mal et de toute discordance.»

${ }^{41}$ Voir De procr. animi 1015 D sqq et l'étude de J. Opsomer, «Plutarch's De animae procreatione in Timeo: Manipulation or Search for consistency?», in P. Adamson et Alii (edd.), Philosophy, Science and Exegesis in Greek, Arabic and Latin Commentaries, BICS. Suppl. 83, 1, London 2004,137-162.

${ }^{42}$ On retrouve un même rôle de l'harmonie céleste dans la République (VI 500 b-c, pour le philosophe, qui « contemple les objets qui sont tous sous la loi de l'ordre et de la raison ») et dans les Lois (X 887 e, pour le soleil et la lune); j'ai retenu le Timée en raison de l'accent qui y est mis sur le trouble - auquel il s'agit de substituer une ataraxie qui n'est pas épicurienne. 
« bon ordre ", ou, si on le reformule en termes négatifs, en un ultime avatar de la citation euripidéenne, de fuir, non pas ce monde, comme dans le Théétète, mais, à l'intérieur de ce monde, tout principe mauvais de désordre, exprimé par la simple substantification, d'un adverbe d'abord, puis du syntagme même d'Euripide, où la notation temporelle ö $\tau \alpha \nu$ est seulement remplacée par l'intemporel $\dot{\omega} \varsigma^{43}$.

Qu'il s'agisse ici de « fuir le désordre » ou, au début du texte, de la manière dont Dieu se donne pour modèle à la vertu humaine, « qui est assimilation à lui-même ", c'est bien toujours le Théétète qui est en filigrane, mais l'inversion de la perspective, qui substitue à l'injonction du philosophe à "se rendre semblable au dieu, autant qu'il est possible » la présentation par la divinité de la vertu comme assimilation à elle-même, est révélatrice de la perspective transcendante esquissée ici, ou, pour le dire en d'autres termes, elle s'accorde bien avec le souci primordial de la cause finale $e^{44}$, exprimé déjà, avant le passage que nous venons de commenter, dans la conclusion méthodologique du chapitre 4:

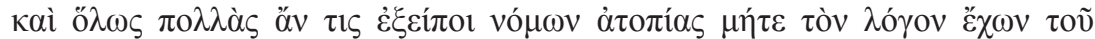

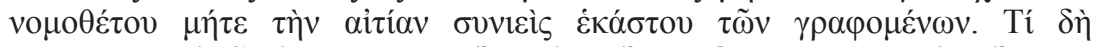

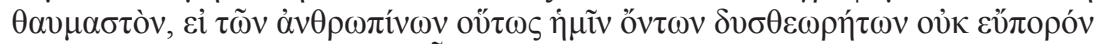

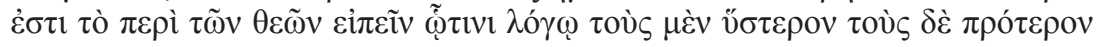

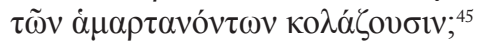

Le logos, qui encadre cette question ultime de l'introduction, c'est ici le logos divin, la cause finale, celle qui donne sens aux événements.

Derechef se dessine une certaine complémentarité avec le De defectu, où les hypothèses de Cléombrote et de Lamprias se concentrent sur le fonctionnement de l'oracle - si l'on veut bien considérer que les daimones ne sont pas la cause divine ${ }^{46}$, mais servent de relais à une causalité divine plus haute, qui a aussi été rapidement évoquée au début, dans deux sens opposés, par le Cynique d'abord, selon lequel la divinité s'est détournée avec horreur de notre monde de perdition, par Ammonios, ensuite et surtout, qui, au contraire, voit dans ces disparitions un signe de la bonté divine: elle n'a pas voulu accuser la désertification de la Grèce en conservant des oracles inemployés. C'est

${ }^{43}$ Alors que pour Proclus (52), la seule véritable guérison est l'apallagè, qui «apporte avec elle la purification du mal véritable et de la maladie véritablement redoutable»-c'est-à-dire l'incarnation de l'âme: c'est l'invitation du Théétète reformulée avec le vocabulaire du Phédon.

${ }^{44}$ Voir F. Frazier, 2005, 116-118.

45 550 C5-8: "D’une manière générale, on pourrait citer mainte étrangeté dans les lois, pour peu qu'on n'ait pas les raisons du législateur et qu'on ne comprenne pas la cause de chaque prescription. Comment alors sétonner, quand il est si difficile de pénétrer les affaires humaines, qu'il ne soit guère aisé de se prononcer pour les dieux et de dire pour quelle raison ils punissent certains coupables plus tard et d'autres plus tôt?"

${ }^{46}$ Je diffère sur ce point de l'avis de D. Babut, 1992, 223, que semble suivre F. Ilddefonse, 2006, 53: il ne s'ensuit pas de la nature divine des daimones qu'ils représentent la cause divine, entendue comme cause finale. Conformément à la conception platonicienne de ces êtres intermédiaires, du metaxu, ils assurent une fonction médiatrice. 
bien dans ces deux interventions qu'il faut chercher la cause finale, le sens de l'événement. Mais, si elle est abordée en introduction ${ }^{47}$, elle n'est pas l'objet propre de la recherche, qui se focalise sur le fonctionnement. Inversement ici la réalisation terrestre du châtiment n'est pas le sujet du De sera, attaché à la cause finale, au règne de la justice dans l'univers, ce qui suppose d'adopter le point de vue divin, radicalement différent du point de vue humain, tout en ayant conscience que l'homme ne peut entièrement le pénétrer ${ }^{48}$.

Se dessine ainsi, au seuil de la réflexion, ce «climat de recherche pieuse» dont parle Jan Opsomer à propos du De Epsilon, où il revient à Ammonios de le définiri ${ }^{49}$. Le rôle est ici repris par Plutarque, qui tire ainsi les conclusions de la question précédemment citée:

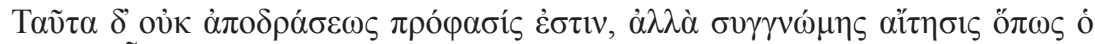

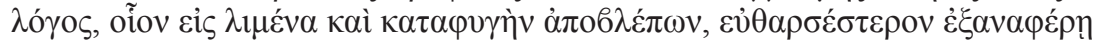

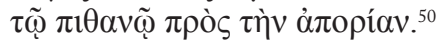

C'est la fin du préambule méthodologique qui s'était ouvert sur l'invitation à " prendre pour point de départ le foyer de nos pères, je veux dire cette circonspection face au divin des philosophes de l'Académie, pour se garder pieusement de dire quoi que soit sur ce sujet comme des gens qui savent ${ }^{51}$ ». Et de fait, toute la suite sera marquée par l'usage de la vraisemblance, de l'analogie, du raisonnement $a$ fortiori, de la mise en contradiction de l'adversaire soutenue par un emploi massif de parataxes mettant en relief l'incompatibilité logique de deux propositions. Surtout, cette même réserve prudente se retrouve exactement au moment où Timon intervient pour soulever le second point annoncé: c'est aussi le début de la seconde partie, celle qui, après l'individu, se consacre à la collectivité et qui confirme que la référence à l'Académie doit être prise au sérieux.

\section{(2) Le mouvement du texte et les «notes» anti-épicuriennes}

Lorsque Timon prend la parole, Plutarque a, dans un premier temps, réfuté l'idée soutenue par Patrocléas et Olympichos que le châtiment immédiat serait le plus utile, en proposant une redéfinition du « bon » châtiment, lié au kairos et non à l'intervalle temporel ${ }^{52}$ (ch. 5-8); puis, dans un second temps,

${ }^{47}$ Et reprise dans la mise en garde finale d'Ammonios: voir D. BAвUT, 1992, 221.

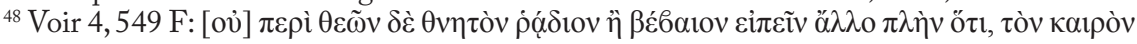

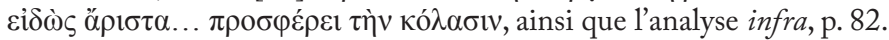

49 J. Opsomer, 2006, 155: «Tout l'entretien se place donc sous l'égide d'Ammonius. C'est dans l'espace défini par lui que se déroule la conversation, dans un esprit académicien de recherche pieuse, conduite collaborativement et caractérisée par la réserve et la modestie épistémologiques » (c'est moi qui souligne).

50 5, 550 C9-12: «Il ne s'agit pas là de chercher une échappatoire, mais de solliciter l'indulgence, pour que notre raisonnement, ayant en vue une sorte de havre où se réfugier, puisse s'appuyer sur le probable afin d'affronter plus hardiment cette embarrassante question.»

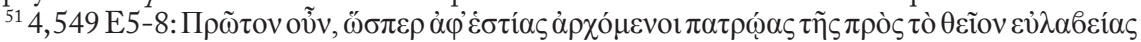

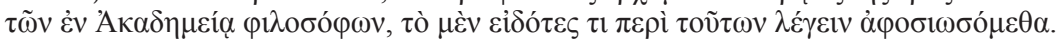

52 Toujours pour comparaison, Proclus, donnant l'explication " plus vraie que les autres » 
il a pris le contrepied de cette thèse - là encore le mouvement qui consiste à réfuter l'adversaire avant d'avancer sa propre conception s'inscrit parfaitement dans la pratique antique de la discussion philosophique - et il a insisté sur le châtiment intérieur et invisible du remords qui taraude aussitôt le coupable (ch. 9-11), lequel se retrouve en butte à toutes les deisidaimoiniai que les Épicuriens prétendent dissiper, craignant partout le châtiment. On aboutit ainsi à cette conclusion, plus ou moins dans l'esprit des paradoxes du Gorgias, que si l'âme est mortelle, alors le châtiment le plus rapide est aussi le plus doux (11. 555 D1-533. De nouveau l'hypothèse suggérée appartient aux Épicuriens, tout comme, à l'extrême limite, l'idée qu'il nest pas besoin de justicier divin - ni même humain, il est vrai - si chacun se consume ainsi de soi-même dans le

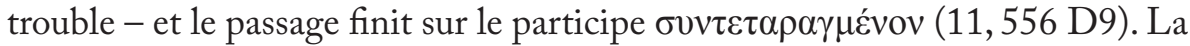
perspective individuelle ainsi épuisée, on peut passer au second temps.

Timon intervient donc (ch. 12) pour introduire ce qui a été présenté au chapitre 4 comme «la troisième vague», expression qu'emploie Platon ${ }^{54}$ pour désigner une objection plus grave. On n'a pas ainsi une simple juxtaposition du point de vue individuel et du point collectif - comme le fera Proclus en consacrant le Problème VIII au premier et le Problème IX au second ${ }^{55}$ - mais bien une progression: les dieux ne sont plus seulement «mous», mais franchement injustes, en rattrapant leur lenteur sur des descendants innocents (12, 556 E9-11). Et, à l'instar de l'Épicurien, Timon accumule les atopa, avant de poser

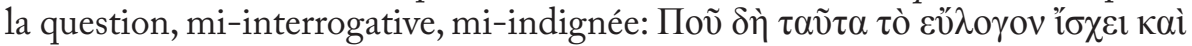

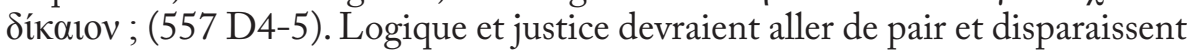
en fait de concert. Il revient donc à Plutarque, «craignant de le voir entamer

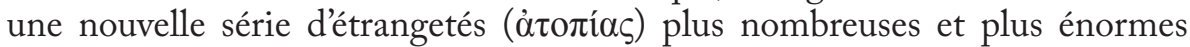
encore» $(13,557$ E7-8), de prendre au plus vite la parole et de «réduire» le problème: or, le «circonscrire», c'est encore une façon de se prémunir contre le désordre et l'illimitation agressifs, contre les «accusateurs trop âpres» de la Providence ${ }^{56}$, qui apparaissent en conclusion de son préambule, substituant à son frère la figure des Épicuriens.

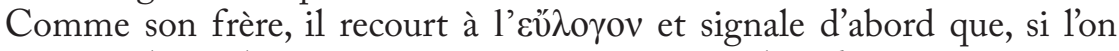
trouve normal que les récompenses se transmettent héréditairement, on ne

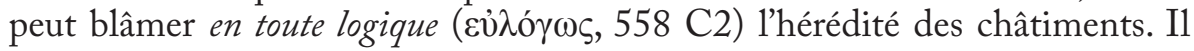

(52), redéfinit « ce que c'est, en fin de compte, que d'être justement puni et quel est le mal... », si bien que ce n'est pas le châtiment, mais le «vrai mal» qui devient son objet principal et que l'on quitte le bic et nunc terrestre (voir supra, n. 43).

${ }^{53}$ Le succès de la réfutation est discrètement marqué par le retour du même vocabulaire: Patrocléas avait dénoncé la $\rho a ̣ \theta v \mu i ́ \alpha$ des dieux (2, 548 D5); Plutarque souligne que ce sont les

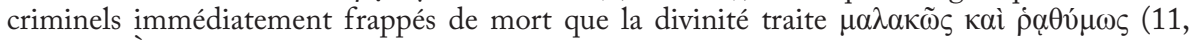
555 D4). À nouveau l'importance du vocabulaire et de sa récurrence est rendu sensible par les choix différents de Proclus, qui - si l'on s'en remet du moins aux extraits d'Isaac Sebastocrator -

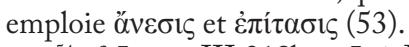

${ }^{54}$ cf. Lettre III $318 \mathrm{~b}$ et Lois I 674c.

55 Le second problème est simplement introduit comme «une autre anomalie qui apparaît dans les œuvres de la providence» (58).

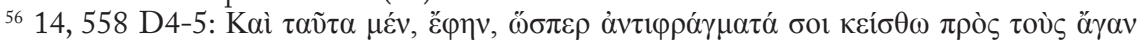

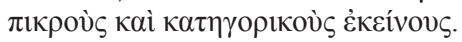


faut donc reprendre à nouveaux frais, mais toujours avec la même prudence, cette épineuse question:

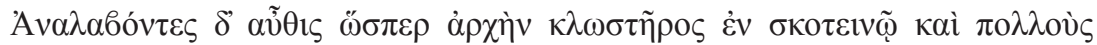

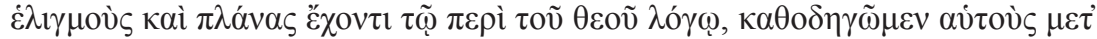

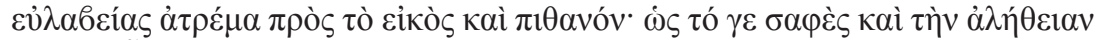

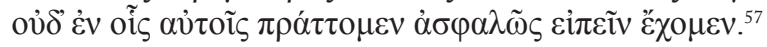

Dans ce recours au vraisemblable et à la circonspection, on retrouve, comme au chapitre 4, le même type de raisonnement: comme Plutarque avait invoqué alors l'obscurité de certaines lois humaines pour conclure à la difficulté supérieure de cerner les desseins divins, il évoque ici des pratiques qui nous restent obscures à nous-mêmes avant d'évoquer la sympathie dans le temps qu'il n'y a pas de raison de repousser alors que celle qui joue dans l'espace est bien établie.

Le raisonnement, le recours à l'analogie et à la vraisemblance continuent donc de prévaloir. Mais en même temps, la progression dans la gravité des griefs articulés contre la Providence s'accompagne d'un élargissement temporel, qui mène de la peine immédiate réclamée par Patrocléas aux châtiments dans l'Hadès racontés par quelqu'un dont la partie pensante est sortie du corps et de la temporalité bumaine On passe ainsi peu à peu du logos au mythos, passage clairement introduit comme tel par Plutarque, à l'instar de Socrate dans le Gorgias. Une nouvelle intervention d'Olympichos, comme la précédente, met en lumière la portée métaphysique de cette seconde discussion, en soulignant, comme dans le livre X de la République ${ }^{58}$, que le développement suppose l'immortalité de l'âme. Plutarque lui répond par l'affirmative ${ }^{59}$ et introduit en conclusion, non sans quelque réticence, le mythe:

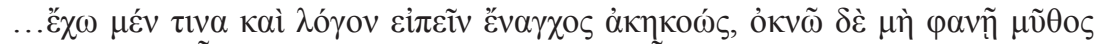

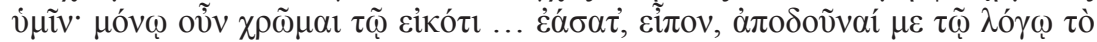

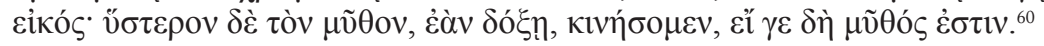

57 14, 558 D6-11: «Reprenant à présent, pour ainsi dire, le fil par son extrémité, dans le labyrinthe obscur, plein de détours et d'errances que constitue notre discussion sur Dieu, frayons-nous un chemin tranquillement et avec circonspection vers des conclusions vraisemblables et plausibles - attendu que l'évidence et la vérité, même dans nos propres actions, nous ne pouvons les dire avec certitude.»

${ }^{58}$ Rep. X 608 c-612 a et le commentaire de D. Babut, Parerga, Lyon, 1994, 242-243 («on ne peut donc parler de la sanction ultime de la justice sans évoquer la nature véritable de l'âme, définie par sa "parenté avec ce qui est divin et éternel" (611 e2-3) et sans rappeler par conséquent que cette âme est immortelle.»); voir aussi 259-263.

${ }^{59}$ Le passage sera analysé infra, dans la dernière partie.

${ }^{60}$ 18, 561 B6-8 et10-11 (entre les deux, Olympichos le prie de dire aussi le mythe): « ...j’ai, pour le montrer, un récit que j'ai entendu récemment, mais je crains qu'il ne vous fasse l'effet d'un mythe [à comparer à Gorg. 523 a1-3]. Je vais donc m’en tenir au vraisemblable » ... « Laissez-moi d'abord, dis-je, donner à mon raisonnement tout ce qu'autorise la vraisemblance. Ensuite, si vous voulez, nous mettrons en branle le mythe, si mythe il y a. » 
On ne peut manquer d'être frappé de l'accent qui continue d'être mis sur la vraisemblance.

Ainsi, dans la reprise qui suit, destinée à payer à l'eikos tout ce qui lui est dû, la même méthode est conservée et la réfutation est suivie d'une correction, plus rapide, mais néanmoins présente: la Divinité ne punit pas les descendants qui sont bons $\left(21,562\right.$ E9-563 A $\left.{ }^{61}\right)$. On retrouve, comme en ouverture, la connaissance de l'âme que seule a la Divinité et qui lui permet de prévenir l'éclosion du mal (ch. 20), comme argument ultime, et la même ironie qu'en première partie pour stigmatiser notre faiblesse outrecuidante: là où le chapitre 10 moquait ceux qui croient que le châtiment se confond avec le moment de l'exécution capitale et qu'on n'est pas puni tant qu'on n'a pas bu la ciguë, le chapitre 20 dénonce l'erreur qui nous fait croire que le criminel le devient à son premier forfait, « comme si l'on pensait que le dard vient au scorpion lorsqu'il pique, le venin aux vipères lorsqu'elles mordent » (562 C5-7). Prévaut toujours la même opposition entre la faiblesse humaine, enfoncée dans l'immédiateté et l'apparence, et l'omniscience divine, opposition majeure posée dès le préambule du chapitre 4, où Plutarque soulignait que "lorsqu'il s'agit des dieux, un mortel ne peut facilement et en toute sûreté dire autre chose que " c'est avec une parfaite connaissance du moment propice au traitement de la méchanceté que le dieu administre à chacun le remède du châtiment, pour lequel il n'y a pas de mesure de grandeur commune ni de temps valable dans tous les cas" » (549 F5-550 A2). Toute la discussion (le logos) sur le sujet est ainsi encadrée par cette clairvoyance de la Providence, garante de la justice. Il revient ensuite au mythe d'éclairer, partiellement, cet exercice de la justice, en rendant visible ce que les hommes ne peuvent voir ${ }^{62}$.

Olympichos en effet refuse de tenir Plutarque quitte et de «renoncer au mythe, comme si le développement rationnel suffisait à la démonstration ${ }^{63}$ ». Plutarque s'exécute donc et passe au mythos, non sans une dernière «pique» contre la vision épicurienne. Thespésios, le héros de l'aventure, est un de ces «méchants» qui devait avoir en lui des possibilités d'amendement visibles à la seule clairvoyance divine, puisque, à son réveil, il devint le plus juste de tous les Ciliciens: avant même de commencer, le récit confirme une des thèses majeures du dialogue, que les délais autorisent le changement possible de ceux dont les passions sont susceptibles d'«être fléchies et amenées au repentir» $(6,551$ C12-D1). Et l'occasion qui a permis aux amis de Plutarque, dont Protogène, de connaître l'expérience vécue par Thespésios, esquisse une dernière fois l'opposition entre mise en ordre divine et hasard épicurien. Ils ont interrogé le personnage «en se disant qu'une réforme ( $\delta 1 \alpha \kappa o ́ \sigma \mu \eta \sigma \imath v)$ si complète de son

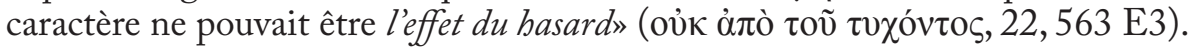

${ }^{61}$ Cette rectification est bien marquée par la reprise de la citation d'Euripide que Timon

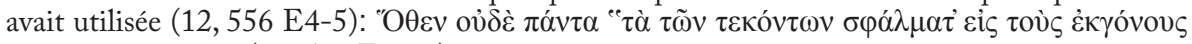

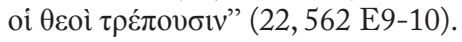

${ }^{62}$ Pour une étude détaillée de cette mise en évidence, de la qualité des âmes et de leur traitement, voir mon étude à paraître dans les Mélanges Brenk.

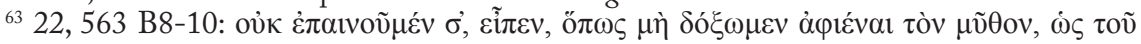

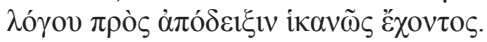


Rien en effet n'est « hasardeux » dans le spectacle de l'au-delà et chacun y reçoit le traitement (au double sens de châtiment et de médecine) qu'il a mérité.

\section{Philosophie et religion: un dialogue delphique}

Après le préambule, où l'émotion suscitée par l'Épicurien donnait déjà au problème un retentissement «existentiel», les premières " harmoniques " véritablement religieuses se sont fait entendre à l'occasion de l'intervention d'Olympichos sur l'immortalité de l'âme. Affirmant, comme Socrate en préambule au mythe d'Er, l'immortalité de l'âme qui fonde toute la discussion, depuis le début ${ }^{64}$, liée ici à l'existence de la Providence, Plutarque s'appuie sur la réalité religieuse, sur " notre Dieu ", mettant en avant, dans un passage célèbre, tant les hommages exigés pour les âmes défuntes que l'existence des oracles:

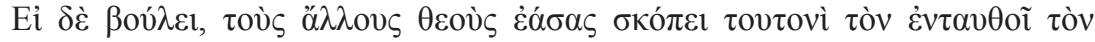

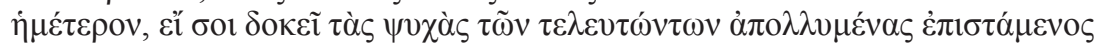

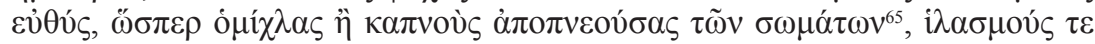

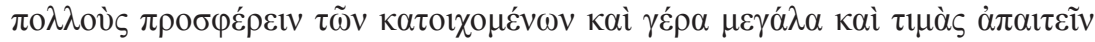

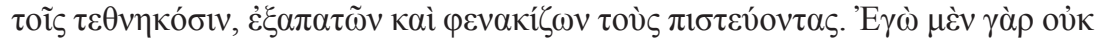

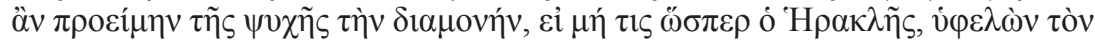

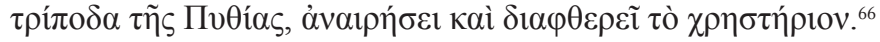

La ressemblance avec les objections qu'Ammonios oppose, dans le $D e$ defectu, à la théorie de Lamprias, susceptible de mettre en danger la causalité divine, ne peut manquer de frapper. Le maître de Plutarque non plus, n'est pas disposé à renoncer à attribuer l'origine et l'établissement de l'oracle à la Providence « quand il considère tous les bienfaits dont cet oracle a été cause pour les Grecs lors des guerres et des fondations de cités, lors des épidémies et des périodes de stérilité désastreuse ${ }^{67}{ }^{~}$. C'est un nouveau point de rencontre avec les Dialogues Pythiques et l'on voit que, dans le De sera aussi, les oracles sont invoqués et manifestent la sollicitude divine pour le monde humain.

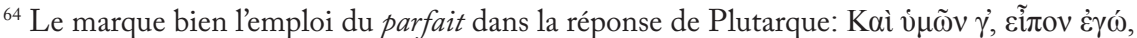

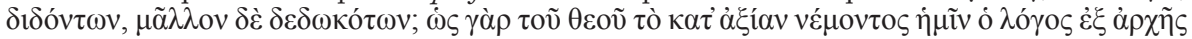
$\pi \rho \circ \varepsilon \lambda \dot{\eta} \lambda v \theta \varepsilon(17,560 \mathrm{~B} 2-4)$.

65 À comparer à Phaedo 70a.

${ }^{66}$ 17, 560 C8-D5: «Si tu veux, laisse de côté les autres dieux pour considérer celui d'ici, le nôtre: crois-tu que c'est en sachant que les âmes des morts périssent sur le champ, exhalées des corps comme une vapeur ou une fumée, qu'il prescrit tant de sacrifices expiatoires pour les défunts et réclame des présents et des marques d'honneur si considérables en faveur des morts, trompant et abusant ainsi ceux qui croient en lui? Pour moi, je ne saurais renoncer à la survivance de l'âme à moins que quelqu'un, à l'exemple d'Héraclès, n'enlève et n'emporte le trépied de la Pythie et ne détruise l'oracle.»

${ }^{67}$ Le texte reprend même l'opposition entre ordre providentiel et simple hasard. Voici le

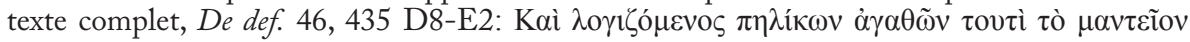

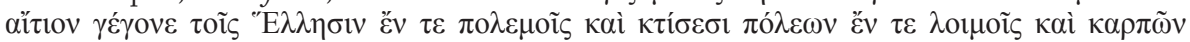

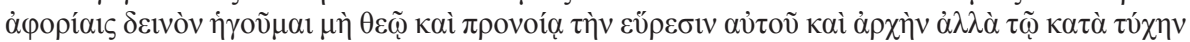

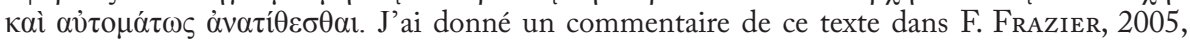
128-129. 
À ce point du texte, ils jouent un rôle argumentatif de première importance, mais ce n'est pas la première fois qu'apparaît la question de la communication entre hommes et dieux, du rapport au divin. Déjà dans le long développement sur les remords qui donne un contenu psychologique à la détérioration de l'âme soulignée dans le Gorgias, l'accent mis sur les deisidaimoniai reprend sans doute un thème cher aux Épicuriens, mais Plutarque ne s'en tient pas là et, après avoir montré comment l'audace criminelle, une fois retombée, se trouve en proie à toutes les terreurs et les deisidaimoniai, il continue:

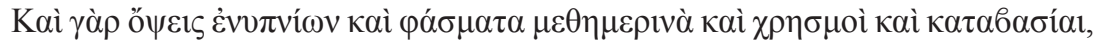

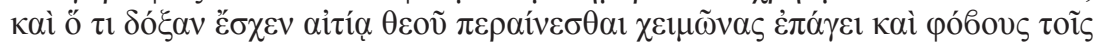

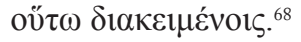

C'est ainsi toute la communication avec la divinité qui est atteinte. Aux antipodes de la situation privilégiée dont jouissent des Sages comme Socrate, dont l'âme pure est réceptive aux signes divins, les criminels ne voient plus que menaces dans tout ce qui les entoure. De nouveau la comparaison avec Proclus me semble éclairante, d'autant qu'il revient par deux fois sur le thème. La première fois (53), il le mentionne comme un supplice et un redoublement de la punition, puisque nêtre pas puni, c'est nêtre pas même jugé digne de guérir. Il y revient encore dans sa dernière réponse (57), lorsqu'il évoque la vraie expiation, qui aura pour cadre l'espace plus vaste et éternel de l'Au-delà, en comparaison duquel notre terre n'est rien. Dans l'attente de cette expiation, le coupable «demeure le reste du temps dans l'angoisse, obsédé par l'idée du châtiment dont il perçoit dans sa vie les prémices». Le remords est devenu «un signe précurseur des épreuves immenses qui attendent les coupables»: de même que le mal réel est l'incarnation, la guérison réelle l'apallagè, le remords n'est que préfiguration d'un au-delà plus important et la perspective de Proclus est comme tendue vers le moment de vérité dans l'Hadès. Or si Plutarque réserve bien tout un mythe à ce traitement des âmes après la mort, il cantonne le remords au vécu terrestre, sans en minimiser par là l'importance. Au contraire c'est bien la rupture de la confiance de l'homme en dieu qui ouvre la voie à toutes les superstitions, et son refus absolu qui fonde inversement ce que j'appellerais l'argument «delphique» de l'existence de l'immortalité de l'âme.

Terreur du coupable ou confiance du «fidèle», ces notes sont significatives de l'univers religieux dans lequel, selon Plutarque, vivent les hommes, où la sollicitude divine se manifeste et où les oracles sont «la source de tants de bienfaits», comme le dit Ammonios dans le De defectu. La réflexion ne saurait négliger cette dimension si elle veut véritablement penser notre situation dans le monde - et Plutarque n'est pas de ceux qui invitent à le «fuir». Dans ce monde qui est le nôtre, Delphes, où « tout est plein de divinité69"», est un

${ }^{68}$ 10, 555 A9-B1: «Visions des rêves, apparitions des veilles, oracles, coups de tonnerre et tout ce dont la divinité est réputée responsable apportent la tempête et la terreur aux hommes ainsi disposés. »

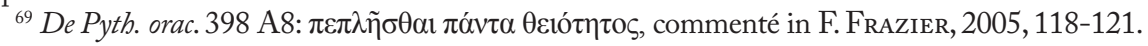


des hauts lieux où cette présence divine peut se rendre sensible. Or, si l'on se tourne désormais vers le mythe, on constate que, à l'instar de Platon, Plutarque inscrit la description du sort des âmes dans un «paysage» cosmique plus large, dessinant une géographie céleste qui figure la vérité du monde. Chez Platon déjà, ce cadre varie d'un mythe eschatologique à l'autre, en fonction du sens général du mythe: insistant dans la République sur la Nécessité qui rend irrévocable et donc plus crucial le choix du lot, il figure dans la «vraie terre» du Phédon l'état des âmes plus ou moins attachées au sensible qu'il n'a cessé d'évoquer dans le dialogue ${ }^{70}$, ou propose, dans le Phèdre, une explication de la diversité des âmes, de la réminiscence et de l'aspiration à remonter à travers la peinture des cortèges célestes.

Le cadre ici va précisément permettre à Plutarque de nouer métaphysique et religion, nature de l'âme et piété delphique. Dans son voyage, Thespésios arrive au bord du gouffre du Léthé (27, 565 E-566 A), là où, « gorgée d'oubli », l'âme va tomber sur terre. On ne peut que songer au Phèdre ou encore au «tournant de la génération» du mythe de Timarque $\mathrm{e}^{71}$. Le lieu intermédiaire qui apparait ici est celui qu'Orphée a assigné à l'Oracle de la Nuit, laquelle, toujours selon lui, partagerait avec Apollon l'oracle de Delphes (28, 566 B). Ce rappel n'a d'autre but que de provoquer une rectification: il n'y a rien de commun entre Apollon et la Nuit, Orphée a confondu avec l'oracle de la Nuit et de la Lune, source des rêves et des apparitions, oracle placé sous le signe du mélange et de l'errance ${ }^{72}$. Une telle nature ne peut pas inspirer la même confiance, mais les implications métaphysiques l'emportent encore sur la valeur religieuse. Le paysage qui se dessine permet de donner un aperçu du monde transcendant et une vision de l'espace intermédiaire, au-delà duquel Thespésios ne peut aller pour le moment. Il faut, à ce point, lire les paroles de son guide:

Tò $\delta$ A A

Le premier verbe n'est pas très bien établi (les manuscrits portent une

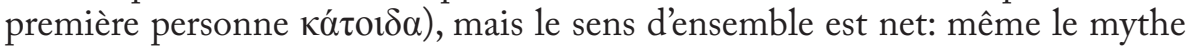
ne peut rendre visible l'au-delà du sensible, le monde transcendant n'est accessible qu'au voũ sotalement libéré du corps, alors qu'une partie de l'âme de Thespésios est restée dans son corps. Le guide continue:

${ }^{70}$ C'est l'interprétation que j'ai essayé de soutenir dans F. Frazier, « Une relecture du mythe final du Phédon. Le philosophe et son logos ", in Troïka. Parcours antiques, Mélanges offerts en hommage à $M$. Woronoff, Besançon, 2007, 189-201.

${ }^{71}$ De Genio 591 B-C.

${ }^{72}$ Ce passage a fait l'objet d'un excellent commentaire (déjà très ancien) de G. MÉAutis, 1935, p. 310: cette opposition de la mantique de Delphes « expression de la vérité absolue », et de la mantique "lunaire ", qui a " quelque chose d'équivoque et de trouble », doit se lire comme une mise en garde contre une mantique qui pouvait facilement porter à la superstition, si bien que « Plutarque, en écrivant comme il fit, travailla, en fait, à une spiritualisation de la religion antique. »

${ }_{73}^{73}$ 29, 566 C10-D1: «Quant à l'oracle d'Apollon, tu ne le reconnais pas, dit-il, et tu ne pourras pas réussir à le voir.» 


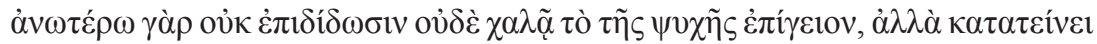
$\tau \tilde{\omega} \sigma \omega ́ \mu \alpha \tau \imath \pi \rho \sigma \eta \eta \rho \tau \eta \mu \varepsilon ́ v o v .{ }^{74}$

Le verbe $\chi \alpha \lambda \tilde{\alpha} \nu$ et son antonyme $\kappa \alpha \tau \alpha \tau \varepsilon i ́ v \varepsilon ı v$ décrivent très exactement les effets du lien qui unit corps et âme : la tension nous attire vers la terre et elle doit se relâcher pour permettre la libération. C'est le même relâchement qui est invoqué pour expliquer les voyages de l'âme d'Hermotime de Clazomènes dans le mythe du De Genio (592 D5-7), et, là encore, l'explication permet de rectifier une opinion erronée: «son âme ne quittait pas le corps, mais obéissant toujours à son daimon et relâchant le lien qui l'attachait à elle, elle lui permettait de circuler et d'aller et venir à sa guise ${ }^{75}$ ».

De la parole au geste, de l'âme au monde, le récit continue et le guide tente de montrer Delphes et Apollon:

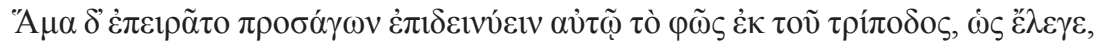

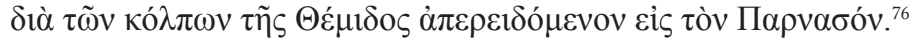

Le Parnasse, Thémis un temps détentrice de l'oracle, une lumière qui part du trépied : tout désigne Delphes, mais, comme annoncé, la tentative échoue. Thespésios ne peut pas voir le dieu transcendant, mais seulement entendre ce qui appartient à la région démonique:

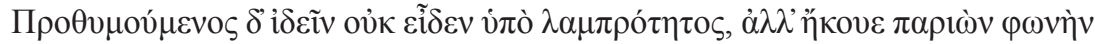

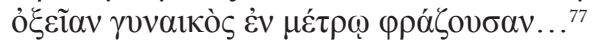

Le mythe en lui-même rapproche plutôt notre texte du De Genio ou du De facie, mais la place centrale de l'oracle de Delphes et sa transcendance absolue rappellent les Dialogues Pythiques. Le mythe ne se borne pas à manifester la qualité réelle des âmes et de leur châtiment: il s'élargit à une vision métaphysique et cosmologique du sensible et de l'intelligible. Dans ce cadre s'opposent, dans l'esprit du Phèdre ou du Phédon, les âmes qui s'élèvent et celles, alourdies par l'humidité du désir, qui subissent l'attraction de la génération, tandis que, au niveau du monde, la Justice se trouve elle-même replacée dans la perspective plus large de la Providence.

${ }^{74}$ 29, 556 D1-3: «C'est que la partie terrestre de ton âme ne peut progresser plus haut ni se relâcher de la tension vers le bas due au corps. »

75 On retrouverait encore ce mouvement de tension et relâchement pour les passions en Resp. I 329c8-9.

76 29, 566 D3-5: «En même temps il essayait de le faire approcher pour lui montrer la lumière qui sortait du trépied, selon ses indications, et qui, à travers le sein de Thémis, rayonnait sur le Parnasse.»

77 29, 566 D5-7: « Mais malgré son vif désir de la voir, il n’y parvint pas, ébloui qu'il était par sa splendeur: il ne fit qu'entendre en passant une voix féminine aiguë qui proférait en vers (diverses prophéties)...» 
Il est remarquable que, dans ce cadre, une certaine attention soit réservée aussi à cet autre point majeur de la réflexion de Plutarque que sont la communication entre hommes et dieux, les oracles, et singulièrement l'oracle de Delphes, dont le De Pythiae, sous un angle sensible, avec la renaissance du sanctuaire, et le De Epsilon, avec l'ex-voto delphique et les "énigmes » qui sont autant de provocations divines à la philosophie, marquent l'importance fondamentale. La divinité, transcendante mais pleine de sollicitude pour le monde d'ici-bas, providente, y assure la justice et s'y rend sensible par les oracles, sans pour autant perdre sa transcendance. L'opposition à l'absence des dieux soutenue par les Épicuriens, qui met en perspective toute la discussion, doit être prise au sérieux, tout comme la double affirmation, de l'allégeance à l'Académie et du lien infrangible entre existence de la Providence et immortalité de l'âme, ne sont pas que des concessions à la tradition philosophique. Il faut y voir l'expression de la conviction profonde de Plutarque, platonicien et prêtre de Delphes, qui tout à la fois reconnaît la faiblesse de la raison humaine et construit le plus rigoureusement possible son apologie de la divinité. En considérant ainsi toujours les deux aspects, théorique et existentiel, il donne toute sa portée à la conception de la philosophie comme " maîtresse de vie ", et prend acte de la nature et de la condition humaines que le philosophe a à penser et à vivre ici-bas. 


\section{Bibliographie}

Babut, D. « La composition des Dialogues Pythiques de Plutarque et le problème de leur unité ", JS 27 (1992) 198-234 (= Parerga, Lyon, 1994, 457-504).

- «Polémique et Philosophie dans deux écrits antistoïciens de Plutarque ", REA 100 (1998) 11-42.

Baldassari, M. «La difesa della Providenza nello scritto plutarcheo de sera numinis vindicta», Anc.W. 25 (1994) 147-158.

del Cerro Calderón, G. «El problema del mal y la providencia en Plutarco y en la Biblia », in M. García Valdés (ed.), Estudios sobre Plutarco: Ideas religiosas. Actas del III Simposio Internacional sobre Plutarco (Oviedo 30 de abril a 2 de mayo de 1992), Madrid, 1994, 223-234.

Frazier, F. « Göttlichkeit und Glaube. Persönliche Gottesbeziehung im Spätwerk Plutarchs », in R. Hirsch-Luipold (hrsg), Gott und die Götter bei Plutarch, Berlin / New York, 2005, 111-137.

— «Quand Plutarque actualise le mythe d'Er. Delphes, la Justice et la Providence dans le mythe de Thespésios (De sera 22, 563 B-33, 568 A) », in L. Van der Stockt \& Alii (edd.), Gods, Daimones, Rituals, Myths and History of Religions in Plutarch's Works. Studies Devoted to Pr F. E. Brenk by the I.P.S (à paraître).

Görgemanns, H. Einführung in Plutarch. Drei Religionsphilosophische Schriften, Düsseldorf / Zürich, 2003, 318-339.

Helmig, C. « A Jumble of Disordered Remarks? Structure and Argument of Plutarch's De sera numinis vindicta », in M. Jufresa \& Alii (edd.), Plutarc e la seva època: Paideia $i$ societat. Actas del VIII Simposio Internacional (Barcelona, 6-8 nov. 2003), Barcelona, 2005, 323-332.

Ildefonse, F. Introduction à Plutarque, Dialogues Pythiques, Paris, GF, 2006, 7-76.

MÉautis, G. "L'apologétique de Delphes dans un traité de Plutarque », Mélanges O. Navarre, Toulouse, 1935, 305-311.

- Plutarque, Des délais de la justice divine, Lausanne, 1935.

Opsomer, J. «Éléments stoïciens dans le De E apud Delphos de Plutarque », in J. Boulogne, M. Broze \& L. Couloubaritsis (edd.), Les platonismes des premiers siècles de notre ère: Plutarque, E de Delphes, 2006, 147-170.

Saunders, T.J. «Plutarch's De Sera Numinis Vindicta in the Tradition of Greek Penology ", in O. Diliberto (a cura di), Il Problema della pena criminale tra filosofia greca e diritto romano, Napoli, 1993, 65-94.

Sirinelli, J. Plutarque de Chéronée. Un philosophe dans le siècle, Paris, 2000. 
Torraca, L. « Linguaggio del reale e linguaggio dell'imaginario nel De sera », in

I. Gallo (a cura di), Strutture formali dei Moralia, Napoli, 1991, 91-120. 


\section{Appendice: \\ LA PROGRESSION DE LA PENSÉE DANS LE DE SERA}

\section{1- 4 Mise en place du thème et de ses enjeux}

1. L'Épicurien s'en va brutalement: faut-il répondre ? à quoi ?

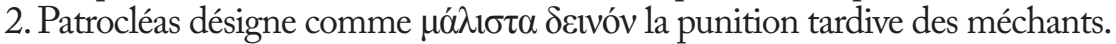

3. Olympichos en souligne l'enjeu, la mise en cause de la $\pi \dot{i} \sigma \tau(\varsigma) \tau \eta \tilde{\varsigma} \pi \rho o v o i ́ \alpha \varsigma$.

4. Timon : annonce une « troisième vague ».

Plutarque s'en tient d'abord aux $1^{\text {ères }}$ questions et se met d'entrée sous l'égide de l'eulabeia académique (4, $549 \mathrm{E})$

5-11 [Point de vue individuel] Les délais dans la punition du coupable, signe de mollesse divine?

A. Discussion de la thèse : l'utilité des délais, Dieu médecin et justice thérapeutique (5-8)

5. A $\lambda \lambda \grave{\alpha} \sigma \kappa о \pi \varepsilon \tilde{\tau} \varepsilon \pi \rho \tilde{\omega} \tau o v:$ Dieu modèle de patience.

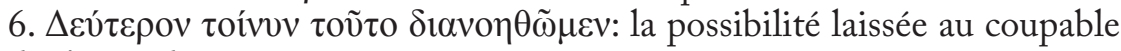
de s'amender.

7. Cas où le délai a permis un événement utile.

8. Redéfinition du châtiment autour de la notion de kaıpós.

B. Correction de la thèse : l'immédiateté du châtiment intérieur - et invisible - (9-11)

9. Remords et bonheur apparent : le châtiment le plus tardif est le plus pénible.

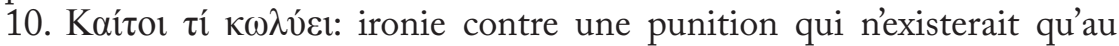
moment de l'exécution du coupable ; tourments des songes et des deisidaimoniai.

11. Conséquences paradoxales: le châtiment immédiat est le plus doux, s'il n'y a rien après la mort; à la limite, il n'est pas besoin de justicier extérieur, divin ou humain.

12-21 [Point de vue collectif] La punition des descendants, une injustice divine?

12. Timon introduit le problème du châtiment tombant sur les descendants:

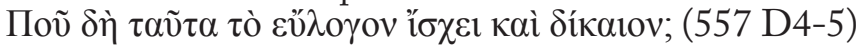

13. Plutarque circonscrit la question : si les récompenses se transmettent, il doit en être de même pour les châtiments en toute logique (củ $\lambda$ ó $\gamma \omega \varsigma, 558$ $\mathrm{C} 2$ ), puis, il reprend le problème toujours sous le signe de la vraisemblance et de l'eulabeia $(14,558 \mathrm{D})$ 
14. Il y a des correspondances mystérieuses dans le temps comme dans l'espace.

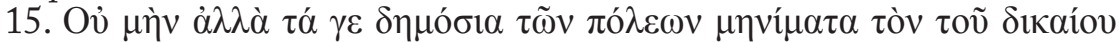

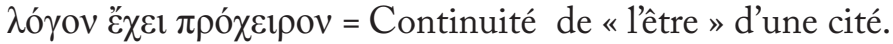

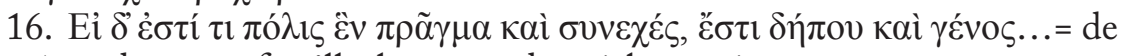
même dans une famille, le germe de méchanceté se transmet.

17-18. Olympichos explicite le présupposé, la survivance de l'âme, et Plutarque l'appuie sur la tradition delphique avant d'affirmer que Providence et immortalité de l'âme sont indissociables, puis il oppose les rétributions que nous voyons et le pire des châtiments, voir le mal causé à ses descendants. Il annonce un mythe qui le montrerait $(18,561 \mathrm{~B})$, mais s'en tient d'abord au vraisemblable.

\section{9-21 Reprise du logos, de l'exposé rationnel}

19. Critique de la comparaison de Bion entre Dieu et un médecin qui soignerait les descendants du malade.

20. Dieu discerne l'état réel de l'âme, alors que le criminel ne l'est pour nous qu'au moment du crime.

21. «Correction»: les descendants sains ne sont pas punis.

22-33 Récit d'un mythos: le mythe de Thespésios, interrogé par Protogène et

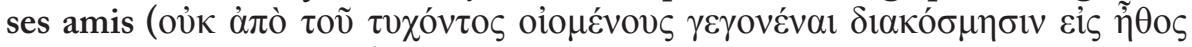

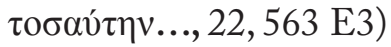




\title{
Socrates' $\delta$ aluóviov in MaXimus of \\ Tyre, Apuleius, and Plutarch
}

\author{
Geert Roskam \\ K. U. Leuven
}

\begin{abstract}
This paper deals with the positions of three Middle Platonists towards Socrates' divine sign.

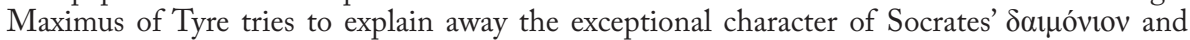
hardly deals with the interaction between the philosopher and his divine sign. Apuleius' general demonology is much more systematic, yet his more particular interpretation of Socrates' $\delta a 1 \mu o ́ v ı v$ hardly surpasses Maximus' views. Plutarch's interpretation in De genio Socratis, on the other hand, is more interesting from a philosophical perspective, as is shown by an analysis of the fundamental interpretations proposed by different speakers in this dialogue.
\end{abstract}

\section{A remarkable case of demonic providence}

Should a philosopher be extravagant? This frank opening question may come as a surprise, certainly among a contemporary, philosophically minded audience. Of course not: why should he? A man's capacities and credibility as a philosopher obviously do not depend on outward idiosyncracies. An educated audience of the second century $\mathrm{AD}$, however, may have been a little less surprised. More than one self-proclaimed philosopher seems to have based his claims primarily on his extravagant looks (esp. the notorious threadbare cloak or $\left.\tau \rho^{\prime} \beta \omega v\right)$ and behaviour (e.g. his disdain for, and harsh insults against everyone he encountered), which, of course, prompted others to unmask such unfounded imposture and self-display ${ }^{1}$.

Should a philosopher, then, perhaps be a man of paradoxes and/or oversophisticated logical quibbles? Again, why should he? Yet again, in antiquity, many younger students were presumably attracted by precisely this aspect ${ }^{2}$, and it is well known that the Stoics liked to express some of their basic doctrines in pithy paradoxes ${ }^{3}$.Other philosophical schools, however, were often less enthusiastic about such paradoxes ${ }^{4}$. Plutarch, for instance, repeatedly blames the Stoics for their $\pi \alpha \rho \alpha \delta o \xi o \lambda o \gamma i \alpha^{5}$, and in De facie, Lamprias argues

${ }^{1}$ Cf., e.g., Plutarch, De prof. in virt. 82B; De Is. et Os. 352C; Dio Cassius, 6,13,1a; Lucian, Pisc. 31 and 46; Bis acc. 6-7; Epictetus, 4,8,4-9, 15 and 34; Athenaeus, 5, 211de; Aulus Gellius, 9,2,4; cf. already Plato, $A$ p. 29 de.

${ }^{2}$ See, e.g., Plutarch, De prof. in virt. 78EF; cf. De aud. 43AB.

${ }^{3}$ While adding, though, that such doctrines had nothing paradoxical for the sage (Diogenes Laertius, 7,123).

${ }^{4}$ Cf., e.g., Cicero, ac. 2,136.

${ }^{5}$ See, e.g., De facie 924A and CD; De comm. not. 1060B; 1068B; 1071D; cf. De Stoic.

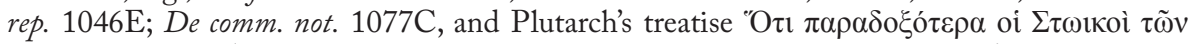

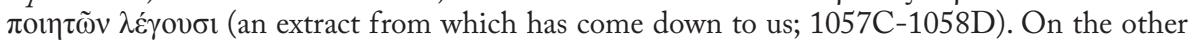
hand, Plutarch realises that his own interpretation of Plato's Timaeus also contains paradoxical elements, which he wants to justify (De an. procr. 1014A). 
that one should not listen to philosophers who wish to ward off paradoxes by means of other paradoxes ${ }^{6}$.

However that may be, there can hardly be any doubt that Socrates was remembered as both an extravagant philosopher and a man of paradoxes. A particularly salient illustration of both these aspects can be found in his

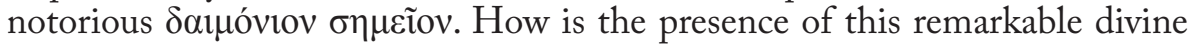
sign to be explained in a man who in every situation only relied on his sober reason $^{7}$ and who was especially interested in human issues, being the first, in Cicero's famous formulation, to call philosophy down from heaven in order to place it in the cities and houses of men ${ }^{8}$ ? Even during Socrates' lifetime, the strange phenomenon was presumably widely discussed in Athens ${ }^{9}$, and when the divine voice was finally silenced by the philosopher's execution, it was not forgotten by Socrates' followers. Plato and Xenophon ${ }^{10}$, but also other "Socratic" philosophers ${ }^{11}$ and Plato's disciples ${ }^{12}$ gave much attention to the divine sign in their writings. The period of so-called Middle Platonism saw a revival of interest in the issue ${ }^{13}$, and also in Neoplatonism, the topic received attention $^{14}$.

The reason for this age-long interest cannot only be found in the remarkable idiosyncrasy of the famous philosopher. For one can easily think of behaviour or claims of other illustrious thinkers that were even more remarkable and yet received far less attention. Empedocles, for instance, was clothed in purple and gold, and used shoes of bronze and a Delphic wreath ${ }^{15}$. Pythagoras would have showed more than once his striking prophetic skills, but several of these

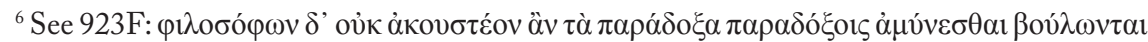
$\kappa \tau \lambda$.

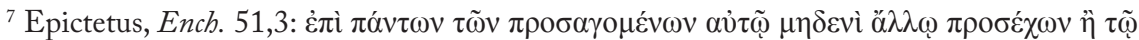
$\lambda$ ó $\omega$; Plutarch, De genio Socr. 580C; cf. already Plato, Cri. 46b.

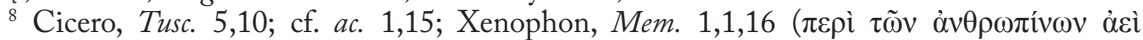
$\delta 1 \varepsilon \lambda \varepsilon \dot{\gamma \varepsilon \tau o) ; ~ c f . ~ a l s o ~ t h e ~ e v e n ~ s t r o n g e r ~ c l a i m ~ i n ~ P l u t a r c h, ~ D e ~ g e n i o ~ S o c r . ~ 582 B: ~ \varphi ı \lambda o б o p i ́ \alpha v ~}$ $\dot{\varepsilon} \xi \alpha v \theta \rho \omega \pi \dot{\sigma} \sigma \alpha \nu \tau \sigma \varsigma$.

${ }^{9}$ Cf. Plutarch, De genio Socr. 581E; Nic. 13,6. This would later enable Meletus, Anytus, and Lycon to charge Socrates for introducing new $\delta \alpha \mu$ óvia (cf. Plato, Ap. 24c and 31cd; Xenophon, Mem. 1,1,1; Diogenes Laertius, 2,40).

${ }^{10}$ A convenient survey of relevant passages can already be found in R.E. Macnaghten (1914); see further M. Joyal (2000), 65-71. On Plato, see also the thorough discussions of H. Gundert (1954); M.L. McPherran (1996), 185-208; Th.C. Brickhouse - N.D. Smith (2000), 244-252.

${ }^{11}$ Cicero, div. 1,122.

12 On the date of composition of the Theages, see M. Joyal (2000), 135-155 (arguing for 345-335 B.C.); on its discussion of Socrates' Saınóviov, see Id. (2000), 72-97. On Xenocrates' demonology in general, see, e.g., J. Dillon (2003), 129-131 and 146-147.

${ }^{13}$ Although it should be noted that our picture may be distorted due to the loss of so many important texts. It cannot be excluded, then, that in the intermediate period Socrates' $\delta \alpha \mu$ óviov was also discussed, e.g. in the context of philosophical debates about divination (cf. Cicero, div. 1,122-124), or in Epicurean attacks against Socrates' supposed $\alpha \lambda \alpha \zeta o v \varepsilon i ́ \alpha$ (cf., e.g., Plutarch, Quaest. Plat. 999C; J. Opsomer (1998), 128).

${ }^{14}$ Proclus, in Alc. 78.8-85.17; Olympiodorus, in Alc. 21.1-14; Hermias, in Phdr. p. 65.2669.31 Couvr.

${ }^{15}$ Diogenes Laertius, 8,73; Aelian, VH 12,32. 
achievements have only come down to us through a few late biographies ${ }^{16}$.

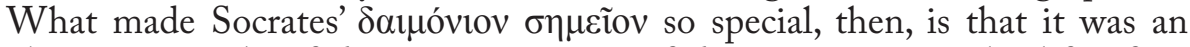
obvious example of direct intervention of divine powers in the life of an individual. Educated Athenians were familiar with such interventions from the Homeric epic literature ${ }^{17}$ and from tragedy (with the deus ex machina as the most tangible example), to be sure, but in Socrates' case, the god(s) seemed to interact with a human being no longer in myths and literature but in real life. In this - admittedly quite extraordinary - individual, the gap between the divine world and that of human beings appeared to be bridged to a certain extent. The gods' providential care for men had no longer to be derived from the general teleological character of nature, nor from prophetic dreams, oracles, and so on, but was illustrated in one particular person. Furthermore, the positive results of this divine guidance were impressive, fascinating, and undeniable: the divine sign enabled Socrates not merely to predict the débâcle of the Sicilian expedition ${ }^{18}$ or to avoid a herd of dirty swine ${ }^{19}$, but even saved his life in the battle of Delium ${ }^{20}$.

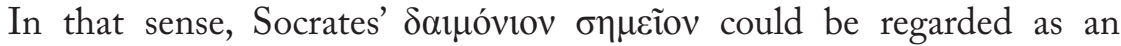
interesting example of the active influence of divine providence in the life of a single individual. In later Platonic school doctrine, however, this fairly general conclusion was made more specific, through an attempt to distinguish between several levels of providence. In the interesting treatise De fato, for instance, which was transmitted under Plutarch's name but was in all likelihood not written by him ${ }^{21}$, a distinction can be found between three different providences, connected with three different levels in the divine realm. On the basis of a few passages in Plato, the author argues that the intellection or will of the highest god should be regarded as primary providence, whereas secondary providence belongs to secondary gods (the stars and planets) and tertiary providence to daemons ${ }^{22}$, and that primary providence includes fate, tertiary providence is included by fate, and secondary providence exists side by side with fate ${ }^{23}$. The details of this theory need not detain us here. What is important for our purpose

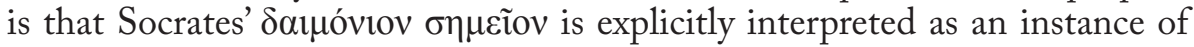
tertiary providence, which yields immediate results that conform to fate ${ }^{24}$. The

${ }^{16}$ Porphyry, VP 25, 28 and 29; Iamblich, VP 28. On the other hand, Pythagoras' notorious claim that he could remember his previous lives was often mentioned in ancient literature; see E. Rhode (1925), II, 417-421.

${ }^{17}$ Maximus of Tyre (8,5a) and Apuleius (Socr. 145) both refer to the famous scene in the first book of the Iliad (1,194-198), where Achilles, who intended to kill Agamemnon, was restrained by Athena. Cf. also Plutarch, De genio Socr. 580CD, who refers to Homer, Od. 13,301.

${ }_{18}^{18}$ Ps.-Plato, Thg. 129cd; Plutarch, De genio Socr. 581D; Nic. 13,6; Alc. 17,4.

${ }^{19}$ Plutarch, De genio Socr. 580D-F.

${ }^{20}$ Plutarch, De genio Socr. 581DE; Cicero, div. 1,123; Epist. Socr. 1,9.

${ }^{21}$ The question of the (in)authenticity of the work has often been examined; see E. Valgiglio (1993), 34-42 for a recent thorough discussion.

${ }_{22}$ Ps.-Plutarch, De fato 572F-574A.

${ }^{23}$ Ibid. 574B-D.

${ }^{24} \mathrm{Ibid}$. 574BC, with reference to Ps.-Plato, Thg. $129 \mathrm{e}$. 
parallels that can be found in other authors ${ }^{25}$ show that this strange theory belongs to the period of Middle Platonism ${ }^{26}$ and drew its main inspiration from a Platonic perspective ${ }^{27}$. It is a typical example of a formalised school doctrine which tries to introduce everything, including even highly personal phenomena such as Socrates' divine sign, into a systematic and hierarchical Platonic world view.

Interesting though such attempts at systematisation may be, they are often bought at the price of oversimplification and neglect of particularities. In this case, too, the theory does not provide any further information about the concrete way in which the tertiary, "demonic" providence precisely worked in Socrates' case. In order to find an answer to this question, one should turn to other sources, more precisely to two speeches of Maximus of Tyre (or. 8 and 9), to Apuleius' De deo Socratis, and to Plutarch's De genio Socratis. In none of these texts is the above mentioned doctrine of the three providences explicitly discussed (although we can be sure that at least Apuleius was familiar with $\mathrm{it}^{28}$ ). Instead, they focus on the providential working of demons in general,

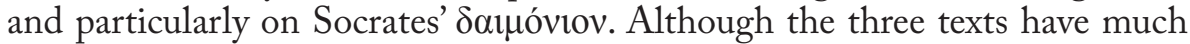
in common, they also show several significant differences. In fact, the three authors took up the topic at issue in a variety of ways, for a variety of audiences, and for a variety of exegetic purposes.

\section{Maximus of Tyre}

The point of departure of Maximus of Tyre's two speeches about Socrates' $\delta a \mu$ óviov is the audience's supposed astonishment ${ }^{29}$ at Socrates' possession of a divine sign. By means of a first lengthy series of concrete examples - Laconic brevity was not one of his qualities -, Maximus then attempts to demonstrate that such phenomenon is not so remarkable after all: if all kinds of people can indeed through many oracles make contact with the demonic realm, a pure and virtuous philosopher such like Socrates is a fortiori able to keep in touch with a $\delta \alpha \mu$ óviov, even on a more individual basis ${ }^{30}$. At the end of his first speech, Maximus even suggests that Socrates was not the only famous thinker who could benefit from such an association with a $\delta \alpha i ́ \mu \omega v$ : Plato too, and Pythagoras, and Zeno and Diogenes all had their personal daemonic supervisor ${ }^{31}$. And through his passing remark that the daemons order him to

${ }^{25}$ Apuleius, de Plat. 1,12 p. 205-206; Nemesius, Nat. hom. 43, p. 125.21-126.12 Morani; cf. Chalcidius, comm. 146.

${ }^{26}$ See further A. Gercke (1886), 284-286; J. Beaujeu (1973), 273-274; J. Dillon (1977), 324-326; S. Gersh (1986), 280-285; R.W. Sharples (2003).

27 P. Moraux (1984), 503-504: “Die Erörterungen über die Vorsehung ( $\pi \rho o ́ v o 1 \alpha)$ und ihr Verhältnis zur Heimarmene stützen sich fast ausschließlich auf platonisches Material, besonders aus dem Timaios. Inhaltlich bieten sie nichts, was auf die aristotelische Tradition zurückzuführen ist."

${ }^{28}$ Cf. supra, n. 25.

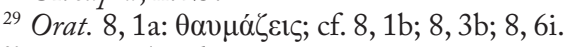

${ }^{30}$ Orat. $8,1 \mathrm{~b}-3 \mathrm{~d}$.

${ }^{31}$ Orat. 8, 8f. 
speak on their behalf ${ }^{32}$, Maximus subtly suggests that he himself can be added to this list of distinguished thinkers. A first important aim of Maximus' speeches, then, consists in explaining away the exceptional character of Socrates' divine sign. The philosopher's $\delta \alpha \mu$ óviov may have been an individual entity ${ }^{33}$, to be sure, but it can perfectly be related to similar phenomena. It should be clear that this argument is not merely a neutral piece of instruction ${ }^{34}$, but that it is also of paramount importance for Maximus' self-presentation. The author indeed presents himself as the competent expert who is able to free his audience from their ignorant amazement. He is the man who, even on such quite obscure and startling issues, can speak from personal experience.

After this piece of indirect self-promotion, Maximus turns to the crucial problem of the precise nature of Socrates' $\delta \alpha \mu$ ovviov $^{35}$, though only to reformulate the question: a correct understanding of this specific instance presupposes an insight into the more general genus of $\delta \alpha \mu$ vova $^{36}$. This is sound methodology, no doubt, which moreover recalls similar Platonic principles ${ }^{37}$, but at the same time, this self-confident methodological strategy enables Maximus to escape embarrassing difficulties: the particularly complex problem of Socrates'strange $\delta \alpha \mu$ óviov can now be replaced by the much less demanding topic of demonology in general ${ }^{38}$. This, apparently, is a subject that better suits Maximus' rhetorical talents. After a lengthy discussion of Homer's treatment of daemons $s^{39}$, which once again helps in explaining away the exceptional nature of Socrates' divine sign (and helps to show how traditional religion is to be understood from a philosophical point of view), Maximus finally begins to develop his views on a hierarchic universe, governed by a benevolent deity who is assisted by secondary immortal beings, the daemons. These daemons occupy an intermediate position, sharing their immortality with the god and their susceptibility to passions with human beings, and thus act as a kind of interpreters between both levels ${ }^{40}$. More precisely, daemons are disembodied souls who, out of pity for kindred souls which are still linked to the body and in accordance with the god's command, involve in human matters ${ }^{41}$. In that sense, and in spite of the fact that Maximus never uses the term $\pi \rho$ óvor $\alpha$ in this

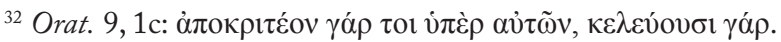

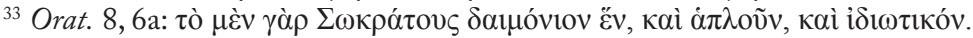

${ }^{34}$ That Maximus' speeches are primarily addressed to the young is argued by G.L. Koniaris (1982), 113-114 and M.B. Trapp (1997), xx-xxii.

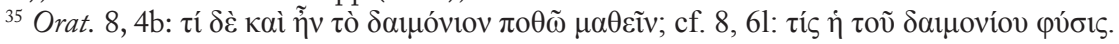

${ }^{36}$ Orat. 8, 4bc; cf. 61 .

${ }^{37}$ Cf., e.g., Meno 71ab. That Maximus' two discourses reflect a Platonic perspective is argued by J. Puiggali (1983), 192-240.

${ }^{38}$ It should be noted, however, that we do not know what title(s) these two lectures were delivered and/or published under. It is not impossible that the original titles promised an account of daimones rather than an explanation of the Socratic daimonion. If that is true, Maximus uses the well-known individual case of Socrates as an effective and striking point of entry to an exposition of an important area of philosophical cosmology and theology.

${ }^{39}$ Orat. 8, 5a-61.

${ }^{40}$ Orat. 8, 8a-9, 4e.

${ }^{41}$ Orat. 9, 6a-g. 
context, these daemons obviously contribute to the highest god's providential care for the world of human beings.

While this general, and fairly superficial perspective is rhetorically elaborated with many examples and parallels ${ }^{42}$, the knotty problem of the

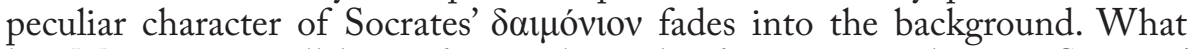
has Maximus to tell his audience about the daemonic working in Socrates' particular case? How should the interaction between Socrates and his $\delta \alpha \mu$ óviov be understood? On this point, Maximus' verbosity conceals a remarkable lack of ideas. His arguments can be reduced to two basic observations. First of all, he more than once underlines Socrates' exceptional purity ${ }^{43}$, which serves both as an a fortiori argument ("if other people, then a fortiori Socrates") and a conditio sine qua non (daemons only assist virtuous people ${ }^{44}$ ), without, however, explaining the individual nature of the phenomenon. Secondly, throughout the two speeches, Maximus is particularly vague about the precise way in which the $\delta a \mu$ óviov communicated with Socrates. At the very outset of the first speech, he merely asserts that the $\delta \alpha \mu$ óviov always "attended" Socrates and was "all but mixed up with his mind" 45 , without further even clarifying whether the Saluóviov had its seat in the body ${ }^{46}$, the soul ${ }^{47}$, or the mind. Socrates' association with the $\delta \alpha \mu$ óviov, or vice versa, is usually described with the

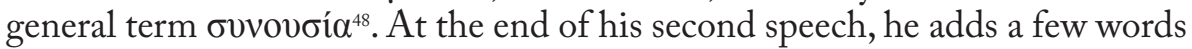
about the visual perception of daemons ${ }^{49}$, and Maximus would not have been Maximus if he would not have pointed out that he himself had seen several of them, not in a dream but in waking reality ${ }^{50}$. One could of course wonder what all this has to do with the divine voice that Socrates could apparently perceive. The less educated members of Maximus' audience may perhaps have been greatly impressed by the sophist's grand finale, but more erudite listeners probably recalled that Socrates used to regard men who claimed to have had visual communication with the divine as boastful charlatans ${ }^{51}$. Was Maximus an $\dot{\alpha} \lambda \dot{\alpha} \zeta \omega v$ ?

I think he was, though a brilliant one! In both speeches, he used traditional material in order to present himself as a virtuoso speaker. His goal is not

${ }^{42}$ Cf. M.B. Trapp (1997), 68: “Maximus' discussion provides the fullest surviving development of the notion that daimones are an indispensable rung in the hierarchy of living beings in the cosmos, but otherwise contains nothing not amply paralleled in the other sources, and at several points side-steps difficulties or refinements which they take into account."

${ }^{43}$ Orat. 8, 1a; 8, 3b; 8, 4a; 8, 6i-1.

${ }^{44}$ Orat. 8, 8g.

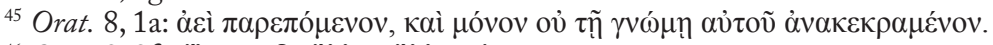

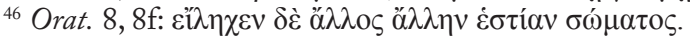

${ }^{47}$ Orat. $8,8 \mathrm{~g}$.

${ }^{48}$ Orat. 8, 3d (

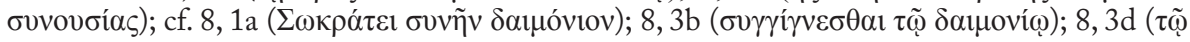

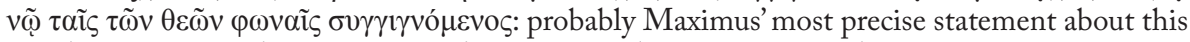

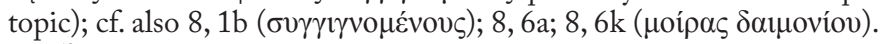

${ }^{49}$ Orat. $9,7 \mathrm{c}-\mathrm{i}$.

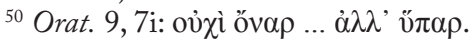

${ }^{51}$ See Plutarch, De genio Socr. 588C. 
so much to provide a systematic exposition of philosophical doctrines, but primarily to impress his audience (by such an exposition). This is $\dot{\pi} \pi \dot{\delta} \delta \varepsilon 1 \xi 1 \varsigma$ aiming at $\pi \varepsilon 1 \theta \omega$ and self-display, rather than a search for the truth. To that purpose, Maximus completely does away with the listeners' initial wonder about Socrates' $\delta \alpha \mu$ óviov and about the tangible influence of the divine world on the life of an individual. And in thus killing wonder, he actually destroys the $\dot{\alpha} \rho \chi \eta$ of philosophy. If there is any place for wonder in the world view which Maximus proclaims, it is wonder about the extraordinary genius of Maximus himself.

\section{Apuleius of Madaura}

The title of Apuleius' speech De deo Socratis is somewhat misleading, since the work is primarily a systematic discussion of demonology. Only a relatively small section is devoted to the particular case of Socrates' $\delta \alpha \mu$ óvıov. The work begins $^{52}$ with a reference to Plato's division of the universe into three levels. At the top is the realm of the first god and the lower gods ${ }^{53}$, at the bottom the world of human beings $\mathrm{s}^{54}$, and no direct contact is possible between both ${ }^{55}$. Nevertheless, this gap does not imply that man is entirely left to himself, bereft of any divine help, for there exists an intermediate level of "divine" beings, the daemons, who act as intermediaries between gods and men, and all have their own domain or provincia: dreams, entrails, birds, and so on ${ }^{56}$. Apuleius thus depicts a strongly hierarchical universe, in which all sections have their own function: a kind of perfectly streamlined company, as it were, structured into different departments, administrated by a general manager who is assisted by a series of executive officers. It is clear that this view bears striking resemblance to that of Maximus, and in all likelihood, the view of both authors should directly or indirectly - be traced back to a key passage of Plato's Symposium ${ }^{57}$. Apuleius and Maximus both in their own way draw from their copia verborum in order to elaborate in great detail the Platonic material, but Apuleius' speech is no doubt the more detailed, well considered, and systematic of the two ${ }^{58}$.

That also holds true for the interpretation of the notion of "daemon" itself. Again, Apuleius provides his audience with a systematic division into different categories. A daemon can be both (1) a human mind which is still in the body and (2) a disembodied mind. Moreover, there also exists (3)

${ }^{52}$ On the much-discussed problem of the so-called false preface, see, e.g., V. Hunink (1995); G. Sandy (1997), 192-196; F. Regen (1999), 432-438; S. Harrison (2000), 141-144; M.-L. Lakmann (2004), 23-26.

${ }^{53}$ Socr. $115-124$.

${ }^{54}$ Socr. $125-127$.

55 Socr. 127-132.

${ }^{56}$ Socr. $133-134$.

${ }^{57}$ That is, Smp. 202e-203a.

${ }^{58}$ General studies of Apuleius' demonology include F. Regen (1971); Id. (1999), 451-456; Id. (2000), 41-54; C. Moreschini (1978), 19-27; W. Bernard (1994); P. Habermehl (1996); cf. also S.J. Harrison (2000), 151-161. 
a higher kind of daemons, which have never been linked to the body and act as the individual supervisors of human beings, observing their lives and bringing them to trial after their death ${ }^{59}$. This classification, which is once again a clear-cut systematisation and combination of several isolated ideas in Plato's works ${ }^{60}$, follows upon an extensive discussion of the body of daemons ${ }^{61}$, a characterisation of them as both immortal and susceptible to passions ${ }^{62}$, and a concise, summarising definition ${ }^{63}$.

It is only after this thorough general discussion that Apuleius finally turns to the specific problem of Socrates' $\delta \alpha \mu$ óvıov. Just like Maximus, he begins with an attempt to downplay the extraordinary, exceptional nature of the phenomenon, pointing out that something similar could already be found in Homer ${ }^{64}$. Apuleius' and Maximus' appeal to the supposed surprise of their respective audiences obviously reflects basically the same rhetorical strategy ${ }^{65}$, yet from a more general point of view, their approach is diametrically opposed: whereas Maximus indeed takes the particular case as his starting point for more general reflections, Apuleius only deals with the concrete issue after having elaborated a more general perspective. Although the latter approach makes it easier to explain the phenomenon to an audience that is already introduced to the basics of the Platonic demonology, it is no doubt also the more demanding one, since Apuleius can no longer avoid the more difficult particular questions by escaping towards a more universal perspective. In that sense, Apuleius' challenge is much greater than Maximus'. His answer to it, however, which mainly focuses on two aspects, is almost equally disappointing, at least for philosophically interested listeners ${ }^{66}$.

First, Apuleius deals with the exclusively apotropaic character of Socrates'

${ }^{59}$ Socr. $150-156$.

${ }^{60}$ See, e.g., $P h d .108 \mathrm{~b}$ and $113 \mathrm{~d} ; R$. 620de for the daemon as personal guardian, and Ti 90a

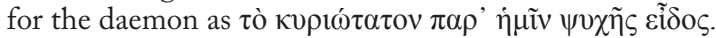

${ }^{61}$ Socr. $140-145$.

${ }^{62}$ Socr. 146-147.

${ }^{63}$ Socr. 148: daemones sunt genere animalia, ingenio rationabilia, animo passiva, corpore aeria, tempore aeterna.

${ }^{64}$ Socr. $158-162$.

${ }^{65}$ According to J. Beaujeu (1973), 240 and S.J. Harrison (2000), 139-140 and 161; Id. (2001), 188, the similarities between Maximus and Apuleius suggest the existence of a common source: "The incredulous rhetorical questions and the stress on the great virtue of Socrates similarly expressed suggest a common origin; both authors are also raising an obvious problem, why the wise Socrates needed a daimonion in the first place, which is likely to have featured in previous writing on the subject." I am not sure whether this is correct: in my view, the similarities are less obvious than Harrison believes - after all, both authors describe Socrates' virtue in very different ways - and may find their origin in basically the same rhetorical strategy, that is, questioning the alleged feelings of the listeners in order to subtly enhance one's own reputation as an erudite, clever speaker. Moreover, both authors do not refer to the audience's surprise that Socrates needed a daimonion, but rather to their wondering about the phenomenon itself (abstracting from the question whether he needed it or not).

${ }_{66}^{6}$ Though perhaps not for Apuleius' listeners; cf. G. Sandy (1997), 211. On the audience of De deo Socratis, see further B.L. Hijmans (1987), 431-433; S.J. Harrison (2001), 187-188; M.-L. Lakmann (2004), 17. 
$\delta a 1 \mu o ́ v ı v$. In his view, the reason why Socrates never received positive advice should be sought in the philosopher's virtuous disposition, which never required positive exhortations but sometimes needed warnings against possible dangers ${ }^{67}$.This is an intelligent suggestion, which recalls Maximus' argument but also surpasses it, in that it uses the traditional element of Socrates' purity not only to explain the presence of the $\delta \alpha \mu$ óviov, but also its general character. On the other hand, Apuleius does not take further advantage of this topic in order to throw more light on the precise nature of the voice or sign that Socrates could perceive.

This crucial question, which directly thematises the communication between god and man, is discussed next, but here, Apuleius' answer is rather disappointing: the voice was not an ordinary one but came from a divine source $^{68}$, as is also indicated by Socrates' claim not just to hear a voice but "a certain kind of" voice ${ }^{69}$. Apuleius thus rejects the interpretation of Socrates' $\delta \alpha \iota \mu o ́ v ı v$ as a kind of ominous chance utterance ( $\kappa \lambda \eta \delta \omega ́ v)$, but only in order to argue - quite remarkably - that Socrates was able to see his strange voice or sign. The basic argument on which this suggestion rests is an argumentum ex auctoritate: the Pythagoreans used to be astonished if anyone claimed that he had never seen a daemon (a testimony the reliability of which is guaranteed by Aristotle, yet another argumentum ex auctoritate $)^{70}$. If all this is true, an easy rhetorical a fortiori argument suffices to make the point: if everyone, then certainly Socrates, the pure sage ${ }^{71}$. In the end, Apuleius thus resembles Maximus both in replacing Socrates' daemonic voice by a visual apparition and by failing to do justice to the exceptional character of Socrates' $\delta \alpha \mu$ óvıv, which becomes a more or less ordinary phenomenon ${ }^{72}$.

In that sense, Apuleius' discussion of the particular nature of Socrates' $\delta \alpha \mu$ óvıov does likewise not surpass the level of a few vague commonplaces. Just like Maximus, Apuleius has to conceal the poverty of his ideas on this issue by means of his brilliant rhetoric. Many question marks are self-confidently replaced by exclamation marks, but behind the façade of rhetorical self-display, many essential questions are left untouched. Apuleius surpasses Maximus, however, in that his rhetoric is coupled with a much more systematic discussion. De deo Socratis happily combines the brilliant rhetoric of the Apology and the Florida with the philosophical

${ }^{67}$ Socr. 162-163. No doubt Socrates was an important model for Apuleius, who may have fashioned his own defence De magia after Plato's Apology; cf. U. Schindel (2000).

${ }^{68}$ Socr. 163: vocem quampiam divinitus exortam; cf. 166: divinitus editam.

${ }^{69}$ Socr. 165: Socrates non vocem sibi, sed vocem quampiam dixit oblatam, which refers to Plato,

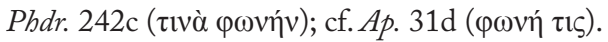

${ }^{70}$ Socr. 166-167.

${ }^{71}$ Socr. 167.

72 S.J. Harrison (2000), 165 correctly notes that Apuleius' "arguments for visual contact between Socrates and his daimonion are weak in the extreme." The reason why Apuleius nevertheless chose to include them can be found, always according to Harrison, in the intellectual context of the work: "The idea of private communion with a god was a highly popular one in the age of the Second Sophistic" (ibid.). 
system of the De Platone, and thus strikingly illustrates both the self-display and the careful philosophical instruction of the self-proclaimed philosophus Platonicus.

\section{Plutarch of Chaeronea}

Plutarch situates his discussion of Socrates' $\delta \alpha \mu$ óvıov in a historical context, viz. the liberation of Thebes in $379 \mathrm{BC}$. This entails a completely

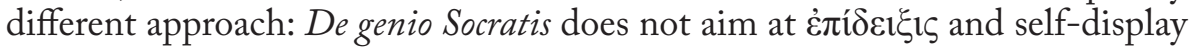
but contains an erudite discussion among philosophically minded conspirators, who are obviously interested in problems of divination. Moreover, the topic of Socrates' divine sign does not come out of the blue, but is the logical consequence of the previous discussions ${ }^{73}$.

The question is raised by Theocritus, as an objection against Galaxidorus, who argued that Socrates was opposed to superstitious beliefs regarding the apparition of divine signs and only relied on sober reasoning ${ }^{74}$. Theocritus' view is fairly superficial ${ }^{75}$ : from his childhood Socrates had a kind of daemonic vision (ö $\psi 1 v$ ) which showed him the way in obscure decisions ${ }^{76}$. It is quite remarkable that it is with regard to this view, which is used by Plutarch in order to introduce the question on a rather general and even somewhat naive level, that several striking parallels can be found with Maximus of Tyre and Apuleius: the mention of Pythagoras, the reference to Athena in Homer, the intervention of the $\delta$ aluóviov in obscure matters, the interest in anecdotes, and, of course, the visual interpretation of the divine voice. Those many significant parallels throw an interesting additional light on the level and scope of Maximus' and Apuleius' discussions. In a certain sense, they do not go (far) beyond a mere introduction of the question. In other words, they stop where Plutarch starts. Their view reflects a pre-philosophical position, and this is precisely the level to which they usually appeal. They are not interested in difficult technical issues, through which they would lose the attention of their audiences. For Plutarch, on the other hand, such pre-philosophical convictions are only the starting point of a more thorough, philosophical inquiry.

The first serious attempt at interpretation comes from Galaxidorus. Briefly, he regards Socrates' $\delta \alpha \mu$ óviov as a trivial external matter, a sneeze or chance

${ }^{73}$ See, e.g., D. Babut (1984), 63-68 on the importance of the theme of divination throughout De genio Socratis. This observation, however, does not solve the complex problem of the unity of De genio Socratis. M. Riley (1977), D. Babut (1984) and A. Georgiadou (1995) regard the relation between vita contemplativa and vita activa as the unifying theme of the work, whereas F.E. Brenk (1996) points to the importance of the theme of freedom, and A. Barigazzi (1988) to the figure of Epameinondas.

${ }^{74}$ De genio Socr. $579 \mathrm{~F}-580 \mathrm{C}$.

${ }^{75}$ And to a certain extent conditioned by the story about Theanor, who spent the night at Lysis' tomb in order to remove the remains and bring it to Italy, unless some $\delta \alpha \mu$ óviov would oppose it

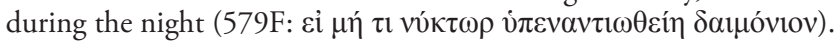

${ }^{76}$ De genio Socr. 580CD. 
remark $(\kappa \lambda \eta \delta \dot{\omega} v)$ which the philosopher used in matters of equipollence ${ }^{77}$. This is a very rationalistic interpretation, which is both in line with Galaxidorus' general view of Socrates and not devoid of important philosophical credentials, as it can be traced back to Socrates' companion Terpsion ${ }^{78}$. It is such an interpretation which is rejected by Apuleius, and Plutarch, too, brings forward several objections. If Socrates was really guided by a sneeze, why then did he not admit this and spoke instead of a divine sign? Is this not evidence of vain affectation? Moreover, the philosopher's behaviour usually seemed to rest on a stable foundation, and anecdotes about the working of the $\delta \alpha \mu$ óviov also seem to point in a different direction ${ }^{79}$. These are interesting counter arguments, and several of them are much more fundamental, at least from a philosophical point of view, than those adduced by Apuleius. But what especially distinguishes Plutarch from Apuleius is the mere fact that he allows Galaxidorus to defend himself. Galaxidorus indeed intelligently argues that Socrates' conduct had nothing to do with conceited affectation: the philosopher realised that the sneeze was merely an instrument of the divinity, and preferred to focus on the divine source rather than on the trivial instrument ${ }^{80}$. This may not be an answer to all problems which Galaxidorus' view entails, to be sure, but the view is interesting enough to be taken into account ${ }^{81}$. It is clear that this is perfectly in line with the dynamics of a philosophical dialogue rather than a rhetorical monologue. The reader is not introduced to ready-made answers, but enters a process of enquiry into the truth ${ }^{82}$.

Then it is Simmias' turn. After having underlined that Socrates' $\delta \alpha \mu$ óviov should be understood as an auditory phenomenon, not a visual one, he elaborates a particularly interesting philosophical alternative, starting from traditional insights about human speech as a blow against the air ${ }^{83}$. In Socrates' case, however, the communication with the daemon did not entail such violent blows, but the philosopher was directly 'touched' in his mind by the daemonic messages ${ }^{84}$. This is not the place to enter at length into the details of Simmias' interpretation ${ }^{85}$, but I would like to emphasise that his approach is completely different from that of Maximus and Apuleius. Simmias' physicalistic interpretation is not based on argumenta ex auctoritate but looks for rational insight, and aims at the truth rather than at $\pi \varepsilon 1 \theta \omega$. Moreover, Simmias does neither try to remove wonder nor explain away the idiosyncratic aspect of

${ }^{77}$ De genio Socr. 580F-581A.

${ }^{78}$ De genio Socr. 581A. On Terpsion, see also Plato, Phd. 59c and Tht. 142a-143c; Suda IV, 404.23 Ad.

${ }^{79}$ De genio Socr. 581B-E.

${ }^{80}$ De genio Socr. $581 \mathrm{~F}-582 \mathrm{C}$.

${ }^{81}$ See esp. D. Babut (1988), who argues that Plutarch never utterly rejects Galaxidorus' point of view, and that such 'rationalism' was one aspect of Plutarch's own philosophical outlook.

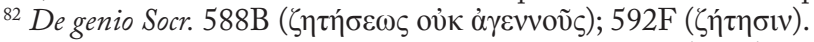

${ }^{83}$ De genio Socr. 588E and 589C; cf. L. Van der Stockt (1992), 57-58.

${ }^{84}$ De genio Socr. 588B-589F.

${ }^{85}$ Good discussions can be found in A. Corlu (1970), 53-60; K. Döring (1984), 379-381; K. Alt (1995), 82-83; A.A. Long (2006). 
Socrates' $\delta$ aluóviov. Socrates is rather depicted as one of the few exceptional men whose outstanding purity enables them to perceive the unuttered messages of daemons ${ }^{86}$. The traditional element of Socrates' perfect virtue is thus used in a particularly interesting way. It does not explain the mere presence of the sign, but is part and parcel of an investigation into the precise way in which the daemon communicated with the human philosopher, and even becomes the interpretative key in order to translate the ordinary theory of language towards the special case of Socrates.

Having developed this view, Simmias goes on to relate what he heard from Timarchus. The core of the latter's view is that the daemon should be equated with the human mind or voṽ, , that is, the part of the soul which does not come into contact with the body ${ }^{87}$ and which guides - or tries to guide - the soul ${ }^{88}$. From this section on, the specific question of Socrates' $\delta \alpha \mu$ óvıov begins to fade into the background. However, this shift of focus towards a more general perspective is not a clever way to ignore puzzling specific questions. The previous interventions of Galaxidorus and Simmias have already shown that Plutarch, unlike Maximus, does not evade the question of the peculiar nature of Socrates' divine sign. On the other hand, Timarchus' view does not contain a systematically elaborated demonology (such like that of Apuleius) either. What, then, is the function of the Timarchus section within the whole discussion?

First of all, it is important that both at the beginning and at the end, Simmias explicitly characterizes his account as a myth ${ }^{89}$. As such, it can contribute to reaching the truth - $\alpha \lambda \eta \dot{\eta} \theta \varepsilon 1 \alpha$ again, no $\dot{\varepsilon} \pi \dot{\delta} \delta \varepsilon 1 \xi 1 \varsigma-$, although in a less accurate way than reason ${ }^{90}$. No less important is the actual place of the myth in the discussion. It is not to be found at the beginning of the discussion ${ }^{91}$ but only occurs after reason has first got all the chances to throw its light on the matter. The myth then provides an additional perspective, not

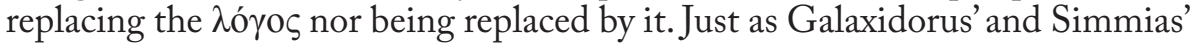
rational, philosophical reflections follow the pre-philosophical convictions of Theocritus, so the myth is only introduced when the philosophical $\lambda$ ó done its work. Such a composition can also be found elsewhere in Plutarch's works ${ }^{92}$, and reflects both his fundamental willingness to rely as much as possible on sober reasoning in his search for the truth and his openness for a complementary perspective. In this, he merely followed the example of his distinguished master Plato himself ${ }^{93}$.

${ }^{86}$ De genio Socr. 588DE and 589C. Socrates was apparently not the only one who attained that level of purity; cf. 592CD on Hermodorus of Clazomenae.

${ }^{87}$ De genio Socr. 591DE.

${ }^{88}$ De genio Socr. 592A-C.

${ }^{89}$ De genio Socr. 589F; 592E and F.

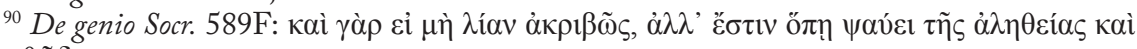
$\tau$ ò $\mu v \theta \tilde{\omega} \delta \varepsilon \varsigma$.

${ }^{91}$ Simmias even hesitates to relate it at all (perhaps $\sigma 1 \omega \pi \tilde{\alpha} v$ is $\alpha$ $\left.\mu \varepsilon เ v o v\right)$, and has to be persuaded by Theocritus; De genio Socr. 589F.

${ }^{92}$ See De facie $937 \mathrm{CD}$ for an interesting parallel example.

${ }^{93}$ The same composition, in which philosophical $\lambda$ ó $\gamma \circ \varsigma$ precedes $\mu \tilde{v} \theta \mathrm{o} \varsigma$, can be found in 
Is there anything to be added after the myth? The last word is for Theanor. He regards daemons as disembodied souls who help kindred souls which are still in the body but which have made much progress and are about to reach the end of the reincarnation process ${ }^{94}$. On the one hand, Theanor recalls several key topics which played an important part in the views of previous speakers, such as the idea of the exceptional nature that is worthy of communication with the gods ${ }^{95}$ or the notion of moral excellence as the conditio sine qua non for the assistance of demons ${ }^{96}$. On the other hand, he also adds a few new elements, the most important of which is that of the daemon as personal supervisor and thus indirectly the providential working of the daemons. This combination of looking back on the previous discussion and introducing a few new ideas shows that Theanor's contribution should be understood as an original evaluative conclusion. This is no mere addendum but the introduction of a broader perspective from which the previous contributions, including both $\lambda$ ó $\gamma \circ$ and $\mu \tilde{v} \theta \mathrm{o} \varsigma$, can be understood ${ }^{97}$. This is also the reason why his contribution has such a general scope: in a retrospective evaluation there is no room for a discussion of particulars, although the introduction of the new perspective can stimulate further thinking. Even after the myth, philosophical reflection can in principle go on. The conspirators, however, do not take this opportunity. For them the time has come to deliver Thebes, for us to conclude.

\section{Conclusion}

In the second half of the fifth century BC, many voices could be heard in Athens. There were the dignified voices of the tragedians, the critical voices of the historians and the humorous voices of the comedians. Sophists discussed with philosophers, politicians with the people, and Socrates with everybody. But in this impressive chorus of usually extremely dissonant, though in some respects also remarkably harmonious voices, there was one strange, divine voice, which never directly took part in the public debates, had perhaps little more to say than a simple and clear "No!" it was this strange voice that became a challenge to later thinking for many ages to come and gave rise to a new chorus of often dissonant voices, three of which were those of Maximus, Apuleius, and Plutarch. Although Socrates' daemonic voice was confined to a brief but crucial period in the history of Western civilisation, at least part of the many voices and the torrents of words which it inspired have come down to us.

\footnotetext{
Plato's Phaedo, Gorgias, and Republic.

${ }^{94}$ De genio Socr. 593A-594A.

${ }^{95}$ De genio Socr. 593D.

${ }^{96}$ De genio Socr. 593F-594A.

${ }^{97}$ Significant in this respect is that Theanor explicitly expresses his approval of both Simmias' and Timarchus' interpretation; De genio Socr. 593A.

${ }^{98}$ Cf. Th.C. Brickhouse - N.D. Smith (2000), 248; contra M.L. McPherran (1996), 204-205.
} 


\section{BibLIOGRAPHY}

Alt, K.(1995), 'Das sokratische Daimonion in der Darstellung Plutarchs', in H. Kessler (ed.), Sokrates. Geschichte, Legende, Spiegelungen. Sokrates-Studien II, Kusterdingen, 71-96.

Babut, D. (1984), 'Le dialogue de Plutarque sur le démon de Socrate.Essai d'interprétation', $B A G B$ 51-76.

- (1988), 'La part du rationalisme dans la religion de Plutarque: l'exemple du De genio Socratis', ICS 13.2,383-407.

Baltes, M. et al. (2004), Apuleius. De deo Socratis.Über den Gott des Sokrates. Eingeleitet, übersetzt und mit interpretierenden Essays versehen von Matthias Baltes, Marie-Luise Lakmann, John M. Dillon, Pierluigi Donini, Ralph Häfner, Lenka Karfíková, Darmstadt (Sapere 7).

Barigazzi, A. (1988), 'Una nuova interpretazione del De genio Socratis', ICS 13.2, 409-425.

Beaujeu, J. (1973), Apulée. Opuscules philosophiques (Du dieu de Socrate, Platon et sa doctrine, Du monde) et fragments. Texte établi, traduit et commenté, Paris (CUF).

Bernard, W. (1994), 'Zur Dämonologie des Apuleius von Madaura', RhM NF 137, 358-373.

Brenk, F.E. (1996), 'Time as Structure in Plutarch'sThe Daimonion of Sokrates', in L. Van der Stockt (ed.), Plutarchea lovaniensia. A Miscellany of Essays on Plutarch, Lovanii, 29-51.

Brickhouse, Th.C. - Smith, N.D. (2000), The Philosophy of Socrates, Boulder.

Corlu, A. (1970), Plutarque. Le démon de Socrate. Texte et traduction avec une introduction et des notes, Paris.

Dillon, J. (1977), The Middle Platonists. A Study of Platonism 80 B.C. to A.D. 220, London.

- (2003), The Heirs of Plato. A Study of the Old Academy (347-274 B.C.), Oxford.

Döring, K. (1984), 'Plutarch und das Daimonion des Sokrates (Plut. de genio Socratis Kap. 20-24)', Mnemosyne 37, 376-392.

Georgiadou, A., (1995), 'Vita activa and vita contemplativa. Plutarch's De genio Socratis and Euripides' Antiope', in I. Gallo - B. Scardigli (eds.), Teoria e prassi politica nelle opere di Plutarco, Napoli, 187-200.

Gercke, A. (1886), 'Eine platonische Quelle des Neuplatonismus', RhM 41, 266-291. 
Gersh, S. (1986), Middle Platonism and Neoplatonism.The Latin Tradition, Notre Dame.

Gundert, H. (1954), 'Platon und das Daimonion des Sokrates', Gymnasium 61, 513-531.

Habermenl, P. (1996), 'Quaedam divinae mediae potestates. Demonology in Apuleius' De deo Socratis', in H. Hofmann - M. Zimmerman (eds.), Groningen Colloquia on the Novel.Volume VII, Groningen, 117-142.

Harrison, S.J. (2000), Apuleius. A Latin Sophist, Oxford.

—- (2001), 'Introduction' [to De deo Socratis], in Id. (ed.), Apuleius. Rhetorical Works. Translated and annotated by S. Harrison, J. Hilton, and V. Hunink, Oxford, 185-194.

Hijmans, B.L. (1987), 'Apuleius, Philosophus Platonicus', in ANRW II.36.1, Berlin - New York, 395-475.

Hunink, V. (1995), 'The Prologue of Apuleius' De deo Socratis', Mnemosyne Ser. IV, 48, 292-312.

Joyal, M. (2000), The Platonic Theages. An Introduction, Commentary and Critical Edition, Stuttgart.

Koniaris, G.L. (1982), 'On Maximus of Tyre: Zetemata (I)', ClasAnt 1, 87121.

Lakmann, M.-L. (2004), 'Einführung in die Schrift', in M. Baltes et al. (2004), 13-44.

Long, A. (2006), 'How does Socrates' divine sign communicate with him?', in S. Ahbel-Rappe - R. Kamtekar (eds.), A Companion to Socrates, Oxford, 63-74.

Macnaghten, R.E. (1914), 'Socrates and the Saluóviov', CR 28, 185-189.

McPherran, M.L. (1996), The Religion of Socrates, University Park PA.

Moraux, P. (1984), Der Aristotelismus bei den Griechen von Andronikosbis Alexander von Aphrodisias. Zweiter Band: Der Aristotelismus im I. und II. Jh. n. Chr., Berlin - New York.

Moreschini, C. (1978), Apuleio e il platonismo, Firenze.

Opsomer, J. (1998), In Search of the Truth. Academic Tendencies in Middle Platonism, Brussel.

Puiggali, J. (1983), Étude sur les Dialexeis de Maxime de Tyr, conférencier platonicien du IIème siècle, Lille.

Regen, F. (1971), Apuleius philosophus Platonicus. Untersuchungen zur Apologie (De magia) und zu De mundo, Berlin - New York. 
_- (1999), 'Il De deo Socratis di Apuleio', Maia 51, 429-456.

- (2000), 'Il De deo Socratis di Apuleio (II parte)', Maia 52, 41-66.

Rhode, E. (1925), Psyche. Seelencult und Unsterblichkeitsglaube der Griechen, Tübingen.

Riley, M.(1977), 'The purpose and unity of Plutarch's De genio Socratis', GRBS $18,257-273$.

Sandy, G. (1997), The Greek World of Apuleius. Apuleius and the Second Sophistic, Leiden - New York - Köln.

Schindel, U. (2000), 'Apuleius - Africanus Socrates? Beobachtungen zu den Verteidigungsreden des Apuleius und des platonischen Sokrates', Hermes 128, 443-456.

Sharples, R.W. (2003), 'Threefold Providence: The History and Background of a Doctrine', in Id. - A.D.R. Sheppard (eds.), Ancient Approaches to Plato's Timaeus, London, 107-127.

Trapp, M.B. (1997), Maximus of Tyre. The Philosophical Orations. Translated, with an Introduction and Notes, Oxford.

Valgiglio, E. (1993), [Plutarco]. Il Fato. Introduzione, testo critico, traduzione e commento, Napoli.

VAn der Stockt, L. (1992), Twinkling and Twilight. Plutarch's Reflections on Literature, Brussel. 


\section{Embaucadores y Falsos Adivinos \\ en ORÁCULOS DE LA PITLA $407 \mathrm{~B}-\mathrm{C}^{1}$}

Ana Isabel Jiménez San Cristóbal
Universidad Complutense de Madrid

\section{Resumen}

En Los oráculos de la Pitia (407B-C) Plutarco cuestiona la actuación de quienes intervienen sobre las respuestas oraculares para plegarlas a su interés personal porque minan la credibilidad de la mántica y la labor de los verdaderos profesionales del santuario délfico. Plutarco menciona la vinculación con el oráculo de hombres con dotes poéticas que versificaban las respuestas oraculares, de cresmólogos y de oficiantes de cultos orientales. El propósito de la comunicación es analizar quiénes eran esos personajes y las prácticas que ejercían para tratar de determinar su responsabilidad en la decadencia de la mántica.

\section{Introducción}

En el diálogo Los oráculos de la Pitia Plutarco aborda, entre otras cuestiones, la escasez de respuestas oraculares dictadas en verso en su tiempo y se pregunta si este hecho puede suponer un descrédito para el santuario ${ }^{2}$. Plutarco, sacerdote de Delfos durante más de veinte años, trata de salvar la credibilidad de los oráculos argumentado que la mayor parte de las respuestas antiguas también eran dictadas en prosa y que, en cualquier caso, el dios las impulsa, pero no las redacta ${ }^{3}$. Entre las causas de la preeminencia de la prosa en su tiempo Plutarco cita la falta de talentos dotados para la poesía, la situación política contemporánea, que había provocado que las preguntas al oráculo fuesen sencillas y se hiciese innecesario el recurso a la ambigüedad del verso, pero, sobre todo, la actuación de quienes intervenían de un modo u otro sobre las respuestas oraculares para plegarlas a su interés personal. Plutarco señala a personajes no ligados al templo como causantes de haber minado la credibilidad de la mántica y haber empañado la labor de los profesionales del santuario.

El propósito de este trabajo es tratar de determinar quiénes eran esos personajes y qué prácticas ejercían.

${ }^{1}$ Este trabajo forma parte del Proyecto de Investigación Consolider C "Cosmogonía y escatología en las religiones del Mediterráneo oriental: semejanzas, diferencias, procesos", financiado por el MEC (HUM2006-09403).

${ }^{2} \mathrm{El}$ problema se plantea en el capítulo séptimo $(397 \mathrm{D})$ y se convierte en tema central en los catorce últimos (402B-409D). Aunque en la tradición ha prevalecido el título latino del catálogo de Lamprias De Pythiae oraculis, los manuscritos transmiten el título griego

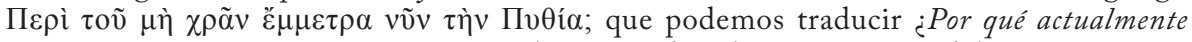
la Pitia no da sus respuestas en verso?, lo que indica la importancia del argumento en cuestión.

${ }^{3}$ Plu., Pyth. or. 403 A-F, 405 D-E. 


\section{Los Versificadores}

En la primera parte del pasaje que nos ocupa, Oráculos de la Pitia 407 B-C, Plutarco menciona la existencia de hombres con dotes poéticas que versificaban las respuestas oraculares a la manera de los rapsodos:

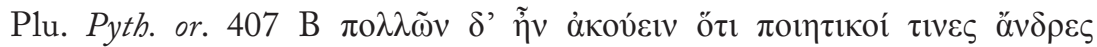

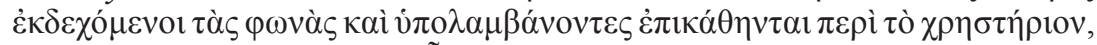

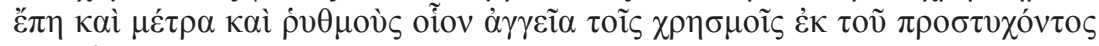
$\pi \varepsilon \rho \imath \lambda \lambda \dot{\kappa} \kappa o v \tau \varepsilon \varsigma$.

Y a muchos se les podía oír decir que ciertos hombres con dotes poéticas estaban sentados juntos al oráculo recibiendo y recogiendo las sentencias y componían improvisadamente versos, metros y ritmos a modo de recipientes para los oráculos.

Es posible que se trate de los mismos personajes a los que en otro diálogo pítico se denomina $\pi \rho \circ \varphi \tilde{\eta} \tau \alpha$ y que formaban parte del clero del santuario délfico ${ }^{4}$. Su labor consistía en redactar las respuestas que transmitía la Pitia al consultante y versificarlas cuando era preciso, ya que en muchos casos la Pitia, mujer campesina y de escasa cultura, no podía darles forma hexamétrica ${ }^{5}$. Heródoto y Eurípides dan cuenta de la existencia de estos personajes, pertenecientes a la clase noble de Delfos, y Estrabón especifica que son servidores del templo dedicados a versificar las respuestas en prosa ${ }^{6}$. Parece que también en los oráculos de Claros y Dídima funcionarios similares se encargaban de la redacción de las respuestas en tiempos de Adriano ${ }^{7}$.

La presencia de los versificadores puede haber arrojado una sombra de duda sobre la autenticidad de los oráculos, que los delfios presentaban como producto genuino de la Pitia, y haber socavado su credibilidad. Plutarco, servidor él también del santuario, no cuestiona, sin embargo, la labor de estos

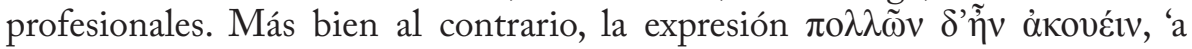
muchos se les podía oír decir', parece señalar el distanciamento voluntario del de Queronea respecto a quienes responsabilizaban a los versificadores de la decadencia del oráculo.

\section{Los Cresmólogos}

Plutarco parece querer distanciarse también de quienes achacan la pompa y el estilo trágico de los oráculos a los seguidores de Onomácrito, Pródico y Cinetón: $386 \mathrm{~B}$.

${ }^{4}$ Plu., Def. orac. 414 E, 438 B; véase también la denominación de icpeúc en $E$ ap. Delph.

${ }^{5}$ H. W. Parke, 1940; W. E. McLeod 1961; R. Flacelière, 1965, pp. 57-58; J. A. Fernández Delgado, 1991. S. Schröder, 1990, pp. 392-393, piensa, en cambio, que se trata de empresarios privados que habrían bajado al oráculo.

${ }^{6}$ Hdt., VIII 36; Eu., Io 413-416; Str., IX 3.5.

${ }^{7}$ H. W. Parke, 1940, 86, 1985, 220-221; J. Fontenrose, 1988, pp. 43, 78-80. 


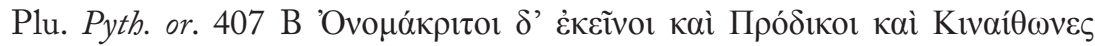

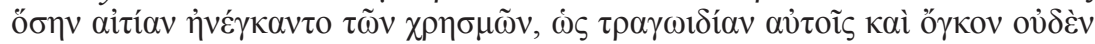

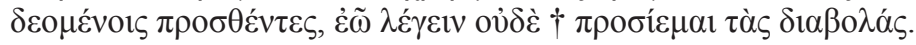

Cuánta responsabilidad en los oráculos tuvieron los Onomácritos, Pródicos y Cinetones, al añadirles estilo trágico y pompa sin que en absoluto los necesitaran, omito decirlo y no tolero las calumnias.

La mención de Onomácrito implica una referencia a los llamados $\chi \rho \eta \sigma \mu \mathrm{\lambda}$ ó $\gamma$ ol, compiladores de oráculos que trabajaban al margen de los grandes centros. Se dedicaban a comerciar con las respuestas y eran capaces de modificar un oráculo existente o forjar uno a medida para sus clientes. Estos cresmólogos, cuya edad de oro se sitúa durante la Guerra del Peloponeso, ponían en circulación oráculos anónimos o atribuidos a profetas legendarios, como Museo o Baquis, o a algún santuario famoso 8 .

Onomácrito vivió en la corte ateniense de los Pisistrátidas a finales del s. VI a. C. y se le atribuye la sistematización de los oráculos del legendario Museo, la participación en la redacción de los poemas homéricos y la compilación y composición de poemas atribuidos a Orfeo ${ }^{9}$. Según Heródoto $^{10}$, Onomácrito fue expulsado de Atenas por Hiparco cuando fue sorprendido en el flagrante delito de intercalar un oráculo propio en la recopilación de Museo. Marchó entonces a Susa donde puso su ciencia al servicio de Jerjes. La reconciliación con los Pisistrátidas debió de tener lugar cuando éstos, expulsados por los atenienses, recalaron también en la corte del rey persa.

Los Pisistrátidas eran adversarios políticos de los Alcmeónidas, quienes tenían gran influencia y control sobre el sacerdocio délfico. No parece verosímil la hipótesis de que Onomácrito, un cresmólogo filopisistrátida, hubiese realizado una recopilación de oráculos píticos y hubiese introducido en ella sus acostumbradas interpolaciones ${ }^{11}$. Es más probable que su actividad se limitase a recopilar e interpolar profecías en verso que los Pisistrátidas habrían depositado en el templo de la Acropólis para contraponerlas a los vaticinios provenientes del santuario hostil ${ }^{12}$. Es decir, Onomácrito y otros cresmólogos habrían contribuido al uso político de los oráculos en favor de determinadas ciudades, una manipulación que habría perjudicado la reputación de los oráculos y habría provocado el progresivo desafecto de los griegos por la adivinación ${ }^{13}$.

${ }^{8}$ Th., II 8; Ar., Au. 960, cf. M. P. Nilsson, 1954, pp. 218-219; R. Flacelière, 1965, pp. 67-72.

${ }^{9}$ Sobre el cual véase E. D’Agostino, 2007, pp. XI-XXIX; A. Bernabé, 2008, pp. 229-230;

M. Herrero, 2008, pp. 255, 261 n. 62, pp. 264, 277; R. Martínez Nieto, 2008, pp. 571-576.

${ }^{10}$ Hdt., VII 6.

${ }^{11}$ Véase, en cambio, F. Stoesse, 1972, cols. 304-305.

${ }^{12}$ Véase Hdt., V 62-63; V 90; VI 123, cf. E. D’Agostino, 2007, 58-59.

${ }^{13}$ R. Flacelière, 1965, 78. 
Más problemática resulta la mención de los otros dos individuos, Pródico y Cinetón ${ }^{14}$. Se ha propuesto identificar al primero con Pródico de Focea o con Pródico de Samos. El de Focea era conocido como autor de un poema épico titulado Miníada que trataba el castigo pagado por Támiris en el Hades ${ }^{15}$. A Pródico de Samos se le atribuía una obra órfica titulada Catábais de Orfeo ${ }^{16}$. Cinetón se ha vinculado con Cinetón de Esparta, un poeta genealógico y épico ${ }^{17}$. Carecemos de testimonios que relacionen a Pródico y Cinetón con los vaticinios oraculares, pero su evocación junto a Onomácrito podría justificarse por otros motivos. En primer lugar, ambos son autores épicos y la poesía oracular se inserta en el seno del epos tradicional en el que distintos autores pudieron tratar más de un género, como el épico y el mántico ${ }^{18}$. En segundo lugar, la temática escatológica de las obras de Pródico y Cinetón puede haber favorecido su vinculación con Onomácrito, ya que las catábasis ocupaban un lugar primordial entre los poemas órficos de los que la tradición le hacía compilador. Incluso, uno o dos versos de la Nekyia odiseica fueron atetizados y atribuidos a Onomácrito ${ }^{19}$. Desde el s. I d. C. su nombre se había convertido en comodín al que adscribir la literatura órfica o semejante cuya autencidad se pusiera en duda.

\section{Los Oficiantes de Cultos Orientales}

En la última parte del pasaje de Plutarco que nos ocupa, el de Queronea denuncia que lo que más descrédito causó al verso oracular fue la tropa embaucadora y feriante que vagabundea en torno al templo de la diosa Madre y de Serapis, recitando oráculos a esclavos y mujerzuelas:

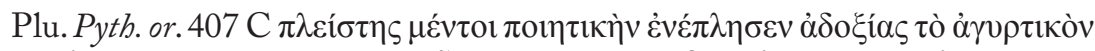

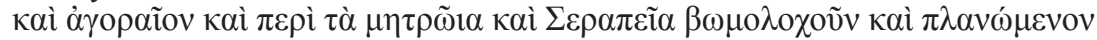

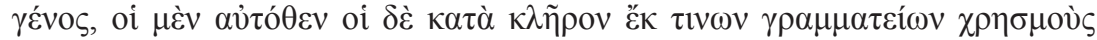

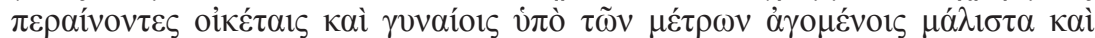

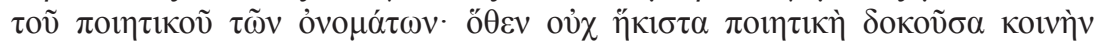

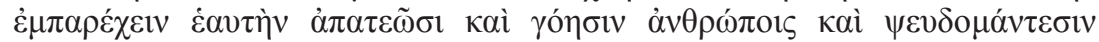

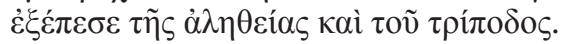

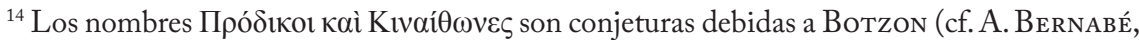
2005, p. 341 [OF 808], p. 530 [OF 1112]; E. D’Agostino, 2007, 5-6), no aceptadas por todos

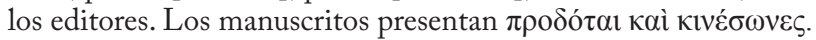

${ }^{15}$ A. Bernabé, 19962 , pp. 137-142. El tema es compatible con una catábasis.

${ }^{16}$ Clem. Al. Strom., 1.21.131.3, cf. A. Bernabé, 2005, p. 264 (OF 707), p. 469 (OF 1018 III). M. L. West, 1983, p. 10 n. 17 y A. Bernabé, 2005, p. 534 (OF 1124) sostienen que Clemente habría atribuido la catábasis a Heródico y que la lectura 'Pródico' de Samos sería una alteración de los copistas.

${ }^{17}$ A. Bernabé, 1996 , pp. $115-117$.

${ }^{18}$ Cf. J.A. Fernández Delgado, 1985, pp. 155-156 y n. 17.

${ }^{19} \mathrm{Sch}$. Hom. Od. XI 602 (525 Dindorf). No es claro si la atétesis afecta a 602 o 602-604. Los versos se ocupan de Heracles y son muy similares a otros pasajes de Hesíodo marcados con obelos en el Catálogo (Fr. 25 M.-W.) y la Teogonía (947-955). La razón de la atétesis tampoco está clara, cf. West ad loc. y M. Herrero, 2008, p. 264. 
Pero a la forma poética la colmó de pésima reputación la prole pedigüeña y demagoga que hace bufonadas en torno al culto de la Gran Madre y de Serapis y va de acá para allá recitando oráculos, unos de forma instantánea, otros sacándolos a suerte de ciertas tablillas, a esclavos y mujerzuelas que se dejan persuadir especialmente por los metros y la poesía de las palabras. De ahí precisamente que la forma poética, que parecía servir igualmente a embaucadores, hechiceros y falsos adivinos, haya quedado apartada de la verdad y del trípode.

Los cultos de origen oriental proliferaron en numerosas provincias del imperio romano, incluida la de Acaya, y gozaron de un gran favor sobre todo entre las clases populares ${ }^{20}$. El culto de Cíbele, la Gran Madre, diosa frigia que los griegos asimilaron a Rea, había penetrado en Grecia desde las Guerras Médicas y estuvo siempre caraceterizado por su dimensión mística y orgiástica $^{21}$. El culto de Serapis, una divinidad en la que se reconoce la fusión de Osiris y Apis ${ }^{22}$, fue implantado oficialmente en Alejandría durante el período helenístico en un intento de revestir de caracteres griegos a un dios de origen egipcio. En él confluyen los rasgos ctónicos de Osiris y Plutón, la fecundidad asociada a Apis y formas rituales propias de los misterios eleusinios ${ }^{23}$.

La intención de Plutarco parece haber sido denunciar el apropiamento indebido del oráculo por parte de ciertos sacerdotes de estos cultos y el menoscabo que ello produjo al prestigio de la institución. El de Queronea

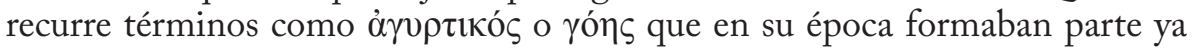
del vocabulario tradicional para referirse a oficiantes de ritos que conjugaban su labor con prácticas adivinatorias y oraculares.

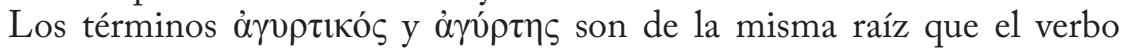
à $\gamma \varepsilon i ́ p \omega^{24}$, que significa 'mendigar o vivir de limosna'. Los vocablos puede aplicarse a distintos ámbitos ${ }^{25}$, pero los encontramos mayoritariamente referidos a personajes que se dedicaban a la adivinación y, en contexto religioso, a sacerdotes mendicantes que se ganaban la vida celebrando ritos asociados a la magia y a las prácticas adivinatorias ${ }^{26}$. Designan, por tanto, a quienes trataban de obtener beneficios materiales recurriendo por lo general a prácticas mágicas $\mathrm{y}$ adivinatorias, en principios ajenas a su profesión.

Adivinos ilustres son calificados de pedigüeños por querer sacar excesivo beneficio de su arte. Es el caso de Lampón en un texto de Lisipo y de Tiresias

${ }^{20}$ Sobre estos cultos, cf. J. Alvar, 2001; E. SAnzi, 2003, con bibliografía.

${ }^{21}$ E. Sanzi, 2003, pp. 38-40; J. Alvar, 2001, pp. 185-188.

${ }^{22}$ Clem. Al. Prot., 4.48.6.

${ }^{23}$ J. Alvar, 2001, pp. 58-67.

${ }^{24}$ Cf. P. Chantraine, 1968-1980 s. v. àyzípw; G. Lanata, 1967, pp. 41-42. 15.1.16.

${ }^{25}$ Como, por ejemplo, la medicina: Hp., Morb. Sacr. 1.10 (60 Grenseman); Luc., DDeor

${ }^{26} \mathrm{E} 1$ significado de mendigo, del que deriva lógicamente el de sacerdote mendicante, puede

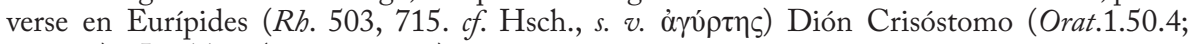
30.20.2) y Jámblico (Myst. 10.2.13). 
en otro de Sófocles ${ }^{27}$. En ocasiones la línea que dividía la frontera entre magia, adivinación y mendicidad debía de ser muy frágil, según denuncia Estrabón ${ }^{28}$.

El propio Plutarco parece considerar sinónimos los términos $\mu$ óv $\tau \imath \varsigma$ y

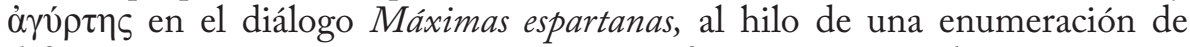
diferentes gremios, como comerciantes y sofistas, cuyo nexo de unión parece ser la obtención de ganancias ${ }^{29}$.

Además de los adivinos, reciben frecuentemente el calificativo de $\alpha \gamma u ́ \rho \tau \alpha \iota$ los sacerdotes de ciertos cultos. Por ejemplo, en un pasaje de la República, Platón dirige sus críticas contra 'sacerdotes mendicantes y adivinos', $\alpha \gamma u ́ \rho \tau \alpha 1$

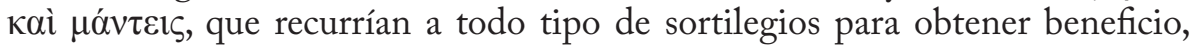
en especial, de los ricos ${ }^{30}$. En este y otros pasajes el filósofo traza una imagen despectiva de ciertos oficiantes de ritos órficos que, en su opinión, atacaban de lleno los postulados de la filosofía y amenazaban con romper el orden asegurado por la religión oficial ${ }^{31}$. El orfismo vinculaba la promesa de un destino mejor tras la muerte al cumplimiento de determinados ritos. No es de extrañar que junto a los sacerdotes que actuaban convencidos de la eficacia de esos ritos surgiesen falsarios dedicados a comerciar especulativamente con las promesas de salvación, aprovechándose de la buena fe de sus clientes. Platón critica esta degeneración, haciendo especial hincapié en el carácter heterogéneo y desordenado de las actividades de estos charlatanes (sacrificios y ritos de purificación y liberación, junto a ensalmos, encantamientos y actividades mágicas), no menos sorprendente e irracional que la oferta de potenciales beneficios: cancelación de culpas y delitos, acciones "teúrgicas" para constreñir a los dioses y provocar daños al enemigo, y liberación de las penas en el otro mundo. El rechazo que Platón podía sentir hacia estos cultos mistéricos se vería agudizado por el hecho de que los oficiantes, muy persuasivos y con gran poder de convocatoria ${ }^{32}$, pudieran influir sobre personajes poderosos, pertenecientes a las capas más altas del Estado y capaces de arruinar ciudades enteras ${ }^{33}$.

Siglos más tarde, Estrabón caracteriza a Orfeo como mago, mendigo, músico, adivino y oficiante de ritos orgiásticos, en una descripción en que la figura del cantor encarna rasgos propios de los orfeotelestas de la época ${ }^{34}$. La posición defensiva del historiador frente a la amenaza de las religiones mistéricas justifica la caracterización peyorativa de Orfeo, insistiendo en los

${ }^{27}$ Lysipp., VI (PCG 5, p. 620 K.-A.); S., OT 387-389.

${ }^{28}$ Str., X 3.23, cf. A. BernabÉ, 2002, pp. 62-63.

${ }^{29}$ Plu., Apophth. Lac. 226 D.

${ }^{30}$ P1., R. 364b-c (OF573 I), cf.A.I.JIMÉNEZ SAN CRistóBAL, 2008, 775-777, con bibliografía.

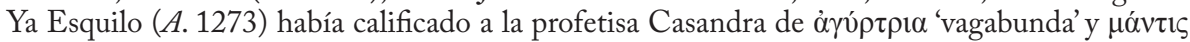
'adivina', reuniendo, por tanto, ambas facetas.

${ }^{31}$ Cf. et. P1., R. 364e, Lg. 909b.

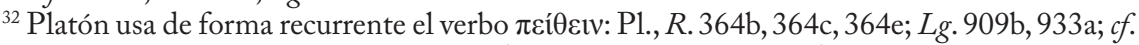

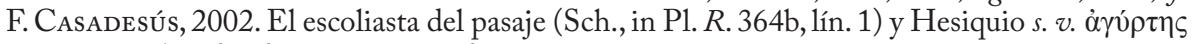
insisten en el poder de convocatoria de estos personajes.

${ }^{33}$ Pl., Lg. 908d, cf. F. Casadesús, 2002.

${ }^{34}$ Str., VII fr. 10a Radt (OF 554); A. Bernabé, 2002 considera que se trata de una lectura política del mito de Orfeo. 
aspectos que más lo acercan a los especuladores con fines ajenos a la religión.

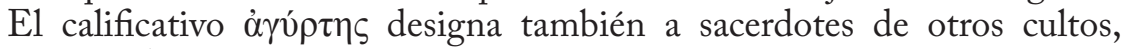
como el de Afrodita del que Plutarco ofrece un ejemplo en sus Historias griegas y romanas ${ }^{35}$. El vocablo denomina asimismo con relativa frecuencia a los oficiantes del culto de la Gran Madre. Ya en Aristóteles encontramos un término específico para referirse a los sacerdotes de Cíbele en tono despectivo, $\mu \eta \tau \rho \alpha \gamma \tilde{v} \rho \tau \alpha{ }^{36}$. Dioniso de Halicarnaso lo usa, pero ya sin ánimo peyorativo, para referirse a sacerdotes que celebran sus ritos en Roma, recorriendo las calles y pidiendo limosna, mientras entonan su cantos en honor de la Diosa

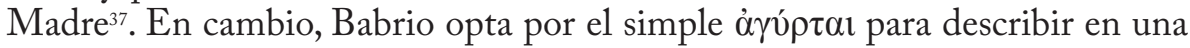
de sus Fábulas el comportamiento de los oficiantes de Cíbele, que vagan de un lado a otro recogiendo provisiones y celebrando ritos ${ }^{38}$. Por su parte, el lexicógrafo Hesiquio explica que los poetas cómicos denominaban ơ $\gamma u ́ \rho \tau \alpha \imath$ a los sacerdotes mendicantes de Cíbele precisamente por su relación con la magia y la realización de sacrificios ${ }^{39}$. En el pasaje de los Oráculos de la Pitia, Plutarco

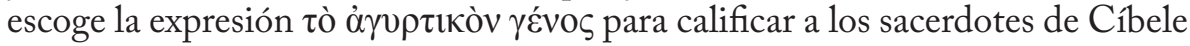
y Serapis. La elección este término, en lugar del más específico $\mu \eta \tau \rho \alpha \gamma u ́ \rho \tau \eta \varsigma$, quizá no se deba sólo a la inclusión de los oficiantes de Serapis. Nótese que en ninguno de los ejemplos citados de $\mu \eta \tau \rho \alpha \gamma u ́ \rho \tau \alpha l$ se precisa su relación con la mántica. En cambio, el vínculo es constante en los ejemplos del genérico

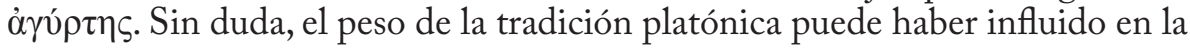
preferencia por este último.

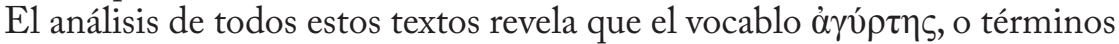
de su misma familia, señalan la degeneración que el lucro personal podía ocasionar entre adivinos y sacerdotes, unas veces porque corrompía a verdaderos profesionales, como Tiresias o Lampón, otras porque favorecía el intrusismo de falsos expertos en el oficio. En esta última categoría podrían incluirse ciertos sacerdotes de cultos orientales que en tiempos de Plutarco comerciaban con oráculos en verso.

Significativo es también el término yoń $\varepsilon \varsigma$ ‘hechiceros', con que Plutarco califica al final del pasaje a los oficiantes de cultos orientales. En principio, este nombre designa en griego a una figura compleja que aúna el éxtasis y el lamento ritual, la curación mediante ritos y las prácticas adivinatorias ${ }^{40}$, sentidos que lo convierten en término apropiado para calificar a los oficiantes de cultos mistéricos ${ }^{41}$.

${ }^{35}$ Plu., Aetia Romana et Graeca 303 C.

${ }^{36}$ Arist., $R$ h. 1405a 20. Plutarco también emplea el término para referirse en tono despectivo a Ptolomeo Filopátor: Plu., Cleom. 36. Sobre el vocablo, cf. F. Poland, i 932.

${ }^{37}$ D. H., II 19.

${ }^{38}$ Babr., 141-149.

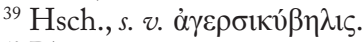

${ }^{40}$ Pl., Smp. 203a, Phlb. 44c; cf. W. Burkert, 1962; F. Graf, 1994, p. 35.

${ }^{41}$ Orfeo (Str., VII fr. 18), Pitágoras (D. L., VIII 36) y Empédocles (Gorg., A 3 D.-K., ap. D. L. VIII 58. 59) son llamados yớ $\varepsilon \varsigma$. Según E. R. Dodds, 1960, pp. 141-142, Empédocles representa al chamán que combina las funciones indiferenciadas de mago, naturalista, poeta y filósofo, predicador, sanador y consejero público. Cf. W. Burkert, 1962, p. 38 y n. 10, p. 48 y n. 
En un pasaje de las Leyes, Platón emplea el participio del denominativo

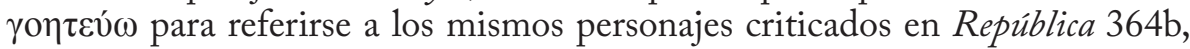

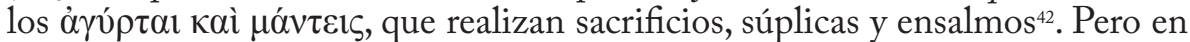
otros pasajes el vocablo tiene también el significado despectivo de 'estafador', 'mentiroso' o 'charlatán', en particular referido a los sofistas ${ }^{43}$.

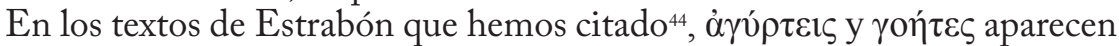
unidos en referencia a oficiantes que embaucan interesadamente a su clientela, lo mismo que en el texto de los Oráculos de la Pitia. Гóns encierra, por tanto, los valores de oficiante de ritos, hechicero, mago, adivino y timador. Todos ellos reaparecen posteriormente en Luciano. Así en Alejandro o el falso profeta, el de Samósata dirige su aguda crítica contra quienes se dedicaban a comerciar con el miedo y la superstición de los hombres vendiendo oráculos y remedios a supuestos males, emulando a los sacerdotes de ciertos cultos. ${ }^{45} \mathrm{~A}$ esa caterva pertenece el protagonista del diálogo, un truhán, medio sacerdote, medio milagrero-curandero y medio adivino. En Sobre la muerte de Peregrino Luciano ataca, en los mismos términos, a los magos y hechiceros que se aprovechaban de las circunstancias para hacerse ricos entre los cristianos, mientras que en $L a$ Asamblea de los dioses su crítica se centra en los charlatanes y timadores que se dedicaban a dar oráculos provocando el desprestigio de la sede délfica ${ }^{46}$. Las denuncias previas de Plutarco parecen no haber surgido efecto.

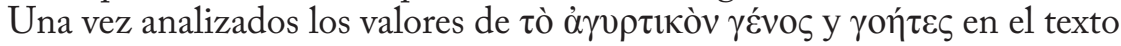
de Plutarco, podemos suponer que la denominación despectiva $\psi \varepsilon v \delta \delta \mu \alpha{ }^{2} v \tau \varepsilon 1 \varsigma$, 'falsos adivinos', que cierra el pasaje hace referencia a las actividades asociadas a este tipo de personajes, y no a la práctica de la cleromancia, es decir, la adivinación sacando al azar palabras escritas en ciertos guijarros ( $\kappa \lambda \tilde{\eta} \rho \circ \varsigma)$, que está bien atestiguada en relación al oráculo de Delfos y se supone anterior a la adivinación inspirada por el entusiasmo ${ }^{47}$. En cualquier caso, da la impresión de que, en cierta medida, Plutarco responsabiliza también de la decadencia del oráculo a la clientela que acude a estos embaucadores y falsos adivinos. La falta de juicio de mujerzuelas y esclavos habría propiciado un aumento del negocio y la consecuente proliferación de estos personajes. En este sentido, cabe destacar que en el diálogo Sobre la superstición Plutarco reprocha a los supersticiosos su

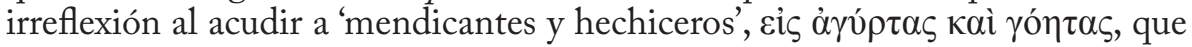
no son sino falsos profesionales ${ }^{48}$.

61; Ch. Riedweg, 1997, pp. 35, 38-41, 51 y n. 116.

${ }^{42}$ Pl., Lg. 909b (OF 573 IV).

${ }^{43}$ P1., Sph. 241b, Plt. 291c, 303c. Cf. Aeschin., III 137; D. XVIII 276, XIX 102, 109, XXIX

32. Sólo en tres pasajes parece no tener ese valor negativo: A., Ch. 822.; Gorg., 82 A 3 D.-K.; P1., Smp. 203.

${ }^{44}$ Str., X 3.23; VII fr. 10a Radt (OF 554).

${ }^{45}$ Luc., Alex. 1, 5, 6, 25, 60.

${ }^{46}$ Cf. Luc., Peregr. 13, Deor. Con. 12. En DMort. 10.2 ataca a Trofonio por sus hechizos

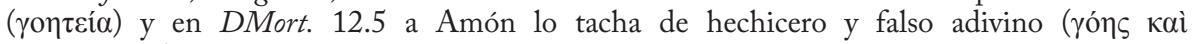
$\psi \varepsilon v \delta o ́ \mu \alpha v \tau \iota \varsigma)$.

${ }^{47}$ Cf. R. Flacelière, 1965, pp. 23-24, 41, 54-55; P. Amandry, 1950, 25ss.

${ }^{48}$ Plu., Superst. 166 A. 


\section{Conclusiones}

Llegados al final podemos extraer algunas conclusiones. Plutarco distingue diversos niveles de responsabilidad en la decadencia del oráculo. No cuestiona la labor de los versificadores, a los que se refiere en términos no peyorativos como

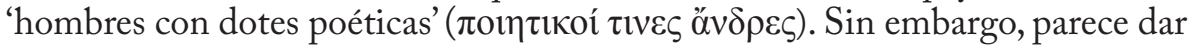
a entender que la forma poética ha podido ensombrecer la autenticidad de los oráculos, en principio presentados como productos genuinos de la Pitia. La poesía podía constutituir la puerta de entrada de falsos profetas. Algo similar pudo ocurrir con los cresmólogos, quienes, en principio, no tenían por qué ser causantes de la decadencia oracular. Ahora bien, la manipulación de las respuestas para obtener réditos políticos en ciertos casos pudo afectar a la reputación del oráculo y provocar el progresivo desafecto de los griegos por la adivinación. Finalmente, Plutarco señala como verdadero origen del descrédito de la mántica a falsos oficiantes de cultos orientales que traficaban con prácticas

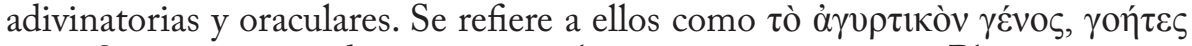
y $\psi \varepsilon v \delta o \mu \alpha ́ v \tau \varepsilon 1 \zeta$, usando una terminología que aparece ya en Platón y que se mantiene a lo largo de la tradición posterior para designar a 'falsos oficiantes' que con el pretexto de celebrar ritos pretendían simplemente ganar dinero. Del uso de dicha terminología se desprende que la intención de Plutarco no es tanto criticar estos cultos como desenmascarar a quienes en su nombre recurrían a la práctica y a la adivinación con fines exclusivamente lucrativos. 


\section{Bibliografía}

Alvar, J., Los misterios. Religiones "orientales" en el Imperio Romano, Barcelona, 2001 (= Romanising Oriental Gods. Myth, Salvation, and Ethics in the Cults of Cybele, Isis, and Mithras, Leiden-Boston, 2008).

Amandry, P., La mantique apollinienne à Delphes. Essai sur le fonctionnement de l'Oracle, Paris, 1950 (reimp. New York, 1975).

Bernabé, A., Poetae Epici Graeci. Testimonia et fragmenta, Pars. I, Stuttgardiae et Lipsiae, $1996^{2}$.

—, “Un 'resumen de historia del orfismo' en Strab. 7 fr. 18”, en J. F. GonzÁlez Castro \& J. L. Vidal (eds.), Actas del X Congreso Español de Estudios Clásicos, vol. III, Madrid, 2002, 59-66.

—,Poetae Epici Graeci. Testimonia et fragmenta, Pars. II, Orphicorum et Orphicis similium testimonia et fragmenta, fasc. II, Monachii et Lipsiae, 2005.

-, "Atribución a Orfeo de una tradición poética", en A. Bernabé \& F. Casadesús (eds.), Orfeo y la tradición órfica: un reencuentro, Madrid, 2008, 227-237.

Burkert, W. "ГОН $\Sigma$. Zum griechischen 'Schamanismus”, RhM, 105, 1962, 36-55.

Casadesús, F., "La crítica platónica de la magia”, en J. Peláez (ed.), El dios que hechiza y encanta. Magia y Astrología en el mundo clásico y helenistico, Madrid, 2002, 191-201.

D’Agostino, E., Onomacrito. Testimonianza e frammenti, Pisa-Roma, 2007.

Dodds, E. R., Los griegos y lo irracional, Madrid, 1960 (ed. or.: The Greeks and the Irrational, Berkeley-Los Angeles, 1951).

Fernández Delgado,J.A., "Poesía oral mántica en los oráculos de Delfos”, en J. L. Melena (ed.), Symbolae Ludovico Mitxelena septuagenario oblatae, Vitoria, 1985, 153-166.

--, "El testimonio de Plutarco y los modernos estudios sobre el oráculo de Delfos", en Homenaje a A. Holgado, Universidad de Extremadura, 1991, 57-72 (non vidi).

Flacelière, R., Adivinos y oráculos griegos, Buenos Aires, 1965 (ed. or.: Devins et oracles grecs, Paris, 1961).

Fontenrose, J., Apollo's Oracle, Cult, and Companions, Berkeley-Los AngelesLondon, 1988.

Graf, F., La magie dans l'antiquité Gréco-Romaine, Paris, 1994 (= Magic in the Ancient World, Cambridge, 1997). 
Herrero, M., “Tradición órfica y tradición homérica”, en A. Bernabé \& F. Casadesús (eds.), Orfeo y la tradición órfica: un reencuentro, Madrid, 2008, 247-278.

Jiménez San Cristóbal, A. I., "Los orfeotelestas y la vida órfica”, en A. Bernabé \& F. Casadesús (eds.), Orfeo y la tradición órfica: un reencuentro, Madrid, 2008, 771-799.

Lanata, G., Medicina magica e religione popolare in Grecia fino all'età di Ippocrate, Roma, 1967.

Martínez Nieto, R., “Otros poetas griegos próximos a Orfeo”,en A. Bernabé \& F. Casadesús (eds.), Orfeo y la tradición órfica: un reencuentro, Madrid, 2008, 549-576.

McLeod, W. E., "Oral Bards at Delphi”, TAPhA, 92, 1961, 317-325.

Nilsson, M. P., La religion populaire dans la Grèce antique, Paris, 1954.

Parke, H. W., "A note on the Delphic priesthood”, CQ, 34, 1940, 85-89.

—, The Oracles of Apollo in Asia Minor, London, 1985.

Poland, F., "Metragyrtai”, RE XV, 2, Stuttgart, 1932, cols. 1471-1473.

Riedweg, CH., "Orfismo en Empédocles", Taula, 27-28, 1997, 33-59 (= "Orphisches bei Empedokles", $A \mathcal{E} A$, 41, 1995, 34-59).

SANZI, E., I culti orientali nell'impero romano, Cosenza, 2003.

Schröder, S., Plutarchs Schrift De Pythiae oraculis, Stuttgart, 1990.

Stoessl, F., “Onomakritos”, Der Kleine Pauly 4, München, 1972, cols. 304-305.

West, M. L., The Orphic Poems, Oxford, 1983. 


\title{
Le Monde des Rêves à l'Époque Hellénistique dans les VIES ET LES MORALIA
}

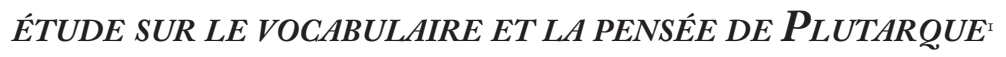

\author{
Mónica Durán Mañas \\ Universidad Complutense de Madrid
}

\begin{abstract}
In this contribution, we examine Plutarch's use of dreams, paying special attention to their influence on the historical process of development. For this purpose, we analyse some of the

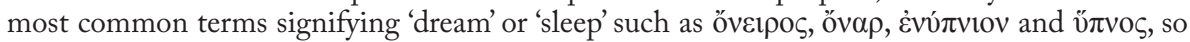
that we can appreciate their semantic evolution (if appropriate), focusing on texts that make reference to the Hellenistic period. Finally, we try to shed some light on the opinion of our author about the subject.
\end{abstract}

Plutarque est l'héritier de toute une tradition et, tout naturellement, sa conception du rêve témoigne aussi de l'évolution historique, que nous allons retracer à grands traits. Dès les origines, en effet, toutes les civilisations se sont intéressées aux songes et la recherche de leur interprétation a inquiété de nombreux penseurs. En général, les peuples primitifs pensaient que certains rêves étaient envoyés par les dieux pour apporter des informations aux mortels. Par conséquent, les rêves étaient un moyen de divination ou de guérison ${ }^{2}$ de nature divine de manière qu'ils constituaient le message prophétique des dieux, empreint d'espoirs mais aussi de menaces ${ }^{3}$. Les Grecs étaient aussi persuadés que les rêves pouvaient prédire l'avenir et influencer subséquemment l'histoire. En fait, les livres anciens ${ }^{4}$ racontent souvent les rêves des souverains, probablement parce que l'on considérait que les dieux ne pouvaient délivrer des messages qu'aux rois et non à de simples mortels. Nous comprenons ainsi que les devins qui expliquaient les rêves des monarques pouvaient exercer une forte influence sur leurs décisions et de ce fait sur la marche historique des événements 5 .

À partir du IV e siècle av. J.-C. les citoyens se trouvent pris dans les bouleversements de tous ordres qui ouvrent une période nouvelle et perdent leurs repères. L'homme ne trouve plus de points d'appui dans un système qui le projette alors dans la sphère de l'universalité, ce qui l'amène à chercher un sens à son existence à travers les chemins de la philosophie et de la religiosité. C'est dans cette ambiance que les cultes à mystères apparaissent avec un contenu plus profond que la religion olympienne. Ainsi, de manière générale, il se produit un mouvement individualiste, laissant les affaires politiques entre les

\footnotetext{
${ }^{1}$ Je voudrais remercier la Professeur Françoise Frazier pour les corrections du français ainsi que pour ses observations critiques qui m' ont été d'une grande utilité.

${ }^{2}$ Cf. Plu., Per. 13.13; Quomodo in virtute 73D; De facie 920B. Vid. également GiL, 1969, pp. 351-399.

${ }^{3}$ Cf. Dodds, 1986, pp. 105-106.

${ }^{4}$ Vid. Cantarella, 1972, p. 215.

${ }^{5}$ Cf. Legras, 2002, pp. 976, 986-987 et 990.
} 
mains des grands monarques hellénistiques, adorés comme des dieux. Ce cadre nouveau accroît encore l'importance de la dimension morale d'une philosophie maîtresse de vie, dont Plutarque sera l'héritier.

Parallèlement, à la fin de la période, et en intime connexion avec le déclin des royaumes hellénistiques, il se produit dans le domaine égyptien le passage d'une religiosité en grande partie syncrétique ${ }^{6}$ à une "superstition " généralisée. La culture égyptienne était déjà extrêmement superstitieuse avec les animaux sacrés, spécialement les éléphants, les serpents et les crocodiles ${ }^{7}$. Et Plutarque lui-même en porte témoignage. Ainsi, on croyait que l'éléphant était l'animal le plus apprécié par les dieux à cause du geste révérencieux de sa trompe au moment de se purifier dans la mer; les serpents étaient associés aux héros et l'attitude des crocodiles était interprétée comme reflet de l'expression divine. Pour cette raison, d'après Plutarque (De soll. anim. 972C), quand Ptolémée IV Philopator sacrifia quatre éléphants pour honorer la divinité à cause de sa victoire sur Antiochus III

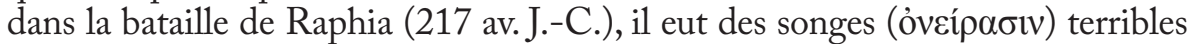
où le dieu le menaçait, irrité par ce sacrifice inouï. Pour réparer son erreur il ordonna l'érection de quatre éléphants en bronze en échange de ceux qu'il avait immolés. De manière similaire, quand le corps de Cléomène se trouvait encore crucifié après l'exécution, ses gardiens virent un serpent énorme qui lui couvrait le visage et empêchait qu'aucun oiseau pût s'en approcher. À partir de ce moment, une peur superstitieuse s'empara du roi et ce fut le début de nombreux sacrifices expiatoires dans l'idée que le meilleur homme et le plus aimé des dieux avait été détruit (Cleom. 39.3). Quant au troisième animal, une anecdote raconte l'histoire d'un crocodile qui nobéissait pas aux ordres du monarque Ptolémée -Plutarque ne précise pas duquel il s'agit- de façon que ce fait fut interprété comme présage de sa mort (De soll. animal. 976B). Ces quelques exemples montrent bien quelle importance le religieux avait dans la vie quotidienne des hommes hellénistiques, se distinguant souvent à peine de la superstition et influençant l'existence des monarques profondément conditionnés par ce type de croyances ${ }^{8}$. Dans cette situation, c'est le monde des rêves qui va servir de pont entre les deux sphères', celle de la religion et celle de la superstition. Mais, voyons ce qu'est la superstition $\left(\delta \varepsilon 1 \sigma ı \delta \alpha \iota \sigma^{\prime \prime} \alpha\right)^{10}$ pour notre auteur:

6 Par exemple, sur le syncrétisme religieux gréco-égyptien dans la figure de Sérapis, vid. Bevan, 1968, pp. 41-48. Pour d'autres versions sur son origine, $c f$. Jacob-Polignac, 1992, pp. 180-3.

${ }^{7}$ En effet, les Égyptiens croyaient, entre autres, au dieu crocodile Sebek au Fayoum. Vid. García-Santana, 2002, p. 47. De plus, le serpent avait une signification magique et il se trouvait associé aux divinités chthoniennes -car ces animaux se rattachent à la décomposition du corps humain- comme nous le voyons dans les représentations de Sérapis avec un serpent entrelacé autour du corps. Cf. De Is. et Os. 362A. Pour la signification de rêver de serpents dans d'autres cultures, $c f$. BuRKe, 1973, pp. 331-332.

${ }^{8}$ Ceci arrive non seulement chez les rois grecs, mais aussi chez les étrangers. Vid. Plu., De frat. amor. 490A où Cambyse tue son frère à cause d'un rêve.

${ }^{9}$ Sur la relation entre le contenu des rêves et la culture du rêveur, vid. Burke, 1973, p. 332.

${ }^{10}$ Cf. Thphr., Char. 16.1 et le commentaire de Diggle, 2004, pp. 349 et ss. Voir aussi Veyne, 1999, vol. 4, p. 437. 


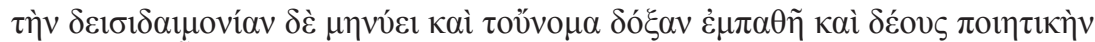

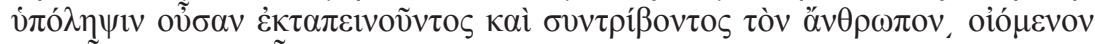

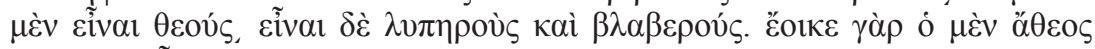

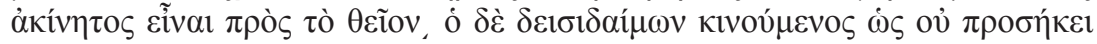
$\delta 1 \alpha \sigma \tau \rho \varepsilon ́ \varphi \varepsilon \sigma \theta \alpha \mathrm{l}$.

(tandis que) la superstition, son nom même la désigne comme une opinion entachée de passion, une supposition créatrice d'une crainte qui déprime et brise l'homme par la croyance qu'il existe bien des dieux, mais qu'ils sont méchants et nuisibles. En effet l'athée, semble-t-il, reste ferme en face de la divinité, tandis que le superstitieux s'agite et se livre à des mouvements inconvenants (De superst. 165B-C) )1 $^{11}$.

Dans les pages qui suivent nous nous proposons de voir la fonction des songes d'après les textes de Plutarque, matière qui a été déjà partiellement étudié par F. E. Brenk dans un article consacré aux rêves des Vies ${ }^{12}$. Nous nous sommes limitée, cependant, au contexte de la politique d'époque hellénistique, car les références aux rêves dans l'ensemble de l'ouvrage du Chéronéen sont trop nombreuses pour qu'on puisse les aborder dans cette modeste présentation. Mais il est clair à nos yeux que l'on pourrait aussi mener cette étude pour d'autres périodes ou du côté romain ${ }^{13}$. Pour commencer notre analyse, nous dirigerons notre attention sur les termes qui désignent le plus fréquemment le

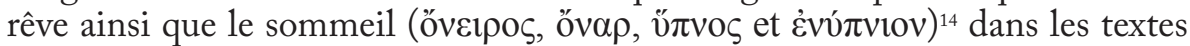
qui font référence à l'époque hellénistique afin d'apprécier leur éventuelle évolution sémantique et d'entrevoir l'opinion de l'auteur sur la matière. Nous résumons dans les tableaux suivants les données des textes:

${ }^{11}$ Trad. de Defradas, J.-Hani, J.-Klaerr, R., Plutarque, Euvres Morales, vol. II, Paris, 2003. Cf. Plu., Alex. 75.1 où Plutarque rappelle que l'athéisme et la superstition sont également pernicieux. Tout comme dans le De superst., le premier membre de phrase est consacré à l'athéisme ( $\dot{\eta} \mu \dot{\varepsilon} v \dot{\alpha} \theta \varepsilon o ́ \tau \eta \varsigma)$.

${ }^{12}$ Brenk, F. E., “The Dreams of Plutarch' Lives”, Latomus 34, 1975, 336-349.

${ }^{13}$ En effet, l'influence des rêves dans la sphère politique est également claire chez les Romains. Vid., entre autres, Caes. 42.1; Caes. 43.9; Sull. 9.4; Sull. 28.4; Crass. 12.4; Pomp. 23.1; Pomp. 68.2.

${ }^{14}$ Nous incluons le terme vँ $\pi v o \varsigma$ même s'il s'agit du nom du sommeil et s'il n'intervient que comme circonstance du rêve, parce que dans certains contextes il fait implicitement référence à l'idée du songe, car c'est en dormant que les rêves se produisent. Il ne pourrait être question d'inclure dans ce travail tous les termes relatifs aux rêves mais n'oublions pas qu'il existe aussi

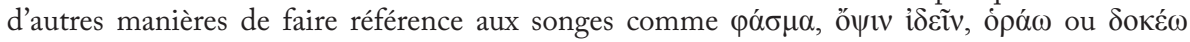

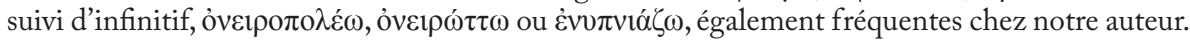
Cf. Plu., Alex. 3.1; Alex. 26.5; Demetr. 29.2; De E. 393D; De superst. 166C et CatMa. 23.6, respectivement. De plus, il existe d'autres passages où Plutarque parle du sommeil mais sans utiliser aucun des termes attendus comme dans Quomod. adulat.71C-D où une anecdote sur le rêve sert à caractériser le monarque Ptolémée face aux flatteurs. 


\section{ONEIPO}

\begin{tabular}{|c|c|c|}
\hline PASSAGE & EXPRESSION & SENS $^{1}$ \\
\hline Pyrrh. 29.2 & 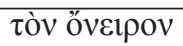 & Prémonition \\
\hline Alex. 18.6 & ỏveípov & Prémonition \\
\hline
\end{tabular}

\section{ONAP}

\begin{tabular}{|c|c|c|}
\hline PASSAge & EXPRESSION & SENS \\
\hline Phil. 18.14 & óv $\alpha \rho$ & $\begin{array}{l}\text { Impossibilité (circonstance } \\
\text { dérivé de l'emploi adverbial) }\end{array}$ \\
\hline Alex. 2.4 & 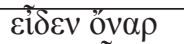 & Prémonition \\
\hline Alex. 24.5 & 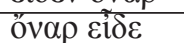 & Prémonition \\
\hline Agis 28.3 & óv $\alpha \rho$ i $\delta \varepsilon \tilde{i} v$ & Conseil d'un défunt \\
\hline Demetr. 27.14 & őv $\alpha \rho$ & Résultat d’un désir \\
\hline Reg. et imper. apophth. 183A & 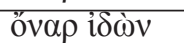 & Prémonition \\
\hline Parall. min. $307 \mathrm{~B}$ & 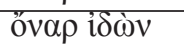 & Prémonition \\
\hline $\begin{array}{l}\text { De Alex. magn. fort. aut } \\
\text { virt. 329B }\end{array}$ & őv $\alpha \rho$ & Imposibilité \\
\hline De Is. et Os. $361 \mathrm{~F}$ & öv $\alpha \rho \varepsilon \tilde{\imath} \delta \varepsilon$ & Conseil divin \\
\hline De soll. anim. 972C & óvé́p $\alpha \sigma v$ & Message divin \\
\hline Advers. Colot. 1109A & óv $\alpha \rho$ & $\begin{array}{l}\text { Impossibilité (circonstance } \\
\text { dérivé de l'emploi adverbial) }\end{array}$ \\
\hline
\end{tabular}

\section{ENYIINION}

\begin{tabular}{|c|c|c|}
\hline PASSAGE & EXPRESSION & SENS \\
\hline Alex. 47.1 & غ̇vót & Imaginaire \\
\hline Demetr. 4.2 & 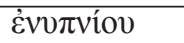 & Prémonition \\
\hline De frat. amor. $490 \mathrm{~A}$ & 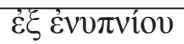 & Superstition \\
\hline
\end{tabular}

\section{YINO}

\begin{tabular}{|c|c|c|}
\hline PAssage & EXPRESSION & SENS \\
\hline Phil.3.4 & $0 \tilde{\pi \nu \omega}$ & Sommeil \\
\hline Pyrrh. 11.4 & 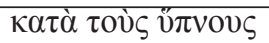 & Prémonition \\
\hline Eum. 13.5 & 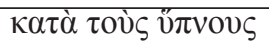 & Conseil d'un défunt \\
\hline Alex. 23.2 & v๊ $\pi \nu \circ \varsigma$ & Sommeil \\
\hline Alex. 24.6 & 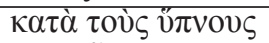 & Conseil divin \\
\hline $\begin{array}{l}\text { Alex. } 24.8^{2} \\
\text { Alex. } 24.9\end{array}$ & 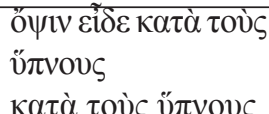 & Prémonition \\
\hline Alex. 32.1 & $v ँ \pi v \omega$ & Sommeil \\
\hline Alex. 32.2 & טँTvov & Sommeil \\
\hline
\end{tabular}




\begin{tabular}{|c|c|c|}
\hline Alex. 41.6 & 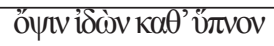 & Superstition \\
\hline Alex. 50.6 & 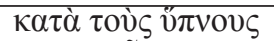 & Prémonition \\
\hline Demetr. 19.2 & 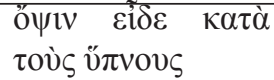 & Prémonition \\
\hline Demetr. 27.12 & 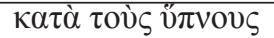 & Résultat d’un désir \\
\hline Demetr. 29.2 & 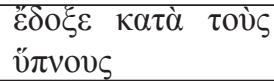 & Prémonition \\
\hline Mul. virt. $252 \mathrm{~F}$ & 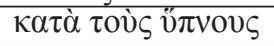 & Conseil d'un défunt \\
\hline De sera num. vind. 555B & 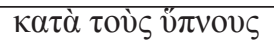 & Résultat de la culpabilité du rêveur \\
\hline
\end{tabular}

Au premier coup d'œil, nous voyons qu'il n'y a pas de grande différence

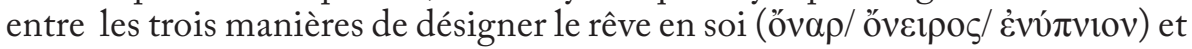
sa désignation indirecte par une «localisation» (び $\pi v o \varsigma$, «pendant le sommeil»). En effet, nous remarquons que les quatre termes peuvent également signifier l'action de faire un songe qui peut contenir une prémonition, un conseil provenant d'un défunt ou un message divin. Néanmoins, quand le contenu de ce rêve se présente comme un reflet de la réalité ${ }^{15}$, au sens aristotélicien ${ }^{16}$, Plutarque emploie les termes ővap ou v̌ $\pi v o \varsigma$-quand le rêve reflète un désir-17 ou bien $̋ \pi v o \varsigma$-quand il se présente comme une sorte de libération de la culpabilité d'un personnage- ${ }^{18}$. D'un autre côté, le seul terme qui désigne l'action de dormir est v̌ $\pi v o \zeta$, selon la tradition ${ }^{19}$, de la même manière que le

${ }^{15}$ Vid. Quomodo in virtute 82F-83D; De virt. et vit. 101A; De tu. san. praec.129B et 133F; De def. orac. 437E-F; Quaest. conv. 734F, 735A; Amat. 759C; fr. 178; Pomp. 73.5; Caes. 32.9 et 63.9; Demetr. 27.14; Cor. 38.4; Brut. 37. Cf. Arist., Div. somn. 2.2 et 10; fr. 60 Rose et Insomn. $459 \mathrm{~A}$ et $460 \mathrm{~B}$.

${ }^{16}$ Dans le traité De la divination dans le sommeil, Aristote propose une typologie des rêves

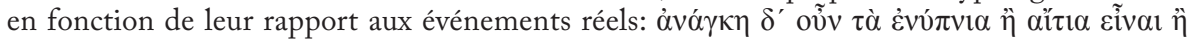

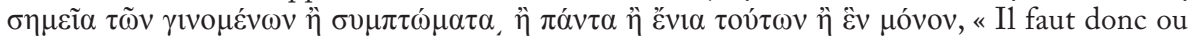
que les rêves soient la cause des phénomènes, ou qu'ils en soient les signes, ou qu'ils soient de simples coïncidences ; ils peuvent être tout cela, ou seulement quelques-unes de ces choses, ou même n'en être qu'une seule » (Arist., Div. somn. 462B 26-30). Aristote admet cependant que certains rêves paraissent inspirés par la divinité, parce qu'ils prédisent les événements futurs ou rapportent les événements éloignés. En tout cas, pour lui, ces songes sont, si l'on veut, l'œuvre des génies et non des dieux. Cf. Laks-Louguet-Adoménas, 2002, p. 456 : " Aristote entend donner une explication rationaliste de ce type de rêves et c'est sans doute ce qui justifie la référence à l'explication de Démocrite, qui est, semble-t-il, animée par le même projet »; p. 456, n. 25: " Pour simplifier, disons que Démocrite n'exclut pas que les rêves aient quelque chose de divin (voir par exemple Diogène d'Oenoanda, fr. 9 Smith), mais il s'efforce de donner l'explication la plus naturaliste des influences divines et de la genèse des rêves»; p. 456: «Démocrite, on le voit, propose une interprétation par les effluves de simulacres ( $\left.\varepsilon^{\prime} \delta \omega \lambda \alpha\right)$ en provenance de l'objet représenté, Aristote (De la divination... 2, 464a 5-11) recourt à la théorie des projectiles et à l'explication des cas de motricité par contigüité des corps mus (vid. note 27: antiperistasis, cf. De la mémoire...2, 453a 14-31; Du sommeil..., 3, 457a 27; Des rêves 3, 461a 22; De la divination...2, 463b 17; 464a 32). Il montra ainsi que les rêves apparemment inspirés sont en fait mécaniquement provoqués par des événements réels ».

${ }^{17}$ Cf. Demetr. 27.12; Demetr. 27.14.

${ }^{18}$ Cf. De sera num. vind. 555B.

${ }^{19} C f$. Barrigón-Nieto, 1992, pp. 471-472 et Fernández-Vinagre, 2003, p. 73. 
rêve au sens figuré ${ }^{20}$ apparaît exclusivement sous le terme غ̇vv́ $\pi v i o v$ - même si parfois őv $\alpha \rho$ s'approche de cette signification, comme nous le verrons par la suite-. Ainsi nous relevons une différence significative entre les rêves qui ont un lien avec les expériences des personnages qui les font et les rêves qui représentent une prémonition ou un message procédant du divin, de l'au-delà ou de l'imaginaire. Le terme övo et la mention "pendant le sommeil", ü $\pi v o s$, peuvent également désigner les deux types de rêves, tandis que غ̇vó $\pi v i o v$ et őveipo $\varsigma$ appartiennent à une sphère rattachée au monde surnaturel. Il faut cependant ajouter que Plutarque emploie fréquemment dans le même passage deux expressions différentes, qui a priori offrent un effet de variatio. Par exemple, dans Demetr. 27.12, le rêve (öv $\alpha \rho$ ) avait calmé la passion qu'un jeune homme ressentait pour la courtisane Tionis, car il lui

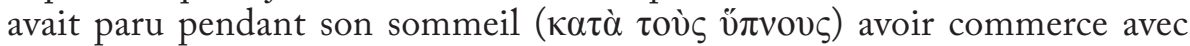
elle. La localisation "pendant son sommeil" ne fait pas de doute sur la nature onirique de cette union, mais précisément la référence à cet état permet de poser plus nettement le problème «juridique» et l'opposition avec l'état de veille où il y aurait eu service «réel» de la courtisane, car souvent il n'y a pas seulement variatio, mais aussi effet de sens.

Comme nous venons de le percevoir, par rapport aux époques précédentes Plutarque présente quelques particularités sémantiques dans l'usage des termes qui désignent les rêves. D'un côté, il est vrai que notre auteur suit généralement les emplois traditionnels. Par exemple, les termes őv $\alpha \rho^{21}$ et $̋ \pi v o \varsigma$ pouvaient désigner également le concept de «rêver» au sens littéral, c'est-à-dire, "faire des rêves en dormant » et «songer » avec les yeux ouverts ou « s'absorber dans ses désirs ou ses souhaits $»^{22}$ et c'est peut-être pour cela que chez Plutarque on les trouve rattachés au champ de la réalité. Mais le Chéronéen emploie aussi le terme óv $\alpha$ avec d'autres significations, comme nous l'observons dans De Alex. magn. fort. aut virt. 329B où nous attendrions plutôt غ̇vó $\pi v i o v$, car Plutarque utilise -au moins dans les textes étudiés ${ }^{23}$ - ce dernier terme pour signifier le rêve au sens figuré:

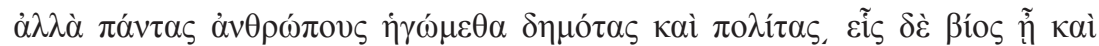

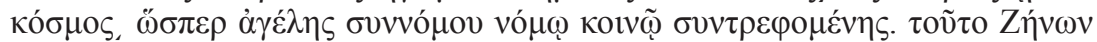

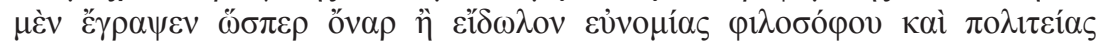
$\dot{\alpha} v \alpha \tau v \pi \omega \sigma \alpha ́ \mu \varepsilon v o \varsigma$

[Zénon tend à ce que] nous considérions l'humanité tout entière comme une seule communauté politique, à ce quill n'y ait plus qu'un mode de vie, qu'un ordre unique,

${ }^{20}$ Est regroupé sous cette appellation tout ce qui se situe en état de veille, de la vision inconsistante à la construction imaginaire, chimérique ou idéale.

${ }^{21}$ En termes généraux, nous pouvons affirmer que őva signifiait, dans son origine, « rêve » au sens de " rêve trompeur » ou " image apparue en rêve ", parfois avec un emploi adverbial « en rêve », probablement ancien, que nous trouvons également chez Plutarque. Vid. Chantraine, 2009, p. 773.

${ }^{22}$ Cf. Kessels, 1978, p. 193 et Fernández -Vinagre, 2003, p. 71, n. 6.

${ }^{23} \mathrm{Vid}$.Alex. 47.1. Cependant il ne faut pas oublier que notre travail fait référence à un corpus limité et qu'une étude plus exhaustive pourrait donner des résultats sensiblement différents. 
comme d'un grand troupeau vivant sur le même pâturage. Zénon, dans son ouvrage, a donné forme au rêve confus d'une constitution parfaite fondée sur la philosophie ${ }^{24}$.

Néanmoins, dans ce cas, nous serions, pour notre part, encline à penser que la similitude du sens ne provient pas de la proximité sémantique entre

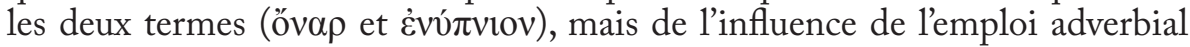
de ővap (" en rêve ») qui le rapproche du champ de l'abstraction. En tout cas, il s'agit ici de désigner une construction philosophique idéale et, en outre, d'insister sur son caractère purement imaginaire, jusqu'au moment où Alexandre lui donne réalité et consistance. Froidefond rend par un bendiadyn ơv $\alpha \rho$ ì $\varepsilon^{\prime} \delta \omega \lambda o v,{ }^{25}$ mais le second terme souligne bien ce caractère d'image inconsistante et, dans le cadre de l'opposition avec la réalité tangible, il est probable que, pour le premier terme, Plutarque est influencé par l'opposition platonicienne entre ט̋ $\pi \alpha \rho$ (le réel) et őv $\alpha \rho$ (l'ontologiquement inférieur), que lui-même reprend dans l'Erotikos (764F) ou le Non posse (1105D) ${ }^{26}$. En somme ici, il y a bien toujours poids de la tradition, mais d'une tradition spécifique, les images platoniciennes.

D'un autre côté, őveıpo $\varsigma$ pouvait représenter le « Rêve personnifié $»^{27}$, « la puissance qui pénètre dans l'homme qui dort puis repart » ou bien le "rêve » en général et la forme neutre ővetpov équivalait à $\varepsilon i \delta \omega \lambda o v$ au sens de «image apparue en songe ${ }^{28}$. Plutarque, pour sa part, emploie la forme masculine (őveipos) avec un sens non marqué, pour indiquer une prémonition ou un message divin. En tout cas, ce songe se détache, comme nous l'avons vu, de toute relation avec le monde empirique du rêveur ${ }^{29}$.

Quant à غ̇vó $\pi v ı v$, il est très intéressant d'examiner son évolution. Chez Homère, il avait une valeur adverbiale signifiant " pendant le rêve " ou " pendant l'état de repos » bien qu'il n'apparaisse qu'une seule fois dans chacun des poèmes ${ }^{30}$. D'après Artémidore (IV 64), óveıpos faisait référence à un songe révélateur par opposition à Ėví $v$ viov qui était un simple rêve ${ }^{31}$. Cet auteur (I 1-2) établit une première division entre le rêve prédictif (őveipos) et le non prédictif ( $\dot{\varepsilon} v 0 ́ \pi v i o v)$, mais dans son livre IV, il signale que les deux termes se distinguent uniquement quand on parle d'une manière scientifique ( $\tau \varepsilon \chi v i \kappa \tilde{\omega} \varsigma$ )

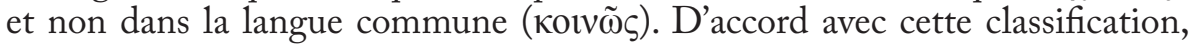
le rêve oraculaire ou prophétique (őveipos), où la figure onirique délivre son

${ }^{24}$ Trad. de C. Froidefond, Plutarque, Euvres Morales, vol. V, Paris, 1990.

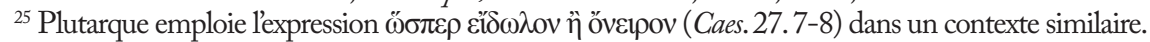

${ }^{26}$ Vid. Frazier, 1999, pp. 347-348 et n. 19.

${ }^{27}$ Cf. Hom., Il. II, 6 et ss. et Hes., Th. 212.

${ }^{28}$ Sur l'étymologie et le sens des termes abordés dans ce travail, vid. Chantraine, 2009. Cf. Snell, 1955 et Wodt Ko-Irslinger-Schneider, 2008.

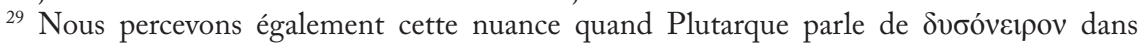
Quomod. adol. poet. 15B. Pour la valeur du préfixe $\delta v \sigma-$, vid. Martínez Hernández, M., "La

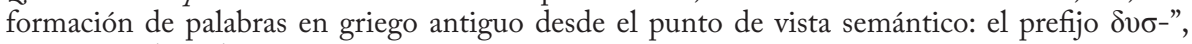
$C F C(G) 2$ (1993), 95-122.

${ }^{30}$ Vid. Hom., Il. 2.56 et $O d .14 .495$.

${ }^{31}$ Cf. Daremberg et Saglio (s.v. divinatio). 
message, s'oppose au rêve symbolique (غ̇vv́ $\pi v i o v)$. Mais dans les textes étudiés

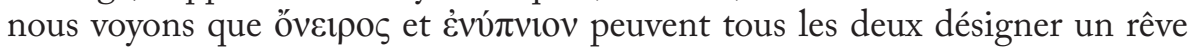
prémonitoire, mais que őveıpo la même façon que غ̇vót $v v_{10}{ }^{32}$.

Enfin, ט̋ $\pi v o \varsigma$ exprime l'état de repos dans lequel se trouve la personne qui reçoit le songe. Ainsi, chez Plutarque ce terme désigne toujours le sommeil ${ }^{33}$ même si nous comprenons -comme nous l'avons déjà signalé plus haut- que

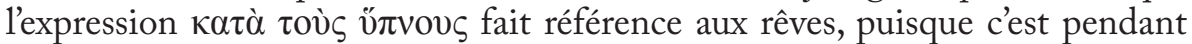
le sommeil que les songes émergent. Cela est spécialement évident dans des

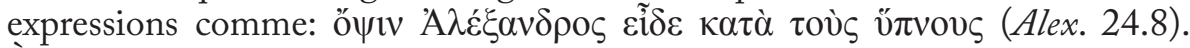
À ce propos, Fernández-Vinagre (2003: 96, n. 103) signalent, comme un phénomène significatif, qu'à de nombreuses reprises nous trouvons chez notre

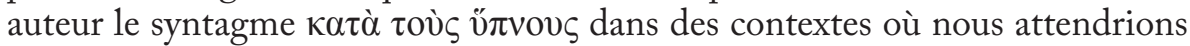
plutôt óvap (par exemple, dans Demetr.19.2 et 29.2). Selon eux, cette situation anticipe peut-être le fait que, dans des textes postérieurs, le substantif $̋ \pi v o \zeta$ apparaîtra comme synonyme de غ̇vó $\pi v i o v$ sans désigner l'état de repos (cf. SIG3 $1152)^{34}$. Ainsi, il serait possible de parler d'une certaine évolution, avec toute la prudence que les témoignages exigent, car la notion de rêve s'y trouve plutôt signifiée par d'autres expressions: le mot ő $\psi 1 v^{35}$ dans Demetr. 19.2 (ő $\psi 1 v$ cĩ $\delta \varepsilon$

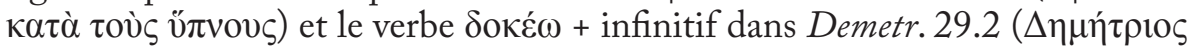

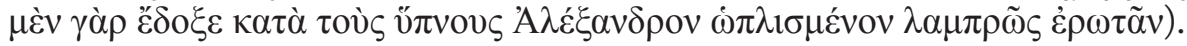

Toutefois, si nous observons des changements dans le choix de ces termes il est clair qu'il n'y a pas une évolution logique qu'on pourrait dessiner entre les différentes époques de la littérature grecque ni chez les différents auteurs et que chacun montre une préférence pour un usage ou un autre. En effet, chez Homère, öva et öveipos - ov (au masculin ou au neutre) font référence $\mathrm{au}$ «rêve» et peuvent désigner sa personnification (qui se présente à quelqu'un pendant qu'il dort) ou bien son contenu. Peu à peu, les différences sémantiques entre les termes commencent à disparaître, de façon que chez les poètes lyriques

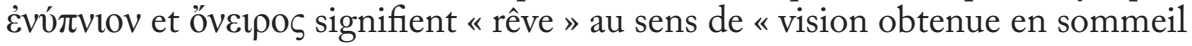
$»^{36}$. Mais chez les tragiques nous ne trouvons jamais la forme $\dot{\varepsilon} v v ́ \pi v t o v$, excepté chez Eschyle qui l'utilise à trois occasions. Aristophane, de son côté, emploie

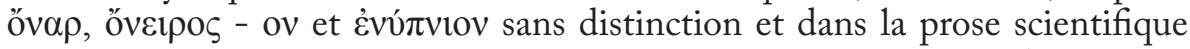
et philosophique d'époque classique, il y a aussi des flottements. Ainsi, nous constatons que les traités sur les rêves compris entre les $V^{e}$ et $I V^{e}$ siècles av. J.-C ne présentent jamais őva $\rho$ ni ővetpos, comme nous le voyons dans le

${ }^{32}$ Cependant il est également possible de trouver chez Plutarque le terme öveipo $̧$ avec un sens figuré. Cf. Caes. 27.7-8. Vid.n. 25.

33 Vid. Liddell-Scott-Jones et Bailly (s.v. vँ $\pi v o \varsigma)$.

${ }^{34}$ On pourrait cependant discuter sur l'interprétation de l'inscription de Patmos SIG III 1152, dont il existe une réédition plus récente signalée par le Supplementum Epigraphicum Graecum, 39, $\mathrm{n}^{\circ} 854$.

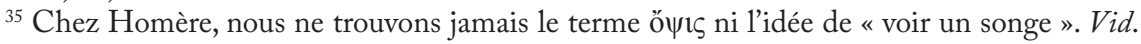
Fernández -Vinagre, 2003, p. 82.

${ }^{36}$ Les données relatives à l'évolution historique des termes abordés sont tirées du travail de FERnándeZ -Vinagre, 2003, pp. 73-102. 
Traité d'bygiène d'Hippocrate ou l'Art de prévoir les maladies du corps humain par l'état du sommeil attribué à Hippocrate, où l'on ne trouve qu'Ėvítrviov. Par contre, Platon emploie seulement غ̇vó $\pi v i o v$ dans trois messages divins. Curieusement, Aristote utilise Ẻvv́ $\pi v ı v$ comme synonyme de ő $\psi 1 \varsigma$ et encore

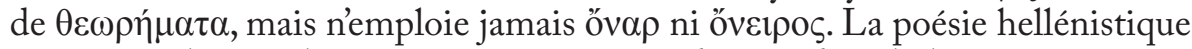
connaît seulement le terme öveipos -ov, tandis que dans la langue commune غ̇vú $\pi v i o v$ est le terme préféré, constituant une sorte de distribution entre les deux synonymes. De même, la situation que nous trouvons chez Plutarque ne semble pas répondre à une évolution, mais plutôt à un choix particulier de l'auteur.

Après avoir vu le vocabulaire du rêve chez Plutarque dans les œuvres traitant de l'époque hellénistique, portons maintenant notre attention sur l'opinion de Plutarque à propos des rêves. Ainsi, nous voyons que le Chéronéen relate de nombreux songes de personnages illustres en se contentant de transmettre la tradition -ce qui ne l'empêche pas éventuellement de manipuler l'information en fonction de son propos biographique ${ }^{37}$. Ces rêves peuvent avoir différentes valeurs en fonction des contextes où ils apparaissent: parfois Plutarque les emploie pour expliquer la cause ou l'origine d'un fait (valeur étiologique); parfois il les présente comme un moyen de communication entre les vivants et les mort ou entre les mortels et les dieux afin d'apporter au rêveur un message qui contient un conseil (valeur de conseil) ou, bien interprété par l'oniromancie, enferme une prédiction sur le futur (valeur prémonitoire). D'autres fois, Plutarque présente des songes qui servent à influencer l'attitude des personnages grâce à leur croyance aux rêves prémonitoires car, même si leurs rêves ne contiennent pas une vraie prédiction, ils les interprètent comme un signe envoyé par les dieux (valeur psychologique). Enfin nous trouvons des songes inventés qui, grâce à la même croyance du peuple aux rêves prémonitoires, servent pour manipuler les masses à la volonté de leurs dirigeants (valeur manipulatrice). Voyons quelques exemples.

Comme nous venons de le dire, fréquemment ces rêves répondent à une intention étiologique. Ainsi, par exemple, Plutarque (De Is. et Os. 361F-362A) $)^{38}$ raconte la genèse du culte à Sérapis ${ }^{39}$ à partir d'un rêve de Ptolémée I Soter où la statue colossale de Pluton à Sinope lui dit qu'il devait la transporter jusqu'à Alexandrie. Il envoya alors deux émissaires, Sotèles et Dionysios, qui arrivèrent, non sans de grandes difficultés, à la voler. Á Alexandrie deux experts, l'exégète Timothée d'Athènes et Manéthon ${ }^{40}$, interprétèrent qu'il s'agissait d'une statue de Pluton, car elle était accompagnée de Cerbère et des serpents, et l'appelèrent Sérapis, nom de Pluton parmi les Égyptiens.

\footnotetext{
${ }^{37}$ Vid. BRENK, 1975 , p. 346.

${ }^{38}$ Cf. Tac., Hist. 4.83; Athenodor. Tars., FHG 111, 487, CIL VIII 1007.

${ }^{39}$ Sur la genèse du culte à Sérapis et son lien avec les rêves, vid. López Salvá, 1992, pp. 161-165 et 182-192.

${ }^{40}$ Sur le rôle historique de Manéthon dans cette tradition, vid. Legras, 2002, pp. 976-977.
} 
Les rêves peuvent également annoncer l'arrivée de la vengeance divine ${ }^{41}$ ou bien avoir une fonction prémonitoire. Dans ce cas, le dormeur rêve habituellement d'un dieu ${ }^{42}$-ou d'un héros-43 qui vient lui montrer le futur, parfois accompagné d'un ordre ou d'un conseil, ou bien avec un animal ${ }^{44}$ qui représente une qualité rattachée au contenu de la prémonition. Ainsi, par exemple, Philippe avait rêvé qu'il scellait le sein de sa femme et que le cachet portait l'empreinte d'un lion ${ }^{45}$, ce qui signifiait que son fils aurait le courage de cette bête (Alex. 2.4). D'autres fois, comme nous l'avons fait voir dans le tableau précédent, les rêves servent de pont de communication entre les vivants et les morts qui s'approchent d'eux pour les conseiller ${ }^{46}$.

Quand Plutarque présente un rêve prémonitoire il le fait généralement en suivant la tradition sans questionner sa valeur. C'est en tout cas ce que l'on trouve surtout dans les Vies, où il reproduit d'abord l'opinion de son personnage, alors que son propre avis s'exprime plutôt dans les Moralia ${ }^{47}$ où il semble parfois croire aux rêves comme une authentique méthode de divination ${ }^{48}$. Pour illustrer la narration du point de vue du personnage nous pouvons mentionner, par exemple ${ }^{49}$, la Vie d'Agis et Cléomène 28.3-550 où nous lisons que Cléomène doute d'abord de la véracité du récit d'un éphore. Celui-ci, après avoir dormi dans le temple de Pasiphaé, racontait qu'il avait vu, dans le lieu où les éphores donnaient leurs audiences, que leurs quatre sièges avaient été enlevés et qu'il n'en restait plus qu'un. Alors qu'il demeurait perplexe, une voix qui venait du temple lui dit que ce changement était avantageux pour Lacédémone. Au début, Cléomène croyait que ce magistrat, soupçonnant son propre dessein,

${ }^{41} \mathrm{Il}$ est fréquent que les monarques souffrent la colère des dieux à cause de leur insolence. Cf. Plu., Arat. 54.

${ }^{42}$ Vid. Plu., De soll. anim. 972C; Alex. 24.6; De Is. et Os. 361F.

${ }^{43}$ Vid. Plu., Alex. 24.5.

${ }^{44}$ Vid. Plu., Alex. 2.4.

${ }^{45}$ Cf. Plu., Per. 3.3. Pour la figure du lion chez Plutarque, vid. Salcedo, M., "Un león en la ciudad: el perfil leonino del Alcibiades de Plutarco" dans Boulogne, J. (ed.), Les Grecs de l'antiquité et les animaux. Le cas remarquable de Plutarque, Lille, 2005, pp. 135-141.

${ }^{46}$ Vid. Plu., Pyrrh. 11.4; Agis 28.3; Mul. Virt. 252F; Parall. min. 307B.

${ }^{47}$ Vid. Plu., Cons. ad Apollo. $120 \mathrm{D}$ et Sept. sap. conviv.159A.

${ }^{48}$ C'est peut-être pour cela que BRENK, 1975, pp. 347-8, à la différence de VEYNE, 1999/4, p. 415 , pense que Plutarque montre une foi implicite en la véracité des rêves.

${ }^{49}$ Cf. Reg. et imper. apophth. 183A où Plutarque raconte comment Antigone le Borgne voulait faire périr Mithridate parce qu'il l'avait vu dans un songe moissonner des épis d'or: 'E $\pi \varepsilon i ~^{\prime}$ ' óv $\alpha \rho$

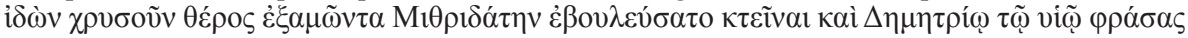

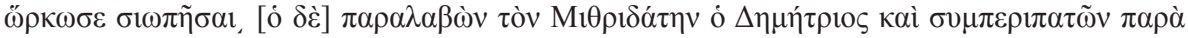

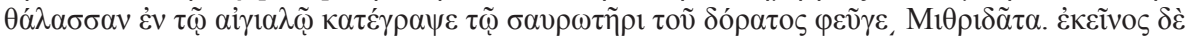

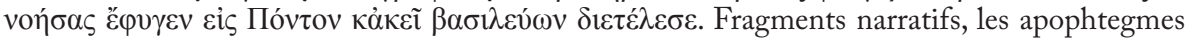
sont plus proches d'une $V$ ie que d'un traité où Plutarque développe sa propre réflexion, ce qui explique que l'attitude face au rêve soit identique dans ce cas.

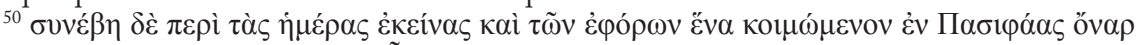

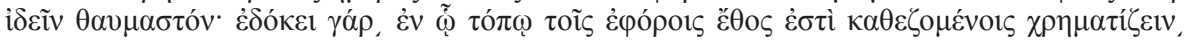

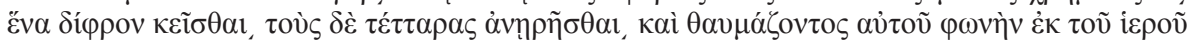

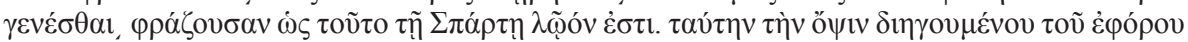

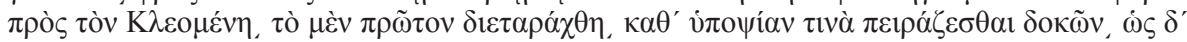

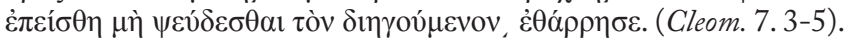


avait imaginé ce songe pour le sonder. Mais finalement, il fut convaincu de la sincérité de son récit et continua ses expéditions. Ici, l'auteur reflète l'opinion de son personnage ${ }^{51}$ : Cléomène d'abord ne croit pas au rêve de l'éphore, puis se laisse convaincre. Ainsi, ces témoignages suggèrent que les rêves appartiennent d'une certaine manière, comme les présages et comme tous les signes, à l'univers mental de cette époque.

D'autres fois, les rêves ont valeur psychologique et servent à donner du courage à des personnages qui doivent accomplir une entreprise, généralement de caractère militaire ${ }^{52}$. Ainsi, Pyrrhus ${ }^{53}$, encouragé par une vision nocturne, traversa en diligence le pays qui le séparait de Béroia, arriva promptement devant cette ville, s'en empara et, après y avoir logé la plus grande partie de son armée, il envoya ses généraux pour soumettre les autres villes, ce qui fâcha Démétrius. En effet, la nuit qui précédait son départ, il avait cru voir en songe Alexandre qui l'appelait. Il s'était approché de lui et l'avait trouvé malade dans son lit. Ce prince, l'ayant accueilli avec amitié, lui tint les propos les plus obligeants et l'assura de son empressement à le secourir. Pyrrhus ayant hasardé de lui dire: «Comment donc, ô roi, malade comme tu es, pourras-tu me secourir? - Par mon seul nom» lui répondit Alexandre, qui aussitôt, montant sur un cheval de Nysée, avait marché devant Pyrrhus, comme pour lui servir de guide $^{54}$.

${ }^{51}$ On a la même chose pour le rêve d'Antigone, cité n. 49, à ceci près que le roi croit son rêve, là où Cléomène est d'abord incrédule.

${ }^{52}$ Comme le signale Bృ̈̈Rck, 1964, p. 309, qui compare les songes homériques et les songes dans les sagas, chez les Grecs, dès Homère le rêve peut constituer un puissant mobile d'action, à différence des romans islandais où le rêve peut présager les conflits, mais n'influence pas le cours de l'action.

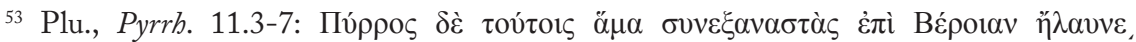

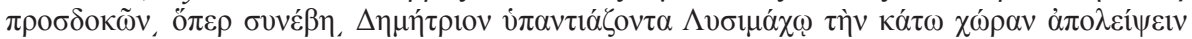

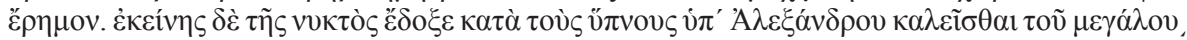

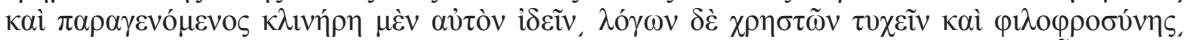

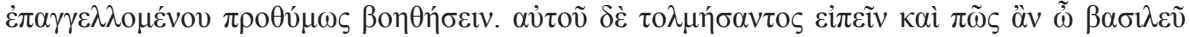

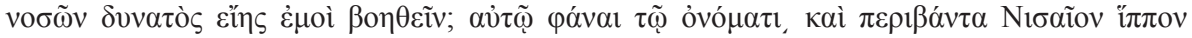

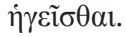

${ }^{54}$ De façon similaire, une vision nocturne encourage Eumène et le prépare psychologiquement pour le combat. En effet, la nuit où il voulait lever le camp, il avait cru voir deux Alexandre s'apprêtant à combattre l'un contre l'autre et commandant chacun une phalange: au secours de l'un vint Athéna et Déméter au secours de l'autre. Après un violent combat dans lequel celui qui était avec Athéna fut vaincu, Déméter tressa pour le vainqueur une couronne d'épis moissonnés. Aussitôt il supposa que la vision était en sa faveur, car il combattait pour une terre excellente, qui alors avait beaucoup de beaux épis en herbe. Il fut encore confirmé dans son espoir quand il apprit que le mot d'ordre des ennemis était «Athéna» et "Alexandre». Il donna donc lui-même pour mot d'ordre «Déméter» et «Alexandre» et il ordonna à tous ses hommes de se couronner d'épis

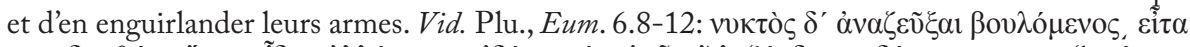

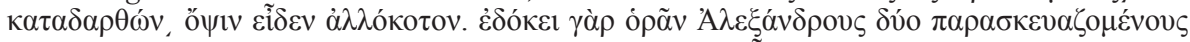

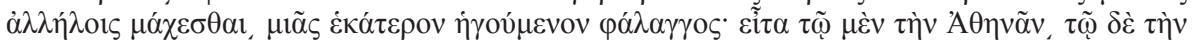

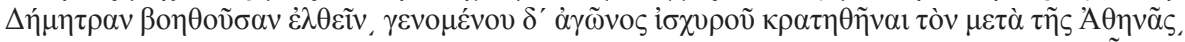

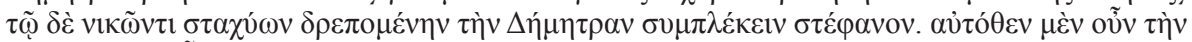

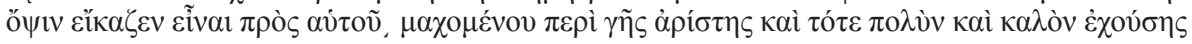

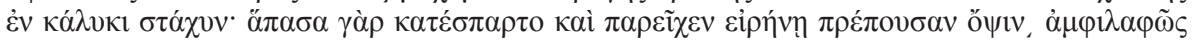


Enfin à d'autres occasions notre auteur laisse entrevoir - plutôt dans les Moralia que dans les Vies- des traits de ce qui à notre avis fait partie de sa pensée. Le rêve entre dans la réflexion plus large sur la communication entre hommes et dieux et sur le problème des signes. Celle-ci pose à la fois un problème métaphysique (touchant les interventions surnaturelles) et un problème plus éthique, ou psychologique (comment éviter la superstition) ${ }^{55}$. Concernant ce second point, nous sommes persuadée que Plutarque est assez méfiant face à l'oniromancie, qui lui paraît particulièrement menacée de tomber dans la superstition. Ainsi, dans le De sera (566C), s'il admet bien un oracle commun de la Lune et de la Nuit d'où partent songes et visions, il l'oppose à l'oracle d'Apollon ${ }^{56}$ et insiste sur son instabilité, son errance, et sur le mélange "où la tromperie et la confusion voisinent avec la simplicité et la vérité" qui constitue les rêves. En tout cas, la référence au mythe du De sera montre bien que la réserve face à l'oniromancie est une conviction du philosophe Plutarque, mais, selon les contextes, il peut être amené à la laisser de côté pour prendre en compte les opinions des $\pi \mathrm{o} \lambda \lambda$ ó́, si l'on veut employer des termes platoniciens.

L'utilisation «machiavélique» de la religion pour obtenir l'obéissance du peuple est aussi une réalité de ses personnages ${ }^{57}$. Nous le voyons, par exemple, dans le fait que plusieurs d'entre eux utilisent des rêves inventés pour manipuler le peuple ${ }^{58}$. Ainsi le fait, entre autres ${ }^{59}$, Eumène qui, d'après Plutarque (Eum. 13.5), "recourut contre eux [Antigène et Teutame] à la superstition» en disant qu'Alexandre lui avait parlé dans un rêve. Sertorius aussi (Sert. 11.7 et 20.3) utilise la superstition en employant le rêve comme instrument de manipulation ${ }^{60}$. Nous trouvons l'explication de ce fait dans De gen. Socrat. 579F$580 \mathrm{~A}^{61}$ où la divination et les visions des rêves s'opposent à la démonstration philosophique. Dans ce passage, Galaxidoros admet qu'il est vraiment difficile de trouver un homme tout à fait exempt de vanité et de superstition, car les uns, entraînés vraisemblablement malgré eux par les passions, sont dupes de

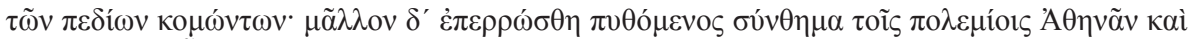

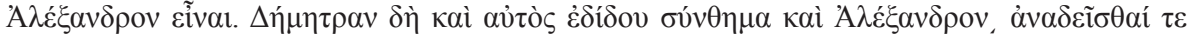

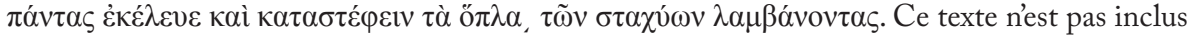
dans le tableau précédent car il fait référence au rêve sous le terme ő $\psi$ iv.

${ }^{55}$ Le cadre de pensée est donné dans l'analyse de BABut, 1969, p. 504 et ss, sur les dangers de la superstition, mais aussi sur les limites du rationalisme.

${ }^{56} \mathrm{Vid}$. Frazier, p. 85 dans ce même volume.

${ }^{57}$ Ce machiavélisme peut se rapprocher du "noble mensonge" platonicien (Rep. III 414 b et ss.).

${ }^{58}$ Sur d'autres instruments de manipulation politique des masses à l'époque hellénistique, vid. Gómez Espelosín, 1985, pp. 165-176.

${ }^{59}$ Cf. Plu., Dem. 22.1.

${ }^{60}$ N'oublions pas que Sertorius et Eumène sont associés dans les Vies.

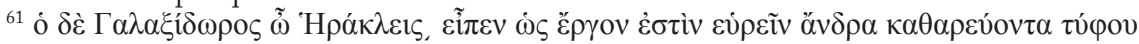

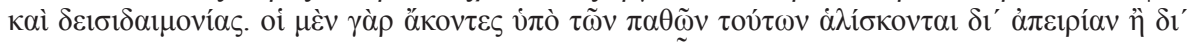

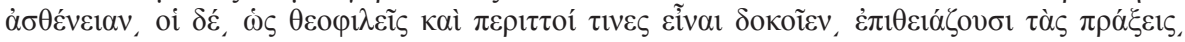

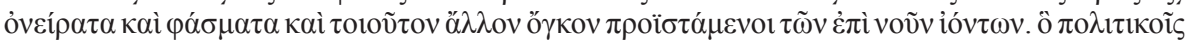

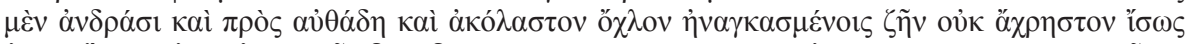

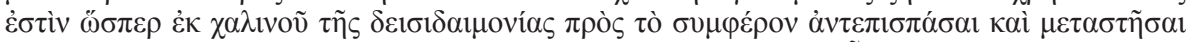

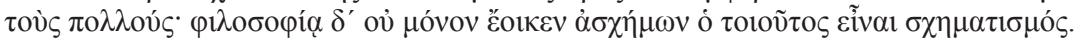


leur ignorance ou de leur faiblesse, tandis que les autres, pour paraitre des hommes extraordinaires et singulièrement chéris des dieux, divinisent leurs actions et regardent toutes les pensées qui leur viennent à l'esprit comme des songes et des visions, parce qu'ils croient par là leur donner plus d'importance. Ce moyen, affirme Galaxidoros, peut être bon pour des hommes d'État qui ont à traiter avec une multitude indocile et licencieuse qu'il faut contenir et amener au bien par le frein de la superstition; mais un tel déguisement est indigne de la philosophie. Ici on ne peut pas faire totalement l'économie, pour situer le rêve, de la vision métaphysique du De sera $566 \mathrm{C}$, où l'on voit où rêves et apparitions prennent naissance et pourquoi ils sont si douteux: c'est un mélange de vrai et de faux, -d'où la méfiance nécessaire, dont Galaxidôros est l'interprète dans le De genio. Mais là aussi, il faut un peu plus de prudence (à l'image de Plutarque): Galaxidôros a la position critique la plus rationaliste, car il déblaie le terrain, pour ainsi dire, si bien que les autres peuvent réfléchir aux possibilités d'intervention de la divinité une fois écartée l'hypothèque de la superstition.

D'un autre côté, Plutarque nous laisse entrevoir la fragilité de l'interprétation des songes, qui se trouve souvent influencée par le désir du rêveur. Ainsi, nous le voyons, par exemple, dans Alex.18.6-8 bien tout le scepticisme qu'inspirent à Plutarque les songes prémonitoires. Dans ce texte, Plutarque raconte comment Darius était parti de Suse plein de confiance, surtout encouragé par un songe dont les mages lui avaient donné une interprétation dictée plutôt par le désir de lui plaire que par la vraisemblance. Il avait rêvé que la phalange macédonienne était tout environnée de flammes, qu'Alexandre, vêtu de la même robe qu'il avait autrefois portée lui-même lorsqu'il était astande du roi de Perse, le servait comme un de ses officiers et qu'après être entré dans le temple de Bélos, il avait subitement disparu. Le dieu, par cette vision, paraissait annoncer assez clairement que la puissance des Macédoniens parviendrait au plus grand éclat, que leur roi serait un jour maître de l'Asie, comme Darius l'était alors, après être devenu roi de Perse, d'astande qu'il était auparavant, mais qu'Alexandre mourrait bientôt comblé de gloire. En fait, les songes sont toujours l'objet d'une double interprétation ${ }^{63}$, dans un sens ou un autre, de façon que si la prémonition ne s'accomplit pas, cela résulte d'une erreur de l'interprète ${ }^{64}$.

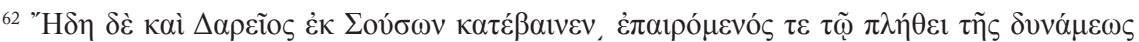

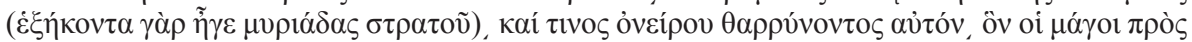

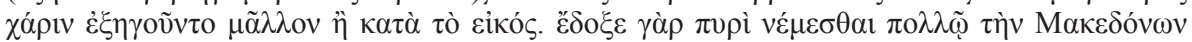

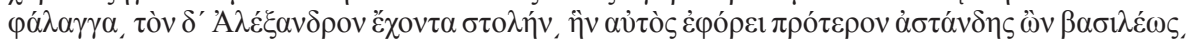

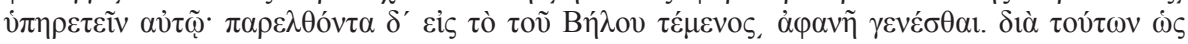

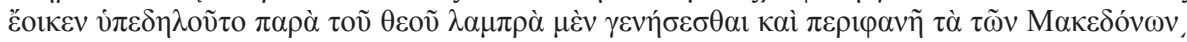

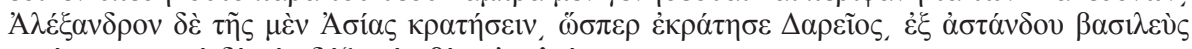

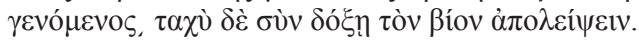

${ }^{63}$ Cf. Plu., Pyrrh. 29.2.

${ }^{64}$ C'est une vieille tradition, qu'on trouve très largement chez Hérodote, ainsi que dans les oracles de Sophocle. Sur la résistance du medium et l'arbitraire des interprétations chez Plutarque, vid. VEYne, 1999, vol. 4, pp. 428-432. 
De plus, nous observons que, surtout dans les Moralia mais aussi dans les Vies $5^{65}$, Plutarque introduit des notes qui permettent de classer le monde de l'interprétation onirique dans le domaine de la superstition. En effet, dans le De superst.165E-166A ${ }^{66}$, Plutarque nous rappelle que le repos du superstitieux ressemble au Tartare, car il y voit toujours des spectres effrayants et des supplices affreux qui le réveillent en sursaut ${ }^{67}$. Il se trouve fréquemment agité par des songes terribles, il se tourmente et se punit lui-même, semblable à un tyran cruel attaché à son châtiment. A son réveil, au lieu de mépriser ces songes vains et de reconnaître la fausseté des visions qui l'ont troublé, pour fuir l'ombre d'une erreur qui n'a rien de dangereux, il se livre à des illusions qui ne font qu'augmenter son trouble.

Mais l'interprétation des rêves a aussi toute sa place dans la religiosité de cette époque comme nous le montre un des Propos de Table ${ }^{68}$, qui aborde les sujets de conversation à propos desquels, au dire de Xénophon, il est le plus agréable d'être interrogé à table. Ainsi, de la même manière que le chasseur aura plaisir à être questionné sur ses chiens, l'amateur d'exercices, sur les luttes des athlètes et l'homme d'amoureuse complexion, sur les jolies femmes, celui qui est plein de piété et qui se plaît aux sacrifices, est enclin à raconter quels songes il a faits, quels heureux succès il a dus aux réponses des oracles, aux victimes ou à la bienveillance des Dieux. C'est pourquoi il aimera aussi qu'on l'interroge sur des sujets analogues.

Assez importante dans la mentalité de l'époque pour être un sujet de conversation entre adultes, l'oniromancie n'est pas sans danger pour les jeunes gens et figure parmi les choses négatives qui capturent l'attention des jeunes par opposition aux choses utiles ${ }^{69}$. D'après Plutarque (De rect. rat. aud. $38 \mathrm{~F}-$ $39 \mathrm{~A})^{70}$, si l'on se trouve avec une personne qui raconte un festin, une cérémonie,

${ }^{65}$ Cf. Plu., Alex. 41.6; Alex. 50.6; Demetr. 19.2.

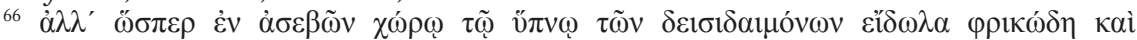

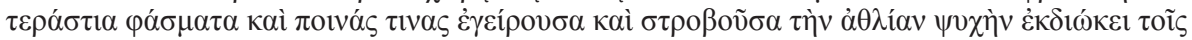

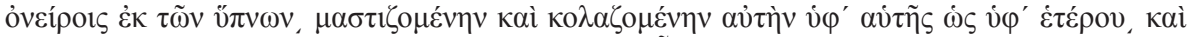

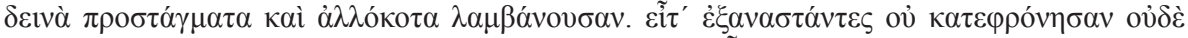

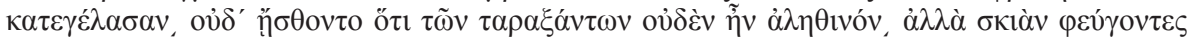

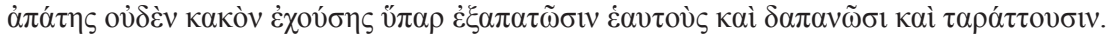

${ }^{67} \mathrm{Il}$ se peut aussi que ces rêves soient la traduction psychologique des remords causés par quelque mauvaise action. Vid. Plu., De sera. 555B.

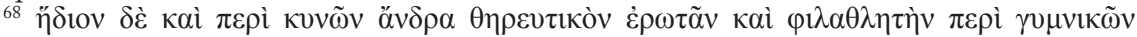

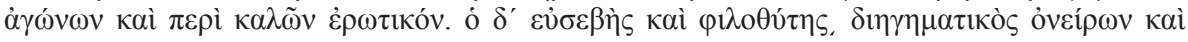

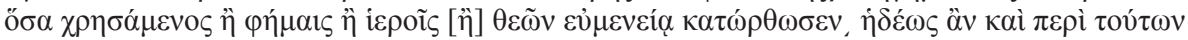

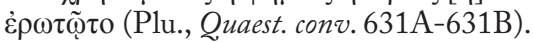

69 "Utile» signifiant toujours pour Plutarque «moralement utile»; comme on est toujours menacé de superstition, la raison des jeunes gens n'est peut-être pas encore assez ferme. Il faut donc une ferme maîtrise par la raison pour aborder le sujet.

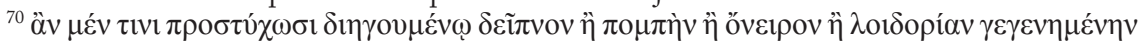

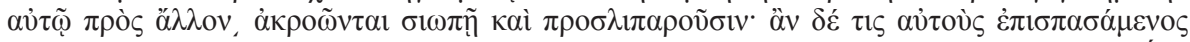

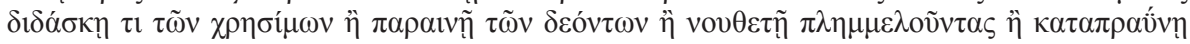

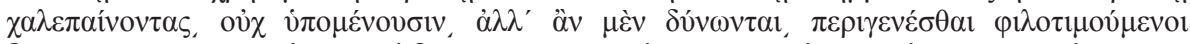

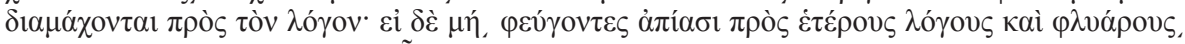

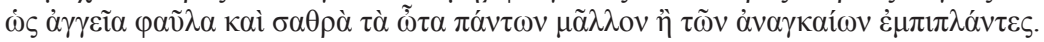


un songe ou une altercation injurieuse qu'elle a soutenue, on écoute en silence et l'on supplie le narrateur d'achever son récit. Mais si un autre personnage, après avoir attiré des auditeurs, entreprend de leur enseigner quelque vérité utile, de les avertir de leurs devoirs, de les réprimander sur leurs fautes ou d'adoucir leur humeur chagrine, ils ne peuvent l'endurer; et même, pour peu qu'ils en soient capables, ils combattent ce qu'a dit ce raisonneur, ils tâchent de rester victorieux dans la discussion et s'ils ne peuvent y parvenir, ils s'enfuient pour aller écouter des propos d'un autre genre et tout à fait frivoles. Comme des vases en mauvais état et fendus, ils remplissent leurs oreilles de toutes sortes de discours, plutôt que de ce qui leur est véritablement nécessaire.

On voit ainsi comment le monde des rêves chez Plutarque se situe la plupart du temps parmi les éléments négatifs de l'existence. De cette manière, le point commun semble plutôt l'importance des rêves dans la mentalité de l'époque, puisque, avec les Propos de table ou le De recta ratione, on a quitté les Vies et le passé pour le monde présent.

\section{Conclusions}

À la lumière des passages que nous avons étudiés, il n'est pas difficile d'entrevoir que les rêves avaient encore à l'époque hellénistique une influence directe sur les événements historiques. En effet, ils pouvaient être à l'origine de l'institution d'un culte, changer le déroulement d'une bataille, provoquer l'assassinat d'un frère ou d'un ami ou même être utilisés pour imposer la volonté d'un monarque ou gouverneur en exploitant la superstition des masses. Par conséquent, la typologie des rêves chez Plutarque répond à des intentions différentes, de manière que coexistent dans son ouvrage le songe étiologique, le songe prémonitoire, le rêve encourageant, le rêve manipulateur ou celui qui donne un conseil. De plus, le concept de songe apparaît parfois désignant une abstraction et, comme nous l'avons déjà signalé plus haut, nous percevons dans ce fait une sorte de spécialisation des termes du champ sémantique du rêve.

Quant à l'opinion de Plutarque sur la matière, c'est dans les Moralia, plutôt que dans les Vies qu'il nous faut la chercher. Encore que parfois Plutarque semble considérer les rêves à la façon traditionnelle, il est clair qu'il ne croit pas à leur valeur prémonitoire, car les songes, comme nous l'avons vu, sont un mélange de vrai et de faux (De sera. 566C). Sa conception du rêve semble, dans l'ensemble, plus proche des théories «scientifiques» aristotéliciennes et il nourrit à l'égard du monde des rêves une méfiance toute philosophique qui trouve sa meilleure expression dans le traité Sur la superstition. Le De sera montre cependant qu'il peut leur donner une place dans la structure du monde, mais, le plus souvent, il les situe dans le monde humain, s'attachant aux effets qu'ils ont sur l'homme ou, en amont, aux expériences ou aux désirs dont ils sont l'expression: le monde onirique se trouve alors, comme pour Aristote, étroitement rattaché à la psychologie. Il s'agit donc, comme le souligne Brenk (1975: 338 et 344), de pénétrer, encore une fois, l'âme des personnages, mais cette fois-ci, à travers leurs rêves, reflet de leurs sentiments et leurs pensées. 


\section{BibliogRAPHIE}

Arroyo de la Fuente, Ma.A., "Iconografía de las divinidades alejandrinas", publié dans Liceus. Portal de Humanidades, E-Excelence, http:/www. liceus.com., 2006, 36 págs.

Babut, D., Plutarque et le Stoïcisme, Paris, 1969.

Bailly, A., Dictionnaire Grec-Français, Paris, 1950.

BArrigón, C.-Nieto, J.Ma., "Algunos problemas de la traducción de la terminología onírica griega al castellano”, Epos 8, 1992, 465-472.

BJörck, G., "ONAP I $\triangle E I N$. De la perception de rêve chez les anciens", Eranos 44, 1964, 306-314.

Brenk, F.E., “The Dreams of Plutarch' Lives”, Latomus 34, 1975, 336-349.

Bur ke,P.,"L'histoire sociale des rêves", Annales. Économies, Sociétés, Civilisations 28, 1973, vol. 2, 329-342.

ByL, S., "Sommeil et insomnie dans le Corpus Hippocraticum", RBPh 76, 1998, 31-36.

Cantarella, R., La literatura griega de la época helenistica e imperial, Buenos Aires, 1972.

Casevitz, M., "Les mots du rêve en grec ancien”, Ktema 7, 1982, 67-73.

Chantraine, P., Dictionnaire étymologique de la langue grecque, Paris, 2009 [Repr. de 1968].

Daremberg, Ch.- saglio, Edm., Dictionnaire des Antiquités grecques et romaines, Paris, 1877.

Defradas, J.-Hani, J.-Klaerr, R., Plutarque, Euvres Morales, vol. II, Paris, 2003.

Diggle, J., Theophrastus, Characters, Cambridge, 2004.

Dodds, E. R., Los griegos y lo irracional, Madrid, 1986.

Donnadiéu Sánchez, V., "Acerca del léxico onírico de Aristóteles y Artemidoro", Nova Tellus 17 (1), 1999, 13-41.

Fernández Garrido, Ma.R.-Vinagre Lobo, M.A., "La terminología griega para 'sueño' y 'soñar”, $C F C(G)$ 13, 2003, 69-104.

Freyburger-Galland, M.-L., "Les rêves chez Dion Cassius", REA 101, 1999, 533-545.

Frazier, F.-Froidefond, F., Plutarque, Euvres Morales, vol. V, Paris, 1990.

Frazier, F., «Platonisme et patrios pistis dans le discours central (chs 13-20) 
de l'Érotikos» dans Pérez Jiménez, A.-García López, J.-Aguilar, R. $M^{a}$. (1999: 343-355).

García Fleitas, L.M.-Santana Henríquez, G., La imagen de Egipto en los fragmentos de los historiadores griegos. Una primera aproximación, Las Palmas de Gran Canaria, 2002.

Gil, L., Therapeia, Madrid, 1969.

Gómez Espelosín, F.J., "La manipulación de las masas como arma política en el mundo helenístico", Revista de Estudios Politicos (Nueva Época) 45, 1985, 165-176.

Kessels, A.H.M., Studies on the Dream in Greek Literature, Utrecht, 1978.

Laks, A.-Louguet, C.-Adoménas, M., Quiest-ce que la philosophie présocratique?, Presses Universitaires du Septentrion, 2002.

Lazzeroni, R., "Il nome greco del sogno e il neutro indoeuropeo", $A G I$ 87, 2002, 145-162.

Legras, B., "Les experts égyptiens à la cour des Ptolémées", Revue Historique 624, 2002, vol. 4, 963-991.

LÉvy, E., "Le rêve chez Hérodote”, Ktèma 20, 1995, 17-27.

Liddell, H.-Scott, R-Jones, H.S., A Greek-English Lexicon, Oxford, 1940.

López Salvá, M., "Isis y Sarapis: difusión de su culto en el mundo grecorromano", Minerva 6, 1992, 161-192.

Pecci Tenrero, H., "Isis, la Gran Maga”, Espacio, Tiempo y Forma, Serie II, $H^{a}$. Antigua 15, 2004, 11-26.

Pérez Jiménez, A.-García López, J.-Aguilar, R. Ma. (eds.), Plutarco, Platón y Aristóteles, Actas del V Congreso Internacional de la I.P.S. (MadridCuenca, 4-7 de mayo de 1999), Madrid, 1999.

Poltera, O., Le langage de Simonide. Étude sur la tradition poétique et son renouvellement, Bern, 1997.

SNELL, B. (ED)., Lexikon des frühgriechischen Epos, Göttingen, 1955.

Struve, V.V., Historia de la Antigua Grecia, Madrid, 1974.

SuÁRez, E., "E1 sueño y la fenomenología onírica en Aristóteles”, CFC 5, 1973, 279-311.

Veyne, P., "Prodiges, divination et peur des dieux chez Plutarque", Revue de l'histoire des religions 216, 1999, vol. 4, 387-442.

Vinagre, M.A., "Die griechische Terminologie der Traumdeutung", Mnemosyne 49, 1996, 257-282. 
Wodtko, D.S.-Irslinger, B.-Schneider, C., Nomina im indogermanischen Lexikon, Heidelberg, 2008.

(Footnotes)

1. Nous préférons le mot "sens" pour aborder les différentes significations des expressions étudiés parce que ce terme a lui-même plusieurs "significations", qui s'articulent essentiellement autour de trois thèmes qui sont: la sensation, l'orientation et la signification. Plus large que le mot "signification", il fait ainsi davantage de place à l'interprétation et à la subjectivité que suggère la notion de "sensation".

2. Nous recueillons ensemble les expressions qui font référence à la même anecdote. 


\section{INTERPRÉTER L'ACTION HUMAINE}




\title{
Polybe, la Tú $\chi$ et la marche de L’histoire ${ }^{1}$
}

\author{
Marie-Rose Guelfucci \\ Université de Franche-Comté, Besançon
}

\section{Résumé}

Bien que Polybe marque nettement les limites de toute explication par une Tychè supérieure, on a pourtant pu voir dans l'œuvre une Tychè Némésis ou, au contraire, une Tychè providentielle pour un homme ou un Etat. En tenant compte du lexique et des modalisations de l'énoncé, nous reprendrons le dossier sous l'angle nouveau des différentes focalisations du récit, et dans trois

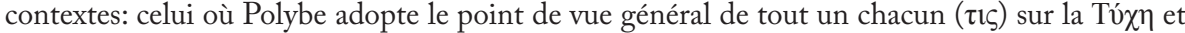
le signale ; celui où il dramatise l'histoire, mais pour mieux former; celui, enfin, où il construit pour son lecteur une démonstration et lui retrace à grands traits ce que nous appellerions plus simplement " la marche de l'histoire ». Dans cette relecture rationalisée du passé, l'évolution politique (l'anacyclose) s'explique alors, loin de tout déterminisme extérieur, par des lois, loi naturelle (sur le modèle biologique) et loi physique (déséquilibre des forces), mais celles-ci n'en reçoivent pas moins un correctif (ou au contraire, en cas de manque, un adjuvant) avec la responsabilité morale du Politique.

Dans les Histoires, les différentes facettes de la $\tau \dot{\chi} \chi \eta^{2}$ sont d'autant plus déconcertantes pour les commentateurs et les historiens qu'elles semblent contradictoires. C'est ainsi qu'alors même que Polybe s'efforce d'expliquer rationnellement les causes et les circonstances de l'action sans recourir à la Tychè ou à une autre force supérieure, en historien rigoureux et en moraliste qui veut rendre l'homme responsable, on a pu ou voulu remarquer encore récemment, dans l'œuvre, une Némésis parfois implacable ou, au contraire, une Fortuna favorable à un homme, voire une Raison supérieure et présciente, Pronoia qui ordonnerait le monde et l'histoire à l'avantage de Rome ${ }^{3}$. Sans doute certains exemples sembleraient, de prime abord, corroborer de telles interprétations si des indicateurs ou des indices stylistiques très marqués ne venaient précisément,

\footnotetext{
${ }^{1}$ Cet article reprend le matériau, bien évidemment réorganisé, revu et actualisé, du chapitre d'un ouvrage figurant au dossier d'une HDR soutenue en janvier 1994, Polybe moraliste, et resté inédit, la parution du livre d'A. M. EcKstein sur ce même thème, l'année suivante, m’en ayant fait interrompre la publication. Je remercie tout particulièrement Françoise FrazIER d'avoir en toute amitié - exigé sa publication et relu ces pages. Ses remarques et suggestions mont été très précieuses.

${ }^{2}$ Les études ponctuelles sur la Tychè polybienne sont nombreuses, mais reviennent souvent à des synthèses parfois très anciennes (R. Hercod, 1902; W. WARde Fowler, 1903; K. VoN Fritz, 1954, pp. 388-397; A. Roveri, 1956, pp. 275-293; F. W. Walbank, 1999 [1970] (ci après Comm. I), pp. 16-26, et 1972, pp. 58-65; P. PÉDECH, 1964, pp. 331-354). Pour un point très précis sur les données du problème, P. PÉDECh, id., pp. 332-336; J. -L. FERRARY, 1988, pp. 265-276. Il ne s'agit évidemment pas ici de reprendre la question à nouveaux frais, mais plutôt d'en réexaminer les principaux aspects en nous attachant au détail des textes et en suggérant d'autres approches et clefs de lecture possibles.

${ }^{3}$ Ainsi dans l'article récent et stimulant, même si l'on ne peut toujours souscrire à ses conclusions ou au commentaire de ses annexes, de J.-M. Pailler, 2003, qui, pour établir une

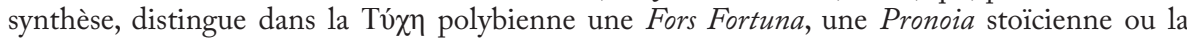
Felicitas du vainqueur.
} 
dans le même temps, signifier une nécessaire mise à distance: ainsi en est-il

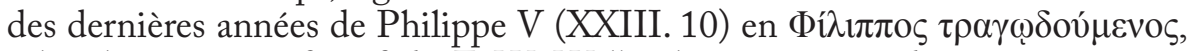
selon le titre significatif de F. W. Walbank ${ }^{4}$, mais aussi de cette Tychè qui serait l'arbitre ou le metteur en scène des événements et de l'histoire, jusque dans les termes choisis - mais si nettement, précisément - par l'historien

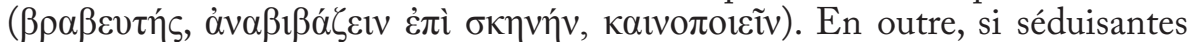

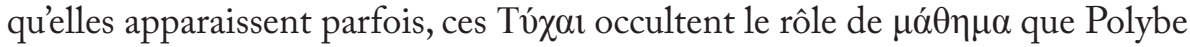
assigne à l'histoire, apprentissage de science politique à partir de l'exemple de Rome; or la leçon porte clairement, non pas sur la prédestination de Rome à gouverner le monde, mais sur la conquête du pouvoir et les conditions de son maintien (III. 4): car Rome, quoique temporairement préservée par sa politeia ${ }^{5}$, tout comme Lacédémone ou Carthage avant elle, ou par une action politique adéquate, n'en est pas moins explicitement destinée elle aussi à périr (VI. 57). Il s'agit donc pour le commentateur d'éviter deux pièges: isoler et ne traiter que certains passages singuliers pour en tirer des conclusions générales, dissocier les deux aspects complémentaires et consubstantiels des Histoires, récit historique, certes, mais récit explicitement construit pour former un destinataire, homme d'État potentiel, avec la structure et la forme très particulières qui en découlent (récit des faits et commentaire sur ceux-ci, choix ponctuels et réfléchis de certaines formes génériques).

Un dernier élément vient compliquer la tâche: complexe s'il en est ${ }^{6}$, le terme

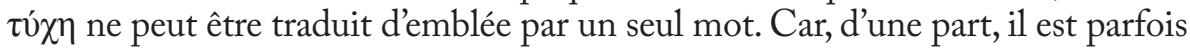

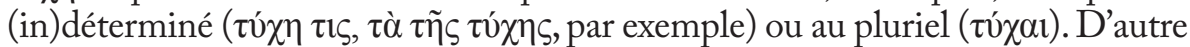
part, ses significations multiples(«les circonstances », «le sort », « la chance », « la Fortune », par exemple) demandent que, loin de toute théorie plus générale, on entre dans le détail du contexte pour en cerner le sens; la difficulté est patente en français où la traduction par le terme "Fortune ", doté d'une majuscule, surdéterminé et particulièrement connoté, tend, beaucoup plus que l'italien "fortuna " par exemple, à introduire des catégories trompeuses (Fortune, vengeresse ou capricieuse, force motrice de l'histoire etc.), qui peuvent forcer le texte et fausser ou trahir le sens. Un passage, plus anodin dans ses conséquences et sur lequel les commentateurs s'accordent, mais moins simple à traduire qu'il n'y paraît, permet d'illustrer immédiatement ce risque ; il montre également comment les débats sur ce qu'est, plus généralement, la Tychè polybienne peuvent influencer et rendre difficile l'interprétation même du sens. En XXVII 16. 4-5, le pressentiment de son hôte, Nestor le Crôpien — inconnu par ailleurs -, empêche que le consul A. Hostilius Mancinus, qui traverse l'Épire pour gagner la Thessalie, soit fait prisonnier par certains Épirotes hostiles à Rome et livré à Persée. La nature de cette prémonition rationnellement inexplicable, et suivie des mesures adéquates, est rendue par une métaphore, immédiatement

\footnotetext{
${ }^{4}$ F. W. Walbank, 1985 [1938], pp. 210-23.

${ }^{5}$ Le terme recouvrant plus que les seules institutions (P1b., VI 47.2), nous prenons le parti de ne pas le traduire en introduction.

${ }^{6}$ F. W. Walbank, Comm. I, pp. 16-17, n.4 en particulier. En outre, les différents sens, souvent immédiats pour le lecteur grec (W. WARDE FowLER, 1903, p. 445), le sont moins pour nous.
} 


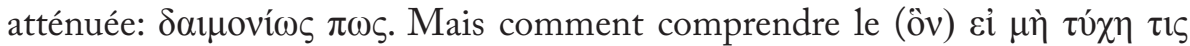

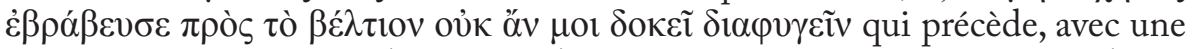

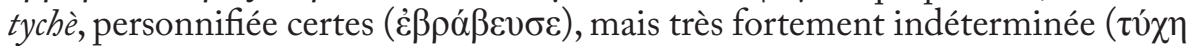
$\tau(\varsigma)$ ? Si F. W. Walbank n'y voit qu'une manière de parler sans conséquence, il n'en garde pas moins, avec la majuscule, une Fortune hypostasiée ${ }^{7}$. Dans sa traduction, D. Roussel choisit de négliger l'indéfini: «si la Fortune ne s'était pas déclarée pour lui». Or traduire, par exemple, par «Si une circonstance n’en avait, pour son bien ${ }^{8}$, décidé autrement» éviterait ici la surdétermination du terme $\tau u ́ \chi \eta$.

Il semble donc préférable, sans préjuger du sens exact du terme en proposant immédiatement une traduction, de donner, si nécessaire, le mot translittéré avant d'en préciser le sens. Pour cela, nous tiendrons plus particulièrement compte, dans les passages les plus complexes, de trois éléments: la palette des

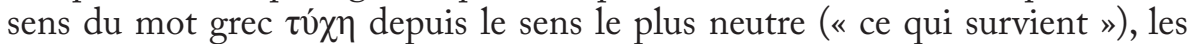
différentes focalisations du récit que Polybe met en œuvre - ce qui n'a pas été fait -, les modalisateurs que sont, par exemple, les atténuations explicites - ce qui ne l'a pas toujours été . Nous partirons ainsi de la lettre du texte comme du refus, explicite et constamment marqué, d'une Tychè qui permettrait à l'homme de décliner toute responsabilité. En tenant compte de ce cadre rationnel très net, nous examinerons, dans un deuxième temps, trois contextes particuliers, mais qui ne contredisent pas la volonté scientifique des Histoires:

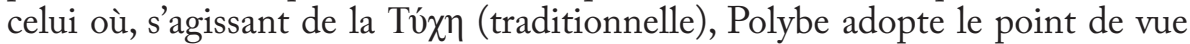
général de tout un chacun $(\tau \imath \varsigma)$ et le signale; celui où il dramatise l'histoire (comme pour les dernières années de Philippe V), mais un peu à la manière dont Rome met en scène, selon lui, la religion ou le triomphe pour former ses citoyens à l'honnêteté et à la gloire; celui, enfin, où il construit pour son lecteur une démonstration et lui retrace à grands traits ce que nous appellerions plus simplement « la marche de l'histoire».

\section{La responsabilité humaine et le jeu des points de vue}

De la manière la plus générale, quand Polybe intervient en historien et est confronté à des causes difficiles à déterminer, il s'interdit autant que possible toute explication hâtive par une puissance surnaturelle. Dans le passage fondamental qu'est l'examen de la dépopulation de la Grèce (XXXVI.17), Polybe, on le sait, refuse les explications irrationnelles faciles par la Fortune

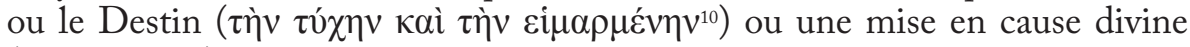

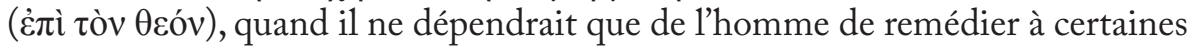
situations. Nettement encadrée par le refus d'une consultation des dieux et

\footnotetext{
${ }^{7}$ F. W. Walbank, Comm. III, p. 317.

${ }^{8}$ Le comparatif rendant compte d'une alternative. Pour une autre interprétation, F. CANali DE Rossi (Polibio Storie, D. Musti (dir.), Milano, BUR, 2004): « se un caso fortuito non lo avesse guidato a sorte migliore».

${ }^{9}$ Voir pourtant, mais non systématiquement, R. Hercod, 1902, p. 113; F. W. Walbank Comm. I, n. 4 p. 25; K. SAcks, 1981, n.32, p.137.

${ }^{10}$ Seul emploi en ce sens. Cf. par ailleurs XVI 32. 4 et XVIII 54. 12.
} 
l'affirmation claire d'une responsabilité humaine ${ }^{11}$, son explication de la dépopulation de la Grèce est purement sociologique: c'est par égoïsme et recherche du confort que les gens ne se marient plus, refusent d'avoir des enfants, ou n'en veulent pas plus d'un ou deux " afin de leur laisser un bel héritage tout en les élevant dans les raffinements du luxe ${ }^{12} »$. Ce n'est donc que pour des catastrophes climatiques, des épidémies (\$2), ou des conduites humaines incompréhensibles (\$12-14) que l'historien reconnaît ses limites et est tenté (comme le montrent les modalisateurs, sikó $\tau \omega \varsigma$ ou l'optatif) de réagir,

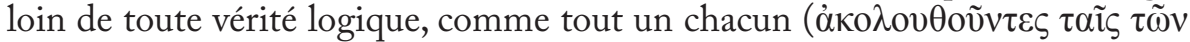
$\pi 0 \lambda \lambda \tilde{\omega} \nu \delta o ́ \xi \alpha 1 \varsigma)$ : s'en remettre aux dieux (XXXVI 17.3), expliquer l'inexplicable

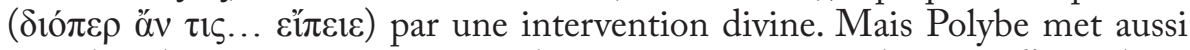
en valeur les circonstances particulières et extrêmement limitées d'un tel cas en insistant, par la présence répétée de termes appartenant au champ lexical de la perplexité, sur l'absence de toute solution comme de toute explication possibles; en revanche, cette absence a elle-même une explication précise: les limites naturelles de la compréhension humaine, et celui qui s'interroge est tout naturellement conduit, dans ce cas très défini, à accepter l'aporie - ảov́vatov,

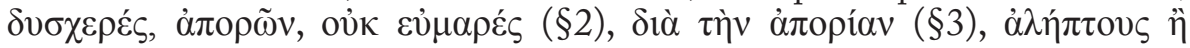

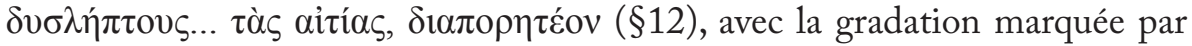
le dernier préverbe.

Une telle analyse qui, loin de tout déterminisme extérieur à l'homme, sauf celui qui est traditionnellement lié par essence à sa condition, met chacun face à ses vraies responsabilités et à ses manques, est une constante de son œuvre qui apparaît dès le livre I. Elle trouve un symétrique essentiel: le refus de laisser attribuer à la chance ou à la Fortune un résultat positif qui est le fruit d'un effort bien pensé, bien conduit, et méritoire. La position de Polybe est certes à mettre en relation avec les controverses qui occupent les écoles de rhétorique sur les rôles

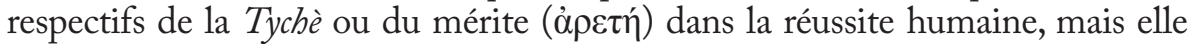
s'inscrit surtout, si l'on tient compte du lien particulier de Polybe avec la Nouvelle Académie, dans l'un des débats philosophiques du temps, Carnéade critiquant l'argumentation donnée par Chrysippe pour défendre son idée du destin contre l'argument paresseux (åpyòs $\lambda o ́ \gamma o \varsigma)$ qu'on lui oppose: si les événements à venir

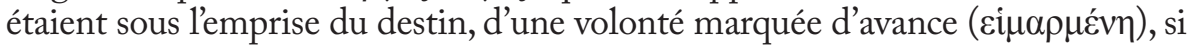
tout était inscrit dans le devenir, toute action humaine et tout effort deviendraient inutiles, sans possibilité d'une quelconque liberté d'action ${ }^{13}$.

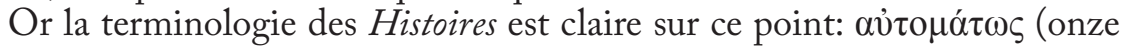
formes adverbiales et seize formes du substantifi ${ }^{14}$ ) et $\tau \hat{\chi} \chi \eta$, le plus souvent, ne

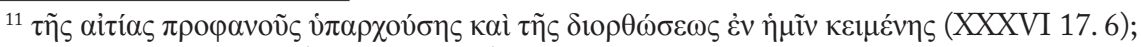

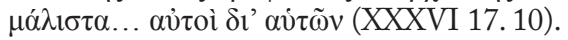

${ }^{12}$ Sans autre précision, les traductions sont les nôtres.

${ }^{13}$ Sur la définition et la discussion de l'«argument paresseux», Cic. De Fato, XII-XVII, 39, XII-XIII plus particulièrement. Sur les nuances à apporter, C. DARbo-Peschanski, 2007, p. 305 (sans que l'on puisse la suivre (n. 78, p. 538) pour l'importance du stö̈cisme dans la conception polybienne du devenir).

${ }^{14}$ Sur les onze formes adverbiales, certaines sont sans réel rapport avec une intervention du

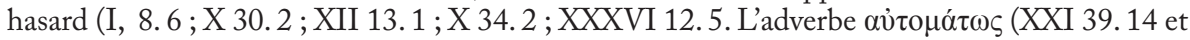


représentent guère de force implacable ou surnaturelle. Quant à $\pi \rho o ́ v o r \alpha, ~ l e$ terme, certes très fréquent dans les Histoires, ne se trouve pas dans l'œuvre au sens de la Providence des Stoïciens ${ }^{15}$, mais met toujours en valeur, au contraire, loin de tout déterminisme, l'action bien menée d'un stratège ou d'un politique

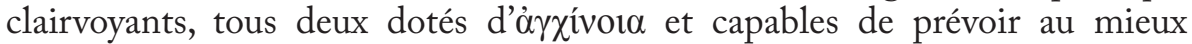
(c'est-à-dire, dans les limites humaines, jusqu'à l'imprévisible) une situation et ses différentes possibilités d'évolution ${ }^{16}$.

Dans un cadre rationnel aussi nettement marqué,Polybe semble néanmoins introduire dans plus d'un passage une Tychè qui soutiendrait ou non l'action humaine; on peut cependant lever l'apparente contradiction en remarquant le double point de vue qui est alors introduit. Ainsi dans les passages polémiques - les plus clairs -, il joue d'un contraste entre le point de vue de l'opinion ou celui des mauvais historiens qui, loin de la vérité historique, en focalisation externe si l'on veut, privilégient les apparences et font intervenir la Tychè, et son propre point de vue, quand il intervient en historien pour redresser la vérité, en focalisation zéro; dans ceux où la Tychè se fait une excuse à l'incompétence, se mettent cette fois en place une focalisation zéro (la sienne) et une focalisation

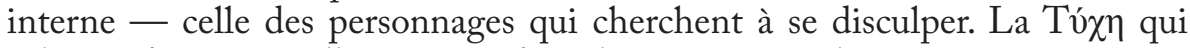
subsiste s'en trouve elle-même réduite là encore, nous le verrons, à une marge d'influence traditionnelle et très délimitée. Mais le destinataire à former par l'exemple de l'histoire peut ainsi immédiatement disposer du récit des faits et d'un commentaire qui l'éclaire.

\section{1.a. Focalisation externe et focalisation zéro}

Les mises au point polémiques abondent dans les Histoires, et

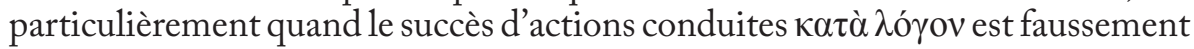
attribué, sans recherche des véritables causes, à une situation d'ensemble favorable ou à un concours de circonstances ponctuellement clément, hasard

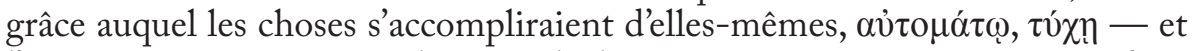
l'on peut remarquer, en règle générale, le jeu sur $\lambda$ ó $\gamma_{0} \varsigma$ et ses antonymes dans ces passages. Lexamen minutieux des armements et des formations de combat (phalange et manipule) qui assurent la victoire romaine à Cynoscéphales est ainsi l'une des causes réelles à connaître

dans le fragment 65) renvoie à des hasards heureux, mais l'état du texte ne permet pas de savoir comment ceux-ci ont été exploités.

${ }^{15}$ Voir sur ce point, P.PÉDECH, 1964, p. 333. Sur $\pi$ póvota désignant, au contraire, les qualités de prévoyance et de perspicacité, id., p. 211, avec, en particulier, la note 35 renvoyant à l'étude de R. Hercod (sur 68 emplois du terme, 40 apparaissent dans la locution $\pi \rho o ́ v o i \alpha v ~ \pi o 1 \varepsilon i ̃ \sigma \theta \alpha 1$, et 24 désignent la faculté de prévoyance) et, pour le cas particulier d'Hannibal, p. 218. Voir aussi R. Hercod, 1902, pp. 97-103.

${ }^{16}$ On trouve chez Thucydide la même opposition entre celui dont l'action est soigneusement prévue (I 144. 4 ; VI 29. 3) et ceux qui s'en remettent à la chance (III 97.2 et III 98. 2, par exemple). Mais de manière générale, Thucydide met moins l'accent sur la responsabilité humaine que sur un mécanisme psychologique, les effets de la chance comme facteur favorable à l'bybris politique (voir J. de Romilly, La construction de la vérité chez Thucydide, Paris, 1990, pp. 114-120 en particulier). 
... afin qu'au lieu de n'avoir que la Fortune à la bouche et de faire des vainqueurs les favoris des dieux ( $\mu \alpha \kappa \alpha \rho \dot{\zeta}(\omega \mu \varepsilon v)$, sans chercher à comprendre ( $\dot{\lambda} \hat{\alpha} \gamma \omega \varsigma)$, nous accordions aux généraux, en pleine connaissance de cause ( $\kappa \alpha \tau \grave{\alpha} \lambda o ́ \gamma o v)$, les éloges et l'admiration qu'ils méritent ${ }^{17}$. (XVIII 28)

Mais dès le premier livre des Histoires, il en va de même pour ceux qui sont les artisans de leur réussite, hommes ou États, Rome ou la Confédération achaienne $^{18}$, fussent-ils idéalisés comme dans le second exemple.

Représentatif de ces prises de position polémiques très claires (X 2), le cas du grand Scipion illustre également le jeu sur les points de vue : loin d'être un

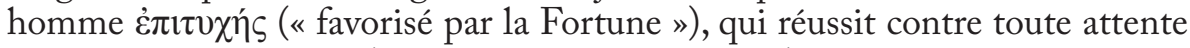
et avec l'aide du hasard ( $\pi \alpha \rho \alpha \lambda o ́ \gamma \omega \varsigma \kappa \alpha i ̀ ~ \tau \alpha u ̉ \tau o \mu \alpha ́ \tau \omega)$, il fait au contraire partie, comme Hannibal (III 48, ${ }^{19}$ ) ou Scipion Emilien (XXXI 30), de ceux qui sont

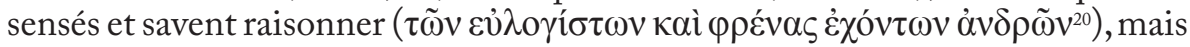
également de ceux qui savent jouer, pour leur bien, sur les croyances d'autrui (X 2. 10-13; X 5.4-8). Mais, précise l'historien, pour éviter à son lecteur de suivre

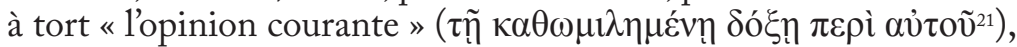

Ceux qui ne sont pas capables d'avoir une juste vue globale des occasions, des causes et des dispositions de chaque circonstance, soit par manque de jugement, soit par inexpérience et par négligence, attribuent aux dieux et aux interventions de la

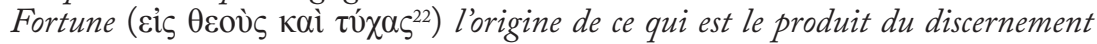

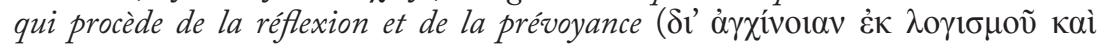

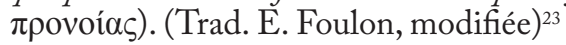

Dans le récit lui-même, les modalisations (oĩov, ஸ்s) apportées par l'historien mettent alors en évidence les fausses impressions que crée, chez ceux qui ne s'en tiendraient qu'aux apparences, un sens stratégique et tactique hors pair : ainsi, après avoir porté la guerre en Espagne, Scipion «redoute une bataille en rase campagne avec un ennemi plusieurs fois supérieur en nombre» (XIV 1.5) ; se présente une à $\varphi \circ \rho \mu \eta ́$, puisque les cabanes des Carthaginois sont en bois et en branchages sans terre, les cabanes des Numides de Syphax en bois et en chaume, pour la plupart à l'extérieur du fossé de retranchement (§\$6-7). Il prépare donc dans le moindre détail ${ }^{24}$ un incendie pour surprendre l'adversaire, avec ruse, précautions et enquête supplémentaire, et réussit : «Les

${ }^{17}$ Trad. D. Roussel (1970, Gallimard, Paris), avec une modification pour $\dot{\alpha} \lambda \hat{\gamma} \gamma \omega \varsigma$.

${ }^{18}$ I 63.9 ; II 38. 5.

${ }^{19} \mathrm{Ce}$ sont l'enquête minutieuse et l'audace parfaitement calculée d'Hannibal qui expliquent

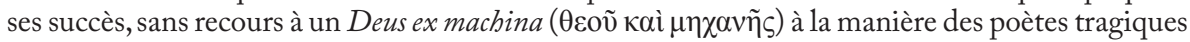

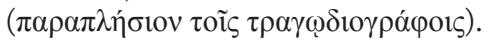

${ }^{20}$ X 2.7.

${ }^{21}$ X 5. 9 .

${ }^{22}$ Il existe la même dualité chez Thucydide entre plans concertés et coups de chance (ainsi I 84. 4 ; II 87. 3; IV 18. 4 en particulier; VI 4.6).

${ }^{23}$ Paris, 1990 (les Belles Lettres).

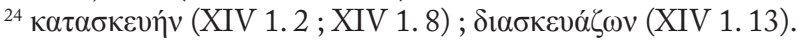


cabanes semblaient faites exprès (oĩov غ̇ $\pi i ́ \tau \eta \delta \varsigma$ ) pour être incendiées, comme je l'ai dit plus haut. » (XIV 4. 6). Il n'y a pourtant là que de l'intelligence tactique, et Hasdrubal a le bon sens de reconnaître précisément, derrière le

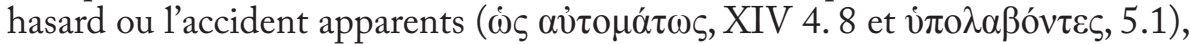

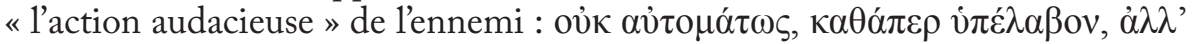

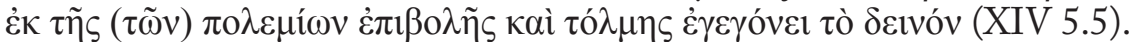

Mais sa faculté de $\pi \rho o ́ v o r \alpha$ relève également de ce que Platon appelle dans la République (III 414b) « le noble mensonge », mensonge politique dans l'intérêt de la cité. Car Polybe (X 2. 10-13) montre comment Scipion, tout comme Rome (VI 56) ou Lycurgue, à qui il le compare, use des croyances d'autrui et du surnaturel pour servir des desseins personnels, mais également utiles à l'État. Il se donne donc comme inspiré en songe par Poséidon, laissant

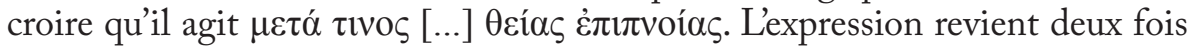

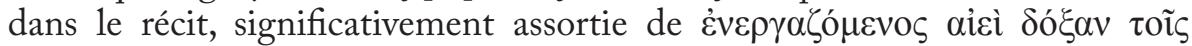

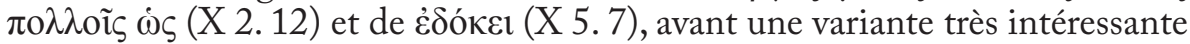

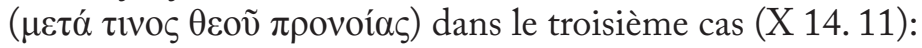

comme ils voyaient l'un et l'autre que la plupart des hommes n'admettent pas les desseins qui sortent de l'ordinaire, et n'osent pas s'exposer aux périls sans l'espoir de l'aide divine, Lycurgue, d'une part, en prenant comme auxiliaire de ses propres entreprises l'oracle de la Pythie, rendait ses conceptions personnelles plus acceptables

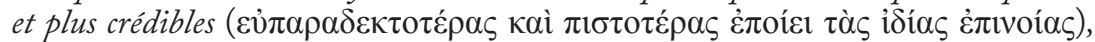
Scipion, d'autre part, presque identiquement, en faisant toujours croire au peuple

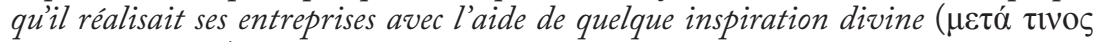

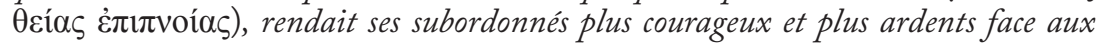

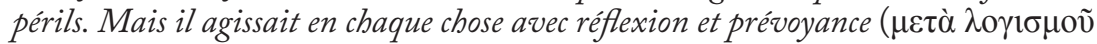

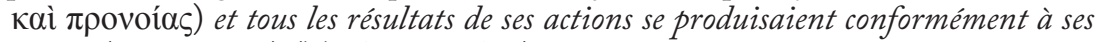

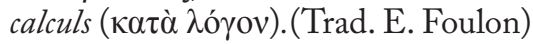

Scipion influence donc sa mère avec un faux rêve, qui se répète, pour se présenter en même temps que son frère à l'édilité puis, une fois élu, laisse croire

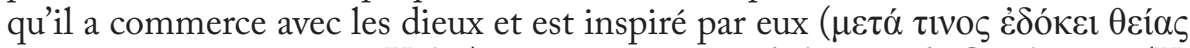

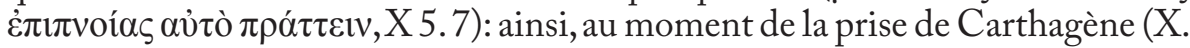
8-15), il promet à ses soldats une intervention surnaturelle, puisque Poséidon lui est apparu en songe, en taisant bien évidemment ses calculs rigoureux et sa prévision du détail, son information sur l'étang qui entoure la ville, presque partout guéable et avec un reflux à heure fixe en soirée. Malgré les difficultés, ils sont galvanisés par ses paroles (X 11.6-8) et, au moment du reflux (X.14.

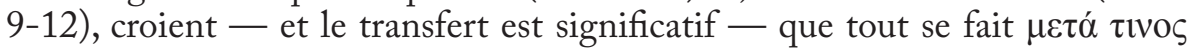

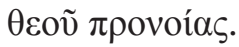

Plus significatifs encore de la position de Polybe sont les cas où aucune circonstance atténuante n'excuse un personnage, comme pour les Épirotes, en II 6-725. Polybe, comme il le fera plus précisément à propos de la guerre d'Achaïe

${ }^{25}$ Le passage est historiquement plus contestable parce qu'il n'est pas sans quelque partiale 
(XXXVIII.1-3), établit une opposition nette entre deux catégories de victimes des circonstances (II. 7) : s'il faut réserver sa pitié aux cas où l'homme est accablé par un concours de malheurs inattendus - et l'on incrimine la Tychè et/ou les responsables (selon la connaissance des causes) - l'inconséquence, elle, n'autorise aucune excuse (II 7.1-4) ; or c'est là le tort des Épirotes et la cause, aux conséquences inévitables, de leur sort, comme le marque l'abondance

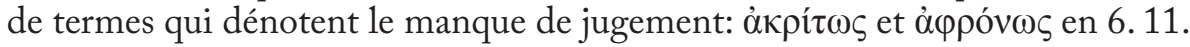

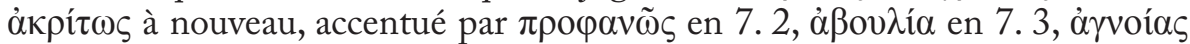

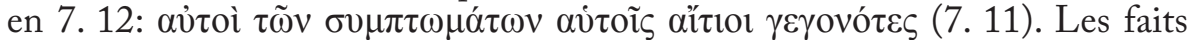
rapportés (II 5.3-6. 8) deviennent donc, avec le développement de Polybe, un exemple assorti d'un commentaire, en 6.11 et dans tout le chapitre 7 , qui incite les lecteurs à la vigilance et à la prise de conscience de leurs responsabilités.

C'est à propos de la guerre d'Achaïe que cette mise en garde s'accompagne d'une intéressante distinction terminologique qui souligne la responsabilité humaine dans l'échec. Polybe conteste l'emploi trop large qui est fait des termes

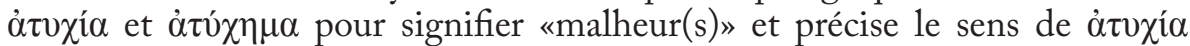
pour l'appliquer aux bouleversements de la guerre d'Achaïe (XXXVIII. 1-3) ${ }^{26}$. Il donne ainsi une définition personnelle du terme, reprise dans une double distinction terminologique essentielle, entre, d'une part, les "catastrophes " subies $(\sigma v \mu \pi \tau \omega \dot{\omega} \mu \tau \alpha)^{27}$, que ne peuvent absolument pas traduire $\dot{\alpha} \tau v \chi \eta \dot{\mu} \mu \alpha \tau \alpha$

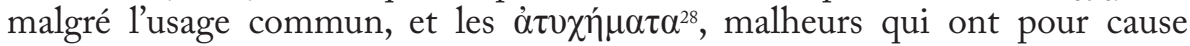
l'irréflexion ( $\alpha \beta o v \lambda i ́ \alpha)$ et entraînent, en outre, avec eux le déshonneur et la honte; il oppose, d'autre part, selon les mêmes critères $\dot{\alpha} \kappa \lambda \eta \rho \varepsilon \tilde{v} v$ et $\dot{\alpha} \tau v \chi \varepsilon \tilde{\varepsilon}^{29}$ (XXXVIII 3.7). La distinction se précise en fonction d'une durée, limitée pour les premiers, passant les générations pour les seconds. Deux usages du même terme sont ainsi mis en évidence : le langage commun, qui fait intervenir, avec

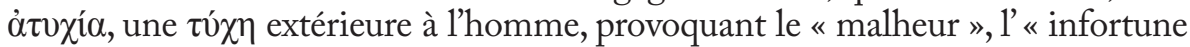
"; l'interprétation polybienne, qui reprend, certes, certains traits de cette tradition (le malheur sur au moins deux générations), mais rompt avec elle en

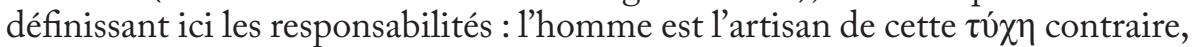
et de même que le succès s'explique logiquement, et non par le hasard, la chance ou la Fortune, ces malheurs, symétriquement, ont pour cause l'ảßov $\lambda i^{30}$. Dans les Histoires, cependant l'usage du terme est de manière générale moins strict, sinon quand il renvoie à la guerre d'Achaïe, y compris dans les premiers livres (III 5. 6). Il est appliqué à la défaite de Trasimène, due à l'incompétence de

intransigeance (voir F.W. WALBAnk, Comm. I, p. 158).

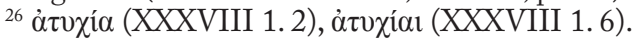

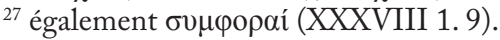

${ }^{28}$ XXXVIII 2. 10. Voir aussi XXXVIII 2. 12 ( $\dot{\beta} \beta$ ov $\left.\lambda i ́ \alpha\right)$. Pour le lien (ou non) avec le déshonneur : XXXVIII 1. 8; 2. 4; XXXVIII 3.9-10.

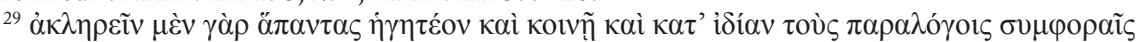

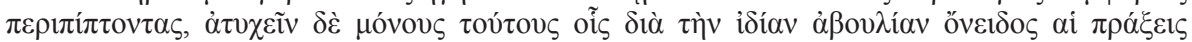

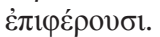

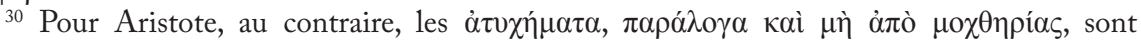
excusables (Rhét., 1374b). 
Flaminius (III 84. 13, III 85. 7) 31, ou dans l'exemple précédemment vu des Épirotes (II 6. 1), mais avec, néanmoins, un certain flottement dans l'emploi des termes ${ }^{32}$.

\section{1.b. Focalisation zéro et focalisation interne}

Ce jeu sur des points de vue différents face à une situation donnée est constant dans les Histoires; mais, faute d'avoir été identifié quand il introduit une focalisation zéro (recherche sans complaisance des véritables causes par l'historien) et une focalisation interne (croyance réelle des acteurs de l'histoire en une fatalité ou excuse commode à leur négligence), il a pu prêter à confusion. Dans le cas des Béotiens par exemple (XX. 4-7), la Fortune qui apparaît en XX.7.2 est moins la déesse jalouse que l'on y a parfois vue ${ }^{33}$ que, de façon analogue, l'expression, comme en style indirect libre, du point de vue commun de ceux qui déclinent toute responsabilité. Au moment de l'alliance des Béotiens avec Antiochos III, en 192 av. J. C., en effet, l'historien esquisse à grands traits la dégradation de l'état politique de la Béotie, depuis Leuctres, et il en montre les causes réelles et identifiables: non seulement l'absence d'énergie et l'abandon à la bonne chère et à la boisson (XX 4.7), mais aussi l'erreur politique, àyvoías (XX 5.1) ${ }^{34}$, avec l'absence de gouvernement et de règles (\$6), l'illogisme et le désordre qui ont été en s'aggravant; si tout cela est resté relativement longtemps sans conséquences, c'est qu' "ils ont eu

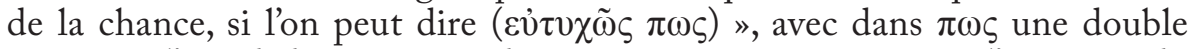
réserve à l'égard de ce qui se dit ou vient communément à l'esprit et du risque de s'en remettre ainsi à la chance. Aussi, au moment où la situation change ( $§ 7)$, Polybe donne-t-il, en plus de l'opinion commune et comme en style indirect libre encore, la réaction des Béotiens à ce moment-là, logiques avec eux-mêmes en laissant le sort décider pour eux; mais, dans le texte,

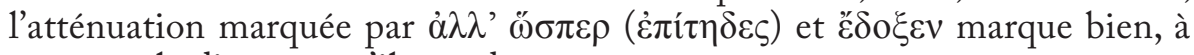
nouveau, la distance qu'il prend:

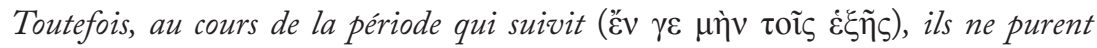
échapper aux conséquences; la Fortune, comme si elle avait voulu leur faire payer leur chance passée, sembla s'acharner durement contre eux. C'est ce que montrera la suite

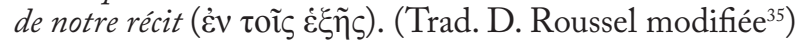

${ }^{31}$ Mais il n'y a pas là, compte tenu des autres occurrences et de la conviction exprimée en XXXVI 17, matière à établir un lien entre un raisonnement parfaitement logique du $\pi \rho \alpha \gamma \mu \alpha \tau$ ikò $\varsigma$

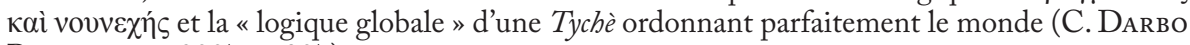
Peschanski, 2007, p. 307).

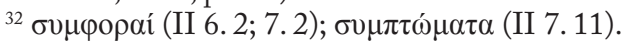

${ }^{33}$ Fortune capricieuse et changeante, par exemple, pour R. Hercod ; Némésis traditionnelle, jalouse du bonheur et du succès pour P. PÉDECH (1964, p. 340); de même pour F. W. Walbank, (Comm. I, pp. 20-21), qui note pourtant, p. 25, le rôle essentiel des atténuations.

${ }^{34}$ Sur ce sens, voir F. W. Walbank, Comm. III, p. 293.

${ }^{35}$ Nous avons ici repris la traduction de Denis Roussel, mais en la modifiant sur des points essentiels («conséquences» plutôt que «destin»; logique différente d'un enchaînement plutôt

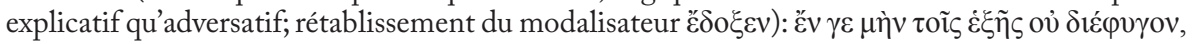




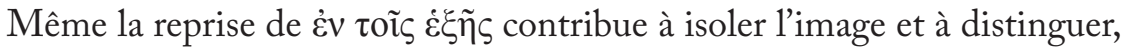
dans le texte, une double explication, le commentaire rationnel de l'historien et les propos ou avis communs, tandis qu'un strict jeu d'oppositions: $\varepsilon \dot{v} \tau \chi \chi \tilde{\omega} \varsigma$

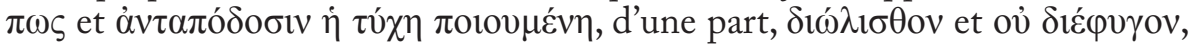
de l'autre, fait apparaître le danger de l'inconséquence générale. Si cet exemple ne comporte donc pas de référence de l'historien à une Tychè supérieure, il y a néanmoins là, nous semble-t-il, beaucoup plus que le seul recours à « un artifice rhétorique " pour condamner, dans un commentaire d'ensemble qui n'est pas exempt de partialité, une politique que Polybe n'approuve effectivement pas ${ }^{36}$. Car le contraste ainsi établi entre la vraie recherche des causes et les mauvaises raisons qui sont une excuse à la négligence est, dans les Histoires, une constante à mettre en relation avec la volonté de former par l'histoire le destinataire de l'œuvre.

Un dernier exemple est significatif. Dans le cas des responsables romains, au moment de la tempête au large de Camarine (I 37.3-4), Polybe, dans les paragraphes 3 à 6 , ouvre et conclut clairement l'épisode, en historien, sur une explication rationnelle du désastre :

Il faut à ce sujet incriminer moins la Fortune que le commandement (ì

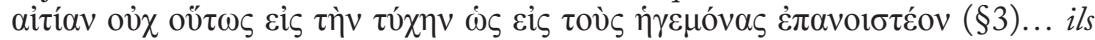
reconnurent alors leur inconséquence (

Dans un passage qui s'ouvre effectivement sur un rejet de la $\tau u ́ \chi \eta$ (remplacée par $\alpha \beta$ ov $\lambda i \alpha$ ) comme cause première, la présence de trois termes dérivés de $\tau u ́ \chi \eta$ dans le corps du texte est à considérer ; car tout en montrant leur incompétence à évaluer l'ensemble d'une situation, elle traduit aussi, en focalisation interne tout d'abord, le point de vue des responsables : s'en remettant, sans suivre aucun conseil, à une Fortune favorable, ils espèrent impressionner les villes de la côte par "l'étalage de leur récent succès " ( $\tau$ ñ

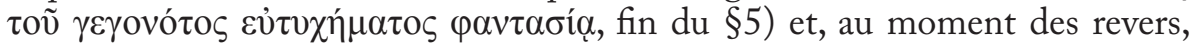
semblent, dans un premier temps, incriminer le sort plus que la cause véritable : «ces hommes, qui étaient allés à la rencontre de grands malheurs

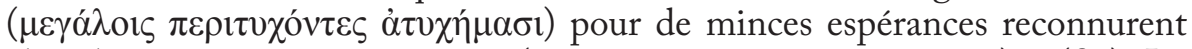

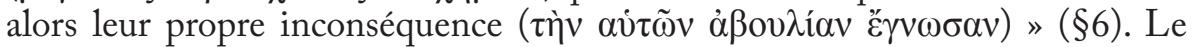
passage se termine par l'intervention de l'historien, qui permet de relire ce qui précède de son propre point de vue, cette fois, avec l'analyse et la critique d'un défaut romain, nettement mis en évidence par un jeu d'oppositions

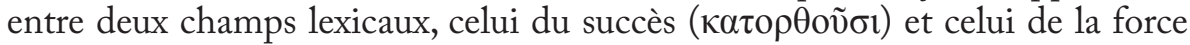
( $\beta i ́ \alpha, 3$ occurrences ici, et une création: $\left.\beta 1 \alpha 10 \mu \alpha \chi \tilde{\omega} \sigma \mathrm{r}^{37}\right)$ : l'habitude de forcer

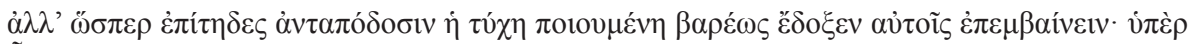

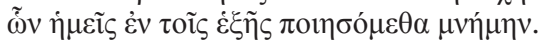

${ }_{36}$ Voir sur ces points le commentaire ad loc. de J. Thornton (Polibio Storie, BUR 2004, op. cit.), qui rapproche le passage de XV 20.5-8 (n. 1, p. 313).

${ }_{37}$ Deux autres emplois de $\beta 1 \alpha 10 \mu \alpha \chi \varepsilon i v v$ (I 27.12; V 84.2, pour un combat entre éléphants). 
les situations. Or ce qui est remarquable, par comparaison avec le précédent passage et le choix très précis de termes appartenant précisément au champ lexical de la Tychè, ce sont dans l'analyse polybienne, plus large cette fois (I 37. 8-10), les variantes lexicales plus communes: ainsi, le « succès » est traduit par

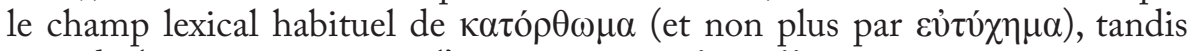

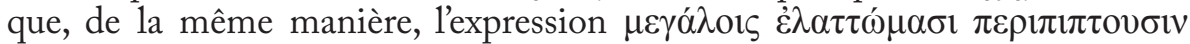
traduit l'échec (I 37.9) ; mais celle-ci souligne, par comparaison terme à terme, l'ironie de la double variante dans l'exemple précédent ( $\mu \varepsilon \gamma \alpha \dot{\lambda} 01 \varsigma \pi \varepsilon \rho \imath \tau v \chi o ́ v \tau \varepsilon \varsigma$

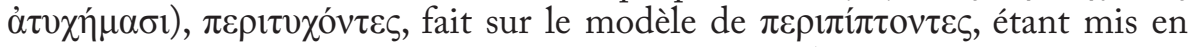
valeur et, en outre, inapproprié avec ce complément. Ainsi, les deux acceptions de $\dot{\alpha} \tau \cup \chi \eta ́ \mu \alpha$ sont simultanément présentes ici, excuse d'une Fortune absente pour les responsables, mais malheur dû à l'àßoviía et qui porte la honte, pour l'historien, selon la définition donnée en XXXVIII 2.

\section{1.c. La prise en compte d'une situation et de ses revers}

En privilégiant, toujours dans un but également didactique, l'aptitude de l'homme d'État ou du stratège à évaluer la situation et à réagir face à des circonstances défavorables ou imprévisibles, Polybe montre constamment que si l'on ne peut contrôler l'incident fortuit, on peut l'intégrer à l'action en cours et reprendre le contrôle d'une situation. La remarque s'applique d'abord au domaine militaire, comme on peut le voir en X 33. 4-5: le chef de l'armée doit, selon le principe connu, d'autant plus se protéger qu'il sera le seul capable, même

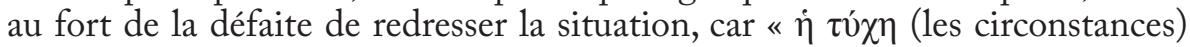
offre(nt) bien des occasions de réparer les conséquences des échecs »; sans lui, en revanche, tout est perdu puisque les espérances des soldats sont suspendues au destin de leur chef. Les exemples abondent, comme en XI 15-16, où la victoire est assurée par la perspicacité et l'intelligence de Philopœmen ${ }^{38}$, qui, malgré un échec ponctuel, tire profit d'une erreur stratégique et assure aux Achaiens une victoire inespérée.

L'historien souligne constamment, avec la nette différence entre qui gouverne et le grand nombre, les implications politiques de cette faculté d'adaptation. Si les réactions des peuples aux événements sont immédiates, douleur ou joie (IX. 21), que la Tychè fasse souffler des vents contraires ou non, selon l'image deux fois employée et qui traduit une perception commune des événements (XI 19. 5 et XXV 3), le responsable, lui, doit pouvoir se donner une vue d'ensemble, tels Hannibal qui, " à la façon d'un bon capitaine de vaisseau ", reste égal à lui-même dans une situation ( $\pi \varepsilon \rho ı \tau \tau \alpha ́ \sigma \varepsilon \omega \varsigma)$ complexe ou Philippe, qui se révèle dans l'adversité, après Cynoscéphales (XXV 3.9-10). On le voit plus significativement encore dans l'attitude du Sénat (III 118. 6): alors que dans une longue suite de revers, la mort du préteur Postumius Albinus et l'anéantissement de deux légions en Gaule Cisalpine finissent de décourager la majorité des Romains, « comme si —

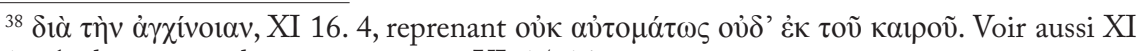
14. 4 et la description des mesures prises, XI. 15-16. 
de vue du grand nombre - la Fortune voulait mettre le comble à ces malheurs et seconder l’ennemi dans le combat »(§6), le Sénat, lui ( $\$ 7-9)$, prend les mesures nécessaires et relève la situation.

Car en politique non plus, il n'y a pas, dans les Histoires, de hasard, providentiel ou fatal en soi. Qu'il s'agisse des individus ou des États, l'événement

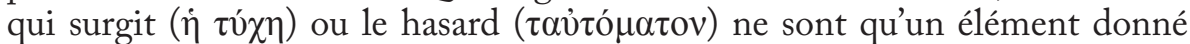
d'une situation, et ils ne se révèlent favorables que s'ils rencontrent une volonté et un effort capables de les rendre tels. Ainsi, dans l'éloge appuyé qu'il fait de Flamininus (XVIII 12. 2-4), Polybe souligne fortement l'opposition entre

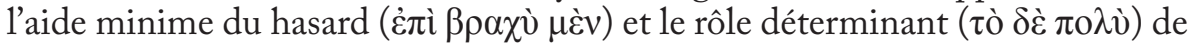
sa pronoia, qui peut seule faire de celui-ci un atout; cette qualité éminemment politique est définie dans les quelques lignes qui suivent: prévoyance, certes,

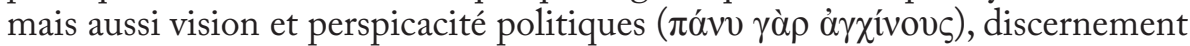

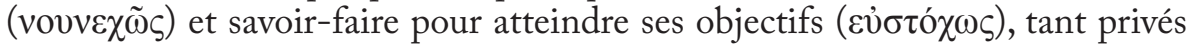
que publics.

Un commentaire analogue conclut la digression consacrée aux efforts de Scipion Emilien pour se former aux trois vertus qui fondent l'autorité du pouvoir, la tempérance ( $\sigma \omega \varphi \rho \circ \sigma v ́ v \eta)$, la générosité ( $\mu \varepsilon \gamma \alpha \lambda \circ \psi v \chi i \alpha$, désintéressement et clémence), le courage ( $\left.\alpha \dot{ } \delta \rho \varepsilon \varepsilon^{\alpha} \alpha\right)$, et pour obtenir une reconnaissance politique (XXXI

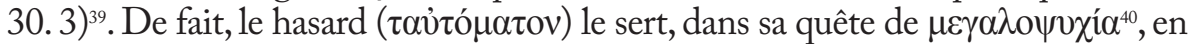
lui donnant loccasion de se montrer trois fois généreux; de même, pour se former

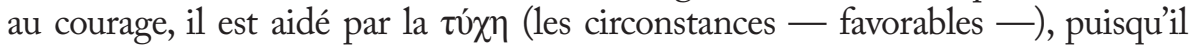
a à sa disposition des terrains pour chasser ${ }^{41}$. Mais dans une Rome marquée par une certaine avarice (XXXI 27.10-11) et où il n'est pas le seul à faire partie de ces jeunes gens favorisés qui recevront, à l'époque augustéenne, le surnom de «rois» mérite, comme le souligne Polybe, est le sien.

Dans ces exemples se pose cependant le problème de la traduction de

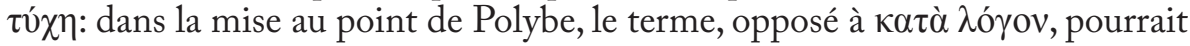
se traduire par "Fortune ", puisqu'il représente le point de vue de ceux qui négligent les causes logiques de chaque succès. Dans le second cas, en revanche, une telle traduction, à la différence du terme grec ou de l'italien, fortuna, surdétermine et fausse le sens en laissant interpréter une Fortuna favorable, une Felicitas de Scipion ${ }^{43}$, ce que Polybe précisément refuse. En outre, comme

${ }^{39}$ «... qu'on n'aille pas retirer à l'homme le mérite des succès qu'il a remportés selon toute logique ( $\tau \dot{\alpha} \kappa \alpha \tau \grave{\alpha} \lambda \hat{o} \gamma o v \kappa \alpha \tau \rho \rho \theta \omega ́ \mu \alpha \tau \alpha)$ pour les attribuer à la tychè (la chance), faute de connaître les causes de chacun d'entre eux. Il n'y a qu'un tout petit nombre d'entre eux que l'on doit

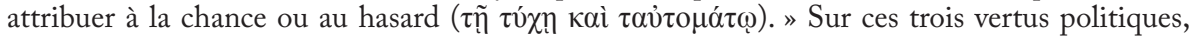
M.- R. Guelfucci, 2003.

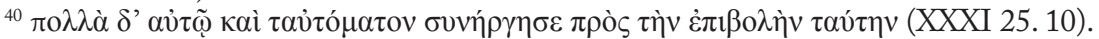

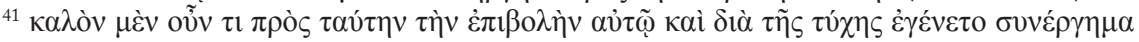
(XXXI.29.3).

${ }^{42}$ P. Grimal (Le siècle des Scipions, Paris, 1975) rappelle les chasses qu'institua ensuite Scipion Emilien dans les forêts de la Sabine et de la Lucanie. Pour le surnom de reges, il renvoie à Horace, Sat. I, 22, 86, etc., et avant lui à Plaute, Capt., 92, pour peut-être le premier emploi du terme (p. 263).

${ }^{43}$ Voir la mise au point de J.-M. Pailler (2003, annexe 2, p. 338) jusqu'à sa conclusion sur des mérites personnels qui facilitent l'œuvre de conquête. Mais elle reste ambiguë : ces mérites 


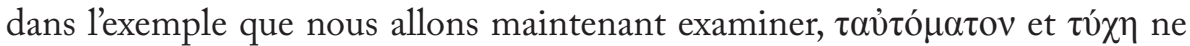
semblent pas présenter de grande différence. Il vaudrait donc mieux harmoniser

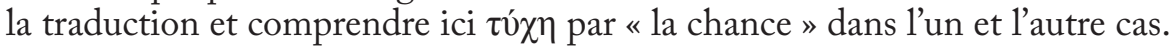

Les trois chapitres des Histoires qui montrent comment un simple

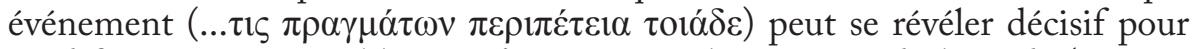
modifier une situation bloquée s'ouvrent sur «le concours du hasard» ( $\mu \varepsilon \gamma \alpha ́ \lambda \alpha$

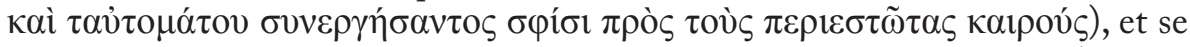
concluent, avec presque la même formulation, sur celui de la tychè, (ícavoṽ

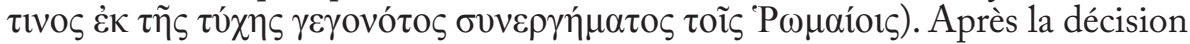
mûrement réfléchie du Sénat d'étendre la guerre en Espagne en franchissant l'Ebre, les Romains ont pu sétablir dans un point stratégique (III 97. 5), mais ne sont ni acceptés ni soutenus par la population jusqu'au revirement soudain et à la trahison d'Abilyx, homme en vue et jusque là dévoué aux Carthaginois (III 97. 8) ${ }^{44}$. L'exemple a été très souvent cité, mais nous voudrions insister sur la volonté de donner ici une double leçon politique à un destinataire qui, guidé dans sa lecture des événements, forge d'abord son expérience par procuration : or ce qui est nettement mis en valeur dans la réussite romaine, ce n'est pas une aide supérieure, mais bien l'exploitation politique de l'occasion qui se présente, sur fond, en outre, d'erreur politique grave. Car c'est en « mettant sous [leurs] yeux la bonté et la magnanimité des Romains en l'opposant à la méfiance et la dureté des Carthaginois ${ }^{45}$ » (III 99.7) qu'Abilyx, si traitre qu'il soit (III 98.3), gagne les populations indigènes à la cause romaine. Or l'attitude de $\mathrm{P}$. Scipion en Espagne préfigure déjà celle de son fils ${ }^{46}$, et la sévère critique du mode de gouvernement des Carthaginois sera alors érigée en principe (X 36.5) ${ }^{47}$. Quant aux deux expressions qui construisent la leçon en encadrant le texte de manière parfaitement symétrique, elles ont ici un sens sensiblement équivalent, mais sans doute avec la précision lexicale propre à Polybe : "concours du hasard " au début (III 97. 5), « concours des circonstances » (III 99. 9) en conclusion, une fois qu'elles ont été décrites et sont connues.

C'est donc plutôt, dans ces cas, la lecture que l'historien fait des événements qui, après coup, donne sens à tel ou tel hasard ou concours de circonstances, en fonction de la manière dont ils ont été exploités et de la leçon politique à faire valoir. De la même façon, l'historien distingue dans

s'inscriraient «eux-mêmes dans un "Dessein" globalement favorable à l'expansion romaine».

${ }^{44}$ Conscient de la nouvelle supériorité des Romains, Abilyx trahit la confiance du général carthaginois, Bostar, en jouant un double jeu: il fait valoir à celui-ci, «un homme sans malice et doux par nature» (III 98. 5), la reconnaissance qu'auraient les Espagnols pour Carthage s'il lui permettait de rendre les enfants otages à leurs parents ; puis il fait de même avec les généraux romains, et leur livre les otages que lui a confiés Bostar. Devenu l'intermédiaire des Romains, à la demande de Publius Scipion, qui le fait en outre escorter, il rend alors les enfants et gagne leurs familles à la $\varphi \imath \lambda i ́ \alpha$ romaine.

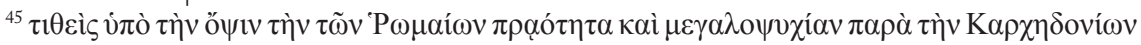

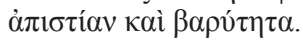

${ }^{46}$ X 35.6 - 38, 6. Scipion sera même deux fois salué pour cela du titre de roi.

${ }^{47}$ Il y a sans doute une mise en perspective de la lignée des Scipions, mais, même si l'importance de l'événement est sans doute historiquement exagérée, la leçon politique tirée de l'expérience est, elle, fondamentale. 
l'événement fortuit l'élément déclencheur qui, dans une situation de crise (IV 3.1-3 par exemple), vient « servir» l'absence de toute conduite rationnelle,

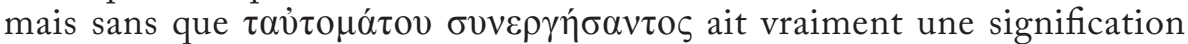
plus forte que sa variante $\dot{\varepsilon} \kappa \tau \alpha \hat{v} \tau$ o $\mu \alpha ́ \tau o v$. L'importance variable du hasard est alors le résultat d'une estimation que fait l'historien,en fonction de sa

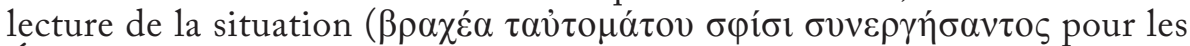

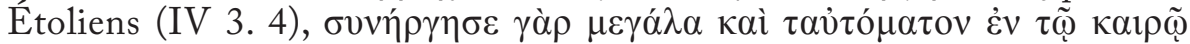

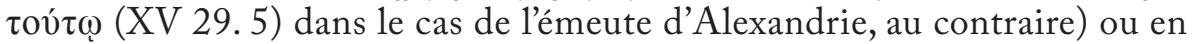
fonction de la reconstitution chronologique des faits, comme l'indique la

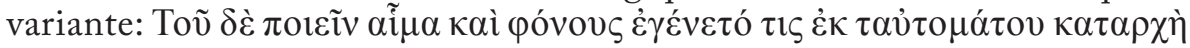

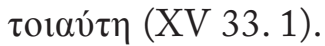

Le rôle décisif des hommes sur l'événement a néanmoins ses limites, et en sachant s'adapter aux circonstances, l'homme d'action doit pouvoir, logiquement mais aussi moralement, reconnaître et admettre celles-ci, prévoir les revers autant qu'une issue favorable (XI 2. 5-6), et rester fidèle à lui-même. Ainsi Hamilcar Barca (I 62.3-6) sait céder devant

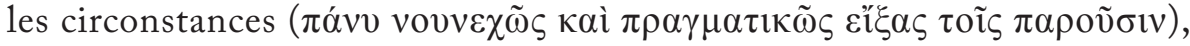
ravaler sa colère contre l'abus romain après la guerre des mercenaires et préparer sa revanche en Espagne. Son fils Hasdrubal choisit la mort, en dernier recours, à la bataille du Métaure : " lui coupant toute issue $e^{48}$, la

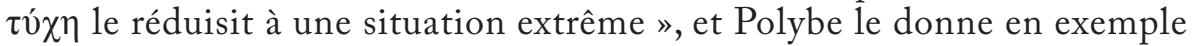
(XI 2.11).

Mais ce dernier passage montre aussi plus particulièrement l'ambiguité du terme $\tau \hat{\chi} \chi \eta$ où deux sens sont simultanément perçus en grec, "Fortune » ou simplement " circonstances (contraires) ", et il n'y a pas ici nécessité de trancher. Car, indépendamment du succès ou de l'échec de l'action, ces exemples proposent en modèles des hommes capables d'accepter « les revirements du

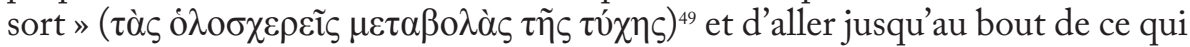
dépend d'eux. Il n'y a cependant là d'autre philosophie qu'un sens de l'honneur (XI 2.10), et il n'est pas indifférent que la lutte contre la $\tau u ́ \chi \eta$, perdue d'avance et en toute conscience, soit posée en termes militaires. Deux points de vue de Polybe lui-même semblent alors coexister, sans être contradictoires : celui de l'historien, qui déduit des faits une situation contraire («vaincu par les circonstances ») ; celui du moraliste, qui y reconnait, de longue tradition, les limites du génie d'un homme, parce qu'il n'est qu'un homme (« vaincu par la

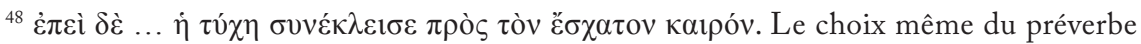
$\left(\sigma v v^{-}\right)$traduit ici la situation désespérée d'Hasdrubal. Sur la très grande précision du vocabulaire de Polybe qui va jusqu'à créer $\delta 1 \alpha \kappa \lambda \varepsilon i ́ \varepsilon ı v$, sur le modèle latin, pour traduire toutes les nuances de " enfermer ", " couper une retraite », voir M. Dubuisson, 1985, p. $158 \mathrm{sq}$.

${ }^{49}$ VI 2. 6, pour mesurer le relèvement romain après Cannes: "parce qu'on estime que l'unique pierre de touche de la perfection chez un homme, c'est qu'il sache supporter avec grandeur et noblesse les changements radicaux de la fortune ( $\tau \dot{\alpha} \varsigma \dot{o} \lambda \sigma \sigma \chi \varepsilon \rho \varepsilon \tilde{c} \varsigma \mu \varepsilon \tau \alpha \beta o \lambda \grave{\alpha} \varsigma \tau \tilde{\eta} \varsigma$

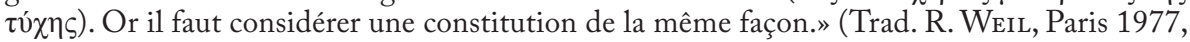
Les Belles Lettres). 
Fortune »). On le voit plus nettement dans l'éloge d'Épaminondas, loué pour

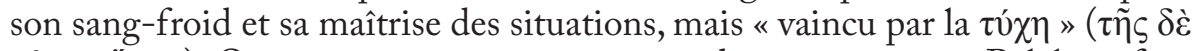

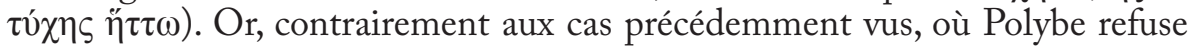

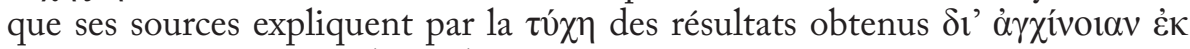

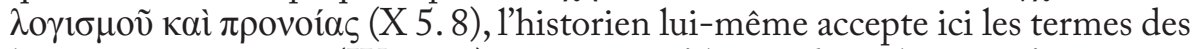
historiens antérieurs (IX 8.13); mais ce qu'il considère alors, ce n'est pas un résultat, qui devient même indifférent ${ }^{50}$, mais bien la qualité politique et morale de ceux qu'il donne en exemples aux dirigeants comme aux futurs politiques.

C'est peut-être en raison de cette proximité des éloges conjoints d'Hannibal ${ }^{51}$ et d'Épaminondas, d'une part, et de la double acception possible du terme $\tau \hat{\chi} \chi \eta$ dans ces lignes, d'autre part, que le terme a été surdéterminé dans l'ensemble du passage. En effet, la place faite à une théorie finaliste dans les Histoires a donné plus d'importance au hasard qui sauve Rome quand

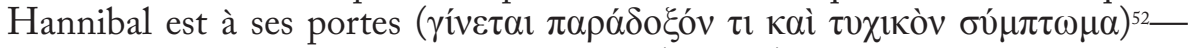

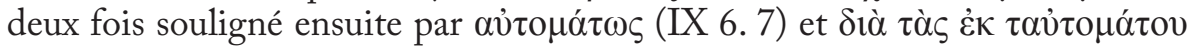
$\pi \varepsilon \rho 1 \pi \varepsilon \tau \varepsilon i \alpha_{\text {S }}$ (IX 9.3) - qu'à la présence d'esprit et à l'action des consuls romains, qui mettent en échec les plans d'Hannibal, ou à la ténacité et au courage des Romains (IX 9. 8 en particulier) ${ }^{53}$.Aussi, sans nier le fait que, d'un autre point de vue, Polybe propose une lecture et une interprétation globales des faits historiques, et affirme, par exemple, qu'Hannibal ne pouvait quêtre vaincu par Rome (XI 19.6-7) - mais pour des raisons politiques, nous y reviendrons en dernière partie - , le hasard présent ici n'est-il pas différent des autres cas examinés précédemment.

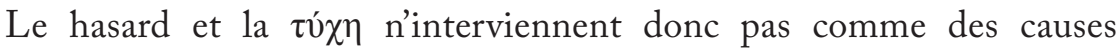
extérieures et supérieures à l'action humaine, mais représentent, avec l'événement qui surgit, un élément d'évolution des faits en fonction, Polybe $\mathrm{y}$ insiste, de la réaction humaine. Ils permettent ainsi de mesurer une aptitude d'adaptation au monde, politique ou morale, en particulier quand

${ }^{50}$ «Je souhaite en effet que le souvenir de certains faits et le spectacle d'autres leur inspirent de l'émulation < pour des actions qui, paraissant> avoir un côté extraordinaire et dangereux, comportent au contraire une audace qui est la sécurité même, une conception qui mérite l'admiration, un choix qui est à jamais mémorable et glorieux, qu'elles aient réussi ou échoué, indifféremment, dès lors qu'il s'agit d'actions conduites avec intelligence.» (IX 9. 10, Trad. R. WeIL, Paris, 1982, Les Belles Lettres).

${ }^{51}$ Vaincu par la tournure imprévisible des événements (IX 6. 5-7), il échoue devant Rome (IX 6.5-7.1) et manque de peu la prise de Rhégion, après avoir fait tout ce qu'il devait (IX 9. 1-5). A Zama, l'éloge est le même, l'échec d'Hannibal étant exemplaire de la condition humaine

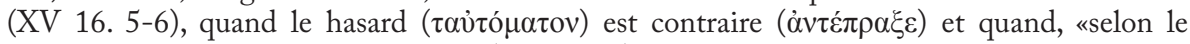

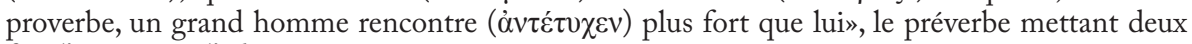
fois l'accent sur l'adversité.

${ }^{52}$ La présence à Rome d'une légion en armes nouvellement recrutée et la sélection d'une seconde légion (IX 6.5).

${ }^{53}$ P. PÉDECH, 1964, p. 343: « on peut voir seulement dans les faits de hasard ( $\sigma v ́ \mu \pi \tau \omega \mu \alpha)$ des cas plus étroits et plus immédiatement palpables de l'intervention de la fortune dans les affaires de l'univers". 
il faut s'incliner devant les circonstances. Dans ce cas précis, néanmoins,

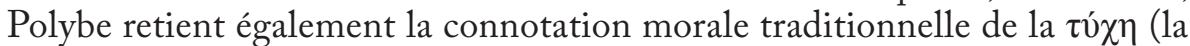
Fortune), rappel des aléas et des limites de la condition humaine, comme dans le cas de Philopœmen (XXIII 12. 3-4) ${ }^{54}$, et mise en garde contre la griserie du succès. En revanche, pour un renversement du sort qui tiendrait à une cause humaine, il laisse l'excuse facile d'une intervention supérieure à ceux qui refusent de faire ce qu'il faut. Aussi, dans un monde où la Tychè est constamment présente, dans les monuments, la statuaire, les monnaies, et où le souverain hellénistique a sa Tychè, comme de nombreuses cités, le paradoxe de l'œuvre semble-t-il plutôt être l'absence d'allusion, dans l'œuvre, aux Fortunae locales, alors que trois temples sont dédiés à la Fortune pendant le séjour à Rome de l'historien ${ }^{55}$, et l'importance donnée, au contraire, à l'action et à la responsabilité humaines ${ }^{56}$.

\section{Le point de vue de l'honnête homme et les mises en scène de l'historien}

Il est quelques cas cependant qui paraissent infirmer les analyses précédentes. Faisant référence à la Tychè, Polybe semble, en effet, y partager la réaction première de l'honnête homme, si l'on peut dire, comme si luimême ne pouvait constamment aller jusqu'au bout d'une analyse purement rationnelle ou assimiler illogisme et échec, en excluant complètement toute idée d'une intervention supérieure. Mais l'ambiguïté n'existe que si l'on ne prend pas garde aux atténuations explicites qui, dans le même temps, identifient l'opinion commune et/ou marquent clairement, en l'absence de toute explication logique ou morale, une aporie de la raison. Ainsi, face à l'injustice, le sort qui frappe les Abydiens ou, au contraire, la belle mort de

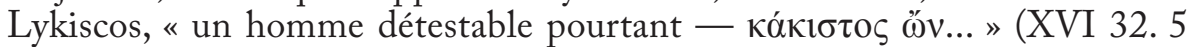
; XXXII 4. 3), par exemple, ou devant les malheurs qui frappent, comme à juste titre cette fois, la Macédoine et la Syrie, coupables envers le jeune Ptolémée (XV 20. 5 et 8), Polybe fait état de la réaction commune, dictée par l'émotion, et qui exclut donc la recherche des causes ${ }^{57}$. Mais elle est

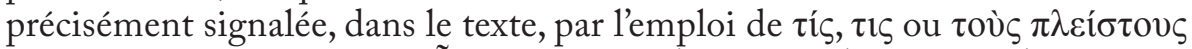

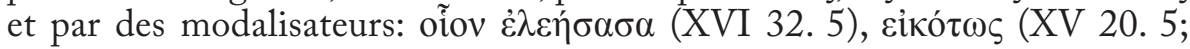
XXXII 4.3), ou l'optatif, par exemple ${ }^{58}$.Il faut donc distinguer, ici, entre ce qui serait une croyance de l'historien en une justice vengeresse, à l'action parfois

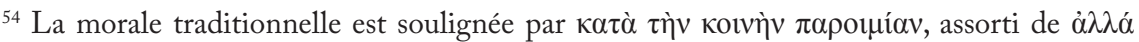
$\mu о \imath ~ \delta о к \varepsilon \tilde{. ~ O n ~ n o t e r a ~ a u s s i ~ l ' a u t r e ~ m o d a l i s a t e u r ~(\delta o ́ \xi \alpha \varsigma) . ~ V o i r, ~ a u ~ c o n t r a i r e, ~ d a n s ~ l a ~ s u i t e ~ d ' u n e ~}$ interprétation ancienne (R. Hercod, p. 113), C. Darbo-Peschans ki, 2007, p. 306.

${ }^{55}$ Warde Fowler, 1903, p. 446.

${ }^{56}$ Lisible aussi dans une citation répétée d'Euripide (I 35. 4 ; VIII 3.3) et ses adaptations (VIII 7. 7 et IX 22.1).

${ }^{57}$ Voir II 7. 1: « Si des hommes tombent de façon imprévue dans quelque dommage, on n'accuse pas les victimes mais la Fortune et les auteurs du mal ».

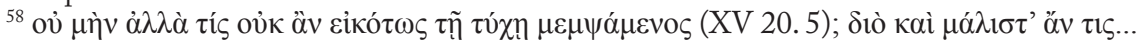

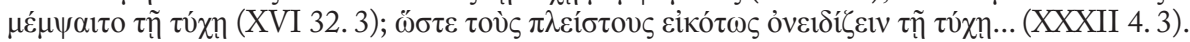
De même en IV 81.5 (...ö́v $\tau 1 \zeta \varphi \eta ́ \sigma \varepsilon 1 \varepsilon)$. 
capricieuse, à l'œuvre dans l'histoire, et l'expression de la réaction générale à certains faits, qui peut être aussi celle de Polybe lui-même. Ainsi, dans le dernier exemple (XV 20), il compte bien faire partager à son lecteur une

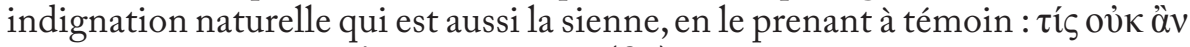

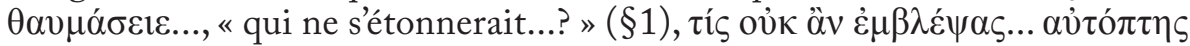

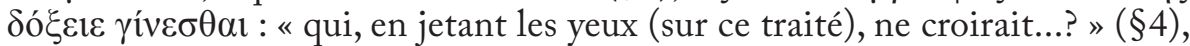

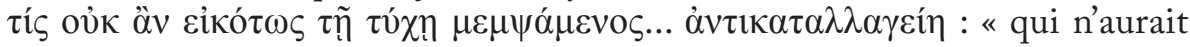
naturellement adressé des reproches à la Fortune mais se sentirait réconcilié avec elle...? » $(\$ 5)^{59}$. Mais ce n'est pas en tant qu'historien qu'il intervient alors.

Quant aux apories de la raison devant des conduites humaines incompréhensibles, (XXXVI 17. 12-15), elles sont signalées au destinataire par l'emploi de termes d'une autre famille que celle de $\tau \dot{\chi} \chi \eta$, celle de $\delta \alpha \mu$ óviov (dont $\delta \alpha \mu$ ovo $\beta \lambda \alpha ́ \beta \varepsilon \imath \alpha$, en hapax), pour signifier une déraison ( $\alpha \lambda \sigma \gamma 1 \sigma \tau i ́ \alpha)$ qui dépasse l'entendement (XXVIII 9. 5) ${ }^{60}$. Ces termes traduisent ce qu'une conduite a de positivement irrationnel dans l'unique cas du pressentiment de Nestor le Crôpien, de sacrilège le plus souvent (XXXI 9. 1-4). $\Delta$ aı désigne en outre une divinité vengeresse, mais dans des propos rapportés ou commentés (XII 12b. 3 et 23. 3). De même la référence à une causalité que peuvent établir les croyances populaires, comme la colère des dieux punissant

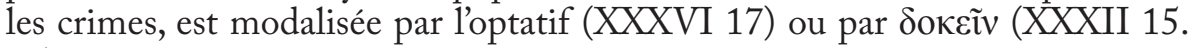
14).

Reste l'un des passages qui a le plus surpris, malgré le dessein moral ${ }^{61}$ qui y est annoncé d'emblée puis explicité: le récit des dernières années de Philippe V (XXIII 10) ${ }^{62}$, les dernières années du roi se prêtant effectivement, du reste, à une construction dramatisée. Polybe y transforme Philippe en héros tragique, et la contradiction entre la manière ainsi adoptée et les reproches de méthode que l'historien fait à Phylarque (II. 56), a été à ce point soulignée qu'elle a parfois occulté ce qui pouvait motiver ce choix formel, pourtant très fortement signalé. Nous voudrions donc examiner la manière dont Polybe fait apparaittre la leçon politique dans la facture du texte et dans le jeu de rappels internes qu'il tisse dans l'œuvre.

Ce fut comme si la Tychè, voulant châtier Philippe pour toutes les impiétés et tous les forfaits quil avait commis tout au long de sa vie, attach a alors à ses pas les Furies, les

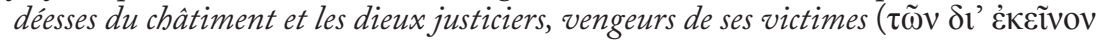

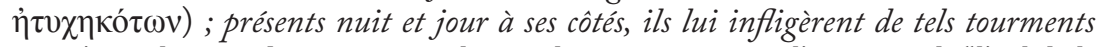
jusqu'à sa dernière heure que tout le monde put reconnaître l'existence de "l'oeil de la

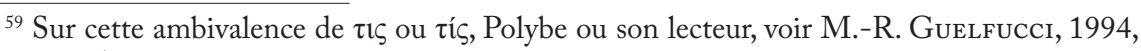
pp. 242-245.

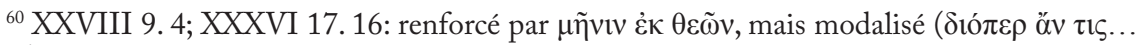
$\varepsilon i ́ \pi \varepsilon 1 \varepsilon)$. Cela n'exclut pourtant nullement la virulence devant des conduites politiques qu'il réprouve (comme le montre le dernier exemple).

${ }^{61}$ Voir F. W. Walbank, 1985 [1938], pp. 210-223.

${ }^{62}$ Sur la méfiance des historiens, par exemple E. S. Gruen, 1974, p. 223; E. Will, Histoire politique du monde hellénistique (323-30 av. J.C.), tome II, Nancy, 1982, p. 254. 
Justice", comme le dit le proverbe, Justice qu'il ne faut jamais mépriser quand on n'est quiun homme. $(\$ 2-3)^{63}$.

Le drame est clairement structuré en trois épisodes ${ }^{64}$, la Tychè deux

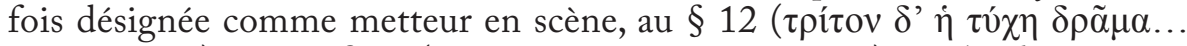

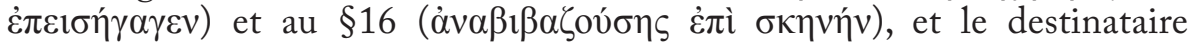
explicitement averti de la construction dramatique par des modalisateurs,

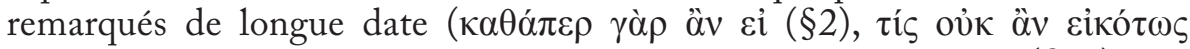

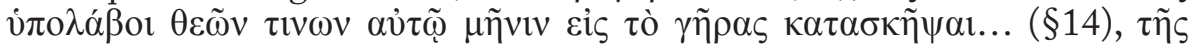

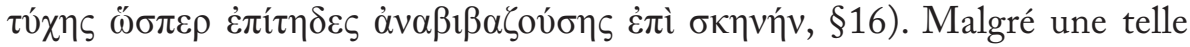
présentation, néanmoins, les trois épisodes font eux-mêmes référence à des éléments précis: un transfert de populations pour remplacer, en cas de guerre, certains éléments peu sûrs des cités du littoral, envoyés en Emathie, par des Thraces dévoués au pouvoir ( $\S 4-7)$; l'arrestation des enfants des opposants éliminés $(\$ \S 8-11)$; la rivalité entre ses fils $(\$ \S 12-13)^{65}$. Polybe part donc des difficultés politiques du roi qui, tout à la préparation de la guerre contre Rome, rencontre un double obstacle: une opposition intérieure et une querelle dynastique, Rome soutenant Démétrios contre Persée, l'héritier en titre (XXIII 3 ; XXIII 7).

Les éléments mis en valeur — qui soulignent les erreurs politiques sont instructifs et ressortent encore davantage si l'on confronte le texte avec celui de Tite-Live (XL 3. 1 - 16. 3), qui ne présente ni la même sobriété ni la même économie de moyens: Polybe marque la réprobation de l'opinion,

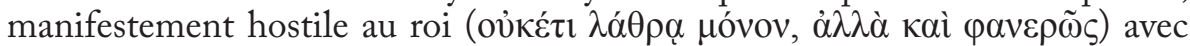
l'indication des appels manifestes à la vengeance divine ; en outre, par le

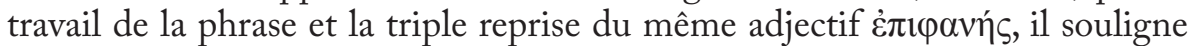
non seulement la rupture entre le roi et les populations, mais entre le roi et les personnages les plus influents ${ }^{66}$, ainsi que la compassion générale envers

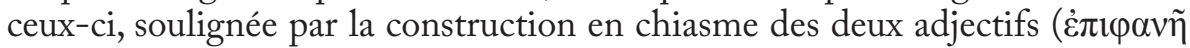

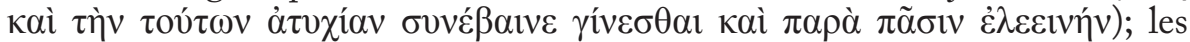
tourments de Philippe face à la rivalité de ses deux fils apparaissent, enfin, comme une sorte de punition méritée et différée de ses crimes passés, si l'on

${ }^{63}$ Sur les allusions tragiques, le rapprochement voulu de Philippe avec Oreste poursuivi par les Furies, voir R. Von Scala, 1890, pp. 80-83 ; F.W. Walbank, Comm. III, p. 229 et p. 230 (utilisation d'un proverbe qui peut avoir son origine dans la tragédie).

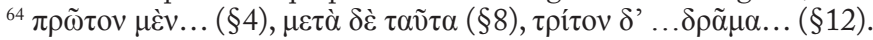

${ }^{65}$ De l'année 185 av. J.-C. (le passage se situant en 182) jusqu'à la mort du roi dans l'été 179 (suggérée en XXIII 10.3), la tension politique avec Rome ne cesse de s'aggraver : griefs de Philippe, persuadé d'avoir été lésé d'abord au profit des Étoliens, puis dans ses litiges territoriaux (obligatoirement soumis à l'arbitrage romain) avec les Grecs et avec Eumène (XXII 6 ; et 13-14, XXIII 1-3; 8; 10, 4-7); préparation de la guerre contre Rome, avec des mesures de restauration intérieure et une politique de transfert de populations (XXIII 10. 4-5) qui l'incite à étendre la Macédoine vers le nord (XXIII 8 et 10.4-5); conflit dynastique enfin.

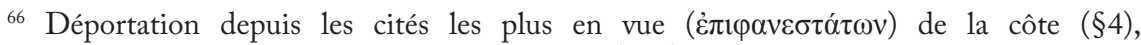
emprisonnement des fils de ceux qu'il avait fait périr (\$11), et qui sont eux-mêmes des hommes

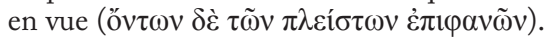


pense, par contraste, au modèle que représente politiquement, pour Polybe, la famille d'Attale face aux tentatives romaines de division ${ }^{67}$.

Il n'en reste pas moins que la forme choisie est insolite. En recourant très ostensiblement dans le passage à la figure traditionnelle de la Tychè comme Némésis et à la métaphore d'une Tychè metteur en scène, Polybe objective, tout d'abord, la crise de conscience du roi devant l'impopularité croissante ; dans le même temps, la figure de la Tychè lui permet de mettre en évidence, pour son destinataire, le drame moral intérieur et les tourments de Philippe comme de reproduire, en focalisation interne cette fois, la hantise du coupable. Le choix et la reprise des termes du passage tissent nettement, en effet, le lien entre les actions de Philippe et ses angoisses, comme si Philippe lui-même pouvait l'établir : rappel de ses entorses à la justice, divine et humaine, tout

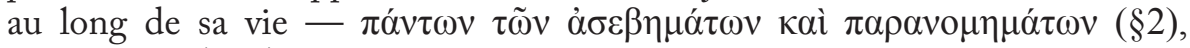

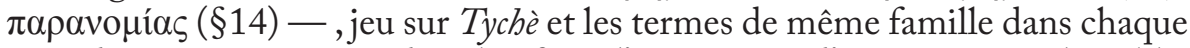
épisode, comme pour rendre plus forte l'impression d'une justice inéluctable: $\tau \tilde{\omega} \nu \delta$ '

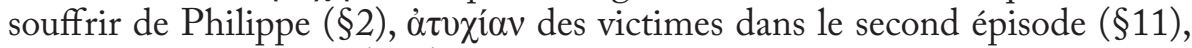

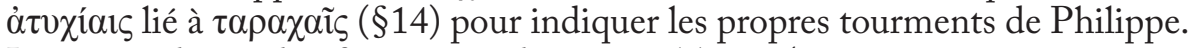

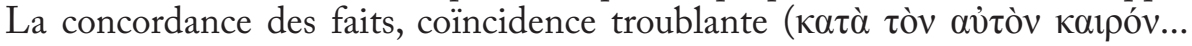

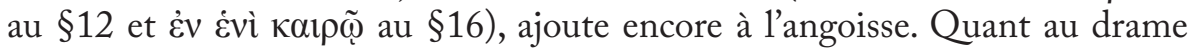
moral, accru par la permanence du malaise ${ }^{68}$, il est rendu par la référence à la métaphore proverbiale $(\S 3)$ de « l’œil de la Justice » qui voit tout et punit les crimes - et n'est sans doute ici que l'obsession d'une conscience torturée ${ }^{69}$ mais également par le choix des verbes, si imagés que Polybe lui-même atténue

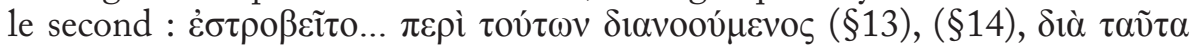

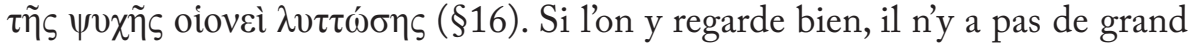
changement, dans la méthode, entre la façon dont Polybe dramatise, en VII 12, la crise de conscience de Philippe $V$ jeune, déchiré entre deux conseillers et deux tendances de son caractère, et les tourments de Philippe âgé; la différence due au ton et à la forme du passage peut s'expliquer, en partie, par cette différence d'âge, âge que le texte souligne plusieurs fois, de façon générale au début du passage $(\$ 2)$, de façon très marquée dans le dernier épisode et liée

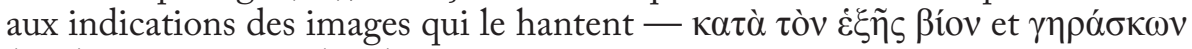

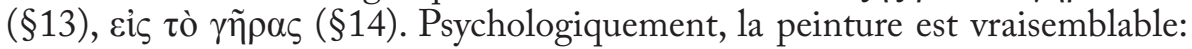
Philippe peut se sentir plus vulnérable si l'on songe, par exemple, au Céphale

${ }^{67}$ XVIII 41. 10; XXII 20 et XXXII 8. 6; XXX 1 et 2, avec l'échec des Romains dans leur l'effort de désunion. Tout apocryphe qu'il est, l'exercice d'école qui figure à la suite (XXIII. 11) met bien en valeur le contraste.

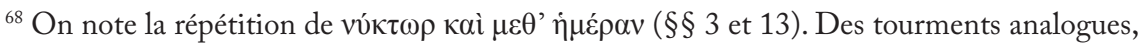
quoique nettement moins dramatisés, assaillent les traîtres (XVIII 15.12-13) pour les mêmes raisons profondes (réputation qui fait leur châtiment - $\varphi \eta \mu \eta \tau 1 \mu \omega \rho o ́ s, ~ § 12-)$, avec la conscience de l'hostilité et de la haine qui les entourent $(\$ 13)$ : angoisses, de jour comme de nuit, cauchemars qui troublent leur sommeil ( $(13)$.

${ }^{69}$ Hist., XVIII 43. 13 : " Car il n'y a pas de témoin plus redoutable ou d'accusateur plus terrible que la conscience qui réside en l'âme de chacun. » 
devenu plus inquiet de la République de Platon ${ }^{70}$. En ce sens, l'indication du $\S 14$ : « devant son âme confrontée à de tels malheurs et de tels tourments, qui n'imaginerait naturellement que la colère de certains dieux... ", indication qui fait suite aux inquiétudes supposées du roi au sujet de ses enfants, peut être

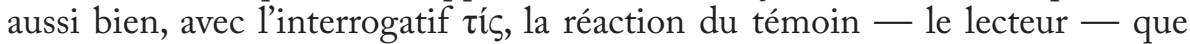
celle de tout homme, comme nous l'avons vu précédemment,ou de Philippe lui-même.

L'emploi de $\lambda v \tau \tau \omega ́ \sigma \eta \varsigma$, néanmoins, introduisant l'image de la rage et de la démence, est d'autant plus intéressant que le terme est employé une première fois par Polybe en V 11. 4, au moment des premiers sacrilèges de Philippe ${ }^{71}$, dans un passage qui établit la différence entre l'attitude politique véritable, la mansuétude du vrai roi, et la folie du tyran qui rend coup pour coup, sans réfléchir à l'avenir. Or, si Philippe est le seul que Polybe dépeigne avec une telle intensité, c'est sans doute parce qu'il représente peut-être pour l'historien un regret, en tout cas l'exemple par excellence, pour les futurs hommes d'État, de l'échec tragique d'une politique: au début de son règne, en effet, il apparaît - au moins dans l'interprétation qu'en donne Polybe - comme le roi le plus proche de la figure royale idéale définie au livre VI, paraissant juste et accepté comme tel $^{72}$, celui que les Crétois avaient choisi pour les gouverner en raison de sa justice (VII 11.9). Mais Polybe montre comment, au lieu de s'assurer l'appui des Grecs pour réaliser ses ambitions de conquête contre Rome, Philippe, bien avant Cynoscéphales (XV 24. 6), déconsidère son pouvoir; sa conduite à l'égard du jeune Ptolémée préfigure une politique de même nature à l'égard des Grecs: sacrilèges, violations du droit, asservissement des cités. En accumulant ainsi tous les crimes possibles ${ }^{73}$ (impiétés, perfidies, injustices), il voue à l'échec la guerre qu'il mène, conduite sous l'effet d'une passion dévorante ; les termes du registre de la démence scandent, en effet, son action jusqu'à Cynoscéphales:

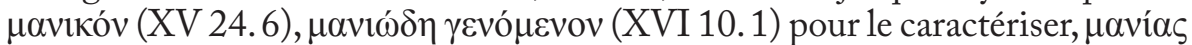
Épyov (XVIII 3. 8), pour marquer sa perfidie, son manque de générosité et sa folie dans la destruction des territoires traversés lors de sa retraite; c'est parce qu'il apparaît - selon le jugement général sur sa politique avant sa défaite -

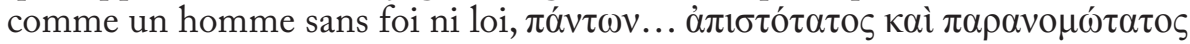
(XXV 3.9), que Rome a pu, au contraire, se poser en libératrice de la Grèce (XVIII 46.14). Trop provisoires, la leçon de la défaite et la modération (citée en XXV 374) n'empêchent pas Philippe, en 185, de reprendre son projet de

${ }^{70}$ Rép., I, 330d-e: « quand un homme croit sentir les approches de la mort, il lui vient des craintes et des inquiétudes sur des choses qui auparavant le laissaient indifférent $[. .$.$] ; ... en tout$ cas, son âme se remplit de défiance et de frayeur ; dès lors il repasse et il examine les injustices qu'il a pu commettre. S'il trouve dans sa conduite beaucoup d'iniquités, il se réveille souvent de son sommeil, comme les enfants, il a peur et vit dans une affreuse attente; [...]» (Trad. E. Chambry, Paris 1959, Les Belles Lettres).

${ }^{71} \mathrm{Il}$ revient à propos de l'attitude sacrilège de Prusias sur le territoire de Pergame (XXXII 15. 8).

${ }^{72}$ Sur le lien politique entre gouvernant et gouvernés, M. -R. Guelfucci, 2003, pp. 278-279.

${ }^{73}$ Sur le classement de tous les crimes en trois catégories et leur définition, voir XXXVI 9. 15 , à propos de Rome.

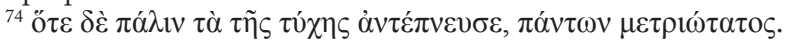


conquête, mais en renouvelant d'abord contre les Grecs puis contre ses propres sujets les mêmes erreurs; contraint par Rome à se retirer des cités de Thrace,

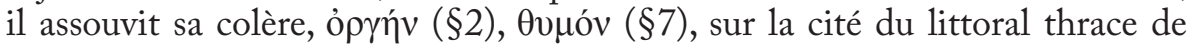
Marônée, et compte sur la peur pour obtenir le silence de la population (XXII 13.11). En XXIII 10 l'échec général apparaît dans un raccourci saisissant, avec des erreurs comme en surimpression, celles du moment renvoyant aux mêmes

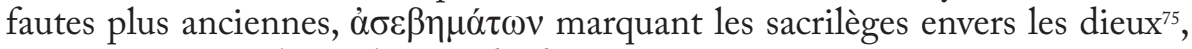
$\pi \alpha \rho \alpha v o \mu \eta \mu \alpha ́ \tau \omega v$, les violations du droit.

Ce n'est pas la seule fois, dans les Histoires, où Polybe voit dans la dramatisation un moyen de mieux faire comprendre une leçon : c'est en tout cas ainsi qu'il interprète en partie la religion romaine, avec la crainte bénéfique

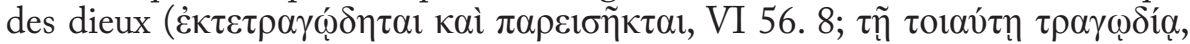
VI 56. 11), la cérémonie des imagines ( $\theta \dot{\varepsilon} \alpha \mu \alpha$, VI 53.9 et 10) ou le spectacle

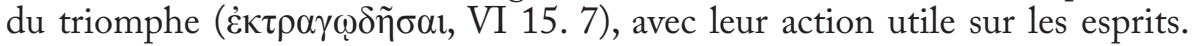
Son dessein - loin de tout examen de la pertinence de sa position - est plus explicité dans les deux autres emplois de la même métaphore d'une Tychè metteur en scène, à propos des Étoliens (XI 5.8) ou des Rhodiens (XXIX 19.2),

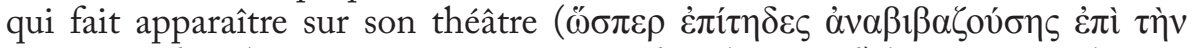

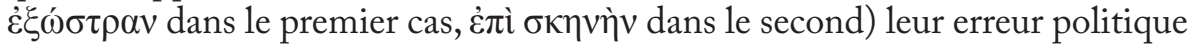

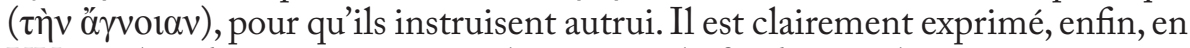
XV 20.5-8, dans un passage analogue pour le fond et par le soin apporté à sa construction rhétorique : Polybe y montre l'impudence criminelle de Philippe et d'Antiochos III à l'égard de Ptolémée $V$, jeune orphelin: dans un texte qui s'ouvre sur trois interrogations oratoires $(\S \S 1,4,5)$ : «Qui ne s'étonnerait...? », il

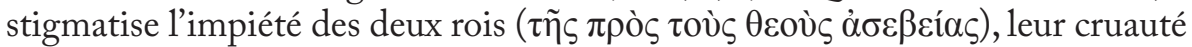

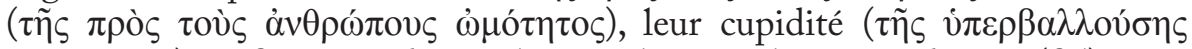
$\pi \lambda \varepsilon 0 v \varepsilon \xi i ́ a \varsigma)$, au $\$ 4$, avant de conclure sur le juste châtiment du sort (§5):

elle (la Tychè) a, en faisant un exemple avec les rois dont il est question, offert aux

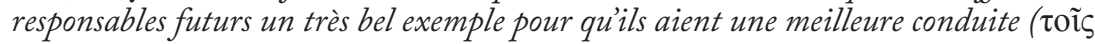

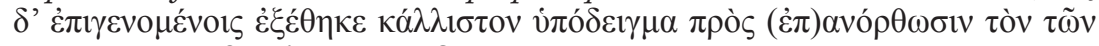

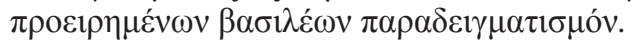

Mais si la structure marque l'indignation naturelle et commune devant une telle attitude, la fin témoigne clairement, avec le jeu sur vं le caractéristique $\pi \alpha \rho \alpha \delta \varepsilon \imath \gamma \mu \alpha \tau \imath \sigma \mu o ́ v$, du dessein de l'auteur. Ainsi, dans la leçon des Histoires, la figure de la Tychè, sciemment dramatisée, vient sanctionner très ostensiblement ${ }^{76}$ pour Philippe, mais comme pour toute hégémonie, l'erreur logique (l'abandon au choix du moment et l'absence de gouvernement concerté) et l'erreur morale, la démesure et les manquements

${ }^{75} \mathrm{Il}$ est atteint d'une sorte de frénésie (oĩov cỉ $\left.\lambda v \tau \tau \tilde{\omega} v \tau \imath \tau \tilde{\varphi} \theta 0 \mu \tilde{\omega}\right)$ contre les sanctuaires de Pergame (XVI 1). Voir le très important commentaire politique de Polybe lors de la première

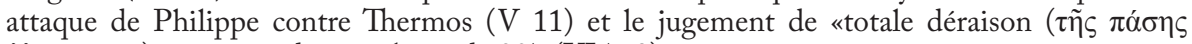

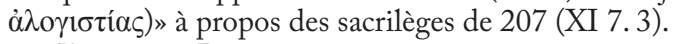

${ }_{76} \dot{\varepsilon} \xi \dot{\varepsilon} \theta \eta \kappa \varepsilon$. Pour $\pi \alpha \rho \alpha \delta \varepsilon 1 \gamma \mu \alpha \tau 1 \sigma \mu o ́ v$, voir notamment VI 38. 4; XXX 8. 8. 
d'un pouvoir qui ne s'attache qu'à un objectif temporaire, et ne mesure pas les conséquences de ses actes sur la relation de pouvoir elle-même et l'attitude de ceux qu'il gouverne. Si Philippe échoue dans le projet de conquête universelle qui le dresse contre Rome (XV 20. 6-8; XXII 7-8; XXIII 10), ce n'est pas parce que Rome est prédestinée à l'hégémonie, mais parce que, tout comme les hégémonies passées, ou Carthage (X 36.5-7) ou, après lui, Persée (XXIX 20), il ne pourrait conduire cette hégémonie dans l'intérêt collectif (VI 6.10-11). Mais le même risque existe pour Rome si elle n'y prend garde (XXXVIII 21). C'est ce lien intime entre Tychè, morale et politique, apparent dans la citation commentée de Démétrios de Phalère sur la mutabilité de la Fortune et la succession des empires (XXIX 21), qu'il reste à examiner. Nous le ferons en nous interrogeant sur l'exceptionnelle unité de l'œuvre, si forte qu'elle reste perceptible malgré l'état fragmentaire, et en considérant - ce que l'on ne fait pas - l'historien à l'œuvre dans son texte.

\section{La Tó $\chi$, la marche de l'histoire et les politeiai}

Polybe, on le dit trop peu, étudie l'ascension du pouvoir romain en scientifique $^{77}$, et Rome, dans les Histoires, est d'abord pour l'historien un objet d'étude, non seulement pour sa conquête de l'hégémonie, mais également pour le maintien, plus difficile, de ce pouvoir sur le monde (III 4) ${ }^{78}$. C'est donc en théoricien politique qu'il examine les atouts de Rome dans la conquête, la politeia surtout. Or la politeia ne renvoie pas seulement à une définition institutionnelle, mais également aux mœurs d'un Etat, les ع̌ $\theta \eta$ (VI 47. 1-2)79. Les valeurs politiques et morales fondamentales sont elles-mêmes définies: la modération et le courage pour tout citoyen, et pour le gouvernant, homme ou État, la $\mu \varepsilon \gamma \alpha \lambda o \psi v \chi i ́ \alpha$, le désintéressement et la clémence, les trois vertus politiques auxquelles, précisément, se forme Scipion Emilien ${ }^{80}$. Établi au livre VI, le schème de dégénérescence des régimes pose un agent de corruption unique, la pleonexia, qui, donnant la prédominance à l'intérêt propre sur l'intérêt collectif, a lui-même un double effet : l'amoindrissement général des valeurs, la dégradation d'un pouvoir politique reconnu et accepté, qui devient un gouvernement tyrannique rejeté. Le palliatif, pour retarder, sans pouvoir l'écarter, la dégénérescence des civilisations inscrite dans la nature humaine, est, aussi bien en politique intérieure qu'extérieure, la compensation (au sens étymologique) des pouvoirs - constitution mixte pour Rome, comme pour

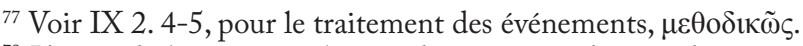

${ }^{78}$ L'unité de la pensée politique des Histoires n'a sans doute pas été assez soulignée ; nous n'en préciserons ici que les grandes lignes, en nous permettant de renvoyer pour le détail à certains de nos articles.

79 «'estime qu'il y a dans toute constitution deux éléments fondamentaux ( $\delta$ '́ $\alpha \rho \chi \alpha)$ ), qui commandent notre préférence ou notre aversion pour les qualités et les structures de la

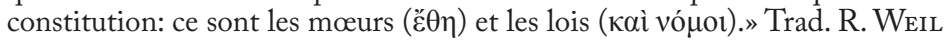

${ }^{80}$ M.-R. Guelfucci, 2003. 
Lacédémone ou Carthage, équilibre des puissances ${ }^{81}$. Or, incontestée après Pydna, la puissance romaine doit, loin de toute compensation des pouvoirs (I 82. 2-4 et XXIV 13.1-4), éviter la tendance tyrannique en restant fidèle à ses principes et veiller autant que possible à privilégier l'intérêt collectif, faute de quoi elle est destinée à décliner et céder la place, tout comme Lacédémone et Carthage avant elle ${ }^{82}$.Il s'agit donc (et le but des Histoires est, en cela, également moral) d'instruire par l'histoire et de former les destinataires essentiels, les (futurs) hommes d'État, par des commentaires en forme comme par tout un jeu de rappels internes qui, à travers des exemples commentés, forgent une expérience et tissent la leçon ${ }^{83}$. Ainsi, ajoutés au projet initial (l'examen de la conquête de l'hégémonie par Rome), les dix derniers livres doivent permettre au lecteur de porter un jugement sur l'exercice de cette hégémonie (III 4. 6-9) et de prendre, s'il est un homme d'État, les mesures correctives nécessaires, à l'exemple de Scipion Emilien.

Quel est dès lors le rôle de la tychè? Elle intervient d'abord dans le rappel des principes et la mise en garde contre certaines dérives, ressortant de contrastes voulus: éloge, dans le bilan de la première guerre punique, des valeurs civiques romaines (courage, obstination tenace, dévouement à l'intérêt commun, l'effort financier étant assumé par les particuliers), qui font que ce n'est pas « avec l'aide de la Fortune, comme le croient certains Grecs, ou par hasard " qu'ils ont cherché et réussi à conquérir l'hégémonie mondiale (I 63. 9) ${ }^{84}$. Que l'on choisisse de retenir le point de vue dépréciatif (« avec l'aide de la Fortune...») $)^{85}$ ou l'explication plus rationaliste (" comme cela s'est trouvé... »), les deux interprétations, sans doute présentes ici en même temps, sont, de toute façon, un rappel aux principes: car le chapitre suivant est une mise en garde pour la Rome victorieuse, où l'engagement personnel et l'esprit civique sont moindres (I. 64) ${ }^{86}$.

En politique extérieure, de même, la citation de Démétrios de Phalère, avec sa référence à la Tychè (XXXIX 21. 5), souligne la précarité du pouvoir humain, et forme, avec les appels à la modération de Paul-Emile auxquels elle fait suite (XXIX 20), une mise en garde traditionnelle contre l'orgueil ou l'bybris existants et un pouvoir de démesure, comparable à celles que nous avons déjà examinées pour le stratège. C'est du reste cette précarité que souligne

${ }^{81}$ M.-R. Guelfucci, 1998.

${ }^{82}$ Voir, dans le schème explicatif, VI 7.2; VI 7. 8-9; 8. 6; 9. 5; pour Carthage, I 72 et X 36.

${ }^{83}$ M.-R. Guelfucci, 2010.

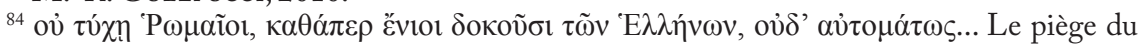

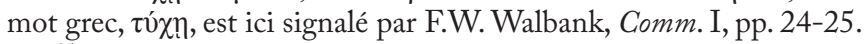

${ }^{85}$ K. Von Fritz, 1954, p. 394. Sur l'incontestable mérite des Romains, qui tirent seulement parti de la chance, les exemples sont nombreux : conquête du Latium (I 6.4); conquête de la mer avec l'énergie et l'audace (I 20.11 et 12) et la chance (I 20.15-16, mais voir aussi VI 25.11); seul système des corbeaux, à Myles (I 22-23). Sur les implications politiques et les risques de ce point de vue grec, voir J.-L. FERRARY, 1988, pp. 273-276.

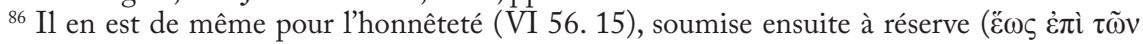

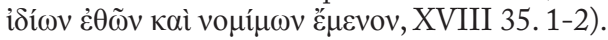


Polybe, en commentant les larmes d'Antiochos (VIII 20. 10) ${ }^{87}$ ou les craintes de Scipion devant Carthage (XXXVIII 21).

D'autres figures de la Tychè sont, en revanche, d'un tout autre ordre, et viennent traduire, non pas, comme il est souvent dit, l'action d'une force extérieure qui ordonnerait le monde, mais bien la propre perception polybienne de la marche de l'histoire, à un moment particulier où, dirions-nous, semble se jouer l'histoire. Ces moments sont de deux ordres: soit ils représentent un tournant de l'évolution des événements et du récit, et Polybe représente ce moment critique par une Fortune arbitre (I 58. 1); soit ce sont, historiquement, des moments clefs, qui rendent l'évolution des événements explicable ${ }^{88}$. Polybe les distingue et les choisit parce qu'ils marquent un changement dans le cours des choses, comme l'olympiade qui voit accéder au pouvoir les chefs d'État qui peuvent potentiellement conduire l'hégémonie (II 71.2 et IV 2.4-10). Ainsi, en IV 2 (et le texte est significatif), l'historien justifie son « excellent point de départ » en ajoutant une quatrième raison:

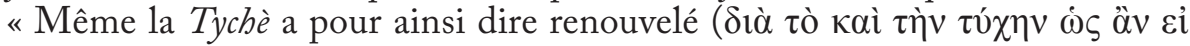

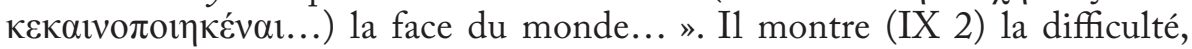
stimulante pour lui, de rendre compte de ces changements, justifiant son choix

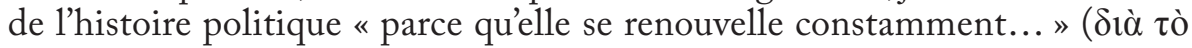

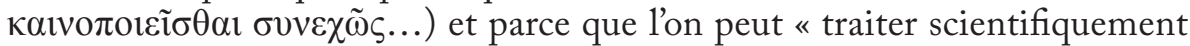

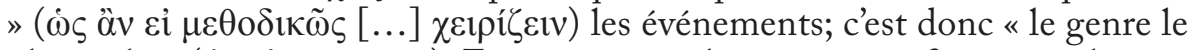

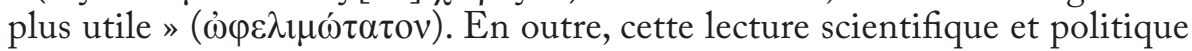
de l'évolution du monde exige, outre le cadre d'une histoire universelle, une composition très précise de l'œuvre, l'historien marquant formellement les grandes étapes, avec l'intervention des digressions scientifiques (livres VI, XII, XXXIV) ou des digressions intégrées ${ }^{89}$.

Nous voudrions conclure sur l'étonnant parallèle par lequel Polybe renouvelle le topos des prologues historiques que constitue la singularité de son sujet, la conquête qui conduit à une hégémonie sur tout le monde habité. Il y met en valeur l'histoire universelle (I 4. 6-11), seule apte à rendre compte du " plus beau et plus instructif des ouvrages de la Tychè», qui a orienté vers un seul but l'histoire du monde. Dans le passage, très rhétoriquement construit si on le compare avec la forme beaucoup plus sobre de VIII 2 (VIII 2.3 notamment), on peut voir, avec

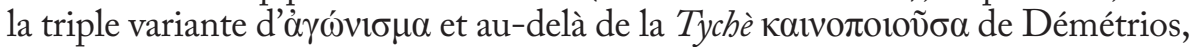

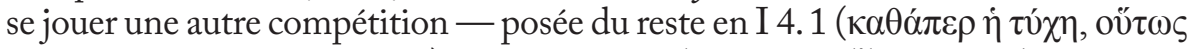

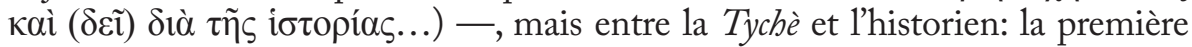
oriente vers un seul but les événements, l'historien, qui en a conscience (I 4.2), doit pouvoir donner à ses lecteurs cette vue d'ensemble (I 4.1 $)^{90}$. Si l'on considère

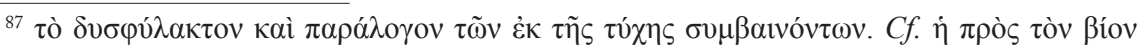

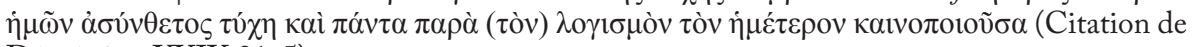
Démétrios, XXIX 21.5).

${ }^{88}$ K. SAcks, 1981, remarque (p. 141) que Polybe impose un ordre dans les faits.

${ }^{89}$ Sur la structure des Histoires, M.-R. Guelfucci, 2010, pp. 336-354.

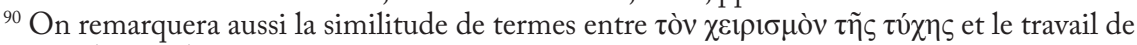
l'historien (IX 2. 5). Voir, pour une autre lecture attentive au parallèle, J.-M. PAILlER, 2003, p.

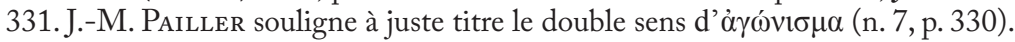




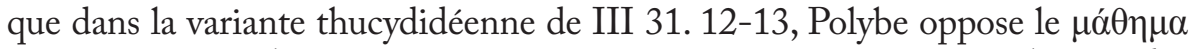
que constitue son histoire à un $\alpha \hat{\gamma} \omega ́ v ı / \sigma \mu \alpha$ sans mise en perspective explicative des faits, on peut voir ici une autre manière de dire la valeur, instructive de surcroît, d'une œuvre qui sauve de l'oubli l'histoire des hommes.

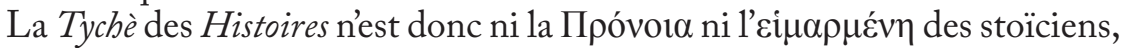
ni la Moira ou la Fortune de Rome qu'elle sera après Polybe ${ }^{91}$. Elle signale nettement, en revanche, les interventions de l'historien dans son récit, soit qu'il éclaire les événements selon différents points de vue, soit qu'il fasse (re) lire le déroulement des événements d'un point de vue moral en dramatisant explicitement la leçon. Dans cette relecture rationalisée du passé et cette construction d'ensemble très maîtrisée, la Tychè apparaît, en partie,comme ce que nous appelons "l'histoire ${ }^{92}$ (parfois même hypostasiée), en partie également, pour le moraliste qu'est Polybe, comme la figure morale qui, traditionnellement, rappelle à ses lecteurs les faiblesses et la précarité de leur condition. La pensée morale rejoint ici la pensée politique et les préoccupations des intellectuels et des cercles éclairés romains, à l'époque où Polybe écrit son histoire, comme en témoigne ce que nous savons par Cicéron de la conférence de Carnéade, en $155^{93}$. Selon Polybe, ce n'est, dans la tradition classique, qu'en étant conscient du risque de démesure qui accompagne la conquête d'un très grand pouvoir et rend celui-ci précaire, que le Politique ou la puissance hégémonique peuvent prétendre à conduire les autres, faute de quoi ils sont, par essence, condamnés à l'arbitraire - fût-il un temps masqué par l'honorabilité des apparences - et à se voir, mais par leur faute, remplacés à plus ou moins long terme.

${ }^{91}$ Sur le faux rapprochement fait entre la Tychè des Histoires et la Moira de l'hymne en l'honneur de Rome dû à la poétesse Mélinno, voir J.-L. Ferrary, 1988, pp. 265-271.

${ }^{92}$ Voir déjà W. Warde Fowler, 1903, p. 447 : “ It may be paralleled by the way in which some modern historians use the work Evolution, which they find convenient to express the natural course of events, without meaning everything very definite by it".

${ }^{93}$ Sur le texte de Polybe, nous n'avons plus que le témoignage d'Aulu-Gelle sur la véhémence de l'éloquence de Carnéade (VI 14. 8-10 et Hist. XXXIII 2). Sur la conférence elle-même, voir Cicéron de rep., III VIII. 12 (E. BréGuet, Paris, 1980, Les Belles Lettres). 


\section{Bibliographie}

Darbo Peschanski, C., 2007, L'Historia, Commencements grecs, Paris.

Dubuisson, M., 1985, Le latin de Polybe, Paris.

Ferrary, J.-L., 1988, Philhellénisme et impérialisme, Aspects idéologiques de la conquête romaine du monde hellénistique, BEFAR 271, Rome.

Von Fritz,K., 1954, «Polybius' concept of Tychè and the problem of the development of his historical thought", in The theory of the Mixed Constitution in Antiquity, Appendix II, pp. 388-397.

Gruen, E.S., 1974, «The last years of Philip V», GRBS 15, pp. 221-246.

Guelfucci, M.-R., 1994, « Des mots et des manières de lire: le lecteur de Polybe ", in Ch. Kircher-Durand (éd.), Nomina Rerum, Hommage à Jacqueline Manessy-Guitton, L.A.M.A 13 Nice, pp. 241-257.

Guelfucci, M.-R. 1998, « Les origines de la société politique d'après Polybe (Histoires, VI, 5 sq.) », in J.-M. Galy et A. Thivel(éds.), Les origines de l'homme d'après les Anciens, Nice, pp. 153-169.

- 2003, «Pouvoir politique et crise de société chez Polybe», in S. Franchet D'Espèrey, V. Fromentin, S. Gotteland et J.-M. Roddaz (éds.), Fondements et crises du pouvoir, Paris/ Bordeaux, pp. 271-280.

- 2010, «Polybe, le regard politique, la structure des Histoires et la construction du sens», in CEA 47, pp. 329-357.

Hercod, R., 1902, La conception de l'bistoire de Polybe, Lausanne.

Pailler, J.-M.,2003, « Polybe, la Fortune et l'écriture de l'histoire. Le cas de la première guerre punique », in P. Defosse (éd.), Hommages à Carl Deroux, Bruxelles, pp. 328-339.

PÉDech, P., 1964, La méthode historique de Polybe, Paris.

Roveri, A., 1956, «Tyche in Polibio», in Convivium 24, pp. 275-293.

SAcks, K., 1981, Polybius on the writing of history, Berkeley-Los Angeles.

Von Scala, R.,1890, Die Studien des Polybios, Stuttgart.

Walbank, F.W. 1999 [1970, avec addenda et corrigenda de 1967], $A$ bistorical Commentary on Polybius I. Commentary on Books I-VI, Oxford 1957.

- 1999 [1967] A bistorical Commentary on Polybius II. Commentary on Books VII-XVIII, Oxford.

- 1999 [1979] A historical Commentary on Polybius III. Commentary on Books XVIII -XL, Oxford. 


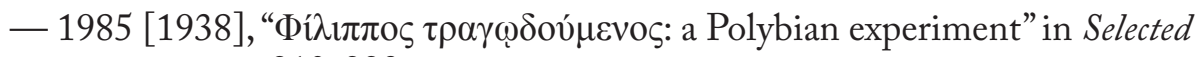
papers, pp. 210-223.

- 1972, Polybius, Berkeley-Los Angeles.

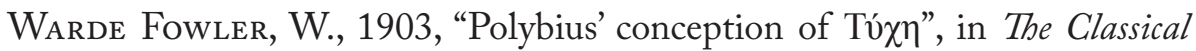
Review (17), pp. 445-449. 


\title{
La Providencia como Salvaguarda de los Proyectos Históricos Humanos en las VIDAS PARALELAS
}

\author{
Aurelio Pérez Jiménez \\ Universidad de Málaga
}

\begin{abstract}
In this paper, I analyse the relationship between the actions of Plutarchan heroes and Providence. Of course, Providence collaborates with them by determining the conduct of minor characters and antagonists, whose performance modifies the future or favours the historical success of the main characters. But, in any case, even when Plutarch underlines the freedom and responsibility of his heroes, the historical evolution of peoples (Athens, Sparta, Macedonia or Rome) appears as a result of their collaboration with Providence: 1 ) they assume as a rule of conduct the human qualities loved by Gods; and 2) these reveal their will by dreams, oracles and prodigies, which are correctly interpreted by the heroes; but 3) divinity always puts the fate of peoples before the interest of individuals, even sacrificing virtuous men like Brutus to the progress of the community. In such cases, the constitutions protected by the gods (like, for example, those of Athens, Sparta or Rome) coincide with political ideas of the biographer himself, who becomes in this way a political propagandist.
\end{abstract}

En el capítulo 7.5 de la Vida de Rómulo, los boyeros de Numítor, que han capturado en una escaramuza a Remo, se lo llevan al viejo rey. Éste se queda admirado de su presencia física extraordinaria, de su resolución y osadía, acordes con aquélla, y de las gestas que ya se atribuían al joven. Pero, sobre todo, a partir de estas evidencias, entra en sospecha y conjetura la verdad, por lo que le formula preguntas sobre su origen y nacimiento que conducirán a reconocerlo como su nieto; desde ese momento planea con él y con Rómulo, que todavía está en casa de Féstulo, el derrocamiento del usurpador Amulio. En este pasaje, la parte última, la sospecha y las preguntas, no vienen determinadas por la fortuna del encuentro, sino que obedecen a todo un plan establecido por los dioses que ya piensan ejecutar un proyecto histórico de tanta envergadura como es la fundación de Roma. Precisamente, eso es lo más importante, tò $\mu \bar{\gamma} \gamma 1 \sigma \tau o v$, en las reflexiones que introduce el biógrafo a propósito de dicho encuentro:

y lo más importante, presumiblemente por la presencia de un dios que ayudaba ya a dirigir los comienzos de grandes empresas... ${ }^{1}$

La intervención divina con objetivos tan claros como el que manifiesta Plutarco en este pasaje no es un hecho aislado en la Vida de Rómulo. En el capítulo 19.2, hablando de la batalla promovida entre sabinos y romanos por

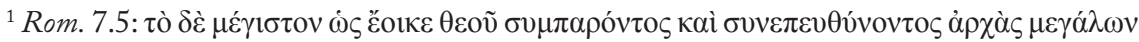
$\pi \rho \alpha \gamma \mu \alpha \dot{\tau} \omega \nu, \ldots$
} 
el rapto de las hijas de aquéllos, la intervención de éstas para que ambas partes asuman los hechos consumados y hagan la paz, que tanto necesita la incipiente Roma, se presume también impulsada por la divinidad:

Pues las hijas raptadas de los sabinos aparecieron ante sus ojos, metiéndose desde distintos lugares con gritos y algarabia por medio de las armas y los muertos, como poseidas de un dios,...2

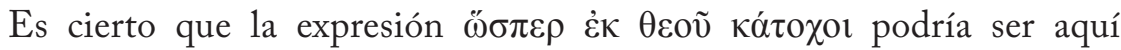
discutible y no tener más valor que el simplemente descriptivo de la alocada violencia de las jóvenes a su entrada, asimilable al delirio de las bacantes; pero, en contexto tan decisivo para el futuro de Roma, sugerimos al menos que Plutarco le da esa funcionalidad providente propia del hecho mismo. Apoya nuestra interpretación la circunstancia de que, como veremos más adelante, el biógrafo recuerda este suceso como paradigma para otro en el que la intervención divina se enuncia más explícitamente, el de la decisión de Valeria de recurrir a Volumnia ante el asedio de Roma por Coriolano. Así que la Providencia está en los inicios de la aventura romana como declara sin ambajes el propio Rómulo, ya convertido en dios Quirino, en su respuesta al viejo Proclo:

Los dioses decidieron, joh Proclo!, que todo ese tiempo hayamos estado con los hombres y que, tras fundar una ciudad que alcanzará el mayor imperio y gloria, de nuevo babitemos el cielo, pues de allí somos. Mas jea!, ve y revela a los romanos que, practicando la prudencia con el valor, llegarán a la cumbre del poder humano.

Naturalmente, las palabras de Rómulo convertido en dios serán para Plutarco una guía a considerar sobre el papel de la intervención divina en los momentos críticos de la historia romana. Incluso cuando la solución positiva de

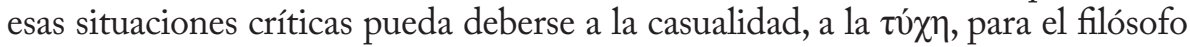
platónico, tan convencido del papel de la Providencia en la historia del hombre, la posibilidad de su intervención siempre estará presente. Así ocurre con la inexplicable renuncia de Aníbal a entrar en el Capitolio después de la victoria de

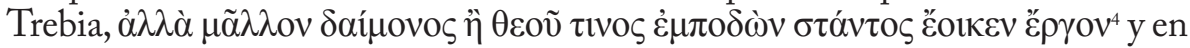
otros momentos que afectan a las acciones individuales de los personajes de las Vidas o al desenlace de episodios de las guerras civiles que marcan la evolución general y deseable de Roma desde la República hacia el Imperio.

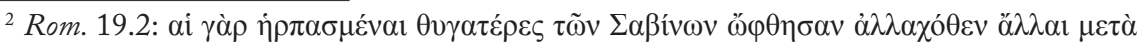

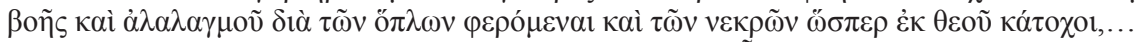

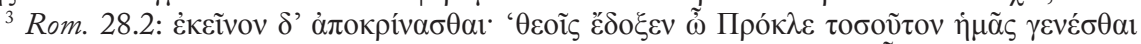

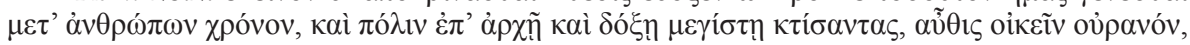

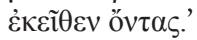

${ }^{4}$ Fab. 17.1: "Pero más bien parece obra de un demon o de un dios que se le puso en contra". De hecho, mientras Livio (XXII 51.3) enfoca esta decisión de Aníbal por su trascendencia histórica, como razón de la supervivencia de Roma, a Plutarco es evidente que lo que le interesa es la intervención divina en los acontecimientos históricos (cf. Babut, p. 478). 
Supuesta, pues, la importancia de la Providencia en el establecimiento de un orden político y militar en el mundo antiguo, veamos cuáles son los fines de esa intervención providente, cuáles las razones que la mueven y cuáles los medios de que se sirven los dioses para llevar a cabo los proyectos históricos de los personajes de las Vidas Paralelas, que, a menudo, se convierten en ejecutores de la voluntad divina, revelada a ellos a través de prodigios, oráculos y sueños.

Del análisis de las Vidas Paralelas se desprende una implicación constante de la divinidad en los empeños históricos de los hombres. Como ya hemos dicho en otro lugar, eso es lo que precisamente convierte la justicia en la virtud que mejor define la naturaleza de los dioses y que permite superar su trascendencia en relación con los hombres ${ }^{5}$. Deducimos -y no podía ser de otro modo- una interpretación optimista por parte de Plutarco del papel ejercido por los dioses en el desarrollo histórico de la vida humana. Es ese orden general diseñado por la Providencia lo que explica la necesidad de sacrificar brillantes carreras que, sin embargo, responden a los principios de virtud y justifican la vida de estos personajes como modelos de conducta dignos de entrar en la obra pedagógica de Plutarco. Valga como hipótesis previa: Esas grandes líneas a que se reducen los proyectos históricos de la divinidad son la culturización gradual del mundo (sustituyendo pueblos bárbaros por pueblos civilizados o incluso restringiendo temporalmente la libertad misma de los griegos $^{6}$ ) y la eliminación de fórmulas políticas despóticas desestabilizadoras (ya sean tendencias tiránicas o demagógicas) para lograr un equilibrio social de Bien común garantizado por la autoridad paternalista y benevolente que representa el buen rey, personalizado para la época de Plutarco en el Emperador Trajano ${ }^{7}$.

En efecto, a lo largo de las Vidas Paralelas vemos triunfar a los derrocadores de tiranos y déspotas, como Bruto y Valerio Publícola (a Tarquinio), Dión y

\footnotetext{
${ }^{5}$ A. Pérez Jiménez, 2005.
}

${ }^{6}$ Así la derrota de Demóstenes será necesaria en los planes divinos para cambiar el curso de los acontecimientos históricos a favor de Alejandro, lo mismo que ocurrirá luego con la de Pompeyo y Bruto, indispensables como instrumento para la instauración del Imperio (cf. Valgiglio, 1988, pp. 34-35). Pero la pérdida de la libertad para los griegos -desde la perspectiva de este proyecto global providente- sólo es temporal: la degeneración despótica del imperio macedonio que deriva a tiranos como Perseo y Filipo, hará posible la restauración romana de esa libertad en las figuras positivas de Emilio y de Flaminino respectivamente, ejemplos de virtud para Plutarco (cf. Flam. 15, Cat. Ma. 12, Aem. 7. 3).

${ }^{7}$ Cf. A. Pérez Jiménez, 2002 y 2004, espec. pp. 59-64. Este Bien común, entendido como el interés de la patria, marca el punto de vista desde el que Plutarco interpreta y valora las actitudes religiosas o no de sus personajes. Lo veremos más adelante, a lo largo de nuestras reflexiones sobre el tema, pero permítaseme recordar ahora que la preferencia por los intereses personales frente a los de Roma es lo que motiva la crítica de Plutarco al acuerdo entre César y Pompeyo (Pomp. 70) que condujo a una deporable situación de Roma (cf. F. Frazier, 1996, p. 147) y que permitirá insertar en los planes divinos para la instauración de la monarquía imperial tanto el fracaso de Pompeyo como luego la muerte de César. 
Timoleón (a los de Sicilia) o Arato, Emilio y Flaminino (a los de Grecia); y vemos especialmente a quienes impulsaron un orden político con controles para evitar esos abusos del poder autoritario e introducir entre pueblos poco civilizados estructuras a favor del conjunto de los miembros de la comunidad. Teseo, Rómulo, Licurgo, Numa, Solón, Publícola y todos los legisladores que organizaron los estados prominentes de la Antigüedad cuentan explícita o implícitamente con la complacencia e incluso con la colaboración divina para realizar esos proyectos estabilizadores. A este respecto, les es aplicable a todos ellos la proclama que el biógrafo hace en la Vida de Numa para explicar como políticamente justificable la relación íntima de los dioses con los hombres, que tantos problemas plantea en el orden filosófico-religioso:

¿̇Acáso es lícito entonces, si admitimos estas historias sobre éstos, que no creamos que la divinidad tenía frecuentes contactos con Zaleuco, Minos, Zoroastro, Numa y Licurgo, cuando pilotaban sus monarquias y ponian en orden sus constituciones?8

No cabe duda de que los personajes positivos de Plutarco, o al menos así lo entiende él, son conscientes de esta dependencia de su misión pública respecto a los dioses. Algunos, como el propio Numa, incluso asumen las funciones políticas como un servicio religioso'; otros dan pruebas de ello cuando, al emprender las acciones más trascendentales de su vida, comienzan indagando la voluntad de aquellos. Plutarco lo subraya a propósito de Teseo ${ }^{10}$, hace hincapié en ello en las Vidas de Licurgo y Numa ${ }^{11}$, y recurre a los historiadores romanos, en un caso, y griegos, en otro, para buscar una actitud religiosa de Fabio ${ }^{12}$ que sirva de bálsamo a los romanos en momentos críticos para la ciudad; o una subordinación de Alejandro a Delfos, antes de iniciar la aventura más importante de su historia, la expedición a Asia que terminará con el imperio bárbaro de los persas ${ }^{13}$.

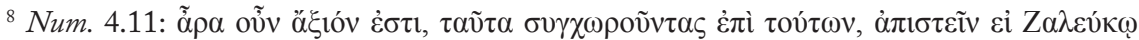

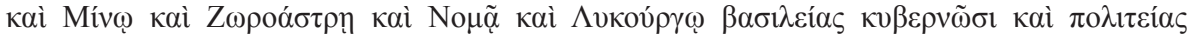

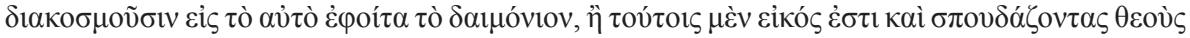

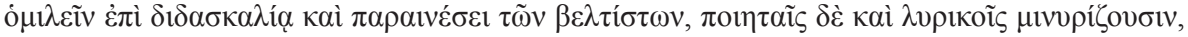

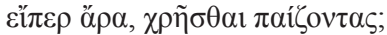

${ }^{9}$ Num. 6.2, 15.1. Véase sobre este tema Ph. Stadter, 2002, p. 5.

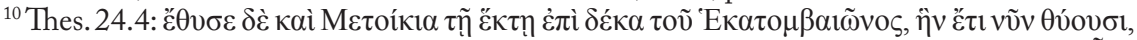

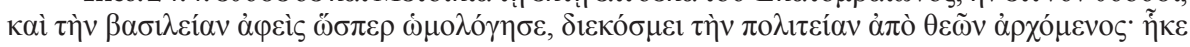

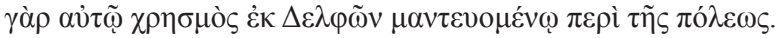

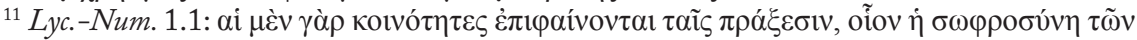

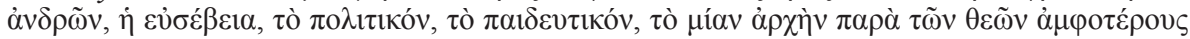

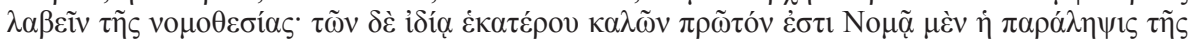

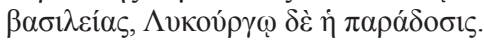

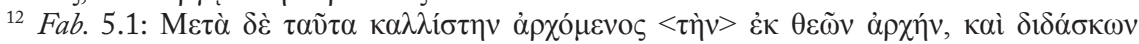

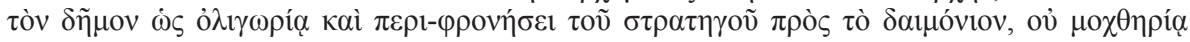

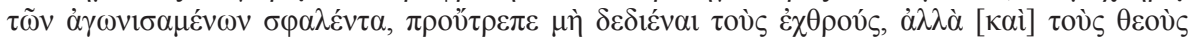

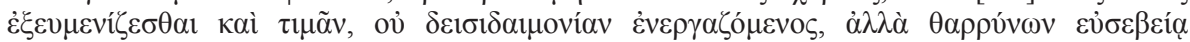

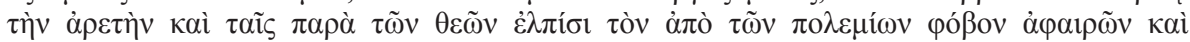
$\pi \alpha \rho \alpha \mu v \theta$ ov́ $\mu \varepsilon v o s$.

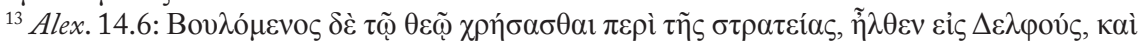


Incluso algunos de estos personajes asumen su misión histórica como un servicio a la divinidad que, por su parte, los utilizará para cumplir designios más altos. Es el caso de Numa, convencido por su padre mediante argumentos de ese tenor para aceptar la corona ${ }^{14}$; o el de Sócrates, empeñado en la educación de Alcibíades ${ }^{15}$. Otros, con su conducta, imitan la acción misma de la providencia divina. Esto hace, por ejemplo, según Plutarco, Licurgo, cuando es asimilado en su diseño de la constitución espartana al demiurgo platónico ${ }^{16}$. Y no faltan personajes secundarios que entienden su papel como instrumento de la divinidad para algún fin; desde la óptica de Plutarco ese fin no es sino contribuir a que se cumpla el papel asignado por los dioses al héroe. Estamos pensando en la salvación del niño Arato que, indefenso tras el asesinato de su padre, es recogido por una mujer de noble naturaleza, capaz por tanto de comprender que aquel niño se ha refugiado en su casa por la providencia de algún dios ${ }^{17}$. Y estamos pensando también en la intervención de Valeria, la hermana de Publícola, que mueve a las mujeres romanas para que acudan a pedirle a Volumnia su intercesión ante Coriolano, con el noble objetivo de salvar nada menos que la República. Ahora es la mujer y no sólo Plutarco quien proclama su misión como obra de los dioses:

Nosotras mismas, ob Volumnia, y tú, Virgilia, mujeres ante mujeres acudimos, no por decreto del Senado ni por encargo de magistrado. Más bien fue la divinidad la que, compadecida, según parece, de nuestras súplicas, puso en nosotras el impulso para dirigirnos aqui ante vosotras y haceros un ruego que supone la salvación de nosotras mismas y del resto de los ciudadanos y que implica para vosotras, si nos hacéis caso, una gloria más brillante que la que tuvieron las hiijas de los sabinos, cuando reunieron a sus padres y maridos en el amor y la paz, apartándolos de la guerra ${ }^{18}$.

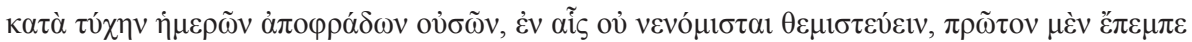

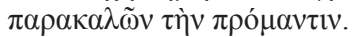

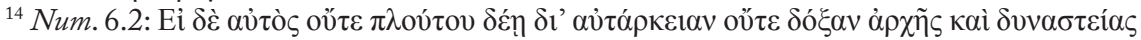

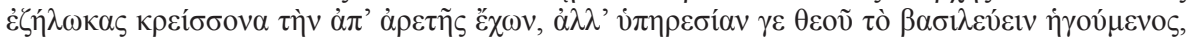

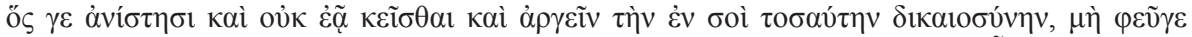

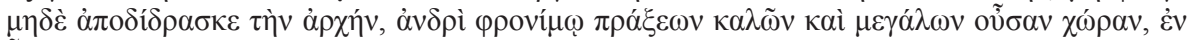

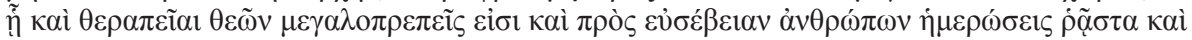

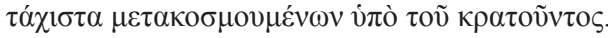

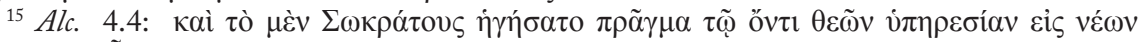

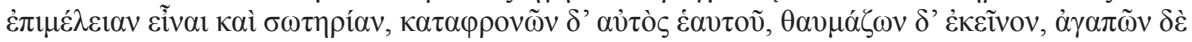

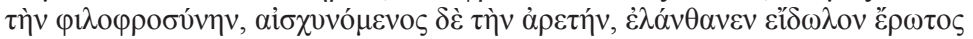

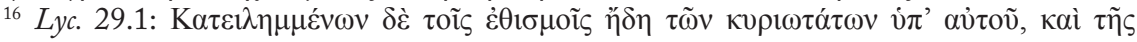

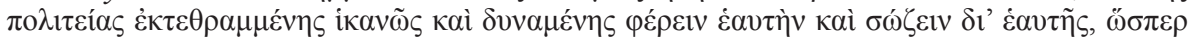

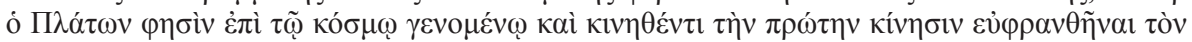

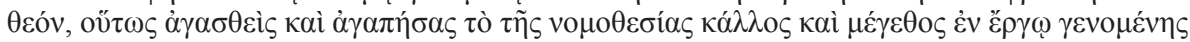

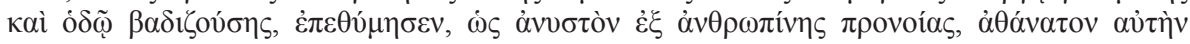

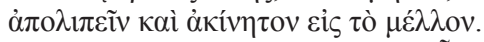

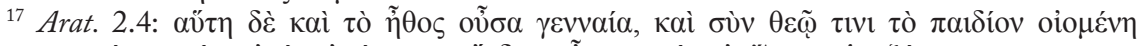

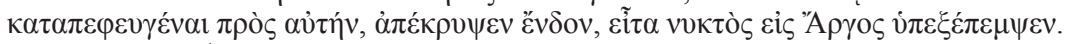

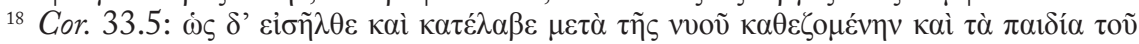

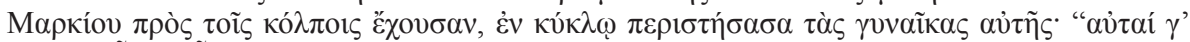

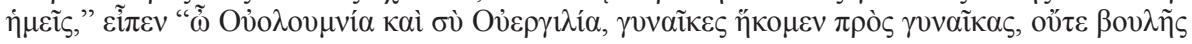

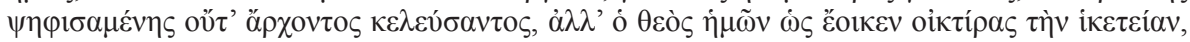


La referencia a las sabinas no está fuera de lugar si, como defendíamos al comienzo de este trabajo, su acción se entiende también movida por los dioses para la salvación de Roma, entonces un proyecto y ahora ya una realidad consolidada.

Así que los dioses utilizan a los hombres a la manera de simples instrumentos para sus fines históricos, como el propio Plutarco asume también a propósito de la situación crítica en que se ve Roma ante el asedio de Coriolano y que se resolverá por la intervención de las mujeres, según acabamos de decir. Así lo expresa el biógrafo, dogmatizando entre filósofo político y teólogo:

En cambio, en las acciones inusuales y extraordinarias y que exigen cierto impulso entusiasta y excitación, no presenta (se refiere a Homero) a la divinidad anulando, sino estimulando la facultad de decisión, ni tampoco generando en nosotros impulsos, sino concepciones que dirigen nuestro impulsos, con las cuales no hace la acción involuntaria, sino que da principio a la voluntariedad y le añade el coraje y la esperanza. Pues o hay que apartar a la providencia divina de toda responsabilidad y puesta en marcha de nuestras acciones, o podría haber alguna otra forma con la que ayudan a los hombres y colaboran con ellos ${ }^{19}$.

Naturalmente, entre ambas opciones, el sacerdote délfico opta por la segunda y vemos a todos estos personajes cumpliendo una misión divina. Que tienen conciencia de ello, tal como leemos en la primera parte del texto citado, en casos extraordinarios del tipo de Valeria o de las sabinas, es un hecho. Pero otros no se dan cuenta. Entonces se podría discutir si esa participación es fruto del azar o de la providencia; un debate este, resuelto a menudo por Plutarco con la subordinación de aquél a ésta. En esta categoría encajaría el corintio que pronunció el nombre de Timoleón (un político prominente, pero hacía tiempo ya apartado de la vida pública) cuando la ciudad buscaba un general para enviarlo a Sicilia a liberar aquellas ciudades griegas del yugo de los tiranos ${ }^{20}$.

En los ejemplos referidos hasta ahora la intervención divina es presumida por el biógrafo debido a la importancia que luego deriva de los hechos de esos

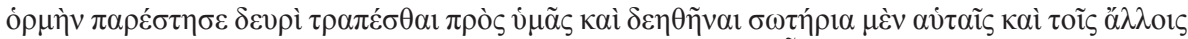

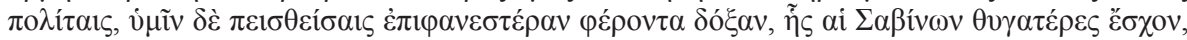

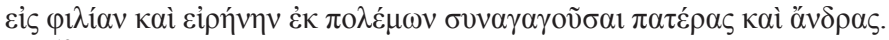

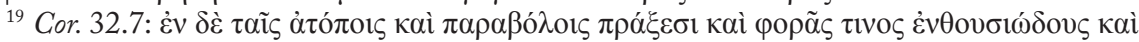

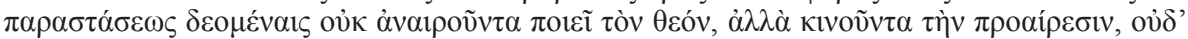

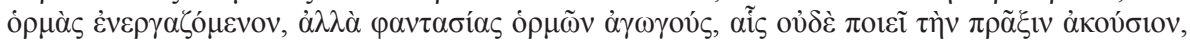

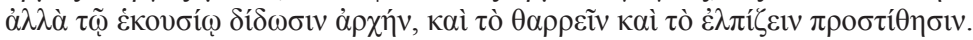

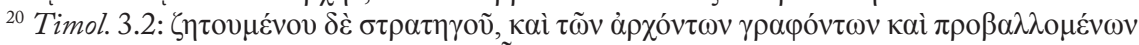

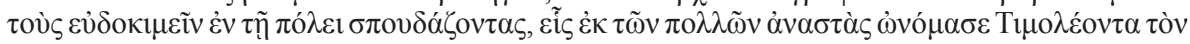

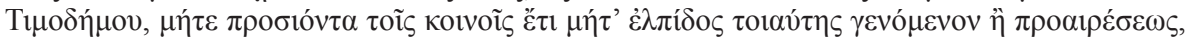

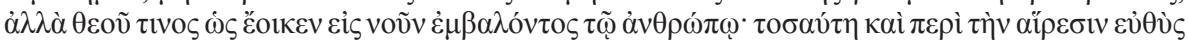

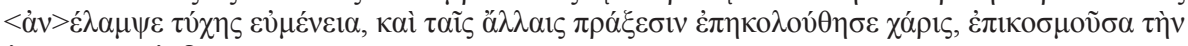

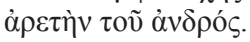


personajes menores, como las sabinas, Valeria, el corintio o la mujer que recoge a Arato. Pero en la mayoría de los casos, el instrumento y objetivo inmediato al mismo tiempo es el héroe principal de la Vida. Plutarco analiza el papel de estos héroes desde una triple perspectiva:

1) Saben que la virtud, el valor y la inteligencia son los ragos humanos a los que la divinidad da su protección y ellos lo asumen como norma de conducta. Fabio está convencido de que los dioses apoyan y conceden el éxito a la virtud y la inteligencia, un convencimiento que es capital para entender su estrategia contra Aníbal ${ }^{21}$. La actitud de Fabio es sin duda la clave para entender los límites entre la acción de la providencia divina y la responsabilidad humana: el uso consciente de la piedad por parte del político para ganarse la voluntad -y por tanto la colaboración- divina en momentos $\operatorname{críticos}^{22}$. $Y$ es que en modo alguno los dioses protegen la indolencia. Sus agentes en la tierra son activos, con la mirada puesta en la gloria y el éxito, uno de los elementos pedagógicos de las Vidas Paralelas ${ }^{23}$. Lo hace Fabio, como acabamos de ver y lo hace Emilio, a cuyas plegarias responden positivamente los dioses, en contraste con la actitud pasiva y cobarde de Perseo ${ }^{24}$. Este se retira a la ciudad con el pretexto de unos sacrificios a Heracles

que no acepta ofrendas cobardes ni tiene en cuenta súplicas injustas. Pues no es justo ni que el que no lanza dé en el blanco, ni que quien no resiste venza, ni, en fin, que quien no actúa tenga éxito, ni el malvado sea feliz. En cambio a las plegarias de Emilio sí atendía el dios; pues pedía la superioridad en la guerra y la victoria, mientras blandía la lanza y combatiendo invocaba como aliado al dios ${ }^{25}$.

A cambio, la Providencia, que realiza sus proyectos a través de esos personajes conscientes de su responsabilidad, los ayuda y protege con sus intervenciones. Para Teseo el amor de Ariadna tan sólo es un expediente divino que le permite cumplir con su misión en Creta $^{26}$. El descubrimiento de

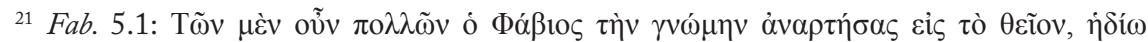

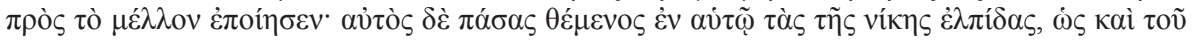

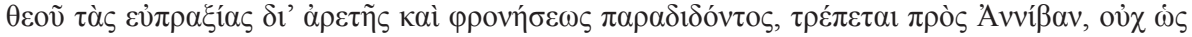

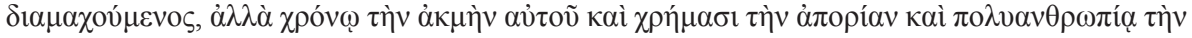

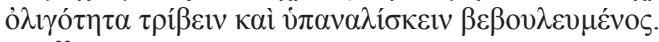

${ }^{22}$ Cf. Fab. 4.4. Para esta interpretación en la que la providencia divina queda subordinada a la virtud humana, véase A. Wardman, 1972, p. 89, Valgiglio, 1988, p. 25, Berardi, 1990.

${ }^{23}$ Como señala con acierto F. Frazier, 1996, pp. 136 ss., es precisamente la consideración como principios activos lo que caracteriza las virtudes de los héroes en las Vidas Paralelas.

${ }^{24}$ En realidad la pasividad de los hombres de Estado es a menudo en las Vidas Paralelas el criterio de que se vale Plutarco para valorar los excesos de la actitud religiosa de sus personajes que deja entonces de ser eusébeia (al servicio de la virtud política) para convertirse en deisidaimonía (causa de males para la comunidad). Ejemplos significativos de ello son las puntualizaciones del biógrafo a propósito del miedo de Nicias ante un eclipse en la expedición de Sicilia y la pasividad del cónsul Octavio en la Vida de Marcelo (42.7-9) que permite pasivamente la toma de su ciudad esperando las instrucciones para actuar de sus astrólogos (A. Pérez Jiménez, 1996, p. 223).

${ }^{25}$ Aem. 19.5-6. Cf. D. Babut, 1969, pp. 393-394.

${ }^{26}$ Thes.-Rom. 1.6:

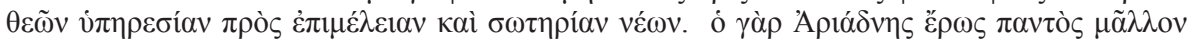


las cartas fingidas de Aníbal, con las que éste quiso engañar a Fabio y hacerle caer en una emboscada, no hay que entenderlo como un suceso casual, $\dot{\alpha} \lambda \lambda \grave{\alpha}$

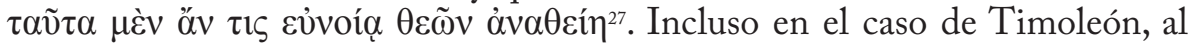
que Plutarco concede más bien como recurso literario la colaboración de la

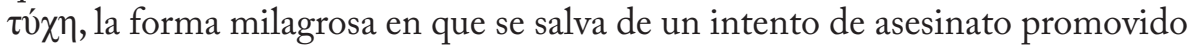
por Hícetas se debe a que la divinidad dirige las casualidades que lo hicieron posible ${ }^{28}$. Pero en realidad sus éxitos en Sicilia no se debieron a la fortuna, sino

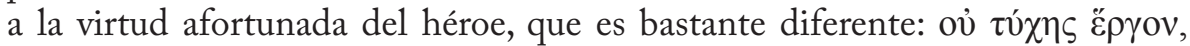

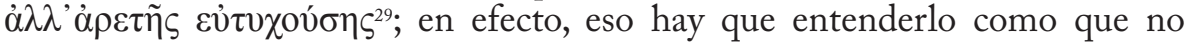
fueron sólo el resultado del azar o de la providencia, sino de los propios méritos del personaje, dignos de la colaboración de ésta. La protección de la virtud es la única razón que deja a Plutarco explicar la invasión de los galos como un castigo divino a los romanos por haber exiliado a Camilo ${ }^{30}$. El Queronense deja claro en estos casos que no es la casualidad por sí sola, sino hábilmente guiada por la divinidad, la que explica estos episodios. Pero tampoco nos permite atribuir los éxitos exclusivamente a la responsabilidad humana, a los méritos de sus héroes. Igual que los dioses están presentes en la solución (aparentemente casual) de situaciones críticas, las grandes gestas que hacen progresar el devenir de la historia en la línea trazada por los dioses, cuentan con la colaboración de éstos. Nos basta con citar aquí el pasaje de Flam.12.10, cuando todos los griegos, agradecidos por la liberación de Grecia, deciden pasarse a Tito y a los romanos:

Pues no sólo aceptaban a sus generales, sino que los buscaban y llamaban para ponerse en sus manos; y no eran únicamente pueblos y ciudades, sino también reyes ofendidos por otros reyes, quienes se refugiaban en sus brazos, de forma que en poco tiempo, quizá por la intervención de un dios, todo se sometió a ellos ${ }^{31}$.

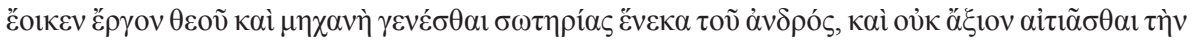

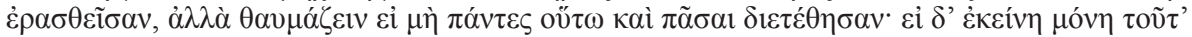

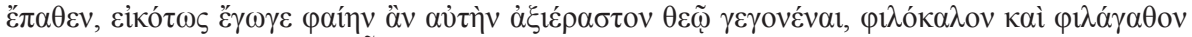

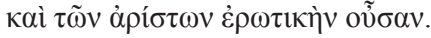

${ }^{27} \mathrm{Fab}$. 19.8: "sino que esto puede atribuirse a benevolencia de los dioses".

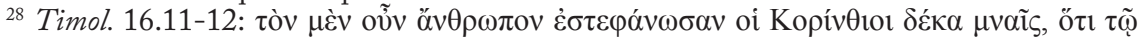

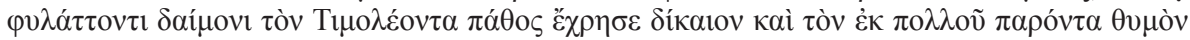

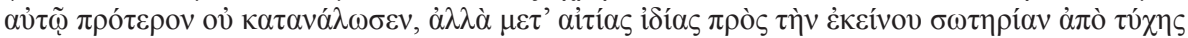

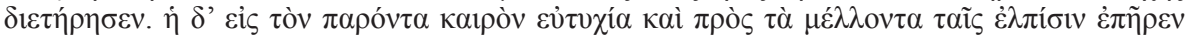

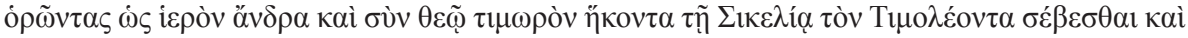

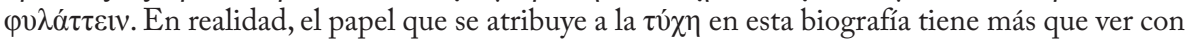
la providencia que con el azar, como ya han advertido otros estudiosos (cf. D. Babut, 1969, p. 479, S. Swain, 1989, pp. 275-276).

${ }^{29}$ Tim. 36.5; cf. S. Swain, 1989, pp. 283-284.

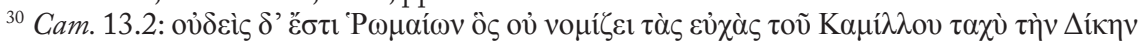

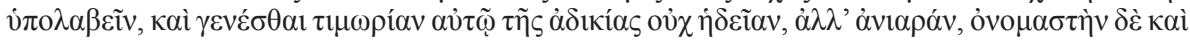

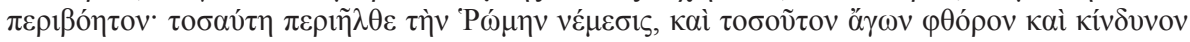

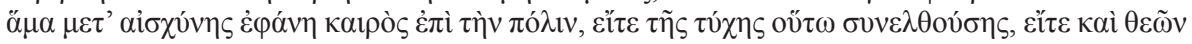

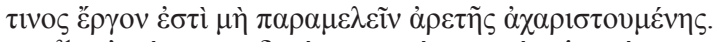

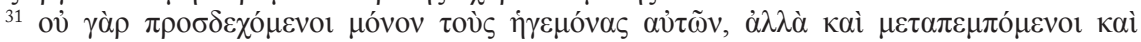

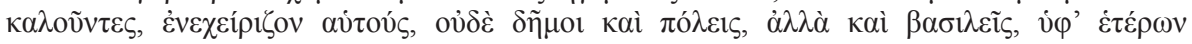


En fin, en la Comparación del Cimón-Lúculo leemos que ambos personajes contaron con la protección divina ${ }^{32}$, algo que es sobre todo evidente en el caso de Lúculo, beneficiario de la protección de dos grandes diosas: Afrodita y Ártemis. La segunda lo utiliza para vengar una antigua ofensa de los del Ponto, enviando una tormenta con cuya ayuda el general romano obtiene la victoria sobre una flota muy superior ${ }^{33}$ y Afrodita se le presenta en sueños en su templo de la Tróade, donde pasa Lúculo la noche, y lo urge a ponerse en movimiento y aprovechar una ocasión para imponerse a las tropas de Mitrídates ${ }^{34}$.

2) No es este el único caso en que los dioses dan información directa a los héroes plutarqueos. Con frecuencia la reciben a través de oráculos, sueños o presagios; de manera que juegan con ventaja ante sus competidores, sabiendo que cuentan con el favor divino para sus acciones o incluso éstas son guiadas y aconsejadas, como en el caso citado de Lúculo, por la divinidad. No vamos a enumerar aquí todos los ejemplos en que se da esta circunstancia en las Vidas. Brenk ha dejado constancia de la habilidad de Plutarco para adaptar este material a las necesidades literarias de su obra e incluso a las exigencias de su creencia en la adivinación y en el papel providente de la divinidad ${ }^{35}$. Tan sólo me permitiré unas cuantas referencias significativas. A Licurgo, la Pitia le comunica no sólo que es persona querida para los dioses, sino que el corpus legislativo que elabore fundamentará el mejor sistema de gobierno ${ }^{36}$ y que, una vez terminada su labor, hará gloriosa a Esparta si mantiene la constitución sin alteraciones ${ }^{37}$. A Rómulo (en este caso con discusión) y a Numa los dioses les confirman mediante las aves su conformidad con el nombramiento. A Camilo, la diosa Juno le manifiesta con un prodigio (su estatua habla, lo que da lugar a una digresión de Plutarco sobre la interpretación racionalista de estos prodigios) que está de acuerdo con su traslado a Roma ${ }^{38}$; y Atenea, por su

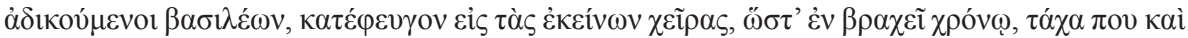

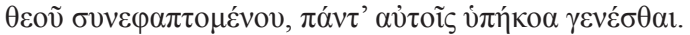

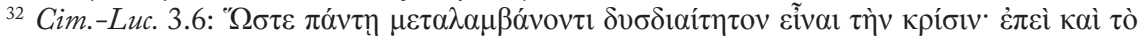

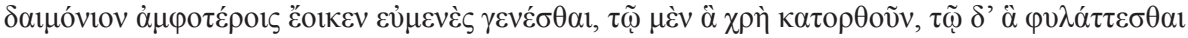

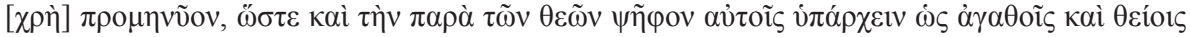

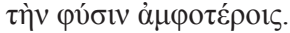

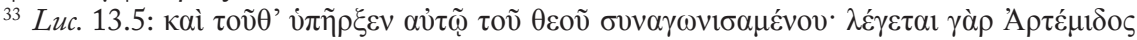

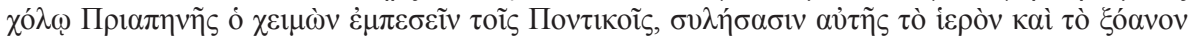
$\dot{\alpha} v \alpha \sigma \pi \alpha ́ \sigma \alpha \sigma 1$.

${ }^{34}$ Luc. 12.

35 E. Brenk, 1977, especialmente, pp. 191, 202, 210, 217, 234-235, etc. En cuanto a la interpretación de los oráculos, sobre todo de Delfos, por los héroes de las Vidas, véase $\mathrm{Ph}$. Stadter, 2005.

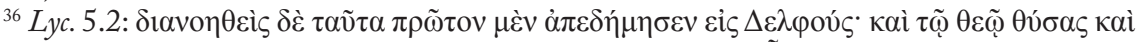

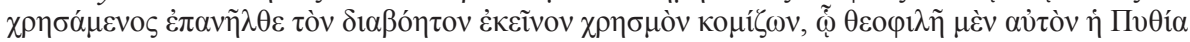

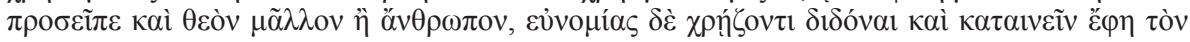

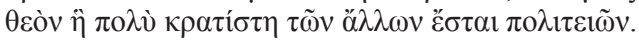

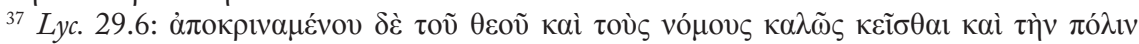

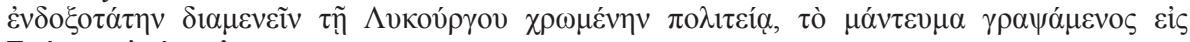

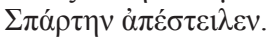

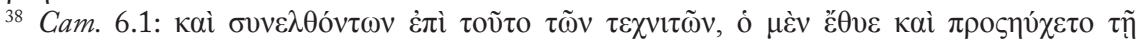


parte, demuestra con sus instrucciones a Pericles en un sueño para curar a un obrero herido durante las obras de la Acrópolis, que está de acuerdo y colabora en aquel proyecto ${ }^{39}$. Las diosas Deméter y Perséfone se aparecen también en sueños a las sacerdotisas de su templo en Corinto y confirman con prodigios que secundan la expedición de Timoleón a Sicilia; aunque el suceso es referido también por Dionisio de Halicarnaso, Plutarco insiste de manera especial en ello ${ }^{40}$. Lo mismo hace el dios Adrano, cuyos prodigios refiere Plutarco no sólo al éxito de Timoleón sobre Hírcetas en la ciudad de los adranitas, sino también a los hechos siguientes ${ }^{41}$. Sila parte inmediatamente contra Mario el Joven y Norbano animado por los buenos presagios del sacrificio, como si los dioses le anunciaran la victoria ${ }^{42}$. La lista es interminable; pero aunque la mayoría de estos personajes se ven estimulados por presagios favorables, hay otros que asumen las consecuencias de saberse al margen del saber divino, como Marcelo, cuando renuncia a presentarse al consulado ante la oposición divina manifestada por un trueno ${ }^{43} \mathrm{o}$ Pausanias, que mantiene a los espartanos pasivos en Platea hasta que obtiene presagios favorables en los sacrificios ${ }^{44}$; o los hay que no atienden a las advertencias divinas por descuido o por incredulidad, sufriendo las consecuencias por ello, como César. De todo ello podemos deducir que la acción humana depende de la revelación divina; pero no es así. Una correcta interpretación del pensamiento de Plutarco al respecto no excluye, sino todo lo contrario, la responsabilidad humana en los hechos de los que sus héroes son agentes principales. Sueños, oráculos y prodigios son indicios de la voluntad divina; pero es la interpretación humana de esas evidencias lo que decide su efecto en los hechos históricos ${ }^{45}$.

3) Sin embargo, la providencia va más allá de los intereses personales, de los éxitos e incluso de la salvaguardia de la vida misma de los protagonistas de las Vidas. En algún caso, la intervención divina no salva al protagonista, pero protege su dignidad evitándole males mayores. Por ejemplo, a propósito de la

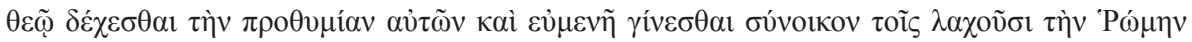

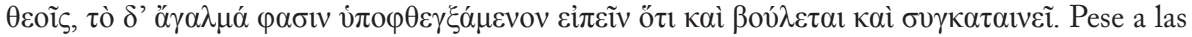
prevenciones de Plutarco sobre el prodigio, lo que nunca se pone en discusión es la voluntad divina favorable a Roma que se desprende del mismo (cf. S. Swain, 1989, p. 287).

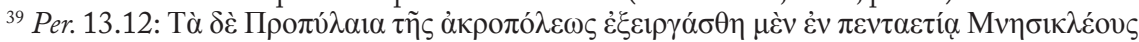

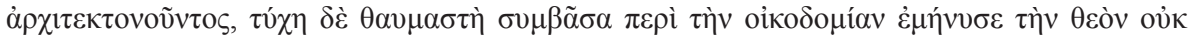

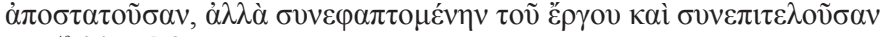

${ }^{40}$ Timol. 8.

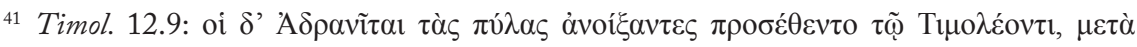

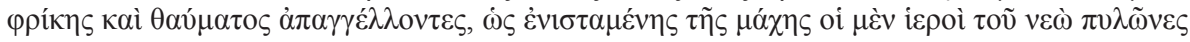

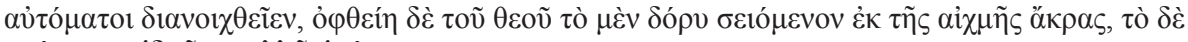

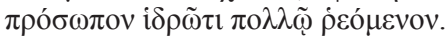

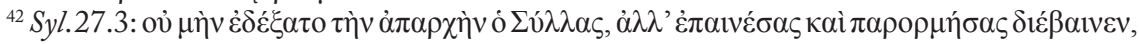

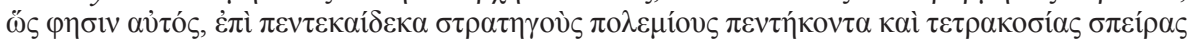

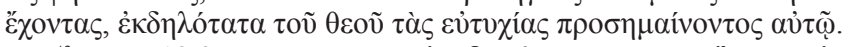

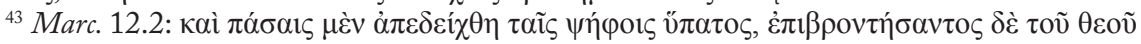

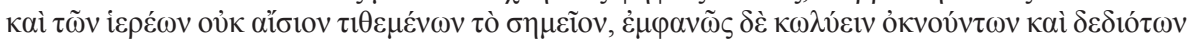

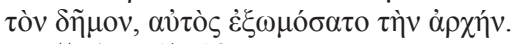

${ }^{44}$ Arist. 17-18.

${ }^{45}$ Ph. Stadter, 2005, pp. 202 ss. 
muerte de Demóstenes, la mayoría de los autores se inclinan por el suicidio de éste mediante un veneno que llevaba habitualmente atado al cuello. Plutarco, en cambio, prefiere la versión de Demócares, para quien el orador ateniense

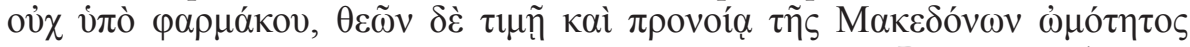

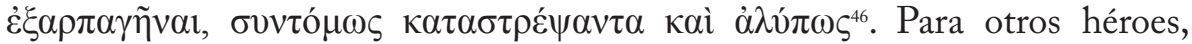
como ocurre con Dión o con César, su muerte será vengada por los propios dioses. Y no faltan casos, éstos más interesantes para nuestro propósito, en que el sacrificio de un héroe virtuoso y que responde a las condiciones exigibles por la providencia para su protección, viene requerido por el guión principal de aquella. El más claro es el de Bruto, cuyo fracaso se interpreta -así lo hace el mismo Plutarco- como un daño colateral, necesario para la implantación de la monarquía. El biógrafo, convertido ahora en propagandísta político es bastante explícito al respecto. Las naves de Bruto tuvieron un éxito aplastante sobre un contingente importante de Octavio y la situación de éste y de Antonio no habría resistido un ataque de aquél, que se habría producido, si hubiera tenido noticia de su victoria. Sin embargo, ésta se retrasó hasta 20 días por razones que Plutarco atribuye exclusivamente a la Providencia:

Pero como la situación, según parece, ya no podía ser manejada por muchos, sino que requería una monarquía, la divinidad, queriendo apartar y retirar al único que podía ser un obstáculo para ese poder absoluto, mantuvo apartada aquella noticia, aunque estuvo muy cerca de ser conocida por Bruto ${ }^{47}$.

Antes que él, seguramente también Pompeyo fue consciente de su papel como víctima de los planes de la Providencia cuando discutía con el peripatético Cratipo en Anfípolis sobre ella, en un momento en que su posición en la guerra estaba perdida y aconseja a sus familiares y amigos acogerse a la benevolencia

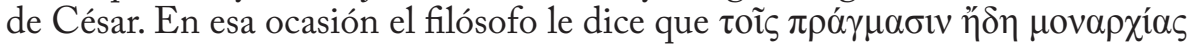

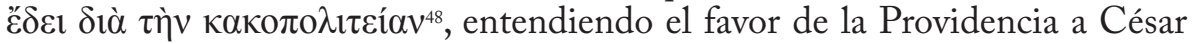
como una medida necesaria para que se realicen los planes divinos, a saber, la implantación de la monarquía frente al desgobierno republicano del momento. Aquí el sacrificio resultó aparentemente inútil; pues César, llamado

${ }^{46}$ Dem. 30.

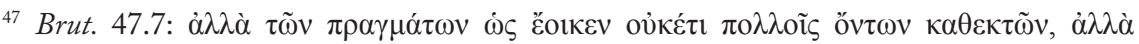

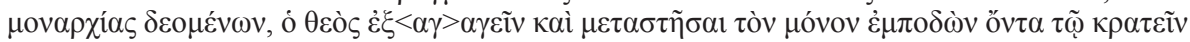

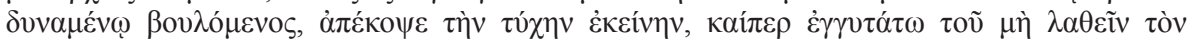

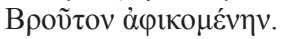

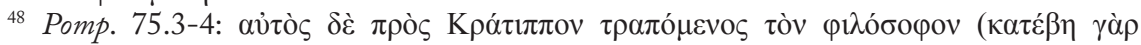

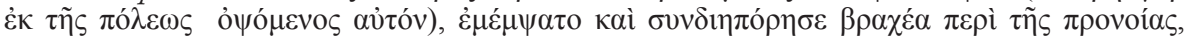

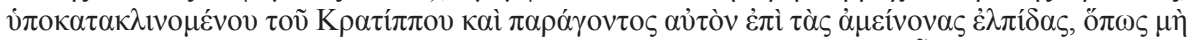

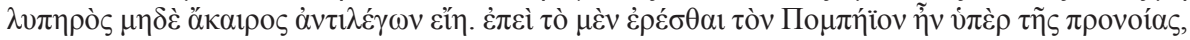

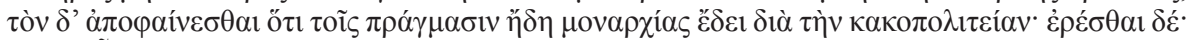

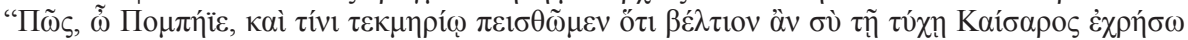

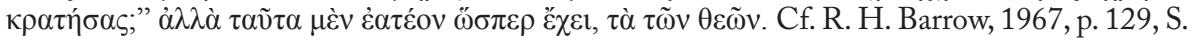
Swain, 1989, pp. 289-290. 
a ser el iniciador de los planes divinos, murió víctima de la casualidad o de la precipitación que no le dejó oír las advertencias con que los dioses trataban de evitar su entrada en el Senado. Seguramente por ello éstos mostraron su descontento con la muerte del personaje e hicieron ver a los romanos como pueblo su voluntad con la venganza y el castigo de los asesinos. O tal vez, al retardar la ejecución de su proyecto, permitiendo el auge de un ser degenerado como Antonio, hicieron más evidentes los males de la República en su último siglo para abrir el período de una nueva Era con la victoria y la instauración de la monarquía imperial por Octavio. 


\section{Bibliografía Citada}

Babut, D., Plutarque et le stoïcisme, Paris, 1969.

Barrow, R. H., Plutarch and his Times, London, 1967.

Berardi, E., "Plutarco e la religione. L'eusebeia come giusto mezzo fra deisidaimonia e atheotes", Civiltà Classica e Cristiana, 11 (1990) 141-170.

Brenk, F.E., In Mist Apparelled. Religious Themes in Plutarch's Moralia and Lives, Leiden, 1977.

Frazier, F., Histoire et morale dans les Vies parallèles de Plutarque, Paris, 1996.

Pérez Jiménez, A., “ $\Delta \varepsilon \imath \sigma ı \delta \alpha \mu o v i ́ \alpha: ~ E 1$ miedo a los dioses en Plutarco”, en L. van der Stockt (ed.), Plutarchea Lovaniensia. A Miscellany of Essays on Plutarch, Lovanii, 1996, pp. 195-225.

- "Exemplum: the Paradigmatic Education of the Ruler in the Lives of Plutarch", en Ph. A. Stadter \& L. Van der Stockt (eds.), Sage and Emperor, Leuven, 2002, pp. 105-114.

- “¿Las biografías de Plutarco como medio de propaganda imperial?, en A. Pérez Jiménez, J. Ribeiro Ferreira \& M. do Céu Fialho (eds.), O Retrato e a Biografia como estratégia de teorização política, Coimbra-Málaga, 2004, pp. 49-64.

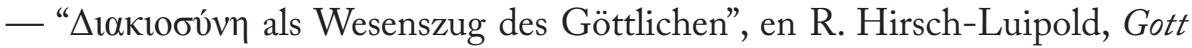
und die Götter bei Plutarch, Berlin-New York, 2005, pp.101-109.

Stadter, Ph. A., "Paidagogia pros to theion: Plutarch's Numa”, en C. Callaway (ed.), Ancient Journeys: A Festschrift in Honor of Eugene Numa Lane, Stoa Consortium (http://www.stoa.org.lane) 2002.

- "Plutarch and Apollo of Delphi”, en R. Hirsch-Luipold, Gott und die Götter bei Plutarch, Berlin-New York, 2005, pp. 197-214.

Swain, S., "Plutarch: Chance, Providence, and History", AJP 110 (1989) 272-302.

VAlgiglio, E., Divinità e religione in Plutarco, Genova, 1988.

Wardman, A., Plutarch's Lives, London, 1974. 


\title{
Tyche, Kairos et Chronos dans le Phocion de Plutarque *
}

\author{
Delfim F. Leão \\ Université de Coimbra
}

\begin{abstract}
Although the terminology employed by Plutarch to express divine influence in human affaires varies a lot, the words tyche, daimon and theos are those that he uses most frequently. In this paper, special attention is given to the action of tyche and other related concepts, precisely because they are attached mainly to fluid and unpredictable factors.

The analysis focuses on the Life of Phocion, which is especially suitable for studying the way the power of divinity is exerted. Phocion had a good character as well as enjoying the benefits of a fine paideia, but despite these important qualities, he was neither capable of preventing Athens from being occupied by the Macedonian forces nor was he able to avoid his own capital punishment. Plutarch does not fail to point out that all this happens because Phocion did not live in a favourable time, and could therefore not exploit completely his own virtues. This notion of a 'favourable time' is explored in order to combine the concepts of kairos and chronos with that of tyche, as a means of justifying Phocion's failures.
\end{abstract}

\section{Remarques préliminaires}

Lorsque les Vitae sont considérées dans leur ensemble, nous pouvons constater que 1'intervention de la Providence divine n'est pas distribuée de façon uniforme, et présente même, à première vue, un tableau assez discordant : en ce qui concerne la partie grecque, l'intervention divine est plus sensible dans les biographies de figures qui ont vécu durant la phase de " décadence " de l'histoire de la Grèce car elle semble être un processus d'une certaine façon irréversible, malgré l'effort d'hommes d'État remarquables comme Phocion; avec Rome, au contraire, la participation de la Providence est plus régulière et apparaît dès la fondation de la ville jusqu'à l'instauration du Principat, fait qui pourrait ne pas être étranger à la perception de l'extraordinaire ascension romaine, dont le succès semblait dû, au moins en partie, à une faveur divine spéciale et durable ${ }^{1}$.

La terminologie utilisée pour exprimer l'influence divine dans les affaires humaines connaît de nombreuses variantes, même si les termes theos, daimon et tyche sont les plus récurrents ${ }^{5}$. Dans cet article, nous ne retiendrons que l'action attribuée à la tyche (et les termes étymologiquement liés), précisément parce que ce concept renvoie, tout particulièrement, à l'action de facteurs à la nature plus fluide et imprévisible. La discussion portera sur la Vita de Phocion, une

* Je remercie Françoise Frazier d'avoir eu la gentillesse de relire la version française du manuscrit.

1 Vide Swain (1989) 280. La contribution d’A. Pérez Jiménez pour ce volume [pp. 169-181] souligne le fait que les héros fondateurs et les premiers grands législateurs ont pu également compter, de façon implicite ou explicite, avec la collaboration divine pour mener à bien leurs projets de stabilisation de la société. Des figures comme Thésée, Romulus, Lycurgue, Numa, Solon et Publicola entrent dans ce champ.

${ }^{2}$ Pour les termes qui renvoient à la Providence divine, vide la liste présentée par Swain (1989) 298-302. 
figure qui, en comparaison avec d'autres hommes d'État, a été relativement négligée par les spécialistes de Plutarque. Pourtant l'existence de Phocion semble réunir des conditions particulièrement favorables pour contrebalancer l'action de la tyche: en effet, Phocion possédait de bonnes qualités de caractère, auxquelles s'ajoutait une éducation soignée, conjonction qui aurait pu en faire un personnage exceptionnel. C'est ainsi qu'il a été nommé général quarante-cinq fois, un nombre sans précédent, que ce soit parmi ses contemporains ou parmi les hommes d'État qui l'ont précédé3. Malgré cela, il n'a réussi ni à empêcher que la ville soit occupée par les forces macédoniennes aux ordres d'Antipatros, ni à échapper à la disgrâce de la peine capitale. Cela est survenu, précisément, parce que Phocion n'a pas vécu durant le temps adéquat pour faire fructifier ses qualités et en tirer le meilleur parti. Ainsi il faut prendre en compte les notions d' "occasion ", kairos, et de « temps chronologique » (marqué par le fil des générations), chronos, conjuguées avec la tyche pour expliquer le malheur de Phocion dans son action publique, association que l'on trouve déjà chez Platon 4 .

\section{Tychelfortune}

Il est hors de question de discuter où même d'esquisser, dans les limites de ce travail, la complexité du terme tyche (et de l'équivalant latin fortuna). En effet, bien que tyche ne soit pas mentionnée par Homère, elle apparaît déjà chez Hésiode (Th. 360), comme une des Océanides, et sa présence s'affirme dans la littérature postérieure. Outre cette abondance de témoignages, qui rendent plus difficile une compréhension globale de son domaine d'action, il faut aussi être conscient du fait que le terme tyche n'a pas toujours les mêmes implications sur l'existence humaine. Si l'on se réfère à l'étymologie, la connexion de tyche avec

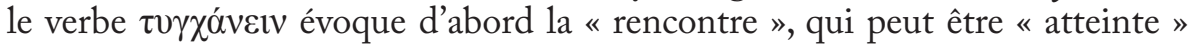
du succès mais aussi heurt contre des obstacles, ou encore, de façon plus neutre, « coïncidence » avec telle ou telle circonstance 5 . Enfin, étant donné que Plutarque est un Grec qui a vécu sous l'empire romain, il semble pertinent de commencer par quelques remarques sur la relation possible entre les concepts de tyche et de fortuna durant le Principat. Le culte populaire de la fortuna dans le monde romain est très ancien. Étymologiquement lié à ferre, le mot signifierait à l'origine 'quelqu'un qui apporte', donc une divinité favorable 'qui apporte la

${ }^{3}$ Cf. Plutarque, Phoc. 8.1-2. Bien que cette information soit généralement admise, Bearzot (1993), 124-126, doute de son exactitude historique, parce qu'elle ne trouve pas de confirmation dans les autres sources. Comme on le verra plus tard, il s'agit probablement d'une exagération de Plutarque destinée à renforcer le caractère supérieur de Phocion.

${ }^{4}$ Platon, dans un passage des Lois (4.709b7-8) soutient que la divinité (theos) contrôle tout, mais que la tyche et le kairos peuvent collaborer avec la divinité dans la conduite des affaires humaines. À ces facteurs, Platon joint encore l'intervention d'un quatrième facteur: 1'art (techne). La référence à techne n'a pas un parallèle direct chez Plutarque, mais peut être assimilée à l'importance attribuée à la paideia, comme nous le verrons plus loin, d'autant plus que, dans le cas de Phocion, l'éducation fut reçue à l'Académie (cf. infra commentaire à Phoc. 4.2). Je remercie Françoise Frazier d'avoir eu la gentillesse de $m$ 'indiquer ce passage très intéressant de Platon.

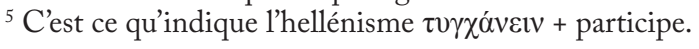


bonne chance, le succès', un esprit protecteur des hommes et des lieux, apparenté au genius ${ }^{6}$. Dans la littérature, néanmoins, l'éventail des significations était plus vaste et assumait, encore une fois, des idées contradictoires. Cette réalité s'est accentuée au fur et à mesure que l'influence de la tyche grecque, en tant que personnification de la fortuna caeca, s'est superposée aux notions romaines initiales, préférentiellement positives. En effet, durant la période républicaine, la notion de fortunaltyche était encore peu fréquente chez les auteurs latins. Son importance grandit dans la production littéraire de l'époque d'Auguste, mais ce n'est que lors de la pleine période impériale qu élle devint, de fait, une entité importante ${ }^{7}$. Or, c'est précisément la réalité de ce moment qui est la plus intéressante, étant donné qu'elle correspond au temps de Plutarque ${ }^{8}$. Pline l'Ancien, qui fut contemporain du biographe de Chéronée, rapporte, dans un passage particulièrement expressif, 1'omnipotence de cette divinité capricieuse qui gagnait de plus en plus de terrain sur le panthéon olympique traditionnel ${ }^{9}$. Il conviendrait pour cela d'évoquer une partie des réflexions qu'il dédie à la nature de la fortuna, qui se présente comme conditionnant toutes les actions humaines et qui devient objet de toutes ses attentions, au point d'assumer le rôle même de Dieu (N.H. 2.22):

Toto quippe mundo et omnibus locis omnibusque horis, omnium uocibus Fortuna sola inuocatur ac nominatur, una accusatur, rea una agitur, una cogitatur, sola laudatur, sola arguitur et cum conuiciis colitur, uolu<cris uolu>bilisque, a plerisque uero et caeca existimata, uaga, inconstans, incerta, uaria indignorumque fautrix. Huic omnia expensa, buic feruntur accepta, et in tota ratione mortalium sola utramque paginam facit, adeoque obnoxiae sumus sortis, ut ipsa pro deo sit qua deus probatur incertus.

De fait dans le monde entier, en tout lieu, à toute heure les voix de tous les hommes invoquent et nomment la seule Fortune; on n'accuse qu'elle, elle seule est coupable, on ne pense qu'à elle, à elle seule vont les éloges, les reproches, et on l'adore en l'insultant ; ailée et volage, regardée même comme aveugle par la plupart, vagabonde, inconstante, incertaine, changeante, elle favorise ceux qui n'en sont pas dignes. On lui impute tout le passif et tout l'actif ; sur le grand livre de comptes de l'humanité, elle seule remplit les deux colonnes, et notre condition est si soumise que la Fortune même, qui prouve l'incertitude de Dieu, prend la place de Dieu ${ }^{10}$.

Les caractéristiques de la fortuna évoquées ici correspondent, en effet, à l'importance qui lui est accordée dans des œuvres comme le Satiricon de

${ }^{6}$ Kajanto (1981) 505 et 521.

${ }^{7}$ Vide Kajanto (1981) 533, 538 et 542, respectivement.

${ }^{8}$ Même en reconnaissant qu'on ne peut pas tout simplement appliquer à Plutarque ce qu'on dit d'autres auteurs qui ont vécu dans la même époque que lui. L'idée c'est présenter seulement un parallèle qui nous semble être très suggestif.

${ }_{9}^{9}$ Une importance qu'elle partageait, du reste, avec l'attention dédiée aux cultes orientaux et au christianisme émergent.

${ }^{10}$ Texte établi et traduit par Jean Beaujeu, Pline l'Ancien - Histoire Naturelle. Livre II (Paris, 1950). 
Pétrone ou l'Âne d'or d'Apulée (comparable à celle de la tyche dans le roman grec), où cette divinité apparaît comme la réelle instigatrice de 1'action ${ }^{11}$. Il a déjà été également souligné que les caractéristiques littéraires de la fortuna étaient, à cette époque, pratiquement communes à celle de la tyche hellénistique. Cette réalité était motivée, du moins en partie, par certaines conditions historiques, que Kajanto ${ }^{12}$ synthétise de la façon suivante : "Tyche was a dominant figure in the literature of the Hellenistic period. Two factors contributed to her popularity. The Olympic gods were rapidly losing ground. This created a religious vacuum, which was in part filled by Tyche. Again, the time of Alexander the Great and of the Epigoni was a period of great upheavals. Many great states, e. g. the Persian Empire, fell to pieces, and new ones were founded instead. The success of an individual seemed often to depend more upon chance than upon his own efforts. This may explain why fickle Tyche, the personification of blind chance, gained so important a position in men's minds. "Cette proximité entre la notion de fortuna et celle de la tyche hellénique ${ }^{13}$, ainsi que le fait que Phocion ait vécu précisément à une époque où commençaient à se faire sentir les effets des grands changements évoqués dans le passage de Kajanto, aide à comprendre l'importance de la tyche dans la biographie de Phocion. C'est l'application pratique de ce point concret que nous allons maintenant examiner dans le cas spécifique de Phocion ${ }^{14}$.

\section{La Vita de Phocion}

La Vie de Phocion présente, au départ, des conditions exceptionnelles pour étudier l'interaction de concepts de tyche, kairos et chronos, puisque l'existence de Phocion (qui vécut entre 402 et 318 avant J.C.) a coïncidé avec la progressive décadence politique et militaire d'Athènes, parallèle à l'irrésistible ascension de la Macédoine (avec Philippe et Alexandre), et connu les incertitudes des premières années des Diadoques. Du reste, la façon dont Plutarque ouvre la biographie, en comparant l'action de Démade et de Phocion, le marque nettement (Phoc. 1.1-6) :

${ }^{11}$ Au sujet de cette réalité dans le Satiricon de Pétrone, vide Leão (1998) 119-131. Du reste, du point de vue de la structure narrative, l'intervention d'une divinité comme la Fortuna est très utile, puisqu'elle permet d'imprimer du dynamisme et de la variation au rythme discursif. Mais il est pertinent de remarquer que la Fortune pouvait aussi fonctionner comme un agent indirect d'une divinité plus haute, comme est le cas de son l'action dans l'Âne d'or d'Apulée (lui même un platonicien), à l'égard de l'affirmation de la puissance d'Isis et Osiris (e.g. 11.15.1-3).

12 (1981) 527-528.

${ }^{13}$ Sur la nature de la tyche hellénistique, voir aussi le célèbre passage de Polybe (citant Démétrios de Phalère), 29.21, et les réflexions de Marie-Rose Guelfucci dans ce même volume, sur la relation entre tyche, la marche de l'histoire et les politeiai [pp. 162-165].

${ }^{14}$ Une lecture plus vaste de l'utilisation du concept de tyche dans l'œuvre de Plutarque est hors de nos objectifs. De toute façon, il nous semble difficile trouver une définition et un domaine d'application qui soient également valables pour les Moralia et pour les Vitae. Sur les difficultés que pose cette notion, vide l'introduction générale de F. Frazier [pp. III-XXIII]. 


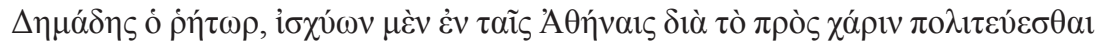

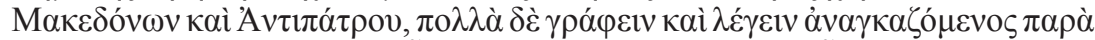

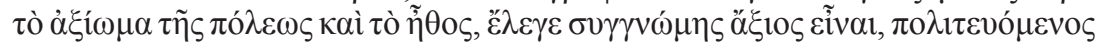

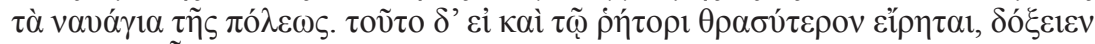

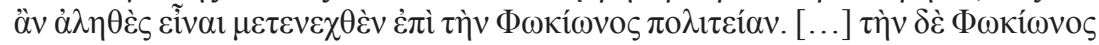

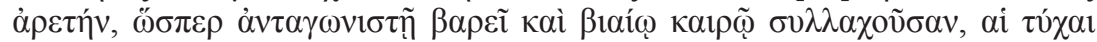

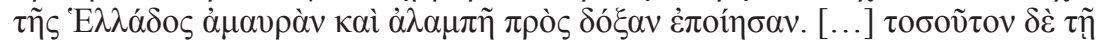

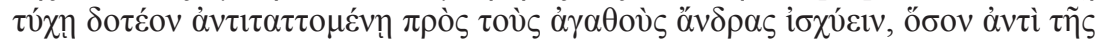

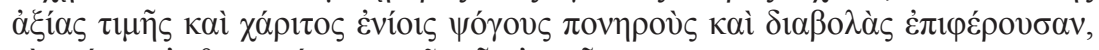

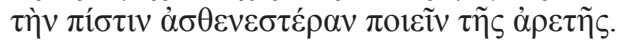

L'orateur Démade, dont la grande influence à Athènes provenait de sa politique de complaisance à l'égard des Macédoniens et d'Antipatros, étant contraint de faire beaucoup de discours et de propositions contraires à la dignité et au caractère de la ville, disait: «Je mérite le pardon parce que j’administre les débris du naufrage de la cité. » Cette parole, si elle paraissait pleine d'effronterie dans la bouche de Démade, pourrait bien être vraie, appliquée au gouvernement de Phocion. [...] Tout au contraire, la vertu de Phocion, par un effet du sort, eut à se mesurer à des circonstances pénibles et cruelles, au point d'être éclipsée et privée de l'éclat de la gloire par les malheurs de la Grèce. [...] Tout ce qu'il faut accorder à la Fortune, quand elle s'attaque aux hommes de coeur, c'est qu'elle attire à quelques-uns d'entre eux, au lieu de la reconnaissance et de l'honneur qui leur sont dus, de méchantes critiques et des calomnies, qui font paraître plus faible leur réputation de vertu ${ }^{15}$.

Même si l'on admet que Plutarque puisse être trop sévère avec Démade, dans la mesure où cet orateur avait en effet rendu de nombreux services à la cité $\mathrm{d}^{\prime}$ Athènes ${ }^{16}$, il est important de souligner, dans cette ouverture, 1'idée exprimée à travers l'allégorie bien connue du vaisseau de 1'État — que la ville

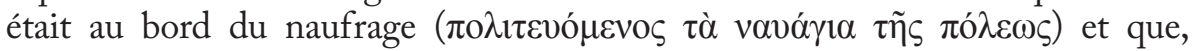
dans ces circonstances, il était difficile de faire plus que parer aux urgences qui survenaient ${ }^{17}$. Et si le biographe répugne à reconnaître la pertinence du jugement en ce qui concerne Démade, il l'admet sans réserve quand il est appliqué à Phocion : ses qualités intrinsèques (arete) n'ont pu se développer pleinement,

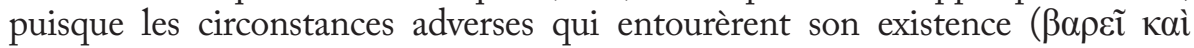

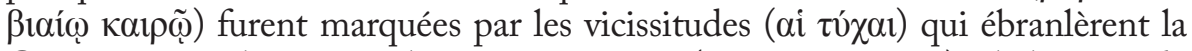
Grèce et empêchèrent qu'il eût une notoriété (doxa, time, charis) à la hauteur de son mérite et obtînt le crédit et la confiance (pistis) qui auraient dû lui revenir. Dès l'ouverture de la Vita, Plutarque marque bien que l'arete ne suffit pas pour garantir le succès escompté, puisqu il faut compter avec la présence de la tyche $e^{18}$

15 Texte établi et traduit par Robert Flacelière et Émile Chambry, Plutarque. Vies. Tome X. Phocion - Caton le Jeune (Paris, 1976).

${ }^{16}$ Qui auraient justifié que lui soit dédiée une statue dans l'agora (cf. Dinarque, 1.101) ; sur son action, voir l'étude de Brun (2000).

${ }^{17} \mathrm{Cf}$. Praec. ger. reip. 803a. On détecte ici une influence très proche du Politique de Platon (e.g. 272e-273e, 296e-297a, 298a).

${ }^{18}$ Ici comprise comme 'infortune' ou 'disgrâce', lorsque, au pluriel, elle désigne les vicissitudes 
et du kairos (« l'occasion »), qui peuvent empêcher les potentialités d'un caractère d'exception de se réaliser, de donner toute leur mesure ${ }^{19}$. Cette idée est reprise et amplifiée dans le chapitre suivant de la biographie, qui souligne la relation entre bybris, tyche et le gouvernement de la polis.

Après cette considération plus théorique, Plutarque reprend le tableau spécifique des Vitae, en introduisant la comparaison entre les circonstances qui entourèrent l'action politique du Romain, Caton le Jeune, où les mêmes principes se trouvent opérants (Phoc. 3.2-5):

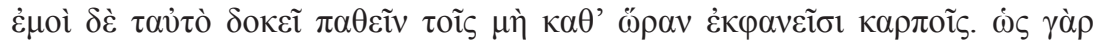

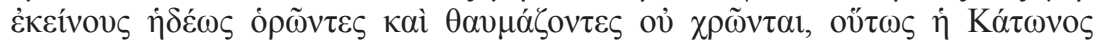

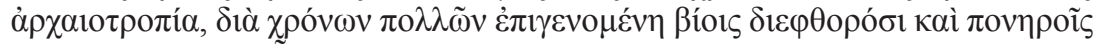

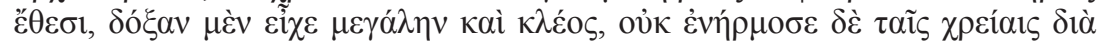

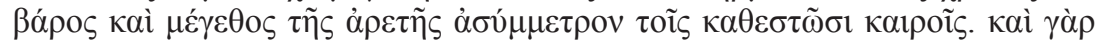

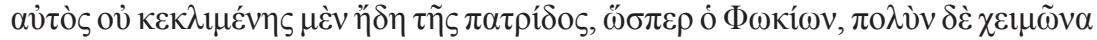

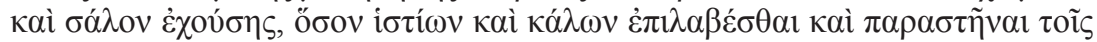

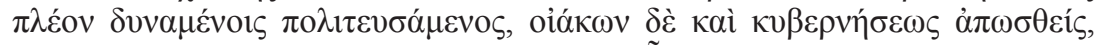

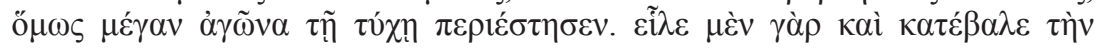

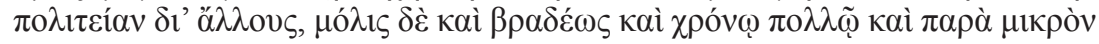

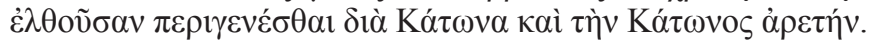

Il lui advint, selon moi, ce qui arrive aux fruits venus hors saison: on les voit avec plaisir, on les admire, mais on n'en use pas. De même, les mœurs antiques de Caton, apparaissant après plusieurs siècles dans une société corrompue et dépravée, lui valurent beaucoup de renommée et de gloire, mais elles nétaient pas ajustées aux nécessités de la politique, à cause de l'austérité et de la grandeur de sa vertu, disproportionnées par rapport à lépoque où il vivait. En fait, lorsque parut Caton, sa patrie ne penchait pas encore vers la ruine, comme celle de Phocion, mais elle était agitée par une grande tempête, et, dans la direction du vaisseau de l'État, il mit seulement la main aux voiles et aux cordages à côté d'hommes plus puissants que lui, et il fut écarté du gouvernail et de la barre, ce qui d'ailleurs ne l'empêcha de livrer un grand combat contre la Fortune. Si celle-ci renversa et perdit la République grâce à d'autres que lui, ce fut à grand-peine, lentement et après de longs efforts, et encore s'en fallut-il de peu que la République ne triomphât grâce à Caton et à la vertu de Caton.

Il a déjà été signalé que, même si les Vitae de Phocion et de Caton appartiennent au groupe des quatre paires de biographies auxquelles manquent

(tychai) qui marquaient la décadence de la Grèce, et comme 'chance' ou 'fortune', à la fin du passage cité, qui a une application plus générale. Dans le commentaire à ce passage, Duff (1999), 137 , identifie l'action de la tyche avec " fate or the will of the gods ", une idée qu'il avait déjà exprimée un peu avant (p. 123), quand il affirma « often in the Lives tyche means either chance or providence ». Même si on a des difficultés à souscrire immédiatement à cette déclaration, elle souligne néanmoins le fait que, dans les Vitae, tyche et Providence ne sont pas nécessairement opposées.

${ }_{19}$ Bearzot (1993), 123-124, considère que la présentation de Phocion est une création littéraire trop positive pour être réelle, et relève les contradictions et exagérations dérivées des intentions apologétiques de Plutarque. 
la synkrisis finale ${ }^{20}$, en réalité, la comparaison n'est pas réellement supprimée, mais plutôt anticipée au commencement du récit, invitant ainsi le lecteur à établir dès le début des parallèles et dont la portée réelle ne sera confirmée que plus tard ${ }^{21}$. Ici, cependant, il est plus important de souligner que Plutarque ouvre ses considérations au sujet de Caton avec le recours à une métaphore agricole pour renforcer à nouveau le poids déterminant qu'a la notion d'occasion opportune. En effet, quand les fruits mûrissent en dehors du temps adéquat ( $\mu$ خे $\left.\kappa \alpha \theta^{\prime} \omega \check{\rho} \alpha \nu\right)$, ils stimulent le plaisir et l'admiration, mais finissent par ne pas remplir la fonction pour laquelle ils ont été créés. De même, la dureté archaïque de Caton a traversé plusieurs générations ( $\delta 1 \grave{\alpha} \chi \rho o ́ v \omega v \pi \mathrm{o} \lambda \lambda \tilde{\omega} v$ ) pour fleurir à une époque qui ne s'accordait plus avec le dépouillement qu'il incarnait. Et même si son action lui apportait une grande renommée ( $\delta$ ó $\xi \alpha v$

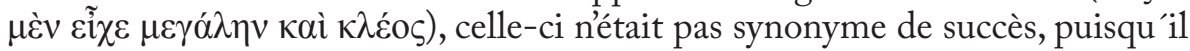
ne réussissait pas à faire adopter ses pratiques par les autres. Et il en était ainsi parce que son arete, si remarquable fût-elle, apparaissait comme 'inadaptée' aux

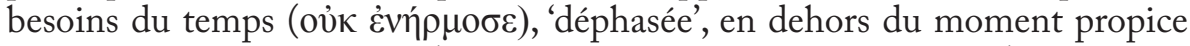

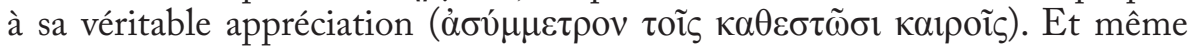
si la situation de Rome au temps de Caton n'était pas comparable à celle d'Athènes - puisque la première bravait seulement une tempête alors que la seconde était entrée dans une décadence irréversible -, il s'est également engagé dans le sauvetage du vaisseau de l'État, menant une grande lutte contre

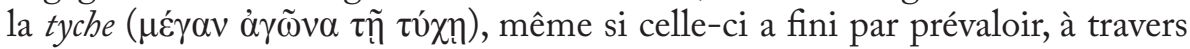
la durée du temps $(\chi \rho o ́ v \omega \pi \mathrm{o} \lambda \lambda \tilde{\omega})$. Ce passage est particulièrement éclairant, puisqu il révèle la façon dont la tyche agit, en articulation avec la notion de kairos et de chronos: en effet, ici, plus qu'un simple hasard ou circonstance, tyche semble correspondre à une action avec des effets à long terme et dont la vraie dimension n'est révélée qu'à travers le temps. Au delà de "l'occasion ", ou 'temps opportun'(kairos), la tyche se sert du chronos (le 'temps chronologique' visible au fil des générations et dans la lenteur de son inexorable action) pour atteindre ses objectifs, ne permettant pas que l'arete de personnes de valeur soit appréciée dans toute sa dimension ${ }^{22}$.

Ce tableau d'une tyche qui combat l'arete d'hommes valeureux est encore plus accentué si l'on prend en compte que Phocion a pu acquérir une paideia du plus haut niveau, à l'Académie, où il a eu l'opportunité de suivre les leçons de Platon et de Xénocrate, qui ont réveillé en lui, dès le début, le désir de rivaliser

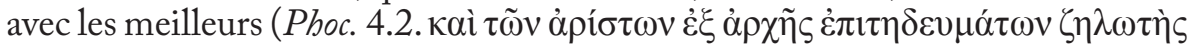
$\gamma \varepsilon v \varepsilon ́ \sigma \theta \alpha \imath)^{23}$. La conjugaison de bonnes qualités innées avec une éducation

${ }^{20}$ Les autres paires sont Thémistocle et Camille, Pyrrhus et Marius, Alexandre et César.

${ }^{21}$ Comme le rappela de façon opportune Trapp (1999) 487-488.

${ }^{22}$ Comme le remarque Tritle (1992), 42-67, l'excellence de Phocion et de Caton émane de leur archaiotropia, de leurs manières démodées, qui, malgré le fait qu'elles renvoient à une arete intemporelle, se révèlent incompatibles avec les circonstances politiques du temps où tous deux vécurent.

${ }^{23}$ Il est souligné, avec pertinence, que ce lien avec l'Académie prépare également le rapprochement entre la figure de ces hommes d'État et celle de Socrate, visible en particulier dans les circonstances qui entourèrent leur mort. Vide Alcalde Martín (1999) 161-163; Trapp (1999) 488. 
soignée commence par donner ses fruits, dès les premiers succès que le jeune Phocion connut, sous les ordres de Chabrias, où, selon Plutarque, il aurait eu un rôle décisif dans la victoire de Naxos. Si ce détail biographique, dont l'authenticité suscite quelques réserves ${ }^{24}$, n'a qu'une importance relative, il faut néanmoins souligner que le triomphe coïncida avec un moment hautement symbolique pour Athènes (Phoc. 6.5-7):

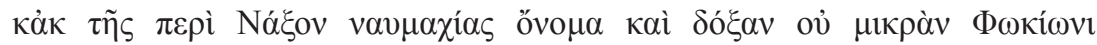

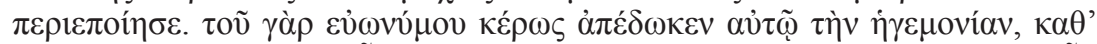

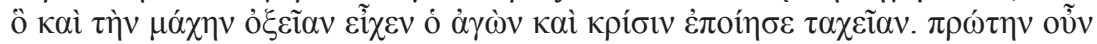

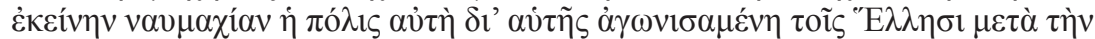

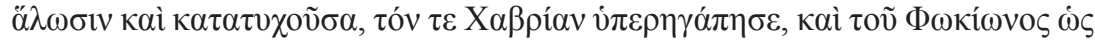

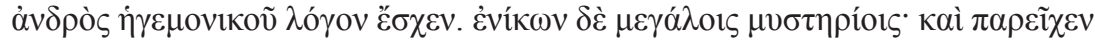

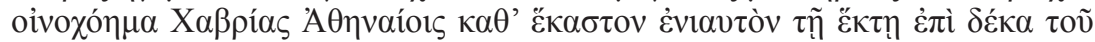

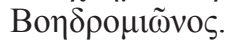

A la bataille navale de Naxos, en particulier, il procura à Phocion une renommée et une gloire éclatantes, en lui donnant le commandement de l'aile gauche, où la lutte fut vive et la décision rapide. Ce fut le premier combat qu'Athènes soutint sur mer contre les Grecs avec ses seules forces après la prise de la ville; ce succès redoubla l'affection des Athéniens pour Chabrias et leur fit concevoir de l'estime pour Phocion, qu'ils jugèrent capable de commander en chef. La victoire de Naxos eut lieu pendant la célébration des Grands Mystères ; c'est pourquoi Chabrias faisait chaque année, le seize de Boédromion, une distribution de vin aux Athéniens.

Le biographe renforce la singularité du moment avec deux aspects notables. La victoire obtenue au large de Naxos était le premier triomphe d'Athènes depuis qu'elle avait été prise par le spartiate Lysandre, dont les troupes avaient démoli les Longs Murs, en 404, au terme de la Guerre du Péloponnèse ${ }^{25}$. Le lien de Phocion avec ce triomphe, dès le début de sa carrière militaire, suggérait qu'il pouvait infléchir l'histoire récente de 1'Attique et permettre à Athènes de récupérer son ancien pouvoir politique et militaire ${ }^{26}$. Un deuxième détail vient souligner cette éventuelle attente :

${ }^{24}$ Diodore (15.34.5) ne mentionne pas Phocion et dit que le commandement de l'aile gauche incombait à Cedon. On ne peut exclure totalement 1'hypothèse que Plutarque ait ajouté cet épisode pour enregistrer un exploit de la jeunesse de Phocion. Bearzot (1993), 127, dit que cette information « ha tutta l'aria di essere l'invenzione di una tradizione apologetica, mirante a sottolineare l'assoluta superiorità di Focione rispetto ai politici ateniese suoi contemporanei e anche predecessori ». Vide aussi Alcalde Martín (2001) 48.

25 Sur les lourdes conditions de la défaite athénienne, vide Hammond (1986) 418 et 488-489.

${ }^{26}$ Cette idée de retour à un passé plus prospère est suggérée aussi par le fait que, plus loin (Phoc. 7.5-6), Plutarque affirme que, en alliant la compétence militaire et oratoire, Phocion se rapprochait des grands politiques d'antan, comme Solon, Aristides et Périclès. En effet, la spécialisation autonome dans ce type de compétences, ainsi que dans le domaine des applications financières, est une des marques de l'époque hellénistique et aussi de la séparation croissante entre le citoyen commun et l'administration de la polis. Au contraire, l'incarnation de l'idéal 
c'est précisément la coïncidence avec la célébration des Mystères d’Éleusis

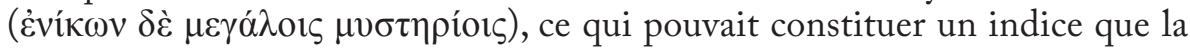
Providence serait favorable à ce projet. Les implications ironiques de cette suggestion voilée s'éclaircissent à la fin de la biographie, lorsque, une fois frustrées les attentes d'un retour de la splendeur passée et après la mort d'Alexandre, Athènes se voit obligée de négocier avec Antipatros les termes de l'accord avec la Macédoine, en ayant recours à nouveau aux services de Phocion. La situation était dure pour Athènes, puisqu'elle prévoyait qu'une garnison macédonienne s'installât en Attique, et serait aggravée par les circonstances où ces changements étaient survenus (Phoc. 28.1-3):

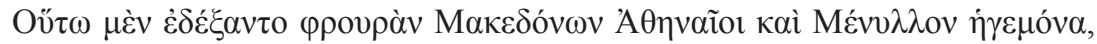

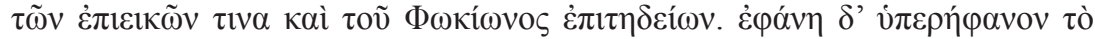

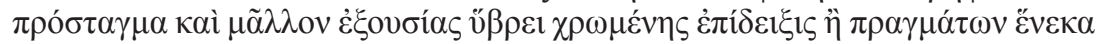

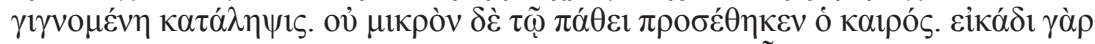

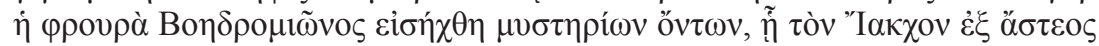
'E

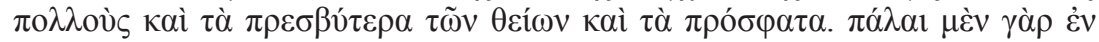

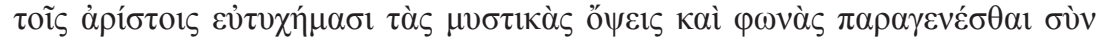

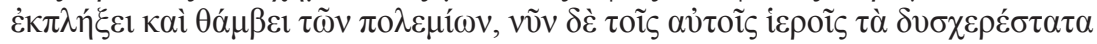

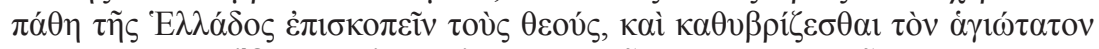

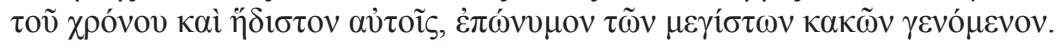

C'est ainsi que les Athéniens reçurent une garnison macédonienne, commandée par Ményllos, homme modéré et ami de Phocion, mais cette exigence d'Antipatros paraissait insultante, et l'on y vit l'étalage d'une autorité fondée sur la violence plutôt qu'une occupation imposée par les circonstances. La date de l'événement accrut beaucoup l'émotion qu'il provoqua: ce fut en effet le vingt de Boédromion que la garnison s'installa, pendant la célébration des mystères, le jour où l'on conduit Iacchos de la ville à Éleusis. En voyant le trouble apporté aux initiations, la plupart des citoyens comparaient les cérémonies présentes à celles d'autres fois : jadis, au temps des grandes victoires, il y avait des apparitions et des voix mystérieuses qui frappaient d'effroi et d'épouvante les ennemis ; maintenant, dans les mêmes solennités, les dieux avaient sous les yeux les plus pénibles malheurs de la Grèce et voyaient profaner les jours les plus saints et les plus joyeux pour eux, marqués désormais par les plus terribles épreuves.

En évoquant la victoire de Naxos (de 376), qui servit de prélude aux succès politiques et militaires de Phocion, Plutarque avait suggéré, sans le dire de façon ouverte, que la coïncidence de cet événement avec la réalisation des Mystères $\mathrm{d}$ 'Éleusis semblait de bon augure pour l'avenir d'Athènes. Cependant, la suite

d'orateur/poète et guerrier (suggéré par l'évocation du frag. 1 Diehl de Archiloque) renvoie à un concept de citoyenneté qui se rapprochait, dans sa formule, de l'idéal nostalgique de la patrios politeia, qui a commencé à se développer à Athènes précisément à la fin de la Guerre du Péloponnèse, tout particulièrement à la suite du désastre de l'expédition en Sicile. À ce sujet, vide Leão (2001) 43-72. 
des événements a exposé la vanité de cet espoir. Et la constatation de cette réalité est présente quand la garnison macédonienne entre à Athènes, près d'un demi-siècle plus tard (en 322), signe éclatant de soumission à Antipatros et de perte réelle de liberté27. La sensation d'un cycle qui s'achève est accentuée par la coïncidence de l'entrée de la garnison dans la ville avec la célébration des Mystères d'Éleusis. Plutarque utilise ici expressément le terme kairos pour souligner toute la tragique ironie du moment. Le terme utilisé généralement pour indiquer l'idée "d'occasion » opportune renforce maintenant le pathos provoqué par la démoralisation des Athéniens, qui comprennent que les dieux

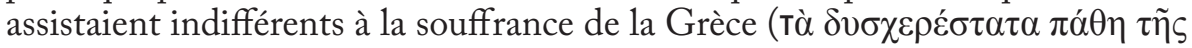

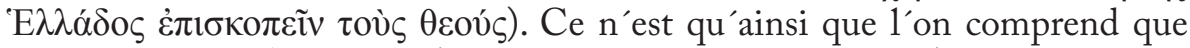
l'acte d'hybris d'Antipatros (deux fois évoqué dans ce passage) puisse entacher le caractère sacré du 'temps' (chronos) de la célébration. Le fait que, dans ce contexte, Plutarque utilise le terme theoi (mais aussi ta theia) pour désigner l'action divine suggère que la décadence de la Grèce correspondait, d'une certaine façon, à un inéluctable dessein supérieur, dont la lecture se révélait finalement dans le long déroulement du 'temps chronologique' (chronos) mais aussi dans le choix symbolique d'un moment spécifique ou 'temps opportun' (kairos) pour rendre évidentes les implications d'une réalité d'une plus grande portée $e^{28}$.

Cet épisode marque, également, le début de la fin politique et biologique de Phocion. Accusé peu après de trahison, l’homme d'État subit les conséquences d'une nouvelle époque marquée par la faillite des idéaux de la polis. La composition de l'assemblée qui prononça sa condamnation à mort témoigne de cette évolution : tous purent y participer, sans distinction de statut ${ }^{29}$. En contraste avec cette décadence généralisée, Phocion présente l'ultime preuve de son arete, en affrontant avec grandeur la mort décidée par cette ville qui lui devait tant. L'exécution coïncide, de nouveau et symboliquement, avec un jour de festivités en 1'honneur de Zeus, ce qui fait que cet assassinat se double d'un crime d'impiété religieuse (Phoc. 37.2:

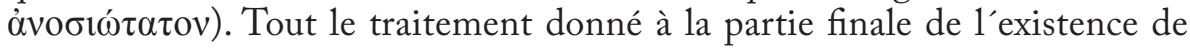
Phocion évoque le jugement de Socrate ${ }^{30}$, que Plutarque place, de façon

${ }^{27}$ En des termes encore plus tragiques que ceux vécus en 404, comme le synthétise de façon suggestive Hammond (1986) 648-649.

${ }^{28}$ Vide Swain (1989) 282.

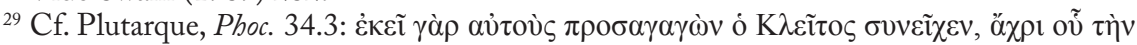

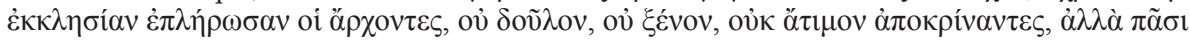

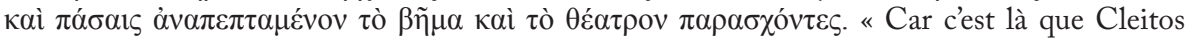
les conduisit et les garda jusqu'à ce que les magistrats eussent réuni l'assemblée. On n'exclut de celle-ci ni les esclaves, ni les étrangers, ni les personnes privées de leurs droits civiques, et on laissa la tribune et le théâtre ouverts à tous et à toutes. » Maria do Céu Fialho, dans sa contribution pour ce volume ("The interplay of textual references in Plutarch's Life of Phocion", p. 202), souligne le fait que le jugement de Phocion est une mascarade démocratique recréée par le dominateur macédonien (Polyperchon) : «For true citizens, the staged trial denounced the farsical democracy that was being acted out, making them aware of danger and demise - the 'shipwreck' of the city, in fact ».

${ }_{30}$ À propos des ressemblances et des différences en ce qui concerne le traitement de la mort 
suggestive, à la fin de la biographie, dans un cadre identique d'irréflexion (Phoc. 38.5):

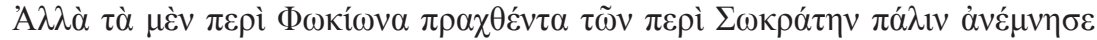

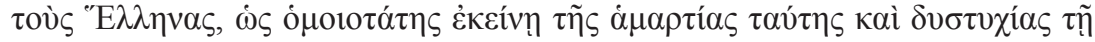

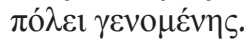

La façon dont périt Phocion rappela aux Grecs la mort de Socrate: ce fut pour la ville une faute et un malheur tout à fait semblables.

L'erreur (hamartia) représentée par cette mort est doublement tragique, puisqu'elle souligne le danger de l'irréflexion collective, ainsi que le gâchis sans gloire d'une des rares sources d'espoir avec laquelle les Athéniens auraient pu compter dans ce moment de grande agitation. Il est également hautement significatif que la biographie se termine sur 1'idée que la mort de Phocion constitue une 'infortune' (dystychia) ou 'mauvaise fortune', dotant ainsi la biographie d'une sorte de composition circulaire : malgré son arete naturelle et son excellente paideia, il lui aurait été nécessaire d'avoir aussi l'appui d'une tyche propice et de vivre dans un temps plus favorable (autant dans le sens de kairos comme dans celui de chronos) afin que ses qualités puissent donner toute leur mesure.

de Socrate, Phocion et Caton (vu que la comparaison est plus favorable à l'homme d'État grec qu'au romain), vide Alcalde Martín (1999); Trapp (1999). Geiger (1999), 358, souligne que, bien que Plutarque mentionne fréquemment Platon et Socrate au cours de son œuvre, ce n'est que dans ce passage des Vitae de Phocion et de Caton que le biographe décrit et discute la mort du philosophe athénien. 


\section{Bibliographie CitÉE}

Alcalde Martín, Carlos, "Rasgos socráticos de la personalidad de Foción en la Vida de Plutarco", in A. Pérez Jiménez, J. García López y Rosa María Aguilar (eds.), Plutarco, Platón y Aristóteles (Madrid, 1999), 159-171.

Alcalde Martín, Carlos, Plutarco. Vida de Foción. Introducción, traducción y notas (Madrid, 2001).

Bearzot, Cinzia, "Introduzione", in Plutarco. Focione e Catone Uticense (Milano, 1993, réimpr. 2001), 91-151.

Brun, Patrice, L'orateur Démade. Essai d'bistoire et d'historiographie (Bordeaux, 2000).

Duff, Timothy E., Plutarch's Lives. Exploring virtue and vice (Oxford, 1999).

Geiger, Joseph, "Plato, Plutarch and the death of Socrates and of Cato", in A. Pérez Jiménez, J. García López y Rosa María Aguilar (eds.), Plutarco, Platón y Aristóteles (Madrid, 1999), 357-364.

Hammond, N. G. L., A History of Greece to 322 B.C. $\left(\right.$ Oxford, $\left.1986^{3}\right)$.

Kajanto, Iiro, "Fortuna” $A N R W$ II.17.1 (1981) 502-558.

LeÃo, Delfim F., As ironias da Fortuna. Sátira e moralidade no Satyricon de Petrónio (Coimbra, 1998).

-, Sólon. Ética e política (Coimbra, 2001).

SwaIn, Simon, "Plutarch: chance, providence, and history", AJPh 110 (1989) 272-302.

Trapp, Michael B., "Socrates, the Phaedo, and the Lives of Phocion and Cato the Younger”, in A. Pérez Jiménez,J. García López y Rosa María Aguilar (eds.), Plutarco, Platón y Aristóteles (Madrid, 1999), 487-499.

Tritle, Lawrence A., "Plutarch's 'Life of Phocion': an analysis and critical report”, $A N R W$ II.33.6 (1992) 4258-4297. 


\title{
The Interplay of Textual References in Plutarch's LiFE OF PHOCION
}

\author{
Maria do Céu Fialho \\ University of Coimbra
}

\begin{abstract}
The pair of Phocion and Cato the Younger contains a kind of anticipated synkrisis. This anticipation has implications for the author's narrative strategy. Plutarch seems to prefer Phocion, if one might judge from the way he highlights the text with clues that organize the interpretation of the macrotext. This is to be seen in the way he cites models or plays with the same hypotexts differently in the cases of Phocion and Cato, both of them close to Socrates' model. It has already been said that the ostentatiousness of the Socratic model in the reading of Phaedo by Cato permits the reader to glimpse a misunderstood appropriation of it. In Phocion's Life, on the other hand, the reader must look for the hypotext and its paradigmatic dimension - either Herodotus (Solon before Croesus' treasure/Phocion before Alexander's treasures) or Plato (Ap., Phd., Cri.) - in Phocion's placid and soft attitude in his last moments, where some coincidences of episodes before his death and that of Socrates are to be seen, or in Phocion's behaviour throughout his life. He kept his constantia of character, even under hard circumstances, when Tyche was adverse to him and caused him to be misunderstood by the people or led to death by the manipulation of demagogues.
\end{abstract}

Phocion is one of the great examples of longevity and constantia of character and behaviour that has lasted from Ancient times to the present. He lived during the turmoil of the $4^{\text {th }}$ century b.C., in an Athens that was defeated and politically weakened and whose identity was badly shaken by a long civil war and by the impending loss of its freedom to the kings of Macedonia, then builders of a new empire.

Although Phocion's political and private conduct was beyond reproach and in the interests of Athens, which both feared and respected him, he was condemned to death by ingestion of hemlock, in 318 b.C. This very same city, or rather, a crowd, manipulated by the representatives of the Macedonian kings, condemned him to death at the age of eighty-four, in an act that could not be further from the genuine democracy of the $5^{\text {th }}$ century. A short time after, his death produced uncomfortable feelings of guilt and weighed heavily on the conscience of the city.

Unlike many of the heroes in Plutarch's biographies, Phocion does not represent the soul and the fate of the political community of the time, through synecdoche. On the contrary, he experiences the problems of his time and fights against them as much as he can by intervening and setting trends of collective behaviour regarding political ethics. His effort is consistent and energetic, but in vain, because he is surrounded by traitors, of which he is well aware.

Phocion's attitudes contrast greatly with the typical behaviour of the members of Athenian society at that time: he follows Socrates' model of conduct and his life is inspired by a kind of pratical philosophy. Therefore, Plutarch chooses another admirer of Socrates, an even greater enthusiast of Stoicism, in Rome, to pair with him: Cato the Younger, from Utica. Although the link 
between the two is sometimes difficult to make and tenuous, which Plutarch himself acknowledges, we witness in both their lives, the Herculean struggle against the course of events and the reigning beliefs of that time, as if it were a struggle against a particularly powerful $T y c h e^{1}$. And they almost defeated it in the echo of themselves which they left behind, after their deaths'.

This pair of lives is part of a small group of four pairs without a final synkrisis ${ }^{3}$. However, in the preface to the Vitae of Phocion and Cato there is a kind of anticipated synkrisis where the author presents his reasons for establishing a comparison between the two.

Plutarch's preference for Phocion is noticeable from the very beginning: Cato's archaiotropia appears in a period of corrupt and depraved

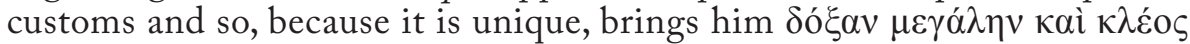
(3.3). However, his virtue and nobility are historically out of context the hardness and the scope of his virtue is disproportionate ( $\dot{\alpha} \sigma \hat{\mu} \mu \mu \varepsilon \tau \rho o v)$ and strange to the needs of the time. He lacks the sense of kairos that Plutarch mentions in a part of the text that is full of references to music. This inability to fit into his own historical era, which is revealed in the very way that Cato intervenes in events, distinguishes the Roman hero from the Greek one.

This type of anticipation of the synkrisis is much more than a mere process of variatio in the presentation of elements in the biographical discourse. On the contrary, it has very specific implications in the interaction between the reader and the text, not only in the way he or she interprets and understands it, but also in his or her comprehension of the profile of the two politicians.

The initial anticipated judgement comparing Phocion to Cato, as well as the general view given about each of the Vitae, lead the reader to examine the protagonists' lives for a kind of confirmation of their expectations. The way to that confirmation demands a global strategy which Plutarch performs. He highlights their Vitae with various signs through facts and different levels of discourse, like a kind of 'Wegweiser' demanding a macrotextual level of reading.

Thus, the analysis of the text in the Lives of Phocion and Cato implies the acknowledgment of various weavings included in it.

${ }^{1}$ This struggle of man against Tyche, even if Tyche means the circumstances and the historical environment was already analysed by Pérez Jiménez (1973) 103 sqq. This model of hero fighting against a tyche is very near to the concept of hero's life by C. Nepos.

${ }^{2}$ SwAIN (1989) 282 asserts even that "The nations of both men were in a bad plight and it is made clear that their virtue was being rendered ineffectual by fortune". I think, specially in what concerns Phocion, his virtue has a special effect post mortem, when the city recognized, with bad conscience, that it judged unjustly this man.

3 The others are those of Themistocles/Camillus, Pyrrhus/Marius, Alexander/Caesar. See Trapp (1999) 487-488. Trapp recognizes, in the case of Phocion/Cato how this strategy rendered the Platonizing analysis so important. 488: "A Platonizing analysis of the relationship between statesman and populace is thus established as central to understanding the resemblance between Plutarch's two subjects, and the figure of Socrates brought, if only hazily so far, into relationship with them". 
The first and foremost obvious one is that of the final product: the macrotext which is open to an interpretative reading through the comparison and anticipated judgement established at the beginning between Phocion's and Cato's Lives.

The second level - the hypotext - is a diverse one, from which the coherence of the reading is built and shown through the indicators referred to. Moreover, it is the complex game of intertwining hypotexts which helps to establish the connection and the contrast between Phocion and Cato. This effect is primarily due to the use of Platonic dialogues focused on the last moments of Socrates' life, as the Apology, Phaedo, Crito, and some references to Gorgias and The Banquet. Much weaker is the hypotextual use of Sophoclean tragedy or of Herodotus' Histories.

Therefore, the model and example of Socrates' conduct towards death underlies the comparative discourse between Phocion and Cato. Interestingly, in both Plutarch's Lives, the more conscious and deliberately acknowledged and displayed this connection is to the Socratian model by those biographied, the more artificial it becomes. Such is the case of Cato.

In Cato's Life this model is very strongly coloured by Stoicism. Nevertheless, Cato's obsessive reading of Phaedo to his circle of friends in his last dinner contrasts with his behaviour afterwards. His attachment to the book and to theoretical culture are dissonant with the spontaneity of his conduct in real life. Cato's outburst of rage towards the loyal slave who does not bring him the sword reaches a climax when he physically attacks him in a brutal manner. Such behaviour is contrary to the constantia animi defended and practised by the Stoics. Cato's first attempt to commit suicide failed due to the weakness of his hand, which he had seriously injured when he attacked the slave, but the second attempt, which proved to be successful, was described by Plutarch with impressive visual effects, so as to convey the brutality with which Cato put an end to his life. Socrates' death, the author suggests, was very different, having been dictated by judges and carried out in a sweet and serene manner. The model was therefore wrongly assimilated, and probably also a reflection of Cato's own inability to adapt to his own time (Phoc.3.1.).

The importance of the Socratic-Platonic model to Cato the Younger was already acknowledged in Ancient Rome, as J.Geiger ${ }^{4}$ reminds us. Trapp, and later A. Zadorojny ${ }^{5}$, pointed to and corroborated the thesis that Plutarch presented Cato as misinterpreting his Greek model. The key to this reading lies mainly in the interplay between the readings of Phaedo and the last night in the life of the Roman. Zadorojnyi explores the use of another hypotext: Sophocles' Ajax ${ }^{6}$. In fact, Cato shouts for his sword, and becomes angry on discovering that it had been hidden to prevent him from carrying out the fate that he had decided on for himself. When he finally held the sword in his

\footnotetext{
${ }^{4}$ Geiger (1999) 359-362.

${ }^{5}$ Trapp (1999) 493-494. This is the guiding thesis of Zadorojny's paper (2007)216-230.

${ }^{6}$ Ibid. This literary resource was already briefly pointed out by Trapp (1999) 498, but Zadorojnyi (2007) analysed it further and derived more extensive conclusions from its use.
} 


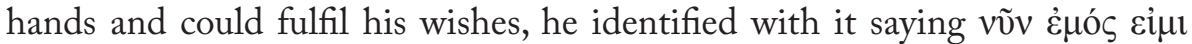
(Cato 70.2). Such behaviour reminds us of Sophocles' protagonist when he spoke to the entities which he felt were part of his world and of his own fate, whether they were the darkness or his sword?

In fact, the Sophoclean hypotext is not so perceptible in the Life of Phocion, since the inadequacy of the lonely Sophoclean protagonist in relation to his own world is not appropriate to suggest the context and the conduct of the Athenian.. I believe, however, that by comparing these two lives Plutarch aimed to appeal to the theatrical culture of the reader. His purpose was to draw the memory of the reader, however weakly, to a tragic Sophoclean theme from another angle which did not focus directly on Phocion. I am referring here to the prohibition on burying Phocion in Athens in an act of demagogical tyranny, and to the courage of his second wife (this passage cannot have any other reading ${ }^{8}$ ). Although weakened by old age, she took the remains of Phocion's body to her home and the speech, which Plutarch places in her mouth, expresses at the same time her civic courage, the bonds of affection and conjugal devotion, as well as the respect owed to the dead and her ties to her ancestors. She predicts that in a moment of regained sophrosyne, perhaps caused by future political misfortune, the city will grant the dead man his right to a proper burial (37.5).

It is very likely that the reader, like us, will remember Antigone. The logic behind 9 the reading allows a retrospective comparison of data, given that it is possible to go back and re-read the text once more. Thus, it seems to me that Ajax's hypotext in the Life of Cato strengthens the thesis of the existence of a crossed reference with the blurred hypotext of Antigone in the Life of Phocion. It is of great significance that Plutarch has used the latter with regards to the strong matrimonial relationship of his wife towards him, as well as the feelings of the City towards him, after his death. On the other side, the hypotext of Antigone in the Life of Phocion, thanks to the crossed reference with the Ajax's hypotext in the Life of Cato, gets wider implications. It leads the reader to think on the Sophoclean discussion about Ajax's burial, that the demagogues Agamamnon and Menelaus wanted to deny him. Lastly they had to sbmit themselves to the will of the gods.

In the first case, we are led to place great importance on the relationship between spouses by the polygraph of Chaeronea and to the acknowledged role of the wife. In fact, at the very beginning of the Life of Phocion, Plutarch rebuts Sophocles' words, which are put into the mouth of Ismene and said to Creon, in Antigone (vv. 563-564): 'Sir, even innate common sense fades away in the midst of misfortune and succumbs to it'. This weakening of virtue (1.5)

\footnotetext{
${ }^{7}$ See Schadewaldt (1966) 55-93 on this connection with Sophocles' hero as a lonely man with his body, his sword and the landscape linked to his fate.

${ }^{8} \mathrm{I}$ agree with the analysis and reasons presented by Flacelière-Chambry for considering Megarikes an interpolation (1976) 162.

${ }^{9} \mathrm{I}$ owe this suggestion to the kindness of F. Frazier, to whom I express my gratitude.
} 
in times of misfortune is not recognized by Plutarch in Phocion. The latter will not side with Ismene - and his wife's conduct will prolong the implicit evocation of Antigone's side.

This strategy allowed Plutarch to emphasize the divergence between Phocion and Cato. The moments before Cato's death were hard on his friends, family and slaves because his behaviour did reveal neither sweetness nor temperance (Cato $68 \mathrm{sqq}$ ), and contrasted with the purpose of his readings during the dinner.

The great force that tested courage, virtue and the coherence of behaviour in relation to the great paradigmatic master/model reference was Tyche. Indeed, Tyche was an ever- present factor in the life of the protagonists, as well as in the life of each man, whether it was propitious or adverse, in the inglorious struggle waged against it or in the indiscriminate use of its favours. The true character of Plutarch's biographized heroes, their $\tilde{\eta} \theta 0 s$, is revealed in their action $(\pi \rho \tilde{\alpha} \xi 1 \varsigma)$ as their 're-action' to $T y c h e^{10}$.

Tyche was particularly adverse to Phocion and to Cato who 'almost' defeated it, but who, in a twist of fate, ended up losing to it. Their efforts and their arete were not duly recognized ${ }^{11}$. Challenging situations and political crisis often trigger strictness and severity in honourable characters that can easily offend the masses.

There is a subtle difference between Phocion and Cato: historically, the former lived in a time of crisis with no return, and the latter in a crisis of the end of an era. The Roman Republic was close to its end, but Caesar's tyranny would be followed by the Empire. Plutarch compares Cato to an out-of-season

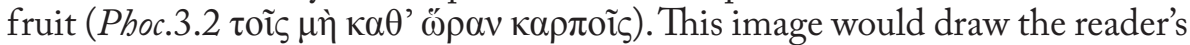
attention to the differences that exist beyond their affinities.

Such a contrast is consolidated, as it was already mentioned, through the perception of the protagonists' different approach to the same paradigm, which is perceptible through the interplay of hypotexts, but it was prepared by the anticipated synkrisis of the initial chapters through the combination of two strategies. I am referring to the explicit use of texts, quoted or just briefly mentioned, as a source of credibility (as in the case of Cicero, for example ${ }^{12}$ ). There are quotations from poets ${ }^{13}$ (Sophocles, Archilochos, Homer) as a more powerful means of suggestion than simple statements, and a remarkable range of imagery reinforces the intended effect.

It is meaningful that this imagery profusion is condensed, mainly, in the initial chapters of the Lives, as it is to be seen in the Life of Phocion, which will guide our reading like a prelude where the musical theme is presented. Let us see an example: Demades' words are quoted in 1.1 so as to allow Plutarch

\footnotetext{
${ }^{10}$ See Pérez Jiménez (1973) 101-110.

${ }^{11}$ At least in the course of their lives. Thereafter, sooner or later, their qualities and virtues were recognized: see Frazier (1996) 120-121.

${ }^{12}$ E. g. Phoc.3.1: Cicero, Ad Att.2.1.8.

${ }_{13}$ Phoc.1.3:Soph., Ant.563-564; Phoc.7. 5: Archilochos, frg. 1 West; Phoc. 17.1: Od.9. 494 and in Phoc. 2.3. an indirect quotation of Od.5.165-166 is to be seen.
} 
to distinguish between the two sympathizers of the Macedonian cause. Such words subvert the traditional image of the ship of state and refer to it as

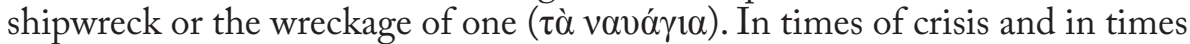
of shipwreck, Demades was himself part of the wreckage. On the other hand, Phocion faced that same shipwreck with an undeniable arete, although the adverse tychai of the Hellas denied him both glory and recognition.

This misunderstood arete in Phocion is justified by the bitterness and impressionability of the crowd in difficult times, which cannot bear to hear harsh words from incorruptible and severe politicians who are little concerned with being liked by the people. And this theme is reinforced through a comparison taken from medical practice: that of the burning sensation that honey causes on wounds while at the same time cleaning them (2.3), and supported by a quotation from Homer (Od.5.165-166). Plutarch next focuses his attention on the phenomenon of an Athens that does not welcome the coarse, but well-intentioned, frankness of Phocion. Now, he resorts to a new comparison using the city and drawn form the area of ophthalmology (2.4) ailing eyes find comfort in the contemplation of dark colours and avoid those that are bright and reflect light, just like a city overcome by adverse fortune can tolerate badly frankness and the pointing out of its mistakes.

The complex comparison that follows presents an initial distribution of elements similar to the previous one. It is taken from the field of astronomy and will extend, drawing near to that of music (2. 6-9). The movement of the sun does not coincide with that of the heavens, but neither is it against it nor does it contradict it. Its trajectory is oblique and curved and its flexibility guarantees universal harmony.

This principle is the beginning of the opportune yielding that ought to govern political practice of those who face the will of the people. The systematic strictness and harshness, which never yield to anything at the right moment, and never learnt sweetness (praotes) which creates bonds of reciprocity, are a dangerous path. Severity and kindness represent an alliance of rhythms similar to the divine ruling of the universe.

These words remind us of Somnium Scipionis and seem to be tacitly applied to Phocion, and explicitly to Cato. For the latter, Plutarch corroborates them with a passage from Cicero. Moreover, Plutarch, as previously mentioned, sees Cato an out-of-season fruit. With regards to Phocion, Plutarch will show, in the anecdotae that testify the nature and specificity of the ethos and praxis of the Greek statesman, up to what point Phocion combined strictness and harshness with a profound philanthropia combined with praotes, which he exhibited right up to the end of his life ${ }^{14}$. Philanthropia is indeed a reference word in the characterization of the Athenian.

I will now focus my attention on the relationship between the macrotext, and its anticipated synkrisis, and the hermeneutical game between it and the

${ }^{14}$ On the importance of philanthropia and praotes as character traits that become evident through the action of the biographized heroes, see Martin (1960) 65-73 and Martin (1961)164175. See also Frazier (1996) 231-239. 
hypotexts, which is strengthened by the poetical discourse of the first chapters. The reading leads us to sympathise with Phocion who was a disciple of Plato and Xenocrates. It is never said or insinuated in an anticipated contrast with Cato that Phocion wants to impose himself like a second Platonic Socrates. His conduct incorporates the moral values and the behaviour of the chosen models, in accordance with his nature and the lessons that he took from them. And this seems to happen naturally in the eyes of his fellow citizens.

Phocion is still young and through sobriety and moderation has the power to correct the temperamental excesses of the strategos Chabrias. His detachment from material things was manifested in the austere lifestyle that he shared with his wife, which gave him a certain political credibility, since he was perceived as a man of integrity, disinterested in action. According to Plutarch (Phoc. 8.1), it was well known that his political conduct was guided by values

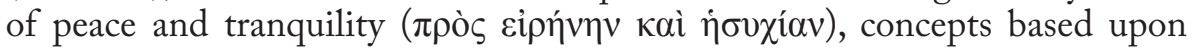
the notion of universal harmony, mentioned in 2.9. Thus, the reader gradually realises that the criticism of intransigence and harshness in the preamble are aimed much more at Cato than at Phocion, whose character is qualified in 5.1

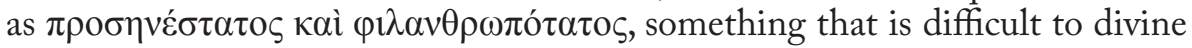
from his somewhat austere and unsociable demeanour. Socrates' description of his rather uncouth appearance and satyr-like face in the Platonic dialogues is also misleading, since his harmony of soul and strength to fight for Good are only revealed to those in his closest circle. Even the executioner acknowledges his sweetness (praotes) and arete in Phaedo (116c).

Thus, we get some idea of the imposing personality of this man, who was elected strategos forty-five times in Athens during a time of crisis, and who

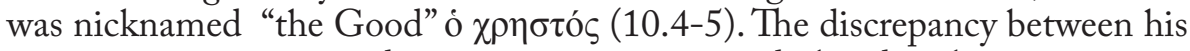
appearance, manners and nature is once again underlined with a comparison from the realm of wine: a wine that leaves a lingering aftertaste may be pleasing to the palate, while another, which perhaps seems sweet at first, may become sickly and harmful later on.

Phocion's ability to endure the hardships of winter and face them with minimal protection was proverbial in Athens. On military campaigns, he would wear light garments and fight barefoot, only donning warmer clothing when the cold became unbearable (4.3-4). As has already been noted, this reference evokes the habits of Socrates, as mentioned by Plato (e. g. Symp. 220a-b) ${ }^{15}$. This natural proximity with Socrates is not made explicit by Plutarch. However, the passage also evokes the Life of Cato (44), who, as elected praetor, is shown going about his duties barefoot, and often without a tunic. Plutarch censures this behaviour, which, he believes, displays scorn and contempt for institutions. We understand that Cato distanced himself ostentatiously, and somewhat arrogantly, from the crowd with this attitude; but we also understand that Plutarch sees this as somewhat forced and out-of-step with reality. The Socratic

\footnotetext{
${ }^{15}$ See also Aristophanes, $N u$. 412-428.
} 
paradigm is far from this and poorly assimilated, which is in keeping with the conclusions that may be drawn from the dissonant connection between the final reading of Phaedo and the scene with the sword and the two suicide attempts.

According to Plutarch, Phocion's coarseness and inexorability had a practical purpose (10.7), just like the energetic sobriety of his speeches which Demosthenes described as "axes" that could cut through his opponents whenever he felt that the well-being of Athens was at stake. The definition that Phocion gives of the sycophant, Aristogiton, as "limping and cowardly" (10.3), though not directly quoted from Archilochus, would seem to correspond to a game of critical defilement of the portrait of the ideal general of that poet from Paros (frg. 114 West).

The manoeuvres of Polyperchon, regent of Macedonia, finally created the conditions for the elimination of Phocion (32 sqq.). With the old democratic regime apparently reinstated through a concession from the Macedonians, the Athens Assembly was filled with a crowd of fugitives, foreigners and people deprived of civic rights through atimia (33.2). It was these men, manipulated by the Macedonians, who accused old Phocion and his companions of betraying their country, and condemned them to death by hemlock. But there was no opportunity at Phocion's trial for a beautiful speech before attentive judges, of the kind that Socrates had made in Plato's Apology. As Plutarch

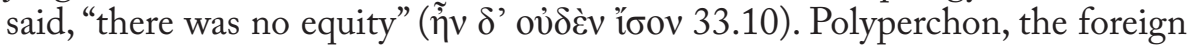
dominator, interrupted Phocion whenever he began to speak, until the latter gave up trying.

For true citizens, the staged trial denounced the farsical democracy that was being acted out, making them aware of danger and demise - the 'shipwreck' of the city, in fact. Plutarch plays with the contrasting situations surrounding the deaths of Socrates and Phocion: both trials took place during religious festivals, but while Socrates' execution was postponed, according to Crito (43d) or Phaedo (58a), until the theoria returned to Athens, this did not happen in the case of Phocion. The foreign master and the unscrupulous crowd fixed the date of the execution for the month of Mounichion, during the festivities in honour of Zeus (37.1). Like Socrates in Phaedo, Phocion only reveals his true nature to those around him at the very last moment - his clarity, sweetness, serenity and philanthropia, and the fact that he did not even have enough money to pay for the hemlock that he was supposed to drink. Plutarch creates a tragic and emotional atmosphere that surrounds the description of Phocion's death in order to stir the sympathy of the reader towards Phocion ${ }^{16}$ and to emphasize the discreet nobility of the ethos of this man, whose political action was misunderstood by a troubled city in a time of

16 Tritle (1988) 30. Bearzot (1993) 143 talks about "la morte «socratica» di Focione" in Plutarch's Life and asserts that Plutarch, such as Diodorus (18.66.4 sqq.), whose sympathy towards Phocion is evident, "trae spunto dalla tradizione favorevole contemporanea per condurre all'estremo la sua esaltazione dello stratego ateniese e per avviare l'edificazione del mito di Focione, mito che, attraverso fase diverse, è giunto fino ai moderni”. 
decadence and political intrigues and conspiracies ${ }^{17}$. Along his life he always acted in order to preserve the peace or the integrity of Athens, but the course of events and other external factors made of Phocion a man rudely struck by Tyche.

In the Apology, Socrates foresees the harsh punishment that will befall those that have condemned him - the trial they will undergo, which will be far more relentless than the one they were presiding over at that moment. When the disturbing voice of Socrates was silenced, other voices, even more disturbing and implacable, would be raised against them (Ap. $38 \mathrm{~d}-\mathrm{e})$. What Socrates foresaw for himself in fact happened to Phocion soon after his death; the city itself was stricken by the guilty conscience that had weighed upon it for a long time. Phocion's memory was rehabilitated. For the city saw its own demise projected onto that condemnation, to some extent like Creon at the end of Antigone - with the realisation coming too late, after disaster had befallen him for having left the dead unburied and innocents condemned.

Although the analogy with Socrates gains a certain life in the biography of Phocion through the interplay of hypotexts, Plutarch nevertheless takes steps to ensure that Phocion does not coincide with the figure of a Socrates daimonios constructed by tradition. The biography instead leaves us with a perception of Phocion as a somewhat misunderstood figure, a sensible politician and sober man, devoted to the city and rich in philanthropia. Phocion remains the politician that lives in accordance with Athens' genuine values and tries to impose a political harmony that he believes might allow them to survive the 'shipwreck'. His efforts were almost rewarded. At least the Athenians retained a sense of guilt with regards to him, were burdened with the weight of remorse and the image of that man of sober speech and gestures that so fitted the profile of the great uncorrupted leaders of the past (such as Solon, who "would rarely remove his hands from inside his cloak" - 4.3 ${ }^{18}$ ), and whose values were made clear in the account of his meeting with Croesus, as told in Herodotus $^{19}$. A similar difference in perspective between an Athenian and a Barbarian is repeated, on the Solon model at the hypotext level, where we identify the presence of Herodotus, in Alexander's incomprehension at Phocion's unresponsiveness to the treasures that he specially tries to offer him (17-18).

This complex interplay of hypotextual suggestions, of initial images, which lead the comprehensive lecture of the Vita, of quotations of poets, that give consistency and life to the narrative or to descriptive passages, also contributes to the final impression that is specially underlined by the Platonic hypotext,

\footnotetext{
${ }^{17}$ See D. Leão in the final part of his paper "Tyche, kairos et chronos dans le Phocion de Plutarque", published in this volume.

${ }^{18}$ That means: as statesman of ancient times, who used to speak with parsimony of gestures. See Aesch. Contra Tim. 25; Demosth. De legat. 251.

19 1.30-34.
} 
as we have seen, more and more evident and natural when Phocion's Life goes near to its end ${ }^{20}$.

The weight on the Athenian conscience also seems to represent the very burden of conscience of an ancient identity, which, with the death of Phocion, was lost for ever ${ }^{21}$. This was the very punition suffered by the city after the masquerade of the trial - Phocion's death by drinking the hemlock could not have meant 'punition' because he was always an aristos, a dikaios, a philanthropos, who took always his political decisions having in account what was the best for the city ${ }^{22}$.

${ }^{20}$ Alcalde Martín (1999) 159-171 shows that this Vita is organized in very precise sections and that there it observes a strategy of progressive evidence of similarities between Phocion and Socrates. Geiger (1988) 256: "The last sentence od the Phocion draws the parallel between the deaths of Phocion and Socrates".

${ }^{21}$ Tritle (1988) 30 sqq.: Plutarch has probably obtained in a written tradition this kind of information about the collective reactions after the death of Phocion.

${ }^{22}$ F. Frazier, in her paper to be published in this volume - "Le De sera, dialogue pythique. Hasard et Providence, Philosophie et Religion dans la pensée de Plutarque" - underlines Plutarch's irony in the chapter 10 of the De sera: «...là où le chapitre 10 moquait ceux qui croient que le châtiment se confond avec le moment de l'éxécution capitale et qu'on est pas puni tant qu'on n'a pas bu la cigüe...». As a matter of fact, in Phocion's Life, it was not that one or those who drunk the hemlock that were punished, because they had no guilt - it was the city, in the time that followed the execution, that was punished through the collective feeling of shame and bad conscience. 


\section{Quoted Bibliography}

Alcalde Martín, C., Plutarco. Vida de Foción. Introd. trad. y notas (Madrid, 2001).

Alcalde Martín, C., "Rasgos socráticos de la personalidad de Foción en la Vida de Plutarco" in: Pérez Jiménez, A., García López, J., Aguilar, R. M. (eds.), Plutarco, Platón y Aristóteles. Actas del V Congreso Internacional de la I.P.S., (Madrid, 1999) 159-172.

Bearzot, C. - Geiger, L. -Ghilli, L., Plutarco. Vite Paralele. Focione, introd., trad., note di C. Bearzot, Catone Uticense, introd. L. Geiger, trad., note di L. Ghilli (Milano, 1993).

Flacelière, R. - Chambry, E., Plutarche. Vies, t. X (Paris, 1976).

Frazier, F., Morale et Histoire dans les Vies Parallèles de Plutarque (Paris, 1996).

Geiger,J., "Nepos and Plutarch: from Latin to Greek Political Biography" ICS 13.2 (1988) 245-256.

Geiger, J.,"Plato, Plutarch and the Death of Socrates and of Cato" in: Pérez Jiménez, A., García López, J., Aguilar, R. M. (eds.), Plutarco, Platón y Aristóteles. Actas del V Congreso Internacional de la I.P.S., (Madrid, 1999) 357-364.

Hershbell, J. P., "Plutarch's Portrait of Socrates” ICS 13.2 (1988) 365-381.

Martin, H., "The Concept of Philanthropia in Plutarch's Lives" AJPh 82 (1961) 164-175.

—, "The Concept of Praotês in Plutarch's Lives" GRBS 3 (1960) 65-73.

Pérez Jiménez, A. (1973) “Atitudes de l'hombre frente a la tyche en las Vidas Paralelas de Plutarco” BIEH 7 (1973)101-110.

Perrin, B., Plutarch's Lives, vol. VIII, ed., transl. (London, 1969 rep.).

Schadewaldt, W., Monolog und Selbstgespräch. Untersuchungen zur Formgeschichte der griechischen Tragödie (Berlin, 1966) 55-93.

Swain, S., "Plutarch: Chance, Providence, and History" AJPh 110 (1989) 272-302.

Trapp, M. B., "Socrates, the Phaedo and the Lives of Phocion and Cato the Younger" in: Pérez Jiménez, A., García López, J., Aguilar, R. M. (eds.), Plutarco, Platón y Aristóteles. Actas del V Congreso Internacional de la I.P.S. (Madrid, 1999)487-500.

Tritle, M., Phocion the Good (New York/Sydney, 1988).

Zadorojnyi, A.,"Cato's Suicide in Plutarch" CQ 57 (2007) 216-230. 


\title{
I Doni di Zeus, il Dono di Prometeo. STRUTTURE RETORICHE ED ISTANZE ETICO-POLITICHE NELLA RIFLESSIONE PLUTARCHEA SULLA $\tau u ́ \chi \eta$.
}

\author{
Rosario Scannapieco \\ Università di Salerno
}

\begin{abstract}
«Non di manco, perché il nostro libero arbitrio non sia spento, iudico potere essere vero che la fortuna sia arbitra della metà delle azioni nostre, ma che etiam lei ne lasci governare l'altra metà, o presso, a noi.»
\end{abstract}

(N. Machiavelli, Il Principe, cap. XXV)

\begin{abstract}
Starting from the analysis of rhetorical structures of aud. poet. 23C-24A and fort. $99 \mathrm{~F}-100 \mathrm{~A}$, this paper aims at underlining the continuous presence in Plutarch's production of a consistent thought about the role played by $\tau \dot{\chi} \chi \eta$ in the life of the people as well as in history, with ethical and political implications. Particularly, the same quotation of Hes. OD 86-87 in both texts allows Plutarch to use Prometheus' figure as a model, in order to show the condition: human being has to learn how to profit by Zeus' or tyche's gifts with

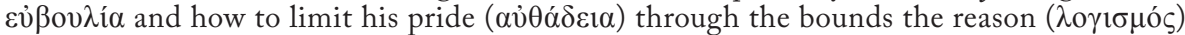
imposes. The model offered by Titan also affects the building of Alexander the Great's character in the two pamphlets about him (Alex. fort. virt. I and II), whose both political and rhetorical nature is underlined. Alexander - Prometheus indeed represents a sort of political and ethical paradigm that is ambivalent and problematic, because it is offered both to the Greeks and to the Romans at the same time, as it seems to come out from the last page of De fortuna Romanorum.
\end{abstract}

\section{Divinità, fortuna, destino in aud.poet. 23C-24A: una prima ricognizione.}

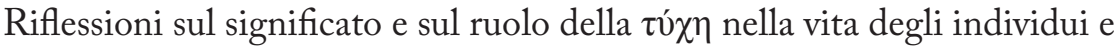
nella storia sono ampiamente sparse nel corpus plutarcheo ed il quadro teorico che da esse emerge appare vario ed articolato, non privo di contraddizioni o, meglio, di evoluzioni e ripensamenti frutto di una meditazione da parte dell'autore costante nel tempo e, per questo, destinata a mutare in relazione a fattori personali e storici, a non tener conto di quelli legati alla natura e alla destinazione dei vari opuscoli che quelle riflessioni ospitano ${ }^{1}$. Tuttavia, l'analisi delle strutture retorico-formali di alcuni di questi testi può contribuire alla ricostruzione di un'idea coerente della fortuna in Plutarco, al di là delle 'variazioni' e degli aggiustamenti inevitabili in un autore tanto prolifico e dai mille interessi.

Nella sezione finale del cap. 6 del Deaudiendis poetis (23C-24A), nell'ambito della polemica platonica sullempietà di alcune affermazioni omeriche sulla

${ }^{1}$ Per alcuni studi complessivi recenti sulla $\tau$ $\left.\chi\right\rceil \eta$ in Plutarco cfr. in particolare L. Torraca, 1996; F. BесCHI, 2000 e la bibliografia dedicata a questo tema in F. BECCH (ed.), 2010, pp. 244-5. 
natura e i comportamenti degli dèi ${ }^{2}$, Plutarco sostiene che i poeti con il nome di Zeus indicano talvolta il dio in senso proprio, talaltra la tú $\chi$, spesso anche

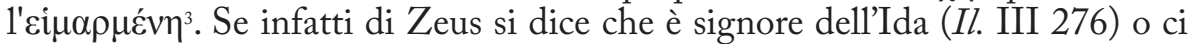
si domanda chi sia più saggio di lui ( $T r G F r$ adesp. 351 Kannicht-Snell) allora si fa riferimento al dio in senso proprio, di cui si evidenziano la potenza e la natura razionale. Ma se i poeti usano il nome di Zeus per indicare le cause di tutti gli eventi, allora si riferiscono all'si $\mu \alpha \rho \mu \varepsilon ́ v \eta$; in questo caso Plutarco adduce ad esempio Il. I 3 e 5, in cui il poeta afferma che la volontà di Zeus si compì gettando all'Ade un gran numero di eroi achei. Ovviamente il dio non può essere causa del male degli uomini e quindi con quelle parole il poeta si riferiva all'ỏvó $\gamma \kappa \eta$, la giusta ed inevitabile conseguenza di un comportamento erroneo dell'uomo 4 . A questo punto Plutarco per chiarire il concetto propone un esempio attinente all'ambito politico: città, eserciti e generali, qualora siano saggi ottengono il successo e la vittoria sui nemici, ma come essi cadano vittime di passioni ed errori è logica conseguenza per loro un comportamento disonorevole, il disordine e l'insuccesso ${ }^{5}$.

Per un esempio poetico di identificazione di Zeus con la potenza della

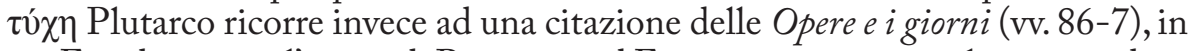
cui Esiodo riporta l'invito di Prometeo ad Epimeteo a non accogliere mai i doni da Zeus Olimpio, ma a rimandarli indietro: infatti - spiega Plutarco - i doni di Zeus sono quelli offerti dalla $\tau u ́ \chi \eta$, cioè i beni esterni come ricchezze, nozze e potere, il cui possesso è privo di giovamento se non se ne fa un uso corretto; per questo Epimeteo, che è insipiente, deve guardarsi dai successi, perché ne

${ }^{2}$ Cfr. D. Babut, 2003 (1969), pp. 414-7; D.M. Schenkeweld, 1982; J. García Lopez, 1984; E. Valgiglio, 1990; J. M. Diaz Lavado, 1996; C. Brechet, 1999; A. Zadorojnyi, 2002; M. Kraus, 2005; S. SaÏD, 2005.

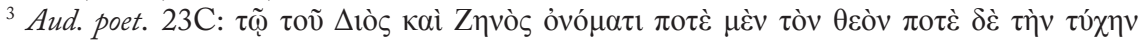

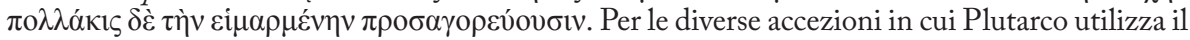

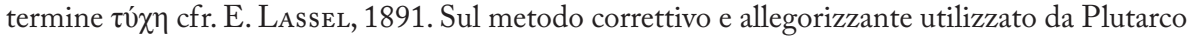
nel De audiendis poetis cfr. D. Babut, 2003 (1969), pp. 106-7; I. Ramelli - G. A. Lucchetta, 2004, p. 402; sul significato assunto dalle strategie ermeneutiche dei testi omerici applicate da Plutarco nell'ambito di una più ampia riflessione sulle modalità di riuso dei testi antichi da parte degli intellettuali d'età imperiale, cfr. T. Whiтмarsh, 2001, pp. 52-4.

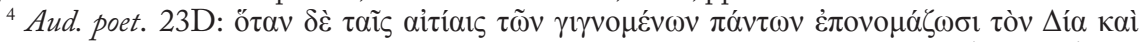

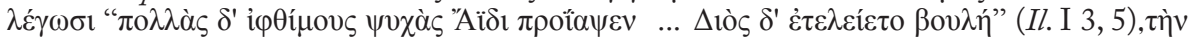

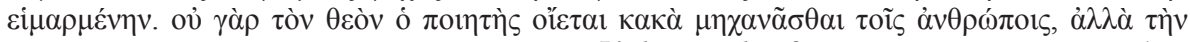

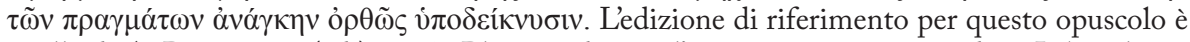
quella di A. Philippon (ed.), 1987. Plutarco discute l'interpretazione stoica di Il. I 5 anche in Stoic. rep. 1050A-D, criticando ovviamente l'identificazione operata da Crisippo tra $\varepsilon i \mu \alpha \rho \mu \varepsilon ́ v \eta$ e Zeus: cfr. M. Zanatta (ed.), 2000, pp. 367s. nn. 5-7; M. Casevitz - D. Babut (edd.), 2004, pp. 284-6, nn. 408-13; F. Casadesús Bordoy, 2005.

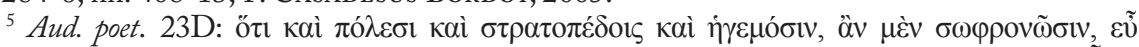

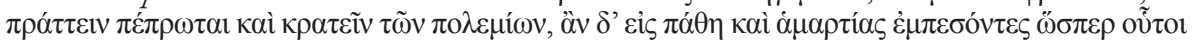

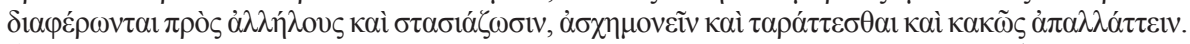
A rafforzare questa tesi Plutarco cita un altro frammento tragico d'autore incerto ( $\operatorname{Tr} G r F$ adesp.

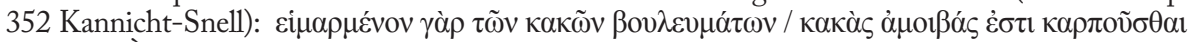

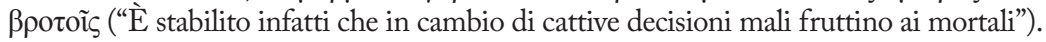


sarà danneggiato e rovinato ${ }^{6}$. Anche la successiva citazione dei vv. $717-8$ delle Opere di Esiodo, secondo cui la povertà non deve essere criticata, perché dono

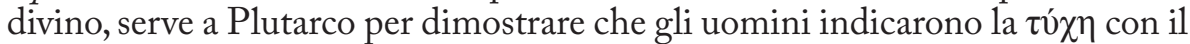
nome degli dèi, perché essi si erano resi conto del suo movimento disordinato e che sfugge al controllo del $\lambda o \gamma 1 \sigma \mu$ ós, proprio come siamo abituati a indicare con i termini "sovrumano" e "divino" comportamenti, parole ed individui fuori dalla norma ${ }^{7}$. Alla luce di queste riflessioni le affermazioni omeriche, secondo cui Zeus sarebbe causa del male per gli uomini, si giustificano dunque soltanto

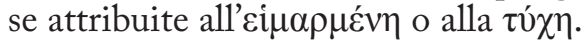

A parte il tentativo di eliminare possibili contraddizioni sul comportamento degli dèi incompatibili con il pensiero di un platonico per cui la divinità è solo dispensatrice di bene, in aud. poet. 23C-24A Plutarco sembra comunque insistere sul ruolo decisivo della scelta da parte dell'uomo del proprio destino e sulla sua responsabilità nell'origine del male nel mondo ${ }^{8}$; in particolare anche sul versante dei comportamenti sociali Plutarco sottolinea la diretta consequenzialità di ciò che viene comunemente chiamato "destino" dall'agire umano, il che sembra un tema di riflessione costante e di cruciale interesse per lo scrittore come dimostra il confronto con altri testi.

\section{Modalità di composizione e strategie retoriche a confronto: aud. poet. 23C-24A e fort. 99F-100A.}

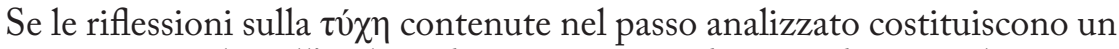
momento marginale nell'ambito di un più ampio discorso di natura letteraria sulle modalità di esegesi dei testi poetici in vista di un loro uso moralistico", tuttavia la persistenza di queste idee in altri luoghi del corpus testimonia comunque l'esistenza di un pensiero di fondo coerente, che prescinde dalle esigenze comunicative proprie delle diverse tipologie di testi in cui quelle osservazioni sono contenute. Infatti, la presenza dello stesso materiale retorico in testi in cui Plutarco discute di $\tau$ ú $\eta$, oltre a fare luce sulle sue tecniche compositive e sulle sue preferenze in relazione ai materiali utilizzati e a sua disposizione, potrebbe essere espressione di un nucleo ideologico resistente strutturatosi intorno a immagini, citazioni, strutture retoriche ricorrenti.

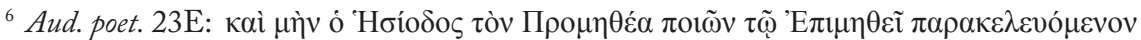

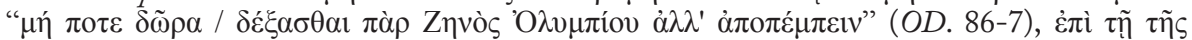

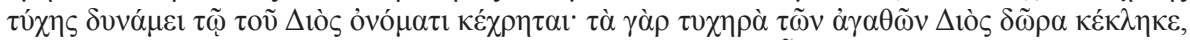

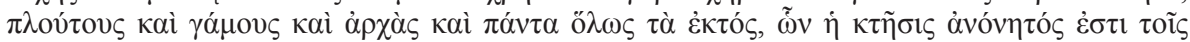

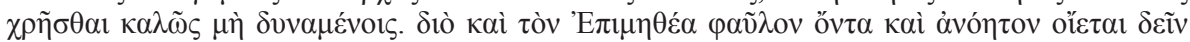

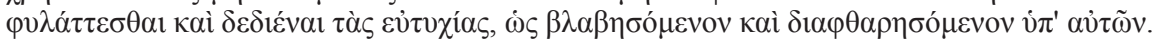

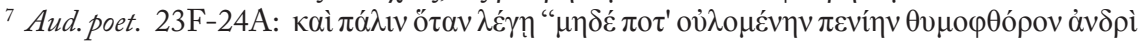

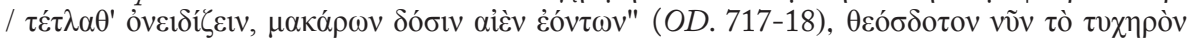

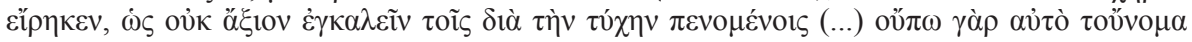

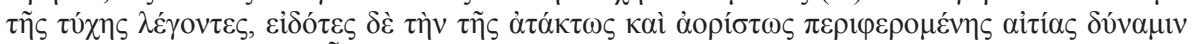

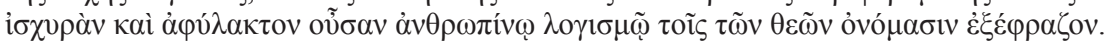

${ }^{8}$ Sul problema dell'attribuzione del male agli dèi cfr. D. BABut, 2003 (1969), pp. 320-34; G. del Cerro Calderón, 1994; L. Torraca, 1994.

${ }^{9}$ Cfr. L. Van der Stockt, 1992, pp. 39-40. 
Proficuo è, per cominciare, il confronto con quanto affermato nel $D e$ fortuna, operetta dedicata al tema della superiorità dell'eủ $\beta o v \lambda i \alpha^{10}$, cioè dell'assennato ragionamento, sulla $\tau u ́ \chi \eta$. Nelle considerazioni conclusive dell'opuscolo (99F-100A) Plutarco sostiene la necessità per l'uomo di servirsi correttamente del $\lambda o \gamma 1 \sigma \mu o ́ s$, che gli permette di dominare i colpi della fortuna;

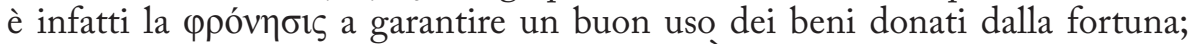
senza di essa gli stessi beni diventano dannosi. $\grave{E}$ a questo punto che si inserisce la stessa citazione esiodea di aud. poet. 23E, al termine della quale Plutarco osserva che i doni di Zeus sono quelli inviati dalla fortuna ${ }^{11}$.

Le due sezioni sembrano dunque riprodurre, secondo una tecnica di composizione ricorrente in Plutarco, "blocchi" di testo ricavati dai suoi $\dot{\tau} \pi \mu_{\nu} \mu^{\prime} \alpha \tau \alpha$ e di volta in volta "ricuciti" e riadattati al contesto specifico ${ }^{12}$. Lorganizzazione dei due testi si può sintetizzare nel seguente schema:

\begin{tabular}{|c|c|}
\hline Aud. poet. $23 \mathrm{D}-\mathrm{F}$ & Fort.99F-100A \\
\hline 1) Esempio politico+citazione lirica & 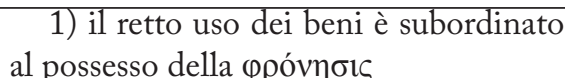 \\
\hline 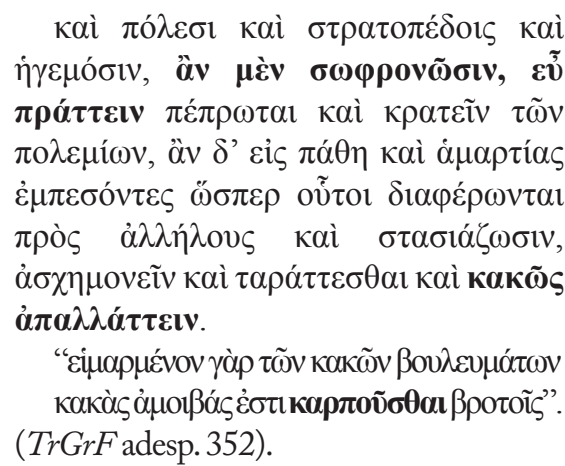 & 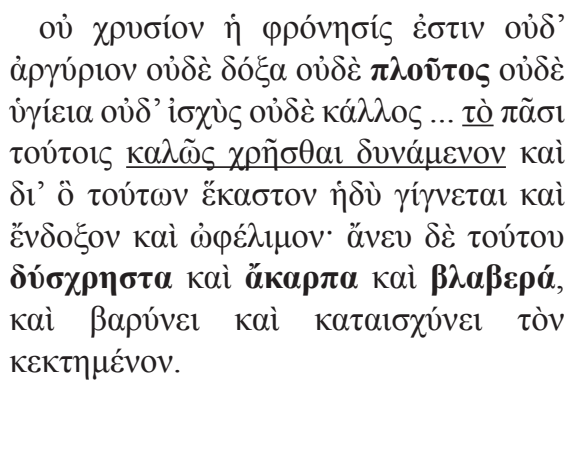 \\
\hline
\end{tabular}

${ }^{10}$ Cfr. F. Becchi, 2008, pp. 41-3; F. Becchi (ed.), 2010, p. 56.

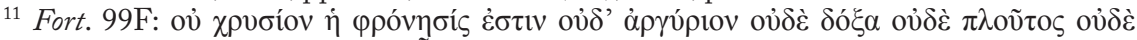

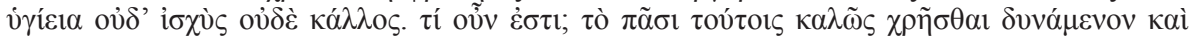

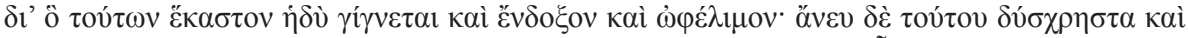

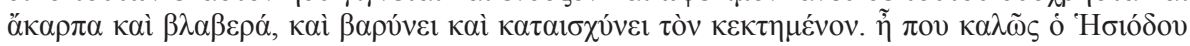

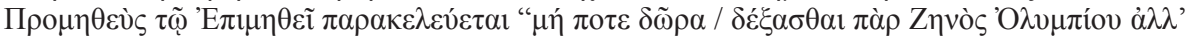

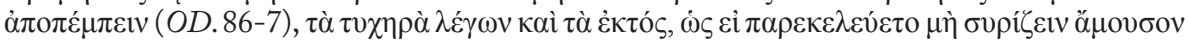

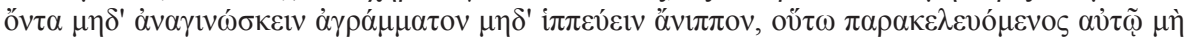

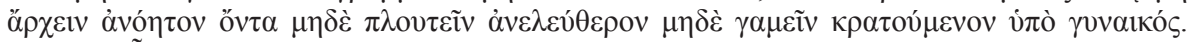

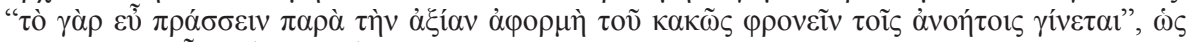

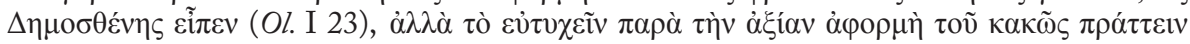

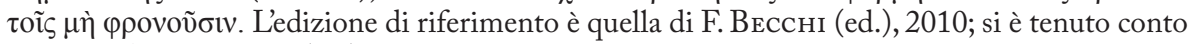
anche di A. BArigazzi (ed.), 1993.

${ }^{12}$ Per questa tecnica compositiva cfr. L. Van der Stockt, 1999; L. VAn der Stockt, 2003; L. VAN DER Stockt, 2004. 


\begin{tabular}{|c|c|}
\hline 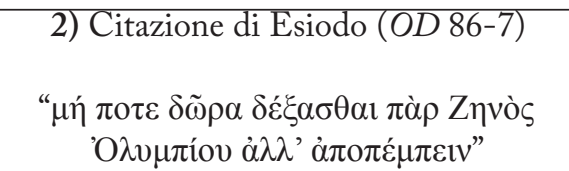 & 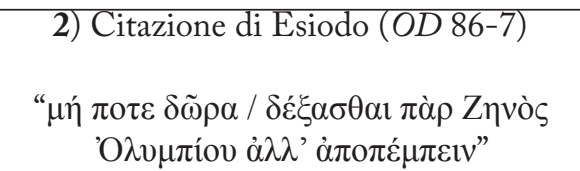 \\
\hline 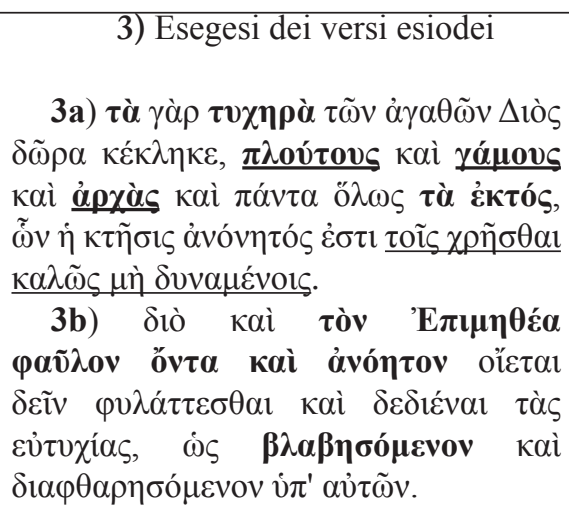 & 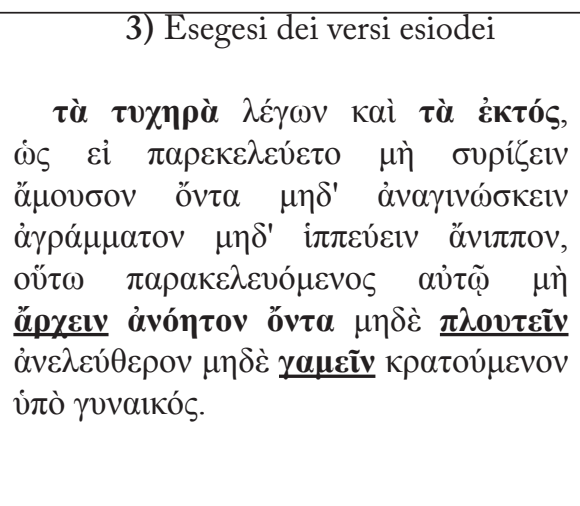 \\
\hline 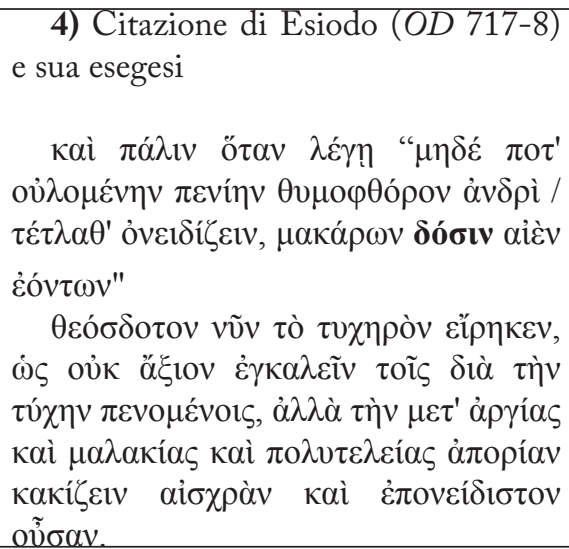 & 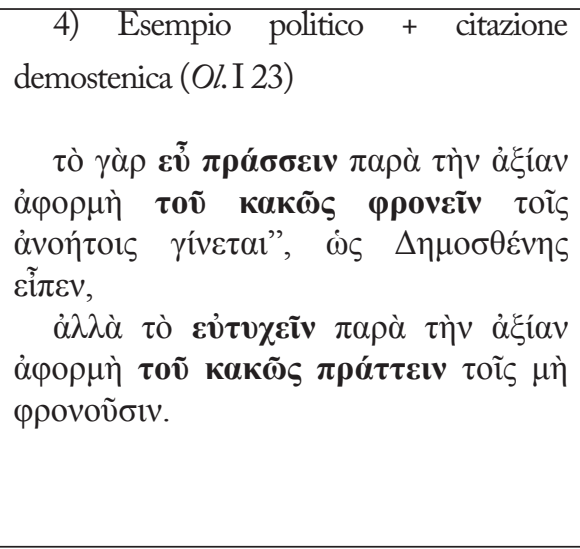 \\
\hline
\end{tabular}

In entrambi i testi la citazione esiodea (2) è spiegata identificando i doni di

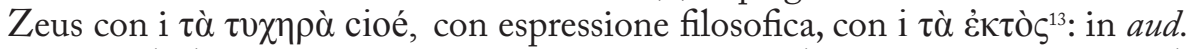

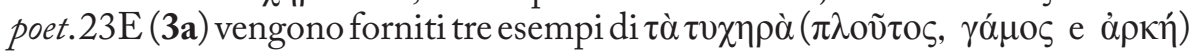

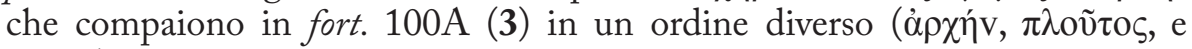

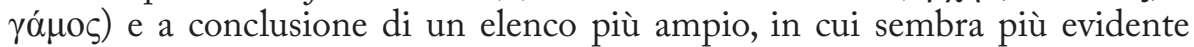
l'amplificazione retorica. Qui infatti Plutarco afferma che occorre dedicarsi ad una attività solo quando si è capaci di svolgerla: se non si è esperti di musica non si può suonare, non si può leggere se non si conoscono le lettere, non si può cavalcare se non si sa guidare un cavallo; e, per concludere, non si può detenere il potere se si è stolti, gestire la ricchezza se si è avari, fare un matrimonio in cui la donna abbia un ruolo dominante. Queste considerazioni costituiscono un ulteriore chiarimento della precedente affermazione (1)

\footnotetext{
${ }^{13}$ Cfr. SVF III 96, 97, 97a, 98, 122 (11. 25-8), 127, 136, 153, 764.
} 
secondo cui il possesso di beni non accompagnato dal loro retto uso li rende

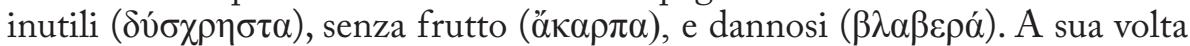

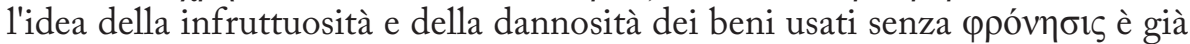

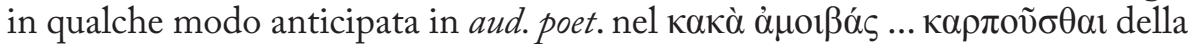
citazione tragica (1) e poi chiaramente espressa nell'esegesi dei versi esiodei

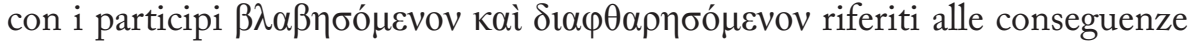

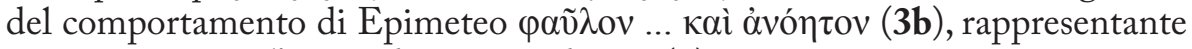
per antonomasia l'uomo dissennato di fort. (3).

Il breve riferimento all'uso scorretto della ricchezza in fort. (1) trova invece uno sviluppo più ampio nella riflessione sulla $\pi \varepsilon v i ́ \alpha$ che in aud. poet. (4) è introdotta per dimostrare che anch'essa è un dono inviato dagli dèi, cioè puramente casuale, secondo l'esegesi plutarchea di Hes. OD 717-8, e diventa un male solo se è conseguenza di un eccesso di lusso, cioè di un suo uso scorretto.

Il De fortuna si conclude con una citazione demostenica, tratta dalla $I$ Olintica (23) secondo cui il successo ( $\varepsilon \tilde{u} \pi \rho \alpha ́ \sigma \sigma \varepsilon t v)$ senza merito è principio

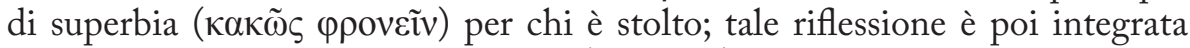

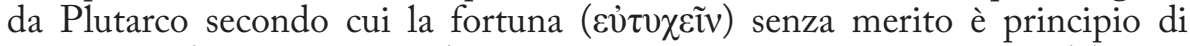

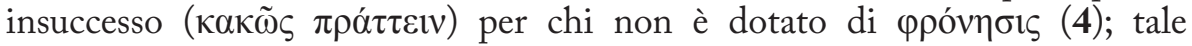
affermazione, che riconduce il discorso su un piano prettamente politico trova un parallelo, anche sul piano linguistico, con le osservazioni immediatamenti precedenti la citazione esiodea di aud. poet. 23D (1), secondo cui successo e

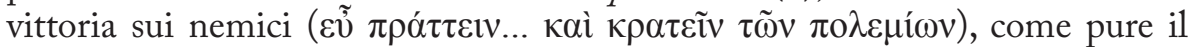

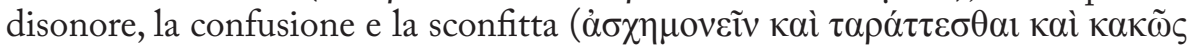

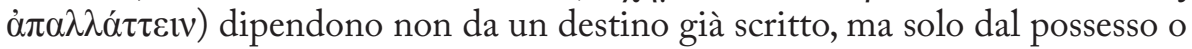

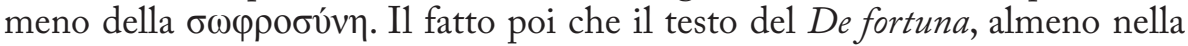
forma in cui esso ci è giunto ${ }^{14}$, termini proprio con un riferimento alla necessità

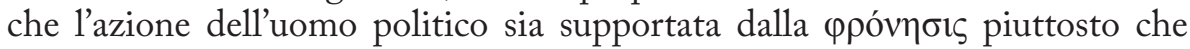

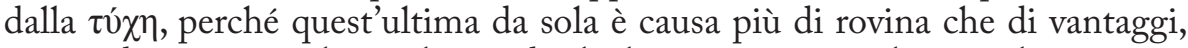
mettendo spesso in luce i limiti di chi la ottiene e non la sa utilizzare con raziocinio, permette di ipotizzare una lettura politica del testo, al di là della sua natura di esercitazione retorica a cui spesso è stato ridotto ${ }^{15}$ : per Plutarco la riflessione sulla $\tau u ́ \chi \eta$, a prescindere dalle posizioni filosofiche che essa rispecchia, doveva convertirsi naturalmente in un discorso innanzi tutto sul profilo del perfetto uomo politico.

\section{Prometeo, un modello non solo retorico.}

La citazione esiodea di fort. 99F con il riferimento a Prometeo rientra in una strategia retorica più complessa, se si tiene conto del fatto che anche

\footnotetext{
${ }^{14}$ Per i problemi relativi allo stato e alla struttura del testo del De fortuna $\mathrm{cfr}$. A. BARIgazzi (ed.), 1993, pp. 11-3; F. Bессні (ed.), 2010, pp. 57-8.

${ }^{15}$ Per il dibattito sulle fonti del testo e sulle sue finalità tutt'altro che retoriche cfr. F. BECCHI, 2000, pp. 315-17; F. BЕссHI, 2008, pp. 48-52; F. BЕсCH (ed.), 2010, pp. 56, 59-79 e il contributo dello stesso studioso contenuto in questo volume.
} 
altrove nell'opuscolo Plutarco si serve del mito di Prometeo (in forma esplicita o implicita) per sviluppare il suo ragionamento. Pertanto l'analisi delle modalità con cui l'autore si riferisce a questo personaggio mitologico o riusa testi che a lui fanno riferimento, permette di stabilire inattese associazioni che introducono nel cuore di un ragionamento di più ampio respiro, in cui si intrecciano istanze filosofiche, etiche e politiche.

Il capovolgimento della prospettiva proposto da Plutarco per cui non

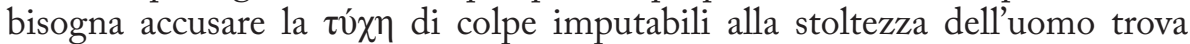
espressione nella paradossale immagine degli uomini che accusano la fortuna di essere cieca, quando invece sono loro ad incappare in essa come ciechi (98A); infatti cieco è l'uomo che si affida alla fortuna quando è privo dell'ev̉ßov $\lambda i ́ \alpha$, la luce della mente. La metafora della cecità viene sviluppata anche nelle riflessioni successive: infatti, subito dopo (98B) Plutarco, nel sostenere che tutte le facoltà fisiche sono state fornite dalla natura all'uomo perché fossero

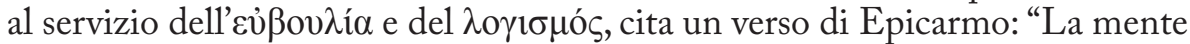
vede e la mente ascolta; tutto il resto è sordo e cieco"16.

A parte il riferimento all'immagine topica della fortuna cieca, Plutarco doveva alludere in questo contesto proprio alla figura di Epimeteo, cieco in quanto privo di $\pi \rho o ́ v o 1 \alpha$. Infatti, la metafora della cecità della mente prima è prolungata in quella della notte dei sensi di cui parla Eraclito in assenza del sole della ragione ${ }^{17}$, poi è sciolta nel riferimento diretto a Prometeo, che è il $\lambda o \gamma 1 \sigma \mu o ́ s ~(98 C)$. Seguendo l'esegesi del mito che vedeva nel Titano il simbolo dell'intraprendenza e della forza della ragione ${ }^{18}$, Plutarco sostiene

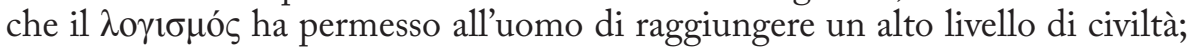
costui dominando grazie al retto ragionamento le forze violente della natura e

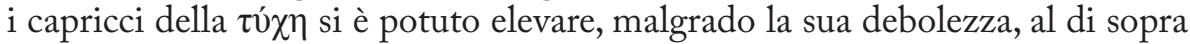
degli altri esseri viventi, sottomettendoli a sé. A questo punto segue anche la citazione del fr. eschileo $194 \mathrm{~N}^{2}$ (= 189a Radt) tratto dal Prometeo liberato ${ }^{19}$, ma Plutarco doveva di certo avere presente il valore assunto dal Titano nel Prometeo incatenato di Eschilo, che ne sottolinea la funzione civilizzatrice: mosso da un

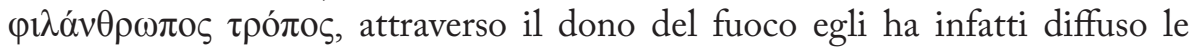
$\tau \varepsilon ́ \chi v \alpha$ tra gli uomini e ha favorito lo sviluppo della civiltà (v. 269) ${ }^{20}$. Tuttavia questo atto di assunzione di responsabilità da parte di Prometeo provoca

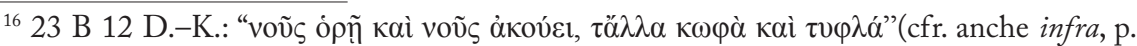
222 e nn. 62-64).

1722 B 99 D.-K. Per la metafora plutarchea della vista e della cecità spirituale cfr. A. I. Dronkers, 1892, p. 11.

${ }^{18}$ Sulla figura mitologica di Prometeo cfr. D. Bremer, 1999; C. Dougherty, 2006.

${ }^{19} \mathrm{Il}$ frammento compare anche in soll. anim. 964F e nel fr. 193 Sandbach. Per la presenza di Eschilo in Plutarco cfr. V. Cittri, 2003, part. pp. 142-3 per una citazione dal Prometeo; I. DAL Pont, 2003(a); I. Dal Pont, 2003(b).

${ }^{20}$ Anche la citazione dall'Eolo di Euripide (fr. $27 \mathrm{~N}^{2}=24 \mathrm{~b}$ Kannicht, di nuovo presente in soll. anim. 959D) va nel senso di una celebrazione delle $\pi \rho \alpha \pi i ́ \delta \varepsilon \varsigma$ che garantiscono all'uomo il controllo della natura: su questo tema cfr. M. - C. LecLerc, 1994. Per l'uso in ambito retorico di questo aspetto del mito cfr. S. SAÏD, 2006 e per una interpretazione del mito di Prometeo nelle versioni di Esiodo, Eschilo, Platone ed Elio Aristide, con particolare attenzione all'ambivalenza del dono della tecnica da parte di Prometeo cfr. U. CURI, 2002, pp. 117- 56. 


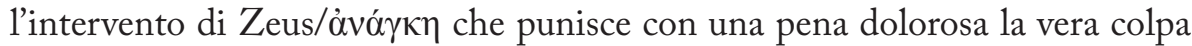
del Titano, l'av̉ $\theta \alpha \delta i ́ \alpha$. Nei vv. 1034-5, infatti, Ermes invita Prometeo a non

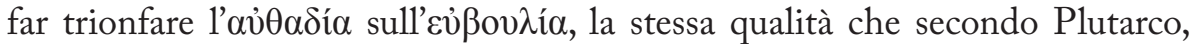

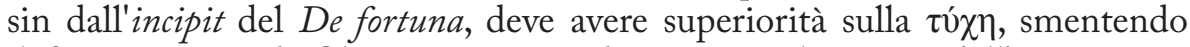
il famoso verso di Cheremone secondo cui tutte le azioni dell'uomo sono dominate dalla fortuna ${ }^{21}$. Ed ancora, i vv. 1073-9, che condensano il messaggio della tragedia, invitando gli uomini a non criticare la $\tau u ́ \chi \eta$ di fronte ai colpi della sventura e a non ritenere responsabile Zeus della loro caduta in un male

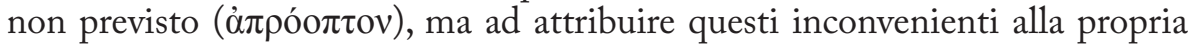
óvora, dovevano essere condivisi anche da Plutarco, che nel De fortuna sostiene appunto la responsabilità dell'individuo nella costruzione del proprio destino attraverso scelte razionali dettate da saggezza.

Nell'uso dell'aggettivo eschileo å $\pi \rho o ́ o \pi \tau o \varsigma$ è infatti da intravvedere un riferimento proprio alla $\pi \rho o ́ v o t \alpha$, cioè alla capacità di previdenza che, sconosciuta allo stolto Epimeteo, è una qualità del saggio Prometeo, come Plutarco sostiene in fort. 98D: qui, per sottolineare come gli altri esseri viventi siano superiori all'uomo in forza e resistenza, ma non nel possesso del voũ $\varsigma$, dopo una breve citazione tratta dal mito di Prometeo contenuto nel Protagora di Platone (321c), in cui si ricorda la debolezza dell'essere umano, Plutarco

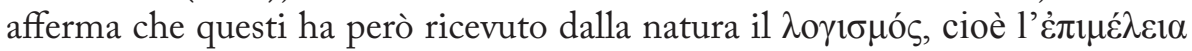

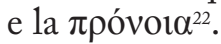

Dunque, anche nel De fortuna la riflessione plutarchea sul tema della

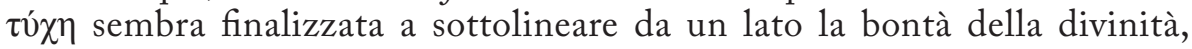
a cui non si può ascrivere il male, dall'altro a valorizzare l'autonomia di scelta dell'uomo, unico responsabile del suo destino; infatti alla $\tau u ́ \chi \eta$ intesa come infinita possibilità nel contingente egli può opporre la virtù e la saggezza, mentre quello che è chiamato comunemente destino ed è inteso come una forza trascendente l'uomo altro non è che la logica ed inevitabile conseguenza del suo comportamento. La figura di Prometeo poteva incarnare proprio questa difficile condizione dell'uomo, saggio ed accorto indagatore delle infinite possibilità di agire, padrone del suo destino, ma anche incline al peccato di hybris se non impara a controllare le risorse donategli dalla divinità. La presenza del male nel mondo poteva così trovare giustificazione come forma di rieducazione, in maniera non dissimile dal pathei mathos eschileo.

${ }^{21}$ Cfr. A. Barigazzi (ed.), 1993, pp. 13-5, 130-2; F. Becchi (ed.), 2010, pp. 149-52, n. 1.

${ }^{22}$ Anche in A. Cornuto, Theol. gr. comp. 18 LAng, Prometeo è allegoria della ragione che ha prodotto la scoperta del fuoco ed è la previdenza dell'anima insita in tutte le cose, cioè la $\pi \rho$ óvota che prima era accanto a Zeus, perché ogni potere e soprattutto quello di Zeus doveva essere dotato di preveggenza ( $\left.\pi \rho \mu_{\eta} \theta \varepsilon i \alpha_{\varsigma}\right)$. Su queste basi Cornuto nel successivo cap. 19 considera Atena allegoria dell'intelligenza di Zeus, cioè della provvidenza. Per la tecniche di esegesi adottate da Cornuto nel suo trattato cfr. I. Ramelli, 2003, pp. 31-42; I. Ramelli - G. A. Lucchetta, 2004, pp. 284-306; per una edizione recentissima accompagnata da una serie di saggi dedicati a vari aspetti del Compendio di Cornuto e al metodo allegorico cfr. H.- G. Nesselrath - F. Berdozzo (ed.), 2009. 


\section{Volontà e destino: il caso di [Hom.] 120-121, Cor. 32 e Stoic. rep. 1048C-1049A.}

Questa lettura dei passi plutarchei finora analizzati trova una conferma alla luce del confronto con altri luoghi del corpus in cui viene affrontato lo stesso tema del rapporto tra individuo e destino. Nel De Homero, che pure è considerata opera pseudoplutarchea ${ }^{23}$, la questione della $\varepsilon i \mu \alpha \rho \mu \varepsilon ́ v \eta$ e del libero arbitrio è affrontata nel cap. 120 su basi ideologiche non dissimili da quelle attribuibili a Plutarco alla luce delle affermazioni contenute nelle opere di certa attribuzione ${ }^{24}$ : l'autore citando i vv. di $I l$. VI 488-9 in cui Ettore, in procinto di andare in battaglia per l'ultima volta, dice ad Andromaca di sapere che il suo destino è già segnato, sottolinea che non tutto avviene secondo destino, ma che qualcosa è anche lasciato nelle mani degli uomini; chi ha la

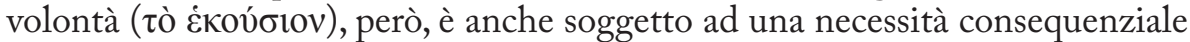
( nelle conseguenze del libero arbitrio, come testimoniano gli incipit dell'Iliade e dell'Odissea. In aud. poet. 23D proprio i versi iniziali dell'Iliade servivano a Plutarco per testimoniare l'uso da parte dei poeti del nome di Zeus al posto di

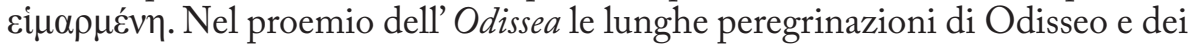
suoi compagni sono la giusta punizione per la loro $\alpha \beta$ ov $\lambda i ́ \alpha$ che li aveva indotti ad offendere il dio Sole.

Nel cap. 121 invece i versi di Od. V 436 e 427-9, in cui Odisseo si salva dalla tempesta scatenata da Poseidone perché spinto da Atena ad aggrapparsi

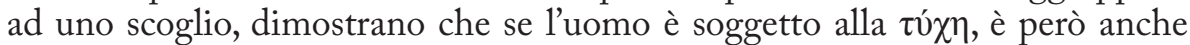
capace di trovare una via di uscita ai mali grazie alla $\pi \rho o ́ v o r \alpha$, qui intesa come la decisione autonoma prodottasi per un impulso della volontà divina ${ }^{25}$.

Anche nel passo del De Homero viene comunque sottolineata l'autonomia

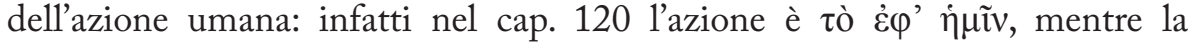

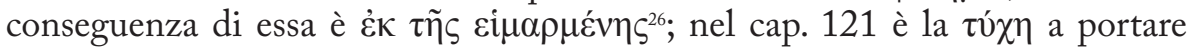

${ }^{23}$ Cfr. K. Ziegler, 1965, pp. 282-6; I. Ramelli - G. A. Lucchetta, 2004, pp. 377-91.

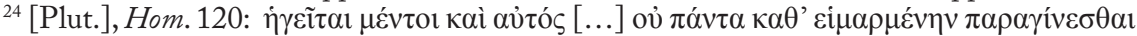

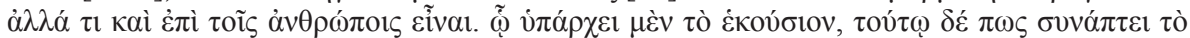

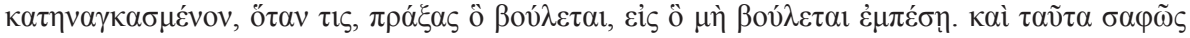

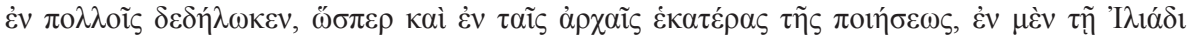

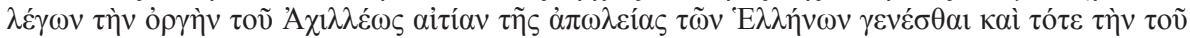

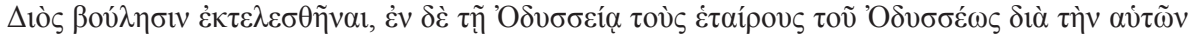

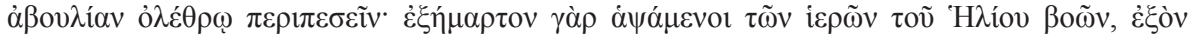

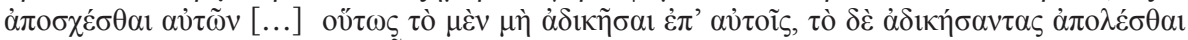

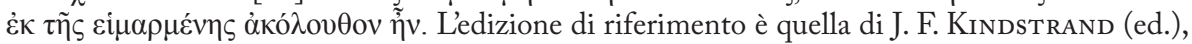
1990.

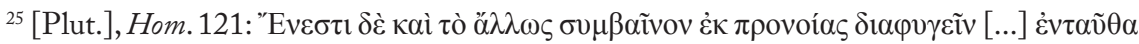

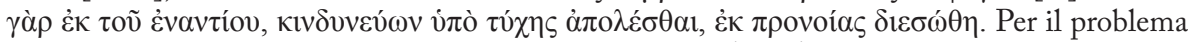
del libero arbitrio in questo opuscolo cfr. D. Вавut, 2003 (1969), p. 187.

${ }^{26}$ Anche in Quaest. conv. 740C-D Plutarco fornisce un'interpretazione molto simile dei concetti di responsabilità personale, destino e caso: la scelta compete all'uomo ( $\tau$ ò $\dot{\varepsilon} \varphi$ ' $\dot{\eta} \mu \mathrm{i} v$ ), perché sia la virtù sia il vizio sono liberi, ma la conseguenza di un'azione buona o malvagia,

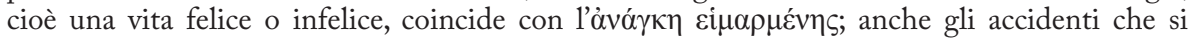
attribuiscono alla $\tau \dot{\chi} \chi \eta$, a ben guardare, rispondono ad una logica, perché legati a particolari 
in punto di morte l'uomo, ma la $\pi \rho$ óvot $\alpha$ a salvarlo; in questa preveggenza

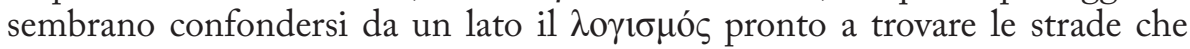
permettano all'uomo di migliorare la sua condizione, dall'altro l'intrinseca $\varphi \imath \lambda \alpha v \theta \rho \omega \pi i ́ \alpha$ della divinità che quando interviene lo fa sempre per soccorrere gli uomini ${ }^{27}$.

Il problema trova un ampio sviluppo nel cap. 32 della Vita di Coriolano ${ }^{28}$ : qui Plutarco sostiene che i versi omerici in cui si indica nella divinità la causa di un determinato comportamento dell'uomo non implicano in realtà una limitazione del libero arbitrio; nel caso di azioni ordinarie, esse vengono attribuite alla volontà dell'individuo ( $\tau$ ò $\dot{\varepsilon} \varphi$ ' $ं \mu$ ĩv); quando si tratta invece di compiere imprese straordinarie l'intervento degli dèi si limita a sollecitare la

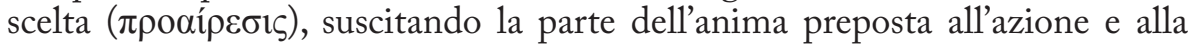
scelta (

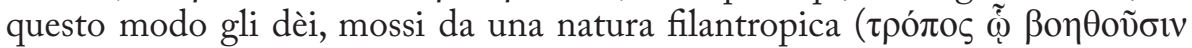

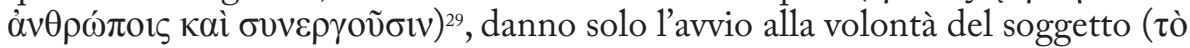
$\dot{\varepsilon} \kappa o v ́ \sigma ı v)$, che rimane quindi libero, ma responsabile delle sue azioni ${ }^{30}$.

Infine in Stoic. rep. 1048C - 1049A Plutarco affronta una questione strettamente collegata con queste riflessioni: egli confuta, infatti, l'opinione

condizioni contingenti in cui l'uomo si trova a vivere e per questo anche ciò che avviene $\kappa \alpha \tau \grave{\alpha}$

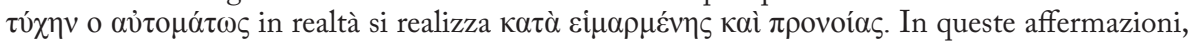

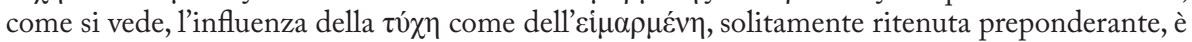
di molto ridimensionata a favore della responsabilità dell'individuo.

${ }^{27}$ Anche nell'altra anonima opera presente nel corpus e dedicata a queste tematiche, il $D e$ fato, l'autore sostiene che esistono delle azioni che sono nelle mani dell'uomo e dipendono da

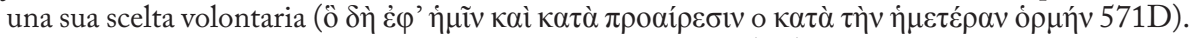
Sul problema dell'attribuzione dell'opera cfr. E. VALgiglio (ed.), 1993, pp. 34-42 e per l'analisi del passo il comm. ad loc., nn. 147, 150, 151; per la discussione su questo tema cfr. D. BABUT, 2003 (1969), pp. 179-83; J. Hani, 1983; L. Torraca, 1996, pp. 127-35; P. Moraux, 2000, pp. 67-76.

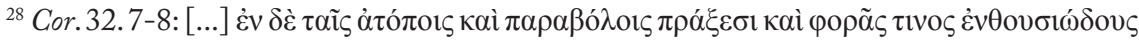

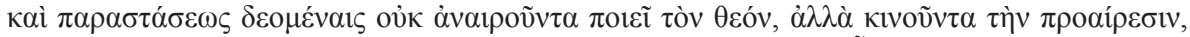

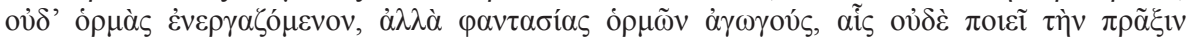

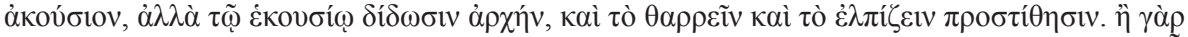

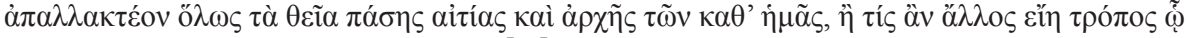

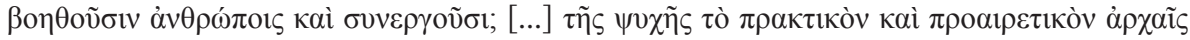

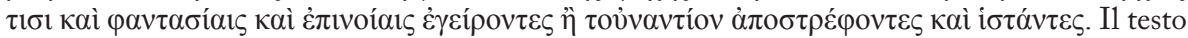
di riferimento è quello di R. Flacelière - E. Chambry (edd.), 1999.

${ }^{29}$ Nei capp. 118 e 119 del De Homero, proprio a ridosso della sezione dedicata al libero

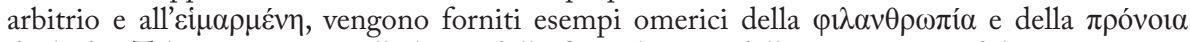
degli dèi. Tali esempi sono alla base della formulazione della teoria stoica del cosmo come casa comune degli uomini e degli dèi che ad essi provvedono secondo giustizia. Per la natura benevola e filantropica della divinità cfr. D. BABUt 2003 (1969), pp. 528-9.

${ }^{30} \mathrm{Di}$ tale concetto, di natura stoica, Plutarco tuttavia metterà in luce le contraddizioni in Stoic. rep. 1055F-1057C, sostenendo che una si $\mu \alpha \rho \mu \varepsilon ́ v \eta$ limitata dall'assenso che la volontà deve

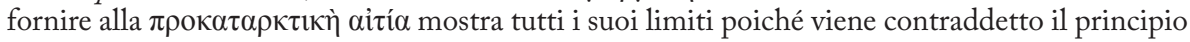
deterministico. Sul tema della presenza del libero arbitrio in un mondo in cui comunque agisce una forza provvidenziale cfr. D. BABUT, 2003 (1969), pp. 341-46 e, in particolare su questo passo della Vita di Coriolano, pp. 348-50. Sul complesso problema del fato, del determinismo e del libero arbitrio nel pensiero stoico cfr. S. Bobzien, 1998; R. Salles, 2005. 
di Crisippo secondo cui il bene morale è una conquista dell'uomo e non è elargito dal dio; questo principio, secondo Plutarco, metterebbe in discussione l'idea stoica di un dio provvidente, sia che possedendo il bene, cioè la virtù, non ne voglia rendere partecipe l'uomo sia che non lo possegga affatto; e senza il dono della virtù ogni cosa anche positiva non è più un bene: è dunque il dono amorevole della virtù da parte della divinità a permettere l'uso corretto degli altri doni concessi all'uomo, e anche qui, come in aud. poet. 23D-F e fort. 99F, Plutarco sostiene che gli stolti non sanno fare buon uso di beni come ricchezza, salute e forza fisica, che in tal caso risultano dannosi.

Queste affermazioni sono coerenti con quanto affermato nel De fortuna:

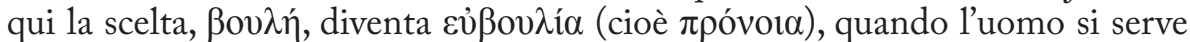
della ragione $(97 \mathrm{~F})^{31}$, che è appunto un dono della púois (98D). Come si vede la riflessione è ricondotta da Plutarco ancora una volta ad una questione di assunzione di responsabilità e, in ultima analisi, di $\pi \alpha 1 \delta \varepsilon i ́ \alpha:$ l'uomo ha ricevuto tutti gli strumenti per agire bene dagli dèi, che talvolta lo indirizzano ad una scelta giusta, ma quando fa il male non può incolpare che se stesso, in quanto la ragione in lui è stata soppiantata, per un difetto di formazione, dalle passioni.

\section{Alessandro -Prometeo, ovvero della virtù pratica.}

Volendo passare dal piano della riflessione teorica all'esempio concreto di un agire mosso dal $\lambda o \gamma ı \mu$ ó $\varsigma$ e quindi in grado di contrastare la forza della $\tau \hat{\chi} \chi \eta$ è utile analizzare i due opuscoli Sulla fortuna e la virtù di Alessandro Magno. Considerate opere di gioventù di stampo retorico ${ }^{32}$, esse offrono tuttavia interessanti spunti di riflessione: assunto di fondo è che l'azione di Alessandro Magno è la più grande opera della Virtù, non della Fortuna, che anzi ha spesso ostacolato le sue imprese contribuendo così a renderle più grandi. Può essere interessante verificare se nei due opuscoli Plutarco abbia modellato la figura del suo Alessandro sul $\pi \alpha \rho \alpha ́ \delta \varepsilon v \gamma \mu \alpha$ offerto da Prometeo e se questo abbia una ripercussione nella interpretazione complessiva dei testi.

Proprio all'inizio della I orazione Plutarco afferma che Alessandro non ha ricevuto in dono $(\pi \rho$ oĩ $\alpha)$ dalla Fortuna i suoi successi, ma è grazie alle sue qualità, $\varepsilon \hat{\beta} \beta o v \lambda i ́ \alpha, \dot{\alpha} v \delta \rho \varepsilon i ́ \alpha, \kappa \alpha \rho \tau \varepsilon \rho i ́ \alpha$ e $\sigma \omega \varphi \rho o \sigma u ́ v \eta^{33}$, che egli si presenta come il civilizzatore dei popoli che ha conquistato ${ }^{34}$; la fortuna invece -

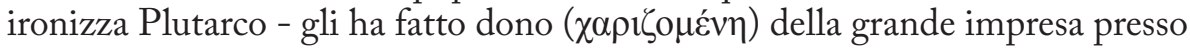

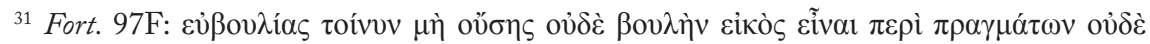

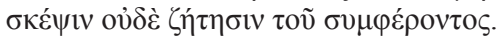

32 Sulla cronologia dei due opuscoli cfr. almeno K. Ziegler, 1965, p. 107; J. R. Hamilton, 1969 , p. XXIII; C. P. Jones, 1971, p. 135. Sottolineano la dimensione retorica dei due discorsi J. R. Hamilton 1969, p. XXXI; M. R. Cammarota, 1992, pp. 109, 115-6; A. D’Angelo, 1995; A. D’Angelo, 1996.

${ }^{33}$ Per altri elenchi delle virtù di Alessandro cfr. anche Alex. fort. virt. I 327E, 332C-D.

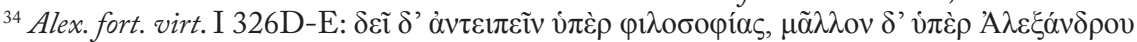

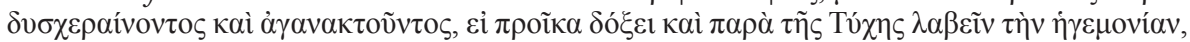

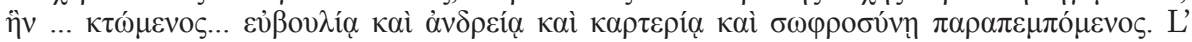
edizione di riferimento per questo opuscolo è quella di A. D’ANGELo (ed.), 1998. 
i Malli, in cui ha rischiato di perdere la vita ${ }^{35}$. Alessandro incarna così l'ideale dell'uomo previdente e saggio che nulla si attende in regalo dalla $\tau$ $\chi \chi \eta^{36}$, ma tutto si procura con la sua ragione, proprio come Prometeo ${ }^{37}$.

Alessandro è anche filosofo superiore a tutti gli altri, perché questi ultimi hanno solo teorizzato un mondo ideale, mentre egli ha provato a realizzarlo unendo popoli lontanissimi nello spazio e diversi per civiltà ${ }^{38}$. Lo strumento principale con cui Alessandro ha realizzato questo progetto è proprio il $\lambda \sigma \gamma 1 \sigma \mu o ́ s$ sobrio e assennato ${ }^{39}$ cui si accompagna, come per Prometeo, la $\varphi \imath \lambda \alpha \nu \theta \rho \omega \pi \alpha^{40}$; nella seconda orazione è, infatti, il suo atteggiamento filantropico a garantire, ancora una volta come Prometeo, lo sviluppo degli ingegni e la difesa delle $\operatorname{arti}^{41}$, il che lo rende, come Eracle altro mitico eroe civilizzatore, l'antitesi dei tiranni contro cui ha combattuto e che ha sottomesso ${ }^{42}$.

Con Prometeo Alessandro non condivide però l'intemperanza, il che costituisce il motivo della sua vittoria sui colpi avversi della Fortuna ${ }^{43}$. Interessante può essere a questo punto il confronto con i vv. 1012-3 del Prometeo di Eschilo, in cui Ermes ricorda che l'av̉ $\theta \alpha \delta$ ía è inutile se non si accompagna alla saggezza ${ }^{44}$ ed ancora con i vv. 1036-8: qui, come si è anticipato, il Coro delle Oceanine, ormai alla fine della tragedia, invita Prometeo, figlio di Temi ỏ $\rho$ ó $\beta o v \lambda o \varsigma$ (v. 18), a deporre su consiglio di Ermes la sua $\alpha \cup ̉ \theta \alpha \delta i ́ \alpha$ e a

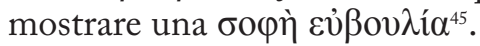

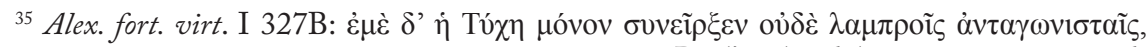

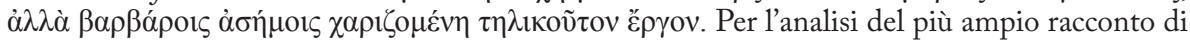
questo episodio contenuto nel secondo discorso cfr. infra, $\S 6$.

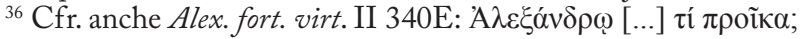

${ }^{37} \mathrm{Nei}$ due opuscoli Plutarco ribadisce più volte che l'opera di Alessandro si è potuta realizzare grazie alla sua virtù, perché senza di essa la fortuna nulla può: cfr. Alex. fort. virt. I 326E-F; II 335F, 336A, 336E, 337B-D, 339B, 340A.

${ }^{38} \mathrm{Cfr}$. Alex. fort. virt. I 329A-D, ma anche 328C-E. Per la funzione civilizzatrice dell'attività di Alessandro cfr. T. Duff, 1999, pp. 245, 301.

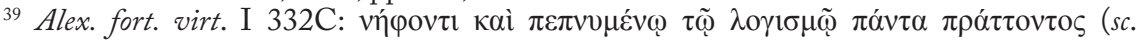
A $\lambda \varepsilon \xi \tilde{\alpha} v \delta \rho \circ)^{2}$.

${ }^{40}$ Cfr. nel Prometeo i vv. 11, 28, 123, 446. Sulla filantropia di Prometeo di molto limitata dalla sua $\alpha$ $\theta$ á $\delta \varepsilon 1 \alpha$ cfr. U. CURI, 2002, pp. 135-6; per la natura filantropica di Alessandro cfr. anche Alex. fort. virt. I 332D, II 333E; Alex. 58.8.

${ }^{41}$ Cfr. vv. $442-71$.

${ }^{42}$ Alex. fort. virt. II 333E. Cfr. per il modello di Eracle, accanto a quelli di Perseo e di Dioniso, anche Alex. fort. virt I 332A-B. Per l'identificazione di Alessandro con Eracle, suo antenato (Alex. fort. virt. II 334D; Alex. 2) con cui condivide l'ostilità della Fortuna (Alex. fort. virt. II 341D-E, F), cfr. anche W. Heckel \& J. C. Hardley (edd.), 2004, pp. 208-14; A. B. Bosworth, 1996, pp. 117-9. Per i modelli epici e tragici seguiti da Plutarco nella costruzione della figura di Alessandro nella sua biografia, in particolare quello di Achille, cfr. J. Mossmann, 1995 (1988) e infra, la n. 48.

${ }^{43} \mathrm{Cfr}$. Alex. fort. virt. I 332D; Alex. 26. 14; 58.2.

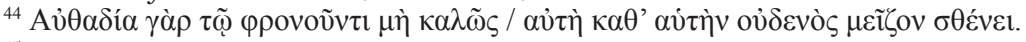

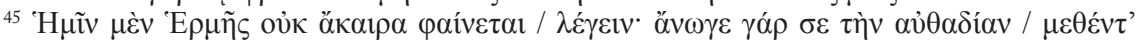

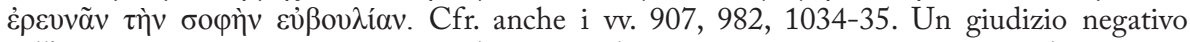

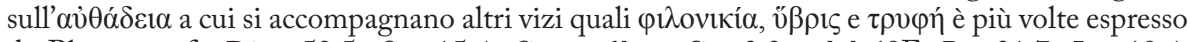
da Plutarco: cfr. Dion. 52.5; Cor. 15.4; Comp. Alc. et Cor. 3.3; adul. 69F; Per. 31.7; Lys. 19.4; Pomp. 60.4; praec. ger. reip. 816C; in particolare nel fr. *25 Sandbach, attribuito al Commentario 
Ma è nell'ultimo capitolo della seconda orazione che Plutarco sembra impegnato a costruire con più insistenza l'immagine titanica di Alessandro sul modello di quella prometeica, mentre la $\tau u ́ \chi \eta$ assume il volto tirannico dello Zeus della tragedia di Eschilo ${ }^{46}$. L'episodio qui rievocato è quello dello scontro con gli Ossidraci, ricordato da Plutarco anche altrove ${ }^{47}$ : la notevole elaborazione formale riservata al passo potrebbe essere una spia dell'importanza ad esso attribuita anche a livello ideologico nell'economia dell'opuscolo.

Plutarco ricorda che in quella occasione Alessandro fece la sua apparizione gettandosi fra i nemici con un terribile balzo dall'alto delle mura della città ed aggiunge: "A cosa si potrebbe paragonare Alessandro se non ad un fulmine scoppiato in cielo e abbattutosi con grande turbine di vento, come piomba sulla terra un'apparizione luminosa, corrusca di armi fiammanti?" ${ }^{48}$.

alle "Opere e giorni" di Esiodo, Plutarco, nel fornire la spiegazione del v. 7 dell'opera, sostiene che

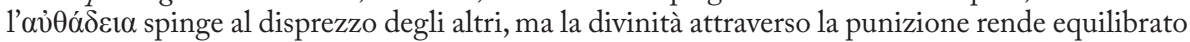
( $\mu \varepsilon ́ \tau \rho ı \varsigma)$ il carattere. Plutarco inoltre ricorda spesso l'affermazione di Plat., epist. 321c secondo

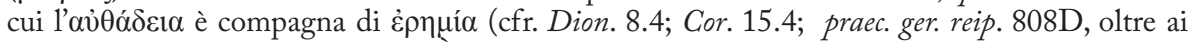
primi quattro luoghi sopra citati). E forse possibile pensare che in queste parole sia adombrato proprio il ricordo del destino di Prometeo?

${ }^{46}$ Cfr. per un quadro generale sulla tragedia I. Ramelli, 2008, pp. 154-9; I. RAmELLI, 2009, pp. 80-91.

${ }^{47}$ Cfr. anche Alex. fort. virt. I 327B; II 341C; Alex. 63. L'episodio, che risale al 325 a.C., è raccontato anche da Strab.,XV 1.38; D. S., XVII 99.2; Curt., IX 4; Arr., VI 10.1. Per l'oscillazione del nome della popolazione ora indicata come Malli ora come Ossidraci cfr. le osservazioni di M. R. Cammarota, 1998 (ed.), pp. 60-1, 280, n. 314.

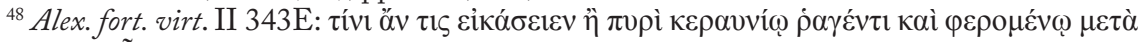

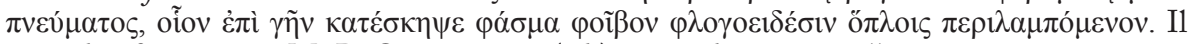
testo di riferimento è M. R. CAmmarota (ed.), 1998, da cui ci si allontana in un punto: nei codici dell'opuscolo è infatti trasmesso dopo $\varphi a ́ \sigma \mu \alpha$ il genitivo poíßov che viene accolto da F. C. Babbitt (ed.), 1936 e da W. NachstäDt (ed.), 1971 nella forma Фoíßov, corretto in Фóßov da D. Wyttenbach, 1796, p. 406 (seguito da C. Froidefond [ed.], 1990) o espunto da M. R. Cammarota (ed.), 1998, p. 280, n. 316 come glossa penetrata nel testo. Malgrado la plausibilità della correzione del Wyttenbach sulla base anche della precedente affermazione di Plutarco

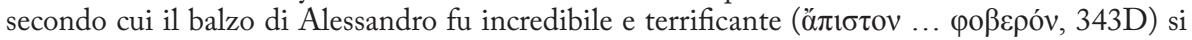
potrebbe pensare di correggere poíßov in poĩ $\beta$ ov sulla base di due considerazioni: innanzi tutto,

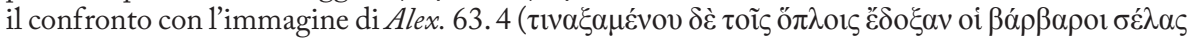

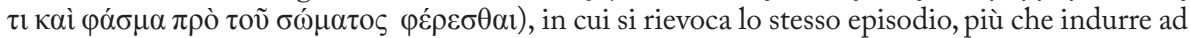
espungere il termine come ritiene la Cammarota, potrebbe far ipotizzare che, anche in questo caso, il sostantivo $\varphi \alpha ́ \sigma \mu \alpha$ fosse accompagnato da un altro termine a sottolineare la luminosità

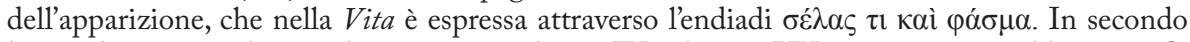
luogo il passo sembra riecheggiare, più che Il. IV 75-80 o XV 237 come vorrebbero sia C. Froidefond (ed.), 1990, p. 236, n. 6 sia M. R. Cammarota (ed.), 1998, p. 281, n. 317, l'episodio dell'apparizione di Achille sul fossato dopo la morte di Patroclo in Il.XVIII 202-227: Atena pone intorno alla testa dell'eroe una nube dorata e fa sprigionare dal suo corpo una fiamma splendente

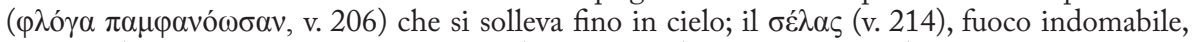

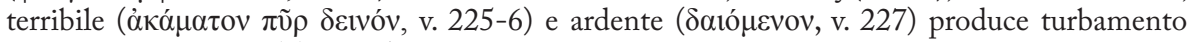
e paura tra le file dei Troiani (ma cfr. anche Il. XIX 375 ss. come propone J. M. Mossmann, 1995 [1988], p. 222, n. 19). La correzione proposta poĩßov, che concorrerebbe, insieme agli

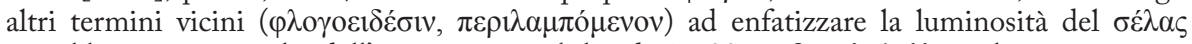

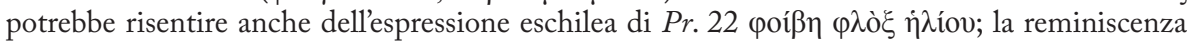
potrebbe essere stata favorita proprio ammettendo l'intenzione da parte di Plutarco di stabilire 
L'immagine del fulmine potrebbe rievocare il prodigio che si mostrò ad Olimpiade, la madre di Alessandro, la notte precedente a quella in cui furono consumate le nozze e che è ricordato da Plutarco in Alex. 2.3: "le sembrò di vedere, dopo lo scoppio di un tuono, che un fulmine le colpisse il ventre e che dalla ferita si alzasse un gran fuoco; da esso sprizzarono molte fiamme in direzioni diverse; poi il fuoco si spense" ${ }^{49}$.

Nel De fortuna la sapienza tecnica che Prometeo ha diffuso tra gli uomini è rappresentata proprio dalla fiamma le cui scintille si diffondono in diverse direzioni ${ }^{50}$, una immagine coerente con quella offerta da Anneo Cornuto, Comp. Theol. gr. 18 $8^{51}$; quindi se la visione di Olimpiade può essere una rappresentazione simbolica della forza civilizzatrice delle future imprese di Alessandro, la sua apparizione tra gli Ossidraci come un $\varphi \alpha ́ \sigma \mu \alpha$ luminoso potrebbe richiamare l'immagine presente in Aesch., $\operatorname{Pr}$. 921-3 nella profezia di Prometeo del $\delta v \sigma \mu \alpha \chi \omega ́ \tau \alpha \tau o v ~ \tau \varepsilon ́ p \alpha \varsigma$ che, con una fiamma più potente della folgore e con un fragore più forte del tuono, si imporrà su Zeus ${ }^{52}$. Alessandro potrebbe pertanto rappresentare la figura preconizzata dal Titano che comparirà sulla terra per piegare la forza della Necessità, identificabile nell'opuscolo con la fortuna avversa. Nella costruzione retorica dell'episodio dello scontro con gli Ossidraci, ad esempio, si possono individuare degli altri elementi che farebbero pensare al modello prometeico: Alessandro appare bloccato come Prometeo in una regione oscura e barbara, ${ }^{53}$ solo e senza aiuto come una fiera in una rete ${ }^{54}$,

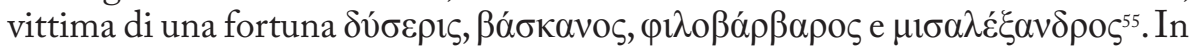

una identità tra Prometeo e Alessandro attraverso la metafora del fulmine, mediata dal modello dell'Achille omerico.

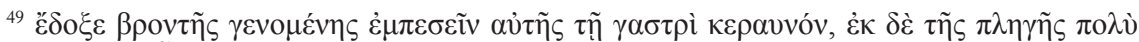

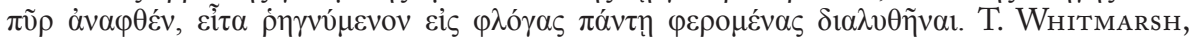
2002 , p. 186-8, sottolinea gli aspetti dionisiaci di questa scena, che rimanda alla nascita del dio; Alessandro porterebbe in sé le tracce di una componente dionisiaca che neppure la paideia riuscirà a moderare e che esploderà al contatto con il mondo orientale (cfr. infra, p. 225, nn. 83, 86; p. 228, n. 105).

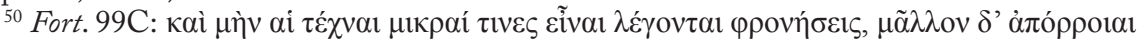

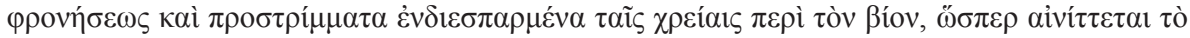

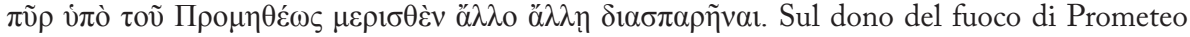
cfr. anche R. BeEs, 1999.

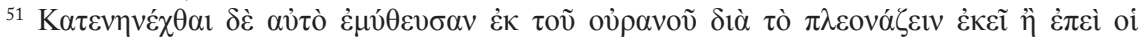

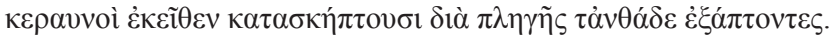

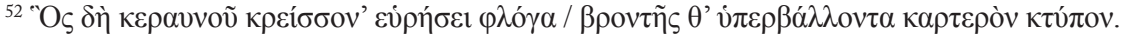

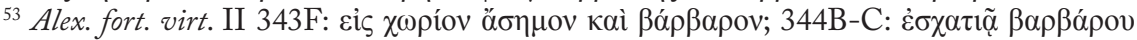

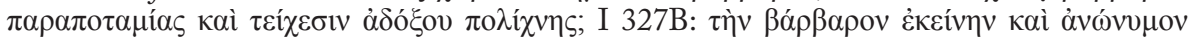

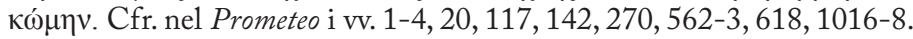

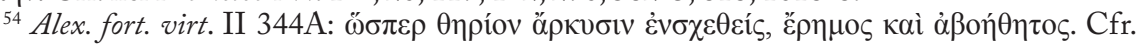
nel Prometeo i vv. 1071-9 in cui Ermes si serve della metafora della rete di sventura per indicare la condizione di chi ribellandosi incappa nella punizione di Zeus. Sulla base dei dati linguistici forniti dai testimoni a partire dai poemi omerici R. B. OnIans, 2006 (1954), pp. 385-416, part. 397-405, 410, sostiene che nell'immaginario greco l'azione del fato e degli dèi nella vita umana era rappresentata dalla rete che imbriglia e dal laccio che blocca.

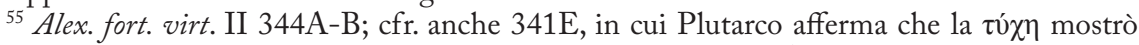
la sua ostilità litigiosa, intollerabile e implacabile nei confronti di Alessandro come aveva fatto

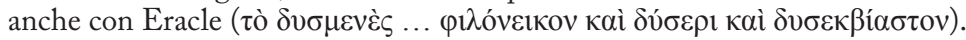


particolare l'immagine della freccia conficcata nella corazza che rimane come

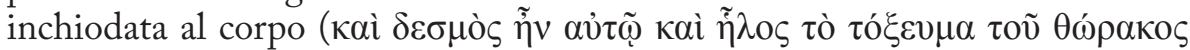
$\pi \rho \grave{\varsigma} \varsigma \tau$ ò $\sigma \tilde{\omega} \mu \alpha, 344 \mathrm{~F}$ ) potrebbe rievocare la scena iniziale del Prometeo con Kratos e Bia che fissano alla rupe del Caucaso il corpo di Prometeo ${ }^{56}$; essa è forse richiamata per contrasto nella scena finale del tentativo dei compagni di estrarre la punta rimasta conficcata nel petto del loro generale ${ }^{57}$.

Plutarco ricorre con una certa insistenza a termini afferenti al campo semantico della immobilità con cui voleva forse rappresentare la condizione dell'anima sepolta nella materia e legata alle passioni: ad esempio al cap. 7

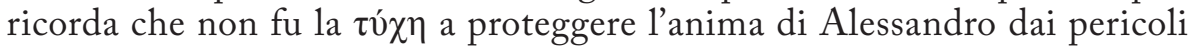
del piacere e dei desideri dopo averla serrata nel corpo, perché il controllo delle passioni era ascrivibile soltanto alla sua formazione e alla sua forza di volontà ${ }^{58}$. In questo modo l'autore ribadisce la necessità di un esercizio morale che liberi l'uomo dalle catene della carne attraverso la virtù ${ }^{59}$. In particolare Plutarco doveva avere in mente il Platone di Phaed. 82e-84b: qui Socrate spiega a Simmia e Cebete che l'anima è sepolta nel corpo come in un carcere da cui guarda a fatica fuori, ingannata da sensazioni come il piacere e il dolore che la conficcano a mo' di chiodo sempre più nel fondo della carne (83d) ${ }^{60}$; l'unico strumento per liberarsi da questa condizione è la filosofia che allontana piaceri, passioni, dolori e paure sciogliendo e liberando l'anima dal grave peso della materia (83a-c). A questo punto anche il finale del primo opuscolo che, come si vedrà fra poco, si chiude con una celebrazione della funzione liberatoria della filosofia potrebbe riecheggiare

${ }^{56}$ Per l'uso di $\delta \varepsilon \sigma \mu$ óv nel Prometeo cfr. i vv. 6, 52, 97, 113, 141, 154, 175-6, 509, 513, 525 , $770,991,1006$.

${ }^{57}$ Tra le imprese che Alessandro ascrive a suo grande successo c'è proprio, come un nuovo Eracle, il superamento del Caucaso (Alex. fort. virt.I 328F; II 335E); la propaganda filomacedone favorì la confusione tra il Caucaso scitico, dove fu inchiodato Prometeo poi liberato da Eracle, e l' Hindu Kush in India superato da Alessandro nel 329 a.C.; in questo modo la figura di Alessandro veniva assimilata al suo mitico antenato, mentre quella di Prometeo sconfitto sul Caucaso da Zeus retrocedeva a modello imperfetto, proprio perché $\alpha$ v̉ $\dot{\delta} \delta \eta \varsigma$ : per le fonti antiche cfr. Str., XI 5; XV 1.8; Arr., V 2; W.W. TARn, 1948, pp. 58-59; I. Worthington, 2003, p. 6.

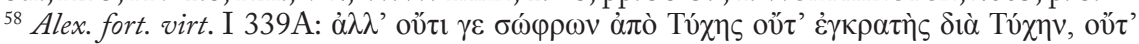

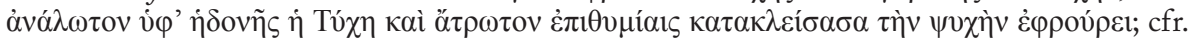

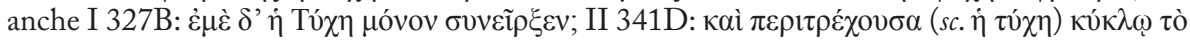

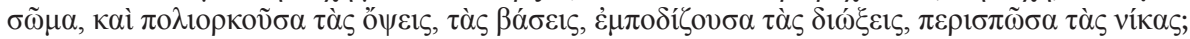

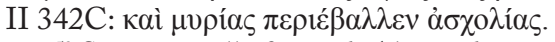

${ }^{59} \mathrm{Si}$ oppone alla figura di Alessandro quella di Filota che non riusciva a tenere sotto controllo

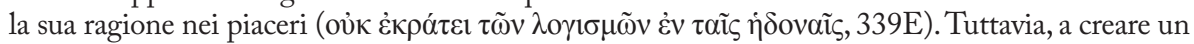
ritratto complesso e 'paradossale' del personaggio va sottolineato che in Alex. 16.14 l'eroe appare

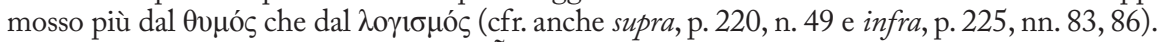

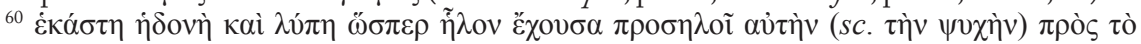
$\sigma \tilde{\omega} \mu \alpha$. Plutarco allude al testo platonico anche in quaest. conv. $718 \mathrm{D}$, in cui si afferma che, mentre il chiodo del piacere e del dolore, con il quale l'anima viene conficcata nel corpo ( $\pi \rho \mathrm{ò}_{\varsigma}$ $\tau$ ò $\sigma \tilde{\omega} \mu \alpha)$, rende più evidenti le cose sensibili, sono le scienze, in particolare la geometria, a permettere la conoscenza degli enti intellegibili. Proprio la presenza del sintagma $\pi \rho \mathrm{ò}_{\varsigma} \tau$ ò $\sigma \tilde{\omega} \mu \alpha$ in Alex. fort. virt. II $344 \mathrm{~F}$ potrebbe essere una spia del modello platonico a cui qui Plutarco allude e che invece in quaest. conv. $718 \mathrm{D}$ è citato in maniera letterale. 
questo stesso passo platonico, in una costruzione perfettamente speculare dei due testi.

Nel Prometeo, in cui è costantemente sottolineata la fissità della posizione di Prometeo inchiodato al Caucaso anche rispetto alla mobilità del Coro delle Oceanine e alla frenesia di Io, il Titano descrive questa condizione di immobilismo della coscienza attraverso la metafora della cecità (vv. 447-8): prima del suo intervento gli uomini pur guardando non vedevano e pur ascoltando non udivano ottenebrati dalla dimensione materiale a cui erano incatenati ${ }^{61}$. Ugualmente Plutarco al cap. $3(336 \mathrm{~B})^{62}$, dopo aver sostenuto che la Fortuna attribuisce il potere e le cariche a uomini stolti che non sono in grado di esercitarli, la qual cosa dimostra che solo la virtù rende grande e nobile un uomo, conclude il suo ragionamento con la citazione dello stesso frammento di Epicarmo presente in fort. 98B 63 ; se è vero, infatti, che la mente vede e ascolta, tutto il resto al contrario, sordo e cieco, ha bisogno della ragione

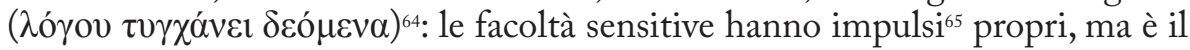
pensiero a giovare e a dare equilibrio, in quanto principio egemone, dominante e sovrano; il resto "cieco e sordo, cioè senz'anima, trascina, grava e disonora quelli che ne sono in possesso in assenza di virtù" ${ }^{6}$.

${ }^{61} \mathrm{Cfr}$. anche i vv. 546-50.

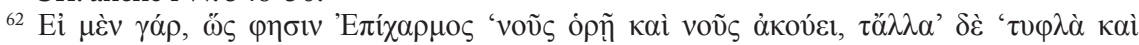

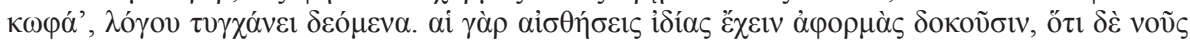

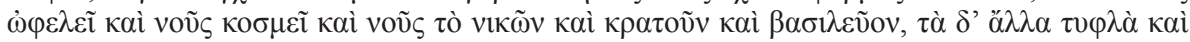

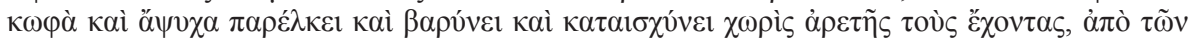

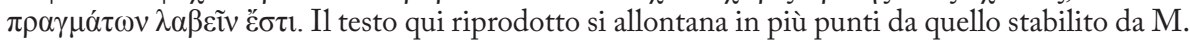
R. CAmmarota (ed.), 1998. Nelle note successive si darà conto delle scelte operate in relazione al ragionamento che si sta svolgendo; qui si può preliminarmente osservare che nella citazione di Epicarmo il $\delta \dot{\varepsilon}$ trasmesso dai codici è dovuto all'intervento di Plutarco e non è necessario espungerlo (cfr. anche C. Froidefond [ed.], 1990).

${ }^{63}$ Lo stesso frammento è citato anche in soll. anim. 961A.

${ }^{64}$ L'espressione $\lambda o ́ \gamma o v ~ \tau v \gamma \chi \alpha ́ v \varepsilon \varepsilon$ $\delta \varepsilon o ́ \mu \varepsilon v \alpha$ è esplicativa dell'affermazione di Epicarmo "tutto il resto è cieco e sordo"; non appare convincente la scelta testuale di M. R. CAmmarota (ed.), 1998, pp. 206-8, n. 92, che preferisce il participio $\delta \varepsilon o ́ \mu \varepsilon v o v$ intendendo "ci si trova ad aver bisogno della parola”. infatti, le cose cieche e sorde di cui parla Epicarmo sono per Plutarco le $\alpha i \sigma \theta \eta \dot{\sigma \varepsilon ı \iota \varsigma ~ c h e ~ h a n n o ~ b i s o g n o ~ d e l l a ~ r a g i o n e, ~ c i o e ̀ ~ d e l ~ g o v e r n o ~ d e l ~ v o u ̃ c . ~ Q u e s t a ~ i n t e r p r e t a z i o n e ~}$ sembra confermata proprio dal confronto con fort. 98B-C, in cui Plutarco spiega che se l'uomo non avesse il voũ $\varsigma$ e il $\lambda$ ó $\gamma$ o $\zeta$ in niente differirebbe dalle bestie con le quali condivide le sensazioni. Anche in Alex. 27.10 è ipotizzabile che Plutarco avesse presente queste idee: infatti egli dice che Alessandro accolse con piacere le parole del filosofo egiziano Psammone secondo cui "è divino

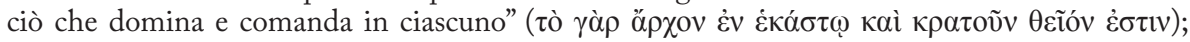
questa espressione appare molto somigliante a quella usata da Plutarco in questo passo di Alex. fort. virt. II per spiegare il senso della prima parte del verso di Epicarmo relativo al voṽ $\zeta$ definito

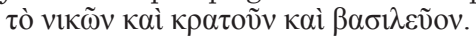

${ }_{65}$ Mentre M. R. Cammarota (ed.), 1998, p. 208, n. 93, preferisce accogliere la lezione

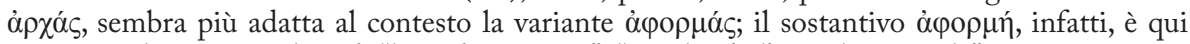
usato con il comune valore di "base di partenza", "ciò che dà l'impulso iniziale".

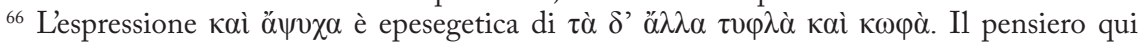
espresso è coerente con quanto affermato in fort. $99 \mathrm{~F}$ (cfr. supra, § 3) e la somiglianza è

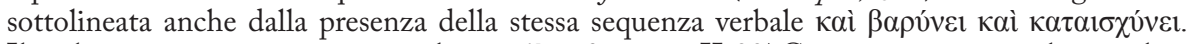

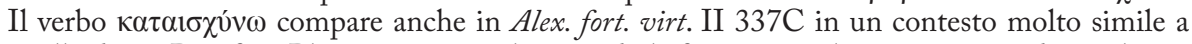
quello di 336B; infatti Plutarco osserva che quando la fortuna innalza un uomo mediocre, la sua 
Anche le parole finali pronunciate da Alessandro, che di fronte ai suoi compagni in lacrime dichiara di non temere la morte, potrebbero essere modellate su quelle di Prometeo rivolte ad Ermes nei vv. 959-6167 e 1002-668, con le quali afferma di non avere paura della divinità né di aver intenzione di chiederle di liberarlo dai ceppi in cui è legato. Nelle ultime battute della tragedia (vv. 1089-90) si sottolinea in particolare il terrore ( $\varphi$ óßos) che si accompagna alla punizione di Zeus, attesa impassibile da Prometeo ${ }^{69}$; potrebbe dunque non essere casuale il fatto che entrambi gli opuscoli plutarchei terminino con

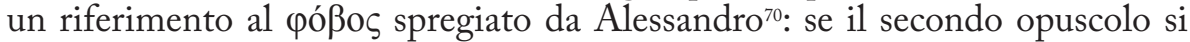
conclude, infatti, con l'invito di Alessandro ai suoi fidi compagni ad estrarre la punta della lancia dal suo petto perché egli non teme, diversamente da loro, la sua morte ${ }^{71}$, il primo riconduce il carattere impavido dell'eroe agli effetti della formazione filosofica e sembra rientrare in una riflessione di più ampio respiro sul rapporto tra teoresi e prassi.

Plutarco nel cap. $12^{72}$, conclusivo del primo opuscolo, propone di mettere a confronto le azioni dei filosofi con quelle di Alessandro ${ }^{73}$ e da questa synkrisis l'azione politica non appare affatto inferiore alla riflessione filosofica: ciò che distingue un uomo comune da un filosofo è che nel primo le capacità razionali e i giudizi possono essere bloccati dal póßos, mentre il secondo è in grado di

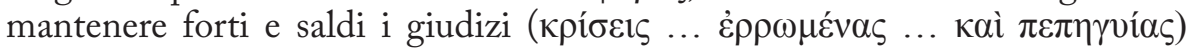
soprattutto nelle avversità, perchè è la filosofia a mettere i lacci intorno alle scelte, alle ambizioni e agli impulsi. La funzione della filosofia infatti è di eliminare le paure e controllare le passioni conferendo stabilità ed equilibrio ai comportamenti; questa idea è espressa da Plutarco attraverso la metafora del

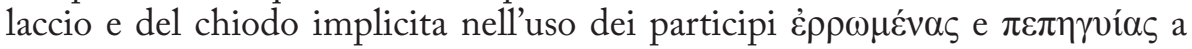

caduta diventa ancora più disonorevole. In questo caso però prevale l'immagine della leggerezza dell'individuo che, non avendo salde basi morali, inciampa e ondeggia nell'incapacità di gestire i beni che ha ricevuto. In 336B, al contrario, la presenza di $\beta \alpha \rho v ́ v \omega$ sembra alludere ad una ottusa dipendenza dalle sensazioni che spinge verso il basso l'individuo legandolo alla materia.

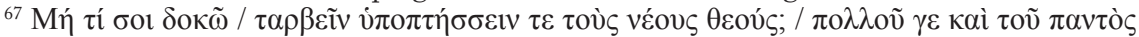
$\dot{\varepsilon} \lambda \lambda \varepsilon \dot{\varepsilon} \pi \omega$.

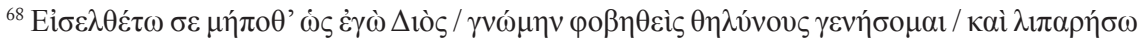

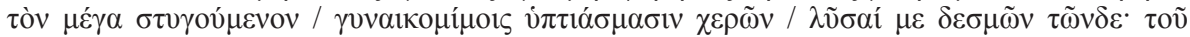
$\pi \alpha \nu \tau$ ò $\zeta \delta \dot{\varepsilon} \omega$.

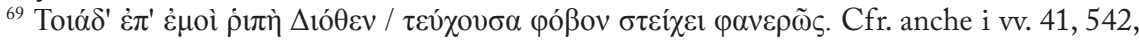
930, 958-60, 1003; per il timore del Coro delle Oceanine cfr. invece i vv. 144, 181-2, 691, 696, 931.

${ }^{70} \mathrm{Cfr}$. anche [De Hom.] 135. Per un Alessandro in preda al póßos cfr. invece Alex. 75. 1-2.

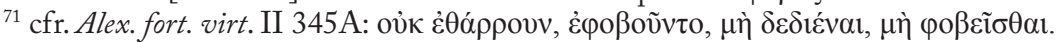

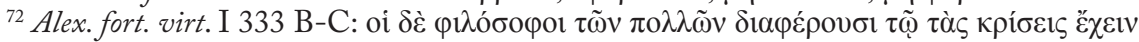

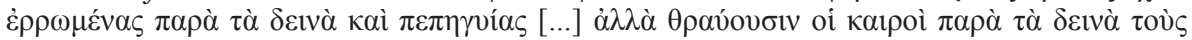

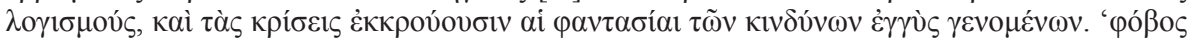

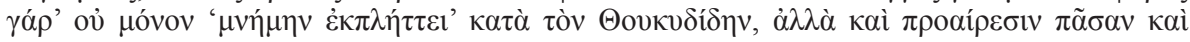

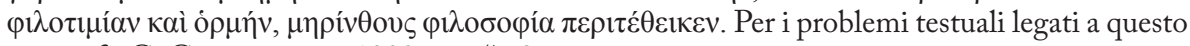
passo cfr. G. GiANGRANDE, 1992, pp. 57-8.

73 Il tema era comunque già ampiamente sviluppato nei capp. 4-6 (327E - 329D) dell'opuscolo: cfr. A. D'Angelo (ed.), 1998, pp. 21-7 e il suo commento, pp. 172, nn. 1-2; 181, n. $19 ; 182$, n. 21. 


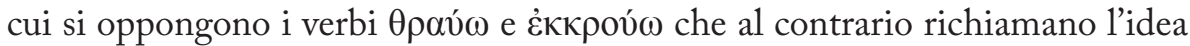
della separazione violenta e dello strappo ${ }^{74}$. Plutarco potrebbe aver attinto di nuovo a Plat., Phaed. $82 \mathrm{c}-84 \mathrm{~b}$, di cui prima si è vista la presenza nel finale del secondo opuscolo per l'immagine del chiodo, ma stavolta ribaltando l'uso delle metafore: se infatti in Platone è la filosofia a liberare ( $\lambda v ́ \varepsilon ı v, 83 a, 84 a)$

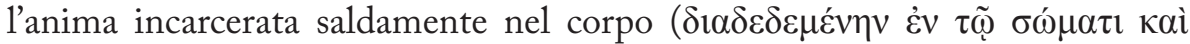
$\pi \rho о \sigma \kappa \varepsilon \kappa о \lambda \lambda \eta \mu \varepsilon ́ v \eta \nu, 82 \mathrm{e})$ e che tende a stringersi sempre di più alla carne

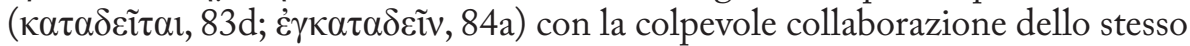

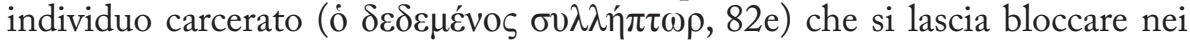
ceppi dei piaceri, in Plutarco al contrario essa è vista nell'atto di legare con corde e rendere stabili le scelte, le ambizioni e gli impulsi eliminando il $\varphi$ óßos che anche per Platone contraddistingue la vita dei $\pi 0 \lambda \lambda$ oì, ma non dei filosofi i quali non temono alcun tipo di passione (82c) e si tengono lontani da piaceri, dolori e paure (83b, 84b).

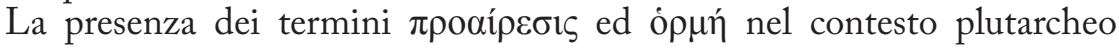
svela inoltre il sostrato filosofico ${ }^{75}$ alla base dell'opuscolo che, a questo punto, è riduttivo ritenere solo un pezzo di bravura retorica ${ }^{76}$. Il modello offerto da Prometeo potrebbe dunque assumere un valore che va ben al di là delle esigenze retoriche: benefattore dell'umanità in quanto ha donato agli esseri

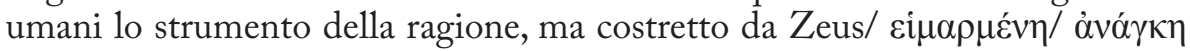
a rimanere legato ad una roccia, Prometeo poteva rappresentare la condizione umana su un piano, per così dire, ontologico; se infatti una divinità benevola ha sparso i semi del $\lambda$ ó $\gamma o \zeta$ nell'uomo, quest'ultimo rimane tuttavia legato alla materia e alle $\dot{\varepsilon} \pi \theta v \mu \dot{a}_{\alpha}$ fonti per lui di mali e sciagure ${ }^{77}$. Egli deve pertanto, con uno sforzo prometeico, liberarsi dai vincoli della materia attraverso il sapere filosofico ${ }^{78}$, che per Plutarco trova la sua più alta realizzazione quando si converte in un'azione saggia e razionale, in particolare nell'attività politica.

Pertanto all'Alessandro posto sullo stesso piano dei filosofi perchè capace di dominare la $\tau u ́ \chi \eta$ attraverso i lacci della ragione nel finale del primo opuscolo, corrisponde nella conclusione del secondo l'Alessandro imprigionato nella sua armatura gravemente ferito e che, come un filosofo in limine mortis, pronuncia

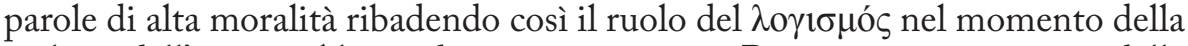
scelta e dell'azione. Alessandro come un nuovo Prometeo imprigionato dalla

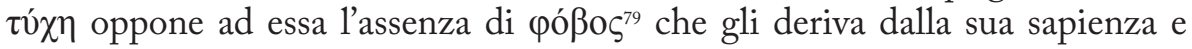

${ }^{74} \mathrm{Cfr}$. per il valore di questi verbi anche Ant.17.4; Pyrrh. 30.5 .

${ }^{75}$ Cfr. Arist., EN III 1112a 15-7, ma anche SVF I 216, 11. 33-35.

${ }^{76}$ Come si è visto (cfr. supra, n. 27), i due sostantivi sono utilizzati dall'anonimo autore del De fato in $571 \mathrm{D}$ per indicare l'azione dell'uomo frutto di scelta libera e personale ( $\dot{\varepsilon} \varphi$ '

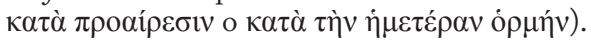

${ }^{77} \mathrm{La}$ difficoltà di estirpare il male e i comportamenti scorretti è ben presente a Plutarco ed anche in questo caso la riflessione più matura condotta nella Vita dedicata ad Alessandro tenderà a mettere in evidenza le ombre e le contraddizioni dell'eroe: cfr. T. Duff, 1999, p. 65; L. Prandi, 2000, pp. 385-6.

${ }^{78}$ Cfr. F. Becchi, 1999; F. Becchi (ed.), 2010, pp. 23-8.

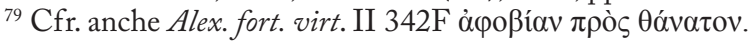


in particolare dalle sue esperienze ${ }^{80}$, ma rispetto al Titano è dotato anche di

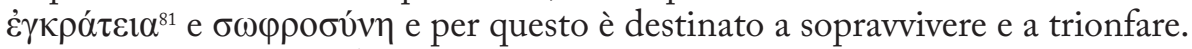
La natura di бoøó $\varsigma$ di Alessandro era del resto dichiarata nel cap. 11 del primo opuscolo (332C-D), perché proprio come il sapiente stoico egli era in possesso di tutte le virtù (coraggio, giustizia, moderazione, mitezza, disciplina, giudizio, filantropia $)^{82}$, a cui è improntato il suo agire politico.

\section{Alessandro, un modello problematico per i Romani?}

Alla luce dell'analisi fin qui condotta gli opuscoli De fortuna e De Alexandri Magni fortuna aut virtute I e II, al di là del ricco apparato retorico che li caratterizza, sembrano costituire momenti di una riflessione coerente sulla superiorità dell'attività pratica rispetto alla filosofia o, meglio, sull'attività pratica come completa realizzazione della riflessione filosofica ${ }^{83}$, tema che del resto li accomuna ad un altro testo di stampo retorico come il De gloria Atheniensium ${ }^{84}$.

Alessandro Magno doveva servire dunque a Plutarco per proporre un $\pi \alpha \rho \alpha ́ \delta \varepsilon i \gamma \mu \alpha$ di uomo attivo, impegnato ad affermarsi nella storia con le sue qualità, in lotta con la fortuna e padrone del suo destino, ma a prezzo

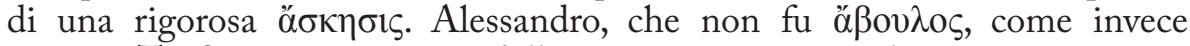
riteneva Teofrasto ${ }^{85}$, ma si servì delle sue virtù per vincere la $\tau u ́ \chi \eta$, rappresenta l'incarnazione di un ideale di agire politico improntato ad una virtù che si fa concretamente $\varepsilon u ̉ \beta o v \lambda i ́ \alpha$ attraverso la $\pi \alpha \imath \delta \varepsilon i \alpha^{86}$; egli poteva perciò costituire un ottimo modello anche per gli uomini politici ${ }^{87}$, se in numerosi luoghi

${ }^{80}$ Cfr. Alex. fort. virt. I 328A, in cui Plutarco sostiene che la formazione "filosofica"

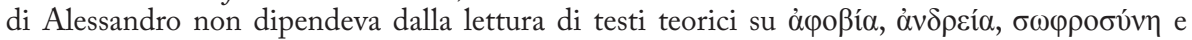
$\mu \varepsilon \gamma \alpha \lambda$ o $\psi v \chi \chi_{i} \alpha$. L'elenco delle ferite che compare in entrambi gli opuscoli, oltre a rispondere ad una esigenza di amplificazione retorica (cfr. M. R. CAmmarota, 2000, p. 71) potrebbe sottolineare la formazione morale avuta sul campo da Alessandro che, attraverso la dura esperienza del dolore, come Prometeo, impara quale sia il ruolo e la dignità dell'uomo nella storia (su questo aspetto della tragedia di Eschilo cfr. almeno W. C. Scotт, 1998-1999).

${ }^{81}$ Cfr. M. D. Sмith, 2003/2004.

${ }^{82} \mathrm{Cfr}$. anche Alex. fort. virt. II 337B, 338E, 339B, 342E-F, 343A-B. Per queste virtù stoiche cfr. fort. 97E, oltre a Stoic. rep. 1034C; virt. mor. 440F; D. BABut, 2003 (1969), pp. 95-6.

${ }_{83}$ M. van RaAlte 2005, ha sottolineato l'importanza attribuita da Plutarco alle qualità personali e alle circostanze esterne nella formazione dell'uomo politico, pur senza sminuire la formazione filosofica; S.-T. TEodorsson, 2008, parla di un atteggiamento più realistico nelle Vite rispetto alla creazione di una immagine di sapiente idealizzata nei Moralia.

${ }^{84}$ Per la datazione di questo opuscolo solitamente ascritto all'età giovanile cfr. K. Ziegler, 1965, p. 115; contra, cfr. F. Frazier (ed.), 1990, pp. 166-7.

${ }^{85}$ Cfr. A. D'Angelo (ed.), 1998, pp. 173-4.

${ }^{86}$ Cfr. [mus.] 1131C. Sulla paideia di Alessandro cfr. G. Santana Henríquez, 2005. T. Whitmarsh, 2002, pp. 186-92, ha tuttavia evidenziato come nella Vita la paideia ellenica di Alessandro finisca per soccombere al fascino del barbarico con tutte le connotazioni negative che lo caratterizzano, in particolare la dismisura morale, assecondando una inclinazione naturale dell'eroe, che appare così un personaggio 'di confine' tra occidente ed oriente, tra civiltà e barbarie (cfr. anche supra, pp. 220-1, nn. 49, 59; p. 228, n. 105).

${ }^{87}$ Per il valore ideologico assunto dalla figura di Alessandro nel dibattito politico d'età imperiale cfr. almeno G. Zecchini, 1984; D. Plácido, 1990; D. Plácido, 1995; C. Mossè, 2003. 
del corpus Plutarco ricorda appunto l'ev̉ßovגía tra le qualità necessarie per svolgere in maniera corretta l'attività politica; si può citare il caso di an seni

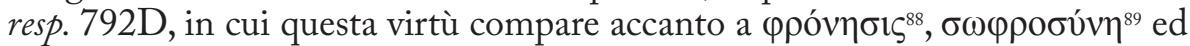

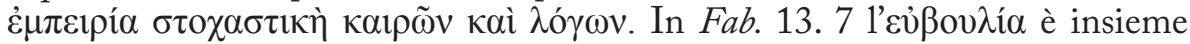

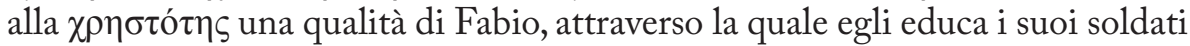
e il collega Minucio ${ }^{90}$ e in Mar. 7.3 essa fa il paio con la $\pi \rho o ́ v o r \alpha^{91}$; è infine

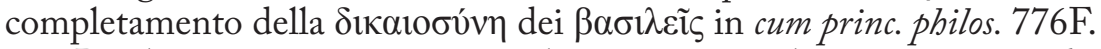

Risulta a questo proposito molto interessante la testimonianza di Crass. 27. 6: qui, subito dopo un disastroso attacco contro i Parti in cui ha perso il figlio, il generale appare solo, isolato e in preda all'angoscia, "un esempio per i più della forza della $\tau u ́ \chi \eta$, ma per chi è saggio di sconsideratezza e ambizione" ${ }^{92}$. Anche in questo caso, dunque, Plutarco ribadisce la centralità della colpa umana rispetto alle accuse rivolte alla fortuna, sottolineando come l'insuccesso

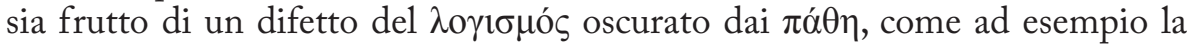
$\varphi \imath \lambda o \tau \iota \mu i^{93}$. Ed ancora nella Comp. Thes. et Rom. 3.1 Plutarco sostiene che le disgrazie non vanno attribuite completamente alla fortuna e che le loro origini vanno ricercate nei comportamenti e nelle passioni di ognuno, le quali possono

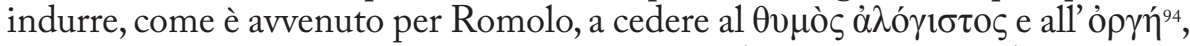
cui si accompagna una scelta rapida e avventata ( $\tau \alpha \dot{\chi} \chi 0 \varsigma$... $\not ß \beta o v \lambda o v)$. Di fronte a questi esempi brilla ancora di più quello positivo fornito da Alessandro che, pur essendo incline alle passioni, seppe far trionfare la virtù su di esse ${ }^{95}$.

Se dunque Alessandro funge da modello di comportamento politico, è a questo punto possibile chiedersi che valore assuma la sua presenza nell'ultimo capitolo del De fortuna Romanorum, un altro opuscolo dedicato all'indagine

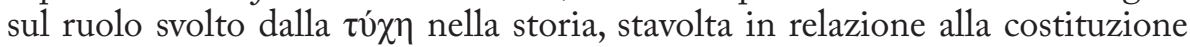
della potenza di Roma ${ }^{96}$. Anche se Plutarco in apertura sostiene che l'impero

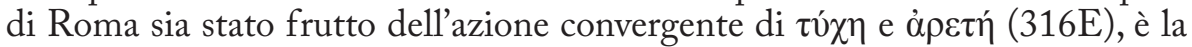
celebrazione della $\tau u ́ \chi \eta$, causa principale dell'incredibile successo del popolo romano, a costituire poi il tema centrale dellopuscolo. Pur essendo aperto il dibattito circa la possibilità che il testo pervenuto sia mutilo e che nella parte mancante si desse ampio spazio alla celebrazione della virtù dei Romani, secondo la tecnica della synkrisis tipica delle esercitazioni retoriche ${ }^{97}$, non è fuori luogo

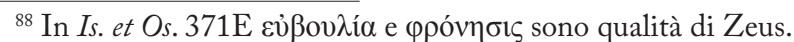

${ }^{89} \mathrm{Su}$ questa virtù cfr. T. Duff, 1999 , pp. 77-8.

${ }^{90} \mathrm{Cfr}$. anche Fab. 1.6.

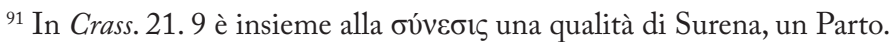

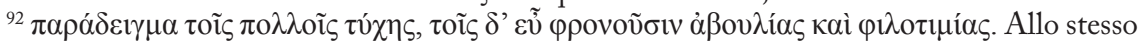

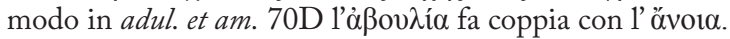

${ }^{93} \mathrm{Su}$ questa come su altre passioni che un eroe/uomo politico deve imparare a controllare cfr. almeno T. Duff, 1999, pp. 75, 83-9.

${ }^{94} \mathrm{Su}$ questi $\pi \dot{\alpha} \theta \eta$ cfr. ancora T. Duff, 1999, 73, 87-9.

95 Sul principio del controllo delle passioni più che sulla loro totale eliminazione cfr. D. Babut, 2003 (1969), pp. 359-60; F. Becchi, 2005; F. Ferrari 2008.

${ }^{96}$ Per il problema della datazione e della pubblicazione del De fortuna Romanorum cfr. M. RAIMONDi, 2005.

${ }^{97}$ Per la struttura del testo e la questione della sua presunta incompiutezza cfr. M.R. Cammarota, 2002. 
ipotizzare che l'opuscolo terminasse proprio con un improvviso riferimento alla sorte di Alessandro Magno, che poteva acquistare un particolare valore se posto in relazione con altri testi più o meno coevi e afferenti allo stesso genere della declamazione, la qual cosa dimostrerebbe che, malgrado la natura scolastica di queste composizioni, anche esse rientravano in un ben meditato progetto culturale e politico.

Come è stato recentemente osservato ${ }^{98}$, malgrado la evidente valutazione positiva dell'impero romano in un'opera che si presenta come un vero e proprio encomio "della più straordinaria delle realizzazioni umane" (316E), non si può escludere che un testo come il De fortuna Romanorum potesse assumere un significato tutt'altro che univoco; anzi, è proprio la sua alta sofisticazione retorica a giustificare una possibile lettura a più livelli ${ }^{99}$, mutevole sia in relazione all'occasione della performance sia rispetto al macrocontesto del corpus

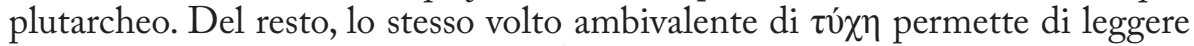
nel finale dell'opuscolo la morte di Alessandro, destinato a conquistare anche l'Occidente se essa non si fosse a lui opposta, come una sventura occorsa alla grecità, ma contemporaneamente come evento provvidenziale per Roma; dunque senza mettere in discussione il potere assunto da questa città, che risponde ad un progetto superiore di ordine e di armonia di natura senza dubbio divina ${ }^{100}$, Plutarco non rinuncia tuttavia a sottolineare in più punti che

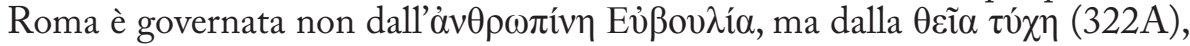
e che i Romani non costruirono templi ad Eủßov $\lambda i ́ \alpha$ e ad A $A \delta \rho \varepsilon i ́ \alpha$, ma a $\Phi \eta \dot{\mu \eta}$ e a K $\lambda \eta \delta \omega ́ v(319 A)$, mentre si ebbero quelli in onore della Virtus e di Mens solo tardi, e come diretta conseguenza della diffusione nella città dell'arte retorica e delle sottigliezze sofistiche dei Greci $(322 \mathrm{C})^{101}$, ma non ne furono

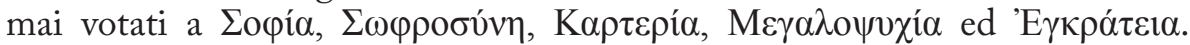
Proprio queste ultime sono le virtù di Alessandro Magno ${ }^{102}$ che gli garantirono la realizzazione di un impero universale portatore di pace e civiltà, prima che il suo astro tramontasse.

La figura di Alessandro è spesso connessa nella Vita come nei due opuscoli a lui dedicati ad immagini di luce e di fuoco, che richiamano attraverso una

\footnotetext{
${ }^{98}$ T. Duff, 1999 , pp. 300-1.

${ }^{99} \mathrm{C}$ fr. per questa modalità di lettura dei testi di età imperiale, in particolare quelli di Dione Crisostomo, T. Whitmarsh 1998, part. pp. 206-13.

${ }^{100}$ Cfr. S. Swain, 1989a, passim, part. 507; S. Swain, 1989b; L. Torraca, 1996, pp. 136, 140; M. R. Cammarota, 2002, pp. 150-1.

${ }^{101}$ Questo elenco di templi compare nel corso dell'opuscolo due volte con lievi divergenze testuali ai capp. 5 (318D-E) e 10 (322C-D); è difficile stabilire se si tratti di una prova evidente dell'incompiutezza dell'opera, che non avrebbe ricevuto la revisione finale da parte dell'autore (come vorrebbe S. Swain, 1989a, p. 505) o piuttosto di una voluta ripetizione: sulla questione cfr. M.R. Cammarota, 2002, 153-6. Il riferimento alla tarda diffusione a Roma del culto di valori personificati come la Virtus e la Mens, attribuibili all'influenza del pensiero greco ridotto a sottigliezza sofistica dall'autore, che potrebbe assumere qui ironicamente il punto di vista del pubblico romano, costituiva forse una implicita polemica con la cultura latina considerata debitrice di quella greca, dalla quale però non è riuscita ad assimilare completamente il culto di quelle virtù che costituiscono il vertice della formazione umana e spirituale.

${ }^{102}$ Cfr. anche Alex. 4. 8; 30.11.
} 
fitta rete di allusioni letterarie le figure di Achille, Eracle, Dioniso, e, come si è cercato di dimostrare, anche di Prometeo. Anche in fort. Rom. 326A-B, proprio sul finire dell'opuscolo, Plutarco afferma che Alessandro, mosso da coraggio invincibile e da un alto sentire, si distese da oriente ad occidente lanciando i bagliori delle sue armi come un astro luminoso ${ }^{103}$. La similitudine con il moto della stella potrebbe sottolineare da un lato il carattere necessitato dell'azione di Alessandro, quasi che essa rispondesse ad un piano più alto, dall'altro l'intrinseco ed inevitabile destino di morte che la accompagnava.

In Alex. fort. virt. I 330D addirittura Plutarco prospetta la possibilità che se l'eroe non fosse morto così presto avrebbe ridotto tutta l'umanità sotto la sua legge e la sua giustizia, irradiandosi come luce sull'intero universo, mentre a causa della sua prematura scomparsa una parte del mondo, non avendo conosciuto Alessandro, è rimasta priva della luce del sole ${ }^{104}$. Il confronto con le affermazioni di fort. Rom. 326A-B permette di ipotizzare che per Plutarco il trionfo di Roma, che pure è da ascrivere ad una

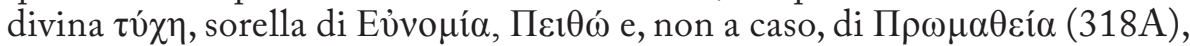
fosse subordinato proprio alla sorte crudele che impedì ad Alessandro di volgersi ad occidente. Tuttavia il fallimento della sua impresa deve essere

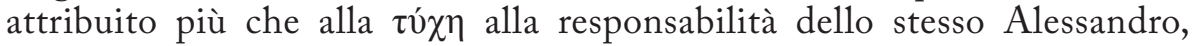
vittima di passioni che sfuggirono al controllo della paideia. Le immagini del fulmine e dell'astro cadente potevano infatti alludere anche alla natura di Alessandro soggetta a infiammarsi per una propensione naturale a sentimenti smisurati e per questo destinata a spegnersi bruciando della sua stessa energia ${ }^{105}$ : in Is. et Os. $360 \mathrm{~B}-\mathrm{D}^{106}$ Plutarco, parafrasando il Platone di $L g$. 716a, colloca Alessandro tra le figure di eroi che, infiammati da alterigia, impulsività giovanile e stoltezza, accettarono onori divini, e

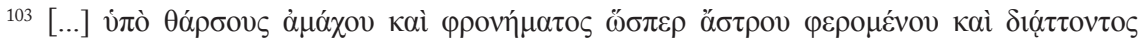

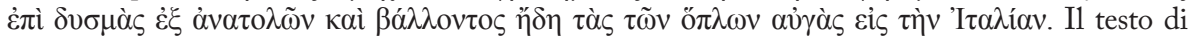
riferimento è quello di F. FrAzier (ed.), 1990, da cui ci si allontana nella conservazione del kaì

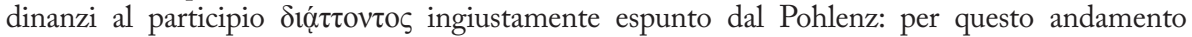

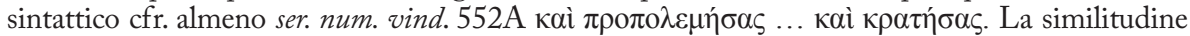
con l'astro che lascia la sua scia in cielo per poi cadere doveva risentire del modello di Il. IV 7580, in cui il balzo di Atena è paragonato al movimento di una stella cadente che costituisce un

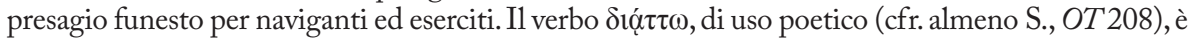
utilizzato spesso anche in riferimento al rapido diffondersi della fama (cfr. A., Pr. 133; E., LA 426) e potrebbe nel contesto plutarcheo alludere anche alla fama di Alessandro. Plutarco comunque usa lo stesso verbo in Pomp. 68. 3 in relazione all'improvviso diffondersi del panico nell'accampamento del generale e in Alex. fort. virt. II 337A per indicare, nel contesto di una metafora medica, il palpitare febbrile dei diadochi alla morte di Alessandro (cfr. anche infra, p. 229, n. 108).

${ }^{104}$ In Pyrrh. 19.2 Plutarco al contrario sostiene che i Romani avrebbero vinto Alessandro.

105 T. Whitmarsh, 2002, pp. 187-90, ha sottolineato la presenza di riferimenti al fuoco e alla fiamma nella Vita di Alessandro per esprimere il progressivo imbarbarimento dell'eroe consumato, nel suo viaggio verso oriente, da una febbre prima morale e poi fisica ( $\mathrm{cfr}$. anche supra, p. 200, n. 49; p. 201, n. 59; p. 225, n. 86).

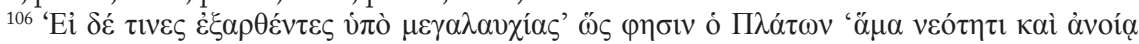

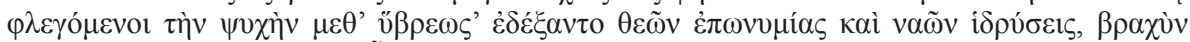

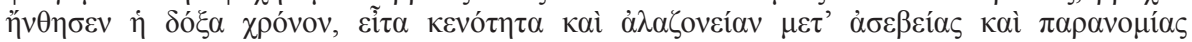

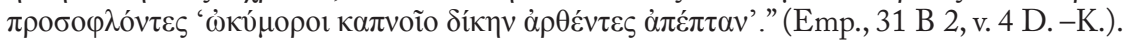


proprio per questo ben presto furono accusati di empietà e caddero in disgrazia scomparendo come fumo nel vento. Non a caso in conclusione del suo ragionamento Plutarco cita l'episodio relativo al ritratto di Alessandro che Apelle rappresentò con il fulmine in mano attirandosi le critiche di Lisippo, che lo aveva rappresentato invece con la lancia, ritenendo empia l'assimilazione a Zeus ${ }^{107}$.

Se dunque si legge il finale del De fortuna Romanorum con l'occhio al passo platonico qui indicato, sia quello citato più o meno alla lettera in $I s$. et Os. 360C, sia il più ampio contesto, il caos in cui cadde il mondo greco disgregatosi in seguito al tramonto dell'astro di Alessandro ${ }^{108}$ poteva costituire un esempio delle conseguenze di un comportamento non equilibrato di chi è chiamato a gestire un impero; ad esso si contrapponeva l'immagine iniziale (317B-C) dell'avvento provvidenziale dell'impero romano: diventato una gomena o un'ancora contro la tempesta e la deriva ${ }^{109}$ prodotte da guerre e contrasti tra popoli, esso è paragonato al processo costitutivo del cosmo con cui si mise ordine nel caos degli elementi ${ }^{110}$. Si trattava dello stesso progetto che Alessandro aveva tentato di compiere ${ }^{111}$ e che come quello rischiava di naufragare per effetto di forze disgreganti insite nella storia stessa.

107 Plutarco doveva comunque tenere presente anche le osservazioni platoniche immediatamente successive al breve passo delle Leggi citato e in cui trovava espressioni ed immagini che ben si adattavano al suo Alessandro: Platone infatti sostiene che l'uomo affetto da superbia, abbandonato dalla divinità, che ama chi è misurato e saggio, in preda ad un furore bacchico, sconvolge tutto quello che ha intorno a sé procurando la rovina a se stesso e a chi lo

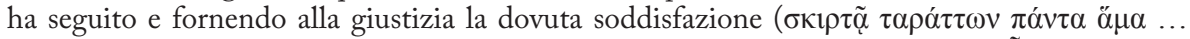

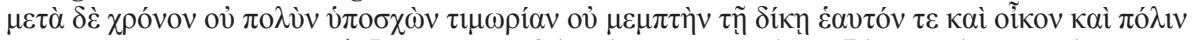

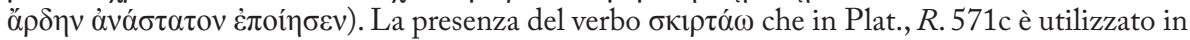
relazione all'elemento ferino e selvaggio dell'anima, rimanda all'ambito dionisiaco (cfr. E., $B a$. 446; Plat., Lg. 653e), il che è coerente con alcuni aspetti della figura di Alessandro.

${ }^{108}$ Tale condizione è efficacemente espressa sul piano formale in Alex. fort. virt. II 336E-337A con il ricorso ad immagini di disordine e instabilità: la potenza di Alessandro, alla sua morte, vagava incerta e inciampava ( $\dot{\varepsilon} \mu \pi \lambda \alpha \nu \omega \mu \varepsilon \dot{v \eta} \kappa \alpha i ̀ ~ \pi \varepsilon \rho \imath \tau i ́ \pi \tau o v \sigma \alpha)$ come il Ciclope accecato che

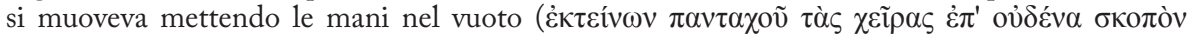

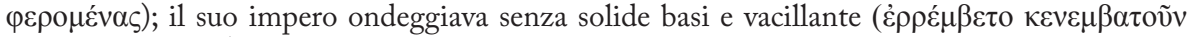

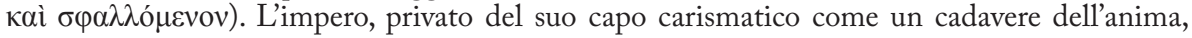
è infine paragonato ad un corpo in preda ad affanno, tremori e febbre; gli indegni generali successori di Alessandro che divampavano con le loro imprese militari spostandosi da una parte all'altra dell'impero sono assimilati ai respiri accaldati e alle palpitazioni che squassano corpi gravemente malati e destinati a morte sicura.

${ }^{109}$ Plutarco cita qui Democr., 68 B 148 D.-K.

${ }^{110} \mathrm{Nel}$ passo Plutarco ricorre al lessico dell'instabilità per indicare la condizione del caos primigenio e quella precedente alla conquista di Roma: come gli atomi che si scontravano erano

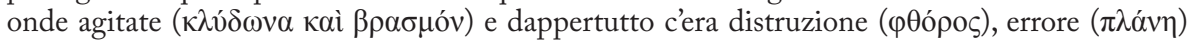

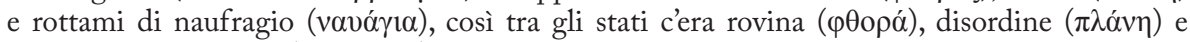
mutamento continuo ( $\mu \varepsilon \tau \alpha \beta o \lambda \eta ́)$; per indicare invece l'ordine raggiunto dal cosmo e quello introdotto da Roma nella storia Plutarco utilizza il lessico della stabilità: come il mondo conquistò equilibrio e si consolidò ("í $\rho v \sigma ı v ~ . . . \pi \alpha \rho \alpha \sigma \chi \varepsilon i v)$ ), così Roma legò a sè ( $\alpha v \alpha \delta \eta \sigma \alpha \mu \varepsilon ́ v \eta)$ popoli diversi dando una sede sicura ( $\check{\delta} \delta \rho \alpha$... $\kappa \alpha \dot{\alpha} \alpha \dot{\sigma} \varphi \alpha ́ \lambda \varepsilon 1 \alpha)$ allo stato e concedendo una pace

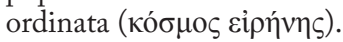

${ }^{111}$ Cfr. Alex. fort. virt. I 329C; II 342A con il comm. di A. D’Angelo (ed.), 1998, p. 206, n. 15. 
La minaccia del mutamento e dell'instabilità, connaturata per Plutarco alla realtà stessa delle cose ${ }^{112}$ malgrado gli sforzi di conservare l'unità e la compattezza, assume sul piano individuale come su quello storico il volto della

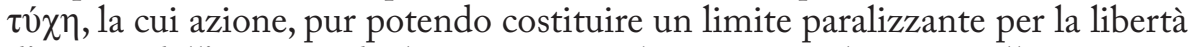
d'azione dell'uomo e degli stati, va combattuta con il ricorso alla saggezza del $\lambda o \gamma 1 \sigma \mu$ óc; come si è visto, quest'ultimo pone a sua volta saldi vincoli, che frenano e controllano gli eccessi in cui possono cadere l'uomo comune come il capo di stato. Gli ostacoli imposti dalla realtà esterna e dalle passioni interne, a

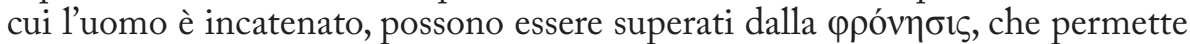
di conservare ordine e compattezza in un universo tendenzialmene caotico e centrifugo; e tuttavia il libero arbitrio rimane soggetto ad una norma più alta che si configura sul piano religioso come provvidenza, espressione della intrinseca bontà del dio che tutto governa, e sul piano storico con l'avvicendarsi degli imperi, che di quella incarnano di volta in volta lo spirito.

Questi testi giovanili, al di là della forte componente retorica che li caratterizza o, forse, proprio in virtù di essa, parlano dunque anche del rapporto di Plutarco con la storia e con Roma: quella dell'AlessandroPrometeo di Alex. fort. virt., portatore di civiltà in virtù della sua paideia ellenica, impegnato a realizzare un progetto di riunificazione e pacificazione

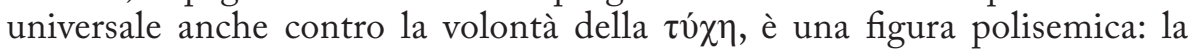
sua lotta contro il destino non va ovviamente letta come un aperto invito al

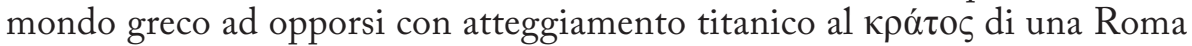
che si presentava ormai, al pari dello Zeus di Eschilo, come dura Necessità storica. Tuttavia il rapporto tra i Greci e l'impero non si riduceva ad una totale ed acritica acquiescenza dei primi al secondo, ma era articolato e complesso; la gratitudine e il rispetto che i Greci mostravano per i loro dominatori, anche nell'ambiguità di alcune posizioni, era infatti sempre accompagnato dalla consapevolezza della loro superiorità culturale, mentre l'aủ $\theta \dot{\alpha} \delta \varepsilon 1 \alpha$ che ai loro occhi doveva talvolta contraddistinguere il comportamento dei loro signori poteva certo essere assimilata a quella del 'dio giovane' della tragedia di Eschilo.

Così proporre ai Greci il modello di un eroe che fu in grado di trasformare il pensiero in azione, di sopportare le difficoltà che gli si presentavano, di controllare le passioni attraverso la ragione incarnando le virtù tradizionali elleniche, poteva essere un modo per tenere alto, laddove ce ne fosse stato bisogno, l'orgoglio per il proprio passato (mitico, storico, culturale) ${ }^{113}$, pur nella coscienza che la Grecità, come Prometeo e come Alessandro, aveva vissuto la sua parabola e si era dovuta piegare ad una forza, che per i più coincideva

${ }^{112} \mathrm{Il}$ mondo è per Plutarco il campo di battaglia in cui si fronteggiano le forze del Bene e del Male, cioè il Dio supremo, garante della permanenza e della stabilità della realtà, e l'anima precosmica irrazionale, causa del mutamento, del disordine e della varietà presenti nel cosmo: cfr. Is. et Os. 370F, 371A-B; fac. Iun. 943A; L. TorracA, 1994, p. 212; F. FErrari, 2002, pp. 249-255, nn. 78-89.

${ }^{113}$ Per un quadro esaustivo della complessità dei rapporti stabilitisi in età imperiale tra dominati e dominatori cfr. P. VEYne, 2007, pp. 141-224, part. per la posizione di Plutarco pp. 158-9. 
con le leggi imperiali e per Plutarco con un progetto superiore dai connotati metafisici, di cui Roma in quel momento era l'espressione storica.

$\mathrm{Ma}$ che valore poteva assumere quella figura di Alessandro agli occhi del pubblico romano? Se Roma doveva sentirsi orgogliosa di aver ripreso e completato il progetto di impero universale intrapreso dall'eroe greco, che diventava così il modello di comportamento fornito dai Greci alla classe dirigente romana e innanzi tutto all'imperatore ${ }^{114}$, il destino di Alessandro, il cui astro si era spento quando la sua virtù era stata sopraffatta dalla sua stessa natura, come Plutarco avrebbe evidenziato nella Vita dell'eroe, non poteva forse costituire anche un funesto presagio di una potenziale, sempre incombente, degenerazione di un equilibrio a fatica raggiunto, qualora la politica di Roma avesse ceduto, proprio come Alessandro, ad un uso smodato e incontrollato del suo potere?

Dalla pagina di Plutarco la figura luminosa di Alessandro, ultima 'incarnazione' dopo Prometeo, Eracle ed Achille della fiamma del tò

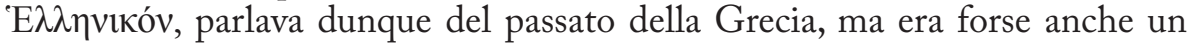
monito per il futuro di Roma.

${ }^{114}$ Per la figura di Alessandro come modello dell'azione di Roma cfr. P. Desideri, 2005, pp. 12, 19. 


\section{RIFERIMENTI BIBLIOGRAFICI}

Babbitt, F.C, Plutarch's Moralia, vol. IV, Cambridge, Mass-London, 1936.

Babut, D., Plutarque et le Stoïcisme, Paris, 1969 (si cita dalledizione italiana, D. B., Plutarco e lo stoicismo, a cura di A. Bellanti, presentazione di R. Radice, Milano, 2003).

Barigazzi, A. (ed.), Plutarco. Se la virtù si debba insegnare, ("Corpus Plutarchi Moralium”, 17), Napoli, 1993.

Becchi, F., "Plutarco tra platonismo e aristotelismo: la filosofia come paideia dell'anima”, in Pérez Jiménez, A., García López, J. \& Aguilar, R. $\mathrm{M}^{\mathrm{A}}$ (eds.), 1999, pp. 25-43.

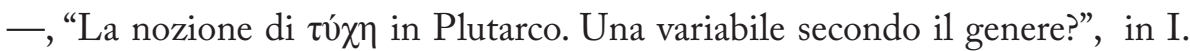
Gallo \& C. Moreschini (a cura di), I generi letterari in Plutarco. Atti dell'VIII Convegno plutarcheo (Pisa, 2-4 giugno 1999), Napoli, 2000, pp. 299-317.

-, "Apatheia e metriopatheia in Plutarco", in A. Casanova (ed.), 2005, pp. 385-400.

-, "Virtù e fortuna nelle Vitae e nei Moralia di Plutarco", in J. Ribeiro Ferreira, L. van der Stockt \& M. Do Céu Fialho (eds.), Philosophy in Society - Virtues and Values in Plutarch, Leuven-Coimbra, 2008, pp. 39-52.

- (ed.), Plutarco. La fortuna, (“Corpus Plutarchi Moralium”, 47), Napoli, 2010.

Bees, R., "Das Feuer des Prometheus: Mythos des Fortschritts und des Verfalls", in E. Pankow - G. Peters (hrsg.), 1999, pp. 43-61.

Bobzien, S. , Determinism and Freedom in Stoic Philosophy Oxford, 1998, rist. 2004.

Bosworth, A. B., Alexander and the East. The Tragedy of Triumph, OxfordNew York, 1996.

Bréchet, C., "Le De audiendis poetis de Plutarque et le procès platonicien de la poésie", $R P h 73$ (1999) 209-44.

Bremer, D., "Prometheus: die Formation eines Grundmythologems", in E. Pankow - G. Peters (hrsg.), 1999, pp. 35-41.

Cammarota, M. R.,"Il De Alexandri Magnifortuna aut virtute come espressione retorica: il panegirico", in I. GALlo (ed.), 1992, pp. 105-24.

- (ed.), Plutarco. La fortuna o la virtù di Alessandro Magno. Seconda Orazione, (“Corpus Plutarchi Moralium”, 30), Napoli, 1998. 
—, "La tradizione retorica in tre declamazioni di Plutarco: De Alexandri Magni fortuna aut virtute, De fortuna Romanorum, De gloria Atheniensium", in L. VAn Der Stockt (ed.), 2000, pp. 69-86.

-, "Nota al De fortuna Romanorum di Plutarco", in L. Torraca (a cura di), Scritti in onore di Italo Gallo, Napoli, 2002, pp. 147-65.

Casadesús Bordoy, F., "Crisipo y la interpretaciòn de los poetas. El testimonio de Plutarco", in M. Jufresa - F. Mestre - P. Gómez \& P. Gilabert (eds.), 2005, pp. 257-64.

Casanova, A. (ed.), Plutarco e l'età ellenistica. Atti del Convegno internazionale di studi (Firenze 23-24 Settembre 2004), Firenze, 2005.

Casevitz, M. - Babut, D. (edd.), Plutarque. Euvres morales, Tome XV, $1^{\text {re }}$ partie, Sur les contradictions stoïciennes; Synopsis du traité "que les stoïciens tiennent des propos plus paradoxaux que les poètes", Paris, 2004.

Citti, V., “Eschilo in Plutarco”, in I. Gallo (a cura di), 2003, pp. 135-45.

Curi, U., Endiadi. Figure della duplicità, Milano, 2002.

Dal Pont, I., "Citazioni eschilee in Plutarco: le citazioni tratte dalle tragedie conservate per intero. 1.”, Schol(i)a 5, 2 (2003) 15-42 (=2003a).

-, "Citazioni eschilee in Plutarco: le citazioni tratte dalle tragedie conservate per intero. 2”, Schol(i)a, 5, 3 (2003) 9-27 (=2003b).

D’Angelo,A., “Un «encomio» di Alessandro Magno in Plutarco: il De Alexandri Magni fortuna aut virtute, or. 1", in I. Gallo (ed.), Seconda Miscellanea Filologica, "Quaderni del Dipartimento di Scienze dell'AntichitàUniversità di Salerno, 17”, Napoli, 1995, pp. 173-84.

—, "Analisi formale e critica del testo nel De Alexandri Magni fortuna aut virtute, or. I plutarcheo", in J. A. Fernández Delgado \& F. Pordomingo Pardo (eds.), Estudios sobre Plutarco: Aspectos Formales. Actas Del IV Simposio Español Sobre Plutarco (Salamanca, 26 -28 de Mayo de 1994), Salamanca, 1996, pp. 115-24.

- (ed.), Plutarco. La fortuna o la virtù di Alessandro Magno. Prima orazione, ("Corpus Plutarchi Moralium", 29), Napoli, 1998.

del Cerro Calderón, G., "El problema del mal y la providencia en Plutarco y en la Biblia”, in M. García Valdés (ed.), 1994, pp. 223-34.

Desideri, P. , "Impero di Alessandro e impero di Roma secondo Plutarco", in A. Casanova (ed.), 2005, pp. 3-21.

Díaz Lavado,J.M., "Poesía y Educación en Plutarco a través del testimonio de De audiendis Poetis", in F. Lisi - J. UReña - J.C. Iglesias Zoido (eds.), Didáctica del Griego y de la Cultura Clásica, Madrid, 1996, pp. 113-20.

Dougherty, C., Prometheus. Gods and Heroes of the Ancient World, New York, 2006. 
Dronkers, A. I., De comparationibus et metaphoris apud Plutarchum, Traiecti ad Rhenum, 1892.

Duff, T., Plutarch's Lives. Exploring Virtue and Vice, Oxford, 1999.

Ferrari, F. - Baldi, L. (a cura di), Plutarco. La generazione dell'anima nel Timeo, (“Corpus Plutarchi Moralium”, 37), Napoli, 2002.

—, "Moderatismo etico e controllo delle passioni in Plutarco", in G. Giardina (a cura di), Le emozioni secondo i fllosofi antichi. Atti del Convegno Nazionale di Siracusa, 10-11 maggio 2007, Catania 2008, pp. 135-62.

Flacelière, R. - Chambry, E. (edd.), Plutarque. Vies parallèles, Alcibiade Coriolan, Paris, 1999.

Frazier, F. (ed.), Plutarque. Euvres morales, tome V-1 ${ }^{\text {re }}$ partie, La fortune des Romains, La glorie des Athéniens, Paris, 1990, pp. 7-66, 157-99.

Froidefond, C. (ed.), Plutarque. Euvres morales, tome V - $1^{\text {re }}$ partie, La fortune ou la vertu d'Alexandre, 1990, pp. 67-156.

Gallo, I. (ed.), Ricerche plutarchee, "Quaderni del Dipartimento di Scienze dell'Antichità- Università di Salerno, 12”, Napoli, 1992.

-. (a cura di), La biblioteca di Plutarco. Atti del IX Convegno plutarcheo (Pavia, 13-15 giugno 2002), Napoli, 2003.

García López, J., "Sobre el De audiendis poetis de Plutarco", Apophoreta Philologica M. Fernández Galiano, EClás 87 II (1984) 411-19.

García Valdés, M., (ed.), Estudios sobre Plutarco: ideas religiosas. Actas del III Simposio Español sobre Plutarco (Oviedo 30 de abril a 2 de mayo de 1992), Madrid, 1994.

Giangrande, G., "Testo e lingua nel De Alexandri Fortuna aut Virtute plutarcheo", in I. GALLo (a cura di), 1992, pp. 39-84.

Hamilton, J. R., Plutarch. Alexander: a Commentary, Oxford, 1969.

Hani, J., "La Notion De Destin Dans le De Fato Du Ps-Plutarque", in Visages du destin dans les Arythologies. Melanges Jacqueline Duchemine, 1 (1983) 105-10.

Heckel, W. \& Hardeey, J. C. (edd.), Alexander the Great: historical sources in translation, Malde, MA, 2004.

Jones, C. P., Plutarch and Rome, Oxford, 1971.

Jufresa, M. - Mestre, F. - Gómez, P. \& Gilabert, P. (eds.), Plutarc a la seva època: Paideia i societat. Actas del VIII Simposio Internacional de la Sociedad Española de Plutarquistas, Barcelona (6-8 nov., 2003), Barcelona, 2005.

Kindstrand, J. F. (ed.), [Plutarchi] De Homero, Leipzig, 1990. 
Kraus, M., "Valor pedagògic de la poesia i crítica platònica de la retòrica en el De audiendis poetis de Plutarc", in M. Jufresa - F. Mestre - P. Gómez \& P. Gilabert (eds.), 2005, pp. 333-42.

Lassel, E., De fortunae in Plutarchi Moralibus notione, Diss. Marburg, 1891.

LeClerc, M. - C., "La résistible ascension du progrès humain chez Eschyle et Sophocle”, REG, 107 (1994) 68-84.

Moraux, P., L'aristotelismo presso i greci, vol. II, t. 2, L'Aristotelismo nei non Aristotelici nei secoli I e II d. C., intr. di G. Reale, tr. it. Milano, 2000 (ed. or. Berlin-New York, 1984).

Mossè, C., Alessandro Magno. La realtà e il mito, Roma, 2003.

Mossmann, J. M., "Tragedy and Epic in Plutarch's Alexander", JHS 108 (1988) 83-93 (ristampato in B. Scardigli (ed.), Essays on Plutarch's Lives, Oxford, 1995, pp. 209-228, da cui si cita).

NAchstäDt, W., (ed.), Plutarchi Moralia, vol. II, Lipsiae, 1935, $1971^{2}$.

Nesselrath, H.- G. -Berdozzo, F. (edd.), Cornutus. Die Griechischen Götter, Tübingen, 2009.

Onians, R. B., Le origini del pensiero europeo, a cura di L. Perilli, tr. di P. Zaninoni, Milano, 2006 (ed. or. 1954).

Pankow, E. -Peters, G. (hrsg.), Prometheus. Mythen der Kultur, München, 1999.

Pérez Jiménez, A., García López, J. \& Aguilar, R. Mª (eds.), Plutarco, Platón y Aristóteles. Actas del V Congreso Internacional de la I.P.S. (Madrid-Cuenca, 4-7 de mayo de 1999), Madrid, 1999.

Philippon, A., (ed.), Plutarque. Euvres Morales, tome I, $1^{\text {re }}$ partie, Comment lire les poètes, Paris, 1987 (il volume contiene anche il De liberis educandis, a cura di J. SiRINELLI).

Plácido, D., "Alejandro y los emperadores romanos en la historiografia griega", in J. M. Croisille (ed.), Neronia IV. Alejandro Magno, modelo de los emperadores romanos, Bruxelles, 1990, pp. 58-75.

-, "L'image d'Alexandre dans la conception plutarchéenne de l'Empire romain", $D H A, 21 / 2$ (1995) 131-38.

Prandi, L., "L'Alessandro Magno di Plutarco. Riflessioni su De Al. Magn. e su Alex.", in L. VAn DER StOckт (ed.), 2000, pp. 375-86.

Raimondi, M., "Damofilo di Bitinia e il De fortuna Romanorum di Plutarco", in L.Troiani - G. Zecchini (a cura di), La cultura storica dei primi due secoli dell'impero romano, Roma 2005, pp. 217-48.

Ramelli, I. (ed.), Anneo Cornuto. Compendio di teologia greca, Milano, 2003. 
-,- Lucchetta, G. A., Allegoria, vol. I L'età classica, intr. a cura di R. Radice, Milano, 2004.

-, "Il pensiero teologico ed etico di Eschilo. Nuove note per uno studio filosofico integrato delle tragedie eschilee", Sileno, 34, 1-2 (2008) 11364.

- (ed.), Eschilo. Tutti i frammenti con la prima traduzione degli scolii antichi, Milano, 2009.

SAÏD, S., "Poésie et éducation chez Plutarque ou Comment convertir la poésie en introduction à la philosophie", in M. Jufresa - F. Mestre - P. Gómez \& P. Gilabert (eds.), 2005, pp. 147-76.

—, "Les dons de Prométhée et leur valeur dans le "Prométhée enchaîné» à la lumière d'une comparaison avec Hésiode, Platon et Aelius Aristide", Lexis, 24 (2006) 247-63.

Salles, R., The Stoics on determinism and compatibilism, Aldershot Burlington, VT, 2005.

Santana Henríquez, G., "La educación de Alejandro en las Vidas Paralelas: la paideia griega en Plutarco", in M. Jufresa - F. Mestre - P. Gómez \& P. Gilabert (eds.), 2005, pp. 637-46.

Schenkeweld, D.M., “The Structure of Plutarch's De Audiendis Poetis”, Mnemosyne, 35 (1982) 60-71.

Scotт, W. C., "Pathei mathos", NECJ, 26 (1998-1999) 10-14.

Sмiтh,M.D., "Enkrateia: Plutarch on Self-Control and the Politics of Excess", Ploutarchos, n.s., 1 (2003/2004) 79-88.

Swain, S., "Plutarch's De fortuna Romanorum", CQ, 39/2 (1989) 504-16 $(=1989 a)$.

—, "Plutarch: Chance, Providence, and History", AJPh, 110/2 (1989) 272-302 (=1989b).

TARn, W.W., 1948, Alexander the Great, vol. II Sources and Studies, Cambridge, 1948, 2002 (da cui si cita).

Teodorsson, S.-T., "The Education of Rulers in Theory (Mor.) and Practice (Vitae), in A. G. Nikolaidis (ed.), The Unity of Plutarch's Work. Moralia' Themes in the Lives', Features of the Lives' in the 'Moralia', Berlin -New York, 2008, pp. 339-50.

Torraca, L., "Il problema del male nella teologia plutarchea", in M. García VALDÉs (ed.), 1994, pp. 205-22 .

-, "I presupposti teoretici e i diversi volti della tyche plutarchea", in I. Gallo (a cura di), Plutarco e la religione. Atti del VI Convegno plutarcheo (Ravello, 29-31 maggio 1995), Napoli, 1996, pp. 105-55. 
Valgiglio, E., "La struttura del De audiendis poetis di Plutarco", in G. D'Ippolito \& I. Gallo (a cura Di), Strutture formali dei "Moralia" Di Plutarco. Atti del III Convegno plutarcheo (Palermo, 3-5 maggio 1989), Napoli, 1990, pp. 375-80.

—, (ed.), [Plutarco]. Il fato (“Corpus Plutarchi Moralium, 16”), Napoli, 1993.

VAN Der Stockt,L., Twinkling and Twilight. Plutarch's Reflections on Literature, Brussel, 1992.

-, “Three Aristotele's Equal but one Plato. On a Cluster of Quotations in Plutarch", in A. Pérez Jiménez, J. García López \& R. Mª Aguilar (eds.), 1999, pp. 127-39.

-, (ed.), Rhetorical Theory and Praxys in Plutarch. Acta of the IV ${ }^{\text {th }}$ International Congress of the International Plutarch Society (Leuven, July 3-6, 1996), Louvain/Namur, 2000.

-, "Plutarch in Plutarch: the Problem of the hypomnemata", in I. Gallo (a cura di), 2003, pp. 331-40.

—, "«With followeth justice always» (Plato, Laws 716A). Plutarch on the "Divinity» of rulers and laws", in L. De Blois - J. Bons Ton Kessels \& D. M. Schen keweld (eds.), The Statesman in Plutarch's Works. Proceedings of the Sixth International Conference of the International Plutarch Society (Nijmegen/Castle Hernen, May 1-5, 2002), vol. I, Leiden-Boston, 2004, pp. 137-49.

Van Raalte, M., "More philosophico: political virtue and philosophy in Plutarch's Lives", in L. De Blois - J. Bons Ton Kessels \& D. M. Schenkeweld (eds.), The Statesman in Plutarch's Works. Proceedings of the Sixth International Conference of the International Plutarch Society (Nijmegen/Castle Hernen, May 1-5, 2002), vol. II, LeidenBoston, 2005, pp. 75-112.

Veyne, P., L'impero greco romano. Le radici del mondo globale, Milano, 2007 (ed. or. Paris, 2005).

Whitmarsh, T., Reading Power in Roman Greece: the paideia of Dio Chrysostom, in Y. L. Too - N. Livingstone (eds.), Pedagogy and Power. Rhetorics of Classical Learning, Cambridge 1998, pp. 192-213.

-, Greek Literature and the Roman Empire: the politics of imitation, Oxford, 2001.

-, "Alexander's Hellenism and Plutarch's Textualism”, CQ, 52 (2002) 174-92.

Worthington, I. (ed.), Alexander the Great: a reader, London-New York, 2003.

Wyttenbach, D., Plutarchi Chaeronensis Moralia, id est opera, exceptis vitis, reliqua, tomus II, Oxonii, 1796. 
Zadorojnyi, A., "Safe Drugs for the Good Boys: Platonism and Pedagogy in Plutarch's De audiendis poetis?", in Ph. -A. STADTER \& L. VAN DER Sтоскт (edd.), Sage and emperor, Leuven, 2002, pp. 297-330.

Zanatta, M., (ed.), Plutarco. Le contraddizioni degli Stoici, Milano, 2000².

Zecchini, G., "Alessandro Magno nella cultura dell'età antonina”, in M. Sordi (a cura di), Alessandro Magno tra storia e mito, Milano, 1984.

Ziegler, K., Plutarco, ed. it. a cura di B. Zucchelli, trad. di M. R. Zancan Rinaldini, Brescia, 1965. 


\title{
Fortuna e Carattere da Menandro a Plutarco con una nota testuale su alcune citazioni di Menandro in Plutarco
}

\author{
Angelo Casanova \\ Università di Firenze
}

\begin{abstract}
Plutarch severely criticizes the opinion on fortune held by both Stoics and Epicureans, and while taking these two positions as ideological extremes - repeatedly refers to Tyche seen as a force acting in opposition to man's virtues. He thus falls back on the Peripatetic doctrine and often quotes Menander, who also studies the way fortune affects the attitudes of his characters. In particular, two quotations from Menander (at De fort. Rom. 318D and Quaest. conv. 3.6, 654D) deserve special attention, not least in view of their importance for establishing Plutarch's own text.
\end{abstract}

Vorrei premettere che basta scorrere l'indice delle sue opere conservate e il sommario delle sue opere perdute (il cosiddetto Catalogo di Lampria) ${ }^{1}$, per avere chiaro che Plutarco era critico e fieramente avverso sia agli Epicurei che agli Stoici ${ }^{2}$ E sappiamo che entrambe queste scuole cercavano, in maniera diversa, di sminuire o annullare l'importanza della tyche, cioè della influenza che l'evento fortuito, la fortuna intesa come caso, può avere nella vita dell'uomo. Non c'è necessità ch'io mi dilunghi in proposito.

Vorrei solo ricordare, rapidamente, la preziosa testimonianza di un contemporaneo di Plutarco, Diogene di Enoanda, che in un bel frammento della sua iscrizione, fa riferimento ad una lettera di Epicuro (fr. 72 Smith = 73 Cas.) $)^{3}$ col racconto del suo naufragio: Epicuro finisce in mare in piena tempesta e, quando sembra destinato a sfracellarsi contro le rocce alte di un'isola a forma di tamburo, un'ondata più forte lo butta invece più in alto, direttamente sull'isola, salvandolo. Osserva dunque che il caso ( $\tau$ ò $\alpha$ vó $\mu \alpha \tau o v)$ a volte porta a compimento il meglio (o la cosa sperata: il testo è qui molto

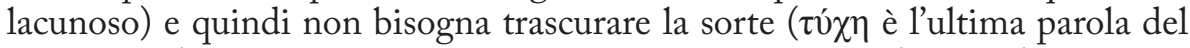
frammento). La sorte esiste, si afferma: nel fr. 71 Smith (72 Cas.) si precisa

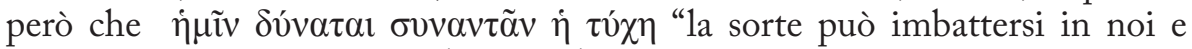
farci del male, ma per poco ( $\sigma \pi \alpha v i ́ \omega \varsigma)$ : infatti non ha materia, come il fuoco, cui attaccarsi. Epicuro dunque, guardando a queste cose, non volle togliere del tutto la sorte dalle cose - infatti sarebbe stata cosa audace e non degna della grandezza di un filosofo mentire su una cosa così chiara e apertamente palese a tutti -, ma [le sottrasse $]^{4}$ non poche cose né piccole. Infatti, come volendo confrontare sempre la disposizione d'animo del saggio agli eventi del caso, attribuì tanta forza ad essa (e poco alla sorte, giustamente) che osò

\footnotetext{
${ }^{1}$ Naturalmente il primo riferimento va ancora alle pagine di K. ZiegLer, 1965, pp. 79 -85.

${ }^{2}$ Mi sia concesso di rimandare ancora ad uno scritto del mio maestro, A. BARIgAZZI, 1990, p. V ss. E si veda il volumetto edito a cura di I. GaLlo, 1988.

${ }^{3}$ M. F. Sмith, 1993; cf. A. Casanova, 1984.

${ }^{4}$ La congettura è mia.
} 
dire: «Per piccole cose incide la sorte sul saggio; le maggiori e più importanti

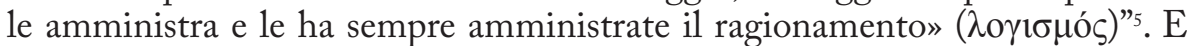
questa è in pratica una citazione di una Kyria doxa di Epicuro, la $R$. Sent. 16, ma si può anche rinviare ad un famoso passo dell'Epistola a Meneceo (134) in cui il filosofo proclama che il saggio epicureo non pensa che la Tyche sia un dio, come fa la gente ${ }^{6}$, ma nemmeno la reputa inesistente: può essere principio e causa di grandi beni e grandi mali ${ }^{7}$.

Sull'altro versante, vorrei invece citare un brano delle Quaest. Conv. (9.5, 740D), dove Lampria sensatamente osserva:

"Bada che è assurdo cercare la ragione delle cose casuali. Infatti se la sorte risulta rientrare in una qualche logica, non avviene più per fortuna né casualmente, ma per una certa predestinazione e provvidenza"

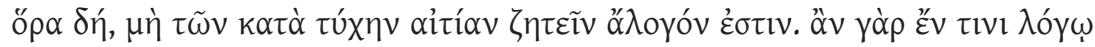

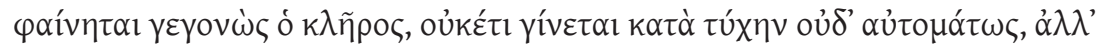

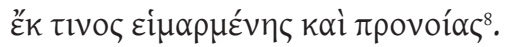

Questa, ovviamente, è una obiezione contro gli Stoici. Infatti sappiamo bene che gli Stoici vedevano nella tyche una manifestazione della pronoia, cioè della grande infallibile Intelligenza che regge il mondo9. Per loro gli uomini comuni possono restare smarriti constatando come i beni e i mali vengano distribuiti 'apparentemente' a casaccio, ma il sapiente sa che esilii, malattie e rovine economiche procedono da superiori necessità: chi riuscirà a rendersi ragione di questi eventi, e ad accettarli intellettualmente, riuscirà anche a sopportarli fisicamente e spiritualmente. A rigore, tyche e pronoia divina sono la stessa cosa, in quanto quella è manifestazione di questa. La pronoia divina include perciò tutto, compresa la pronoia umana: "Anche se si vuole intendere 'previdenza' umana, quale aspetto della sapienza -scriveva Barigazzi ${ }^{10}-$, cè sempre una connessione con la divinità, che è logos supremo, e di esso partecipa anche l'uomo".

Ebbene, tenendo fermi questi due punti di riferimento, si può dire nel complesso che invece Plutarco studia molto la tyche, la osserva, la analizza, puntando a cogliere l'importanza che essa può avere per mettere in evidenza

${ }^{5}$ La traduzione è presa dalla mia citata edizione di Diogene, p. 312 s.; per una interpretazione leggermente diversa del testo vd. quella di Smith, p. 401 e 518 ss.

${ }_{6}^{6}$ Tyche non compare nei poemi omerici, ma è divinizzata in Esiodo (Theog. 360), Archiloco (fr. *16 W.), Pindaro (Ol.12.1 e fr. 41 S.-M.) ecc. Cfr. in proposito F. Becchi, 2001, pp. 111-127, p. $111 \mathrm{~s}$.

${ }^{7}$ Si veda anche l'essenziale commento di G. Arrighetti, 1973, p. 544 e 550.

${ }^{8}$ Per testo e traduzione francese si veda l'edizione Belles Lettres di F. Frazier e J. Sirinelli, 1996, tome IX.3.

${ }^{9}$ Si veda SVF II 1106-1186 e cfr. in proposito M. Pohlenz, 1967, I, 193-200.

${ }^{10}$ A. Barigazzi, 1984, 264-286 = Studi su Plutarco, a c. di A. Casanova, Firenze 1994, 303-330: 310. 
- per contrasto - le virtù dell'uomo, che sono sempre varie e molteplici (non una, come volevano gli Stoici). La sorte mette così in evidenza il tropos, ovvero le capacità dell'uomo di reagire alla tyche, superandola o subendola.

In questo modo egli ritorna sostanzialmente al Peripato, risalendo a monte dell'epicureismo e dello stoicismo: ritorna a Teofrasto e a Demetrio Falereo, riprendendo una tematica che è pienamente menandrea. Non per caso Plutarco cita spessissimo Menandro ${ }^{11}$ : come lui Menandro studia ripetutamente le ripercussioni che la tyche ha sul carattere dei vari personaggi. E stata ampiamente osservato che le sue commedie sono proprio costruite sulla tyche e sul gioco che essa ha sul tropos, cioè sul carattere dei vari personaggi ${ }^{12}$. Analogamente avviene nelle Vite di Plutarco, che possono essere guardate come una galleria di ritratti studiati nella contrapposizione tra tyche e tropos.

Certo, il problema non è così semplice a definirsi. In Menandro, quando la Tyche viene in scena (nell'Aspis, vv. 97-148, presentandosi come theos prologizousa) per illustrare la propria capacità assoluta di intervenire nei fatti umani a piacer suo, finisce per comportarsi in modo opposto al suo nome, sia perché mostra di provare simpatia per i buoni e antipatia per i cattivi (ma la Tyche non dovrebbe avere sentimenti), sia perché mostra di avere in mente un

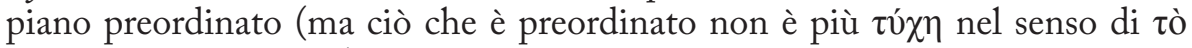

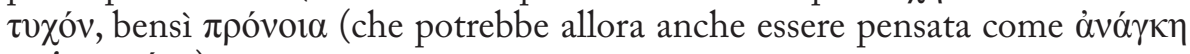
o $\varepsilon i \mu \alpha \rho \mu \varepsilon ́ v \eta)^{13}$.

Per quanto riguarda Plutarco, Simon Swain, in un articolo sul De fortuna Romanorum di vent'anni fa, rilevava che Plutarco nei Moralia distingue con cura la provvidenza dal caso, mentre nelle Vite usa tyche promiscuamente per indicare sia il caso sia la "guiding force" che amministra il mondo ${ }^{14}$. Secondo Swain - che sul concetto di tyche e provvidenza in Plutarco tornò, nello stesso anno, anche in un altro articolo ${ }^{15}$ - ciò si spiega con il fatto che nelle $V i t e$, che non sono scritti teorico-tecnici, Plutarco si è sentito libero di non usare una terminologia rigorosa. Condivido solo in parte l'essenza di questa spiegazione: è importante aggiungere che anche nelle Vite, che pure sono vite di eroi, di condottieri, di uomini di statura tragica, Plutarco può sì parlare

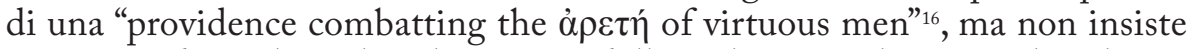
mai in modo unilaterale sul dark side della tyche, né utilizza mai lo schema 'alfieriano' del personaggio generoso iniquamente perseguitato dal fato avverso. In questo, nella relativizzazione di tyche, il Plutarco delle Vite non è troppo diverso dal Plutarco dei Moralia. Se è giusto dire che nel Plutarco dei libelli si riflettono concezioni ellenistiche, non sarebbe altrettanto giusto dire che nel Plutarco storico-biografo si riflettano quelle classiche. Anche da

${ }^{11}$ Cfr. il mio scritto, Plutarco e Menandro, in: A. Casanova (ed.), 2005, 105-118.

12 G. Vogt-Spira, 1992.

${ }^{13}$ Analogamente, nella Samia (163 s.) si afferma che "il caso è un dio, a quanto sembra, e

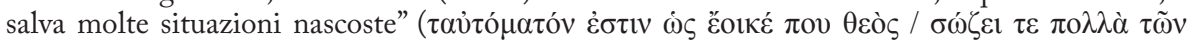
àopó $\tau \omega v)$.

${ }^{14}$ S. Swain, 1989a, 504-516: 506.

${ }^{15}$ S. Swain, 1989b, 272-302.

${ }^{16}$ Swain, 1989b, p. 282 .. 
questo punto di vista la produzione plutarchea si presenta tendenzialmente unitaria.

Plutarco conosce l'inaffidabilità della tyche, ma conosce anche un valido

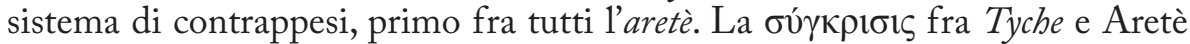
(personificate) è sottesa a due fra i più importanti scritti che il Nostro abbia dedicato all'argomento, il già ricordato De fortuna Romanorum e il De Alexandri Magni fortuna aut virtute. $\mathrm{Nel}$ primo scritto ${ }^{17}$ Plutarco sostiene che l'impero romano si è formato soprattutto per fortuna ${ }^{18}$, nel secondo scritto (che in realtà sono due) che l'impero di Alessandro si è formato soprattutto per virtù. Sintetizzando, la virtù da sola può non bastare alle grandi imprese, ma neppure la tyche ha potere su tutto. Tyche e Aretè si sono eccezionalmente alleate per creare la grandezza di Roma, ma per il resto sono nemiche giurate, e di pari forza ${ }^{19}$.

Nell'uomo physis e phronema sono altri formidabili contrappesi alla

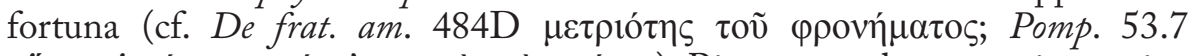

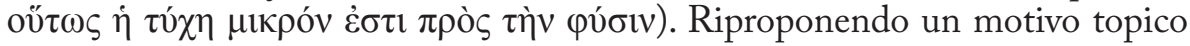
della diatriba cinico-stoica, occasionalmente Plutarco si avvicina un po' alla posizione epicurea e sostiene che solo una piccola, trascurabile parte di noi è esposta ai capricci della sorte. Ne fa fede il classico esempio di Stilpone, perfettamente padrone di sé anche nella disgrazia della famiglia e della patria (De tranq. an. $475 \mathrm{C}-\mathrm{D})^{20}$. Plutarco comunque non è così astratto da credere che ciascuno di noi possa elevarsi a tali altezze. Anche se privo della magnanimità di Stilpone, l'uomo può contrastare efficacemente la tyche per mezzo della eủßov $\lambda$ ía, che ci mette in condizione di comprendere i mutamenti di fortuna fin dal loro primo manifestarsi. La sorte, dice Plutarco, comincia col

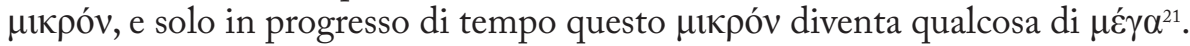
Ciò non implica un ritorno al 'classico' fatalismo, al sentimento dell'inutilità di ogni sforzo, alla deresponsabilizzazione dell'uomo. Al contrario contiene un messaggio di ottimismo: le piccole innocue dimensioni in cui la tyche inizialmente opera ci consentono di intervenire in tempo: cf. $281 \mathrm{E}-\mathrm{F}$, ove

${ }^{17}$ Che Barigazzi (negli Studi su Plutarco, cit.in n. 10,p. 309) definiva tout court una "orazione". Per una rassegna delle varie posizioni critiche sulla cronologia del De fortuna Romanorum si veda ora M. Raimondi, 2005, 217-248: 218 e nn. 4-5.

${ }^{18}$ Illustra bene questa relazione la vicenda di Romolo in 320B: delle fortune di Romolo fu la Tyche a gettare le fondamenta, anche se poi fu senz'altro la Aretè ad innalzare il resto della costruzione.

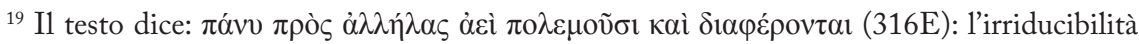
dell'inimicizia è espressa da $\pi$ óvv, che spesso viene omesso nelle traduzioni, ma che ha invece un suo preciso ruolo: Tyche e Aretè sono in guerra specialmente l'una contro l'altra. 468A).

${ }^{20}$ Cfr. in proposito il commento di Emidio Pettine, 1984, p. 640 s. e p. 240 ss. (comm. a

${ }^{21} \mathrm{Il}$ concetto è illustrato con didascalica chiarezza in Ag. et Cleom. 48.8 (Cleom.27.8) $\dot{\alpha} \lambda \lambda^{\prime}$ i $\tau \grave{\alpha}$

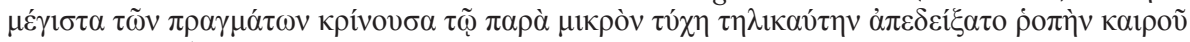

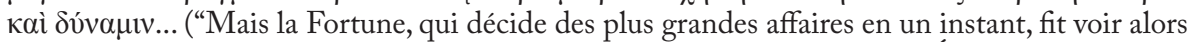
l'influence et le pouvoir du moment critique...", trad. di R. Flacelière e É. Chambry, 1976). Per la sorprendente coincidenza in proposito tra Plutarco e Polibio (2.70.2) vd. il commento di G. Marasco, 1980, II, p. 567 ss. 


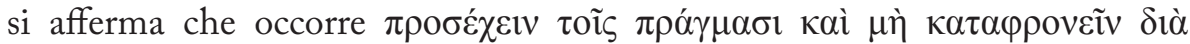
$\mu 1 \kappa \rho o ́ \tau \eta \tau \alpha \tau \tilde{\omega} v \dot{\varepsilon} v \tau \tau \gamma \chi \alpha \nu o ́ v \tau \omega v$. E qui si faccia attenzione: Plutarco rovescia il classico topos dell'imprevedibilità della tyche e lo rimpiazza con un'idea che potrebbe essersi modellata, coscientemente o no, sul paradigma epicureo della continuità piccolo-grande (dalla deviazione minima di un corpo piccolissimo si producono masse cosmiche). Questo nesso probabilmente non può essere provato, ma neppure escluso, specie se si considera il curioso fatto che nel $D e$ fortuna Romanorum il costituirsi della potenza romana, che l'opera di Tyche fa emergere progressivamente da un ribollente e caotico disordine, viene paragonato appunto (317A-B) al formarsi di aggregati di particelle (la parola che Plutarco usa è $\sigma \omega ́ \mu \alpha \tau \alpha)$. Questa comparazione, dice a giusta ragione F. Frazier, solleva "la formation de l'empire à une dimension quasi-cosmique, tendent à la confondre avec la terre entière"22; ma è comunque significativa la scelta, fra i tanti possibili, del modello democriteo-epicureo. Si noti, ancora, che la comparazione è immediatamente preceduta da una citazione da Democrito (B 148 DK).

Secondo Plutarco, però, sono i nostri $\tau \rho o ́ \pi 0$ e i nostri $\ddot{\eta} \theta \eta$ a filtrare gli effetti della tyche: se noi conosciamo noi stessi e i nostri limiti, niente può veramente coglierci impreparati. Stando alla concezione classica, non cè̀ difesa contro l'insulto della sorte ${ }^{23}$, mentre a parere di Plutarco solo le cose precedentemente indebolite vengono colpite dalla tyche in modo rovinoso ( $A n$ vitios. ad inf.499D). Anche il teatro menandreo insegna che talvolta è proprio il favore della sorte che ci nuoce. Nella parte iniziale dell' Aspis, Davo sostiene che una prolungata fortuna si volge prima o poi in disgrazia ${ }^{24}$. L'inizio del discorso lascia presagire una riedizione del vecchio motivo dell'ira o dell'invidia divina contro gli ő $\gamma \alpha v$ ö $\lambda \beta 101$, ma subito dopo si capisce che Davo va a parare in ben

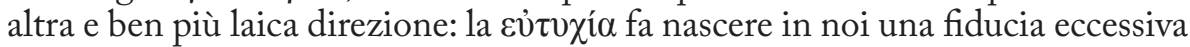
(che, secondo Davo, ci porta a $\kappa \alpha \tau \alpha \varphi \rho o v \varepsilon i ̃ v){ }^{25}$, mentre colui a cui le persone vanno talvolta male (o $\pi \tau \alpha i ́ \sigma \alpha \varsigma \tau \mathrm{l})$ risulterà molto più pronto ad affrontare $\mathrm{i}$ cambi repentini di fortuna quando questi verranno (vv. 27-28).

Mi sembra qui opportuno ricordare che riflessioni analoghe a quella sviluppata da Davo esistevano anche sulla carriera di Alessandro Magno, che è una delle figure-chiave della discussione antica sulla tyche. Nel trattato $D e$ Alexandri Magni fortuna aut virtute Plutarco insiste sul motivo dell'aretè, ma

${ }^{22}$ Plutarque. Oeuvres morales, V.1.texte, établi et traduit par F. Frazier et C. Foidefond, 1990, 24.

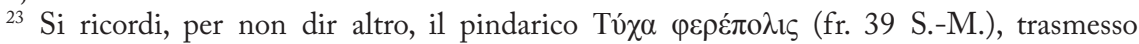
peraltro proprio da Plutarco (De fort. Rom. 322 C). Per l'evoluzione della concezione di Tyche nell'antichità (oltre ai classici scritti di C. Diano, $1967^{3}$ e 1952, 84) vd. I. Kajanto, 1981, 525-558. Quest'ultimo segnala giustamente che la Tyche è importante in Sofocle e più in Euripide, ma diventa "a dominant figure in the literature of the Hellenistic period" (526 s.). Cfr. F. BeCCHI, 2001, p. 111 s.

${ }^{24} \mathrm{Si}$ tratta naturalmente di un vecchissimo principio (basti ricordare i celebri aneddoti su Creso e su Policrate in Erodoto, 1.30-34 e 3.40-43), ma si noti come è ora applicato nella vita comune di tutti i giorni, non solo al mondo degli eroi e dei grandi del passato.

${ }^{25}$ Men. Aspis, v. 30. 
altri, appunto, avevano insistito soprattutto su quello della tyche. Fra costoro vi è ad esempio Curzio Rufo, il quale, attingendo certamente da storici di impostazione peripatetica e quindi ostili ad Alessandro ${ }^{26}$, scriveva che quest'ultimo, cum plurimum virtuti debuerit, plus debuisse fortunae, quam solus omnium mortalium in potestate habuit (10.5.35) ${ }^{27}$. Curzio Rufo osserva peraltro che la tyche, quando è troppo favorevole, sortisce effetti distruttivi sul carattere. Coccolando Dario ${ }^{28}$, la tyche ne prepara la rovina, rendendolo incapace di reagire alle circostanze avverse. E brutti scherzi gioca anche ad Alessandro, il quale si incapriccia di Rossane perché, inter obsequia fortunae, ha perso la capacità di tenere a freno le passioni (8.4.24).

Per ragioni di tempo io non voglio entrare troppo in questa tematica, già ampiamente studiata e trattata da grandi specialisti, alcuni dei quali sono qui presenti. Voglio invece andare a due casi specifici, a due citazioni menandree di cui mi preme discutere valore e significato.

1. Nel De fortuna Romanorum, che - come ho già accennato - è una preziosa declamazione dedicata proprio al tema se sia stata rilevante la fortuna per i grandi del mondo romano, nel cap. 4, 318CD si legge:

"La Fortuna, dopo aver preso e levato Cornelio Silla dagli amplessi dell'etera Nicopoli, lo innalza al di sopra dei trionfi sui Cimbri e dei sette consolati di Mario con investiture di comandi assoluti e dittature. Silla si spacciava apertamente, in virtù delle sue imprese, come figlio della Fortuna, proclamando con le parole dell'Edipo di Sofocle «Mi ritengo figlio della Fortuna», e in lingua latina era chiamato Felix, ma per i Greci scrisse così: «Lucio Cornelio Silla Epafrodito». Anche i trofei che si trovano presso di noi, a Cheronea, per le guerre mitridatiche, recano questa iscrizione. E giustamente: infatti non «la Notte», come dice Menandro, gli portò «il più di Afrodite», bensì la Fortuna" ${ }^{29}$.

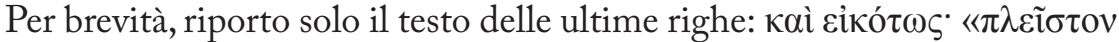

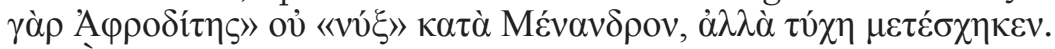
A1-2:30

E facile riconoscere che Plutarco allude qui all'inizio del Misoumenos, vv.

${ }^{26} \mathrm{La}$ questione delle fonti curziane è notoriamente complessa e non è questa la sede per trattarne in modo dettagliato (per una panoramica si veda in particolare J. E. AtKinson, 2009, pp.19-32). È certo comunque che tra queste fonti non ne mancarono di peripatetiche, tant'è vero che secondo alcuni (cf. R. Billows, 2000, 286-307: 298) uno dei primi autori, se non addirittura il primo, ad impostare un confronto fra virtù e fortuna in Alessandro Magno fu

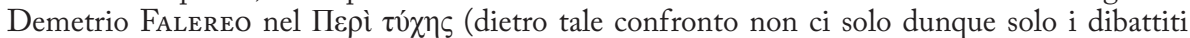
fasulli delle scuole di retorica ellenistiche, come sembra credere Atrinson, 2009, 170). Si veda lo studio specifico di E. Mensching, 1963, 274-282.

${ }^{27}$ Sulla difficoltà di armonizzare questa opinione con altre precedenti (in cui era stata piuttosto la virtù di Alessandro ad affiorare) cf. e.g. W. W. TARn, 1948, II, 100.

${ }^{28}$ Così Curzio Rufo su Dario III: erat Dareo mite ac tractabile ingenium, nisi etiam naturam plerumque fortuna corrumperet (3.2.17).

${ }^{29}$ La traduzione è mia, ma deve molto a quella di Giovanni Forni, 1989, p. 51.

${ }^{30}$ Non più fr. 739 Körte (né fr. 789 Körte-Thierfelder), come annotano - anche di recente - alcuni commentatori di Plutarco! 


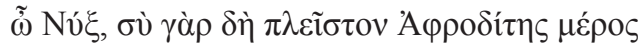
$\mu \varepsilon \tau \dot{\varepsilon} \chi \varepsilon i \varsigma \theta \varepsilon \tilde{\omega} \nu \kappa \tau \lambda$.

"O Notte, (io ti invoco) perché tra gli dei tu hai massima la parte di Afrodite", ovvero - come si ricava anche dai versi che seguono - 'tu hai parte di Afrodite più che di tutti gli altri dei', 'sei il tempo in cui le attività volute e presiedute da Afrodite sono le più importanti e frequenti, rispetto a quelle protette da tutte le altre divinità's1.

Ora c'è da osservare che in Plutarco la citazione menandrea è impiegata con un adattamento piuttosto singolare dal punto di vista linguistico.

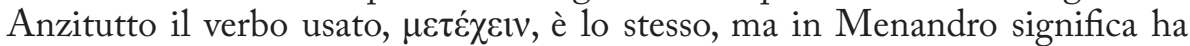
il senso di "partecipare", "avere parte" in senso proprio, mentre in Plutarco è volto in senso per così dire 'causativo' di "partecipare" ad altri, cioè di dare o "procurare" parte di qualcosa ad altri. La Fortuna, non la Notte gli ha 'fatto avere' la parte massima di Afrodite. E poi, soprattutto, l'espressione centrale, $\pi \lambda \varepsilon i ٓ \sigma \tau o v ' A \varphi \rho o \delta i ́ t \eta s$, non è impiegata in senso proprio: chiaramente il testo non allude soltanto all'amore e alla sessualità, come avviene in Menandro, ma è volta ad un senso più ampio, che definirei traslato, perché significa in pratica piuttosto "il massimo dei godimenti, delle soddisfazioni" in tutti i campi possibili. Fu infatti la fortuna del successo politico a portare a Silla le più grandi soddisfazioni, non la cortigiana Nicopoli: e pertanto, secondo Plutarco, fu la Fortuna a portargli i maggiori godimenti, non la Notte. Ovvero: Silla si chiamò Epafrodito, "protetto di Afrodite", perché ne ebbe la protezione sempre, non solo di notte.

L'interpretazione è confermata da un passo della Vita di Silla (34.3-4), in cui Plutarco racconta che dopo la cerimonia di trionfo Silla "prese la parola in assemblea (davanti al popolo) celebrando egualmente le sue fortune e le sue

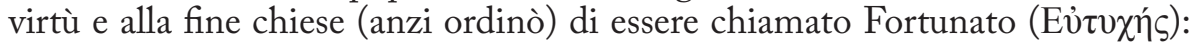
infatti questo vuol dire propriamente il latino Felix. Ma egli stesso scrivendo ai Greci si dava il titolo di Epafrodito, e presso di noi così cè scritto sui trofei: Lucio Cornelio Silla Epafrodito" ${ }^{32}$.

Si può notare che qui Plutarco spiega meglio la sua battuta. Felix significa Fortunato: in greco andrebbe tradotto con la parola Eutychès. Invece Silla si fece chiamare Epafrodito, cioè "protetto da Afrodite". E perciò lo scrittore ci fa una battuta tagliente: protetto da Afrodite non solo di notte, ma sempre. Per lui il massimo potere di Afrodite non lo portò la Notte, come diceva Menandro, ma la Fortuna.

${ }^{31}$ Se ne veda testo e traduzione nell'edizione italiana di F. FERrari, 2001, p. 335 o in quella inglese di W. G. Arnotт, 1996, p. 256 s. Nella classica edizione oxoniense di F. H. SAndbach questo brano compare solo nella Appendix dell'edizione più recente $\left(1990^{2}\right.$, p. 351).

${ }^{32}$ La traduzione è mia, ma deve molto a quella di R. Flacelière e É. Chambry, 1971, p. 280. Sull'importanza che Silla attribuiva alla fortuna si insiste molto nel cap. 6, della sua Vita $(5-13)$. 
2. Con l'occasione, vorrei segnalare che gli stessi versi menandrei sono ripresi da Plutarco in un altro brano egualmente interessante. Nelle Quaest. conv. 3.6 (654D) si discute se abbia ragione o no Epicuro, che sconsigliava di far l'amore di notte, dopo il banchetto serale: a lui si contrappone il parere di Menandro, ricordando che secondo il commediografo di notte spetta ad Afrodite addirittura il primato su tutti gli dei. Dice il testo:

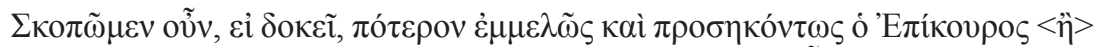

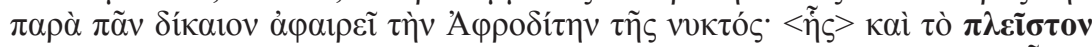

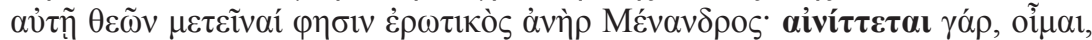

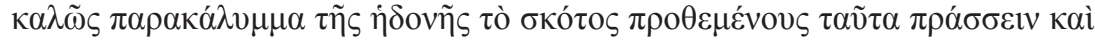

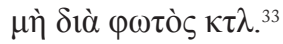

Tradurrei: "Riflettiamo dunque (se vi sembra il caso) se Epicuro ragiona in modo appropriato e conveniente, oppure contrario ad ogni giusta norma, quando toglie Afrodite alla notte: (...) Menandro, esperto d'amore, dice che ad essa va addirittura il suo primato tra gli dei. Dice per enigma (?), credo, che opportunamente gli uomini fanno queste cose (cioè l'amore) mettendo il buio a copertura del piacere e non vogliono, incontrandosi di giorno, eliminare la vergogna dagli occhi e dar forza al vizio e a ricordi vivaci, con cui si eccitano nuovi desideri."

Ho tradotto tutto il periodo, ma ci sono varie cose da precisare. È chiaro che Plutarco allude ancora all'inizio del Misoumenos, ma è evidente che si tratta di una parafrasi, come mostrano l'uso della terza persona al posto della prima e l'impiego di $\mu \varepsilon \tau \varepsilon i ̃ v \alpha l$ a fronte di $\mu \varepsilon \tau \varepsilon \dot{\chi} \chi \varepsilon ı v$. Non cè quindi ragione di correggere $\kappa \rho \alpha ́ \tau ı \sigma \tau o \nu$ dei codici in $\pi \lambda \varepsilon \tilde{\sigma} \sigma \tau \nu$, come fa l'edizione francese accogliendo la vecchia congettura di Wyttenbach. $\grave{E}$ vero che Menandro diceva $\pi \lambda \varepsilon i \tau \sigma \tau o v$ (lo hanno confermato i papiri): ma qui il testo dato dai codici plutarchei è

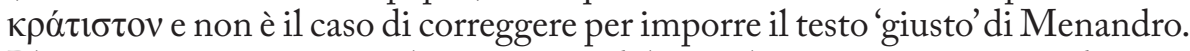

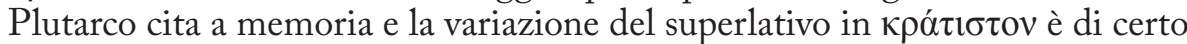

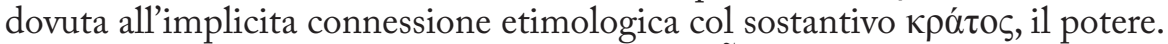

Chiarito questo, è ovvio che la congettura $<\tilde{\eta} \varsigma>$, aggiunta al testo tràdito da Fuhrmann (e già proposto da Doehner, secondo P. A. Clement) ${ }^{34}$ è superflua: anzi, può confondere. Dato che si conosce il testo di Menandro, è chiaro che il passo significa precisamente che il primato di Afrodite tra gli dei ( $\tau$ ò $\pi \lambda \varepsilon$ ĩ $\sigma \tau o v$ A introduce il relativo $\tilde{\eta} \varsigma$, questo sembra riferirsi piuttosto a $v 0 \kappa \tau o ́ s$ e provoca un equivoco ridicolo (la maggior parte della notte spetta ad Afrodite!). Il codice Viennese $\mathrm{T}$ (in pratica codex unicus: tutti gli altri codici ne derivano) ${ }^{35}$

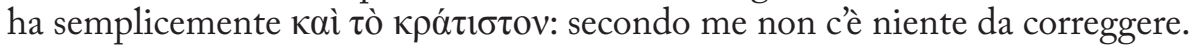

${ }^{33}$ Il testo proposto è quello di F. Fuhrmann, 1972, ma ho evidenziato due parole che intendo discutere, perché - come segnala l'apparato dello stesso editore - nel primo caso la

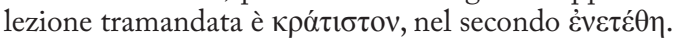

${ }^{34}$ Plutarch's Moralia, VIII, by P. A. Clement - H. B. Hoffleit, 1969.

${ }^{35}$ Come ha dimostrato C.Hubert, 1971, p.XI-XX; cf. Fuhrmann, op. cit., p.XXVII-XXXIV; Cf. J. Irigoin, 1992, p. 24 ss.; I. Chirico, 2001, p. 80-83. 
Tutt'al più, se si sente la mancanza di una congiunzione, si può congetturare

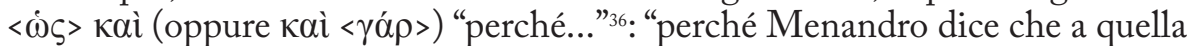
(la notte) appartiene addirittura il suo primato tra gli dei". Il possessivo "suo" (cioè "di Afrodite") è semplicemente sottinteso.

Un problema del tutto particolare si pone col periodo seguente. Fuhrmann (e con lui Teodorsson) ${ }^{37}$ accetta la correzione $\alpha i v i ́ \tau \tau \varepsilon \tau \alpha$ l di Doehner e pensa che il soggetto sia Menandro. E questo è di certo sbagliato. Così si crea una lunga testimonianza su Menandro (anzi, una sua interpretazione) che è assolutamente infondata: il testo menandreo non dice nulla del genere (e noi ora conosciamo perfettamente i primi 45 versi della commedia). In realtà il verbo tramandato dai codici plutarchei è $̇ ̉ v \varepsilon \varepsilon \dot{\theta} \theta$, che è sicuramente corrotto. A mio avviso, o si tenta di recuperare un aoristo passivo con soggetto $\tau \alpha \tilde{\tau} \tau \alpha \pi \rho \alpha ́ \sigma \sigma \varepsilon \varepsilon v(\mathrm{ad}$

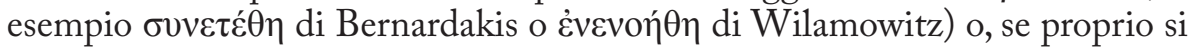
vuole, si ricorre al presente impersonale $\dot{\varepsilon} v \delta \varepsilon ́ \chi \varepsilon \tau \alpha l$ ("si ammette"), non certo ad $\alpha i v i ́ \tau \tau \varepsilon \tau \alpha$. A mio avviso la congettura più probabile è Ėvo $\mu i ́ \sigma \theta \eta$, perché ritengo che il senso sia addirittura ovvio: è sempre stato usuale e legale (conforme ai

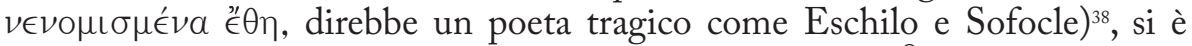

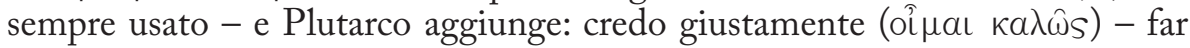
sesso nascondendo il piacere col buio, e non di giorno, incontrandosi alla luce del sole, rinunciando al pudore e concedendo troppo alla vista.

Non ho dubbi che questo sia il senso perché qualcosa di molto simile si dice in Clemente Alessandrino ${ }^{39} \mathrm{e}$ in altri passi di Plutarco: in particolare in

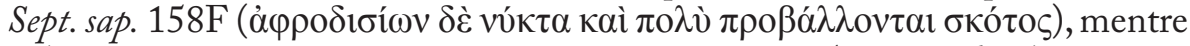
nel trattato Non posse suaviter vivi sec. Epicurum 1089A si ricorda che persino i Cirenaici, "che pure hanno bevuto allo stesso calice" (cui ha bevuto Epicuro), riconoscevano che l'amore va fatto di notte, col buio, perché le immagini dell'azione non abbiano a provocare ulteriore eccitazione attraverso la vista.

Un piccolo esempio di quanto ci sia ancora da lavorare sul testo di Plutarco ${ }^{40}$.

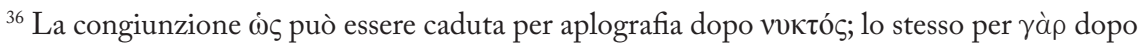

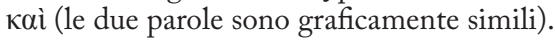

${ }^{37}$ S.-T. Teodorsson, 1989 , p. 359.

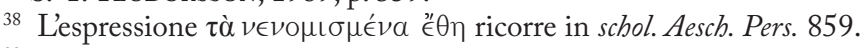

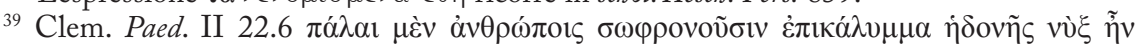

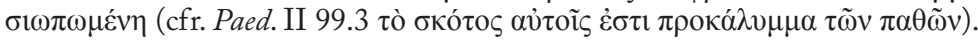

${ }_{40}$ Per altre note sul testo di Quaest. conv. $3.6 \mathrm{vd}$. le mie pagine La hora del amor (Q.C. 3.6): Plutarco y la tradición (literaria y filosófica) nel volume degli Atti del convegno «Plutarco transmisor » (Sevilla, 12-14 Nov. 2009), in corso di stampa a cura di José M. CANDAu Morón, F. J. González Ponce, A.L. Chávez Reino. 


\section{Bibliografia}

Arnott, W. G., Menander, II, London-Cambridge Mass. 1996.

Arrighetti, G., Epicuro, Opere, Torino 1973.

Atrinson,J. E., Curtius Rufus. Histories of Alexander the Great, Book 10, Oxford 2009.

Barigazzi, A., Plutarco: Contro Epicuro, Firenze 1990.

-, Plutarco e il corso futuro della storia, Prometheus 10, 1984, 264-286 = Studi su Plutarco, a c. di A. Casanova, Firenze 1994, 303-330.

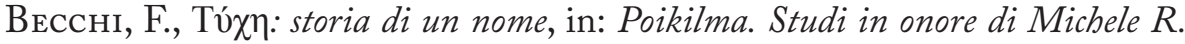
Cataudella in occasione del suo $60^{\circ}$ compleanno, a cura di S. Bianchetti (et alii), La Spezia 2001, pp. 111-127.

Billows, R., Polybius and Alexander Historiography, in: A. B. Bosworth - E. J. Baynham (edd.), Alexander the Great in Fact and Fiction, Oxford 2000, 286-307.

Casanova, A., I frammenti di Diogene d'Enoanda, Firenze 1984.

-, Plutarco e Menandro, in: Plutarco e l'età ellenistica, Atti del Convegno Internazionale di Studi, Firenze 23-24 settembre 2004, a c. di A. Casanova, Firenze 2005, 105-118.

Chirico, I., Plutarco. Conversazioni a tavola, libro III, Napoli 2001.

Clement, P. A., - Hoffleit, H. B., Plutarch's Moralia, VIII, LondonCambridge Mass. 1969.

Diano, C., Forma ed evento. Principi per una interpretazione del mondo greco, Venezia $1967^{3}$.

—, Edipo figlio della Tyche, Dioniso n.s. 15, 1952, 84

Ferrari, F., Menandro e la Commedia Nuova, Torino 2001.

Flacelière, R., - Chambry, É., Plutarque. Vies, tome VI, Paris 1971.

-, - Снambry, É., Plutarque. Vies, tome XI, Paris 1976.

Forni, G., Plutarco. La fortuna dei Romani, Napoli 1989.

Frazier, F., - Froidefond, C., Plutarque. Oeuvres morales, V.1, Paris 1990.

—, - Sirinelli, J., Plutarque, Oeuvres morales, tome IX.3, Paris 1996.

Funrmann, F., Plutarque. Oeuvres morales, tome IX.1, Propos de table, livres I-III, Paris 1972.

Gallo, I. (ed.), Aspetti dello stoicismo e dell'epicureismo in Plutarco, Atti del II 
convegno di studi su Plutarco, Ferrara 2-3 aprile 1987, Quaderni del Giornale Filologico Ferrarese n. 9, Ferrara 1988.

Hubert, C., Plutarchi Moralia, IV, Leipzig 1971.

J. IRIGoIn, Tradizione manoscritta e ecdotica plutarchea, in: I. Gallo - R. Laurenti (eds.), I Moralia di Plutarco fra filologia e filosofia, Salerno 1992, p. 24 ss.

Kajanto, I., Fortuna, ANRW II 17.1 (1981), 525-558.

Marasco, G., Commento alle biografie plutarchee di Agide e di Cleomene, Roma 1980.

Mensching, E., Peripatetiker über Alexander, «Historia» 12, 1963, 274-282.

Pettine, E., Plutarco. La tranquillità dell'anima, Salerno 1984.

Pohlenz, M., La Stoa. Storia di un movimento culturale, trad. ital., Firenze 1967.

Raimondi, M., Damofilo di Bitinia e il De fortuna Romanorum di Plutarco, in: L. Troiani - G. Zecchini (eds.), La cultura storica nei primi due secoli dell'impero romano, Roma 2005, 217-248.

Sandbach, F. H., Menandri Reliquiae selectae, Oxford 1972¹, $1990^{2}$.

Sмiтн, M. F., Diogenes of Oinoanda, The Epicurean Inscription, Napoli 1993.

Swain, S., Plutarch's De fortuna Romanorum, CQ 39, 1989, 504-516.

-, Plutarch: Chance, Providence, and History, AJPh 110, 1989, 272-302.

TArn, W. W., Alexander the Great, London 1948.

Teodorsson, S.-T., A Commentary on Plutarch's Table Talks, vol. 1 (Books 1-3), Göteborg 1989.

Vogt-Spira, G., Dramaturgie des Zufalls. Tyche und Handeln in der Komödie Menanders, München 1992.

Ziegler, K., Plutarco, ed. ital., Brescia 1965. 


\section{INDEX LOCORVM}

Alexandre d'Aphrodise

De fato

41 n. 10,52 n. 52,53 n.53

De anima

52 n. 52

Apulée

L'Âne d'or

186 et n.11

De deo Socratis 99-102

115-124 : 99 n.53

125-127 : 99 n.54

$127-132: 99$ n. 55

133-134 : 99 n.56

140-145 : 100 n.61

$145: 95$ n. 17

$146-147: 100$ n.62

$148: 100$ n.63

150-156 : 100 n.59

158-162 : 100 n.64

162-163 : 101 n.67

$163: 101$ n.68

$165: 101$ n.69

$166-167: 101$ n. 70 et 71

De magia

101 n.67

De Platone

40 n.4
Archiloque

(ed. West)

1 : 190-1 n.26, 199 n.13

$16: 240$ n.6

$114: 202$

Aristophane

Nuées

412-428 : 201 n.15

Oiseaux

$960: 111$ n.8

Aristote

De caelo

295 b30-34 : 14 n.5

De divinatione per somnia

125 n.16

$2,2: 125$ n. 15

2, $10: 125$ n.15

Éthique à Nicomaque

III 1112 a15-17 : 224 n.75

De insomniis

125 n. 15

Poétique

VI n.18

Physique

II 196 a24-198 a : V n.16, 47 n.1

Rhétorique

1374 b : 148 n.30 


$$
\begin{aligned}
& 1405 \text { a } 20: 115 \text { n.36 } \\
& \text { Fragments (éd. Rose) } \\
& 60: 125 \text { n.15 }
\end{aligned}
$$

Arrien

$$
\begin{aligned}
& \text { Anabase } \\
& \text { V } 2: 221 \mathrm{n} .57 \\
& \text { VI } 10,1: 219 \text { n.47 }
\end{aligned}
$$

Artémidore

I 1-2 : 127

IV $64: 127$

$$
\begin{aligned}
& \text { AthénÉe } \\
& \text { 5, } 211 \text { d-e : } 93 \text { n.1 }
\end{aligned}
$$

Athénodore de Tarse

(FHG, éd. Müller)

111, 487 : 129 n.38

\section{Aulu-Gelle}

VI 14, 8-10 : 165 n.93

VII 2 : 42 n. 14,43 n.18

IX 2, 4 : 93 n.1

\section{BABRIUS}

141-149 : 115 n.38

\section{Calcidius}

Ad Timaeum 40 n.4

\section{Cicéron}

$$
\begin{aligned}
& \text { Lucullus (Academica Priora, II) } \\
& 18: 21 \mathrm{n} .30 \\
& 57,2-10: 24 \mathrm{n} .39 \\
& 58,1-4: 25 \mathrm{n} .41 \\
& 77-80: 21 \mathrm{n} .31 \\
& 85: 22 \mathrm{n} .32 \\
& 136: 93 \mathrm{n} .4 \\
& \text { Varro (Academica Posteriora, I) } \\
& 15: 94 \mathrm{n} .8 \\
& 33: 49 \text { n.17 et } 20 \\
& 35: 49 \text { n.20 } \\
& 36-37: 25 \text { n.40 } \\
& 40: 29 \text { n. } 49 \\
& 40-41: 21 \mathrm{n} .30
\end{aligned}
$$

De divinatione

I $122: 94$ n. 11 et 13

I 123 : 95 n.20

De fato

$13: 41$ n. 8

$20: 41$ (n.9), 42

23-25:29 n. 49

30 : 42 n. 16

$39: 144$ n.13

$43: 42$ n. 14

De finibus

4, 43 : 16 n.11, 35-36

4, 47 : 16 n. 11,20 n.26

4. $69: 18$ n.18

$5,12: 49$ n.19

$5,77: 49$ n.19

5, 85-86 : 49 n.19

De natura deorum 72, n.18

2, $115: 40$

De re publica

III VIII, 12 : 165 n.93

VI (Somnium Scipionis) : 200

Lettres

Ad Atticum

2, 1, $8: 199$ n.12

Tusculanes

V 9.24 : 49 n.17

V 9, 24-25 : 49 n.18

$\mathrm{V} 10: 94$ n.8

V 23-25 : 49 n.16

V 85-86 : 49 n.19

Chérémon

(TGF, vol. 1 Snell)

71 F 2 : 49 n.13

\section{Clément d'Alexandrie}

Pédagogue

I $13: 41$

II $22,6: 247$ n.39

II 99, 3 : 247 n.39

Protreptique

4, 48, 6 : 113 n.22

Stromates

1, 21, 131 :112 n.16 
2. $20,108: 20$ n.28

Cornutus

Theologia graeca

$18-19: 214$ n.22

18 : 220 n. 51

C.I. L.

VIII $1007: 129$ n.38

Démétrios de Phalère

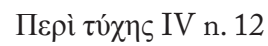

DÉmocrite

Fragments (D-K)

148 : 229 n.109, 243

DÉMosTHÈnE

$1^{\text {ire }}$ Olynthienne (I)

$23: 211,212$

Sur les affaires de Chersonèse (VIII)

69 : IV n.12

Sur la couronne (XVIII)

271 : XVIII n.82

$276: 116$ n.43

Sur l'ambassade infidèle (XIX)

102 : $116 \mathrm{n} .43$

$109: 116$ n.43

251 : 203 n.18

Contre Aphobos III (XXIX)

32 : 116 n.43

\section{Denys d'Halicarnasse}

Antiquités romaines

II $19: 115$ n.37

Diodore de Sicile

$15,34,5: 190$ n.24

$17,99,2: 219$ n. 47

$18,66,4: 202$ n.16

Diogène LAËrce

II $40: 94$ n.9

VII 123 : 93 n.3
VII $162-63: 36$

VII 162 : 22 n.34, 24 n.38

VII 163 : 24 n.39, 50 n.22

VII $178: 51$ n.44

VIII $31: 4$ n. 4

VIII $36: 115$ n.41

VIII $58-59: 115$ n.41

VIII $73: 94$ n. 15

IX 45 : V n.16

IX $62: 22$ n.33

$\mathrm{X} 10: 65$ n. 44

Dion Cassius

$6,13,1^{\mathrm{a}}: 93$ n. 1

Dion Chrysostome 227 n.99

1, 50, $4: 113$ n.26

30, 20, $2: 113$ n.26

ÉLIEN

2, $11: 4$ n.4

$12,32: 94$ n.15

Empédocle

Fragments (D-K)

$2: 228$ n.106

ÉPICTÈTE

Entretiens

4, 8 : 93 n.1

Manuel

51, 3 : 94 n.7

ÉPICHARME

Fragments (D-K)

$12: 213$ et n.16, 222

ÉPICURE

Lettre à Ménécée

$134: 240$

Maximes capitales

$16: 240$

Fragments (éd. Usener)

$169: 65$ n.43

288 sq : 60 n. 21 


$$
\begin{aligned}
& 386: 64 \text { n.41 } \\
& 387: 64 \text { n.42 } \\
& \text { Eschine } 116 \text { n.43 } \\
& \text { C. Ctésiphon (III) } \\
& 137: 116 \text { n. } 43
\end{aligned}
$$

\section{Eschyle}

Agamemnon

$177: 214$ (I)

\section{Choéphores}

822 : 116 n.43

\section{Perses}

$859: 247$ n.38

Prométhée enchaîné 218 n.40, 221

n.56, 223 n.69

$18: 218$

$22: 219$ n.48

$133: 228$ n.103

$269: 213$

442-71 : 218 n.41

447-48 : 222

$546-50: 222$ n. 61

$907: 218$ n. 45

921-23 : 220 n.52

959-61 : 223 n.67

$982: 218$ n. 45

$1002-6: 223$ n.68

$1012-13: 218$

1034-35 : 214, 218 n.45

$1036-38: 218$ n. 45

1073-79 : 214, 220 n.54

$1089-90$ : 223 n.69

Fragments (éd. Radt)

189a : 213 et n.19

\section{Euripide}

Bacchantes

$446: 229$ n.107

Ion

413-416 : 110 n.6

Iphigénie à Aulis

$426: 228$ n.103

Oreste

$420: 74$
Rhésos

$503: 113$ n.26

715 : 113 n.26

Fragments (éd. Kannicht)

24b : 213 n.20

$979: 74$

FAVORInUs

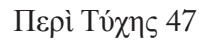

Galien

Protreptique 47-48

Пврі̀ $\alpha \lambda v \pi i ́ \alpha \varsigma$

50-51 : 53 n.54

\section{Gorgias}

Fragments (D-K.)

$3: 115$ n. 41,116 n.43

\section{HÉraclite}

Fragments (D-K.)

$99: 213$ et $n .17$

\section{Hermias}

In Phaedrum 94 n.14

\section{HÉrodote}

Histoires 197

I 30-34 : 203 n.19, 243 n.24

III $40-43: 243$ n.24

V 62-63 : 111 n.12

V $90: 111$ n.12

VI $123: 111$ n.12

VII $6: 111$ n. 10

VIII $36: 110$ n.6

\section{HÉSIODE}

Théogonie

$212: 127$ n. 27

360 : 184, 240 n.6

Les Travaux et les Jours

$7: 218-19$ n. 45

86-87 : 208, 209 n.6, 211

717-718 : 209 et n.7, 211, 212 


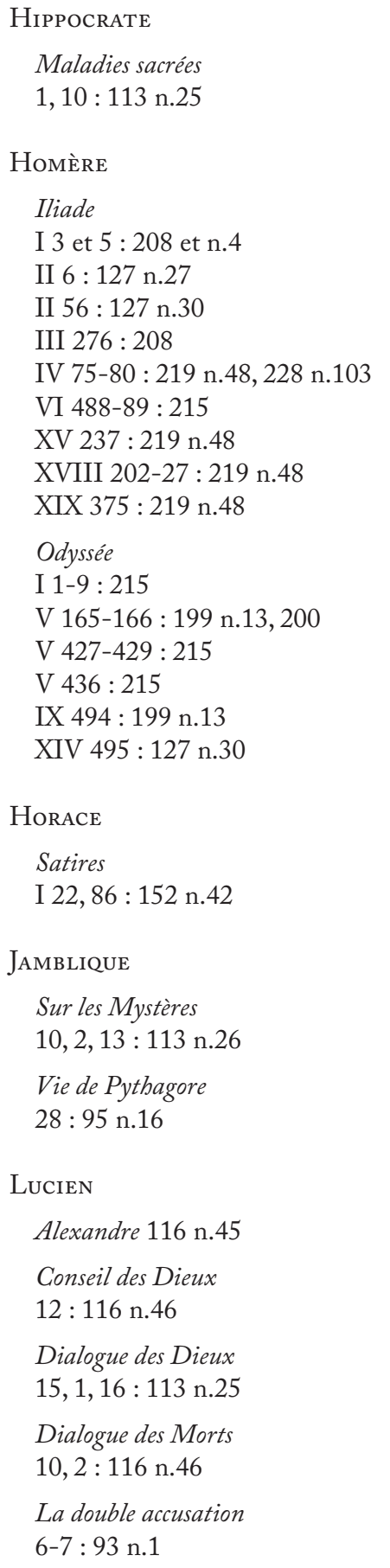

Ménippe

$16: 48$ n. 4

Nigrinos

20 : 48 n.5.

Sur la mort de Pérégrinus

13 : 116 n.46

Le pêcheur

$31: 93$ n. 1

$46: 93$ n.1

LysipPE

(PCG, Kassel-Austin, vol. 5)

fr. $6: 114$ n.27

Maxime de Tyr

Dissertationes

8-9 : 96-99

$8,1 \mathrm{a}: 98 \mathrm{n} .43,45$ et 48

8, 1b : 96 n. 29,98 n. 48

8, 1b-3d : 96 n. 30

8,3 b : 96 n. 29,98 n.43 et 48

8, 3d : 98 n. 48

$8,4 \mathrm{a}: 98$ n. 43 et 48

$8,4 b-c: 97$ n. 35 et 36

8, 5a-61 : 97 n.39

8, 5a : 95 n. 17

8, 6a : 97 n.33, 98 n.48

8, 6i-1 : 98 n. 43

8, $6 \mathrm{i}: 96$ n.29

8, 6k : 98 n. 48

$8,61: 97$ n. 35 et 36

8, 8a : 9, 4e : 97 n.40

8, 8f : 96 n.31, 98 n.46

8, $8 \mathrm{~g}: 98$ n. 44,98 n. 47

9, 1c : 97 n.32

9, 6a-g: 97 n.41

$9,7 \mathrm{c}-\mathrm{i}: 98, \mathrm{n} .49$ et 50

MÉnandre

Le Bouclier

27-28: 243

$30: 243$ n. 25

97-148 : 241

Misoumenos

A 1-2 : 244-245, 246 
La Samienne

163 : 241 n.13

\section{NÉMÉSIUS}

De natura hominis

109, 11-12 : 40 n.4

\section{OlyMPIODORE}

In Platonis Alcibiadem

21, 1-14 : 94 n.14

Orphicorum Fragmenta

554 : 114 n.34, 116 n.44

573 I : 114 n. 30

573 IV : 116 n.42

$707: 112$ n.16

808 : 112 n.14

1018 III : 112 n.16

$1112: 112$ n.14

1124 : 112 n.16

PÉtrone

Satiricon : 186 et n.11

\section{Philon}

De opificio mundi

142: 41

De Providentia 72 n.18

\section{Pindare}

Olympiques

12, 1 : 240 n.6

Fragments (éd. Snell-Maehler)

$39: 243$ n. 23

$41: 240$ n.6

\section{Platon}

Apologie de Socrate 197

24 c : 94 n. 9

29 d-e : 93 n. 1

$31 \mathrm{c}-\mathrm{d}: 94$ n. 9

$31 \mathrm{~d}: 101$ n.69

38 d-e : 203

Le Banquet III, 197

202 e- 4 a : 99 n.57

203 a : 115 n. 40,116 n.43

$220 \mathrm{a}-\mathrm{b}: 201$
Criton 197

$43 \mathrm{~d}: 202$

46 b : 94 n.7

[Définitions]

$414 \mathrm{a}:$ VIII

Gorgias 70 n.9, 72, 80, 81, 104 n.93, 197

523 a1-3 : 81 n.60

Lois IX, 72

653 e : 229 n. 107

674 c : 80 n. 54

709 a2-3 : IV n.9

709 b1 : IV n. 8

709 b7-c1 : IV n.10, 184 n.4

709 c7 : IV n. 11

716 a $: 228$

887 e : 77 n. 42

888 e : III n. 3

889 c5-6 : III n.4, V n.16

901 e $4-6: 74$

$908 \mathrm{~d}: 114$ n.33

909 b : 114 n.31 et 32,116 n.42

933 a : 114 n.32

\section{Lettres}

III 318 b : 80 n.54

IV 321 c : $218-19$ n.45

\section{Ménon}

$71 \mathrm{a}-\mathrm{b}: 97$ n.37

Phédon 76, 78 n.43, 85, 86, 104 n.93, 197

$58 \mathrm{a}: 202$

59 c : 103 n. 78

70 a : 83 n. 65

82 e- 84 b : 221,224

$83 \mathrm{~d}: 221$ n. 60

108 b : 100 n.60

$113 \mathrm{~d}: 100$ n. 60

116 c : 201

Phèdre 85, 86

242 c : 101 n.69

Philèbe

$44 \mathrm{c}: 115$ n. 40

\section{Le Politique}

272 e-73 e : 187 n.17

291 c : 116 n. 43

296 e-97 a : 187 n.17 
298 a : 187 n.17

303 c : 116 n. 43

Protagoras

321 c : 214

La République 72, 73, 83, 85, 104 n.93

329 c8-9 : 86 n.75

330 d-e : 160 n.70

364 b-c : 114 n.30 et 32

364 e : 114 n. 31 et 32

414 b : 132 n. 57,147

500 b-c : 77 n. 42

571 c : 229 n. 107

608 c-12 a : 81 n.58

619 c7-d2 : XVI n.72

620 d-e : 100 n.60

Le Sophiste

$241 \mathrm{~b}: 116$ n.43

Théétète 78

142 a-43 c : 103 n.78

Timaeus 72, 76-77

30 c : VIII n.29

37 c : VIII n.28

$44 \mathrm{c}:$ VIII n.28

$45 \mathrm{~b}:$ VIII n.28

$47 \mathrm{~b}-\mathrm{c}: 77$

90 a : 100 n.60

[Theagès] 94 n.12

129 c-d : 95 n. 18

Plaute

Les Captifs

$92: 152$ n. 42

Pline l'Ancien

$2,22: 185$

Plotin

II 3 (Traité 52), 15 : XVI n.72

Plutarque

1. Moralia

De audiendis poetis

$15 \mathrm{~B}: 127$ n.29

23 C-24 A : 207-212

$23 \mathrm{C}: 208$ n.3

23 D-F : 217
23 D : 208 n. 4,215

$23 \mathrm{E}: 209$ n.6

23 F-24 A : 209 n.7

De audiendo

38 F-39 A : 134 n.70

43 A-B : 93 n.2

De adulatore et amico

$69 \mathrm{~F}: 218$ n. 45

$70 \mathrm{D}: 226$ n.92

71 C-D : 123 n.14

De profectibus in virtute

$73 \mathrm{D}: 121 \mathrm{n} .2$

78 E-F : 93 n.2

82 B : 93 n. 1

82 F-83 D : 125 n.15

De capienda ex inimico utilitate

$88 \mathrm{C}: 53$ n.54

De Fortuna XVII, XX, 47-54

$97 \mathrm{E}: 225$ n. 82

$97 \mathrm{~F}: 217$ et $n .31$

98 A-C : 213

$98 \mathrm{~B}: 222$

98 B-C : 222 n.64

98 D : XIV n.61, 214, 217

99 C : 220 n. 50

99 D : XIV n.61

99 F-100 A : 209-212

$99 \mathrm{~F}: 217,222$ n.66

100 A : 51 n. 35

De virtute et vitio 51

$101 \mathrm{~A}: 125$ n.15

Consolatio ad Apollonium

$103 \mathrm{~F}: 53$ n.55

De tuenda sanitate praecepta

$129 \mathrm{~B}: 125 \mathrm{n} .15$

$133 \mathrm{~F}: 125$ n. 15

Septem Sapientium Convivium $158 \mathrm{~F}: 247$

162 B : VI n.21

De superstitione 62-63

165 B-C : 123

165 E-66 A : 134 n.66

$166 \mathrm{~A}: 116 \mathrm{n} .48$

$166 \mathrm{C}: 123$ n.14

169 F-70 A : 61 n. 30 
$171 \mathrm{E}: 63$ n.34

Regum et Imperatorum Apophtegmata

$183 \mathrm{~A}: 124,130$ n.49

Apophtegmata Laconica

226 D : 114 n.29

Mulierum Virtutes

$252 \mathrm{~F}: 125$

$254 \mathrm{E}:$ VI n. 21

259 B : VI n.21

Quaestiones Romanae

$281 \mathrm{E}-\mathrm{F}$ : 242-43

Quaestiones Graecae

$303 \mathrm{C}: 115$ n.35

Parallela minora

307 B : 124

De Fortuna Romanorum XIII-XIV, 226-227 et nn. 96, 97 et 101

316 D9-E5 : XIII n.57

316 E : 226, 227, 242 n.19

317 A-B : 243

317 B-C : 229

$318 \mathrm{~A}: 228$

318 C-D : 244-245

319 A : 227

320 B : 242 n.18

322 A : VI n.21, 227

$322 \mathrm{C}: 227,243$ n.23

326 A-B : 228 et n.103

De Alexandri Magni fortuna aut virtute I 217-18, 218 n.37

326 D-E : 217 n.34

327 B : 218 n. 35,219 n. 47,221 n.58

327 E-29 D: 223 n.73

$327 \mathrm{E}: 217$ n.33

328 C-E : 218 n.38

$328 \mathrm{~F}: 221$ n. 57

329 A-D : 218 n.38

$329 \mathrm{~B}: 124,126$

329 C : 229 n. 111

$330 \mathrm{D}: 228$

332 A-B : 218 n.42

332 C-D : 217 n. 33,225

$332 \mathrm{C}: 218$ n. 39

333 B-C : 223 et n.72
De Alexandri Magni fortuna aut virtute II 218 n. 37, 225 n.82

$333 \mathrm{E}: 218$ n. 42

$334 \mathrm{D}: 218$ n. 42

$335 \mathrm{E}: 221$ n. 57

336 B : 222 n.62 et 66

336 E-37 A : 229 n.108

$336 \mathrm{E}: 53$ n. 54

337 A : 228 n.103

$337 \mathrm{C}: 222$ n.66

339 A : 221 n. 58

$339 \mathrm{E}: 221$ n. 59

$340 \mathrm{E}: 218$ n.36

$341 \mathrm{C}: 219$ n. 47

$341 \mathrm{D}: 221$ n.58

342 A : 229 n.111

$341 \mathrm{E}: 220$ n. 55

$342 \mathrm{C}: 221$ n. 58

343 D : 219 n. 48

$343 \mathrm{E}: 219$ n. 48

$343 \mathrm{~F}: 220$ n.54

$344 \mathrm{~A}: 220$ n.54 et 55

$344 \mathrm{~F}: 221$ et n.60

De Gloria Atheniensium 225 n.84

De Iside et Osiride

$352 \mathrm{C}: 93$ n. 1

$355 \mathrm{D}: 62$ n. 32

360 B-D : 228 n.106

$360 \mathrm{C}: 229$

$361 \mathrm{~F}-62 \mathrm{~A}: 129$

$361 \mathrm{~F}: 124,130$ n.42

$362 \mathrm{~A}: 122 \mathrm{n} .7$

369 A-B : III n.5, XIII n.54

$370 \mathrm{~F}: 230$ n.112

371 A-B : 230 n.112

$371 \mathrm{E}$ : VIII, 226 n. 88

De E apud Delphos XIII, 70 n.7, 79 n. 49,87

386 B : 110 n.4

393 D : 75 n.31, 123 n.14

De Pythiae oraculis XIII n.53, 72, 76,87

$396 \mathrm{E}: 57$ n.3

$397 \mathrm{D}: 109$ n.2

398 A-B : III n.5, 76 n.35

398 A8 : 84 n.69

398 F6-7 : 76 n.35 
402 B-9 D : 109 n.2

403 A-F : 109 n.3

405 D-E : 109 n.3

407 B-C : XXI, 109-117

407 B3-7 : 110

$407 \mathrm{~B} 7-10: 111$

407 C1-9 : 112-113

409 D5-6 : 75 n.30

De defectu oraculorum XII, XIII n. 53 et $54,72,73,78$

$413 \mathrm{C}: 73$ n. 22

413 D-E : 73 n.23

$414 \mathrm{E}: 110$ n. 4

$414 \mathrm{~F}:$ XII n.49

420 A5-6 : 76 n.36

420 B1-6 : 63 n. 36,76 et n. 37

$420 \mathrm{C}: 76$ n. 36

$425 \mathrm{D}: 40$ n. 5

$431 \mathrm{D}:$ VI n. 21

435 D8-E2 : 83 n. 67

$435 \mathrm{E}: \mathrm{XII}$ n. 49 et 50

$435 \mathrm{~F}: \mathrm{XI}$. 42

437 E-F : 125 n. 15

438 B : 110 n. 4

An virtus doceri possit 51

De virtute morali

$440 \mathrm{~F}: 225$ n. 82

443 F1-4 : XIV n.59

De tranquillitate animi 51

468 A : 242 n.20

$471 \mathrm{D}: \mathrm{X}$

475 C-D : 242

De fraterno amore

$484 \mathrm{D}: 242$

490 A : 122 n. 8,124

Animine an corporis affectiones sint pejores

$499 \mathrm{D}: 243$

$500 \mathrm{E}: 53$ n.56

De garrulitate

510 C-D : 53 n. 57

De cupiditate divitiarum

$523 \mathrm{D}: 53$ n. 55

$524 \mathrm{D}: 53$ n.59

$524 \mathrm{E}: 53$ n. 61
De sera numinis vindicta IX n.35, XII, XX, 3-10, 69-91, 135

548 B3 : 74 n.26

$548 \mathrm{C}: 59$ n. 15

548 C4-8 : 73-74

549 A5 : 74 n. 26

549 A $7-10: 74$

549 B7-C3 : 75

549 D3-6 : 75 n.34, 80 n.53

549 D11-E2 : 74

549 E5-8 : 79 n. 51

$549 \mathrm{~F}: 77$

549 F5-550 A2 : 82

550 C $5-8: 78$ et $n .45$

550 C9-12: 79 et n.50

550 D4-E2 : 77 et n.40

551 C12-D1 : 82

$552 \mathrm{~A}: 228$ n.103

555 A9-B1 : 84 et n.68

555 B : 125 et n. 18,134 n.67

555 D1-5 : 80

556 D9 : 80

556 E4-5 : 82 n.61

556 E9-11: 80

$557 \mathrm{C} 8: 74$ n.26

557 D4-5 : 80

$557 \mathrm{E} 7-8: 80$

$558 \mathrm{C} 2: 80$

558 D $4-5: 80$ n.56

558 D6-11 : 81 et n. 57

560 B2-4 : 83 n.64

560 C8-D5 : 83 et 66

561 B6-11: 81 et n.60

562 C $5-7: 82$

562 E9-63 A1 : 82

563 B $8-10: 82$ n.63

$563 \mathrm{E} 3: 82$

$563 \mathrm{E} 8-\mathrm{F} 1: 5$

$563 \mathrm{~F}-68 \mathrm{~A}: 3-10$

$564 \mathrm{~A}: 4$

565 E-566 A : 85

565 E6-10 : 10

$566 \mathrm{~B}: 85$

$566 \mathrm{C}: 132,133$

566 C10-D1 : 85 et n.73

566 D1-3 : 86 et n.74

566 D3-5: 86 et n.76

566 D5-7 : 86 et n.77 
$567 \mathrm{~F}: 8$

[De fato] 47 n.1, 95

570 E-71 E : VII n.22

$571 \mathrm{D}: 216$ n. 27,224 n.76

$572 \mathrm{~B}-73 \mathrm{~A}: 43$

$573 \mathrm{~B}: 43$

574 B-D : 95 n.23 et 24

De genio Socratis XV-XVI, 3-10,

86, 102-105

575 B10-C9 : XV

579 F-80 C : 102 n.74, 132 n.61

$579 \mathrm{~F}: 102$ n. 75

$580 \mathrm{C}: 94$ n.7

580 C-D : 102 n.76

$580 \mathrm{D}-\mathrm{F}: 95$ n.19

580 F-81 A : 103 n.77

$581 \mathrm{~A}: 103$ n.78

581 B-E : 103 n.79

581 D-E : 95 n.20

$581 \mathrm{D}: 95$ n.18

$581 \mathrm{E}: 94$ n. 9

$581 \mathrm{~F}-82 \mathrm{C}: 103$ n. 80

582 B : 94 n. 8

588 B-89 F : 103 n. 84

588 B : 103 n. 82

$588 \mathrm{C}: 98$ n. 51

588 D-E : 104 n. 86

$588 \mathrm{E}: 103$ n. 83

589 C : 103 n. 84,104 n.86

589 F-92 E : 3-10

$589 \mathrm{~F}: 104$ n. 89,90 et 91

590 B11-C7 : 5

590 B-C : 9

$590 \mathrm{~F}: 4$ n.6

590 F5-91 A2 : 6

$591 \mathrm{~A}: 9$

591 A3-4 : 6

591 B-C : 85 n.71

$591 \mathrm{C}: 9$

591 C11-D5 : 10

591 D-E : 104 n. 87

592 A-C : 104 n.88

$592 \mathrm{~A}: 4$ n. 5

592 C-D : 104 n.86

592 D5-7 : 86

$592 \mathrm{E}: 104$ n. 89

$592 \mathrm{~F}: 103$ n.82, 104 n.89

593 A-94 A : 105 n.94
$593 \mathrm{D}: 105$ n. 95

593 F-94 A : 105 n.96

596 D8-E3 : XVI n.68

De exilio 51

$599 \mathrm{C}: 53$ n. .58

$600 \mathrm{E}: 53$ n.59

602 B : 53 n.59

Consolatio ad uxorem

$609 \mathrm{E}: 53$ n. 55

611 A : 53 n. 55

Quaestiones convivales

618 B : XII n.48

631 A-B : 134 n.68

$635 \mathrm{~A}-\mathrm{C}: 57$ n. 4

$635 \mathrm{E}-36 \mathrm{~A}: 57$ n.5

653 C-54 B : 57 n.6

$654 \mathrm{D}: 246-247$

$673 \mathrm{C}: 57$ n. 3

718 D : 221 n. 60

$734 \mathrm{~F}: 125$ n. 15

$735 \mathrm{~A}: 125$ n. 15

740 C-D : XVI, 43, 215 n.26

$740 \mathrm{D}: 240$

Amatorius

$759 \mathrm{C}: 125 \mathrm{n} .15$

$762 \mathrm{~A}:$ VI n.21

764 E1-2 : 75 n.31

$764 \mathrm{~F}: 127$

Maxime cum pricipibus viris philosopho esse disserendum

$776 \mathrm{~F}: 226$

Ad principem ineruditum

780 E7-F2 : VIII n.34

$782 \mathrm{~A}: 53$ n.55

An seni respublica gerenda sit $792 \mathrm{D}: 226$

Praecepta gerendae reipublicae 803 A : 187 n.17

808 D : 218-19 n.45

816 C : 218 n. 45

De Herodoti malignitate 57 n. 5

Placita philosophorum

886 D-E : XIII n.56

De facie XII, 86

920 B : 121 n.2 
$923 \mathrm{~F}: 94$ n.6

924 A-D : 93 n.5

925 F-26 A : 40 n. 5

927 A12 : XIII n.54

927 C1 : XIII n.54

$928 \mathrm{C}:$ XII n. 48

937 C-D : 104 n.92

$938 \mathrm{C}:$ VII n.22

943 A : 230 n.112

966 A : VI n.21

De sollertia animalium 51

959 D : 213 n.20

961 A : 222 n.63

$964 \mathrm{~F}: 213$ n.19

$972 \mathrm{C}: 122,124,130$ n.42

976 B : 122

Bruta animalia ratione uti 51

989 C : 53 n. 58

Quaestiones Platonicae

999 C : 94 n.13

De procreatione animi in Timaeo

XIX n.92, 70

1014 A : 93 n.5

1015 D : 77 n.41

De Stoicorum repugnantiis

1034 C : 50 n.28, 225 n.82

1034 D : 19 n.23

1035 B : XI n.47

$1037 \mathrm{C}: 30$ n.51

$1037 \mathrm{~F}: 41$

1043 B : XI n. 47

$1044 \mathrm{C}:$ XI n.47

$1044 \mathrm{~F}:$ XI n.47

1045 B : XX, 13 n.1,26 n.44, 30 n.51

1045 B-F : 13-32, 34-35

$1045 \mathrm{C}: 21$ n.29

1045 D-E : 14

$1046 \mathrm{E}: 93$ n. 5

$1047 \mathrm{E}: 30$ n. 51

1048 B : XI n. 47

1048 C-49 A : 216-217

$1048 \mathrm{C}: \mathrm{XI}$ n. 47

1048 E : XI n. 47, 23 n.36

1050 A-D : 42 n. 15,208 n.4

1050 B : XI n. 47

1050 D : XI n. 47

1051 D12-E2 : IX n.36, XI n.47
1052 B : IX

$1052 \mathrm{C}: \mathrm{XI}$ n.47

1053 B : XI n.47

$1054 \mathrm{C}: 40$ n.5

1055 D : VII, XI n.47, 40

$1055 \mathrm{E}: 42$ n. 15

1055 F-56 A : 29 n.49

$1056 \mathrm{~B}: 42$

$1056 \mathrm{C}: 42$ n.15

$1056 \mathrm{D}: 42$

$1056 \mathrm{E}: 42$ n. 15

$1057 \mathrm{~B}: 44$

Stoicos absurdiora dicere 93 n.5

1057 E : XI n.47

De communibus notitiis

1059 B-D : XI n. 47, XIV n.58

1060 B : 93 n.5

1065 D : XI n.47

1068 B : 93 n.5

$1071 \mathrm{D}: 93$ n. 5

1075 B : XI n.47

$1075 \mathrm{E}: \mathrm{XI}$ n. 47

1076 B : 23 n.36

$1077 \mathrm{C}: 15$ n. 8,93 n. 5

1077 D : XI n.47

1077 E : XI n.47

1084 D : 4 n.4

Non posse suaviter vivi secundum

Epicurum XX

1086 D : 59 n. 15

$1086 \mathrm{E}: 57 \mathrm{n} .7$

1087 D-91A : 60 n.27

$1089 \mathrm{~A}: 247$

1092 B : XI n. 47

1100 D : XI n. 47

$1100 \mathrm{E}: \mathrm{XI}$ n. 47

$1101 \mathrm{C}: \mathrm{XI}$ n. 47,62

1101 C-2 E : 63 n. 35

$1102 \mathrm{~A}: \mathrm{XI}$ n. 47

$1102 \mathrm{~B}: 64$

$1105 \mathrm{D}: 127$

1103 A : XI n. 47

Adversus Colotem

1108 D : 59 n. 15

$1109 \mathrm{~A}: 124$

$1110 \mathrm{~F}: 60$ n.22

1111 B : XI n.47 
$1111 \mathrm{C}: 59$ n.19

1111 D-E : 60 n.23

$1111 \mathrm{E}: 60$ n. 20 et 22

1112 B-C : 60 n.20

1118 C-19 C : 60 n.26

$1120 \mathrm{C}: 30$ n.51

1121 A-E : 60 n.26

1121 F-22 F: 28 n.46

1122 B-D : 36-37

1122 C-D : 28 n. 47

$1122 \mathrm{C}: 30$ n. 51

1122 D : 30 n.51

1123 A : XII n. 47

1123 B-24 B : 60 n.26

1124 E : XII n. 47

1125 A : 63 n.36

1125 E : 61 n.29

De latenter vivendo

1129 B : XII n. 47

[De Homero]

118-119 : 216 n.29

120 : 43, 215 n. 24

$121: 215$ n. 25,216

135 : 223 n. 70

[De musica ]

$1131 \mathrm{C}: 225$ n.86

2.Vies

Agésilas - Pompée
$2,1:$ VI n.21
Agis
$28,3: 124$
Alcibiade
$4,4: 173 \mathrm{n} .15$
$17,4: 95 \mathrm{n} .18$
$18,1:$ VIII
33, $2:$ VI n.21
Alcibiade - Coriolan
$1,2:$ VIII
$3,3: 218 \mathrm{n} .45$
Alexandre
$2: 218 \mathrm{n} .42$
$2,3: 220$ et $\mathrm{n} .49$
$2,4: 124,130$ et $\mathrm{n} .44$
$3,1: 123$ n.14
$4,8: 227$ n.102

$14,6: 172$ n.13

$16,14: 221$ n.59

$17,6:$ VI n.21

$18,6: 124$

$18,6-8: 133$ n.62

$23,2: 124$

24, 5 124, 130 n.43

$24,6: 124,130$ n.42

$24,8: 124,128$

$24,9: 124$

26,5 : 123 n. 14

26, 14 : 218 n.43

$27,10: 222$ n. 64

$30,11: 227$ n.102

$32,1: 124$

$32,2: 124$

$41,6: 125,134$ n. 65

$47,1: 124,126$ n.23

$50,6: 125,134$ n.65

$58,2: 218$ n.43

$63: 219$ n. 47

$63,4: 219$ n. 48

$75,1: 123$ n.11

75, 1-2 : 223 n.70

Antoine

3, 9 : VIII

17, 4 : 224 n.74

Aratos

2, $4: 173$ n.17

54 : 130 n. 41

Aristide

17-18 : 178 n.44

Brutus

37 : 125 n. 15

47, 5 : VI n.21

$47,7: 179$ et $n .47$

50, 3 : VI n.21

Camille

6, $1: 177$ n.38

$13,2: 176$ n.30

Caton l'Ancien

12 : 171 n.6

23, $6: 123$ n.14

Caton d'Utique 197-198

11, 3 : VI n.21

$44: 201$ 
$68: 199$

$70,2: 198$

César

9, 1 : VI n.21

27, 7-8 : 127 n.25, 128 n.32

$32,9: 125$ n. 15

$38,5:$ VII

42, $1: 123$ n.13

$43,9: 123$ n.13

$57,1:$ VII n.23

$63,9: 125$ n. 15

Cimon - Lucullus

3, $6: 177$ n.32

Cléomène

2, $1: 51$ n.43

$2,6: 54$

7, 3-5 : 130 n. 50

25, 4 : VIII n.32

$27,8: 242$ n. 21

$36: 115$ n. 36

$39,3: 122$

\section{Coriolan}

15, 4 : 218-19 n.45

$32: 216$

$32,7: 174$ et $n .19$

$32,7-8: 216$ n.28

$33,5: 173$ et $n .18$

$38,4: 125$ n. 15

Crassus

$12,4: 123$ n.13

$21,9: 226$ n.91

27, 6 : XVII n.79, 226 et n.92

\section{Démétrios}

$1,4: \mathrm{X}$

$4,2: 124$

$8,5:$ VI

$19,2: 125,128,134$ n. 65

$27,12: 125$ et $n .17,126$

$27,14: 124,125$ n. 15 et 17

29,2 : 123 n. $14,125,128$

47,3 : VII n.23

Démosthène

19, 1 : VI n.21, XVIII

20, 1 : XVIII n.83

$22,1: 132$ n.59

$30: 179$ n.46
Démosthène - Cicéron

3, 4 : VI n.21

Dion

4, 3 : VI n.21

8, 4 : 218-19 n.45

$26,7:$ VI n.21

$52,5: 218$ n. 45

Eumène

6, 8-12: 131 n.54

$13,5: 124,132$

Fabius Maximus

$1,6: 226$ n. 90

4, 4 : 175 n.22

5, 1 : 172 n. 12,175 n.21

$13,7: 226$

$17,1: 170$ et n.4

$19,8: 176$ n.27

Flamininus

$12,10: 176$ et $n .31$

15 : 171 n.6

Lucullus

3, 8 : VI n.21

4, 4 : VI n.21

$12: 177$ n.34

$13,5: 177$ n.33

19,6 : VI n.21

Lycurgue

5, $2: 177$ n.36

29, 1 : VIII n.28

$29,6: 177$ n.37

Lycurgue - Numa

$1,1: 172$ n.11

Lysandre

19,4 : 218 n.45

Marcellus

$9,6:$ VIII

$12,2: 178$ n.43

Marius

7, $3: 226$

23, 1 : VI n.21

Nicias

1, 5 : XV n.67

13, $6: 94$ n. 9,95 n.18

23, 3-4 : XII n.49 
Numa

3, 6 : VI n.21

$4,11: 172$ et $n .8$

6, 2 : 172 n.9, 173 n.14

9, 12 : VI n.21

$15,1: 172$ n. 9

20, 8 et $9:$ VI n.21

Paul Émile

7, $3: 171$ n.6

$19,5-6: 175$ et $n .25$

27, 2 : XVII n.75

36, 3 : XVII n.78

Pélopidas XV

Périclès

3, $3: 130$ n.45

6, 4-5 : XII, XIII n.52

13, $12: 178$ n.39

$13,13: 121 \mathrm{n} .2$

$31,7: 218$ n. 45

$36,8: 53$ n. 54

$39,2: 53$ n.60

Philopoimen

3, $4: 124$

$18,14: 124$

Phocion 183-193, 195-204

1-2 : XV n.64

$1,1-6: 187$

$1,3: 199$ n.13

$1,5: 198$

2, 3 : 199 n. 13,200

$2,4: 200$

2, 6-9:200, 201

3, 1 : 199 n.12

$3,2: 199$

3, 2-5 : 188-189

3, 3 : XV n.64, 196

4, $2: 184$ n.4, 189

4, 3-4 : 201, 203

$5,1: 201$

6, 5-7: 190

7, 5-6 : 190 n.26, 199 n.13

$8,1: 201$

$10,3: 202$

$10,4-5: 201$

$10,7: 202$

$17-18: 203$

$17,1: 199$ n.13
28, 1-3 : 191-192

$32: 202$

$33,2: 202$

$33,10: 202$

$34,3: 192$ n.29

$37,1: 202$

$37,2: 192$

$37,5: 198$

$38,5: 193$

Pompée

23, $1: 123$ n.13

$53,7: 242$

$60,4: 218$ n. 45

$68,2: 123$ n.13

$68,3: 228$ n.103

$70: 171$ n.7

$73,5: 125$ n.15

75, 3-4 : 179 n.48

75, 4-5 : XVII

Pyrrhos

11, 3-7 : 131 n.53

$11,4: 124$

$19,2: 228$ n.104

$29,2: 124,133$ n.63

$30,5: 224$ n.74

Romulus

$7,5: 169$ et $n .1$

$19,2: 170$ et $n .2$

$28,2: 170$ et $n .3$

Sertorius

1, 1-3 : XVI (n.73)-XIX (n.74) n.92

10,6 : VI n.21, X-XI

$11,7: 132$

$20,3: 132$

Sylla

6, 5-13 : 245 n.32

$9,4: 123$ n.13

$27,3: 178$ n. 42

$28,4: 123$ n.13

34, 3-4 : 245

Thésée

24, 4 : 172 n.10

36, 2 : VI n.21,X-XI

Thésée - Romulus

$1,6: 175$ n.26

$3,1: 226$ 
Timoléon X-XI

3, $2: 174$ n.20

$8: 178$ n. 40

$12,9: 178$ n.41

14,2 : XVII n.77

$16,11-12: 176$ n.28

$21,5:$ VII n.23

$36,5: 176$ n.29

3. Fragments (éd. Sandbach)

$25: 218$ n. 45

$121: 53$ n. 53

177-178 : 70 n.7, 125 n.15

$193: 213$ n.19

Polybe

Histoires XIV n.62, 141-165

I 4, $1: 164$ et n.90

I 4, 6-11: 164

I $6,4: 163$ n. 85

I $8,6: 144$ n. 14

I 20,11-12: 163 n.85

I $20,15-16: 163$ n. 85

I $22-23: 163$ n. 85

I $27,12: 150$ n. 37

I $35,4: 156$ n. 56

I $37,3-6: 150$

I $37,8-10: 151$

I $58,1: 164$

I 62, 3-6:154

I $63,9: 146$ n.18, 163 et n.84

I $64: 163$

I $72: 163$ n. 82

I 82, 2-4 : 163

II $6-7: 147-148$

II $6,1: 149$

II 6,2 : 149 n.32

II $7,1: 156$ n.57

II 7, $2: 149$ n.32

II 7,11 : 149 n.32

II $38,5: 146$ n.18

II $56: 157-160$

II $70,2: 242$ n.21

II $71,2: 164$

III $4: 142,162$

III $4,6-9: 163$

III $5,6: 148$

III $31,12-13: 165$

III $48,8: 146$ et $n .19$
III $84,13: 148-149$

III $85,7: 149$

III $97,5: 153$

III $97,8: 153$

III $98,3: 153$

III 99,7 : 153 n. 45

III $99,9: 153$

III $118,6: 151$

III $118,7-9: 152$

IV 2, 4-10: 164

IV 3, 1-4 : 154

IV $81,1-5$ : 156 n.58

V $11: 161$ n.75

V 11, $4: 160$

V 84, $2: 150$ n.37

VI $2,6: 154$ n.49

VI $6,10-11: 162$

VI $7,2: 163$ n.82

VI $7,8-9: 163$ n.82

VI $8,6: 163$ n. 82

VI $9,5: 163$ n. 82

VI $15,7: 161$

VI $25,11: 163$ n. 85

VI $38,4: 161$ n.76

VI $47,1-2: 162$ et n.79

VI $53,9-10: 161$

VI $56: 147$

VI $56,8: 161$

VI $56,11: 161$

VI $56,15: 163$ n.86

VI $57: 142$

VI $47,2: 142$ n.5

VII $11,9: 160$

VIII $2: 164$

VIII $3,3: 156$ n.56

VIII 7, $7: 156$ n.56

VIII $20,10: 163$ et n.87

IX $2: 164$

IX 2, 4-5 : 162 n.77, 164 n.90

IX 6, 5-7: 155 n.51 et 52

IX $6,7: 155$

IX $8,13: 155$

IX $9,1-5: 155$ n.51

IX $9,3: 155$

IX $9,8: 155$ n.53

IX $9,10: 155$ n.50

IX 16, 5-6 : 155 n.51

IX $21: 151$

IX 22, $1: 156$ n.56 
X $2: 146$ et n.20

X 2, 10-13:147

$\mathrm{X} 5,4-8: 146$

$\mathrm{X} 5,7: 147$

$\mathrm{X} 5,8: 155$

X 5, $9: 146$ n.21

X 8-15: 147

$\mathrm{X} 11,6-8: 147$

X 14, 9-12: 147

$\mathrm{X} 14,11: 147$

X 30, $2: 144$ n.14

X 33, $4-5: 151$

X 34, $2: 144$ n.14

X 35, 6-38, $6: 153$ n.46

X $36: 163$ n. 82

$\mathrm{X} 36,5: 153$

$\mathrm{X} 36,5-7: 162$

XI 2, 5-6:154

XI 2, 10-11 : 154 et n.48

XI $5,8: 161$

XI 7, $3: 161$ n.75

XI 14, 4 : 151 n.38

XI 15-16 : 151

XI 16, 4 : 151 n.38

XI 19, $5: 151$

XI 19, 6-7 : 155

XII 12b, 3 : 157

XII 23, $3: 157$

XII 13, $1: 144$ n.14

XIV 1, $2: 146$ n.24

XIV 1, 5-7 : 146

XIV 1, $8: 146$ n.24

XIV 1, $13: 146$ n.24

XIV 4, $6: 146-147$

XIV 4, $8: 147$

XIV 5, $1: 147$

XIV 5, $5: 147$

XV 20, 1-5 : 157, 161

XV 20, 5 : 156 n.58, 161

XV 20, 5-8 : 150 n.36, 156, 161

XV 24, $6: 160$

XV 29, $5: 154$

XV 33, $1: 154$

XVI $1: 161$ n.75

XVI 10, $1: 160$

XVI $32,3: 156$ n.58

XVI 32, 4 : 143 n.10

XVI $32,5: 156$

XVIII 3, $8: 160$
XVIII 12,2-4 : 152

XVIII 15, 12-13 : 159 n.68

XVIII 28,4-5 : 146

XVIII 35,1-2 : 163 n.86

XVIII 41, 10 : 159 n.67

XVIII 43, $13: 159$ n.69

XVIII 46, $14: 160$

XVIII 54, 12 : 143 n.10

XX 4-7 : 149-150

XX 5, $7: 149$ n.35

XXI 39, 14 : 144 n.14

XXII $6: 158$ n.65

XXII 7-8 : 161

XXII 13-14 : 158 n.65

XXII 13, $11: 161$

XXII $20: 159$ n.67

XXIII 1-3 : 158 n.65

XXIII $3: 158$

XXIII $7: 158$

XXIII $8: 158$ n.65

XXIII $10: 142,157,161$

XXIII 10, 3 : 158 n.65

XXIII 10, 4-7 : 158 n.65

XXIII 12,3-4 : 156 n. 54

XXIV 13, 1-4 : 162

XXV $3: 151,160$ et $n .74$

XXVII 16, 4-5 : 142

XXVIII 9, 4-5 : 157 n.60

XXIX 19, 2 : 161

XXIX $20: 162,163$

XXIX 21 : IV n.12, 162, 186 n.13

XXIX 21, 5 : 163, 164 n.87

XXX 1-2 : 159 n.67

XXX 8, $8: 161$ n.76

XXXI 9, 1-4 : 157

XXXI 25, $10: 152$ n.40

XXXI 27, 10-11 : 152

XXXI 29, $3: 152$ n.41

XXXI $30: 146$

XXXI 30, $3: 152$ n.39

XXXII 4, $3: 156$ n.58

XXXII 8, $6: 159$ n.67

XXXII 15, $8: 160$ n.71

XXXII 15, $14: 157$

XXXIII $2: 165$ n.93

XXXVI 9, $15: 160$ n.73

XXXVI 12, 5 : 144 n.14

XXXVI 17 : 143-144, 149 n.31, 157

XXXVI 17,12-15 : 157 
XXXVI 17, $16: 157$ n.60

XXXVIII 1-3 : 148

XXXVIII 1,2 : 148 n.26

XXXVIII 1,6 : 148 n.26

XXXVIII 1,8 : 148 n.28

XXXVIII 1,9:148 n.27

XXXVIII $2: 151$

XXXVIII 2, $4: 148$ n.28

XXXVIII 2, $10: 148$ n.28

XXXVIII 2, $12: 148$ n.28

XXXVIII 3, $7: 148$ n.29

XXXVIII 3, 9-10 : 148 n.28

XXXVIII $21: 162,164$

XXXIX 21, $5: 163$

Porphyre

Vie de Pythagore

25, 28, 29 : 95 n.16

Proclus

In Alcibiadem

78, 8-85, 17 : 94 n.14

Theologia platonica

$1,15(76,10)$ : XII n.49

De decem dubitationibus circa providentiam VIII-IX : 72, 80

$49: 75$ n. 33

52 : 78 n. 43,79 n. 52

$53: 80$ n. 53,84

$57: 84$

$58: 80$ n. .55

Quinte-Curce

III $2,17: 244$ n.28

VIII $4,24: 244$

IX $4: 219$ n. 47

X 5, $35: 244$

Scholies de l'Odyssée

Ad XI 602 : 112 n.19

SÉNÈQUE

De beneficiis

4, $7: 40$

De providentia 72 n.18
Lettres à Lucilius

16, $4: 52$ n.51

$31,8: 41$

$76,19: 41$ n.13

$94,5: 20$ n.26

$94,12: 20$ n. 25

$113,18: 41$ n. 11

Sextus Empiricus

Adversus Mathematicos

VII 12-13 : 20 n.27

VII 151-52 : 21 n.30

IX $58: 64$ n. 40

XI 64-67 : 17 n.13

XI 65 : 17 n.14, 20 n.26

XI 67 : 20 n.26, 26 n.44

Socratis Epistulae

1, 9 : p. 95 n.20

Sophocle

Ajax 197, 198

Antigone 198, 203

563-564 : 198-199, 199 n.13

Edipe Roi

$208: 228$ n.103

$387-9$ : 114 n.27

Souda (éd. Adler)

IV 404, 23 : 103 n.78

SVF

I $55: 29$ n.49

I $153: 40$

I $191: 25$ n. 40

I $200: 50$ n. 28

I $216: 224$ n.75

I $333: 50$ n. 22

I $356: 20$ n. 27

I $357: 41$

I $359: 16$ n. 12

I 361 : 17 n. 13,20 n.26

I $370: 20$ n. 28

I $481: 51$ n.39

I 493 : 51 n. 40

I $620: 51 \mathrm{n} .44$

I $623: 51$ n. 43

II $33-35$ : 224 n.75 


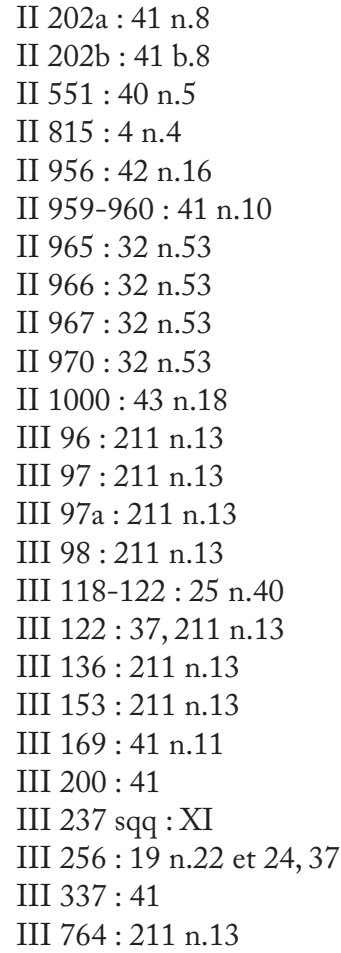

Strabon

VII fr. 10 a : 114 n.34, 116 n.44 VII $f r .18: 115$ n.41

IX $3,5: 110$ n.6

X 3, $23: 114$ n.28, 116 n.44

XI 5 : 221 n. 57

XV 1, $8: 221$ n.57

XV $1,38: 219$ n.47

$S I G$

III $1152: 128$ n.34

\section{TACITE}

Annales

VI $22: 44$

Histoires

IV $83: 129$ n.38

ThÉOPHRASTE 225

Caractères

$16,1: 122$ n. 10
Fragments (éd. Fortenbaugh)

L 53 : 49 n.16

L 55 : 49 n.19

L 56 : 49 n.19

L 57 : 49 n. 20

L 58 : 49 n.19

L 59 : 49 n.19

Thucydide

I 144, $4: 145$ n.16

I $84,4: 146$ n.22

II $8: 111 \mathrm{n} .8$

II $87,3: 146$ n.22

III $97,2: 145$ n.16

III $98,2: 145$ n.16

IV 18,4 : 146 n.22

VI $4,6: 146$ n.22

VI $29,3: 145$ n.16

Tite-Live

XL 3, 1-16, 3 : 158

Tragicorum Graecorum Fragmenta Adespota (éd. Kannicht - Snell) $351: 208$

$352: 208$ n. 5

XÉNOPHON

Mémorables

$1,1,1: 94$ n.9

$1,1,16: 94$ n.8 
IMPRESSION:

Simões \& Linhares, Lda.

Av. Fernando Namora, n. 83 - Loja 4

3000 CoImbra 
Le présent volume trouve son origine dans la rencontre annuelle du Réseau International de recherche et de formation à la recherche Plutarque (RED) qui s'est tenue à la Maison de l'Archéologie et de l'Ethnologie René Ginouvès de Nanterre en novembre 2009 sur le thème " Hasard, Fortune, Providence: la marche du monde selon Plutarque ». Pour constituer ce recueil, l'intitulé a été un peu modifié: l'adoption de la translittération, Tychè et Pronoia, veut mettre d'emblée en lumière la spécificité des notions grecques ici examinées, spécificité qui intéresse le philosophe comme le philologue. 